Improved Geothermometry through Multivariate Reaction-path Modeling and Evaluation of Geomicrobiological Influences on Geochemical Temperature Indicators:

\section{Final Report}

Earl D. Mattson, Robert W. Smith, Ghanashayam Neupane, Carl D. Palmer, Yoshiko Fujita, Travis L. McLing, David W. Reed, D. Craig Cooper, and Vicki S. Thompson

\section{January 2015}

The INL is a U.S. Department of Energy National Laboratory operated by Battelle Energy Alliance 


\section{DISCLAIMER}

This information was prepared as an account of work sponsored by an agency of the U.S. Government. Neither the U.S. Government nor any agency thereof, nor any of their employees, makes any warranty, expressed or implied, or assumes any legal liability or responsibility for the accuracy, completeness, or usefulness, of any information, apparatus, product, or process disclosed, or represents that its use would not infringe privately owned rights. References herein to any specific commercial product, process, or service by trade name, trade mark, manufacturer, or otherwise, does not necessarily constitute or imply its endorsement, recommendation, or favoring by the U.S. Government or any agency thereof. The views and opinions of authors expressed herein do not necessarily state or reflect those of the U.S. Government or any agency thereof. 
INL/EXT-14-33959

Revision 0

Improved Geothermometry through Multivariate Reactionpath Modeling and Evaluation of Geomicrobiological Influences on Geochemical Temperature Indicators: Final Report

January 2015

Idaho National Laboratory

Idaho Falls, Idaho 83415

http://www.inl.gov

Prepared for the

Battelle Memorial Institute, Inc.

Under DOE Idaho Operations Office

Contract DE-AC07-05ID14517 


\section{Executive Summary}

A major barrier to the deployment of geothermal energy is the financial risk associated with geothermal prospecting. One means to reduce such financial risk is to improve the accuracy of geothermometry by taking advantage of recent advances in geochemical analyses and modeling. Geothermometry is an important tool for estimating deep reservoir temperature from the geochemical composition of shallower and cooler waters. The overall project goal was to develop knowledge and methods to improve estimates of reservoir temperatures, which have traditionally been calculated using simple chemical geothermometers. The specific project objectives were to:

(1) develop knowledge required to use chemical geothermometry to predict reservoir temperature to within $\pm 30^{\circ} \mathrm{C}$,

(2) develop an associated geothermometry software technology product that could be commercialized,

(3) advance the scientific state of the art for geothermometry.

To meet these objectives, we have developed the Reservoir Temperature Estimator (RTEst), a program that calculates deep geothermal reservoir temperature and chemical parameters such as fugacity of $\mathrm{CO}_{2}$ based on the water chemistry of shallower, cooler reservoir-derived fluids. RTEst uses a multicomponent optimization approach to reconstruct conditions at which a water sample was equilibrated in deeper portions of the reservoir. RTEst minimizes a weighted sum of squares of the saturation indices of a userselected set of minerals believed to be at equilibrium within the reservoir by adjusting the temperature, fugacity of $\mathrm{CO}_{2}\left(\mathrm{fCO}_{2}\right)$, and mixing fraction with another water. RTEst, which was developed under Windows 7 operating system, uses the React module in The Geochemist's Workbench (GWB) to perform the geochemical calculations while using the parameter estimation code PEST to perform the optimization calculations. Features include several weighting methods and a form to assist users in selecting potential reservoir mineral assemblages given the rock type, water type (acid versus neutral/basic), and general temperature range (low, medium, high).

RTEst was tested against five hypothetical cases: 1) a system open to $\mathrm{CO}_{2}, 2$ ) deep boiling where $15 \%$ of the liquid is converted to steam, 3) flashing with $15 \%$ water loss, 4) a system with missing aluminum data, and 5) a system with mixing between thermal and non-thermal waters. In all five cases RTEst was able to correctly determine the conditions in the reservoir with a high degree of precision. In comparison, traditional geothermometers gave poor results except for the quartz geothermometer which gave reasonable results for cases 1-4 but could not provide a good estimate of reservoir temperature for case 5 (mixing).

The validity of RTEst as a geothermometry tool was also tested with water-rock interaction laboratory batch experiments. Metamorphosed quartz monzonite was reacted with synthetic geothermal water at 200 ${ }^{\circ} \mathrm{C}$ for more than 10 months. Multiple water samples were collected at various times for the chemical analysis and used to evaluate the effect of disequilibrium on temperature estimates. Based on the chemical composition of the fluid in these experimental reactors, RTEst was able to estimate the reactor temperature to within $5^{\circ} \mathrm{C}$. In experiments where the temperature was lowered from $200^{\circ}$ to $150^{\circ} \mathrm{C}$, RTEst was able to estimate the new correct temperature to within $8^{\circ} \mathrm{C}$ after only two weeks of reequilibration. In a series of experimental mixing tests, RTEst provided temperature estimates to within $11^{\circ} \mathrm{C}$, mixing fractions to within $6 \%$ and accurate $\mathrm{CO}_{2}$ fugacities.

Field data from the Raft River geothermal field in south-central Idaho were also used as input to RTEst to determine if it could predict the bottom hole temperatures in a real geothermal system with all of the associated analytical errors and uncertainties in mineralogical composition. Three reservoir mineral assemblages (RMAs) were considered. RMAs I, II, and III resulted in temperature estimates in the range of $106 \pm 4$ to $155 \pm 13{ }^{\circ} \mathrm{C}, 121 \pm 4$ to $166 \pm 14{ }^{\circ} \mathrm{C}$, and $113 \pm 8$ to $160 \pm 17^{\circ} \mathrm{C}$, respectively .

The samples and hypothetical cases discussed thus far have not involved biological activity. However, when temperatures cool below $120^{\circ} \mathrm{C}$, microbial activity can alter the chemical composition of water, and 
these alterations may impact estimates of reservoir temperature and lead to increased uncertainty in geothermal resource evaluation. To address this issue, we developed and applied molecular biomarker methods to assess the potential for microbial alteration of a water sample. We decided to focus on microbial sulfur cycling, and developed quantitative polymerase chain reaction (qPCR) assays to enumerate microbial genes associated with sulfate reducing or sulfur oxidizing activity in samples derived from geothermal waters. The qPCR assays were applied to samples from the Soda Springs area in southeastern Idaho and the Ojo Caliente spring in the Lower Geyser Basin of Yellowstone National Park. Comparison of the biomarker assay results and the RTEst calculations indicate that that biological activity can indeed bias geothermometric predictions. The findings suggest that the level of microbial activity at a site is inversely correlated with the reliability of temperature predictions for that site using RTEst or other current geothermometric approaches. Surface expressions like Ojo Caliente with indications of lower microbial activity yielded more reliable temperature predictions than samples with indications of higher microbial activity such as Sulphur Springs.

We have developed a multicomponent optimization program (RTEst) that is capable of taking into account several processes including formation of a steam phase, loss of volatile solutes such as $\mathrm{CO}_{2}$, and mixing of thermal and non-thermal waters in making geothermometric calculations. The program has been tested against hypothetical scenarios, laboratory experiments, and data from geothermal fields. Results of this testing suggest that RTEst is capable of predicting reservoir temperature to within $\pm 30{ }^{\circ} \mathrm{C}$ under a variety of conditions. We have also developed and tested an approach for identifying waters where biological activity may make such calculations problematic. These efforts have advanced the scientific state of the art for geothermometry and led to the development of a tool that will be available to other researchers within the US and around the world, and ultimately support the reduction of geothermal prospecting risk. 


\section{TABLE OF CONTENTS}

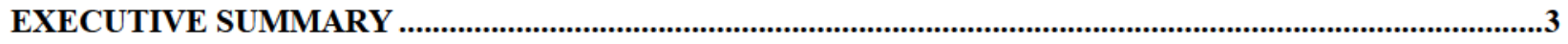

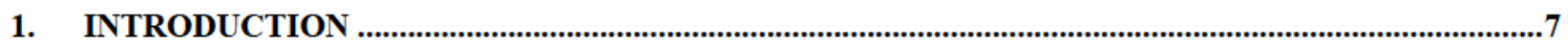

2. GEOTHERMOMETRY .......................................................................................................................

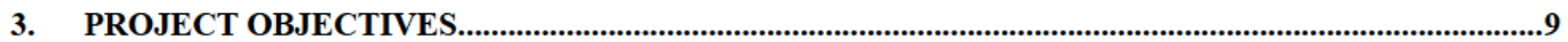

4. PROJECT TASKS..........................................................................................................................................

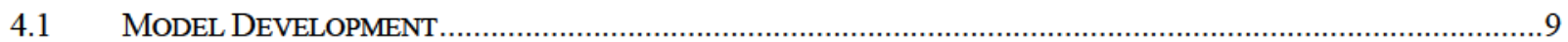

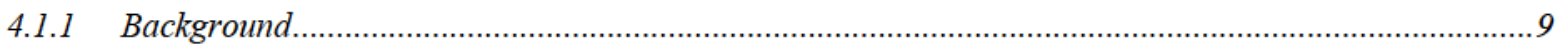

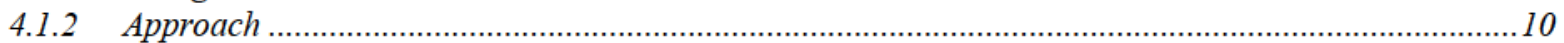

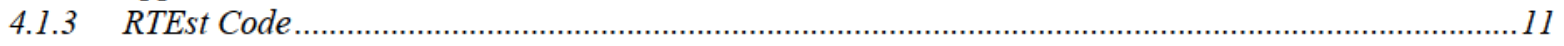

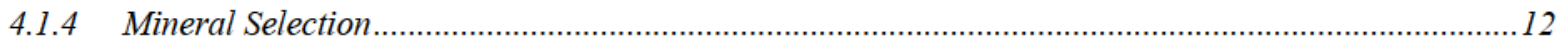

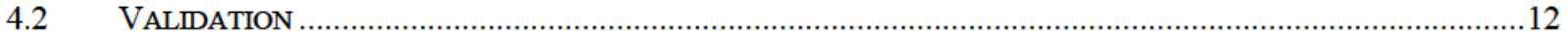

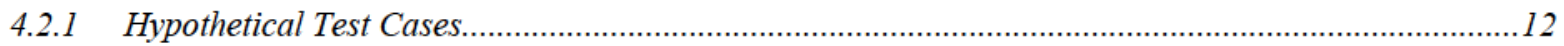

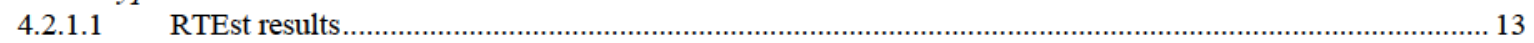

4.2.1.2 Comparison with traditional geothermometers ..................................................................................... 15

4.2.2 Experimental Validation: Equilibrium Experimental Cases...........................................................15

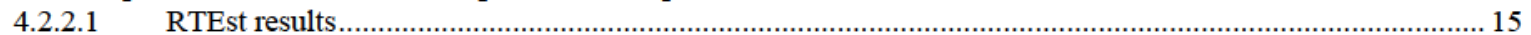

4.2.3 Experimental Validation: Experimental Mixing Cases..............................................................17

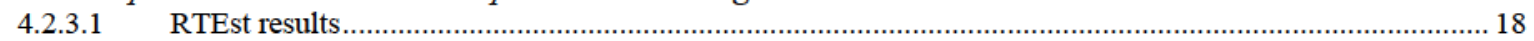

4.2.4 Field Validation: Raft River Geothermal Area ……................................................................19

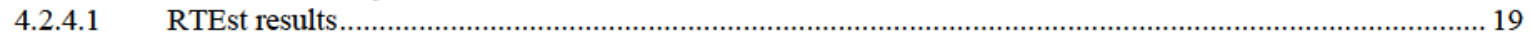

4.2.4.2 Effect of mineral assemblage on temperature estimates....................................................................... 20

4.2.4.3 Optimization on two parameters versus three parameters .............................................................................2

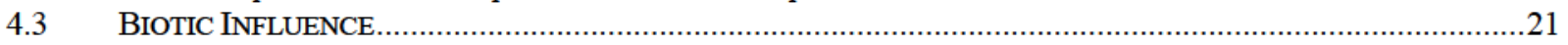

4.3.1 Development of Assay for Sulfate Reducing Genes ..........................................................................22

4.3.2 Development of Assay for Sulfur Oxidizing Genes ....................................................................22

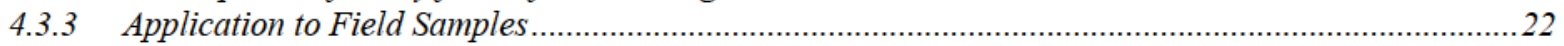

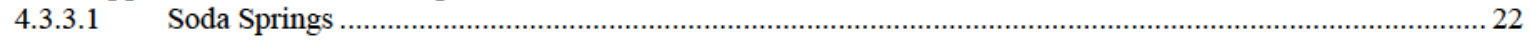

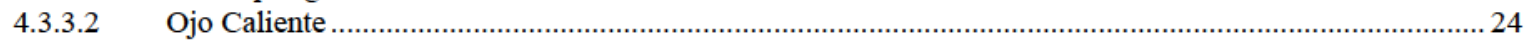

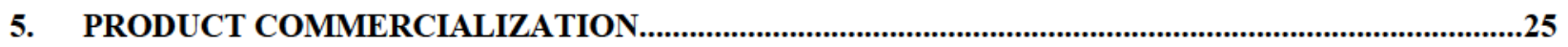

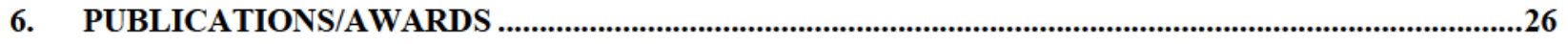

7. HUMAN RESOURCE DEVELOPMENT ……...............................................................................................26

8. SUMMARY .........................................................................................................................................................26

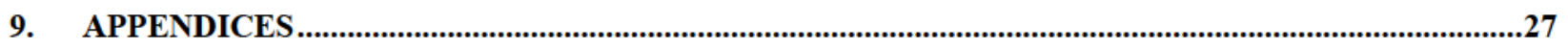

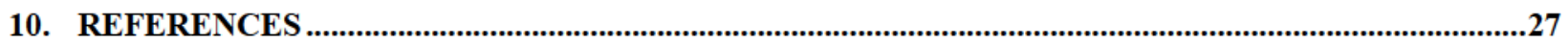




\section{LIST OF FIGURES}

Figure 1. Plot of mineral saturation state versus temperature for a hypothetical closed geothermal system (a) and for the same system but with the water equilibrated with 1 atmosphere of $\mathrm{CO}_{2}$ (b) (after Bethke, 2008) ...................................................................................

Figure 2. General flow chart for RTEst.

Figure 3. MEG temperature estimates for three RRBR-C experimental water samples collected at various water-rock interaction durations. The $\log \left(\mathrm{Q} / \mathrm{K}_{\mathrm{T}}\right)$ curves for minerals calculated using original water chemistries are shown in a, c and e are for samples collected after 1,32 , and 298 days whereas optimized $\log \left(\mathrm{Q} / \mathrm{K}_{\mathrm{T}}\right)$ curves for these water samples are shown in b, d, anf f respectively. (Minerals - alb: albite; cal: calcite; kao: kaolinite; kfs: $\mathrm{K}$-feldspar; mor: mordenite-K; qtz: quartz)

Figure 4. Temperature estimates for experimental waters with RTEst. The error bars represent one standard deviation in each direction. Experiment RRBR-Ib was cooled to $150^{\circ} \mathrm{C}$ after 324 days. The open circles in (c) show the same four temperature estimates for cooled system with time counted after initiation of cooling

Figure 5. MEG temperature estimate for RRG1. (a) The $\log \left(\mathrm{Q} / \mathrm{K}_{\mathrm{T}}\right)$ curves for minerals calculated using original water chemistry with $\mathrm{K}$-feldspar used for FixAl, (b) optimized log $\left(\mathrm{Q} / \mathrm{K}_{\mathrm{T}}\right)$ curves for RMAs I (b), II (c), and III (d) c) (minerals - anl: analcime; bed: beidelite-Mg; cal: calcite; cha: chalcedony; chl: chlorite; cli-clinoptilolite-K; ill: illite; kao: kaolinite; lau: laumontite; mor: mordenite-K).

\section{LIST OF TABLES}

Table 1. Results of calculations using RTEst on hypothetical cases 1-3.............................................13

Table 2. Comparison of results of swapping different Al-bearing solids for aqueous $\mathrm{Al}$ species.

Table 3. Results for Case 5, mixing.

Table 4. RTEst results of mixed samples

Table 5. Cell counts and $d s r B$ and $s o x B$ gene estimates for Soda Springs samples (standard deviation in parentheses).

Table 6. RTEst results for Hooper Spring, Soda Geyser, and Sulphur Springs in Soda Springs, Idaho.

Table 7. RTEst results for Ojo Caliente Spring in Yellowstone National Park, Wyoming. .25 


\title{
Improved Geothermometry through Multivariate Reaction-path Modeling and Evaluation of Geomicrobiological Influences on Geochemical Temperature Indicators: Final Report
}

\author{
Earl D. Mattson, Robert W. Smith, Ghanashayam Neupane, Carl D. Palmer, Yoshiko Fujita, Travis L. \\ McLing, David W. Reed, D. Craig Cooper, and Vicki S. Thompson
}

\section{Introduction}

A major barrier to the deployment of geothermal energy is the financial risk associated with geothermal prospecting (U.S. Department of Energy, 2011). Geophysical surveys and test wells are expensive, and therefore their deployment is understandably limited. New advances in prospecting tools are needed to reduce financial risk and increase the return on geothermal exploration investments. One promising means to reduce prospecting risk is improving the accuracy of geothermometry by taking advantage of recent advances in analytical capabilities and geochemical modeling.

Geothermometry is an important tool for estimating deep reservoir temperature from the geochemical composition of shallower and cooler waters. An underlying assumption of geothermometry is that water samples collected from shallow wells and/or seeps maintain a chemical signature that reflects equilibrium of the fluids with the minerals in the deeper and hotter reservoir. Many of the geothermometers used in practice rely on empirical correlations between water temperatures and composition or on thermodynamic calculations based on a subset (typically silica, cations or cation ratios) of the dissolved constituents. Alternatively, "complete" water compositions can be used in multicomponent equilibrium geochemical models to calculate the degree of disequilibrium (saturation state) for a suite of potential reservoir minerals as a function of temperature. The reservoir temperature is estimated from the common intersection of the saturation indices with the zero (equilibrium) line. Some of the basic concepts of this multicomponent geothermometry approach have been described by others (e.g., Bethke, 2008; Reed and Spycher, 1984; Spycher et al., 2011; Spycher et al., 2014; Cooper et al., 2013) and applied in several geothermal systems (Neupane et al., 2014; Peiffer et al 2014).

In this report, we describe a new multicomponent optimization approach to geothermometry. In addition to considering complete water compositions and multiple mineral equilibria, the approach takes into account several processes that can affect geothermometry such as formation of a steam phase, loss of volatile components such as $\mathrm{CO}_{2}$, and mixing with non-thermal waters. The approach was tested with hypothetical cases, laboratory experiments, and field data, and compared to traditional geothermometers. In addition, techniques were developed to assess whether biological activity, particularly sulfur oxidation and sulfate reduction, could affect the applicability of the multicomponent geothermometry optimization approach to a particular geothermal prospecting sample. A numerical inverse optimization model (Reservoir Temperature Estimator, RTEst) has been developed and is available to other researchers and geothermal prospectors around the world.

\section{Geothermometry}

Chemical geothermometry is an important technique for the identification, characterization, and development of potential geothermal resources. The underlying assumption of geothermometry is that waters collected from shallow wells and seeps maintain a chemical signature that reflects equilibrium with the minerals in the deeper reservoir. Therefore, geothermometry requires the collection of water samples from available locations, detailed chemical and isotopic analyses of the samples, and an empirical- or theory-based model of water composition as a function of temperature (Williams, 2008). There are numerous empirical and semi-empirical traditional geothermometers (e.g., silica 
geothermometers, $\mathrm{Na} / \mathrm{K}$ geothermometers, etc.,) routinely used within the geothermal prospecting community. Although the many of the traditional geothermometers are fitted relationships, there have been some geochemical postulations supporting these relationships. For example, silica geothermometers are based on the assumption of the solubility of solid-phase silica (e.g., quartz, chalcedony, etc.) controlling the aqueous concentration of silica. Similarly, several variations of sodium-potassium geothermometers are based on water-rock interaction involving albite and potassium feldspar. The reliability, sensitivity, and responsiveness of traditional geothermometers to various composition altering processes (such as boiling, mixing, degassing, etc.) vary. For example, geothermometers based on cation concentration ratios are minimally sensitive to boiling or mixing with dilute water; while geothermometers based directly on the concentration of component(s) are highly sensitive to these processes. A drawback to many existing geothermometry approaches is that they do not adequately account for physical processes (e.g., mixing, boiling) and geochemical processes (e.g., mineral dissolution, precipitation, degassing) that may occur after the water leaves the reservoir and thereby alter its composition. If these changes are not taken into account, predictions of $i n$-situ reservoir conditions (e.g., temperature, $\mathrm{fCO}_{2}$ ) based on the chemical composition of water samples taken from shallower depths or at the surface may be erroneous, or too imprecise to be useful.

In addition, it is difficult to quantify uncertainties associated with temperatures estimated with these geothermometers. As a result, it is not uncommon to find diverse temperature estimates for the same water using multiple traditional geothermometers. Nevertheless, because these geothermometers are easy to use and sometimes provide good results, they are considered to be an essential part of the geothermal exploration toolkit.

A more advanced geothermometric approach is multicomponent equilibrium geothermometry (MEG). This approach utilizes multiple chemical constituents measured in water samples for inverse geochemical modeling considering a suite of selected minerals (selected based on some knowledge of the system) so as to provide more robust temperature estimates with quantifiable uncertainties. The approach and some of its limitations are illustrated in the following examples.

A reservoir water equilibrated with quartz, maximum microcline, muscovite, albite and calcite at the reservoir temperature $\left(250^{\circ} \mathrm{C}\right)$ is transported to the near surface where the gas phase is condensed and reconstituted with the liquid phase at $25^{\circ} \mathrm{C}$ and the $\mathrm{pH}$ and dissolved constituents are measured (details are provided in Appendix 'Ai). To estimate the deep reservoir temperature, we first calculate the chemical speciation of the "sample" water at $25^{\circ} \mathrm{C}$ and at the "measured" $\mathrm{pH}$. Then we speciate the water as a function of temperature over the range of $25^{\circ} \mathrm{C}$ to $300^{\circ} \mathrm{C}$, allowing the $\mathrm{pH}$ to be calculated while suppressing all mineral reactions. Plotting the calculated mineral saturation indices as a function of temperature (Figure 1a) shows that the saturation indices for quartz, calcite, albite, K-feldspar, and muscovite converge to a common point where $\mathrm{Q} / \mathrm{K}=1(\log (\mathrm{Q} / \mathrm{K})=0)$ at $250^{\circ} \mathrm{C}$. The point where all of the saturation indices converge to zero is the reservoir temperature estimated by the multicomponent geothermometry approach. This estimated temperature is identical to that used to generate the subsurface fluid chemistry in this simple example.

However, real-world systems are more complex than the above idealized example, and in many situations the approach of varying a single parameter, temperature in this case, is unlikely to yield good estimates of reservoir temperature. For example, consider a case identical to the first example except that as the fluid nears the surface, it loses $\mathrm{CO}_{2}$ and ultimately equilibrates at a $\mathrm{CO}_{2}$ fugacity of 1 . Using this new water chemistry as the starting point and calculating the saturation states for the mineral assemblage in the reservoir as a function of temperature (Figure 1b), no intersection point common to all curves is obtained. The mineral saturation plots for albite, K-feldspar, and quartz appear to converge and suggest a reservoir temperature of about $255^{\circ} \mathrm{C}$ rather than $250^{\circ} \mathrm{C}$. More importantly, the mineral saturation plots for calcite and muscovite intersect the equilibrium line closer to $195^{\circ} \mathrm{C}$ and $238^{\circ} \mathrm{C}$, respectively, and suggest reservoir temperatures between $195^{\circ} \mathrm{C}$ and $255^{\circ} \mathrm{C}$. 

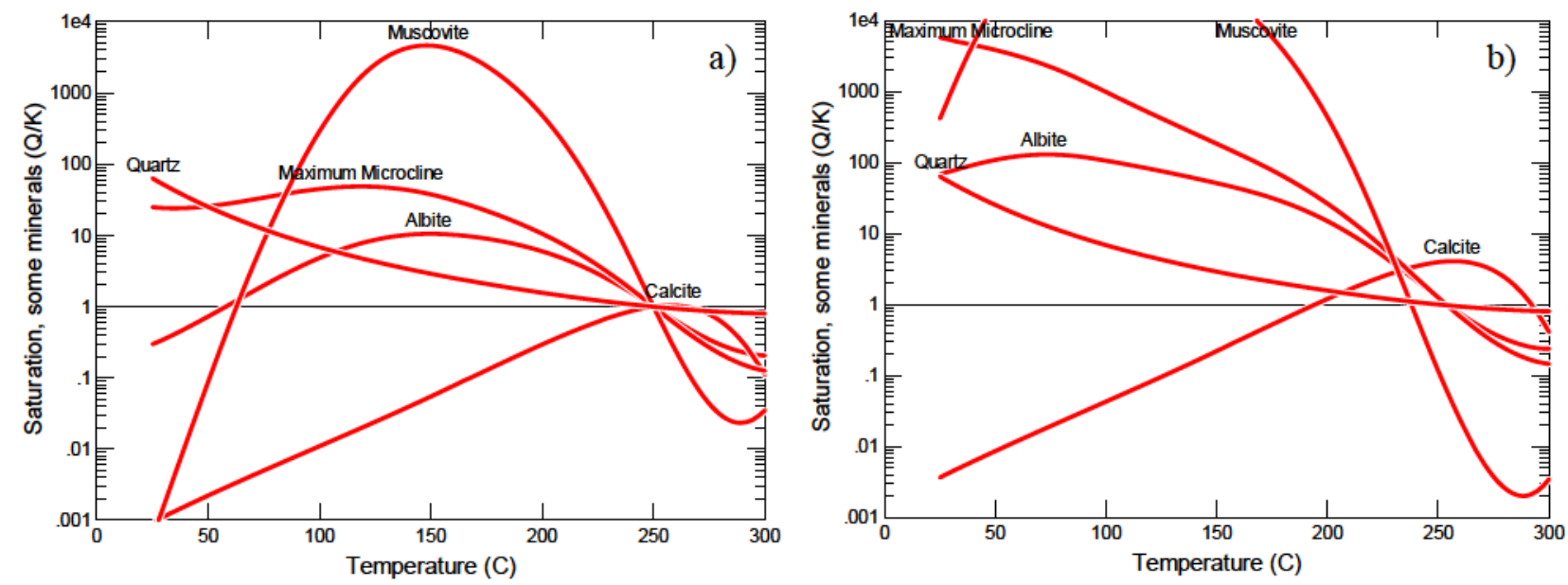

Figure 1. Plot of mineral saturation state versus temperature for a hypothetical closed geothermal system (a) and for the same system but with the water equilibrated with 1 atmosphere of $\mathrm{CO}_{2}$ (b) (after Bethke, 2008).

This result clearly indicates that loss of volatile constituents from a geothermal system can have a significant impact on the relationship between fluid chemistry and estimated reservoir temperature. However, field sampling programs for geothermal exploration often do not gather sufficient data to directly account for loss of volatile constituents. What is needed is a geothermometry approach that can take into account not only the temperature, but also processes such as loss of volatiles, boiling, and mixing that can affect estimates of reservoir temperatures.

\section{Project Objectives}

The project goal was to develop necessary knowledge and methods to enable more accurate estimates of reservoir temperatures, which have traditionally been calculated using simple chemical geothermometers. This project was developed in response to the Funding Opportunity Announcement (DE-FOA-0000522), "Geothermal Technology Advancement for Rapid Development of Resources in the U.S." and specifically addresses Topic Area 6 in the FOA ("Geochemistry/Rock-Fluid Interaction"). The project objectives were to:

(1) develop knowledge required to use chemical geothermometry to predict reservoir temperature to within $\pm 30{ }^{\circ} \mathrm{C}$,

(2) develop an associated geothermometry software technology product that could be commercialized,

(3) advance the scientific state of the art for geothermometry.

\section{Project Tasks}

\subsection{Model Development}

\subsubsection{Background}

The Reservoir Temperature Estimator (RTEst) is a program that can be used to estimate deep geothermal reservoir temperature and chemical parameters such as fugacity of $\mathrm{CO}_{2}$ based on the water chemistry of shallower, cooler reservoir fluids. RTEst uses a multicomponent optimization approach that takes into account several processes that can affect geothermometry including formation of a steam phase, loss of volatile components (e.g., $\mathrm{CO}_{2}$ ), and mixing with other waters to reconstruct conditions to which a water sample was exposed in the deeper portions of the reservoir. RTEst minimizes a weighted sum of squares of the saturation indices of a user-selected set of minerals believed to be at equilibrium within the 
reservoir by adjusting the temperature, fugacity of $\mathrm{CO}_{2}\left(\mathrm{fCO}_{2}\right)$, and mixing fraction with another water. RTEst uses the React module in The Geochemist's Workbench (GWB) (Bethke and Yeakel, 2011) to perform the geochemical calculations while using PEST (Doherty, 2005, 2013) to perform the optimization calculations. RTEst developed under the Windows 7 operating system using Microsoft Visual Basic 2010 and the Intel Visual Fortran Compiler 2013.

\subsubsection{Approach}

In RTEst, the user selects the set of reservoir minerals with which the reservoir fluid is believed to be equilibrated. While the user can only select minerals that are plausible based on the chemical analysis of the water, it is possible to choose a combination of minerals that violates the Gibbs phase rule which defines the maximum number of independent variables within a system. For cases where there is a fluid phase present and system temperature and pressure are correlated (e.g., steam saturated water), a simplified version of the phase rule can be used to determine the maximum number of equilibrium mineral phases that are appropriate for the calculation

$$
M=C-F
$$

where $\mathrm{M}$ is the number of equilibrium minerals, $\mathrm{C}$ is the number of components, and $\mathrm{F}$ is the degrees of freedom. After selecting the minerals to be included in assemblage, the user can check for the independence of the choices and if the phase rule is violated an error message will be generated. Note, however, that although Eq. (1) calculates the theoretical maximum number of mineral phases that may be in equilibrium the true number of phases in the real system may be less.

With the establishment of a mineral assemblage that is consistent with the Phase Rule, RTEst estimates an equilibrium reservoir temperature (as well as a fugacity of $\mathrm{CO}_{2}$ and water mixing or boiling) by minimizing an objective function $(\Phi)$ that is the weighted sum of the squares of the saturation indexes for the selected equilibrium minerals

$$
\Phi=\sum\left(S I_{i} w_{i}\right)^{2}
$$

where $\mathrm{SI}_{\mathrm{i}}=\log \left(\mathrm{Q}_{\mathrm{i}} / \mathrm{K}_{\mathrm{i}, \mathrm{T}}\right)$ for the ith equilibrium mineral $\left(\mathrm{Q}_{\mathrm{i}}\right.$ and $\mathrm{K}_{\mathrm{i}, \mathrm{T}}$ are the ion activity product and temperature dependent equilibrium constant, respectively for ith mineral) and $\mathrm{w}_{\mathrm{i}}$ is the weighting factor for the ith mineral.

The weighting factors ensure that each mineral that contributes to the equilibrium state is considered equally and the results are not skewed by reaction stoichiometry or differences in analytical uncertainty. There are three options for weighting factors in RTEst: inverse of variance, normalization, or unit weights. In general, unit weights are not recommended because during the optimization process, a clay mineral that has many basis species would be artificially weighted over a mineral such as quartz which has only one basis species. The normalization option is the weighting method that was employed in the Cooper et al. (2013) paper. The normalization option is a special case of the inverse variance method in which the analytical error for all thermodynamic components expressed as basis species (or ratio of basis species) are equal and that the thermodynamic activity of water is unity and invariant, and the weights are scaled by the analytical error.

The inverse of variance method calculates the weights based on the conditional variance of the saturation index given the solubility product of the mineral. The method calculates the propagation of error from the analytical uncertainty of the basis species for the mineral and the stoichiometry of the mineral making simplifying assumption about the correlation between the basis species. The weighting factor for the saturation index of the kth mineral in the equilibrium assemblage is approximately 


$$
w_{k} \approx \frac{1}{\left[\sum_{i=1}^{n c} v_{i k}\left(\frac{S_{C_{i}}}{C_{i}}\right)^{2}\right]^{1 / 2}}
$$

where $v_{i k}$ is the stoichiometric coefficient of the ith basis species in the kth mineral phase and $s_{C_{i}} / C_{i}$ is the coefficient of variation of the concentration of the ith basis species, (i.e., the analytical uncertainty in the reported concentration). More details on weighting schemes can be found in Appendix 'B.:

\subsubsection{RTEst Code}

The general structure of the RTEst code is illustrated in Figure 2. In the RTEst form, the user provides the names of the working directory, a GWB *.rea file, and an RTEst input file. When the run button is clicked, RTEst copies the two user files to temporary files and calls the program PEST_File_generator.f90 that creates the files needed to interface with PEST (Doherty, 2005, 2013) that performs the optimization calculations. Communication between RTEst and PEST is done via a template file (RTEst_Input\#\#.tpl), instruction file (RTEst_Output\#\#.ins) and a control file (RTEst_Interf.pst). Template, instruction and control files are described in detail by Doherty $(2005,2013)$ and brief discussion is provided in later sections of this report.

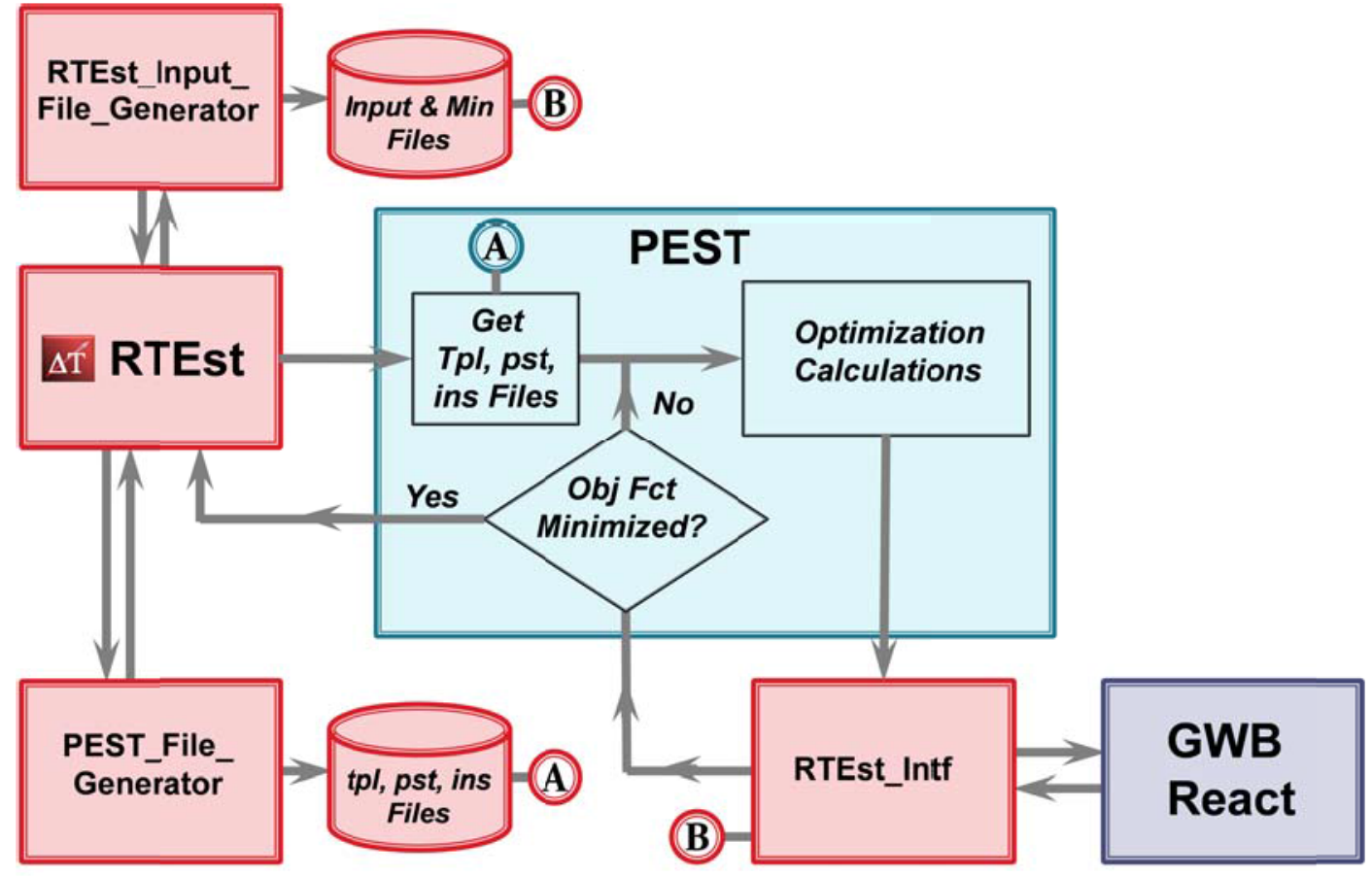

Figure 2. General flow chart for RTEst.

RTEst then calls RTEst_Interf.exe which acts as an interface between the RTEst, GWB which does all of the geochemical calculations, and PEST which does the optimization calculations. RTEst_Interf.exe reads the user input files and generates appropriate commands that are sent to the GWB React module via the provided plugins. RTEst_Interf.exe then gets the mineral saturation data and generates the temporary file RTEst_Output\#.txt. 
PEST then retrieves this output information via the instruction file (RTEst_Output\#.ins) so that it can calculate the objective function. If the objective function has not been minimized, PEST updates estimates of the parameters and invokes RTEst_Interf.exe again. This process continues until the objective function is minimized at which point PEST generates several output files. Program flow then returns to RTEst where the temporary files the output files from RTEst_Interf.exe and PEST are copied to files the user can access and all temporary files are deleted.

While the input RTEst input file can be created in any text editor, RTEst provides the ability to create this file through a series of text, check, and dropdown boxes. The key advantage of creating the input file through RTEst is that there are filters to aid the user in selecting appropriate mineral phases and the likelihood of input error is greatly reduced. The input file is created in the RTEst_Input_File_Generator form which is launched from the RTEst form by selecting File $\rightarrow$ New $\rightarrow$ RTEst Input File.

More detailed descriptions of the program components and the associated files are provided in the Appendix B.

\subsubsection{Mineral Selection}

While multicomponent equilibrium geothermometry can be used for estimating of reservoir temperature based on a given set of minerals, the selection of which minerals that should be used represents an area of continuing uncertainty. The choice of minerals is dependent upon several factors (e.g. Browne, 1978) including the reservoir lithology. The geoscience literature contains numerous studies that identify alteration mineral assemblages that form when hot water interacts with reservoir minerals (e.g., Schwartz, 1959). Many hydrothermal systems are equilibrated with the alteration mineral assemblages rather than the primary reservoir lithology (Bethke, 2008; Giggenbach, 1988).

In the process of the development of representative geothermal alteration mineral assemblages, we reviewed 48 geothermal systems representing all major geologic environments (references listed in Table 'Cl' of Appendix C). This review led us to have 16 different representative mineral assemblages presented in Table 'C2' of Appendix C.

\subsection{Validation}

The reliability and accuracy of MEG as implemented in RTEet is tested with hypothetical, experimental and natural thermal water compositions. Initially, we tested the applicability of potential modeling approach with hypothetical test cases (e.g., Cooper et al., 2013). Similarly, as a part of model validation, we had applied RTEst to numerous natural water samples (e.g., Neupane et al., 2014; Cannon et al., 2014; Neupane et al., 2015a and b) from southeast Idaho and various geothermal sites. In this report, we will provide some examples of RTEst applied to some hypothetical thermal waters, experimental waters, and well-known geothermal waters [Raft River Geothermal (RRG)].

\subsubsection{Hypothetical Test Cases}

To illustrate the potential power and limitations of the multicomponent equilibrium geothermometry approach, Synthetic data was generated for several sampling scenarios with GWB, Version 9 (Bethke and Yeakel, 2011), using the thermo.dat thermodynamic database. These simulated numerical datasets assumed a reservoir mineral assemblage, equilibrated water with that assemblage at a given temperature $\left(250^{\circ} \mathrm{C}\right)$, and then subjected the simulated deep waters to a sequence of thermal and chemical events (e.g., boiling, cooling venting). The computed water chemistry represents the chemistry of water collected from a thermal spring or sampling well.

Five cases representing different scenarios are considered. These are -

Case 1: Open system (after Bethke, 2008),

Case 2: Deep boiling [ $15 \%$ fluid loss while maintaining equilibrium with reservoir mineral assemblage (RMA)] 
Case 3: Flashing (15\% water lost, no reactions after boiling)

Case 4: Missing aluminum data (Case 2 with different Al-bearing minerals for $\mathrm{Al}^{\mathrm{t+1+}}$ )

Case 5: Mixing with non-thermal water

Details about these cases and resulting water chemistries are given in Appendix 'D.'.

\subsubsection{RTEst results}

The results of the optimization runs for the hypothetical test cases are summarized in Table 1. For Cases 1 (open system), the fit is very good with the objective function being $1.00 \mathrm{E}-13$. The estimated temperatures are virtually identical to the expected value of $250^{\circ} \mathrm{C}$; a significant improvement over the results obtained when only temperature is considered. The $\mathrm{CO}_{2}$ fugacity and $\Delta \mathrm{H}_{2} \mathrm{O}$ are also very close to heir expected values $(21.12,0.0000 \mathrm{~kg})$.

Table 1. Results of calculations using RTEst on hypothetical cases 1-3.

\begin{tabular}{|c|c|c|c|c|}
\hline & & \multicolumn{3}{|c|}{ Case } \\
\hline \multicolumn{2}{|c|}{ Parameter } & 1 & 2 & 3 \\
\hline \multicolumn{2}{|c|}{ Objective function } & $1.0032 \mathrm{E}-13$ & $3.0823 \mathrm{E}-18$ & $7.0273 E-14$ \\
\hline \multicolumn{2}{|c|}{ Total Saturation Index } & 3.1673E-07 & $1.7557 \mathrm{E}-09$ & $2.6509 \mathrm{E}-07$ \\
\hline \multirow[t]{3}{*}{ Temp. $\left({ }^{\circ} \mathrm{C}\right)$} & Actual & 250.000 & 250.000 & $250.00 C$ \\
\hline & Estimated & 250.000 & 250.000 & $250.00 C$ \\
\hline & Std. Dev. & $6.301 \mathrm{E}-05$ & $5.018 \mathrm{E}-06$ & $6.03 \mathrm{E}-05$ \\
\hline \multirow[t]{3}{*}{$\mathrm{fCO}_{2}$} & Actual & 21.1220 & 25.6064 & 21.1222 \\
\hline & Estimated & $21.1218^{\circ}$ & 25.6065 & $21.121 \varepsilon$ \\
\hline & Std. Dev. & $5.36 \mathrm{E}-05$ & $5.76 \mathrm{E}-06$ & $5.14 \mathrm{E}-05$ \\
\hline \multirow[t]{3}{*}{$\Delta \mathrm{H}_{2} \mathrm{O}(\mathrm{kg})$} & Actual & $0.000000 \mathrm{E}+00$ & $0.000000 \mathrm{E}+00$ & $1.764706 \mathrm{E}-01$ \\
\hline & Estimated & $2.424581 \mathrm{E}-07$ & $1.000000 \mathrm{E}-12$ & $1.764710 \mathrm{E}-01$ \\
\hline & Std. Dev. & $6.322821 \mathrm{E}-07$ & 3.972911E-08 & $7.122475 \mathrm{E}-07$ \\
\hline \multirow{2}{*}{\multicolumn{5}{|c|}{$\begin{array}{l}1 \text { Open system } \\
2 \text { Deep boiling }\end{array}$}} \\
\hline & & & & \\
\hline \multicolumn{5}{|l|}{3 Flashing } \\
\hline
\end{tabular}

For Case 2 (deep boiling), the temperature is nearly identical to the expected value. $\Delta \mathrm{H}_{2} \mathrm{O}$ for Case 2 is estimated to be $0.000 \mathrm{~kg}$ even though we assumed $15 \%$ evaporation in the setting up the forward problem. Although not immediately intuitive, this estimated value is correct because the approach estimates the conditions in the reservoir when the water was last equilibrated with the mineral assemblage which was after the water had been evaporated. Similarly, the estimated $\mathrm{fCO}_{2}$ in Case 2 is greater than in Case 1 because this was the $\mathrm{fCO}_{2}$ when the reservoir water was last equilibrated with mineral assemblage.

In contrast to Case 2, equilibrium with the mineral assemblage in Case 3 was last achieved prior to evaporation. In the forward problem, the water was evaporated to $85 \%$ of its original volume; therefore, the amount of fluid that must be added back into the system to obtain the same mass is $1 / 0.85$ - 1 (i.e., $0.17647 \mathrm{~kg}$ ). This is the amount estimated by RTEst. Similarly, the estimated $\mathrm{fCO}_{2}$ for Case 3 reflects the value when mineral equilibrium was last achieved and is thus the same as in Case 1. The temperature is nearly identical to the expected value of $250^{\circ} \mathrm{C}$.

For the hypothetical test case 4 , the fits are excellent (Table 2) with the objective functions less than $1.00 \mathrm{E}-8$ regardless of which of the three Al-bearing phases (albite, maximum microcline, muscovite) are swapped for the aqueous aluminum species. 
For Case 5, the results are encouraging. For the fixed $\mathrm{CO}_{2}$ scenario only the temperature and mixing fraction are optimized. If one tried to optimize the fugacity of $\mathrm{CO}_{2}$ as well, the results would be poor since the amount of $\mathrm{CO}_{2}$ in the system is determined primarily by the amount of mixing, i.e., $\mathrm{fCO}_{2}$ and the mixing fraction are highly correlated and thus the system is over determined and the fitted parameters would have large standard deviations. The results of this two-parameter model (Table 3) show a small objective function as well as small standard deviations for the fitted parameters. For the sliding $\mathrm{CO}_{2}$ case, $\mathrm{CO}_{2}$ concentrations are determined by both exsolution and mixing. Thus, three parameters can be used in the optimization. The results for this case show a small objective function as well as small standard deviations for the fitted values of temperature, $\mathrm{fCO}_{2}$, and mixing fraction.

Table 2. Comparison of results of swapping different Al-bearing solids for aqueous Al species.

\begin{tabular}{|ll|rrr|}
\cline { 2 - 5 } \multicolumn{1}{c|}{} & \multicolumn{3}{c|}{ Case } \\
\hline \multicolumn{1}{c|}{ Parameter } & \multicolumn{3}{c|}{ Maximum } \\
Albite & Microcline & Muscovite \\
\hline \hline Objective function & $2.4777 \mathrm{E}-09$ & $8.5032 \mathrm{E}-09$ & $1.1448 \mathrm{E}-09$ \\
Total Saturation Index & $4.9777 \mathrm{E}-05$ & $9.2213 \mathrm{E}-05$ & $3.3835 \mathrm{E}-05$ \\
\hline Temp. $\left({ }^{\circ} \mathrm{C}\right)$ & Actual & 250.000 & 250.000 & 250.000 \\
& Estimated & 250.042 & 250.010 & 250.016 \\
& Std. Dev. & $4.648 \mathrm{E}-02$ & $9.763 \mathrm{E}-02$ & $3.89 \mathrm{E}-02$ \\
\hline $\mathrm{fCO}_{2}$ & Actual & 25.6064 & 25.6064 & 25.6064 \\
& Estimated & 25.6708 & 25.6549 & 25.6513 \\
& Std. Dev. & $2.62 \mathrm{E}-02$ & $5.32 \mathrm{E}-02$ & $2.09 \mathrm{E}-02$ \\
\hline$\Delta \mathrm{H}_{2} \mathrm{O}(\mathrm{kg})$ & Actual & $0.000000 \mathrm{E}+00$ & $0.000000 \mathrm{E}+00$ & $0.000000 \mathrm{E}+00$ \\
& Estimated & $1.000000 \mathrm{E}-12$ & $1.117429 \mathrm{E}-04$ & $3.750000 \mathrm{E}-06$ \\
& Std. Dev. & $2.982979 \mathrm{E}-04$ & $5.398598 \mathrm{E}-04$ & $1.981342 \mathrm{E}-04$ \\
\hline
\end{tabular}

Table 3. Results for Case 5, mixing.

\begin{tabular}{|ll|rr|}
\cline { 3 - 4 } \multicolumn{2}{c|}{} & \multicolumn{2}{c|}{ Case 5 -- Mixing } \\
\hline \multicolumn{2}{c|}{ Parameter } & Fixed CO ${ }_{2}$ & \multicolumn{1}{c|}{ Sliding $\mathrm{CO}_{2}$} \\
\hline Objective function & & $3.5411 \mathrm{E}-09$ & $4.2984 \mathrm{E}-07$ \\
Total Saturation Index & & $5.9507 \mathrm{E}-05$ & $6.5562 \mathrm{E}-04$ \\
\hline Temp. $\left({ }^{\circ} \mathrm{C}\right)$ & Actual & 250.000 & 250.000 \\
& Estimated & 249.992 & 249.672 \\
& Std. Dev. & $1.843 \mathrm{E}-02$ & $3.18 \mathrm{E}-02$ \\
\hline $\mathrm{fCO}_{2}$ & Actual & 0.1348 & 0.1348 \\
& Estimated & $\mathrm{NA}$ & 0.1321 \\
& Std. Dev. & $\mathrm{NA}$ & $8.20 \mathrm{E}-04$ \\
\hline Mixing Fraction & Actual & -1.0000 & -1.0000 \\
& Estimated & -1.0000 & -0.9904 \\
& Std. Dev. & $2.9830 \mathrm{E}-04$ & $9.7008 \mathrm{E}-05$ \\
\hline
\end{tabular}

NA = not applicable 


\subsubsection{Comparison with traditional geothermometers}

The reservoir temperatures for the test cases were also calculated using traditional geothermometers. The results are summarized in Table 'D 31 ' of Appendix D. The Geochemist's Workbench uses an activity coefficient model for neutral, nonpolar species such as $\mathrm{SiO}_{2}(\mathrm{aq})$ that results in activity coefficients that are not equal to unity. As such, use of the concentrations in the estimated reservoir temperature using silica geothermometers can lead to substantial error. We have therefore used $\mathrm{SiO}_{2}$ (aq) activity to estimate the reservoir temperature. The results show that Fournier's (1977) quartz (no steam) geothermometer provides the best estimate of the reservoir temperature being within $5^{\circ} \mathrm{C}$ of the actual value. The other geothermometers performed poorly with some estimates being more than $30^{\circ} \mathrm{C}$ in error. All of the conventional geothermometers underestimated the reservoir temperature except for Fournier and Truesdell's (1973) Na-K-Ca geothermometer which overestimated reservoir temperature.

\subsubsection{Experimental Validation: Equilibrium Experimental Cases}

The validity of RTEst as a geothermometry tool was also tested with batch water-rock interaction laboratory experiments. Metamorphosed quartz monzonite (the reservoir rock for the RRG system) was heated with synthetic geothermal water at $200{ }^{\circ} \mathrm{C}$ for more than 10 months. Multiple water samples were collected at various times for the chemical analysis and used to evaluate the effect of disequilibrium on temperature estimates. The details about the experiments are given in Appendix 胥i

\subsubsection{RTEst results}

Estimates of reservoir temperatures for experimental water samples are developed using a mineral assemblage consisting of albite, calcite, kaolinite, $\mathrm{K}$-feldspar, mordenite-K, and quartz. Figure 3a shows $\log \left(\mathrm{Q} / \mathrm{K}_{\mathrm{T}}\right)$ curves of the assemblage minerals for RRBR-C water sample separated from the system after one day. The $\log \left(\mathrm{Q} / \mathrm{K}_{\mathrm{T}}\right)$ curves of these minerals intersect the $\log \left(\mathrm{Q} / \mathrm{K}_{\mathrm{T}}\right)=0$ at a various temperatures, ranging from $175^{\circ} \mathrm{C}$ (calcite and quartz) to over $210^{\circ} \mathrm{C}$ (kaolinite) indicating that the system is far from equilibrium. This disequilibrium may have been resulted from the reaction kinetics (not enough time to get to the equilibrium) or other physical-chemical process (such as loss/gain of water and/or $\mathrm{CO}_{2}$ ). Since there was no loss or gain of water during sampling (sample was cooled in a closed sampling vessel), the RTEst modeling was conducted using $\mathrm{T}$ and fugacity of $\mathrm{CO}_{2}$ as optimization parameters. Figure $3 \mathrm{~b}$ shows RTEst optimized $\log \left(\mathrm{Q} / \mathrm{K}_{\mathrm{T}}\right)$ curves of this 1-day water. Although the RTEst optimization did not improve the location of $\log \left(\mathrm{Q} / \mathrm{K}_{\mathrm{T}}\right)$ curves of these minerals, RTEst resulted temperature $\left(192 \pm 13{ }^{\circ} \mathrm{C}\right)$ is quite impressive for sample collected after 24 hours.

Water samples with longer water-rock interactions had produced better convergence of $\log \left(\mathrm{Q} / \mathrm{K}_{\mathrm{T}}\right)$ curves (Figure 3c and Figure 3e), and consequently, RTEst estimated temperatures for these waters approach the experimental temperatures with smaller uncertainties. The RTEst temperature estimates for water samples withdrawn after 32 and 298 days of RRBR-C-water interaction are $205 \pm 4{ }^{\circ} \mathrm{C}$ and $205 \pm 1{ }^{\circ} \mathrm{C}$, respectively. For all other samples, RTEst estimated temperatures and associated uncertainties are given in Table E6 of Appendix E. Furthermore, the RTEst estimated temperatures for all samples are also plotted in Figure 4. In general, the RTEst temperatures of water samples representing four experimental sets approach to the experimental temperature with decreasing amount of uncertainties over time (Figure 4).

For one of the experiments, we also performed a 200 day cooling experiment to a temperature of $150{ }^{\circ} \mathrm{C}$ (Figure 4c, sample RRRG-Ib) after 300 days of heating at $200{ }^{\circ} \mathrm{C}$. Although the traditional geothermometers did not properly reflect cooling event implemented to the RRBR-Ib experiment (Appendix ${ }_{-}^{-}$i), RTEst is able to show the cooling trend, and ultimately provide a temperature estimate (Figure 4) close to the final experimental temperature $\left(150^{\circ} \mathrm{C}\right)$. For water samples collected after one week of cooling, the RTEst resulted in a temperature estimate of $167 \pm 5^{\circ} \mathrm{C}$. For the sample collected after the second week of cooling, the estimated temperature is $158 \pm 6^{\circ} \mathrm{C}$. 

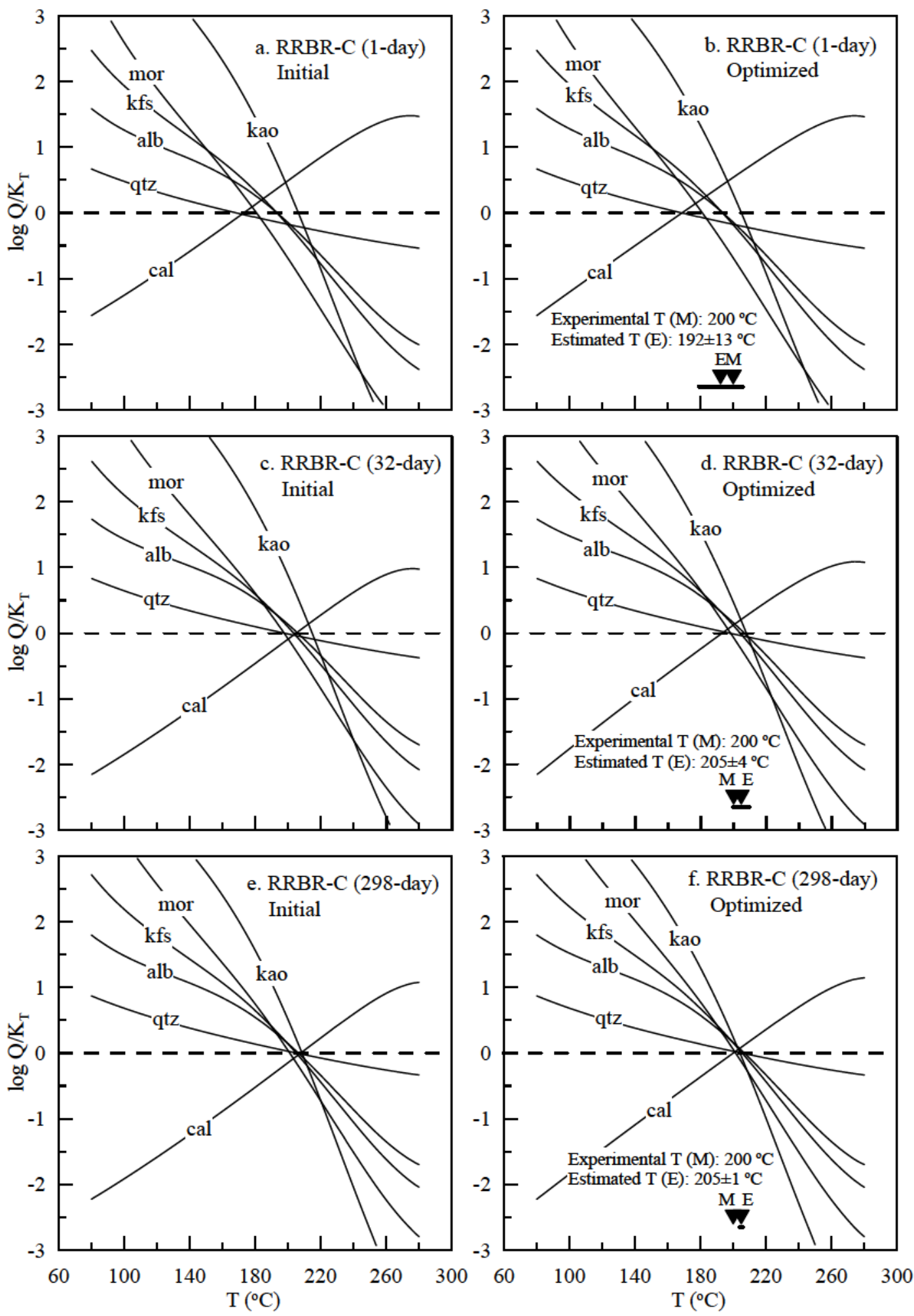

Figure 3. MEG temperature estimates for three RRBR-C experimental water samples collected at various water-rock interaction durations. The $\log \left(Q / K_{T}\right)$ curves for minerals calculated using original water chemistries are shown in a, $c$ and $e$ are for samples collected after 1, 32, and 298 days whereas optimized $\log \left(\mathrm{Q} / \mathrm{K}_{\mathrm{T}}\right)$ curves for these water samples are shown in $b, d$, anf $\mathrm{f}$ respectively. (Minerals - alb: albite; cal: calcite; kao: kaolinite; kfs: K-feldspar; mor: mordenite-K; qtz: quartz). 

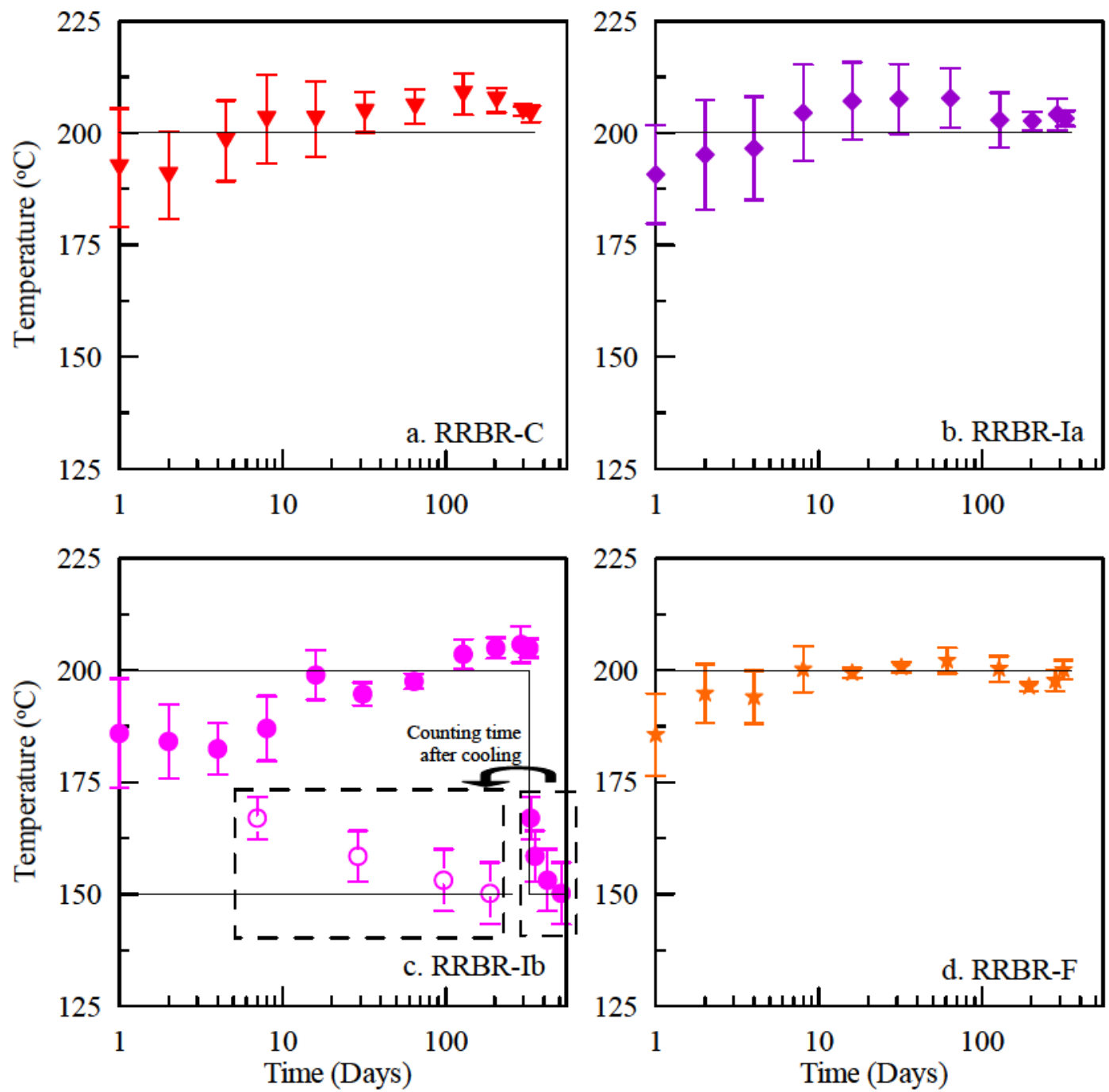

Figure 4. Temperature estimates for experimental waters with RTEst. The error bars represent one standard deviation in each direction. Experiment RRBR-Ib was cooled to $150{ }^{\circ} \mathrm{C}$ after 324 days.

The open circles in (c) show the same four temperature estimates for cooled system with time counted after initiation of cooling.

\subsubsection{Experimental Validation: Experimental Mixing Cases}

An additional experimental set (RRBR-Im) was also prepared following the procedure described in Appendix 佂. This experimental set was heated at $200^{\circ} \mathrm{C}$ for 182 days. At the end of the experiment, the water was separated from the solid. This experiment was used to determine the effect of mixing ESRP aquifer water on equilibrated water. Representative ESRP groundwater sample was collected from a domestic well in Idaho Falls (Wood well, Latitude: N 43.453106 ${ }^{\circ}$, Longitude: W $111.997773^{\circ}$ ). Different fractions of Wood well water were mixed with the experimental water, and resulting waters (Appendix, were used to test mixing part of the RTEst. 


\subsubsection{RTEst results}

Except the equilibrated RRBR-Im water samples, all mixed water samples were altered by mixing with low-temperature ESRP aquifer water. These water samples were therefore subjected to RTEst run using three optimization parameters, temperature, fugacity of $\mathrm{CO}_{2}$, and mixing fraction. This scheme of optimization requires that the user must also provide the composition of end-member water (e.g., Wood well water) that may have been mixed with the thermal water along with the composition of sampled water (in this case mixed water) in the input react file. A mineral assemblage consisting of 6 minerals (albite, calcite, kaolinite, K-feldspar, mordenite-K, and quartz) were included in the input text file for the RTEst modeling. Normalization scheme of weighting was employed during the model runs.

Table 4. RTEst results of mixed samples

\begin{tabular}{|l|c|c|c|c|c|}
\multirow{2}{*}{ Samples } & \multirow{2}{*}{$\begin{array}{c}\text { Measured \% of } \\
\text { Wood well water }\end{array}$} & \multicolumn{5}{c|}{ RTEst Results } \\
\cline { 3 - 6 } & & $\mathrm{T}\left({ }^{\circ} \mathrm{C}\right)$ & $\%$ of Wood well water & $\log$ fCO2 $\pm \sigma$ & $\varphi$ \\
\hline RRBR-Im & $0 \%$ & $207 \pm 2$ & $1 \pm 1 \%$ & $-0.68 \pm 0.10$ & $9.05 \mathrm{E}-04$ \\
\hline Mixed water 1_M & $22 \%$ & $211 \pm 1$ & $22 \pm 1 \%$ & $-0.64 \pm 0.08$ & $8.18 \mathrm{E}-04$ \\
\hline Mixed water 2_M & $26 \%$ & $207 \pm 2$ & $26 \pm 1 \%$ & $-0.75 \pm 0.10$ & $1.22 \mathrm{E}-03$ \\
\hline Mixed water 3_M & $32 \%$ & $210 \pm 2$ & $31 \pm 1 \%$ & $-0.72 \pm 0.09$ & $9.51 \mathrm{E}-04$ \\
\hline Mixed water 4_M & $43 \%$ & $209 \pm 2$ & $43 \pm 2 \%$ & $-0.78 \pm 0.13$ & $1.85 \mathrm{E}-03$ \\
\hline Mixed water 5_M & $59 \%$ & $215 \pm 2$ & $59 \pm 3 \%$ & $-0.69 \pm 0.12$ & $1.54 \mathrm{E}-03$ \\
\hline Mixed water 1_C & $22 \%$ & $208 \pm 3$ & $22 \pm 2 \%$ & $-0.70 \pm 0.09$ & $9.35 \mathrm{E}-04$ \\
\hline Mixed water 2_C & $26 \%$ & $208 \pm 2$ & $26 \pm 1 \%$ & $-0.72 \pm 0.10$ & $1.03 \mathrm{E}-03$ \\
\hline Mixed water 3_C & $32 \%$ & $208 \pm 2$ & $32 \pm 1 \%$ & $-0.74 \pm 0.10$ & $1.12 \mathrm{E}-03$ \\
\hline Mixed water 4_C & $43 \%$ & $209 \pm 2$ & $43 \pm 2 \%$ & $-0.77 \pm 0.11$ & $1.37 \mathrm{E}-03$ \\
\hline Mixed water 5_C & $59 \%$ & $211 \pm 3$ & $59 \pm 6 \%$ & $-0.78 \pm 0.13$ & $1.90 \mathrm{E}-03$ \\
\hline
\end{tabular}

${ }^{1}$ Letter $\mathrm{M}$ indicates the concentrations of mixed waters are measured; ${ }^{2}$ letter $\mathrm{C}$ indicates that the concentrations of mixed waters are calculated using two end member (Wood well and RRBR-Im water compositions).

During the RTEst run, it appeared that the measured $\mathrm{pH}$ values along with the calculated bicarbonate concentrations for these mixed waters were causing model to run a large number of iterations and producing large standard deviations in estimated parameters. The large number of model iterations and standard deviations are believed to be the result of inconsistency between measured $\mathrm{pH}$ and calculated bicarbonate concentrations. To avoid this inconsistency, calculated $\mathrm{pH}$ values were used instead of the measured values for the RTEst modeling for all samples.

The RTEst results for the equilibrated water (RRBR-Im) and mixed water samples are presented in Table 4. The RTEst run for the RRBR-Im water sample was also conducted using the three optimization parameters. The estimated temperature $\left(207 \pm 2{ }^{\circ} \mathrm{C}\right)$ for this water is close to the experimental temperature $\left(200^{\circ} \mathrm{C}\right)$ with insignificant mixing results $(1 \pm 1 \%$ Wood well water). An RTEst run (similar to the RTEst runs employed to all experimental samples in section 3.2.2) for this water using two parameters (temperature and fugacity of $\left.\mathrm{CO}_{2}\right)$ also resulted in very similar temperature estimate $\left(208 \pm 2{ }^{\circ} \mathrm{C}\right)$.

The RTEst is found to be consistently able to estimate temperature and mixed fraction of Wood well water in all mixed water samples (Table 4). The estimated temperatures for the mixed waters range from $207{ }^{\circ} \mathrm{C}$ to $215^{\circ} \mathrm{C}$ with standard deviation in estimated temperatures $\leq 3{ }^{\circ} \mathrm{C}$. These mixing exercises indicate that the mixing part of the RTEst is robust enough to handle the non-reactive mixing cases. 


\subsubsection{Field Validation: Raft River Geothermal Area}

The RRG field in south-central Idaho (Figure 'El' in Appendix E) is a designated Known Geothermal Resource Area (KGRA) with the highest measured bottom-hole temperature of $149{ }^{\circ} \mathrm{C}$ (Dolenc et al., 1981). Extensive exploration and development activities conducted by the USGS and the US Department of Energy in the mid-late 1970's and early 1980's has proved the viability of this area to generate commercial electricity using geothermal energy (Dolenc et al., 1981; Ayling and Moore, 2013).

Currently, U.S. Geothermal, Inc. operates a geothermal power plant at this site with a net capacity of 13 MWe. For more details about this site, see Appendix 'G'.

\subsubsection{RTEst results}

Three alternate RMAs given in Table 'G2' of Appendix G were used for the development of RRG reservoir temperature estimates with RTEst for several RRG wells (Table $\left.{ }^{\prime} l_{i}^{1}\right)$. Figure 5 a shows $\log \left(\mathrm{Q} / \mathrm{K}_{\mathrm{T}}\right.$ ) curves of several minerals based on pre-optimized RRG1 water composition (Table Gli of Appendix G). The log $\left(\mathrm{Q} / \mathrm{K}_{\mathrm{T}}\right)$ curves of these minerals intersect the $\log \left(\mathrm{Q} / \mathrm{K}_{\mathrm{T}}\right)=0$ at different temperatures, ranging from 101 ${ }^{\circ} \mathrm{C}$ (calcite) to over $225^{\circ} \mathrm{C}$ (kaolinite), making the pre-optimized $\log \left(\mathrm{Q} / \mathrm{K}_{\mathrm{T}}\right)$ curves minimally helpful to assess reservoir temperature. Only chalcedony, clinoptilolite- $\mathrm{K}$, laumontite, and mordenite- $\mathrm{K}$ intersect each other close to the $\log \left(\mathrm{Q} / \mathrm{K}_{\mathrm{T}}\right)=0$ within a short range of temperature $\left(123-135^{\circ} \mathrm{C}\right)$, whereas all other $\log \left(\mathrm{Q} / \mathrm{K}_{\mathrm{T}}\right)$ curves intersect the $\log \left(\mathrm{Q} / \mathrm{K}_{\mathrm{T}}\right)=0$ at different temperatures. The presence of such a wide range of equilibration temperature for potential assemblage minerals is a reflection that physical and chemical processes that may have modified the composition of RRG waters prior to sampling. The preoptimized $\log \left(\mathrm{Q} / \mathrm{K}_{\mathrm{T}}\right)$ curves for all other $\mathrm{RRG}$ waters also show similar trends (Figure 'G3' through G9).

The loss of $\mathrm{CO}_{2}$ has the primary consequence of increasing $\mathrm{pH}$ and decreasing (bi)carbonate concentration in geothermal water along with the displacement of $\log \left(\mathrm{Q} / \mathrm{K}_{\mathrm{T}}\right)$ curves of calcite and clay minerals. Particularly, $\log \left(\mathrm{Q} / \mathrm{K}_{\mathrm{T}}\right)$ curve for calcite (Figure 5a) is very important to assess the potential loss of $\mathrm{CO}_{2}$ from the geothermal water before/during sampling. The degassing of $\mathrm{CO}_{2}$ generally results in oversaturation of calcite in geothermal waters as the loss of $\mathrm{CO}_{2}$ increases the $\mathrm{pH}$. Since the $\log \left(\mathrm{Q} / \mathrm{K}_{\mathrm{T}}\right)$ curve for calcite intersects the $\log \left(\mathrm{Q} / \mathrm{K}_{\mathrm{T}}\right)=0$ at lower temperature than other minerals, and it becomes oversaturated at temperature $>101^{\circ} \mathrm{C}$ (Figure 5a), indicating the potential loss of $\mathrm{CO}_{2}$ from RRG1 water. Similar trends are found with other RRG waters (Figure 'G3 through G9). Although the loss of $\mathrm{CO}_{2}$ has created little effect on silica (chalcedony), it has been the primary factor for non-convergence of log $\left(\mathrm{Q} / \mathrm{K}_{\mathrm{T}}\right)$ curves at reservoir temperature along the $\log \left(\mathrm{Q} / \mathrm{K}_{\mathrm{T}}\right)=0$ without RTEst optimization. Therefore, accounting for the lost $\mathrm{CO}_{2}$ from the RRG waters for temperature estimation appears to be a primary requirement to force the minerals to equilibrate with each other and with the geothermal fluid at the reservoir temperature.

The RTEst optimized $\log \left(\mathrm{Q} / \mathrm{K}_{\mathrm{T}}\right)$ curves for minerals included in the first assemblage (beidelite-Mg, calcite, chalcedony, illite, mordenite, and K-feldspar are presented in Figure $5 \mathrm{~b}$. Similarly, $\log \left(\mathrm{Q} / \mathrm{K}_{\mathrm{T}}\right)$ curves for minerals included in the second (calcite, chalcedony, chlorite, clinoptilolite-K, kaolinite, $\mathrm{K}$ feldspar) and third (Analcime, calcite, chalcedony, illite, laumontite, K-feldspar) assemblages are shown in Figure 5c and Figure 5d, respectively. Compared to the pre-optimized $\log \left(\mathrm{Q} / \mathrm{K}_{\mathrm{T}}\right)$ curves for these minerals (except analcime in assemblage III), the optimized $\log \left(\mathrm{Q} / \mathrm{K}_{\mathrm{T}}\right)$ curves intersect each other close to $\log \left(\mathrm{Q} / \mathrm{K}_{\mathrm{T}}\right)=0$ within a narrow range of temperature, thereby facilitating estimation of reservoir temperature. For the RRG1, estimated temperatures with standard errors are $132 \pm 4{ }^{\circ} \mathrm{C}, 135 \pm 4{ }^{\circ} \mathrm{C}$, and $137 \pm 11^{\circ} \mathrm{C}$ with RMAs I, II, and III, respectively (Figure 5). The temperature estimates, optimized $\mathrm{CO}_{2}$ fugacity, and objective function for each RRG water sample with each mineral assemblage are given in Table 'G3!': 

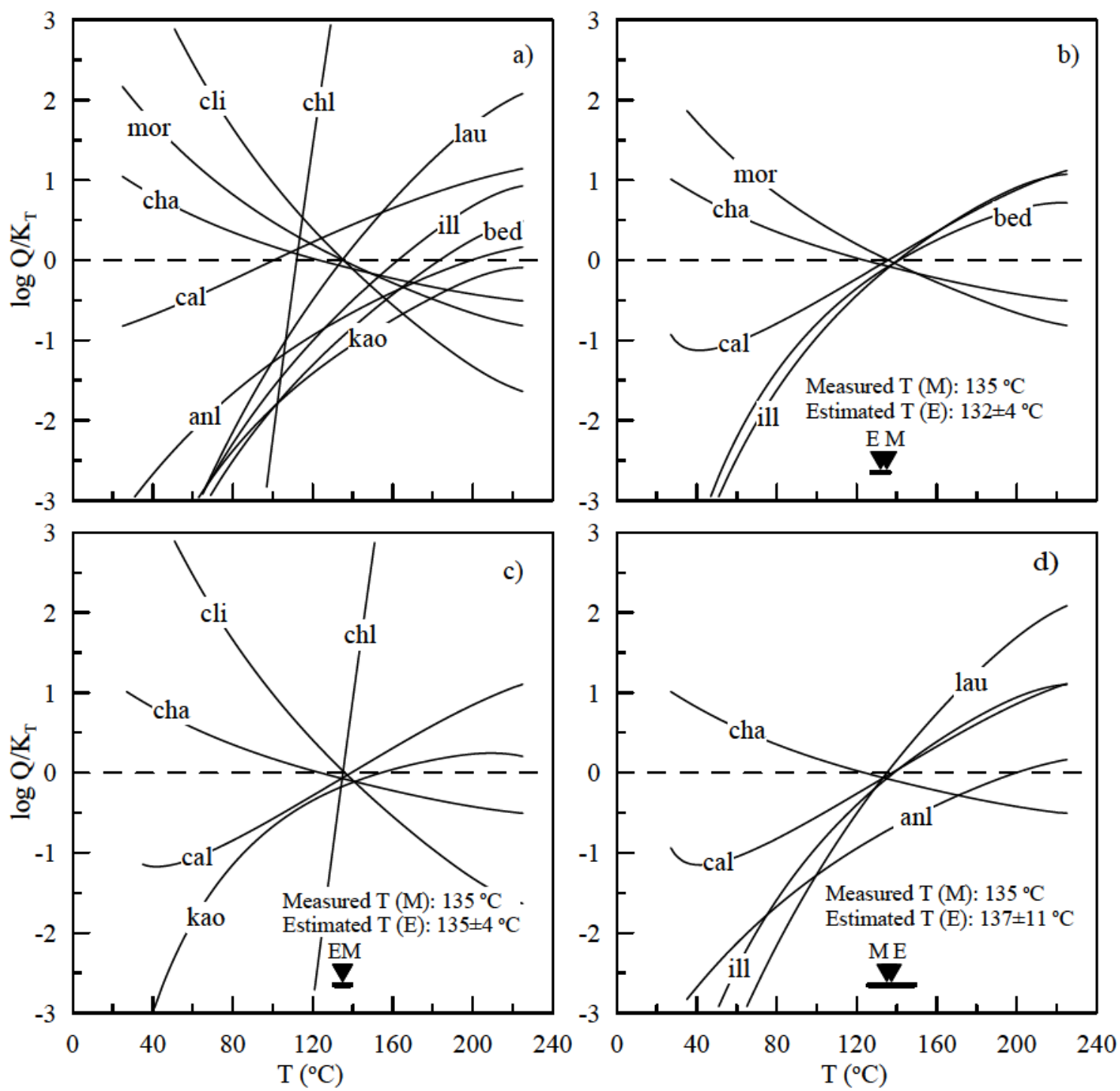

Figure 5. MEG temperature estimate for RRG1. (a) The $\log \left(\mathrm{Q} / \mathrm{K}_{\mathrm{T}}\right)$ curves for minerals calculated using original water chemistry with $K$-feldspar used for FixAl, (b) optimized $\log \left(Q / K_{T}\right)$ curves for

RMAs I (b), II (c), and III (d) c) (minerals - anl: analcime; bed: beidelite-Mg; cal: calcite; cha:

chalcedony; chl: chlorite; cli-clinoptilolite-K; ill: illite; kao: kaolinite; lau: laumontite; mor: mordenite-K).

\subsubsection{Effect of mineral assemblage on temperature estimates}

The RTEst estimated temperature with associated uncertainties for different RRG wells with three alternative RMAs are presented in Table 'G3. For each RRG well, RMAs I, II, and III resulted in temperature estimates in the range of $106-155^{\circ} \mathrm{C}, 121-166^{\circ} \mathrm{C}$, and $113-160^{\circ} \mathrm{C}$ with standard errors of \pm 4 $- \pm 13{ }^{\circ} \mathrm{C}, \pm 4- \pm 14^{\circ} \mathrm{C}$, and $\pm 8- \pm 17^{\circ} \mathrm{C}$, respectively . Particularly, estimated temperatures and associated uncertainties with multiple RMAs are similar to each other. The similarities in estimated temperature with these three RMAs may have been because each of the RMA shares 2 to 3 common minerals. 
The RTEst applied to the RRG waters indicate its robustness for estimating a temperature with quantifiable uncertainty using a single water chemistry data for a geothermal system. However, with a poor choice of RMA or poor choice of optimization parameters (see below), the uncertainty in the estimated temperature can become very large. An additional approach that can be implemented to minimize the uncertainty in the estimated temperature is to calculate a weighted average temperature and weighted average standard error using results of multiple water samples from different springs/wells representing the same reservoir. The weighted mean estimated temperature for RRG is calculated separately using estimated temperature obtained with each alternative RMA for all RRG wells, and presented in Table 'G3'

\subsubsection{Optimization on two parameters versus three parameters}

The results for RRG presented above were derived by RTEst optimization runs using two parameters ( $T$ and fugacity of $\mathrm{CO}_{2}$ ). Although the use of two optimization parameters for the development of temperature estimates for experimental samples seems reasonable because there was no measurable loss/gain of water while sampling. However, the use of only two parameters ( $\mathrm{T}$ and fugacity of $\mathrm{CO}_{2}$ ) may or may not be valid with the RRG samples.

When three parameters ( $\mathrm{T}$, fugacity of $\mathrm{CO}_{2}$, and mass of water) were used during RTEst runs, there have been some variations in estimated temperature and associated uncertainties with the three RMAs for RRG waters. The RTEst results of RRG water with the same mineral assemblages but with three optimization parameters are given in Figure 'G10' through G17 and Table 'G4. Specifically, the uncertainties in estimated temperatures with RMĀIII and RMAIII are higher compared to the results for these assemblages with two optimization parameters. The high uncertainties associated in temperature estimates with RMAs II and III may have resulted in because of strong positive correlation between parameters which may yield a rather flat surface for objective function $(\Phi)$ near the likely reservoir temperature.

\subsection{Biotic Influence}

The objective of the microbial component of this project was to provide an initial evaluation of whether microbial activity could alter the geochemical composition of a prospecting sample so as to render it no longer directly amenable to geothermometry; if so, then ideal methods could ultimately be developed to "correct" or account for the influence of microorganisms, analogous to the ability of RTEst to account for the process of $\mathrm{CO}_{2}$ loss or mixing with shallow groundwater. As noted earlier, traditional geothermometric approaches assume an exploration sample's composition still reflects chemical equilibration with the deep reservoir rocks. However, water chemistry can be altered by the activity of microorganisms that reside in shallower water with cooler temperatures $\left(<120^{\circ} \mathrm{C}\right)$. Microorganisms are ubiquitous in the environment, including geothermally derived waters (e.g. (Marteinsson, Hauksdottir et al. 2001, Konhauser, Jones et al. 2004, Meyer-Dombard, Shock et al. 2005, Niederberger, Ronimus et al. 2008, Takai and Nakamura 2011), and microbially mediated reactions often leave distinctive signatures in the trace element, gas, and stable isotopic composition of a system (Ehrlich, 1996). We hypothesized that knowledge of microbial impacts on exploration sample geochemistry can be used to constrain input into RTEst and thereby improve the reliability of its reservoir temperature predictions. For this initial evaluation, we chose to focus on assessments of microbial sulfur cycling activity, in particular sulfate reduction and sulfur oxidation. Both processes alter $\mathrm{pH}$ and redox conditions, which are critical for delineating mineral stability fields. We developed and applied methods for detecting and estimating the potential extent of past or present sulfate reducing or sulfur oxidizing activity in a given sample derived from geothermal waters. These methods rely on quantitative polymerase chain reaction (qPCR) to quantify microbial genes associated with these functional activities in environmental samples. The qPCR technique allows estimation of the number of target genes in a sample without having to retrieve and characterize the organisms carrying the genes. While the presence of a gene does not necessarily indicate that the associated activity is occurring or has occurred, it does indicate the potential for that activity. The development of the two types of assays (for sulfate reducing genes and sulfur oxidizing genes) is 
described below, followed by presentation and discussion of the results from their application to field samples whose chemistry was also used as input for RTEst.

\subsubsection{Development of Assay for Sulfate Reducing Genes}

Sulfate reducing organisms, which include representatives from both the Bacterial and Archaeal domains of life, obtain energy by oxidizing organic compounds or hydrogen and using sulfate as the electron acceptor, resulting in the production of sulfide. Genes that code for enzymes responsible for sulfate reduction were the target for our qPCR assay. In particular we chose to focus on two genes, $d s r A$ and $d s r B$, that code for the dissimilatory sulfite reductase enzymes that catalyze the conversion of sulfite to sulfide and are highly conserved (similar in DNA sequence) between the Bacterial and Archaeal domains. These genes have been well studied and specific sequences identified for a large number of organisms including thermophilic $\left(45-120^{\circ} \mathrm{C}\right)$ microorganisms. Knowledge of these sequences allows the design of specific PCR primers to use for amplification of the target genes.

Estimating the number of genes in an unknown sample requires comparison against a standard curve created from known numbers of the target genes. To generate a standard curve we constructed the pKN23 plasmid which contained both $d s r A$ and $d s r B$ gene sequences. Different concentrations of pKN23 were then used to create a standard curve for the qPCR reactions. The $d s r B$ gene was chosen as the primary target for the qPCR assay because initial results suggested that the $d s r B$ primers could detect a lower number of gene copies than could $d s r A$ primers. Details of the construction of pKN23 and of the development of the qPCR assay protocol for sulfate reducing genes are provided in a paper prepared for the 2013 Stanford Geothermal Workshop (Fujita, Reed et al. 2013); a copy is provided in Appendix i.

\subsubsection{Development of Assay for Sulfur Oxidizing Genes}

A literature survey indicated that in comparison to the microbial genes associated with sulfate reduction those associated with sulfur oxidation generally are less conserved. Of the multiple pathways identified for sulfur oxidation, the Sox pathway was found to be the most studied and best understood and was therefore chosen as the focus for this project. This pathway has been found in a number of Bacteria, but not in the Archaea (Ghosh and Dam, 2009). For this reason, unlike the qPCR assay developed for the sulfate reducing microorganisms, the qPCR assay developed for the S oxidizing microorganisms does not detect Archaeal S oxidizers. The Sox enzymes are a complex of proteins responsible for complete oxidation of reduced sulfur species to sulfate. In particular, the soxB protein is a critical component of the pathway and has been the direct gene target of other researchers using PCR to detect sulfur oxidizing bacteria (SOB) in environmental samples (Petri et al., 2001; Meyer et al., 2007; Bourne et al., 2013). Consequently we developed our qPCR assay for SOB based on $\operatorname{sox} B$. Using methods analogous to those used to create $\mathrm{pKN} 23$, we constructed a qPCR standard plasmid containing the $s o x B$ gene from the bacterium Sulfurihydrogenibium azorense; we chose this particular sequence because it shares significant homology with other known $\operatorname{soxB}$ genes. The resulting plasmid was named $\mathrm{pS} 1$ and used as the standard for quantitation of $s o x B$ genes. Unlike the case for the more conserved and better studied $d s r$ genes, published qPCR primer sequences for sox $B$ amplification from environmental organisms were not readily available. Therefore we designed our own primers for $\operatorname{sox} B$ quantitation. Details regarding primer design are provided in Appendix $\mathrm{H}$, along with the experimental protocol for the $\mathrm{qPCR}$ assay for sox $B$ genes.

\subsubsection{Application to Field Samples}

The qPCR assays for $d s r B$ and $s o x B$ genes were applied to samples from two different thermal systems, described separately below.

\subsubsection{Soda Springs}

In August 2012, thermal water was collected from three locations (Soda Geyser, Hooper Spring, and Sulphur Springs; Figure 'H1' in Appendix H) in and around the town of Soda Springs, Idaho. Soda Springs is located in the fold and thrust belt on the eastern boundary of the track of the Yellowstone Hotspot. The 
region is known for its carbonated waters; there is a deep carbon dioxide source believed to originate from Mississippian limestone in contact with acidic hydrothermal fluids at depth. Samples were collected and characterized as described in Fujita et al. (2013) (Appendix i'). The chemical compositions of the water samples, used for RTEst modeling, are provided in Table

The results of the cell count and $d s r B$ and $s o x B$ qPCR assays for Soda Springs are presented in Table 5. The data indicate that not only are the microbial loads highest at Sulphur Springs, but also that the proportions of potential S transforming organisms, both sulfate reducers and S oxidizers, are by far the highest at that location. Assuming that there is one copy of the functional gene per genome, at Sulphur Springs the percentage of cells carrying $d s r B$ genes is $1.1 \%$, while the percentage carrying sox $B$ is as high as $31 \%$. The corresponding values for $d s r B$ and soxB at Soda Geyser are $0.03 \%$ and $2.1 \%$, and at Hooper Spring 0.04 and $0.5 \%$, respectively.

Table 5. Cell counts and $d s r B$ and $\operatorname{sox} B$ gene estimates for Soda Springs samples (standard deviation in parentheses).

\begin{tabular}{|l|l|l|l|}
\hline Location & Cells $\left(\mathrm{ml}^{-1}\right)$ & $d s r B$ copies $\left(\mathrm{ml}^{-1}\right)$ & soxB copies $\left(\mathrm{ml}^{-1}\right)$ \\
\hline Hooper Spring & $4.9(1.6) \mathrm{E}+4$ & $1.9(1.3) \mathrm{E}+1$ & $2.4(1.0) \mathrm{E}+2$ \\
\hline Soda Geyser & $9.3(3.1) \mathrm{E}+4$ & $3.1(2.6) \mathrm{E}+1$ & $1.9(2.1) \mathrm{E}+3$ \\
\hline Sulphur Springs & $8.5(3.4) \mathrm{E}+7$ & $9.0(3.4) \mathrm{E}+5$ & $2.6(0.58) \mathrm{E}+7$ \\
\hline
\end{tabular}

Overall, the qPCR results suggest that of the three locations, Sulphur Springs' water chemistry is most likely to be affected by biological S redox activity. Next most affected would be Soda Geyser, and the least affected would be Hooper Spring. These findings were consistent with the hypothesis that more biological activity results in less reliable temperature predictions by geothermometry; the reservoir temperature predictions generated by RTEst are shown in Table 6. Although the whole Soda Springs region is believed to be part of the same geothermal system, the temperatures predicted by RTEst for the three different locations are quite different from each other [Figures $\mathrm{H} 2$ t through $\mathrm{H} 4$ show the $\log \left(\mathrm{Q} / \mathrm{K}_{\mathrm{T}}\right)$ curves generated by RTEst]. Previous estimates of the temperature of the deep geothermal source for the Soda Geyser, based on $\mathrm{SiO}_{2}$ geothermometry, were in the range of $85-90^{\circ} \mathrm{C}$ (Mitchell, 1976). Of the three locations we sampled, the geothermal reservoir temperature predicted based on the chemistry of Hooper Spring (the location with the lowest microbial S cycling population) was closest to the expected value. At the other extreme, Sulphur Springs, with very high microbial influence, yielded the most anomalous temperature prediction. Soda Geyser was intermediate between the two. The uncertainties in estimated temperatures, although relatively small for these three samples, are found to be increasing with increasing number of $\operatorname{soxB}$ copies in the water (Figure $\mathrm{H}^{\mathrm{H}} 5 \mathrm{i}$ ).

Table 6. RTEst results for Hooper Spring, Soda Geyser, and Sulphur Springs in Soda Springs, Idaho.

\begin{tabular}{|l|c|c|c|c|c|}
\hline Location & \multicolumn{2}{|c|}{$\mathrm{RTEst} \mathrm{T} \pm \sigma\left({ }^{\circ} \mathrm{C}\right)$} & \multicolumn{2}{|c|}{$\log \mathrm{fCO}_{2} \pm \sigma$} & $\phi$ \\
\hline Hooper Spring & 97 & 2.5 & 0.74 & 0.05 & $2.83 \mathrm{E}-03$ \\
\hline Soda Geyser & 60 & 5.6 & 1.75 & 0.09 & $2.05 \mathrm{E}-02$ \\
\hline Sulphur Springs & 40 & 6.1 & -0.32 & 0.34 & $8.33 \mathrm{E}-02$ \\
\hline
\end{tabular}

The $\log \left(\mathrm{Q} / \mathrm{K}_{\mathrm{T}}\right)$ plots of the Soda Springs samples (Figures 'H2' through $\mathrm{H} 4$ ) also suggest different biogeochemical and/or physical histories for these waters. Hooper Spring, the sampling site that appeared to host the least microbial activity, showed very good convergence of the $\log \left(\mathrm{Q} / \mathrm{K}_{\mathrm{T}}\right)$ curves for the assemblage minerals even before optimization. In fact, for the Hooper Spring system optimization did not 
improve temperature estimation. Such behavior is expected for a system where secondary processess did not appreciably alter the water composition.

In contrast, the $\log \left(\mathrm{Q} / \mathrm{K}_{\mathrm{T}}\right)$ curves of the assemblage minerals (Figure $\mathrm{H}$ - 3 i') for Soda Geyser before optimization were not at all close to convergence. This behavior prior to optimization may have been related to significant changes in the chemistry of the water because of loss of $\mathrm{CO}_{2}$, precipitation of minerals, and possibly microbial activity. The highly mineralized water charged with $\mathrm{CO}_{2}$ at the Soda Geyser is well documented (e.g., Mitchell et al., 1976). For the Soda Geyser water, even after optimization the convergence of the $\log \left(\mathrm{Q} / \mathrm{K}_{\mathrm{T}}\right)$ curves was still poor despite the relatively good standard error for the estimated temperature.

The $\log \left(\mathrm{Q} / \mathrm{K}_{\mathrm{T}}\right)$ curves of assemblage minerals for Sulphur Springs (Figure i $\mathrm{H}^{4}$ ) were interesting because most of them converged at around $40^{\circ} \mathrm{C}$ before and after optimization. Only paragonite was out of convergence before optimization, and this mineral remained out of convergence even after optimization. The $\log \left(\mathrm{Q} / \mathrm{K}_{\mathrm{T}}\right)$ curves for this spring indicate that the spring water may have actually reequilibrated at lower temperature. It is possible that enhanced microbial activity may have facilitated this reequilibration. It is difficult to generalize however about Sulphur Springs. Within a relatively small geographical area, multiple surface expessions exist and these expressions can have very different chemistry. For example, the example used in this report was at near neutral $\mathrm{pH}$ (6.28) whereas another expression that we have sampled in the past had a measured $\mathrm{pH}$ of $<3$. Unfortunately we were not able to apply our molecular biomarker assays or RTEst to that second expression at Sulphur Springs.

\subsubsection{Ojo Caliente}

The Ojo Caliente spring is in the Lower Geyser Basin of Yellowstone National Park, in Wyoming (Figure H6). It is a slightly alkaline pool with a well-defined outflow system that has been studied extensively by the U.S. Geological Survey (USGS), in particular with respect to its sulfur chemistry. The deep source for Ojo Caliente is believed to be high in sulfide, which undergoes oxidation to thiosulfate as the water reaches the surface (Xu, Schoonen et al. 1998). Whether the oxidation process is facilitated by microbial activity has not been previously reported. The INL team received microbial samples that had been collected at Ojo Caliente in September 2013 by researchers from Montana State University and Rutgers University engaged in another project. Professor Tamar Barkay at Rutgers generously shared $142 \mathrm{~mm}$ cellulose acetate filters used to recover cells from $2 \mathrm{~L}$ volumes of Ojo Caliente water pumped from 5 different depths in the deep shaft that supplies water into the pool; the samples were collected at $0.3,18$, 35,50 and $70 \mathrm{~m}$ below the pool water surface. Filters were shipped to INL on dry ice and stored at $-80^{\circ} \mathrm{C}$ prior to DNA extraction. The extraction was performed on half filters (the filters had been cut using a razor blade or scalpel, in order to reserve half for ribonucleic acid extraction) using a MoBio PowerWater ${ }^{\circledR}$ kit, with minor modifications including a phenol/chloroform/isoamyl alcohol extraction step. Water chemistry data (Table 133 i for samples collected at the same depths and times as the cells for DNA were obtained from McCleskey et al. (2014).

The results of the $d s r B$ and $\operatorname{sox} B$ qPCR assays applied to the Ojo Caliente DNA extracts indicated that populations of both sulfate reducing and sulfur oxidizing organisms detectable by our assays were minimal in the Ojo Caliente samples. None of the samples (from five depths) yielded reliably quantifiable $d s r B$ or $s o x B$ gene numbers. Similar amounts of DNA were extracted from each sample depth. Cell counts were not available for the samples, but assuming extraction efficiencies similar to those from Soda Springs' samples, planktonic cell numbers were estimated to be in the range of $10^{5}$ to $>10^{6}$ per mL. The low quantities of DNA extracted, the predicted cell numbers, and our qPCR results for sulfate reducers and sulfur oxidizers suggest that very little microbially mediated sulfur redox activity is occurring or has occurred in any of the tested depths of the Ojo Caliente spring. It is important to note however that it is possible that sulfate reducing or sulfur oxidizing organisms not amenable to detection with our qPCR primers or assay conditions are present. 
For the development of the reservoir temperature of the Ojo Caliete system, an RMA consisting of quartz, calcite, illite, mordenite, and potassium feldspar was used (Figures ${ }^{\prime} \mathrm{H} 7 \mathrm{i}$ through $\mathrm{H} 9$ ). The RTEst results of all Ojo Caliente water samples are presented in Table 7. The predicted temperatures for the deep geothermal resource based on the chemistry of the water samples were very similar, approximately $200^{\circ} \mathrm{C}$ for all five sampling locations, with very little variance. This is consistent with the qPCR assays, which found that all five samples were similar in terms of minimal $d s r B$ and $\operatorname{sox} B$ gene abundance.

The temperatures estimated by RTest for Ojo Caliente were similar to temperatures measured at numerous drill holes in the park (Fournier and Truesdell, 1970). These results, together with the results of the molecular biomarker assays, support the contention that the level of microbial activity at a site is inversely correlated with the reliability of temperature predictions for that site using RTEst or other current geothermometric approaches. Surface expressions like Ojo Caliente, with minimal microbial activity, tend to be more suitable for the application of geothermometry than biologically active systems like Sulphur Springs.

Table 7. RTEst results for Ojo Caliente Spring in Yellowstone National Park, Wyoming.

\begin{tabular}{|l|c|c|c|c|c|}
\hline Location & \multicolumn{2}{|c|}{ RTEst $\mathrm{T} \pm \sigma\left({ }^{\circ} \mathrm{C}\right)$} & \multicolumn{2}{|c|}{$\log \mathrm{fCO}_{2} \pm \sigma$} & $\phi$ \\
\hline Ojo Caliente $(0.3 \mathrm{~m})$ & 199 & 1.3 & -0.46 & 0.04 & $5.71 \mathrm{E}-04$ \\
\hline Ojo Caliente $(18 \mathrm{~m})$ & 199 & 1.8 & -0.50 & 0.06 & $1.12 \mathrm{E}-03$ \\
\hline Ojo Caliente $(35 \mathrm{~m})$ & 199 & 2.0 & -0.53 & 0.07 & $1.29 \mathrm{E}-03$ \\
\hline Ojo Caliente $(50 \mathrm{~m})$ & 199 & 1.7 & -0.43 & 0.06 & $9.85 \mathrm{E}-04$ \\
\hline Ojo Caliente $(70 \mathrm{~m})$ & 202 & 1.9 & -0.36 & 0.06 & $1.27 \mathrm{E}-03$ \\
\hline
\end{tabular}

\section{Product Commercialization}

The original proposal suggested that the software analysis package could be developed into a commercial package by RockWare or Schlumberger Water Services and distributed to the geothermal community through their existing channels. Alternatively, this product could be provided free to the public. After consideration of both options, we have decided to proceed along the second track of providing a free software package to the public. This decision was in part due to the use of a fairly expensive software geochemical package (i.e., GWB) within the RTEst package and due to a relatively small market within the public sector that could effectively use the software.

On December 18, 2014, INL has submitted an Assertion Copyright request letter (CW-15-02) to DOE in behalf of Carl Palmer. In this letter, it states that Carl D. Palmer under BEA Subcontract Numbers 149535 and 42246 -114, effective date March 7, 2012 contributed to development of the BEA software RTEst. Carl D. Palmer requests permission from DOE to assert copyright in all versions and derivative works prepared by Carl D. Palmer, in software entitled RTEst for the purpose of assignment of such rights to BEA as the M\&O contractor of the Idaho National. This assertion of copyright will effectively allow BEA to distribute the software to the public while maintaining control of the contents of the software.

The software package includes a user's manual (see Appendix (B.'s), and a setup file to install the RTEst program on Windows-based computers. Once BEA finishes acquiring the copyright assignment, we can upload these files to the National Geothermal Database System for public distribution.

To make it more cost effective and more accessible to other researchers to assess geothermal prospecting, we would like to suggest one of these two activities as follow on to make RTEst a standalone tool. This could be achieved either by purchasing the copyright to use GWB geochemical modelling kernel from Aqueous Solutions LLC or by modifying the RTEst code so that it can be used with freely available geochemical code such as PHREEQc (Parkhurst and Appelo, 1999). 


\section{Publications/Awards}

A number of papers/presentations were given at workshops and meeting for the project. The following publications were made during the project period.

(1) Proceeding paper- Stanford Geothermal Workshop-2013 (Fujita et al., 2013) (Appendix 而)

(2) Proceeding paper- Stanford Geothermal Workshop-2013 (Cooper et al., 2013) (Appendix

(3) Proceeding paper- Stanford Geothermal Workshop-2014 (Neupane et al, 2014) (Appendix Ki.)

(4) Proceeding paper: GRC Meeting-2014 (Palmer et al., 2014) (Appendix 'L)

(5) Proceeding paper: World Geothermal Congress-2015 (Neupane et al., 2015) (Appendix 'Mis)

(6) Proceeding paper- Stanford Geothermal Workshop-2015 (Neupane et al., 2015) (Appendix ……

The following presentations were made during the project period.

(1) AGU Fall Meeting, 2012. (Smith et al., 2012) (Appendix 'Oi')

(2) Stanford Geothermal Workshop-2013 (Fujita et al., 2013) (Appendix

(3) Stanford Geothermal Workshop-2013 (Cooper et al., 2013) (Appendix (Ji)

(4) GSA Annual Meeting 2013a (Neupane et al., 2013a) (Appendix'P')

(5) GSA Annual Meeting 2013b (Neupane et al., 2013b) (Appendix Q $\mathrm{Q}$ )

(6) Stanford Geothermal Workshop-2014 (Neupane et al., 2014) (Appendix 'K'

(7) GRC Meeting-2014 (Palmer et al., 2014) (Appendix 'L)

(8) Stanford Geothermal Workshop-2015 (Neupane et al., 2015) (to be presented) (Appendix 奋)

The following awards were presented to group members while working on this project.

(1) Palmer et al. Best presentation award in Geochemistry Session, GRC 2014. (Appendix 㓩)

(2) Baum et al. $1^{\text {st }}$ runner up for poster presentation at INL summer intern session, 2014.

Manual

1. RTEst users' manual (Appendix B)

\section{Human Resource Development}

Postdoc -1

(1) Ghanashyam Neupane (University of Idaho). Ghanashyam was initially hired as a postdoc at University of Idaho to work on this project. Recently, he has been hired by the INL as a project hire to work on this as well other projects.

Interns -5

(1) Sergio Hernandez (Idaho State University). Sergio was involved in the biotic component of the project. Recently, he has been hired by INL.

(2) Ryan Hensleigh (Montana State Unversity). Ryan worked on the sulfur cycling portion of the project.

(3) Kaitlyn Nowak (Carnegie Mellon). Kaitlyn worked on the sulfur cycling portion of the project.

(4) Rebecca Sara Ohly (Idaho State University). Sara worked on developing appropriate sets of mineral assemblages.

(5) Jeff Baum (Brown University). Jeff examined 4 geothermal plant water chemistries and predicted temperatures using RTEst, these estimated temperatures were compared with production well bottom-hole temperatures measured prior to plant production.

\section{Summary}

We have developed a multicomponent optimization program (RTEst) that is capable of taking into account several processes including formation of a steam phase, loss of volatile solutes such as $\mathrm{CO}_{2}$, and mixing of thermal and non-thermal waters in making geothermometric calculations. The program has been tested against hypothetical scenarios, laboratory experiments, and data from geothermal fields. Results of this testing suggest that RTEst is capable of predicting reservoir temperature to within $\pm 30^{\circ} \mathrm{C}$ 
under a variety of conditions. We have also developed and tested an approach for identifying waters where biological activity may make such geothermometric calculations problematic. These efforts have advanced the scientific state of the art for geothermometry and led to the development of a tool that will be available to other researchers within the US and around the world, and ultimately may support the reduction of geothermal prospecting risk.

\section{Appendices}

Supporting materials:

Appendix A. MEG illustrative examples

Appendix B. RTEst Manual

Appendix C. Literature sources considered in developing representative reservoir mineral assemblages Appendix D. Hypothetical test cases

Appendix E. Equilibrium experimental cases

Appendix F. Experimental mixing cases

Appendix G. Raft River geothermal materials

Appendix H. Biotic work related materials

Papers:

Appendix I. Fujita et al., 2013, Stanford Geothermal Workshop-2013

Appendix J. Cooper et al., 2013, Stanford Geothermal Workshop-2013

Appendix K. Neupane et al., 2014, Stanford Geothermal Workshop

Appendix L. Palmer et al., 2014, GRC Meeting -2014

Appendix M. Neupane et al., 2015, WGC Meeting-2015

Appendix N. Neupane et al., 2015, Stanford Geothermal Workshop-2015

Abstracts:

Appendix O. Smith et al. 2012, AGU Fall Meeting-2012

Appendix P. Neupane 2013a, GSA Annual Meeting-2013

Appendix Q. Neupane 2013b, GSA Annual Meeting-2013

Award:

Appendix R. Palmer et al. 2014, GRC award letter and certificate

\section{References}

Armannson, H., Fridriksson, T., 2009. Application of Geochemical Methods in Geothermal Exploration. Short Course on Surface Exploration for Geothermal Resources organized by the United Nations University Geothermal Training Programme, Ahuachapan and Sata Tecla, El Salvador, p. 12.

Armstrong, R.L. and Hills, F.A. (1967). Rb-Sr and K-Ar geochronologic studies of mantled gneissic domes, Albian Range, southern Idaho, USA. Earth and Planetary Science Letters, 3(2), 114-124.

Armstrong, R.L., Smith, J.F., COnvington, H.R., and Williams, P.L. (1978). Preliminary geologic map of the west half of the Pocatello $1^{\circ} \mathrm{X} 2^{\circ}$ quadrangle, Idaho. US Geological Survey, Open File Report 78533.

Arnórsson, S., Gunnlaugsson, and Svavarsson, H. (1983). The chemistry of geothermal waters in Iceland. III. Chemical geothermometry in geothermal investigations. Geochimica et Cosmochimica Acta, 47, 567-577.

Bethke, C.M., 2008. Geochemical and Biogeochemical Reaction Modeling, 2nd ed. Cambridge University Press, New York, New York, USA.

Bethke, C.M., Yeakel, S., 2011. The Geochemist's Workbench User's Guide. Aqueous Solutions, Champaign, IL.

Bourne, D.G., van der Zee, M.J.J., Botté, E.S., Sato, Y., 2013. Sulfur-oxidizing bacterial populations within cyanobacterial dominated coral disease lesions. Environ. Microbiol. Rep. 5, 518-524.

Browne, P. R. L., 1978. Hydrothermal alteration in active geothermal fields. Annual Reviews in Earth and Planetary Science, vol. 6, pp. 229-250 
Chin, K. J., M. L. Sharma, L. A. Russell, K. R. O'Neill and D. R. Lovley (2008). "Quantifying expression of a dissimilatory (bi) sulfite reductase gene in petroleum-contaminated marine Harbor Sediments." Microbial Ecology 55(3): 489-499.

Cooper, D.C., Palmer, C.D., Smith, R.W., \& McLing, T.L., 2013. Multicomponent equilibrium models for testing geothermometry approaches. Proceedings of the Thirty-Eighth Workshop on Geothermal Reservoir Engineering, Stanford University, Stanford, CA.

Doherty, J., 2005. PEST, Model-Independent Parameter Estimation User Manual, 5th ed. Watermark Numerical Computing.

Doherty, J., 2013. Addendum to the PEST Manual. Watermark Numerical Computing.

Ehrlich, H. L. (1996). Geomicrobiology. New York, Marcel Dekker, Inc.

Fournier, R.O. and Truesdell, A.H. (1970). Chemical indicators of subsurface temperature applied to hot spring waters of Yellowstone National Park, Wyoming, USA. Geothermics 2, 529-535.

Fournier, R.O. (1977). Chemical geothermometers and mixing models for geothermal systems. Geothermics 5, 41-50.

Fujita, Y., D. W. Reed, K. R. Nowak, V. S. Thompson, T. L. McLing, R. W. Smith and D. C. Cooper (2013). Microbial impacts on geothermometry temperature predictions. Stanford Geothermal Workshop, Stanford, CA.

Geets, J., B. Borrernans, L. Diels, D. Springael, J. Vangronsveld, D. van der Lelie and K. Vanbroekhoven (2006). "DsrB gene-based DGGE for community and diversity surveys of sulfate-reducing bacteria." Journal of Microbiological Methods 66(2): 194-205.

Ghosh, W. and B. Dam (2009). "Biochemistry and molecular biology of lithotrophic sulfur oxidation by taxonomically and ecologically diverse bacteria and archaea." FEMS Microbiology Reviews 33(6): 999-1043.

Giggenbach, W.F., 1988. Geothermal solute equilibria. Derivation of Na-K-Mg-Ca geoindicators. Geochimica et Cosmochimica Acta 52, 2749-2765.

Hull, C.D. and Reed, M.H. (1987). Chemical geothermometry and numerical unmixing of the diluted geothermal waters of the San Bernandono Valley region of southern California. GRC Transanctions $11,165-184$.

Kepner, R. L. and J. R. Pratt (1994). Use of Fluorochromes for Direct Enumeration of Total Bacteria in Environmental-Samples - Past and Present. Microbiological Reviews 58(4): 603-615.

Konhauser, K. O., B. Jones, V. Phoenix, G. Ferris and R. Renaut (2004). The microbial role in hot spring silicification. Ambio 33(8): 552-558.

Mariner, R. H., Swanson, J. R., Orris, G. J., Presser, T. S. and Evans, W. C. (1980). Chemical and isotopic data for water from thermal springs and wells of Oregon. U.S. Geol. Surv. Open-File Rep. 80-737.

Marteinsson, V. T., S. Hauksdottir, C. F. V. Hobel, H. Kristmannsdottir, G. O. Hreggvidsson and J. K. Kristjansson (2001). Phylogenetic diversity analysis of subterranean hot springs in Iceland. Applied and Environmental Microbiology 67(9): 4242-4248.

Meyer, B., Imhoff, J.F., Kuever, J., 2007. Molecular analysis of the distribution and phylogeny of the soxB gene among sulfur-oxidizing bacteria - evolution of the Sox sulfur oxidation enzyme system. Environ. Microbiol. 9, 2957-2977.

Meyer-Dombard, D. R., E. L. Shock and J. P. Amend (2005). Archaeal and bacterial communities in geochemically diverse hot springs of Yellowstone National Park, USA. Geobiology 3(3): 211-227.

Mitchell, J. (1976). Geothermal investigations in Idaho. Part 6. Geochemistry and geologic setting of the thermal and mineral waters of the Blackfoot Reservoir area, Caribou County, Idaho, Idaho Dept. of Water Resources, Boise (USA): 47.

Neupane, G., Mattson, E.D., McLing, T.L., Palmer, C.D., Smith, R.W., and Wood, T.R., (2014). Deep geothermal reservoir temperatures in the Eastern Snake River Plain, Idaho using multicomponent geothermometry. Proceedings, Thirty-ninth Workshop on Geothermal Reservoir Engineering, Stanford University, Stanford, California, February 24-26, 2014 SGP-TR-202. 
Neupane, G., Mattson, E.D., McLing, T.L., Palmer, C.D., Smith, R.W., and Wood, T.R., Podgorney, R.K., (2015). Geothermal reservoir temperatures in southeastern Idaho using multicomponent geothermometry. Proceedings, World Geothermal Congress 2015, Melbourne, Australia, 19-25 April 2015.

Neupane, G., Jeffrey, B.S., Mattson, E.D., Mines, G.L., Palmer, C.D., and Smith, R.W., (2015). Validation of multicomponent equilibrium geothermometry at four geothermal power plants. Proceedings, Fortieth Workshop on Geothermal Reservoir Engineering, Stanford University, Stanford, California, January 26-28, 2015 SGP-TR-204.

Niederberger, T. D., R. S. Ronimus and H. W. Morgan (2008). "The microbial ecology of a hightemperature near-neutral spring situated in Rotorua, New Zealand." Microbiological Research 163(5): 594-603.

Palmer, C.D., 2014. Reservoir Temperature Estimator (RTEst) User's Manual. Idaho National Laboratory, p. 46.

Pang, Z.-H., Reed, M., 1998. Theoretical Chemical Thermometry on Geothermal Waters: Problems and Methods. Geochimica et Cosmochimica Acta 62, 1083-1091.

Parkhurst, D.L., Appelo, C.A.J., 1999. User's guide to PHREEQC (Version 2)-A computer program for speciation, batch-reaction, one-dimensional transport, and inverse geochemical calculations. U.S. Geol. Survey, Water Resour. Invest. Rep. 99-4259.

Peiffer, L., Wanner, C., Spycher, N., Sonnenthal, E., Kennedy, B.M., Iovenitti, J., 2014.Optimized multicomponent vs. classical geothermometry: insights from mod-eling studies at the Dixie Valley geothermal area. Geothermics 51, 154-169.

Petri, R., Podgorsek, L., Imhoff, J.F., 2001. Phylogeny and distribution of the soxB gene among thiosulfate-oxidizing bacteria. FEMS Microbiol. Lett. 197, 171-178.

Reed, M., Spycher, N., 1984. Calculation of $\mathrm{pH}$ and mineral equilibria in hydrothermal waters with application to geothermometry and studies of boiling and dilution. Geochimica et Cosmochimica Acta $48,1479-1492$.

Schwartz, G.M., 1959. Hydrothermal alteration. Economic Geology 54, 161-183.

Spycher, N.F., Sonnenthal, E., Kennedy, B.M., 2011. Integrating multicomponent chemical geothermometry with parameter estimation computations for geothermal exploration. Geothermal Resources Council Transactions 35, 663-666.

Spycher, N.F., Peiffer, L., Sonnenthal, E.L., Saldi, G., Reed, M.H., and Kennedy, B.M., 2014. Integrated multicomponent solute geothermometry. Geothermics 51, 113-123.

Takai, K. and K. Nakamura (2011). Archaeal diversity and community development in deep-sea hydrothermal vents. Current Opinion in Microbiology 14(3): 282-291.

U.S. Department of Energy, 2011. Exploration Technologies, Technology Needs Assessment, Energy Efficiency and Renewable Energy, Geothermal Technology Program, DOE/EE-0663.

Wagner, M., A. J. Roger, J. L. Flax, G. A. Brusseau and D. A. Stahl (1998). Phylogeny of Dissimilatory Sulfite Reductases Supports an Early Origin of Sulfate Respiration. Journal of Bacteriology 180(11): 2975-2982.

Xu, Y., M. A. A. Schoonen, D. K. Nordstrom, K. M. Cunningham and J. W. Ball (1998). Sulfur geochemistry of hydrothermal waters in Yellowstone National Park: I. the origin of thiosulfate in hot spring waters. Geochimica et Cosmochimica Acta 62(23-24): 3729-3743. 


\section{Appendix A. Multicomponent equilibrium geothermometry}

The following examples are based on Bethke (2008).

A brine containing 2.05163 molal $\mathrm{Cl}$ and 0.05 molal $\mathrm{Ca}$ at $\mathrm{pH} 5.2$ is equilibrated with quartz, calcite, albite, "Maximum microcline", and muscovite at $250^{\circ} \mathrm{C}$. This geothermal water is transported to the surface where the gas phase is condensed and reconstituted with the liquid phase at $25^{\circ} \mathrm{C}$ and the pH and dissolved constituents are measured. The system represents a closed hydrothermal system where both the liquid phase and the gas phase could be sampled. The objective is to determine the temperature of the deep reservoir from the $25^{\circ} \mathrm{C}$ "sample".

To estimate the deep reservoir temperature, we used The Geochemist's Workbench $®$ (Version 9) to first calculate the speciation of the "sample" water at $25^{\circ} \mathrm{C}$ and at the "measured" pH. The water (Table A1) is then speciated as a function of temperature over the range of $25^{\circ} \mathrm{C}$ to $300^{\circ} \mathrm{C}$, allowing the $\mathrm{pH}$ to be calculated while suppressing all mineral reaction. Plotting the calculated mineral saturation indices as a function of temperature (Figure A1) shows that the indices for quartz, calcite, albite, K-feldspar, and muscovite converge common point where $\mathrm{Q} / \mathrm{K}=1(\log (\mathrm{Q} / \mathrm{K})=0)$ at $250^{\circ} \mathrm{C}$. This point where the saturation indices converge to zero is the reservoir temperature estimated by the multicomponent geothermometry approach. This estimate is identical to that used to generate the subsurface fluid chemistry in this simple example. However, real-world systems are more complex than this idealized example, and in many situations the approach of varying a single parameter, temperature in this case, is unlikely to yield good estimates of reservoir temperature.

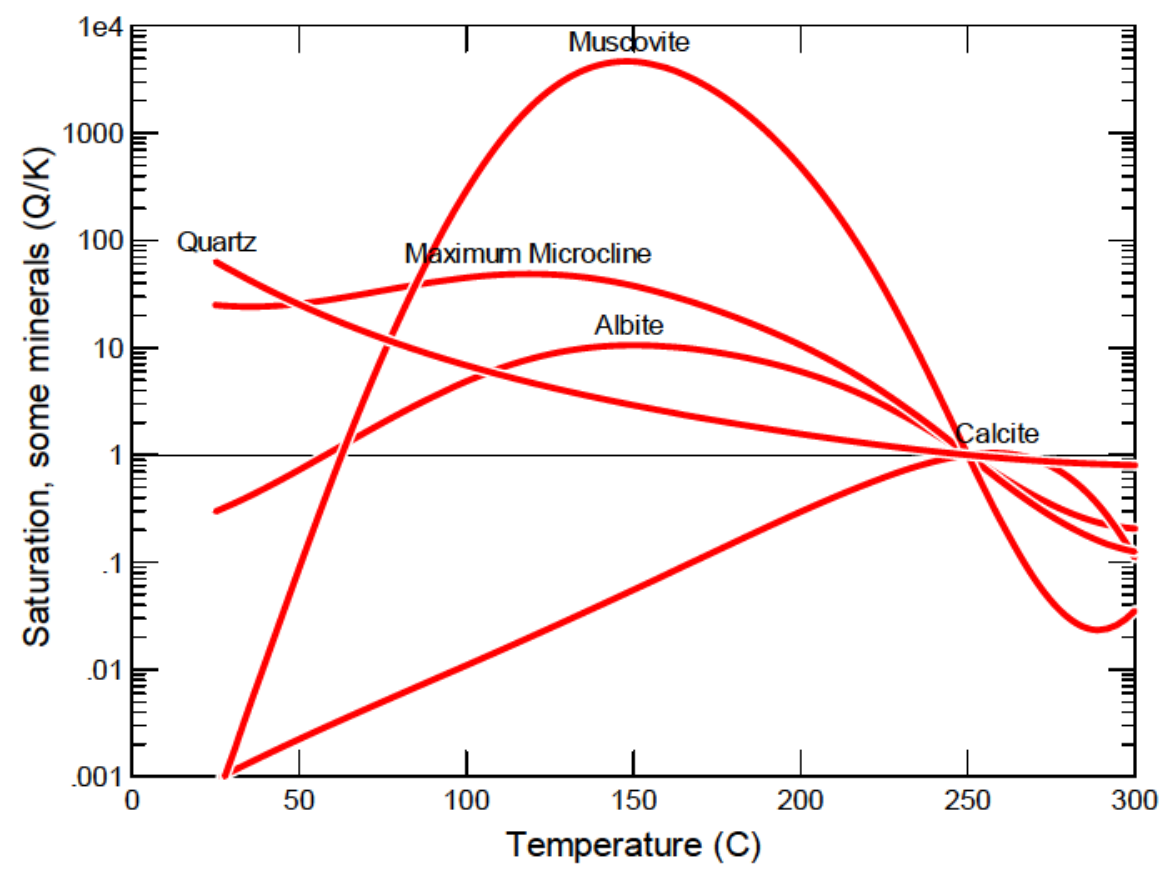

Figure A1. Plot of mineral saturation state versus temperature for a hypothetical closed geothermal system (after Bethke, 2008).

For example, consider case identical to first example except that as the fluid nears the surface, it loses $\mathrm{CO}_{2}$ and ultimately equilibrates at a $\mathrm{CO}_{2}$ fugacity of 1 atmosphere. Using this new water chemistry (Table A1) as the starting point and calculating the saturation states for the mineral assemblage in the reservoir as a function temperature (Appendix A) no unique intersection point is obtained. The mineral 
saturation plots for albite, K-feldspar, and quartz appear to converge, but calcite and muscovite do not. Further, the convergence of albite, $\mathrm{K}$-feldspar and quartz suggests a reservoir temperature of about $256^{\circ} \mathrm{C}$ rather than $250^{\circ} \mathrm{C}$. Even for these three minerals, the saturation occurs at $257.4,256.0$, and $249.8^{\circ} \mathrm{C}$, respectively

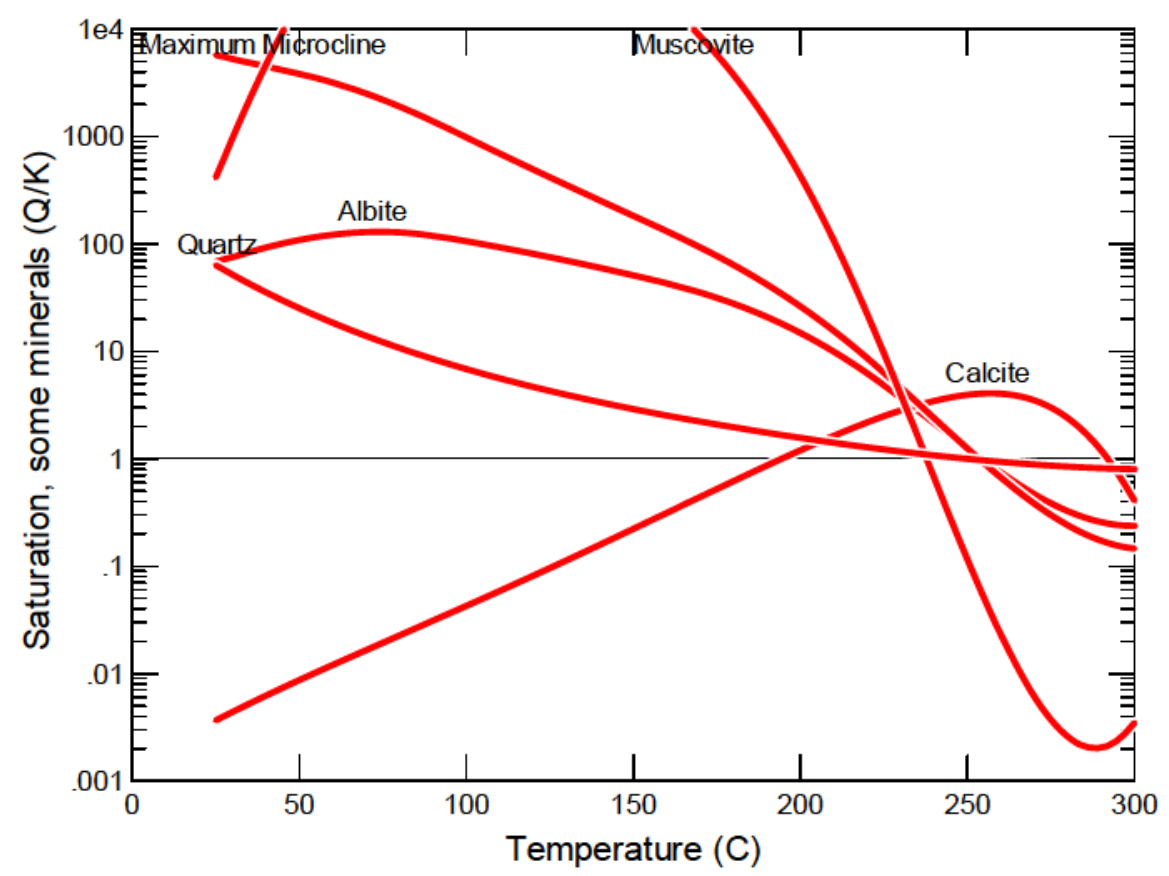

Figure A2. Plot of mineral saturation state versus temperature for the system depicted in Figure A1, but with the water equilibrated with 1 atmosphere of $\mathrm{CO}_{2}$ (after Bethke 2008).

This result clearly indicates that loss of volatile constituents from a geothermal system can have a significant impact on the relationship between fluid chemistry and estimated reservoir temperature. However, field sampling programs for geothermal exploration often do not gather sufficient data to directly account for loss of volatile constituents. Thus, the optimization process should explicitly include volatile components lost $\left(\mathrm{CO}_{2}\right.$ in this case) as an optimization parameter. 
Table A1. Initial concentrations of "sampled" water for the closed and open systems.

\begin{tabular}{|c|rr|}
\hline Analyte & \multicolumn{1}{|c|}{$\begin{array}{c}\text { Closed } \\
\text { System }\end{array}$} & $\begin{array}{c}\text { Open } \\
\text { System }\end{array}$ \\
\hline \hline $\mathrm{Al}^{3+} \mu$ molal & 0.471802 & 0.471781 \\
$\mathrm{Ca}^{2+}$ molal & 0.05 & 0.05 \\
$\mathrm{Na}^{+}$molal & 1.79052 & 1.79052 \\
$\mathrm{~K}^{+}$molal & 0.162405 & 0.162405 \\
$\mathrm{Cl}^{-}$molal & 2.05163 & 2.05163 \\
$\mathrm{HCO}_{3}{ }^{-}$molal & 0.15874 & 0.038055 \\
$\mathrm{SiO}_{2}$ molal & 0.00388 & 0.00388 \\
$\mathrm{pH}$ & 4.173457 & 4.785295 \\
$\mathrm{H}_{2} \mathrm{O}(\mathrm{kg})$ & 1 & 1 \\
$\left.\mathrm{Temp} .{ }^{\circ} \mathrm{C}\right)$ & 25 & 25 \\
\hline
\end{tabular}




\title{
Appendix B
}

\section{Reservoir Temperature Estimator (RTEst) \\ User's Manual}

\author{
Carl D. Palmer \\ Idaho National Laboratory
}

January, 2015

Prepared by Battelle Energy Alliance, LLC

Under Contract No. DE-AC07-05ID14517

With the U. S. Department of Energy 
NOTICE: This computer software was prepared by Battelle Energy Alliance, LLC, hereinafter the Contractor, under Contract No. DE-AC07-05ID14517 with the United States (U.S.) Department of Energy (DOE). All rights in the computer software are reserved by DOE on behalf of the United States Government and, if applicable, the Contractor as provided in the Contract. You are authorized to use this computer software for Governmental purposes but it is not to be released or distributed to the public.

NEITHER THE UNITED STATES GOVERNMENT, NOR DOE, NOR THE CONTRACTOR MAKE ANY WARRANTY, EXPRESSED OR IMPLIED, OR ASSUMES ANY LIABILITY OR RESPONSIBILITY FOR THE USE, ACCURACY, COMPLETENESS, OR USEFULNESS OR ANY INFORMATION, APPARATUS, PRODUCT, OR PROCESS DISCLOSED, OR REPRESENTS THAT ITS USE WOULD NOT INFRINGE PRIVATELY OWNED RIGHTS. This notice, including this sentence, must appear on any copies of this computer software.

EXPORT RESTRICTIONS. The provider of this computer software and its employees and its agents are subject to U.S. export control laws that prohibit or restrict (i) transactions with certain parties, and (ii) the type and level of technologies and services that may be exported. You agree to comply fully with all laws and regulations of the United States and other countries (Export Laws) to assure that neither this computer software, nor any direct products thereof are (1) exported, directly or indirectly, in violation of Export Laws, or (2) are used for any purpose prohibited by Export Laws, including, without limitation, nuclear, chemical, or biological weapons proliferation.

None of this computer software or underlying information or technology may be downloaded or otherwise exported or re-exported (i) into (or to a national or resident of) Cuba, North Korea, Iran, Sudan, Syria or any other country to which the U.S. has embargoed goods; or (ii) to anyone on the U.S. Treasury Department's List of Specially Designated Nationals or the U.S. Commerce Department's Denied Persons List, Unverified List, Entity List, Nonproliferation Sanctions or General Orders. By downloading or using this computer software, you are agreeing to the foregoing and you are representing and warranting that you are not located in, under the control of, or a national or resident of any such country or on any such list, and that you acknowledge you are responsible to obtain any necessary U.S. government authorization to ensure compliance with U.S. law. 


\section{Table of Contents}

\section{Contents}

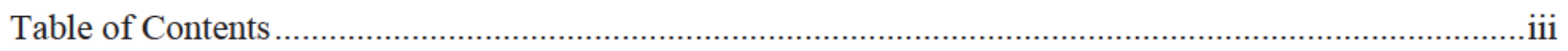

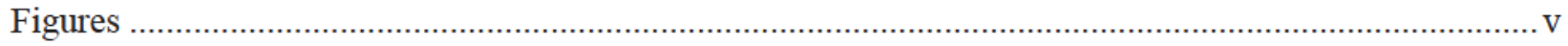

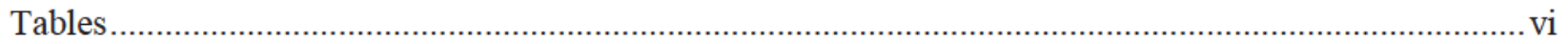

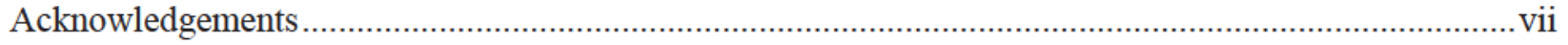

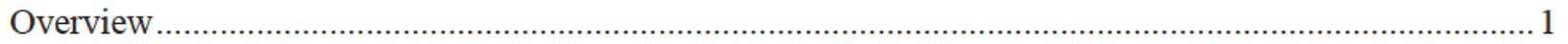

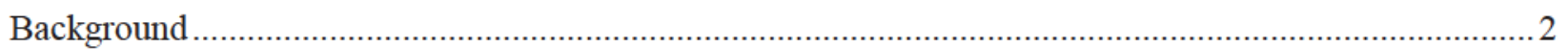

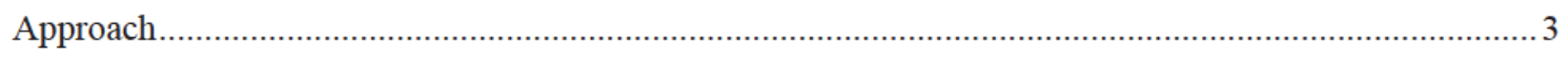

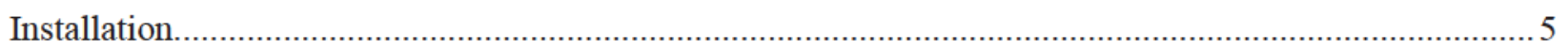

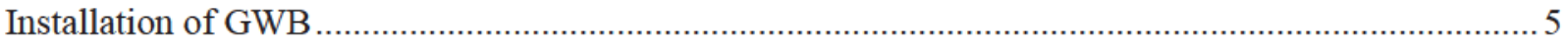

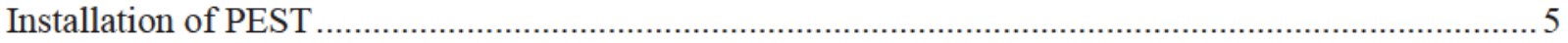

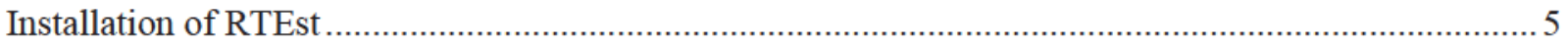

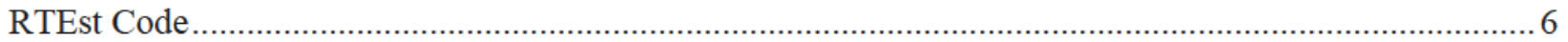

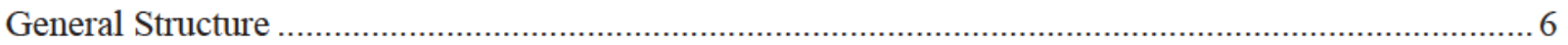

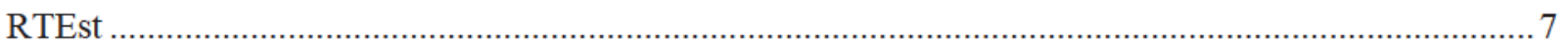

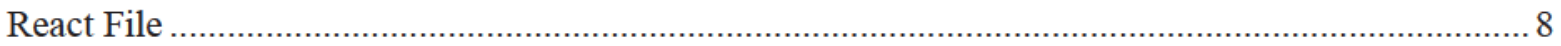

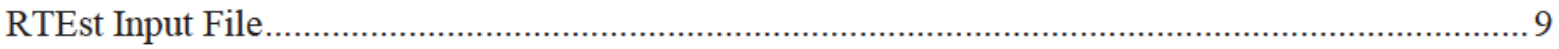

RTEst_Input_File_Generator................................................................................................. 10

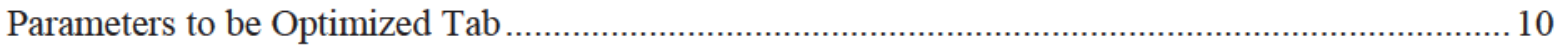

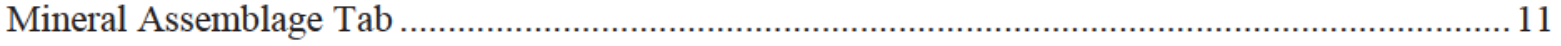

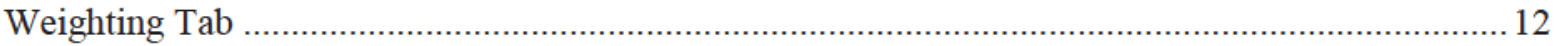

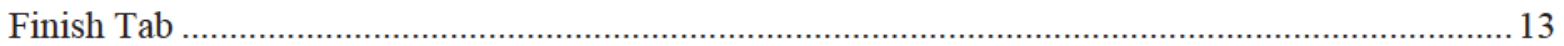

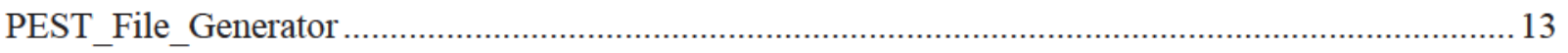

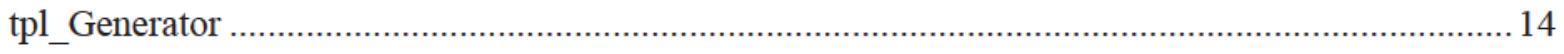

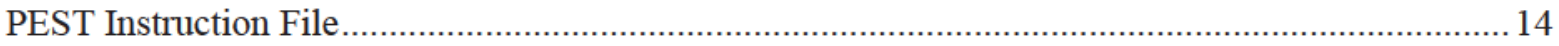

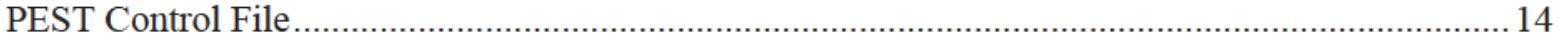

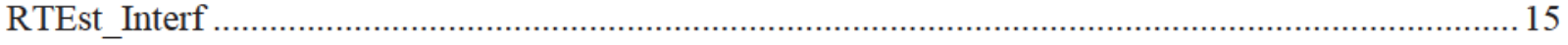

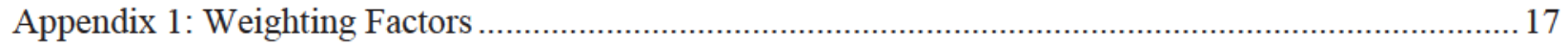

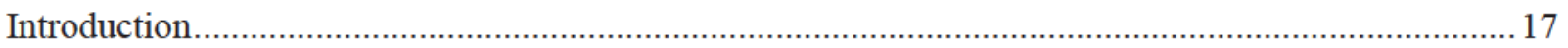

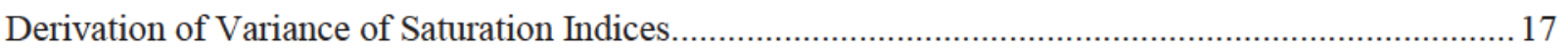

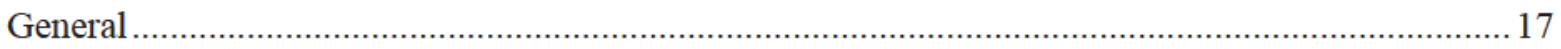




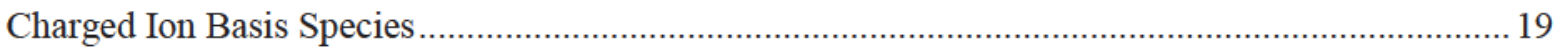

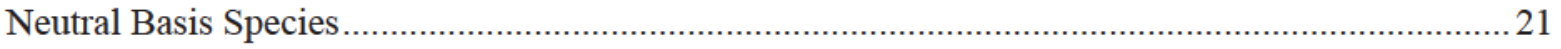

Water

Recommended Weighting Factors for Minerals ......................................................................... 24

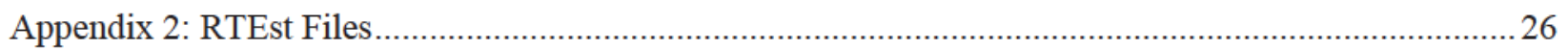

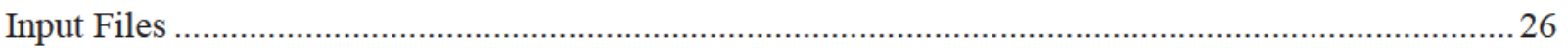

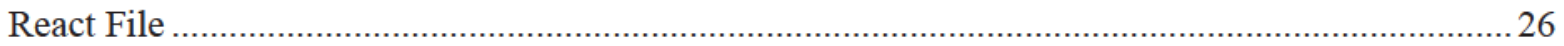

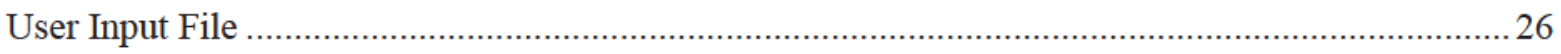

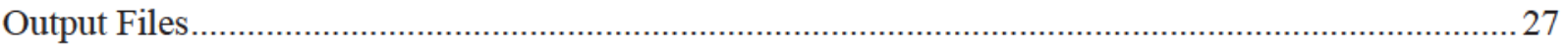

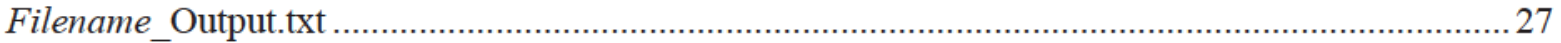

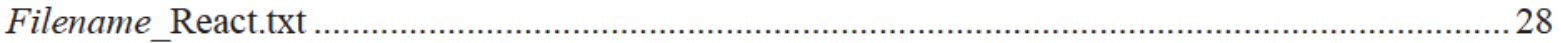

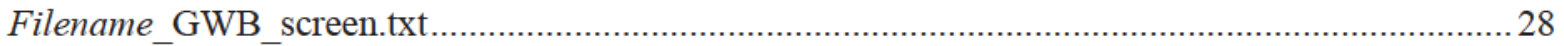

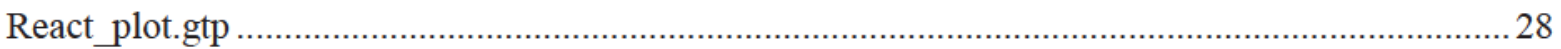

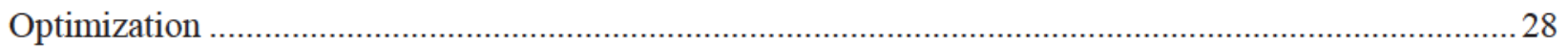

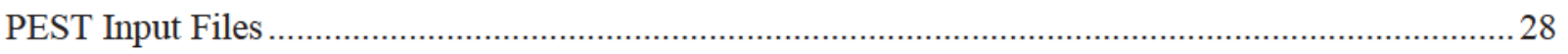

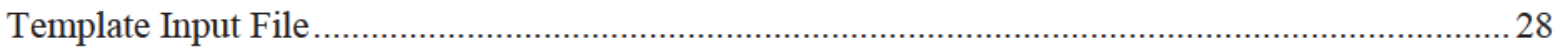

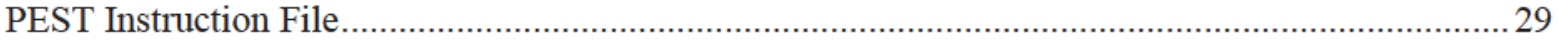

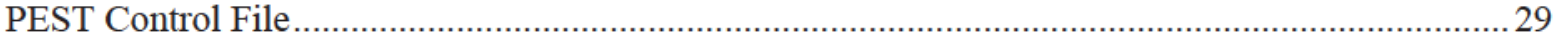

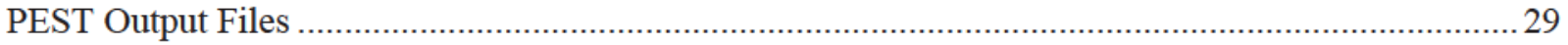

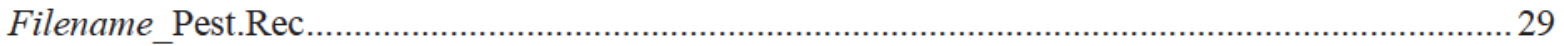

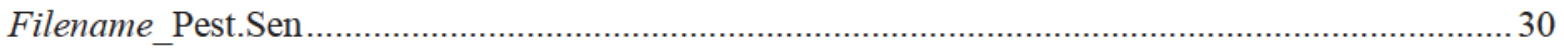

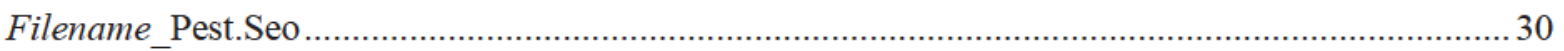

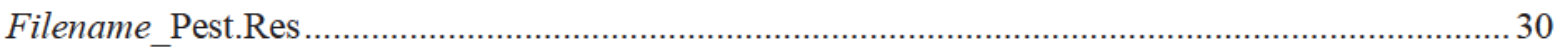

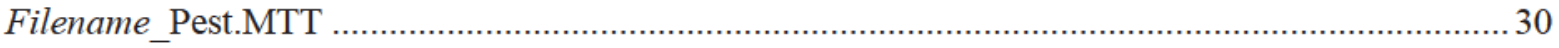

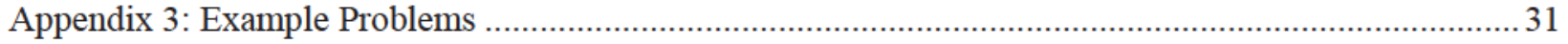

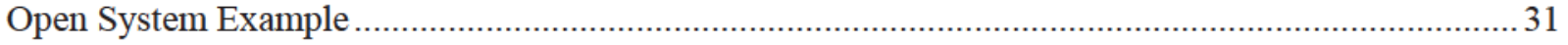

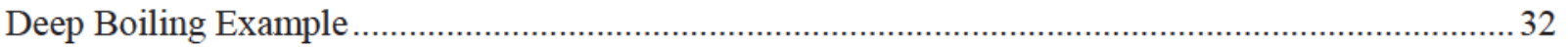

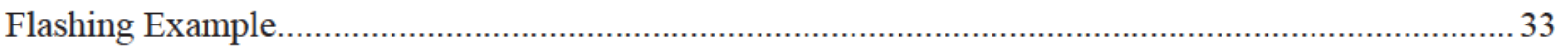

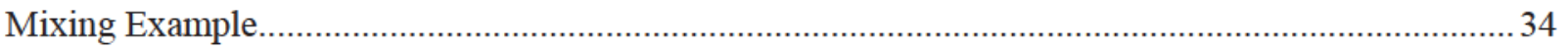

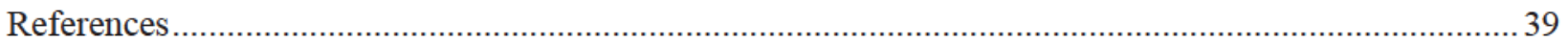




\section{Figures}

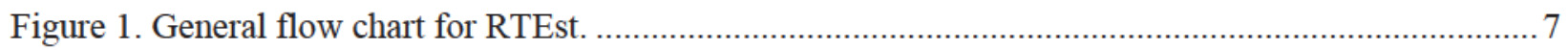

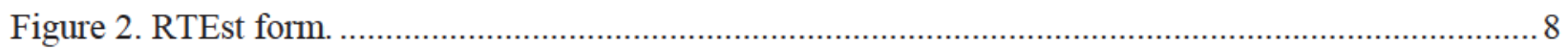

Figure 3. First tab of the RTESt Input File Generator form .............................................................. 10

Figure 4. Mineral Assemblage table of the RTEst_Input_File_Generator form....................................... 12

Figure 5. Weighting tab of the RTEst Input File Generator form...................................................... 13

Figure $6 . \xi_{\mathrm{i}}$ versus ionic strength for univalent cations. The lines are for $\mathrm{H}+$ (solid), $\mathrm{Li}+$ (short dash), $\mathrm{Na}+$ (dash-dot) and $\mathrm{K}+$ (dotted) at 25 (blue), 100 (green), 200 (brown) and 300 (red) ${ }^{\circ} \mathrm{C}$.

Figure 7. $\xi_{\mathrm{i}}$ versus ionic strength for anions. The lines are for SO4-- (solid), Cl- (short dash), and HCO3(dash-dot) at 25 (blue), 100 (green), 200 (brown) and 300 (red) ${ }^{\circ} \mathrm{C}$.

Figure 8. $\xi_{\mathrm{i}}$ versus ionic strength for divalent cations. The lines are for $\mathrm{Ca}++$ (solid), $\mathrm{Sr}++$ (short dash), $\mathrm{Mg}++$ (dash-dot) and $\mathrm{Al}+++$ (dotted) at 25 (blue), 100 (green), 200 (brown) and 300 (red) ${ }^{\circ} \mathrm{C} \ldots \ldots \ldots . .21$

Figure 9. $\xi_{\mathrm{i}}$ versus ionic strength for neutral, nonpolar basis species. The lines are the values at 25 (blue), 100 (green), 200 (brown) and 300 (red) ${ }^{\circ} \mathrm{C}$.

Figure 10. Values of $\eta$ as a function of stoichiometric ionic strength baseed and Eq. (29) and parameters

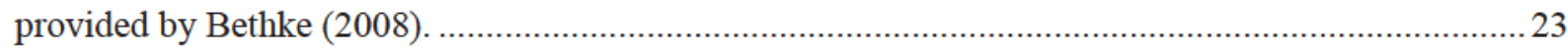

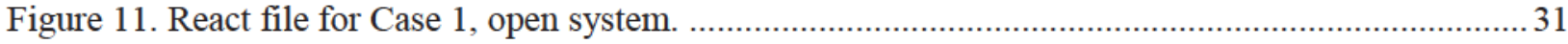

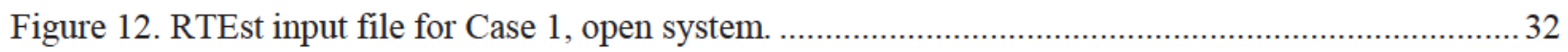

Figure 13. React file for Case 2, deep boiling. ……....................................................................... 33

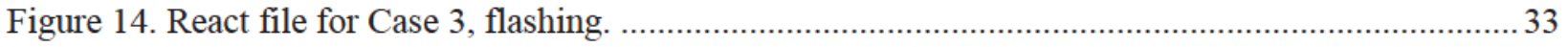

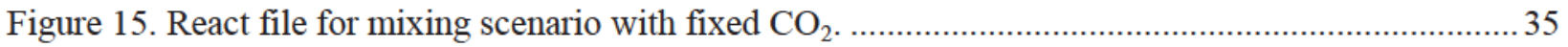

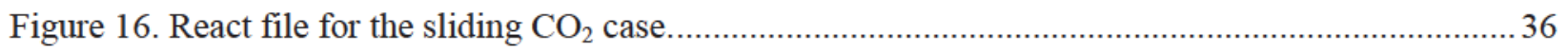

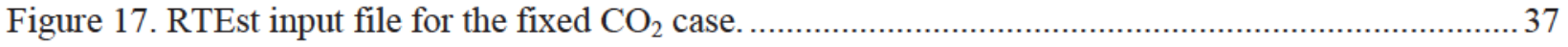

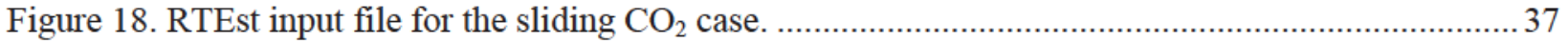




\section{Tables}

Table 1. Ion size parameters, a, for some common ions found geothermal waters that are used in thermo.dat database of GWB.

Table 2. A, B, and b parameters used in GWB.

Table 3. Parameters used to estimate the activity coefficients of neutral, nonpolar basis species (From

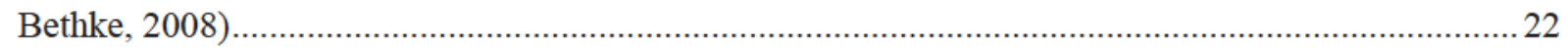

Table 4. Coefficients of variation for several basis species. ................................................................ 25

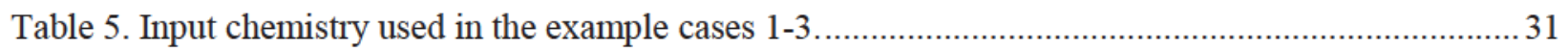

Table 6. Results of calculations using RTEst on hypothetical cases 1-3 .............................................. 32

Table 7. Water chemistries used in the two mixing scenarios. .............................................................. 34

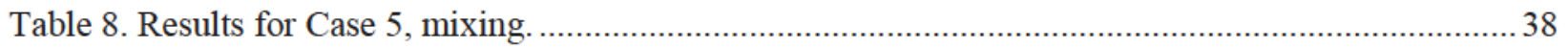




\section{Acknowledgements}

Funding for this research was provided by the U.S. Department of Energy, Office of Energy Efficiency \& Renewable Energy, Geothermal Technologies Program. We are also grateful to the Center for Advanced Energy Studies for providing additional support. 


\section{Reservoir Temperature Estimator}

\section{Overview}

The Reservoir Temperature Estimator (RTEst) is a program that can be used to estimate deep geothermal reservoir temperature and chemical parameters such as fugacity of $\mathrm{CO}_{2}$ based on the water chemistry of shallower, cooler reservoir fluids. The program is a mixed language code (Fortran and Visual Basic) that uses the plugin features provided in The Geochemist's Workbench (Bethke and Yeakel, 2011) and interfaces with the model-independent parameter estimation code Pest (Doherty, 2005) to provide estimated parameters based on the minimization of a weighted sum of squares of a set of saturation indexes from a user-provided mineral assemblage. This manual provides information on the installation and use of the RTEst. 


\section{Background}

Geothermometry is an important tool for estimating deep reservoir temperature from the geochemical composition of shallower and cooler waters. The underlying assumption of geothermometry is that the waters collected from shallow wells and seeps maintain a chemical signature that reflects equilibrium in the deeper reservoir. Many of the geothermometers used in practice are based on correlation between water temperatures and composition or using thermodynamic calculations based a subset (typically silica, cations or cation ratios) of the dissolved constituents. Alternatively, "complete" water compositions can be used in multicomponent equilibrium geochemical models to calculate the degree of disequilibrium (saturation index) for a suite of potential reservoir minerals as a function of temperature and the reservoir temperature estimated from the common intersection of the saturation indices with the zero (equilibrium) line. Some of the basic concepts of this multicomponent geothermometry approach of been described by others (e.g., Bethke, 2008; Reed and Spycher, 1984; Spycher et al., 2011; Spycher et al., 2014; Cooper et al., 2013) and are being applied in several geothermal systems (Neupane et al., 2014).

The Reservoir Temperature Estimator (RTEst) is a program that can be used to estimate deep geothermal reservoir temperature and chemical parameters such as fugacity of $\mathrm{CO}_{2}$ based on the water chemistry of shallower, cooler reservoir fluids. RTEst uses a multicomponent optimization approach that takes into account several processes that can affect geothermometry including formation of a steam phase, loss of volatile components (e.g., $\mathrm{CO}_{2}$ ), and mixing with other waters to estimate conditions to which a water sample was exposed in the deeper portions of the reservoir. RTEst minimizes a weighted sum of squares of the saturation indices of a user-selected set of minerals believed to be at equilibrium within the reservoir by adjusting the temperature, fugacity of $\mathrm{CO}_{2}\left(\mathrm{fCO}_{2}\right)$, and mixing fraction with another water. RTEst uses the React module in The Geochemist's Workbench (GWB) (Bethke and Yeakel, 2011) to do the geochemical calculations while using PEST (Doherty, 2005, 2013) to perform the optimization calculations. RTEst developed under Windows 7 operating system using Microsoft Visual Basic 2010 and the Intel Visual Fortran Compiler 2013. 


\section{Approach}

In RTEst, the user selects the set of reservoir minerals with which the reservoir fluid is believed to be equilibrated. While the user can only select minerals that are plausible based on the chemical analysis of the water, it is possible to choose a combination of minerals that violates the Gibbs phase rule which defines the maximum number of independent variables within a system. For cases where there is a fluid phase present and system temperature and pressure are correlated (e.g., steam saturated water), a simplified version of the phase rule can be used to determine the maximum number of equilibrium mineral phases that are appropriate for the calculation

$$
M=C-F
$$

where $\mathrm{M}$ is the number of equilibrium minerals, $\mathrm{C}$ is the number of components, and $\mathrm{F}$ is the degrees of freedom. After selecting the minerals to be included in assemblage, the user can check for the independence of the choices and if the phase rule is violated an error message will be generated. Note, however, that although Eq. (1) calculates the theoretical maximum number of mineral phases that may be in equilibrium the true number of phases in the real system may be less.

With the establishment of a mineral assemblage that is consistent with the Phase Rule, RTEst estimates an equilibrium reservoir temperature (as well as a $\mathrm{fCO}_{2}$ and water mixing or boiling) by minimizing an objective function $(\Phi)$ that is the weighted sum of the squares of the saturation indexes for the selected equilibrium minerals

$$
\Phi=\sum\left(S I_{i} w_{i}\right)^{2}
$$

where $\mathrm{SI}_{\mathrm{i}}=\log \left(\mathrm{Q}_{\mathrm{i}} / \mathrm{K}_{\mathrm{i}, \mathrm{T}}\right)$ for the ith equilibrium mineral $\left(\mathrm{Q}_{\mathrm{i}}\right.$ and $\mathrm{K}_{\mathrm{i}, \mathrm{T}}$ are the ion activity product and temperature dependent equilibrium constant, respectively for ith mineral) and $\mathrm{w}_{\mathrm{i}}$ is the weighting factor for the ith mineral.

The weighting factors ensure that each mineral that contributes to the equilibrium state is considered equally and the results are not skewed by reaction stoichiometry or differences in analytical uncertainty. There are three options for weighting factors in RTEst: inverse of variance, normalization, or unit weights. In general, unit weights are not recommended because during the optimization process, a clay mineral that has many basis species would be artificially weighted over a mineral such as quartz which has only one basis species. The normalization option is the weighting method that was employed by Cooper et al. (2013). The normalization option is a special case of the inverse variance method which is discussed in the following paragraph. The key difference is that in the normalization method the analytical error for all basis species is assumed to be equal except for the activity of water and $\mathrm{H}^{+}$which are assumed to be zero, and the weights scaled by the analtical error.

The inverse of variance method calculates the weights based on the conditional variance of the saturation index given the solubility product of the mineral. The method calculates the propagation of error from the analytical uncertainty of the basis species for the mineral and the stoichiometry of the mineral making simplifying assumption about the correlation between the basis species. The weighting factor for the saturation index of mineral $\mathrm{k}$ is approximately 


$$
w_{k} \approx 1 /\left[\sum_{i=1}^{n c} v_{i k}\left(\frac{s_{C_{i}}}{C_{i}}\right)^{2}\right]^{1 / 2}
$$

where $\mathrm{v}_{\mathrm{ik}}$ is the stoichiometric coefficient of the ith basis species in the kth mineral phase and $s_{C_{i}} / C_{i}$ is the coefficient of variation of the concentration of the ith basis species, (i.e., the analytical uncertainty in the reported concentration). More details can be found Appendix 1. 


\section{Installation}

\section{Installation of GWB}

It is assumed that The Geochemist's workbench (GWB) has been installed on the hard drive of the computer. Either the Standard or Professional edition of GWB (Version 9 or greater) must be used. If this program has not been installed, the user can go to http://www.gwb.com/ where an appropriate license can be purchased. Users can then download GWB and install the software as per instructions provided at their site. The PATH to the GWB executables must be specified for RTEst to execute. For Windows 7 the PATH can be edited in the following manner.

1. Select Control Panel from the Start menu

2. Choose System and Security

3. Choose System from the context menu

4. Click Advanced system settings in the left-hand panel and select the Advanced tab

5. Click on Environment Variables, under System Variables (or User Variables if you want to change the path only for that user), find PATH, and click on it.

6. In the Edit windows, modify PATH by adding the location GWB files to the PATH, for example, for a 64-bit installation of GWB

\section{$\mathrm{C}:$ Program Files $\backslash$ GWB}

would be added to the path (note that a semicolon should separate this text from the last entry in the PATH file).

7. Restart computer.

\section{Installation of PEST}

It is assumed that PEST has been downloaded and installed on the hard drive of the computer. If the program has not been installed, users can go to http://www.pesthomepage.org/Downloads.php where the latest version of PEST is available. RTEst was developed using PEST version 12.0 and 13.0 and may not be compatible with older versions. The downloaded file should be unzipped to a directory cited in the PATH environmental variables. Follow the procedure described in the preceding section except use the path to PEST files.

\section{Installation of RTEst}

The RTEst program can be easily installed by running the RTEst_xxxx_Setup.exe file and following the instructions. The program is installed in the C: $\backslash$ Program Files $(\mathrm{x} 86)$ folder while data files are written to an RTEst folder in $\%$ LocalAppData\%. 


\section{RTEst Code}

\section{General Structure}

The general structure of the RTEst code is illustrated in Figure 1. In the RTEst form, the user provides the names of the working directory, a GWB * . rea file, and an RTEst input file. When the run button is clicked, RTEst copies the two user files to temporary files and calls the program PEST_File_generator.f90 that creates the files needed to interface with PEST (Doherty, 2005, 2013) that performs the optimization calculations. Communication between RTEst and PEST is done via a template file (RTEst_Input\#\#.tpl), instruction file (RTEst_Output\#\#.ins) and a control file (RTEst_Interf.pst). Template, instruction and control files are described in detail by Doherty (2005, 2013) and brief discussion is provided in later sections of this report.

RTEst then calls RTEst_Interf .exe which acts as an interface between the RTEst, GWB which does all of the geochemical calculations, and PEST which does the optimization calculations.

RTEst_Interf.exe reads the user input files and generates appropiate commands that are sent to the GWB React module via the provided plugins. RTEst_Interf.exe then gets the mineral saturation data and generates the temporary file RTEst_output\#.txt.

Pest then retrieves this output information via the instruction file (RTEst_Output\# . ins) so that it can calculate the objective function. If the objective function has not been minimized, PEST updates estimates of the parameters and invokes RTEst_Interf.exe again. This process continues until the objective function is minimized at which point PEST generates several output files. Program flow then returns to RTEst where the temporary files the output files from RTEst_Interf.exe and PEST are copied to files the user can access and all temporary files are deleted.

While the input RTEst input file can be created in any text editor, RTEst provides the ability to create this file through a series of text, check, and dropdown boxes. The key advantage of creating the input file through RTEst is that there are filters to aid the user in selecting appropriate mineral phases and the likelyhood of input error is greatly reduced. The input file is created in the RTEst_Input_File_Generator form which is launched from the RTEst form by selecting File $\rightarrow$ New $\rightarrow$ RTEst Input File.

More detailed descriptions of the program components and the associated files are provided in the following sections. 


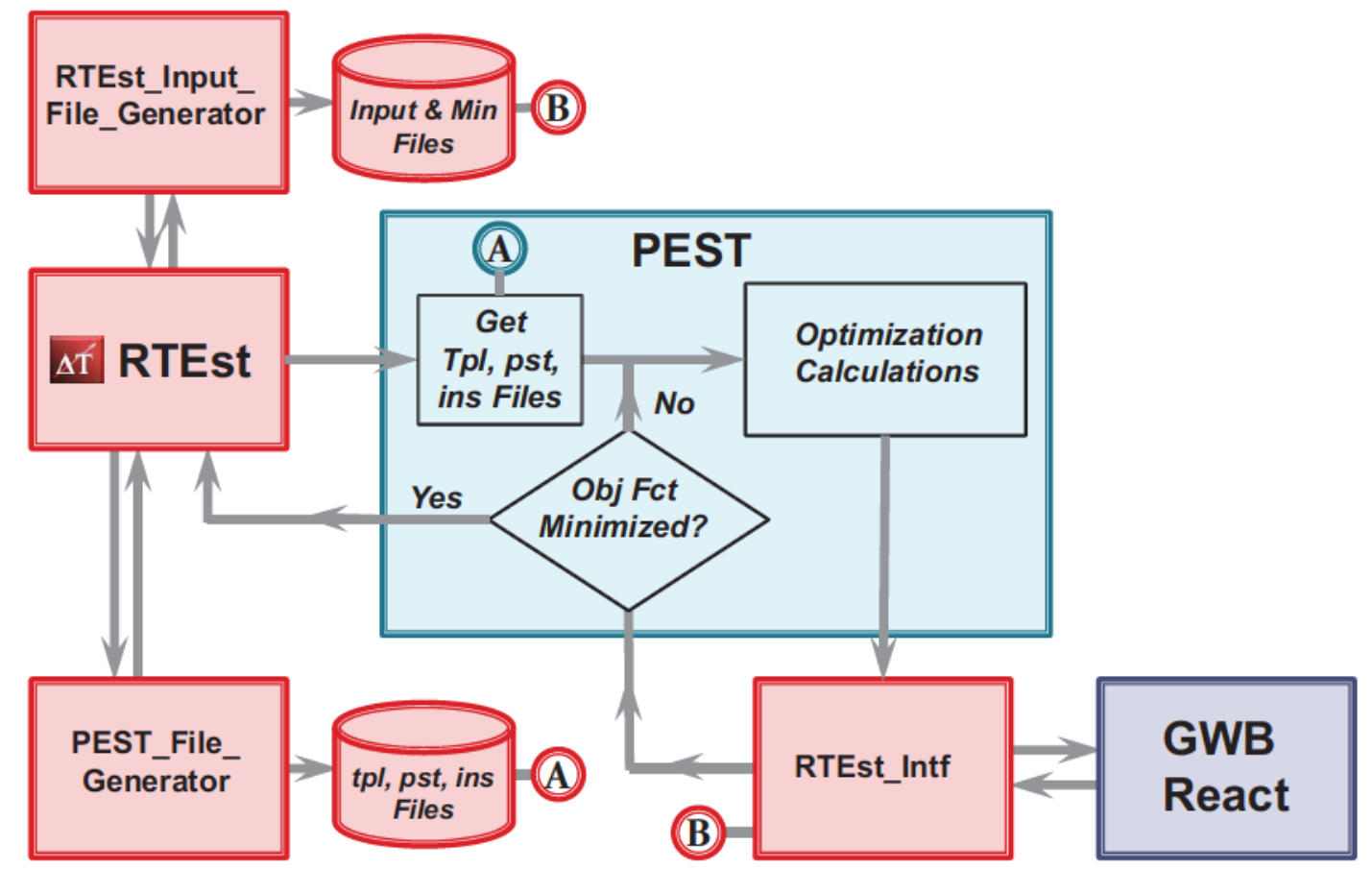

Figure 1. General flow chart for RTEst.

\section{RTEst}

RTEst.exe is the Visual Basic form that directs the overall activity in the progam. When RTEst is launched, the RTEst form (Figure 2) appears. A working directory, GWB React file, and an RTEst input file must be provided by the user before RTEst can be run. The working directory and files can be found by selecting the associated "Browse" button. Alternatively, they can be found by selecting File $\rightarrow$ Working Directory, File $\rightarrow$ Open $\rightarrow$ GWB React File, and File $\rightarrow$ Open $\rightarrow$ RTEst Input File, respectively. The react file must have an extension *.rea or an error message will be generated. If the "Browse" button or "Open" menu item are used, only files with an *.rea extension will be seen. Similarly, the RTEST Input File must have an extension *.txt and only files with that extension are displayed when the "Browse" button or "Open" muenu item are selected.

If the * . rea file does not exist, the user can select File $\rightarrow$ New $\rightarrow$ GWB React File which launches the GWB React module which can be used to create the *.rea file. Similarly, to create an RTEst input file, the user can select File $\rightarrow$ New $\rightarrow$ RTEst Input File to launch the RTEst_Input_File_Generator form. Upon completion of form, the full file path and name will be inserted in the RTEst Input File textbox.

Either the GWB React File or the RTEst Input File can be modified by selecting the appropriate item from the "Edit" option on the menu strip. If there are file names in the textboxes, this selection will open the appropriate file in the Notepad text editor. If the textbox is blank, selecting the edit option will simply launch a blank Notepad session and a file name and path must be entered within the editor. A modified file can then be saved with the same or a different name. If the it is saved with a different name, the user must modify the file name in the appropriate textbox in the RTEst form. 
Under the "Help" menu, the "About" option provides information about the version as well as the project team involved in the development of RTEst. The user can also launch a pdf version of this manual by selecting Help $\rightarrow$ RTEst Manual.

To run the optimization with the specified GWB react and RTEst input files, the user simply clicks either the "Run RTEst" button on the bottom left of the form or the "Run" strip menu item. Either choice invokes the program PEST which calls RTEst_Interf.exe. With each call to RTEst_Interf.exe, GWB is used to calculate the water chemistry based on the user-provided react file (* . rea) and then will calculate the thermodynamic status of the water under the new temperature, $\mathrm{f}\left(\mathrm{CO}_{2}\right)$, and water mass or mixing fraction provided in the input file. The temperature, $\mathrm{f}\left(\mathrm{CO}_{2}\right)$, and water mass in the input file are updated by PEST with each iteration. Output will be written to the Command Prompt window after each iteration. This output can be viewed more easily by pressing the pause button on the keyboard and then pressing any key to continue. At the end of the calculation process, several output files will be generated and written to the working directory and these can be viewed in any text editor.

The user can run additional scenarios simply by changing the names of the GWB react or the RTEst input files and clicking the "Run RTEst" button. When the user is done they can exit the RTEst by clicking the "Exit" button, selecting File $\rightarrow$ Exit, or clicking the application close button in the upper right corner.

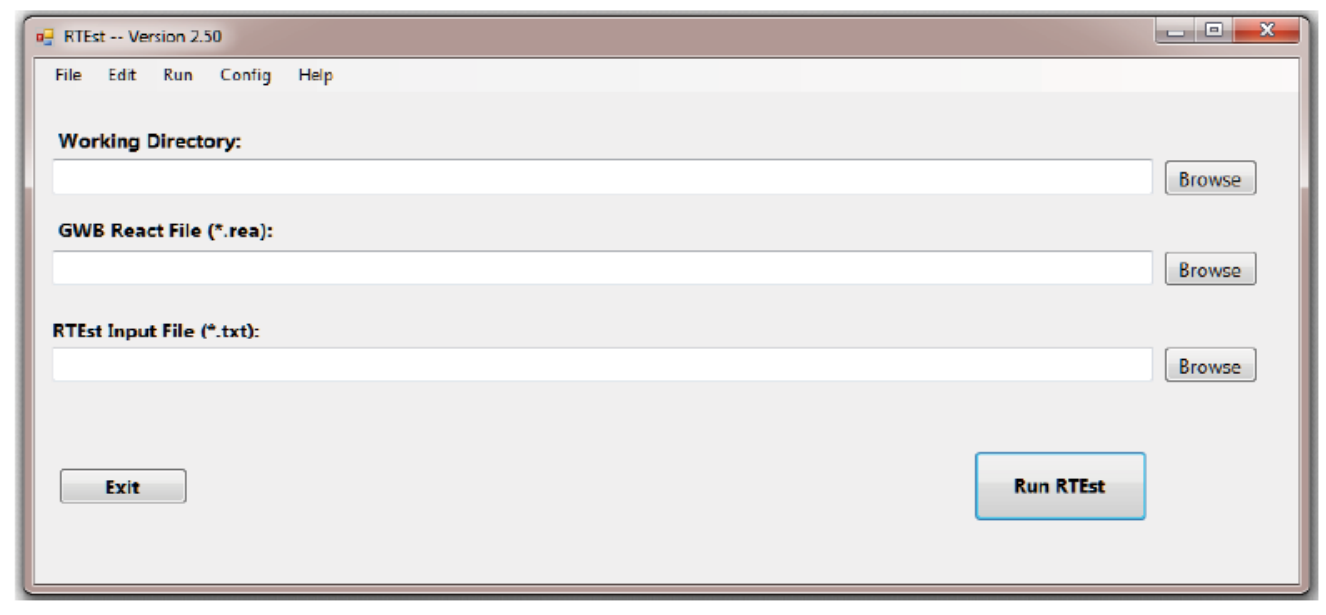

Figure 2. RTEst form.

\section{React File}

The * . rea file represents the water chemistry that is measured in the field from which we wish to estimate the reservoir temperature. The instructions for assembling such a file are provided in the GWB documentation. The react file for Example 1 is

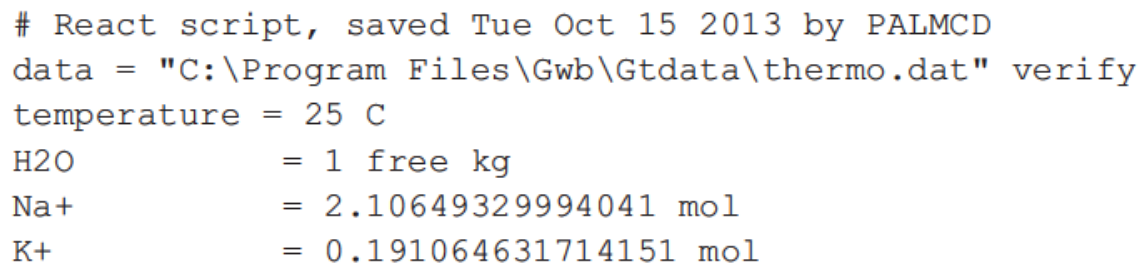




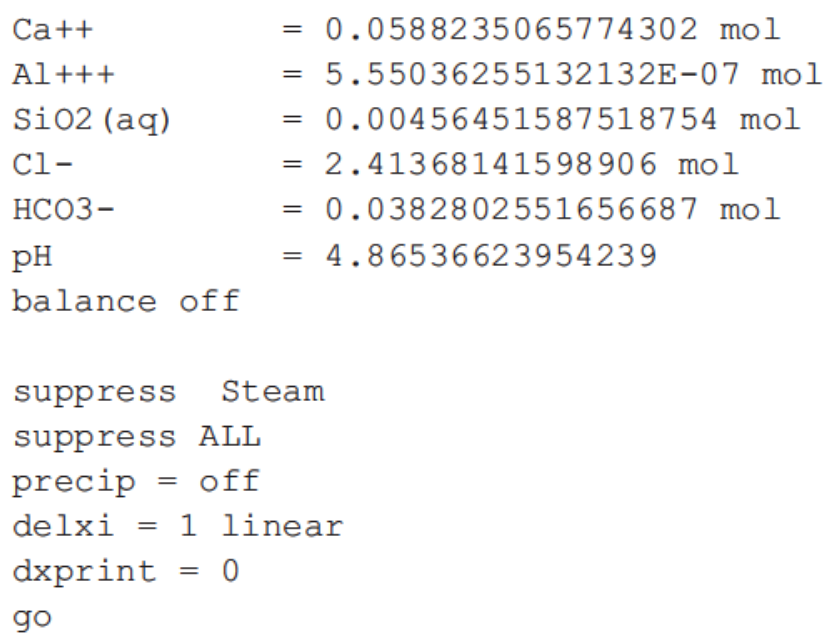

\section{RTEst Input File}

The RTEst input file is used to designate the number and names of the parameters to be optimized and the number and names of the minerals in the assemblage that will be used to calculate the objective function. The input file for Example 1 is:

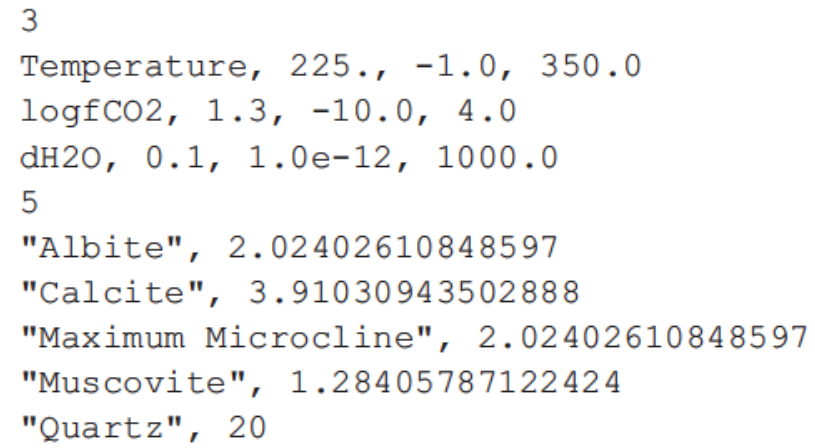

The first line of the input file is the number of parameters that are to be estimated. The next three lines provided the name of the parameter to be estimated, an initial guess for the parameter value, a lower and upper bound for the parameter. The fourth line of the input file is the number (nCheck) of minerals whose saturation indices are to be checked and used in the calculation of the objective function. The maximum value of nCheck is 20 . The next nCheck lines of the input file have two values: 1) the mineral name from the database used in the calculations and 2) the weighting factors (wtFactor) for each of the mineral. Please note that the mineral names must appear exactly as they do in the thermodynamic database being used. If there is a blank in the mineral name, then the entire mineral name must be quotation marks. While the input file is "easy" to prepare in any text editor, we recommend using the RTEst_Input_File_Generator, at least until the user is familiar with the program. 


\section{RTEst_Input_File_Generator}

To create an RTEst input file, the user can select File $\rightarrow$ New $\rightarrow$ RTEst Input File on the RTEst form to launch the RTEst_Input_File_Generator form. This form has four tabs: 1) Parameters to be Optimized, 2) Mineral Assemblage, 3) Weighting, and 4) Finish. These tabs should be filled out in order from left to right.

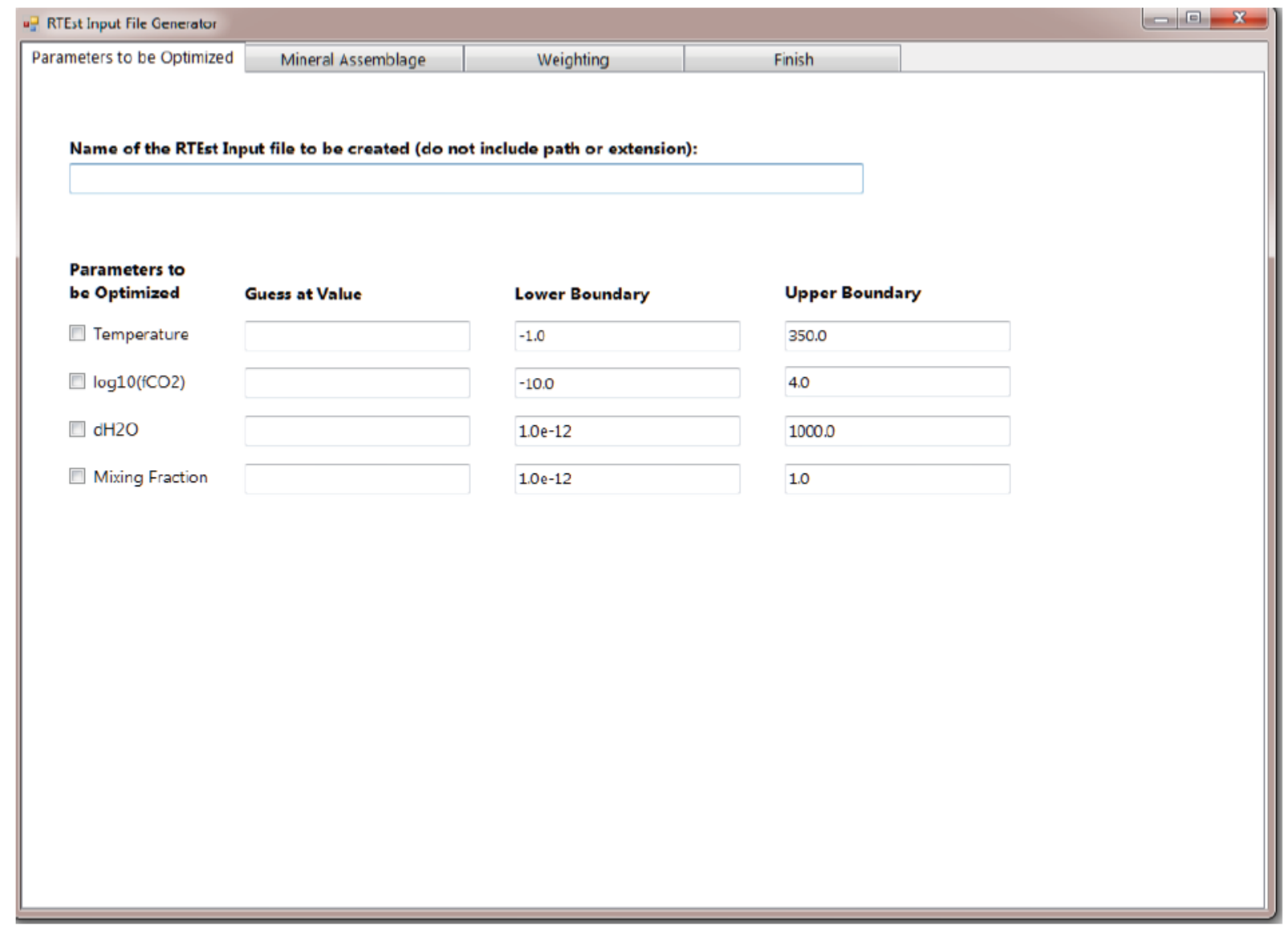

Figure 3. First tab of the RTESt Input File Generator form.

\section{Parameters to be Optimized Tab}

The user should enter the name of the RTEst input file to be created into the textbox near the top of the form. The file will be created in the working directory that was specified on the main RTEst form. Just the file name should be given and a file extension should be NOT be included. A file extension of*.txt will be added automatically when the file is created. The user can then choose which parameters are to optimized by checking the appropriate boxes. A guess for the value of each of the parameters to be optimized must be provided by typing in the appropriate textbox. Default values for the lower and upper boundaries for the parameters are provided. The user can change these default values simply by typing over them. 


\section{Mineral Assemblage Tab}

The Mineral Assemblage tab can be opened simply by clicking on it. When the tab is first opened, the mineral list box is empty. To see the full list of potential minerals that can be added to the mineral assemblage, click the "Update Mineral List" button in the upper right (it will take several seconds for the table to be populated). This list of minerals is NOT all of the minerals in the database but rather only those minerals for which all the basis species have been specified in the * . rea file. The program gets the information from GWB React module and the database specified in the * . rea file. By default, the minerals are listed alphabetically by mineral name. The user can also sort by formula or mineral type by selecting the appropriate option in the "Sort Mineral List by:" dropdown box. The new option will be invoked only after the "Update Mineral List" button is clicked.

To assist the user in making reasonable choices, a series of filters based on our analysis of alteration mineral assemblages (Palmer et al., 2014, Table 1) can be applied to limit the number of choices to minerals that are more likely to be present in the particular geologic setting being considered. There are three groups of filters: host rock type (i.e., lithology), water type, and temperature range. Selections within the host rock type group include tholeiitic, calc-alkaline, silicic, siliciclastic, and carbonate. Water types include acidic or neutral waters, and the temperature range options include low $\left(50-100^{\circ} \mathrm{C}\right)$, moderate $\left(150-300^{\circ} \mathrm{C}\right)$ or high $\left(>300^{\circ}\right)$.

The user can check more than one box within a group. For example, it may be uncertain if the reservoir is best described as silicic or siliciclastic. If more than one box is checked the list of potential minerals is the union of the sets for the individual choices. In addition, the temperature range filter represents an initial assessment of the user of the expected reservoir temperature. If the RTEst estimated temperature is outside of the temperature range, the user can reselect the more appropriate range. The filters can be removed by clicking on the individual check boxes or the "Clear All Filters" button and then clicking the "Update Mineral List" button.

The user can then check those minerals they wish to include in the mineral assemblage and click the "Add- $>>$ " button. To remove a mineral from the assemblage, the user simply checks the mineral name and clicks the "<<-Remove" button. After selecting the minerals to be included in assemblage, the user must test for the independence of the choices by clicking on the "Phase Rule Check" button in the lower right corner of the "Mineral Assemblage" tab. The program then constructs a mineral matrix for which the elements represent the jth basis species in the ith mineral. The singular values of the matrix are calculated using the GESVD subroutine in the INTEL Math Kernal Library. The number of singular values that are greater than 1.0E-6 are taken to represent the rank of the mineral matrix. If the rank of the mineral matrix is $<$ the number of minerals in the assemblage, the phase rule is violated and an error message will be generated. The user can then alter their selections for the mineral assemblage and recheck the phase before continuing. All entries in the "Mineral Assemblage to be used:" box can be removed simultaneously by clicking the "Clear" button. 


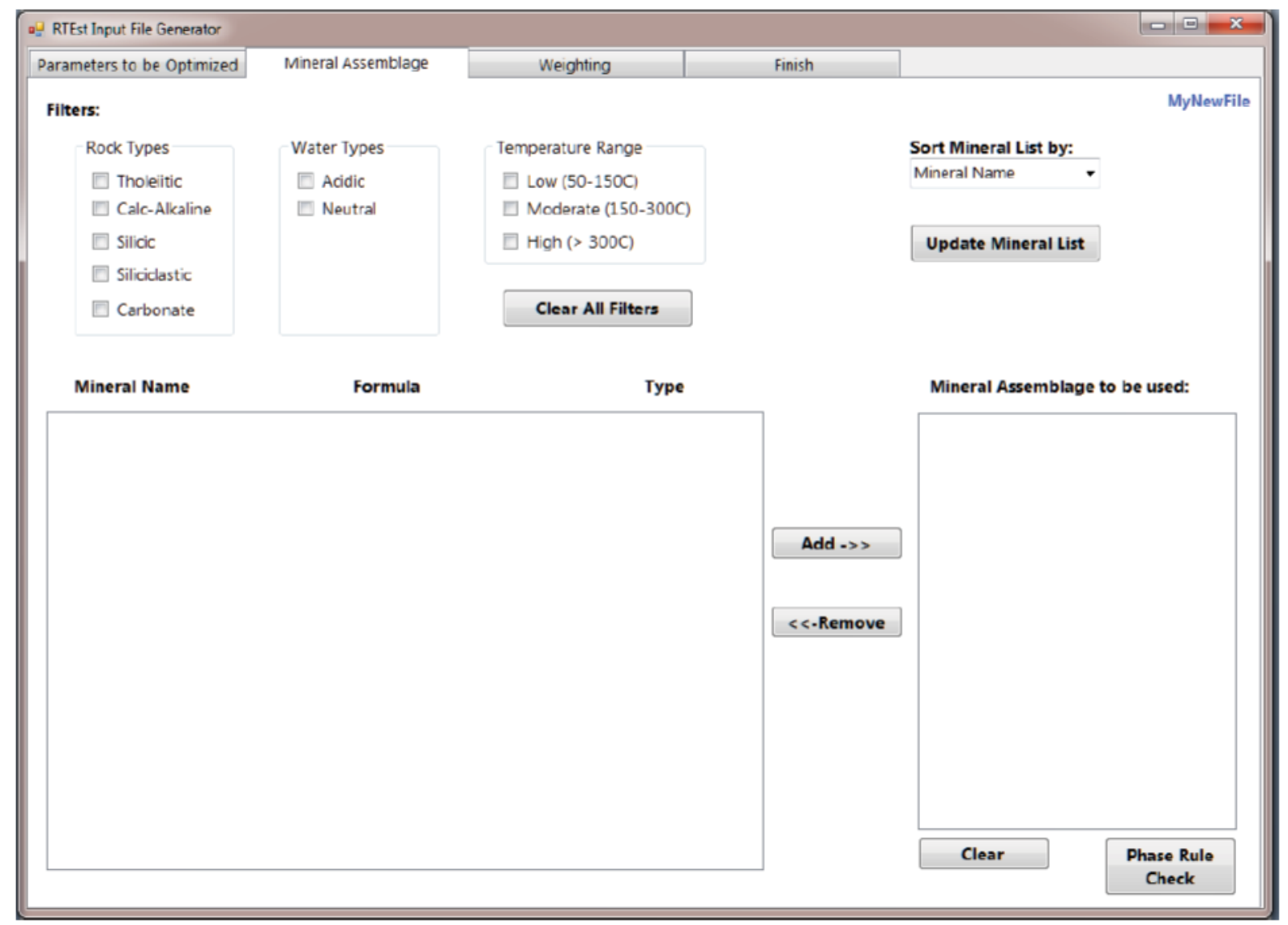

Figure 4. Mineral Assemblage table of the RTEst_Input_File_Generator form.

\section{Weighting Tab}

The weighting tab can be opened by clicking on it at the top of the RTEst_Input_File_Generator form. When the form is first opened, the rich textbox is empty. By choosing an option from the "Weighting Method" dropdown box, the rich textbox will be populated with the mineral names and the associated weighting factors. There are three options of weighting factors in RTEst: inverse of variance, normalization, or unit weights. In general, unit weights are not recommended because during the optimization process, a clay mineral that has many basis species would be artificially weighted over a mineral such as quartz which has only one basis species. The normalization option is the weighting method that was employed by Cooper et al. (2013) and the reader is referred to that work for additional information. The normaliztion method is a special case of the the inverse variance method which is briefly described in the Approach section and in more detail in Appendix 1: Weighting Factors. 


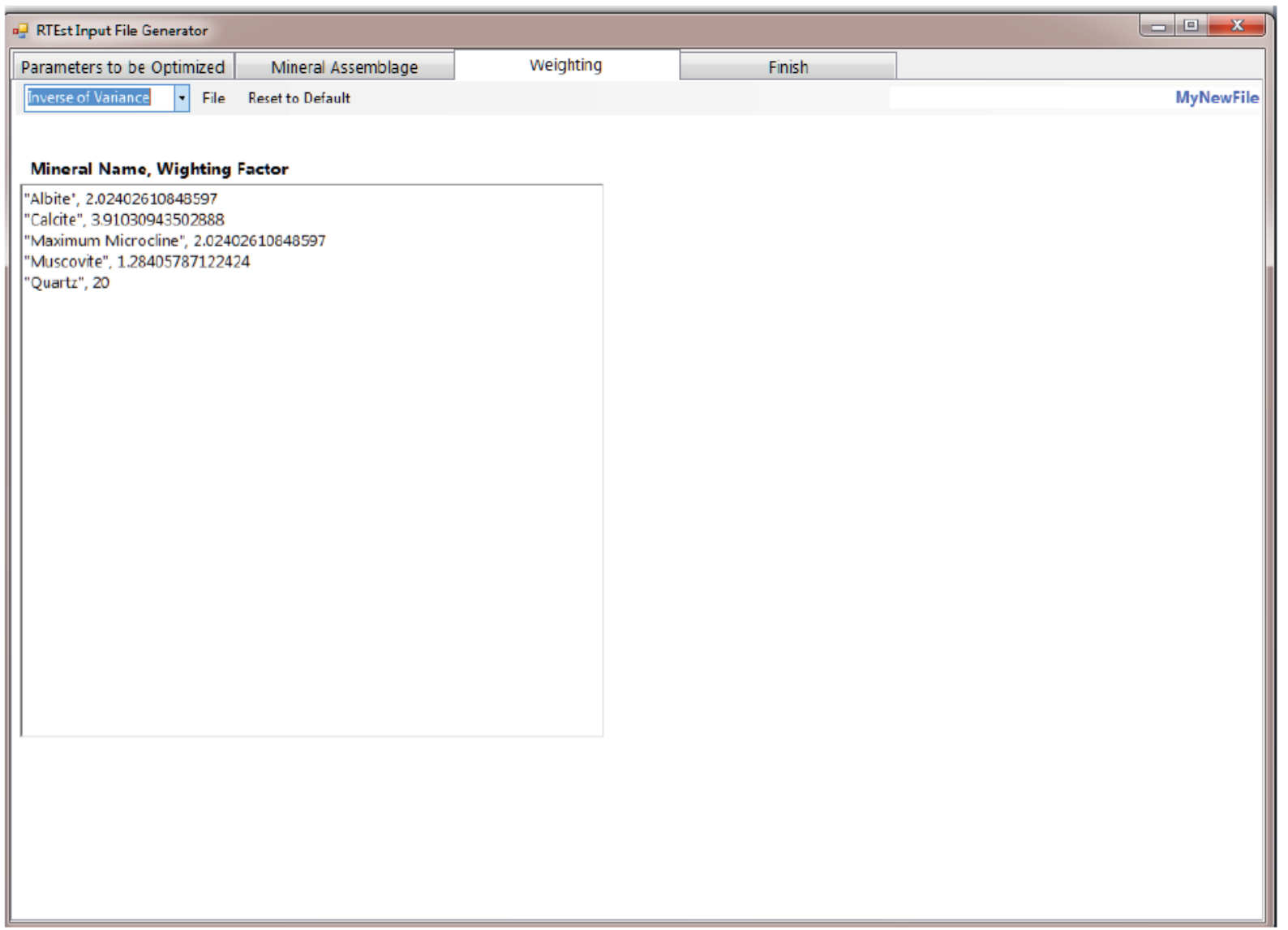

Figure 5. Weighting tab of the RTEst Input File Generator form.

\section{Finish Tab}

Clicking on the "Finish" tab and pressing the "Generate RTEst Input File item on the strip menu will generate the input data in the rich textbox. This file can be manually edited if the user decides to alter any of the input. Clicking the "Finish" button will copy the information to a file in the working directory and produce a messagebox stating that the file has been created and giving the full path name. If the file already exists, it will be over written with the new input.

\section{PEST_File_Generator}

Once the working directory, GWB react file and RTEst input file have specificied, the "Run RTEst" button can be clicked. This action initiates the PEST_File_Generator. exe program to create the files needed for PEST to interact with the RTEst program. It consists of three subprograms: 1) tpl_Generator that creates the PEST template file, 2) pst_Generator that creates the control file, and 3) ins_Generator that creates the instruction file. PEST_File_Generator.exe operates in the background and the user does not directly interface with the program. 


\section{tpl_Generator}

The tpl_Generator generates a PEST template file (*.tpl) that allows PEST to identify the parameters in the RTEst input file and adjust them. The file is identical to the input file to RTEst except that the first line of the file defines the delimiter used ("\#" in the example file), and the location of the parameters that are to be optimized by PEST are delimited and the values replaced by identifiers. For RTEst, the template file is RTEst_Input\#\#.tpl. In the example, the parameters to be optimized are delimited by "\#” and given the identifiers Temperatur, $\operatorname{logfCO} 2, \mathrm{dH} 2 \mathrm{O}$, and MixFrac. The user is referred to the PEST manual for additional details on the template file. The user should not change the template file.

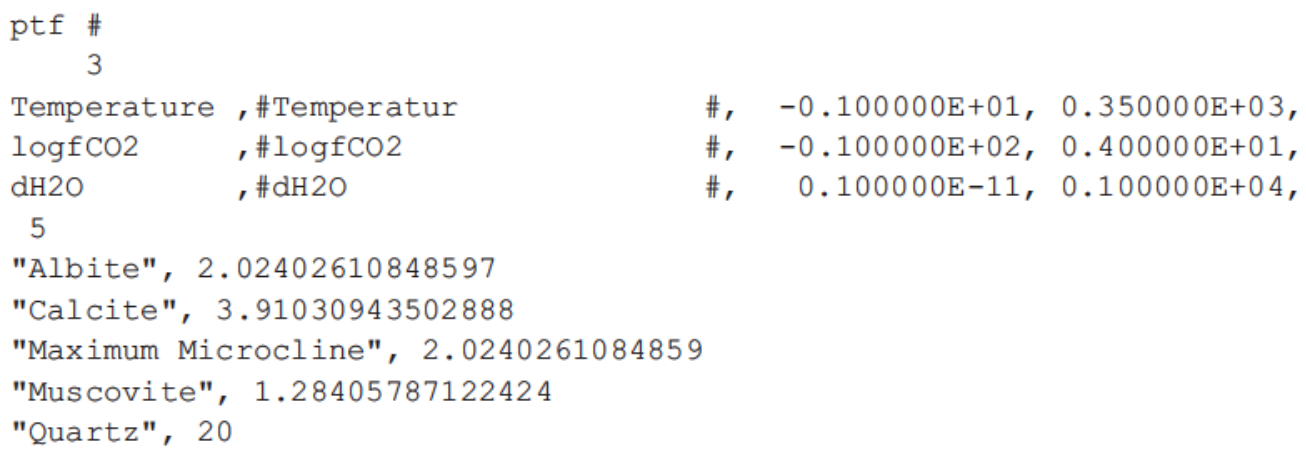

\section{PEST Instruction File}

The instruction file tells PEST where to find the values of the variables used in calculating the objective function. For RTEst, those variables are the calculated weighted saturation indices for the minerals whose names were provided by the user. The values of those are found in output file of RTEst. The first line defines the delimiter ("\#" in the example) while the rest of the define where to find each of the calculated saturation indexes. The first input on the line describes which line to go to, the second input is a identifier for the variable, and the third variable shows the range of columns in which the weighted saturation index for that mineral is found. For example, the second line in Ouput_case01_RT.ins file tells PEST to go to line 7 of the output file, call the variable SI1, and find the value of the weighted saturation index in columns 58 through 74 . The next line in the *.ins file tell pest to go to the next line, call the variable SI2, and find the value of the weighted saturation index in columns 58 through 74 . There instruction file for RTEst is RTEst_Output\#\#.ins; however, this file should not be altered by the user. The user is referred to the PEST manual for more details about setting up instruction files.

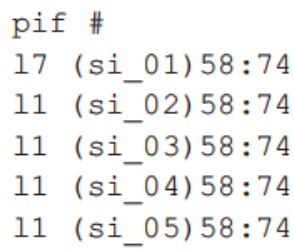

Note that the weighting of the saturation indexes is done in RTEst and that the weights in PEST should be set to unity for the minerals.

\section{PEST Control File}

The PEST Control File (*.pst) brings together information about parameters being estimated, the observations used in the objective function, the files that PEST needs to access and data output options. 
Detailed descriptions of the Control File can be found in Doherty $(2005,2013)$. If PEST does not converge, the user may want to edit the Control file to change the initial guesses and various numerical parameters to promote convergence. The following text is an example of a PEST control file.

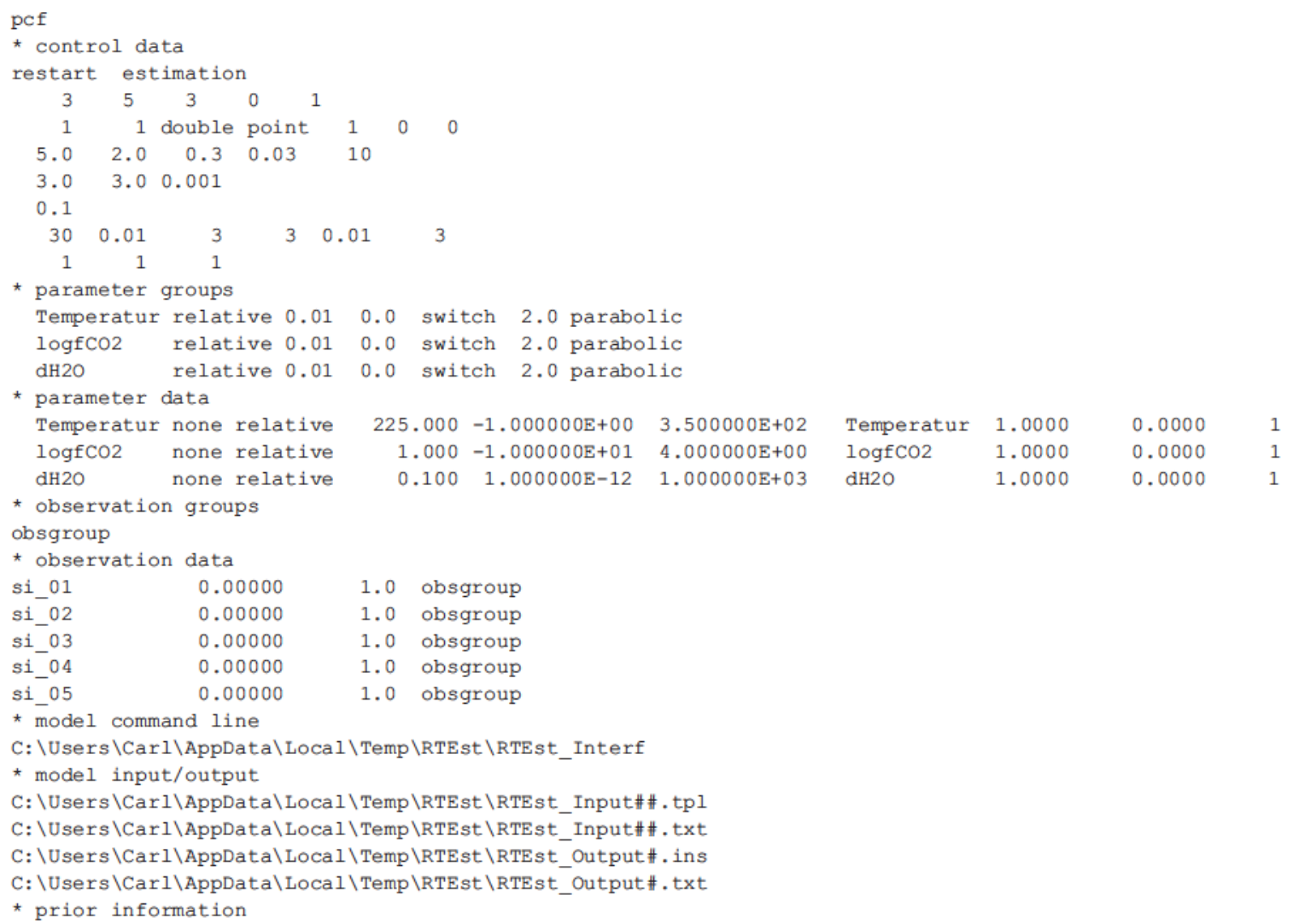

\section{RTEst_Interf}

After PEST_File_Generator.exe creates the template, control, and instruction files to be used by PEST, RTEst. exe calls on PEST to perform the optimization. PEST then calls RTEst_Interf.exe which acts as an interface between RTEst .exe, the React module of GWB, and PEST. Each call to from PEST results in one call to GWB React. After reading the name of the working directory, the react file is run. RTEst_Interf.exe then reads the RTEst_Input\#\#.txt file. The commands that must be sent to the GWB React module to change the temperature, fugacity of $\mathrm{CO} 2$, are generated and then executed. The resulting saturation indices are retrieved and a weighted saturation index $\left(\mathrm{SI}_{\mathrm{i} \text {,weighted }}=\mathrm{SI}_{\mathrm{i}} \mathrm{W}_{\mathrm{i}}\right)$ are calculated. The results are then send to an output file and for the example problem would look like

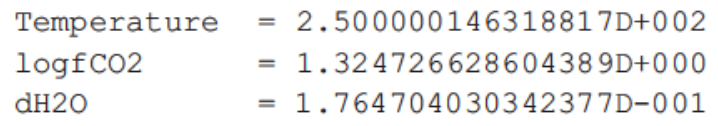

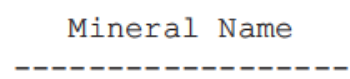

Albite

Calcite

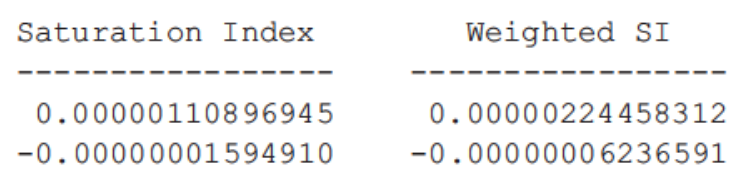


Maximum Microcline

Muscovite

Quartz

Total Saturation Index $=2.73809421132501 \mathrm{E}-06$

Objective Function $=7.49715991009155 \mathrm{E}-12$
$-0.00000075271969$

0.00000005130703

$-0.00000001800350$

$-0.00000152352431$

0.00000006588119

$-0.00000036006995$ 


\section{Appendix 1: Weighting Factors}

\section{Introduction}

RTEst uses a multicomponent optimization approach to estimates reservoir parameters such as temperature, $\mathrm{fCO}_{2}$, and mass of liquid water lost from the sampled fluid. The values of these parameters are a point where the calculated saturation indices of the suite of mineral phases with which the deep reservoir water is believed to be equilibrated all being close to zero. This problem can be stated in terms of the minimization of an objective function, $\Phi$, given by

$$
\Phi=\sum_{k=1}^{n \text { Check }}\left(S I_{k}\right)^{2} w_{k k}
$$

where nCheck is the number of user-supplied minerals with which the water in the reservoir is believed to be equilibrated, $\mathrm{SI}_{\mathrm{i}}\left(=\mathrm{Q}_{\mathrm{i}} / \mathrm{K}_{\mathrm{i}}\right)$ denotes the denotes the saturation index of the ith mineral, and $\mathrm{w}_{\mathrm{ii}}$ is a weighting factor. The $\mathrm{w}_{\mathrm{ii}}$ are often considered to be the inverse of the sample variance in this case the saturation indices of the minerals in the assemblage:

$$
w_{k k}=1 / s_{S I_{k}}^{2}
$$

The variance in the saturation indices can be approximated using a propapagation of error through the series of geochemical equations used to describe the saturation indices of minerals. While the propagation of error through this set of nonlinear equations is best explored through Monte Carlo methods, we believe that an approximation of the variance is sufficient for determining weighting factors that will help ensure that each mineral that contributes to the equilibrium state is considered equally and the results are not skewed by reaction stoichiometry.

\section{Derivation of Variance of Saturation Indices}

\section{General}

The saturation index for mineral $\mathrm{k}, \mathrm{SI}_{\mathrm{k}}$ can be expressed as

$$
S I_{k}=\log \left(\frac{Q_{k}}{K_{k}}\right)
$$

where $\mathrm{Q}_{\mathrm{k}}$ is the ion activity product and $\mathrm{K}_{\mathbf{k}}$ is the solubility product. $\mathrm{Q}$ can be written as

$$
Q_{k}=\prod_{i=1}^{n c}\left(\gamma_{i} C_{i}\right)^{v_{i k}}
$$

where $C_{i}$ is the concentration of the ith component, $\gamma_{i}$ is the associated activity coefficient, and $v_{i k}$ is the stoichiometric coefficient of the ith component in the kth mineral. A propagation of error on Eq. (6) leads to

$$
s_{S I_{k}} \approx \frac{s_{Q_{k} / K_{k}}}{\left(Q_{k} / K_{k}\right) \ln (10)}
$$


But the propagation of error of $\mathrm{Q}_{\mathrm{k}} / \mathrm{K}_{\mathrm{k}}$ is

$$
\left(\frac{s_{Q_{k} / K_{k}}}{Q_{k} / K_{k}}\right)^{2} \approx\left(\frac{s_{Q_{k}}}{Q_{k}}\right)^{2}+\left(\frac{s_{K_{k}}}{K_{k}}\right)^{2}-2 \frac{s_{Q_{k}} s_{K_{k}}}{Q_{k} K_{k}} \rho_{Q_{k} K_{k}}
$$

where $\rho_{Q_{k} K_{k}}$ is the correlation coefficient between $\mathrm{Q}_{\mathrm{k}}$ and $\mathrm{K}_{\mathrm{k}}$. Given that $\mathrm{K}_{\mathrm{k}}$ is a constant while $\mathrm{Q}_{\mathrm{k}}$ varies with the concentration of the associated basis species, it seems reasonable to assume that $\rho_{Q_{k} K_{k}}$ is small. The $\left(s_{K_{k}} / K_{k}\right)^{2}$ can be estimated in the same manner as $\left(s_{Q_{k}} / Q_{k}\right)^{2}$ (described in later sections) which, if the analytical errors are roughly the same, would mean that

$$
\left(\frac{s_{Q_{k} / K_{k}}}{Q_{k} / K_{k}}\right)^{2} \approx 2\left(\frac{s_{Q_{k}}}{Q_{k}}\right)^{2}
$$

However, if other assumptions, such as the establishment of equilibrium when $\mathrm{K}_{\mathrm{k}}$ was determined, are not met, $\left(s_{K_{k}} / K_{k}\right)^{2}$ may be much greater than $\left(s_{Q_{k}} / Q_{k}\right)^{2}$. Note that if Eq. (10) is true, this result would not effectively alter the weighting factors since all of the deviates would be scaled by the same amout (a factor of 1/2). An alternative approach that is used here is to determine the conditional variance of $s_{S I_{k}}$ given the $\mathrm{K}_{\mathbf{k}}\left(\operatorname{Var}\left(S I_{k} \mid K_{k}\right)\right)$. Unless specifically stated otherwise, the reader should assume that we are discussing this conditional variance.

Assuming no correlation between the basis species, the propagation of error for $Q_{k}$ is

$$
\left(\frac{s_{Q_{k}}}{Q_{k}}\right)^{2} \approx \sum_{i=1}^{n c} v_{i, k}\left[\left(\frac{s_{C_{i}}}{C_{i}}\right)^{2}+\left(\frac{s_{\gamma_{i}}}{\gamma_{i}}\right)^{2}\right]+v_{w k}\left(\frac{s_{a_{w}}}{a_{w}}\right)^{2}
$$

where $\mathrm{v}_{\mathrm{wk}}$ is the number of water molecules in the reaction and $\mathrm{a}_{\mathrm{w}}$ denotes the activity of liquid water. The activity coefficients of the basis species depend on the ionic strength of the solution, I, which is given by:

$$
I=\frac{1}{2} \sum_{j=1}^{n} z_{j}^{2} C_{j}
$$

Therefore, the second term on the RHS of Eq. (11) can be expressed as

$$
\left(\frac{s_{\gamma_{i}}}{\gamma_{i}}\right)^{2}=\left(\frac{1}{\gamma_{i}}\right)^{2}\left(\frac{\partial \gamma_{i}}{\partial I}\right)^{2} s_{I}^{2}
$$

where $s_{I}^{2}$ is the variance in the ionic strength. Thus, the variance in the activity coefficient will depend on the ion activity coefficient model used as well as the parameters associated with those models. We consider two common cases: 1) charged ion basis species and 2) neutral, nonpolar basis species. 


\section{Charged Ion Basis Species}

RTEst uses the React module of The Geochemist's Workbench(c) to perform the geochemical calculations. We have therefor chosen the b-dot method that is used in GWB to illustrate an approximation to the variance of the saturation indices. The b-dot model represents individual ion activity coefficients reasonably well up to ionic strengths of about 3 molal in $\mathrm{NaCl}$ solutions (Bethke, 2008) and up to 1 molal for other types of solutions and are therefor useful in exploring the geochemistry of geothermal waters. Expressing the activity coefficient with the b-dot method (e.g., Langmuir, 1997;

Bethke, 2008)

$$
\log \gamma_{i}=-\frac{z_{i}^{2} A I^{1 / 2}}{1+a B I^{1 / 2}}+b I
$$

And taking the derivative we obtain

$$
\left(\frac{s_{\gamma_{i}}}{\gamma_{i}}\right)^{2}=\frac{[\ln (10)]^{2}\left(-2 b\left(1+a B I^{1 / 2}\right)^{2} I^{1 / 2}+A z_{i}^{2}\right)^{2} I}{4\left(1+a B I^{1 / 2}\right)^{4}}\left(\frac{s_{I}}{I}\right)^{2}
$$

where A and B and the Debye-Hückel parameters and b is the b-dot parameter. The variance in the ionic strength is approximately

$$
s_{I}^{2}=\sum_{j=1}^{n}\left(\frac{\partial I}{\partial C_{j}}\right)^{2} s_{C_{j}}^{2}
$$

where $\mathrm{n}$ is number of species in solution. Combining Eqs. (12) and (16) and both sides of the equation by $\mathrm{I}^{2}$, we have

$$
\left(\frac{s_{I}}{I}\right)^{2}=\frac{\sum_{j=1}^{n} z_{j}^{4} s_{C_{j}}^{2}}{\left(\sum_{j=1}^{n} z_{j}^{2} C_{j}\right)^{2}}=\frac{\sum_{j=1}^{n} z_{j}^{4} C_{j}^{2}\left(\frac{s_{C_{j}}}{C_{j}}\right)^{2}}{\left(\sum_{j=1}^{n} z_{j}^{2} C_{j}\right)^{2}}
$$

Factoring out $\left(s_{C_{i}} / C_{i}\right)^{2}$ from the numerator, we obtain

$$
\left(\frac{s_{I}}{I}\right)^{2}=\frac{\sum_{j=1}^{n} z_{j}^{4} C_{j}^{2}\left(\frac{s_{C_{j}} / C_{j}}{s_{C_{i}} / C_{i}}\right)^{2}}{\left(\sum_{j=1}^{n} z_{j}^{2} C_{j}\right)^{2}}\left(\frac{s_{C_{i}}}{C_{i}}\right)^{2} \approx \frac{\sum_{j=1}^{n} z_{j}^{4} C_{j}^{2}}{\left(\sum_{j=1}^{n} z_{j}^{2} C_{j}\right)^{2}}\left(\frac{\bar{C}_{V}}{s_{C_{i}} / C_{i}}\right)^{2}\left(\frac{s_{C_{i}}}{C_{i}}\right)^{2}
$$


where $\bar{C}_{V}$ denotes some weighted average coefficient of variation in the analyte concentration over all of the species. The ratio of $\sum_{j=1}^{n} z_{j}^{4} C_{j}^{2}$ to $\left(\sum_{j=1}^{n} z_{j}^{2} C_{j}\right)^{2}$ is expected to relatively constant. For example for 1:1 salt solutions (e.g., $\mathrm{NaCl}$ ) and 2:2 salt solutions (e.g., $\mathrm{MgSO}_{4}$ ), this ratio is 0.500 at all ionic strengths. For 2:1 (e.g., $\mathrm{CaCl}_{2}$ ) and 1:2 (e.g., $\mathrm{Na}_{2} \mathrm{SO}_{4}$ ) salt solutions, this ratio is 0.556 . Most geothermal waters evolve toward $\mathrm{Na}-\mathrm{HCO}_{3}$ to $\mathrm{Na}-\mathrm{Cl}$ dominated waters, therefore we expect that most multicomponent geothermal solutions will have ratios close to 0.5 and this is the value that we have used in this paper. While $\bar{C}_{V}$ may not be exactly known, some approximations are adequate for our goal of estimating weighting factors. If the coefficients of variation of the of the ith basis species $\left(\mathrm{s}_{\mathrm{Ci}} / \mathrm{C}_{\mathrm{i}}\right)$ are similar to the coefficents of variation of the species that contribute the most to the ionic strength, then $\left(\bar{C}_{V} /\left(s_{C_{i}} / C_{i}\right)\right)^{2}$ is close to unity. In contrast, for a conponent such as $\mathrm{Al}+++$ which has a coefficient of variation approximate 3 times that that of other major anions and cations, $\left(\bar{C}_{V} /\left(s_{C_{i}} / C_{i}\right)\right)^{2}$ is approximately $1 / 9$.

Combining Eqs. (8), (11), (15) and (18) leads to an approximation of the uncertainty in $\mathrm{SI}_{\mathrm{k}}$ of

$$
s_{S I_{k}}^{2} \approx\left(\frac{1}{\ln (10)}\right)^{2}\left[\sum_{i=1}^{n c} v_{i k} \xi_{i}\left(\frac{s_{C_{i}}}{C_{i}}\right)^{2}\right]
$$

where

$$
\xi_{i}=1+\left(\frac{[\ln (10)]^{2}\left(-2 b\left(1+a B I^{1 / 2}\right)^{2} I^{1 / 2}+A z_{i}^{2}\right)^{2} I}{4\left(1+a B I^{1 / 2}\right)^{4}}\right) \frac{\sum_{j=1}^{n} z_{j}^{4} C_{j}^{2}}{\left(\sum_{j=1}^{n} z_{j}^{2} C_{j}\right)^{2}}\left(\frac{\bar{C}_{V}}{s_{C_{i}} / C_{i}}\right)^{2}
$$

Thus, the $\xi_{\mathrm{i}}$ and more generally the variances in the saturation indices depend on not only the ionic strength but also the specific ion being considered (because of the dependence on the ion-size parameter) and temperature (because of the temperature dependence of the A, B, and $\mathrm{b}$ parameters). Using the ion size parameter values in the thermo.dat and thermo.com.V8.R6+.dat databases (Table 1) and the $\mathrm{A}, \mathrm{B}$, and $\mathrm{b}$ parameters in the same databases (Table 2) we can estimate the values of $\xi_{\mathrm{i}}$ as a function of ionic strength and temperature.
Table 1. Ion size parameters, a, for some common ions found geothermal waters that are used in thermo.dat

\begin{tabular}{|c|c|c|c|}
\hline \multicolumn{3}{|c|}{ Ion Size } & \multirow{2}{*}{$\begin{array}{c}\text { Ion Size } \\
\text { Param. (Å) }\end{array}$} \\
\hline Component & Param. (Å) & Component & \\
\hline $\mathrm{H}+$ & 9.0 & $\mathrm{Ba}++$ & 5.0 \\
\hline L+ & 6.0 & Alt++ & 9.0 \\
\hline $\mathrm{Na}+$ & 4.0 & $\mathrm{Mn++}$ & 6.0 \\
\hline $\mathrm{K}+$ & 3.0 & $\mathrm{Fe}++$ & 6.0 \\
\hline Cst & 2.5 & $\mathrm{~F}-$ & 3.5 \\
\hline $\mathrm{Mg}++$ & 8.0 & $\mathrm{Cl}-$ & 3.0 \\
\hline $\mathrm{Ca}++$ & 6.0 & HCO3- & 4.5 \\
\hline $\mathrm{Sr}++$ & 5.0 & SO4-- & 4.0 \\
\hline
\end{tabular}
database of GWB. 
Table 2. A, B, and b parameters used in GWB.

\begin{tabular}{|c|ccc|}
\hline $\begin{array}{c}\text { Temp. } \\
\left({ }^{\circ} \mathbf{C}\right)\end{array}$ & A & B & b \\
\hline 0 & 0.4913 & 0.3247 & 0.0174 \\
25 & 0.5092 & 0.3283 & 0.0410 \\
60 & 0.5450 & 0.3343 & 0.0440 \\
100 & 0.5998 & 0.3422 & 0.0460 \\
150 & 0.6898 & 0.3533 & 0.0470 \\
200 & 0.8099 & 0.3655 & 0.0470 \\
250 & 0.9785 & 0.3792 & 0.0340 \\
300 & 1.2555 & 0.3965 & 0.0000 \\
\hline
\end{tabular}

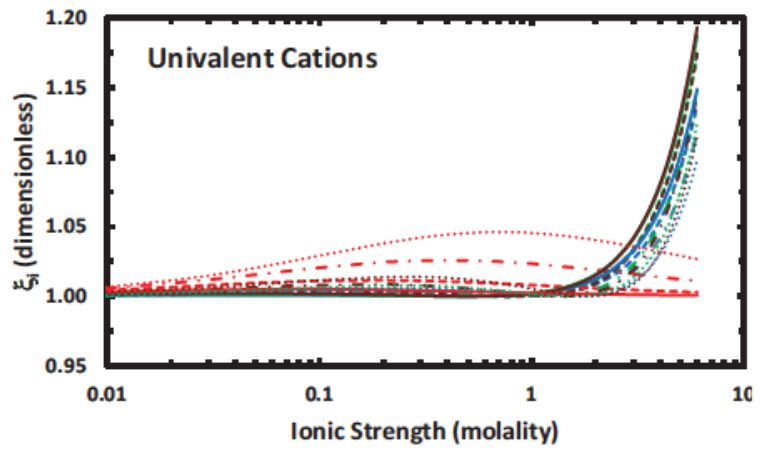

Figure 6. $\xi_{\mathrm{i}}$ versus ionic strength for univalent cations. The lines are for $\mathrm{H}+$ (solid), $\mathrm{Li}+$ (short dash), $\mathrm{Na}+$ (dash-dot) and $\mathrm{K}+$ (dotted) at 25 (blue), 100 (green), 200 (brown) and 300 (red) ${ }^{\circ} \mathrm{C}$.

For univalent cations, the $\xi_{\mathrm{i}}$ generally remain between unity and 1.05 up to ionic strengths of 3 molal and are $<1.2$ even at ionic strengths of 6 molal (Figure 6). For temperatures $\leq 300^{\circ} \mathrm{C}$, divalent cations have 1 $\leq \xi_{\mathrm{i}} \leq 1.27$ (Figure 8). $\xi_{\mathrm{i}}$ for $\mathrm{Al}+++$ is $\leq 1.01$ at all temperatures. $\xi_{\mathrm{i}}$ for univalent anions are $\leq 1.05$ at all temperatures up to ionic strengths of 4.0 molal (Figure 7). In contrast, the $\xi_{\mathrm{i}}$ for the divalent anion $\mathrm{SO}_{4}{ }^{2-}$ reaches a maximum value around 0.4 molal. For temperatures $\leq 250^{\circ} \mathrm{C}$ these maxima are $<1.2$ but reach 1.41 at $300{ }^{\circ} \mathrm{C}$.

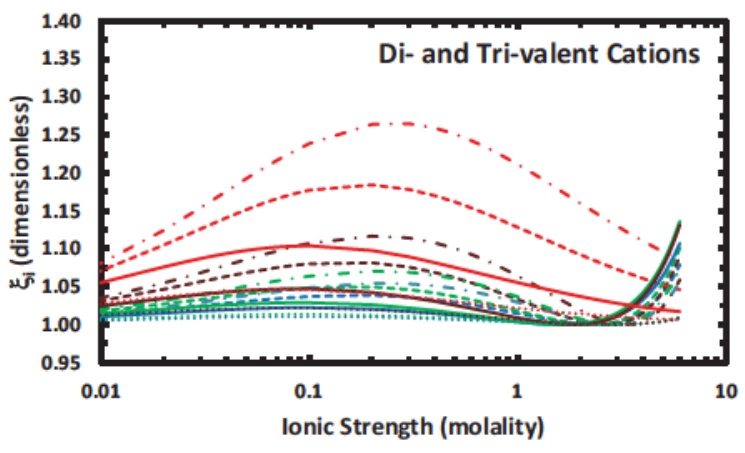

Figure 8. $\xi_{\mathrm{i}}$ versus ionic strength for divalent cations. The lines are for $\mathrm{Ca}++$ (solid), $\mathrm{Sr}++$ (short dash), $\mathrm{Mg}++$ (dash-dot) and $\mathrm{Al}+++$ (dotted) at 25 (blue), 100 (green), 200 (brown) and 300 (red) ${ }^{\circ} \mathrm{C}$.

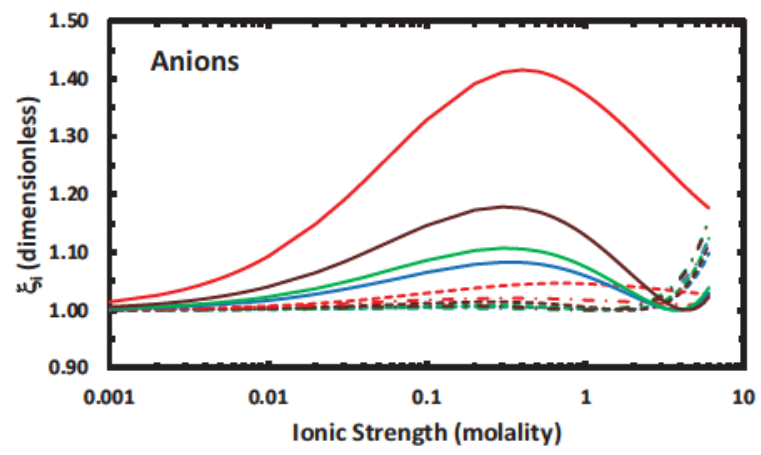

Figure 7. $\xi_{\mathrm{i}}$ versus ionic strength for anions. The lines are for SO4-- (solid), Cl- (short dash), and HCO3- (dash-dot) at 25 (blue), 100 (green), 200 (brown) and 300 (red) ${ }^{\circ} \mathrm{C}$.

\section{Neutral Basis Species}

While b-dot method provides reasonable estimates of activity coefficients of charged ions, it does not provide a good estimate for neutral species. In GWB, neutral, polar species such as $\mathrm{CaSO}_{4}{ }^{\circ}$ are assumed to have activity coefficients equal to unity under all temperatures and ionic strengths. As a consequence, $s_{\gamma_{i}}^{2}=0$ and the second term on the right-hand side of equation (11) is zero in the unlikely case where a neutral, polar species is chosen as a component. 
Table 3. Parameters used to estimate the activity coefficients of neutral, nonpolar basis species (From Bethke, 2008)

\begin{tabular}{|c|ccc|}
\hline $\begin{array}{c}\text { Temp. } \\
\left({ }^{\circ} \mathrm{C}\right)\end{array}$ & $\mathbf{f}$ & $\mathbf{g}$ & $\mathbf{h}$ \\
\hline \hline 25 & 0.1127 & -0.10490 & $1.545 \times 10^{-3}$ \\
100 & 0.08018 & -0.001503 & $0.5009 \times 10^{-3}$ \\
200 & 0.09892 & -0.01040 & $1.386 \times 10^{-3}$ \\
300 & 0.1967 & -0.01809 & $-2.497 \times 10^{-3}$
\end{tabular}

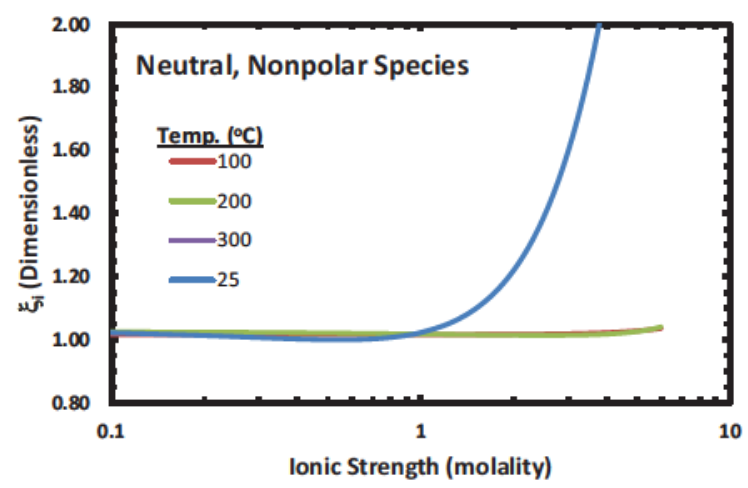

Figure 9. $\xi_{\mathrm{i}}$ versus ionic strength for neutral, nonpolar basis species. The lines are the values at 25 (blue), 100 (green), 200 (brown) and 300 (red) ${ }^{\circ} \mathrm{C}$.

For neutral, nonpolar species such as $\mathrm{SiO}_{2}, \mathrm{CH}_{4}(\mathrm{aq})$, and $\mathrm{H}_{2}(\mathrm{aq})$, GWB calculates the activity coeffients, using a power series of the form

$$
\log \gamma_{i}=f I+g I^{2}+h I^{3}
$$

where the coefficients $\mathrm{f}, \mathrm{g}$, and $\mathrm{h}$ at $25^{\circ}, 100^{\circ}, 200^{\circ}$, and $300^{\circ} \mathrm{C}$ are given in Table 3. Using Eq. (21), it follows that

$$
\left(\frac{s_{\gamma_{i}}}{\gamma_{i}}\right)^{2}=\left(\frac{1}{\gamma_{i}}\right)^{2}\left(\frac{\partial \gamma_{i}}{\partial I}\right)^{2} s_{i}^{2}=[\ln (10)]^{2}\left(f+2 g I+3 h I^{2}\right) \frac{\sum_{j=1}^{n} z_{j}^{4} C_{j}^{2}}{\left(\sum_{j=1}^{n} z_{j}^{2} C_{j}\right)^{2}}\left(\frac{\bar{C}_{V}}{s_{C_{i}} / C_{i}}\right)^{2}\left(\frac{s_{C_{i}}}{C_{i}}\right)^{2}
$$

Assuming that $\left(\bar{C}_{V} /\left(s_{C_{i}} / C_{i}\right)\right)^{2}$ is equal to unity, we can calculate the $\xi_{\mathrm{i}}$ for neutral, nonpolar basis species (Figure 9). For $\mathrm{I} \leq 3$ and temperatures $\geq 100^{\circ} \mathrm{C}$, $\xi_{\mathrm{i}}$ is less than 1.02 . At $25^{\circ} \mathrm{C}, \xi_{\mathrm{i}} \leq 1.023$ but increases up to 1.6 at $\mathrm{I}=3$.

Water

In GWB, the activity of water is calculated from

$$
\ln \left(a_{w}\right)=-\frac{2 I_{S} \phi}{55.5}
$$

where $\mathrm{I}_{\mathrm{S}}$ is the stoichiometric ionic strength and $\phi$ is the osmotic coefficient which is

$$
\phi=1-\frac{\ln (10) A}{a^{3} I_{S}}\left[\hat{b}-2 \ln \hat{b}-\frac{1}{\hat{b}}\right]+\frac{b I_{S}}{2}+\frac{2 c I_{S}^{2}}{3}+\frac{3 d I_{S}^{3}}{4}
$$

and 


$$
\hat{b}=1+a \sqrt{I_{S}}
$$

(Bethke, 2008). It the coefficient of variation of the activity of water is then

$$
\left(\frac{s_{a_{w}}}{a_{w}}\right)^{2}=\left(\frac{1}{a_{w}}\right)^{2}\left(\frac{\partial a_{w}}{\partial I_{C}}\right)\left(s_{I_{S}}\right)^{2}=\left(\frac{1}{a_{w}}\right)^{2}\left(\frac{\partial a_{w}}{\partial I_{S}}\right)^{2} \sum_{j=1}^{n c}\left(\frac{\partial I_{S}}{\partial C_{j}}\right) s_{C_{j}}^{2}
$$

or

$$
\left(\frac{s_{a_{w}}}{a_{w}}\right)^{2}=\left(\frac{1}{a_{w}}\right)^{2}\left(\frac{\partial a_{w}}{\partial I_{S}}\right)^{2} I_{S}^{2} \frac{\sum_{j=1}^{n c} z_{j}^{4} s_{C_{j}}^{2}}{\left(\sum_{j=1}^{n c} z_{j}^{2} C_{j}\right)^{2}}=\left(\frac{1}{a_{w}}\right)^{2}\left(\frac{\partial a_{w}}{\partial I_{S}}\right)^{2} I_{S}^{2} \frac{\sum_{j=1}^{n c} z_{j}^{4} C_{j}^{2}\left(\frac{s_{C_{j}}}{C_{j}}\right)^{2}}{\left(\sum_{j=1}^{n c} z_{j}^{2} C_{j}\right)^{2}}
$$

Similar to what was done in Eq. (18), we can substitute an average coefficient of variation and factor it from the summation in the numerator to give

$$
\left(\frac{s_{a_{w}}}{a_{w}}\right)^{2} \approx\left(\frac{1}{a_{w}}\right)^{2}\left(\frac{\partial a_{w}}{\partial I_{S}}\right)^{2} I_{S}^{2} \frac{\sum_{j=1}^{n c} z_{j}^{4} C_{j}^{2}}{\left(\sum_{j=1}^{n c} z_{j}^{2} C_{j}\right)^{2}}\left(\bar{C}_{V}\right)^{2}=\eta\left(\bar{C}_{V}\right)^{2}
$$

where

$$
\begin{aligned}
& \eta=\frac{I_{S}^{2}}{a^{6}\left(1+a \sqrt{I_{S}}\right)^{4}(55.5)^{2}}\left[2 a^{3}\left(1+a \sqrt{I_{S}}\right)^{2}\left(1+I_{S}\left(b+I_{S}\left(2 c+3 d I_{S}\right)\right)\right)\right. \\
& -a A I_{S}^{3 / 2}\left(10+14 a \sqrt{I_{S}}+5 a^{2} I_{S}\right) \ln (10) \\
& \left.+2 A\left(1+a \sqrt{I_{S}}\right)^{2} \ln (10)\left(4 \ln \left(1+a \sqrt{I_{S}}\right)+a I_{S}^{1 / 2} \ln \left(1+a \sqrt{I_{S}}\right)^{2}\right)\right]^{2}
\end{aligned}
$$

Using the a, b, c, and d coefficients provided by Bethke(2008), we calculated the values of $\eta$ as a function of temperature at $25^{\circ}$ and $200^{\circ} \mathrm{C}$ (Figure 10). The values are similar to each other and are $<0.02$ at stoichiometric ionic strengths $\leq$ 3 molal. Given the similarities in the activity of water in solutions with stoichiometric ionic strengths up to 3 molal for $25^{\circ}$ and $300^{\circ} \mathrm{C}$ (Bethke, 2008, Figure 7.5, p. 114), we expect $\eta$ to be relatively small even at $300^{\circ} \mathrm{C}$

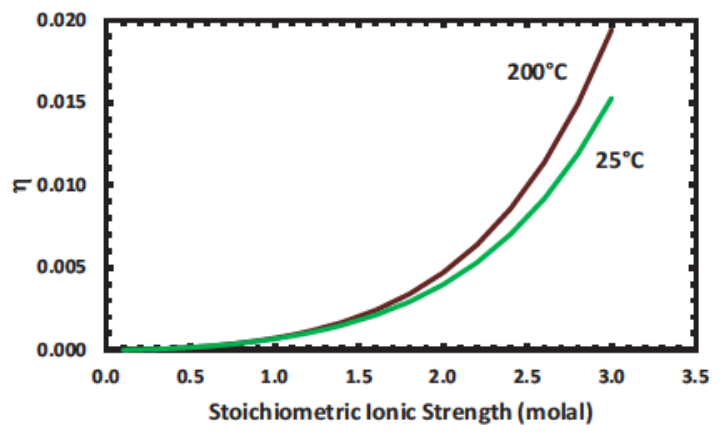

Figure 10. Values of $\eta$ as a function of stoichiometric ionic strength baseed and Eq. (29) and parameters provided by Bethke (2008). 


\section{Recommended Weighting Factors for Minerals}

The analysis in the previous sections suggests that the variance in the calculated saturation indices should sensu stricto depend on the ionic strength and temperature of the system. However, a closer look at the $\eta$ and $\xi_{\mathrm{i}}$ factors in which these dependancies are contained, suggest that simplifying assumptions can be made. The $\eta$ factors are generally $<0.02$ over all ionic strengths and temperatures, therefor, we can assume that the variance in the activity of water does not contribute significantly to the variance in the saturation indices. For most basis species $\xi_{\mathrm{i}}$ varies from 1.0 to 1.25 over a temperature range of $25^{\circ}$ to $300^{\circ} \mathrm{C}$ and for ionic strength up to 3 molal. The key exception to this result is $\mathrm{SO}_{4}{ }^{2-}$ for which $\xi_{\mathrm{i}}$ can reach 1.41. This suggests that the $\xi_{\mathrm{i}}$ can be assumed to be close to unity under all conditions. Given these two simplifications, the conditional variance in the saturation indices can reasonably approximated by

$$
s_{S I_{k}}^{2} \approx\left(\frac{1}{\ln (10)}\right)^{2}\left[\sum_{i=1}^{n c} v_{i k}\left(\frac{s_{C_{i}}}{C_{i}}\right)^{2}\right]
$$

and the weighting factors taken as the inverse of the variance (Eq. (5)). Variance calculated from Eq. (30) will likely be less than the actual variance because of the assumption of unit $\xi_{\mathrm{i}}$ (and to much less extent ignoring the effects of the activity of water). Also, the effect of this assumption is somewhat dampened because the summation over the basis species will lessen the effect of any single component. For the weighting factors, the contant $1 /[\ln (10)]^{2}$ is irrelevant for the minimization problem. We therefore calculate the weighting factors using

$$
w_{k} \approx 1 /\left[\sum_{i=1}^{n c} v_{i k}\left(\frac{s_{C_{i}}}{C_{i}}\right)^{2}\right]^{1 / 2}
$$

The coefficient of variations for the analytes that we used in constructing our recommended weighting values (Table 4) are thosed that are commonly encountered using common analytical techniques. These coefficients of variation are $5 \%$ for most cations and anions (e.g., $\mathrm{Ca}^{2+}, \mathrm{Cl}^{-}, \mathrm{K}^{+}, \mathrm{Na}^{+}, \mathrm{SiO}_{2}$ ), $10 \%$ for $\mathrm{HCO}_{3}{ }^{-}$, and $15 \%$ for $\mathrm{Al}^{3+}$. The uncertainty in $\mathrm{pH}$ is about $\pm 0.1 \mathrm{pH}$ units which yields a coefficient of variation of $\mathrm{H}^{+}$is approximately 0.23 . 
Table 4. Coefficients of variation for several basis species.

\begin{tabular}{|c|c|c|c|c|c|}
\hline $\begin{array}{c}\text { Basis } \\
\text { Species }\end{array}$ & $\begin{array}{c}\text { Coeff. } \\
\text { Variation }\end{array}$ & $\begin{array}{c}\text { Basis } \\
\text { Species }\end{array}$ & $\begin{array}{c}\text { Basis } \\
\text { Species }\end{array}$ & $\begin{array}{c}\text { Basis } \\
\text { Species }\end{array}$ & $\begin{array}{c}\text { Coeff. } \\
\text { Variation }\end{array}$ \\
\hline $\mathrm{H} 2 \mathrm{O}$ & 0.00 & F- & 0.05 & $\mathrm{O} 2(\mathrm{aq})$ & 0.10 \\
\hline $\mathrm{Ag}+$ & 0.10 & $\mathrm{Fe}++$ & 0.05 & $\mathrm{~Pb}++$ & 0.05 \\
\hline $\mathrm{Al+++}$ & 0.15 & $\mathrm{H}+$ & 0.23 & $\mathrm{Ra}++$ & 0.10 \\
\hline $\mathrm{As}(\mathrm{OH}) 4-$ & 0.10 & HCO3- & 0.10 & $\mathrm{Rb}+$ & 0.05 \\
\hline $\mathrm{B}(\mathrm{OH}) 3$ & 0.10 & HPO4-- & 0.10 & Ru+++ & 0.15 \\
\hline $\mathrm{Ba}++$ & 0.05 & $\mathrm{Hg}++$ & 0.20 & SO4-- & 0.05 \\
\hline $\mathrm{Br}-$ & 0.05 & I- & 0.10 & SeO3-- & 0.15 \\
\hline $\mathrm{Ca}++$ & 0.05 & $\mathrm{~K}+$ & 0.05 & $\mathrm{SiO} 2(\mathrm{aq})$ & 0.05 \\
\hline $\mathrm{Cl}-$ & 0.05 & $\mathrm{Li+}$ & 0.05 & $\mathrm{Sn++++}$ & 0.15 \\
\hline $\mathrm{Co}++$ & 0.10 & $\mathrm{Mg++}$ & 0.05 & $\mathrm{Sr++}$ & 0.05 \\
\hline $\mathrm{Cr}+++$ & 0.05 & $\mathrm{Mn++}$ & 0.05 & Th++++ & 0.10 \\
\hline Cs+ & 0.05 & NO3- & 0.05 & U++++ & 0.10 \\
\hline $\mathrm{Cu}+$ & 0.05 & $\mathrm{Na}+$ & 0.05 & V+++ & 0.15 \\
\hline Eu+++ & 0.15 & $\mathrm{Ni}++$ & 0.05 & $\mathrm{Zn++}$ & 0.05 \\
\hline
\end{tabular}




\section{Appendix 2: RTEst Files}

\section{Input Files}

RTEst_Main is a Fortran code that was compiled with the INTEL ${ }^{\circledR}$ Fortran Compiler XE 13.1. The program requires two data input files: a GWB *.rea file, and a *.txt user input file.

\section{React File}

After reading the path and file names, RTEst runs an initialization step in which it runs the provided react file in the React module of the GWB program. The *.rea file represents the water chemistry that is measured in the field and for which we wish to estimate the reservoir temperature. The instructions for assembling such a file are provided in the GWB documentation. The react file for Case 1 is

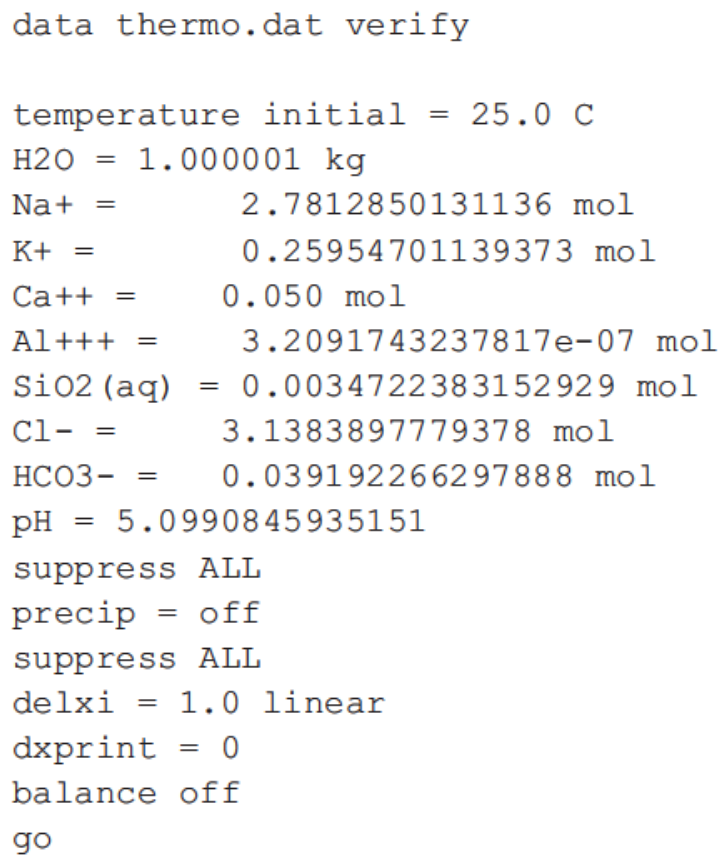

\section{User Input File}

The first three lines of the input file are an initial guesses for the temperature $\left({ }^{\circ} \mathrm{C}\right)$, the fugacity of $\mathrm{CO}_{2}$ and the $\mathrm{kg}$ of liquid water in the system $(\mathrm{kg})$. The fourth line of the input file is the number (nCheck) and names (minCheck) of the minerals whose saturation indices are to be checked and used in the calculation of the objective function. The value of nCheck is read in an I 2 format and can have a maximum value of 10 .

The next nCheck lines of the input file have two values: 1) the mineral name from the database used in the calculations and 2) the weighting factors for each of the mineral. Please note that the mineral names must appear exactly as they do in the thermodynamic database being used. An example input file for the case 01 example is:

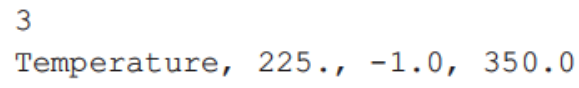




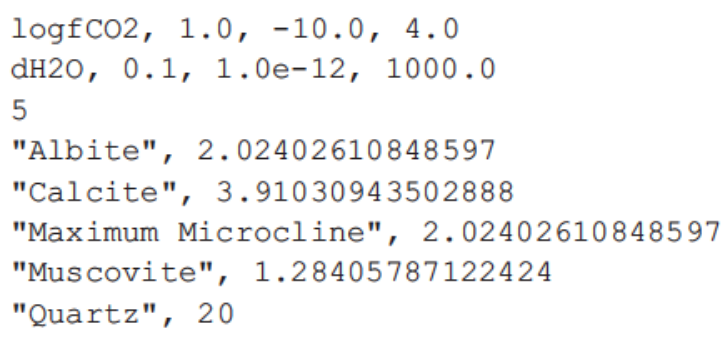

\section{Output Files}

\section{Filename_Output.txt}

If the input file is filename.txt an output file called filename_Output.txt is created. The output file prints the temperature, $\mathrm{CO}_{2}$ fugacity, and the mass of solvent. These values should be the same as those in the input file when directly running RTEst_Main.exe. In addition, the minerals from the input file are listed along with their Saturation Indexes (as reported in GWB) and the Weighted Saturation Indexes. The weighted saturation index is equal to the saturation index divided by the weight for the mineral phase. The objective function, $\Phi$, is

$$
\Phi=\sum_{i=1}^{n \text { Check }}\left(\frac{S I_{i}}{\text { wtFactor }}\right)^{2}
$$

while the total saturation index (TSI) is

$$
T S I=\sqrt{\Phi}
$$

As used here, the TSI represents the length of the vector of weighted saturation indexes and is a measure of the overall deviation of the mineral suite from equilibrium (i.e., the zero vector). Both the TSI and $\Phi$ are written to the Output_filename.txt. The output file for the Case 1 input file is

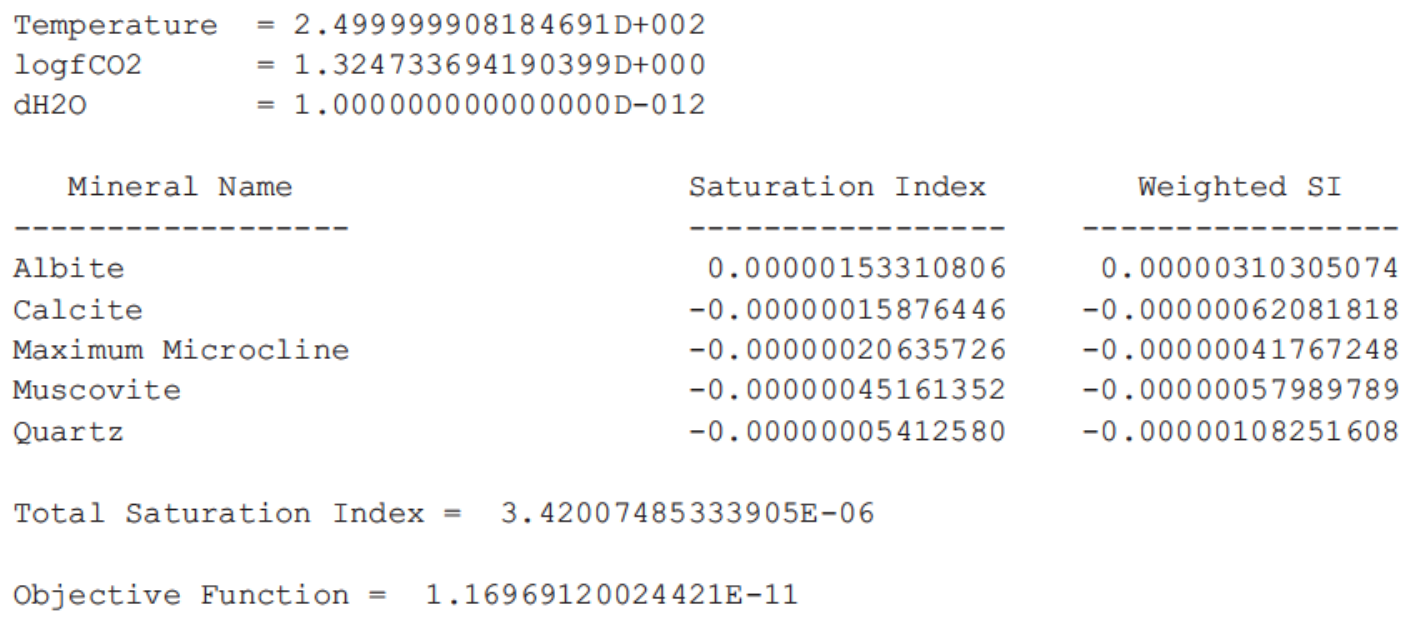




\section{Filename_React.txt}

When the GWB React module is run directly, it creates a output file called React_Output.text. When RTEst is run with an input file called filename.txt, the GWB React file is renamed filename_React.txt to help distinguish it from other GWB output files that may be created. The filename_React.txt file provides the thermodynamic state of the based on the initial chemistry and the thermodynamic state after the optimal values for temperature, $\mathrm{fCO}_{2}$, and liquid water mass have been determined. We assume that the user is familiar with GWB and can interpret the results appropriately.

\section{Filename_GWB_screen.txt}

The filename_GWB_screen.txt file echoes the react file input and provides general information on suppressed minerals, the number of aqueous species, minerals, gases, surface species, elements, and oxides. In addition, it provides information of the number of iterations. The output is the same as that written to the screen when executing a file in directly in the React module of GWB. These results can be useful in identifying potential problems when simulations do not converge or fail in some other manner.

\section{React_plot.gtp}

The *.gtp file is a Gtplot file that is automatically generated with the calls to the React executables. Although it is generally useful if one is looking at "sliding" variables, the single steps required for the optimization problems makes these graphs trivial and they should generally be ignored.

\section{Optimization}

The key purpose of the RTEst.f90 program is to create an interface with through the GWBplugin libraries to the GWB React module that the optimization code PEST can easily access. PEST requires several files to perform this optimization.

\section{PEST Input Files}

\section{Template Input File}

The template file (*.tpl) allows PEST to identify the parameters in the RTEst input file and adjust them. The file is identical to the input file to RTEst except that the first line of the file defines the delimiter used ("\#" in the example file), and the location of the parameters that are to be optimized by PEST are delimited and the values replaced by identifiers. For RTEst, the template file is RTEst_Input\#.tpl. In the example, the parameters to be optimized are delimited by "\#” and given the identifiers Temperature, $\operatorname{logfCO} 2$, and $\mathrm{dH} 2 \mathrm{O}$. The user is referred to the PEST manual for additional details on the template file. The user should not change the template file.

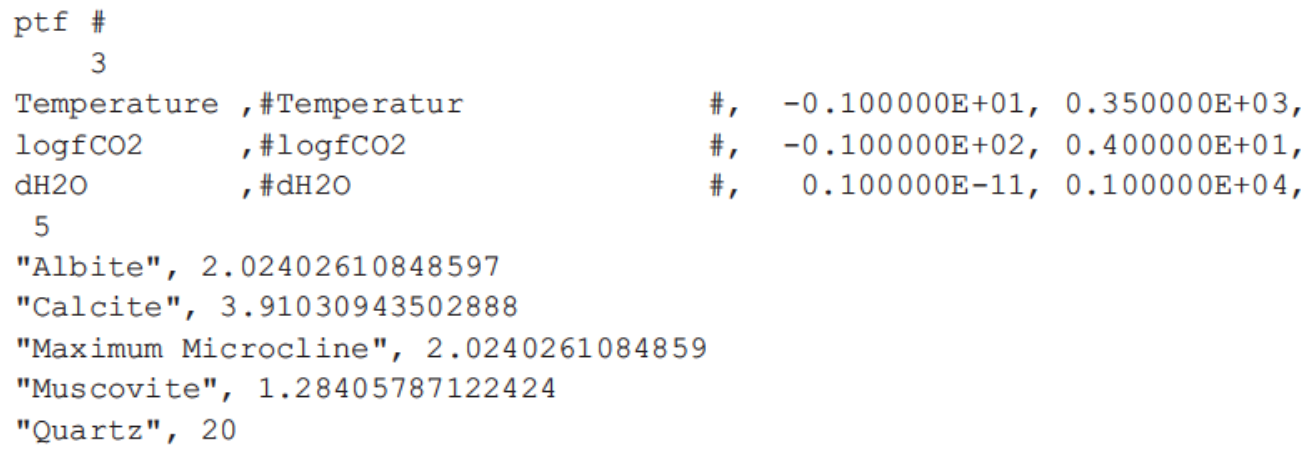




\section{PEST Instruction File}

The instruction file tells PEST where to find the values of the variables used in calculating the objective function. For RTEst, those variables are the calculated weighted saturation indices for the minerals whose names were provided by the user. The values of those are found in output file of RTEst. The first line defines the delimiter ("\#" in the example) while the rest of the define where to find each of the calculated saturation indexes. The first input on the line describes which line to go to, the second input is a identifier for the variable, and the third variable shows the range of columns in which the weighted saturation index for that mineral is found. For example, the second line in Ouput_case01_RT.ins file tells PEST to go to line 7 of the output file, call the variable SI1, and find the value of the weighted saturation index in columns 58 through 74 . The next line in the *.ins file tell pest to go to the next line, call the variable SI2, and find the value of the weighted saturation index in columns 58 through 74 . There instruction file for RTEst is RTEst_Output\#\#.ins; however, this file should not be altered by the user. The user is referred to the PEST manual for more details about setting up instruction files.

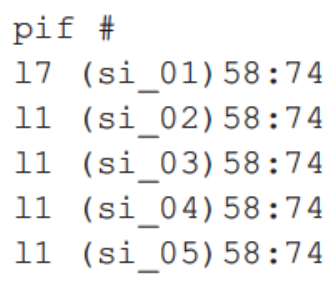

Note that the weighting of the saturation indexes is done in RTEst and that the weights in PEST should be set to unity for actual minerals.

\section{PEST Control File}

The PEST Control File (*.pst) brings together information about parameters being estimated, the observations used in the objective function, the files that PEST needs to access and data output options. Detailed descriptions of the Control File can be found in Doherty $(2005,2013)$. If PEST does not converge, the user may want to edit the Control file to change the initial guesses and various numerical parameters to promote convergence.

\section{PEST Output Files}

\section{Filename_Pest.Rec}

The test run record file, RTEst.rec, contains the full run details of the optimization and is the file that the user is most likely to check. It echoes much of the data input from the PEST Control File and as well as the estimates of values, objective function (phi), and the Marquardt lambda value (a factor used in the Levenberg-Marquardt method to improve numerical behavior). The key results of the optimization are provided in a subsection of the *.rec file under "OPTIMISATION RESULTS". The file provides the best estimate of the parameters and the upper and lower limits of the $95 \%$ confidence limits. In addition, the user will find the parameter covariance matrix, the parameter correlation matrix, the normalized eigenvectors of the parameter covariance matrix, and the eignenvalues. The user is referred to Doherty $(2005,2013)$ for additional information on these parameters. 
Filename_Pest.Sen

Information about the parameter sensitivities is contained in RTEst.sen

Filename_Pest.Seo

Observation sensitivities (i.e., the sensitivities of the saturation indexes) is contained in filename_Pest.seo.

Filename_Pest.Res

Information about the residuals is contained in the filename_Pest.res file.

Filename_Pest.MTT

Information about parameter statistical matrices is contained in the filename_Pest.MTT file. Information includes parameter values, their standard deviations, the prameter covariance matrix, the parameter correlation matrix, the normalized eigenvectors of the covariance matrix, and the eignvalues. 


\section{Appendix 3: Example Problems}

\section{Open System Example}

This example is modeled after that of Bethke (2008). Brine containing 2.05163 molal $\mathrm{Cl}$ and 0.05 molal $\mathrm{Ca}$ at $\mathrm{pH} 5.0$ is equilibrated with quartz, calcite, albite, "Maximum microcline", and muscovite at $250^{\circ} \mathrm{C}$. This geothermal water is transported to the near surface where the fluid cools to $25^{\circ} \mathrm{C}$ and $\mathrm{CO}_{2}$ vents until the $\mathrm{fCO}_{2}$ is 1 atmosphere. Any steam that was formed has condensed and has been reconstituted with the liquid water. The simulation represents geothermal fluid that approaches the surface, cools under closed conditions and then loses $\mathrm{CO}_{2}$ in a finite gas reservoir. The chemistry of the sampled water is provided under Case 1 in Table 5. The react file is provided in Figure 11 and the RTEst input file is provided in Figure 12. The results of the calculations with RTEst are summarized in Table 6.
Table 5. Input chemistry used in the example cases 1-3.

\begin{tabular}{|c|rrr|}
\hline & \multicolumn{4}{|c|}{ Case } \\
\hline Analyte & \multicolumn{1}{|c|}{$\mathbf{1}$} & \multicolumn{1}{c|}{$\mathbf{2}$} & \multicolumn{1}{c|}{3} \\
\hline \hline $\mathrm{Al}^{3+}$ mmolal & 0.471781 & 0.410382 & 0.555036 \\
$\mathrm{Ca}^{2+}$ molal & 0.05 & 0.064296 & 0.058824 \\
$\mathrm{Na}^{+}$molal & 1.79052 & 2.094249 & 2.106493 \\
$\mathrm{~K}^{+}$molal & 0.162405 & 0.192199 & 0.191065 \\
$\mathrm{Cl}^{-}$molal & 2.05163 & 2.413676 & 2.413681 \\
$\mathrm{HCO}_{3}{ }^{-}$molal & 0.038055 & 0.038123 & 0.03828 \\
$\mathrm{SiO}_{2}$ molal & 0.00388 & 0.00368 & 0.004565 \\
pH & 4.785295 & 4.816339 & 4.865366 \\
$\mathrm{H}_{2} \mathrm{O}$ (kg) & 1 & & 1 \\
Temp. ( $\left.{ }^{\circ} \mathrm{C}\right)$ & 25 & 25 & 25 \\
1 Open system & & & \\
2 Deep boiling & & & \\
3 Flashing & & &
\end{tabular}

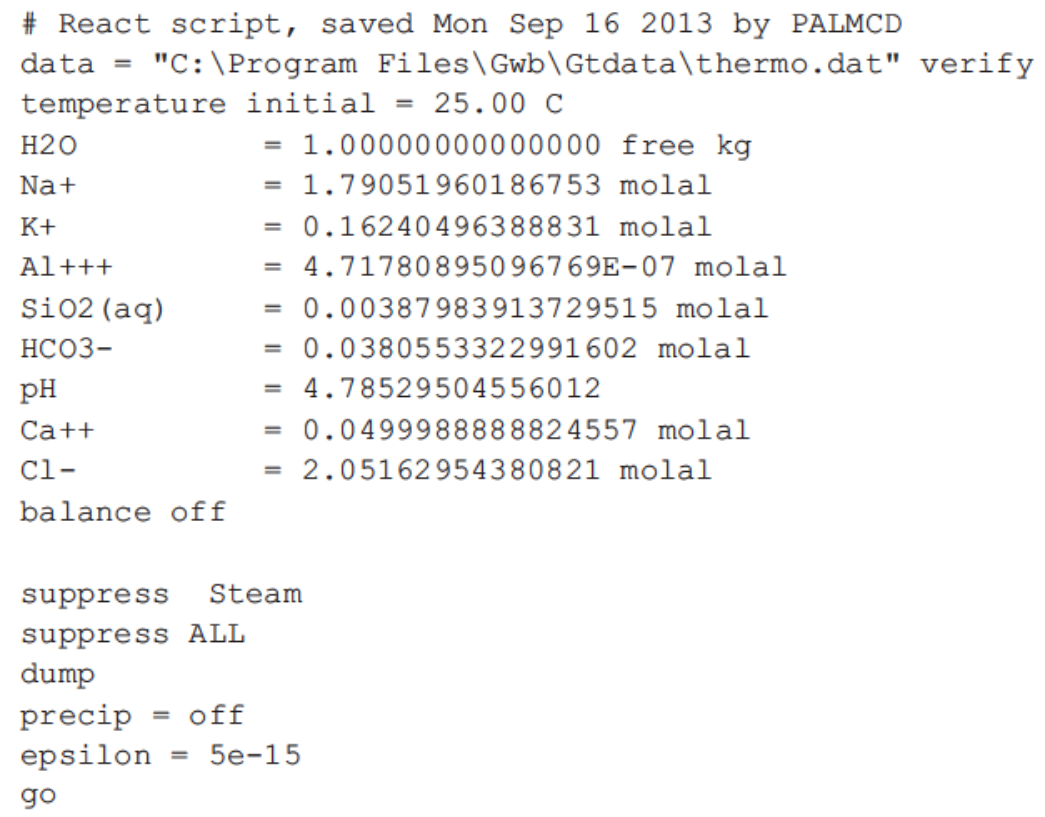

Figure 11. React file for Case 1, open system. 


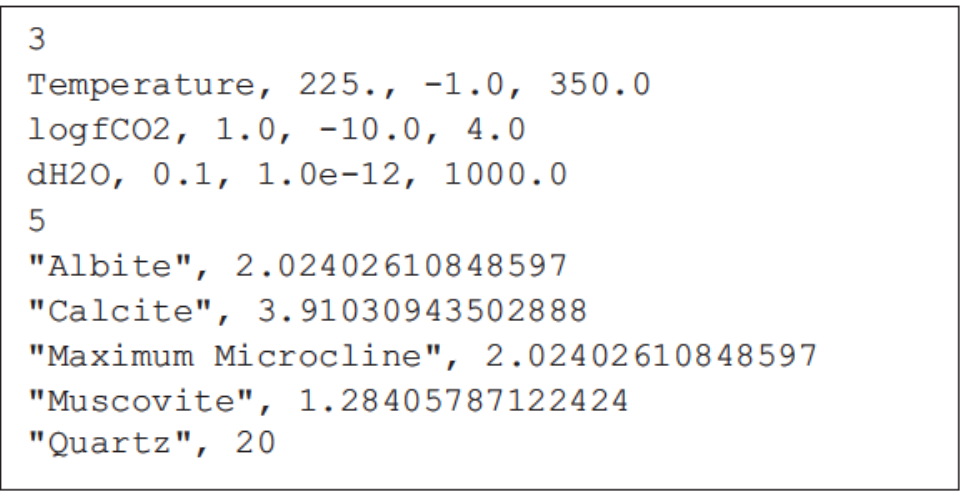

Figure 12. RTEst input file for Case 1, open system.

Table 6. Results of calculations using RTEst on hypothetical cases 1-3.

\begin{tabular}{|c|c|c|c|c|}
\hline & & \multicolumn{3}{|c|}{ Case } \\
\hline \multicolumn{2}{|c|}{ Parameter } & 1 & 2 & 3 \\
\hline \multicolumn{2}{|c|}{$\begin{array}{l}\text { Objective function } \\
\text { Total Saturation Index }\end{array}$} & $\begin{array}{l}1.0032 \mathrm{E}-13 \\
3.1673 \mathrm{E}-07\end{array}$ & $\begin{array}{l}3.0823 \mathrm{E}-18 \\
17557 \mathrm{E}-09\end{array}$ & $\begin{array}{l}7.0273 \mathrm{E}-14 \\
2.6509 \mathrm{E}-07\end{array}$ \\
\hline \multirow[t]{3}{*}{ Temp. $\left({ }^{\circ} \mathrm{C}\right)$} & Actual & 250.000 & 250.000 & $250.00 C$ \\
\hline & Estimated & 250.000 & 250.000 & $250.00 C$ \\
\hline & Std. Dev. & $6.301 \mathrm{E}-05$ & $5.018 \mathrm{E}-06$ & $6.03 \mathrm{E}-05$ \\
\hline \multirow[t]{3}{*}{$\mathrm{fCO}_{2}$} & Actual & 21.1220 & 25.6064 & 21.1222 \\
\hline & Estimated & $21.1218^{\top}$ & 25.6065 & $21.121 \varepsilon$ \\
\hline & Std. Dev. & $5.36 \mathrm{E}-05$ & $5.76 \mathrm{E}-06$ & $5.14 \mathrm{E}-05$ \\
\hline \multirow[t]{3}{*}{$\Delta \mathrm{H}_{2} \mathrm{O}(\mathrm{kg})$} & Actual & $0.000000 E+00$ & $0.000000 E+00$ & $1.764706 \mathrm{E}-01$ \\
\hline & Estimated & $2.424581 \mathrm{E}-07$ & $1.000000 \mathrm{E}-12$ & $1.764710 \mathrm{E}-01$ \\
\hline & Std. Dev. & $6.322821 \mathrm{E}-07$ & 3.972911E-08 & $7.122475 \mathrm{E}-07$ \\
\hline
\end{tabular}

\section{Deep Boiling Example}

Brine containing 2.05163 molal $\mathrm{Cl}$ and 0.05 molal Ca at pH 5.2 is equilibrated with quartz, calcite, albite, "Maximum microcline", and muscovite at $250^{\circ} \mathrm{C}$. This geothermal water is then isothermally boiled until $15 \%$ of the water is lost while maintaining equilibrium with the reservoir mineral assemblage. The resulting water is then transported to the surface where the fluid cools to $25^{\circ} \mathrm{C}$ and $\mathrm{CO}_{2}$ vents until the $\mathrm{fCO}_{2}$ is 1 atmosphere. The chemistry of this "sampled" water is included as Case 2 in Table 5. The react file is provided in Figure 13. The RTEst input file is the same as that for Case 1 (Figure 12). 


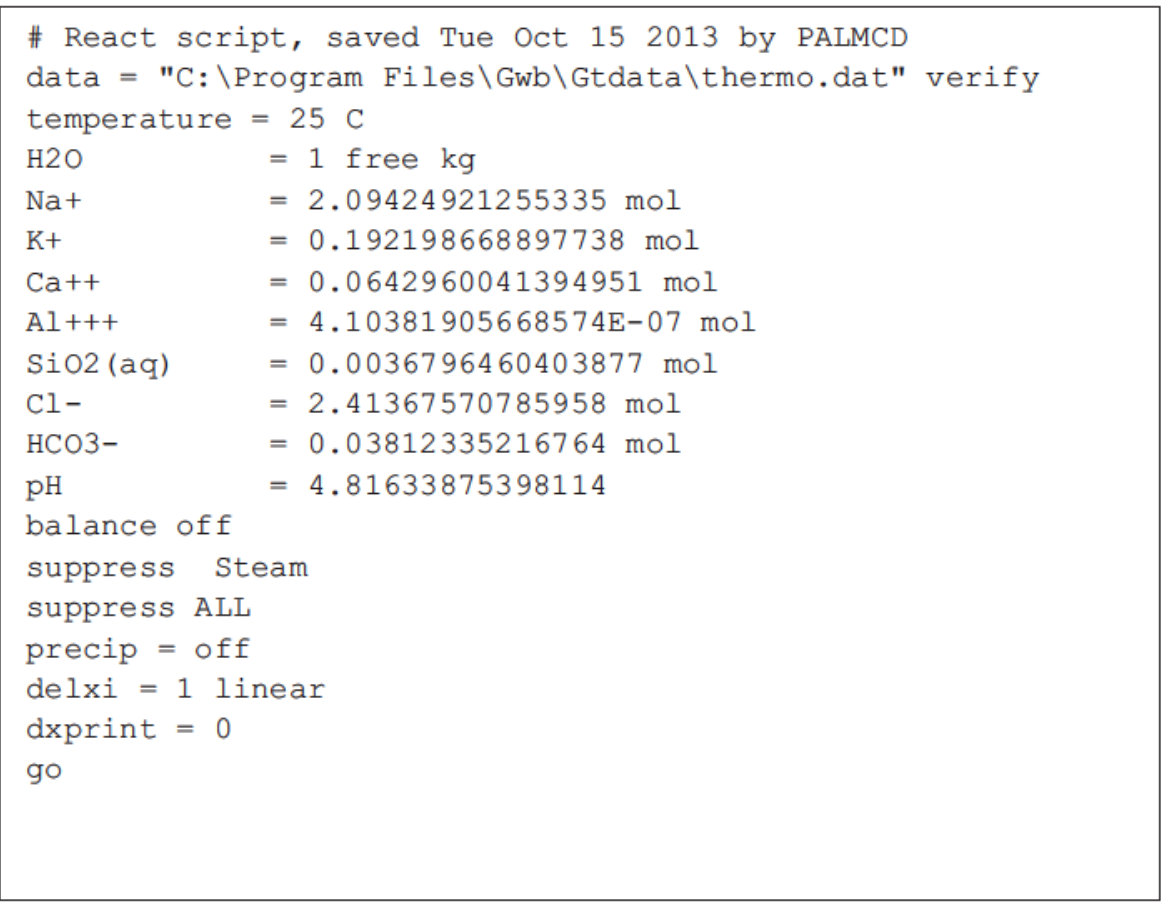

Figure 13. React file for Case 2, deep boiling.

\section{Flashing Example}

Brine containing 2.05163 molal $\mathrm{Cl}$ and 0.05 molal $\mathrm{Ca}$ at $\mathrm{pH} 5.2$ is equilibrated with quartz, calcite, albite, "Maximum microcline", and muscovite at $250^{\circ} \mathrm{C}$. This geothermal water is then isothermally boiled until $15 \%$ of the water is lost but mineral reaction does not occur during boiling. The resulting water is then transported to the surface where the fluid cools to $25^{\circ} \mathrm{C}$ and $\mathrm{CO}_{2}$ vents to the atmosphere. This scenario represents fluid flashing within a well. The chemistry of this sampled water is included as Case 3 in Table 5. The react file is provided in Figure 14. The RTEst input file is the same as that for Case 1 (Figure 12).

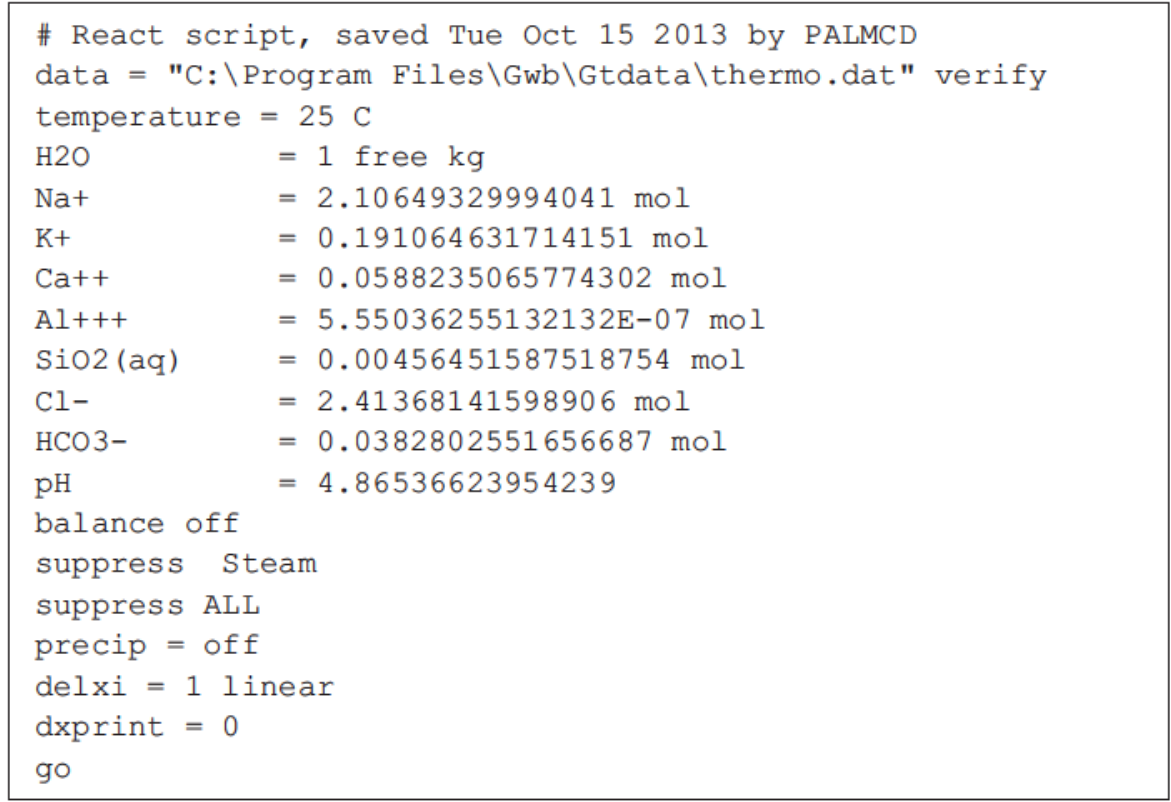

Figure 14. React file for Case 3, flashing. 


\section{Mixing Example}

Many thermal waters are believed to be mixtures of thermal and non-thermal groundwater. To demonstrate the ability of RTEst to address mixing, we tested two mixing scenarios. In both scenarios, a water containing 0.002 molal Ca++ and 0.06775 molal $\mathrm{Cl}$ - is equilibrated with albite, muscovite, chlinochlor-14A, $\mathrm{K}$-feldspar, calcite, and quartz at $\mathrm{pH}$ 6.5. In the first scenario (Fixed $\mathrm{CO}_{2}$ ), this water is cooled to $25^{\circ} \mathrm{C}$ and mixed in a 1:1 ratio with a groundwater representing the mean shallow groundwater in the Eastern Snake River Plain (ESRP) of Idaho. In the second scenario (Sliding $\mathrm{CO}_{2}$ ), the initial water chemistry is cooled to $25^{\circ} \mathrm{C}$ and the $\mathrm{fCO}_{2}$ is allowed to a value of 0.01 before it is mixed with the mean ESRP water. The chemistries of these two mixtures as well as the chemistry of the mean ESRP water are summarized in Table 7.

Table 7. Water chemistries used in the two mixing scenarios.

\begin{tabular}{|c|rrr|}
\cline { 2 - 4 } \multicolumn{1}{c|}{} & \multicolumn{3}{c|}{ Case 5 -- Mixing Scenarios } \\
\hline Analyte & Fixed $\mathrm{CO}_{2}$ & \multicolumn{1}{c|}{ Sliding $\mathrm{CO}_{2}$} & Mean ESRP \\
\hline $\mathrm{Al}^{3+} \mu$ molal & 5.18420 & 5.18420 & 5.18420 \\
$\mathrm{Ca}^{2+}$ molal & 0.00200 & 0.00200 & 0.00126 \\
$\mathrm{Mg}^{2+}$ molal & $9.3537 \mathrm{E}-07$ & $9.3537 \mathrm{E}-07$ & $7.3140 \mathrm{E}-04$ \\
$\mathrm{Na}^{+}$molal & 0.05928 & 0.05928 & 0.00112 \\
$\mathrm{~K}^{+}$molal & 0.00465 & 0.00465 & 0.00010 \\
$\mathrm{Cl}^{-}$molal & 0.06775 & 0.06775 & 0.00078 \\
$\mathrm{HCO}_{3}{ }^{-}$molal & 0.00110 & 0.00055 & 0.00503 \\
$\mathrm{SiO}_{\mathbf{2}}$ molal & 0.00635 & 0.00635 & 0.00052 \\
$\mathrm{pH}$ & 5.60592 & 5.98385 & 7.18730 \\
$\mathrm{H}_{\mathbf{2}} \mathrm{O}$ (kg) & 1.000000 & 1.000000 & 1.000000 \\
$\mathrm{Temp}^{\circ}\left({ }^{\circ} \mathrm{C}\right)$ & 25.00 & 25.00 & 25.00 \\
\hline
\end{tabular}


The react files for the fixed $\mathrm{CO}_{2}$ case is provided in Figure 15 while the react file for the sliding $\mathrm{CO} 2$ case is provided in Figure 16. The masses reported with the key word "react" reflect the composition of the mean ESRP groundwater while the initial masses indicated the composition of the mixed water that was sampled.

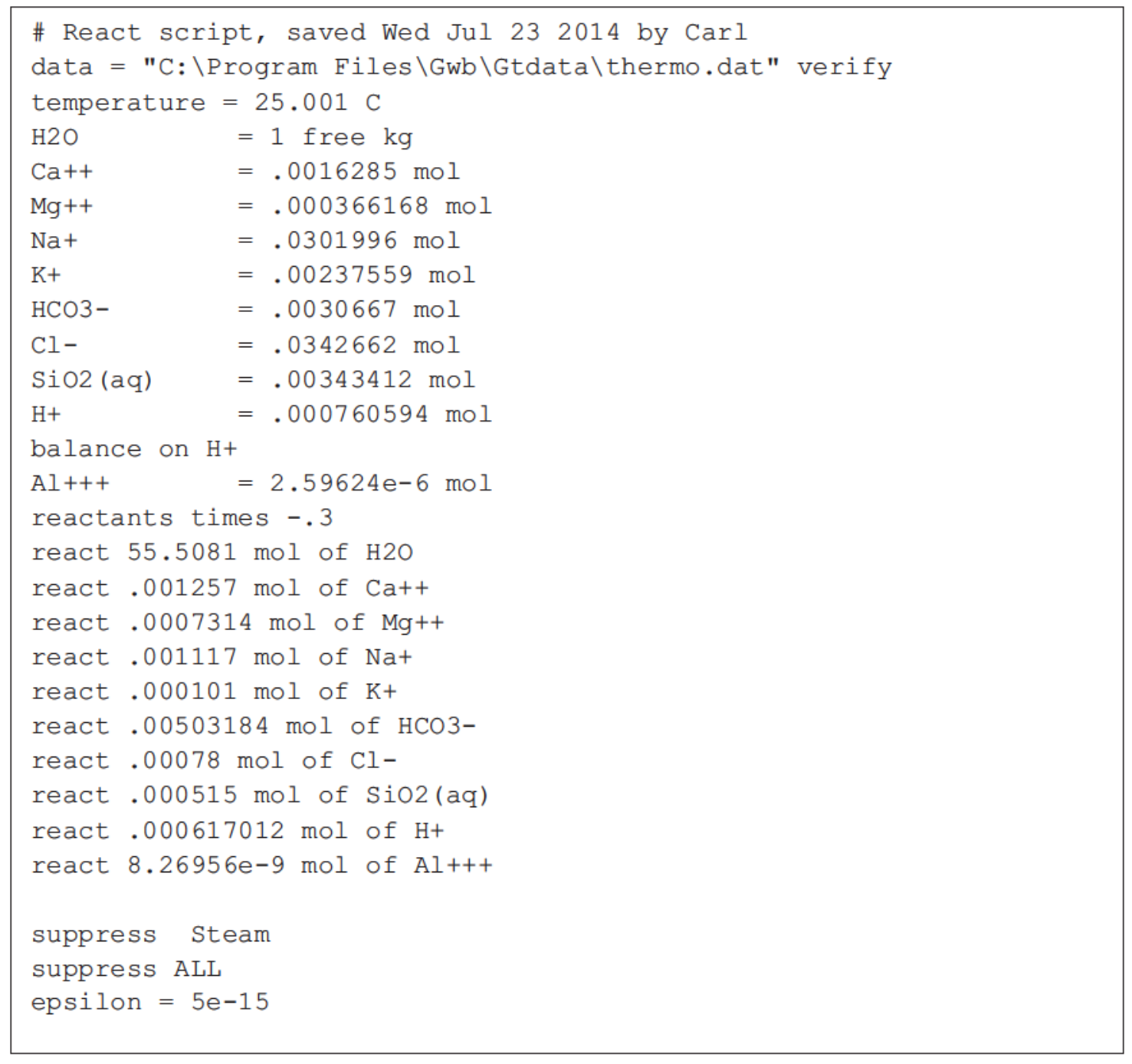

Figure 15. React file for mixing scenario with fixed $\mathrm{CO}_{2}$. 


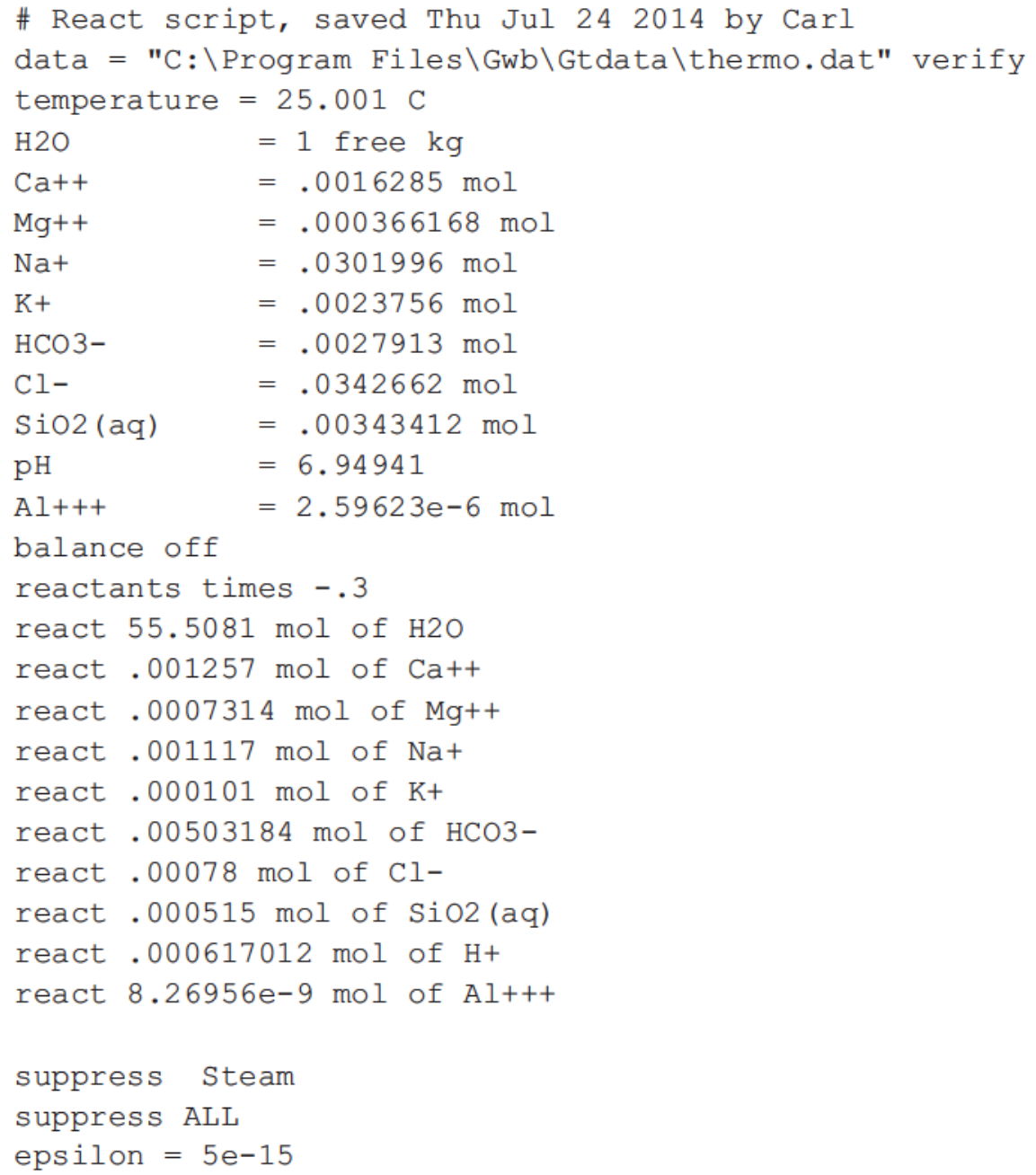

Figure 16. React file for the sliding $\mathrm{CO}_{2}$ case. 
The RTEst file for the fixed CO2 case (Figure 17) contains only two optimization parameters:

Temperature and MixFrac. The reason that there can only be one fitting parameter is because the $\mathrm{CO} 2$ in this scenario was determined from mixing only; thus ,the fCO2 is correlated with the mixing parameter. If the fugacity of $\mathrm{CO} 2$ is also included, the system would be over-determined and the fits would be very poor. In the sliding $\mathrm{CO} 2$ scenario, the amound of $\mathrm{CO} 2$ is affected by both mixing and the loss of $\mathrm{CO}_{2}$; thus, three parameters can be included (Figure 18). chlinochlor-14A is not included as mineral in the optimiztion because it results in much larger errors. This is likely because the amount of $\mathrm{Mg}++$ in the end-member thermal water is low and round off error becomes important.

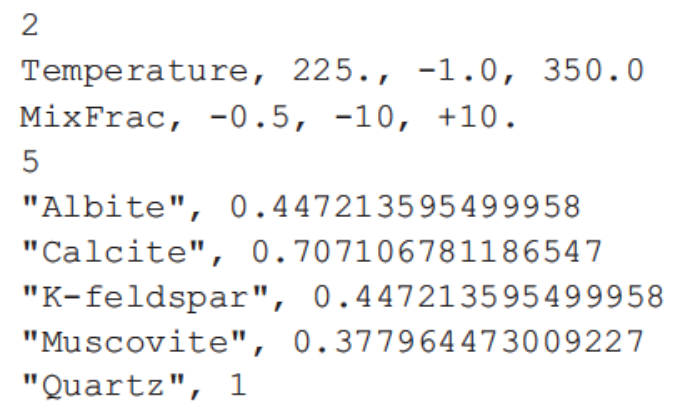

Figure 17. RTEst input file for the fixed $\mathrm{CO}_{2}$ case.

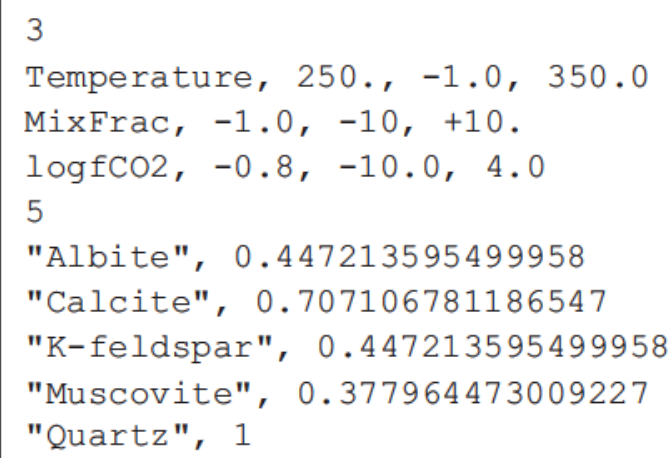

Figure 18. RTEst input file for the sliding $\mathrm{CO}_{2}$ case. 
The results Fixed CO2 scenario (Table 8) show a small objective function as well as small standard deviations for the fitted parameters. For the sliding $\mathrm{CO}_{2}$ case, three parameters can be used in the optimization. The results for this case show a small objective function as well as small standard deviations for the fitted values of temperature, $\mathrm{fCO}_{2}$, and mixing fraction.

Table 8. Results for Case 5 , mixing.

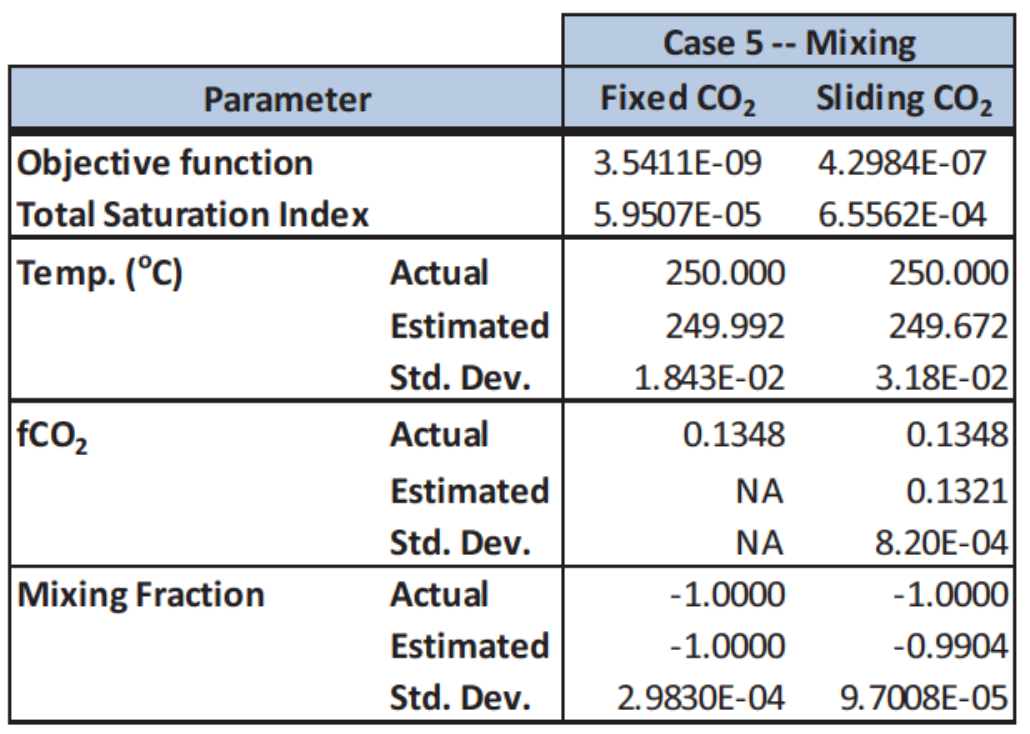

$\mathrm{NA}=$ not applicable 


\section{References}

Bethke, C.M. and Yeakel, S. (2011), "The Geochemist's Workbench User's Guides, Aqueous Solutions $L L C$, Champaign $\mathbb{I L}$.

Bethke, C.M. (2008), "Geochemical and Biogeochemical Reaction Modeling", Cambridge University Press, $2^{\text {nd }}$ Ed., New York, New York, USA, 543 pp.

Doherty J. (2005), "PEST, Model-Independent Parameter Estimation User Manual, $5^{\text {th }}$ Edition", Watermark Numerical Computing, www.pesthompage.org

Doherty, J. (2013), “Addendum to the PEST Manual”, Watermark Numerical Computing, www.pesthompage.org.

Langmuir, D., 1997. Aqueous Environmental Geochmistry, Prentice Hall, Upper Saddle River, New Jersey, $600 \mathrm{p}$. 


\section{Appendix C. Development of Representative Geothermal Alteration Mineral Assemblages}

\section{Mineral assemblages}

We have reviewed 48 geothermal systems representing all major geologic environments typically associated with geothermal activity (references listed in Table C1). For each geothermal field, primary lithology, mineralogy, maximum reservoir temperature, water composition, and secondary mineral assemblages were recorded and evaluated. Although Browne (1978) listed 6 major factors that influence the crystallization of various assemblages in active geothermal fields (temperature, pressure, reservoir rock type, permeability, fluid composition, and duration of hydrothermal activity), in this study, we observed three factors (reservoir lithology, fluid composition, and temperature) were most influential in determining the alteration mineral assemblages. Based on our analysis of the reports listed in the Appendix, we developed a hierarchical 16-category classification of these geothermal systems shown in Figure $\mathrm{C} 1$ that included 5 lithologies or rock types (Tholeiitic, Calc-alkaline, Silicic, Siliciclastic, and carbonates), 3 temperature regimes (low, $50-150{ }^{\circ} \mathrm{C}$; moderate, 150 to $300{ }^{\circ} \mathrm{C}$; and high, $>300{ }^{\circ} \mathrm{C}$ ), and 2 water types (neutral and acid). Representative geothermal alteration mineral assemblages for each of the 16 classification are provided in Table $\mathrm{C} 2$. Figure $\mathrm{C} 2$ shows the generalized relationship among specific types of alteration minerals, lithology, and temperature.

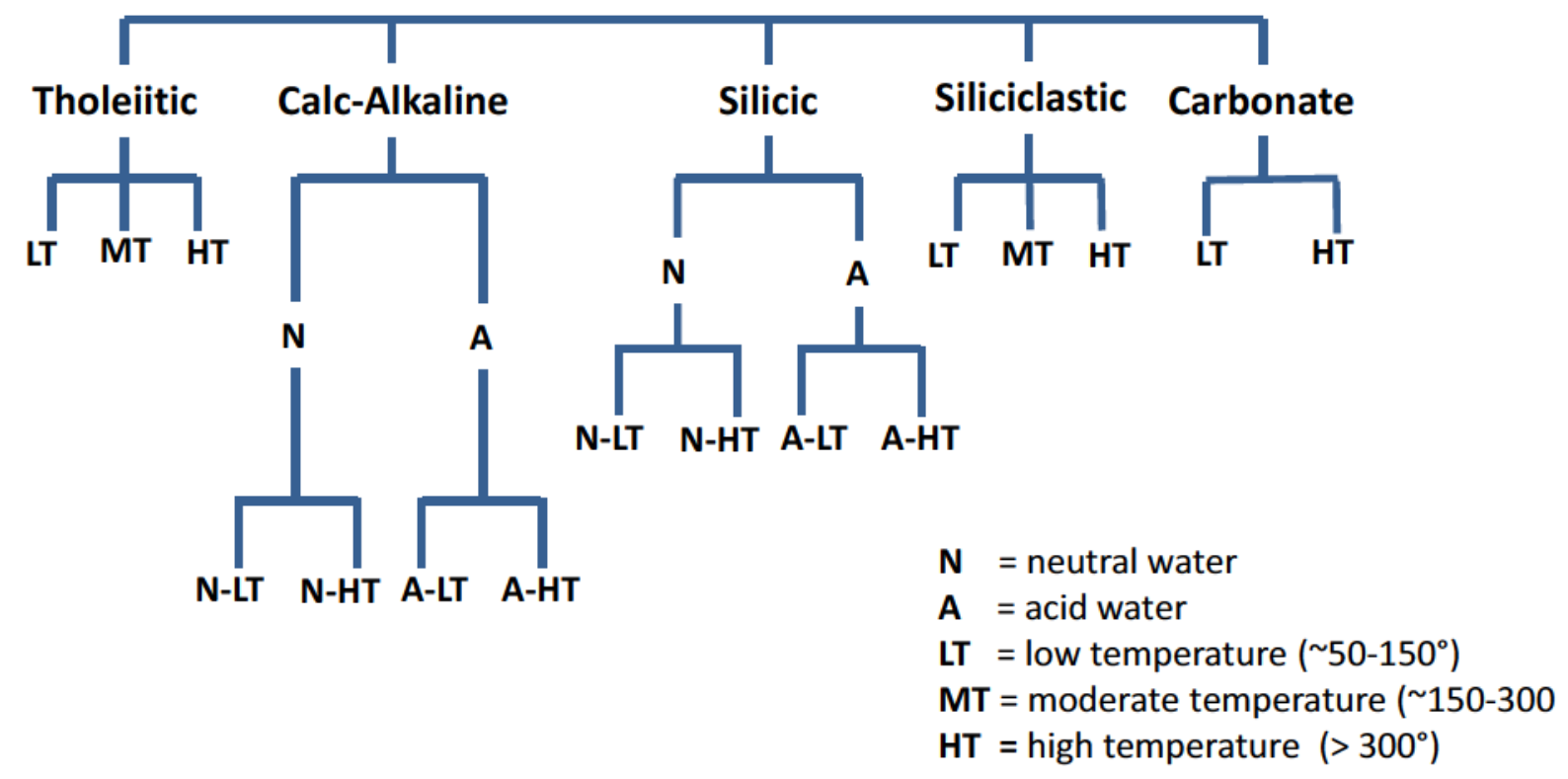

Figure C1. Hierarchical listing of influencing parameters and assemblage groups. 


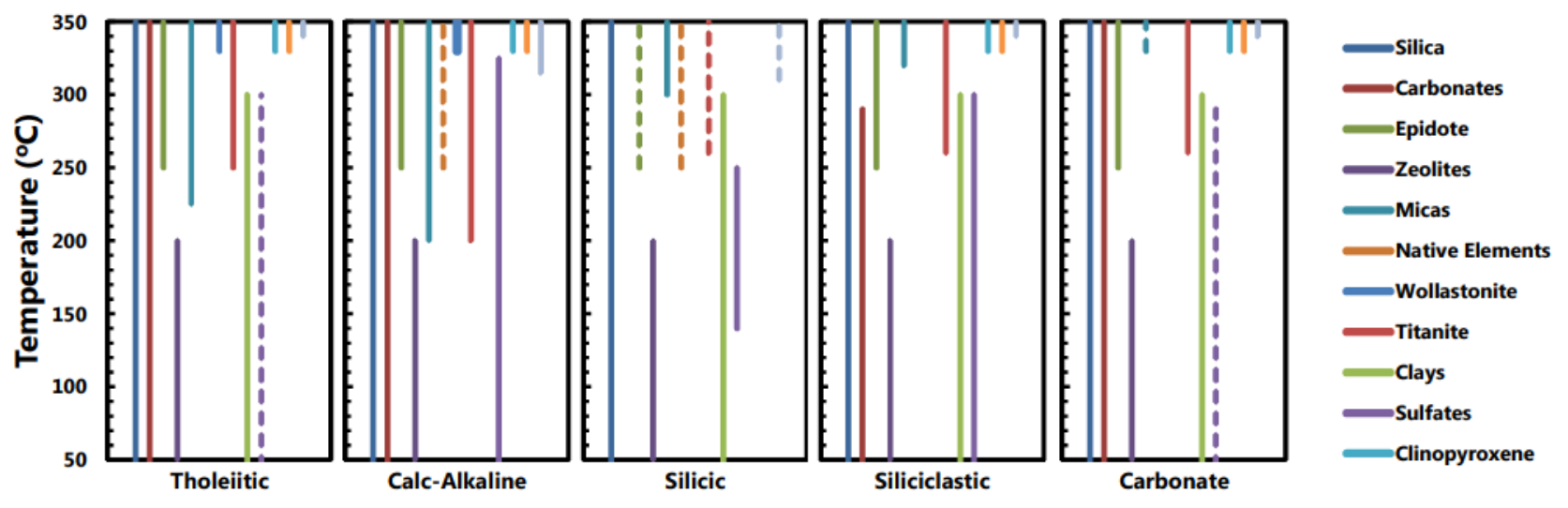

Figure C2. Temperature intervals for mineral groups in rock types. Solid lines indicate significant presence and dashed lines indicate occasional presence.

Table C1. Literature sources considered in developing representative geothermal alteration mineral assemblages

Agostini, S., Corti, G., Doglioni, C., Carminati, E., Innocenti, F., Tonarini, S., Manetti, P., Di Vincenzo, G., and Montanari, D., 2006. Tectonic and magmatic evolution of the active volcanic front in El Salvador: insight into the Berlín and Ahuachapán geothermal areas. Geothermics, vol. 35, pp. 368-408.

Ashley, R. P., Cunningham, C. G., Bostick, N. H., Dean, W. E., and Chou, I.-M., 1991. Geology and geochemistry of three sedimentary-rock-hosted disseminated gold deposits in Guizhou Province, People's Republic of China. Ore Geology Reviews, vol. 6, pp. 133-151.

Ayling, B., Molling, P., Nye, R., and Moore, J., 2011. Fluid geochemistry at the Raft River geothermal field, Idaho: New data and hydrogeological implications. Proceedings, Thirty-sixth Workshop on Geothermal Reservoir Engineering, Stanford University, Stanford, California, January 31-February 2, 2011, $11 \mathrm{p}$.

Battaglia, S., Gianelli, G., Rossi, R., and Cavarretta, G., 1991. The Sulphur Springs geothermal field, St. Lucia, Lesser Antilles: Hydrothermal mineralogy of wells SL-1 and SL-2. Journal of South American Earth Sciences, vol. 4, no. 1/2, pp. 1-12.

Beaufort, D., Westercamp, D., Legendre, O., and Meunier, A., 1990. The fossil hydrothermal system of Saint Martin, Lesser Antilles: geology and lateral distribution of alterations. Journal of Volcanology and Geothermal Research, vol. 40, pp. 219-243.

Bertini, G., Gianelli, G., Pandeli, E., and Puxeddu, M., 1985. Distribution of hydrothermal minerals in Larderello-Travale and Mt. Amiata geothermal fields (Italy). Geothermal Resources Council Transactions, vol. 9, part 1, pp. 261-266.

Blackett, R. E., and Kolesar, P. T., 1983. Geology and alteration of the Raft River geothermal system, Idaho. Geothermal Resources Council Transactions, vol. 7, pp. 123-127.

Cathelineau, M., Oliver, R., Nieva, D., and Garfias, A., 1985. Mineralogy and distribution of hydrothermal mineral zones in Los Azufres (Mexico) geothermal field. Geothermics, vol. 14, no. 1, pp. 49-57.

Cavarretta, G., Gianelli, G., and Puxeddu, M., 1980. Hydrothermal metamorphism in the Larderello geothermal field. Geothermics, vol. 9, pp. 297-314.

Clemente, W. C., and Villadolid-Abrigo, F. L., 1993. The Bulalo geothermal field, Philippines: Reservoir characteristics and response to production. Geothermics, vol. 22, no. 5/6, pp. 381-394.

Cole, D. R., and Ravinsky, L. I., 1984. Hydrothermal alteration zoning in the Beowave geothermal system, Eureka and Lander counties, Nevada. Economic Geology, vol. 79, pp. 759-767. 
Cook, N. D. J., and Ashley, P. M., 1992. Meta-evaporite sequence, exhalative chemical sediments and associated rocks in the Proterozoic Willyama Supergroup, South Australia: implications for metallogenesis. Precambrian Research, vol. 56, pp. 211-226.

De Vivo, B., Belkin, H. E., Barbieri, M., Chelini, W., Lattanzi, P., Lima, A., and Tolomeo, L., 1989. The Campi Flegrei (Italy) geothermal system: A fluid inclusion study of the Mofete and San Vito fields. Journal of Volcanology and Geothermal Research, vol. 36, pp. 303-326.

Donoghue, E., Troll, V. R., Harris, C., O’Halloran, A., Walter, T. R., and Torrado, F. J. P., 2008. Low-temperature hydrothermal alteration of intra-caldera tuffs, Miocene Tejeda caldera, Gran Canaria, Canary Islands. Journal of Volcanology and Geothermal Research, vol. 176, pp. 551564.

Dudoignon, P., Meunier, A., Beaufort, D., Gachon, A., and Buigues, D., 1989. Hydrothermal alteration at Mururoa Atoll (French Polynesia). Chemical Geology, vol. 76, pp. 385-401.

Elders, W. A., Hoagland, J. R., and McDowell, S. D., 1979. Hydrothermal mineral zones in the geothermal reservoir of Cerro Prieto. Geothermics, vol. 8, pp. 201-209.

Enami, M., Liou, J. G., and Bird, D. K., 1992. Cl-bearing amphibole in the Salton Sea geothermal system, California. Canadian Mineralogist, vol. 30, pp. 1077-1092.

Eshaghpour, M., 2003. Borehole geology and alteration mineralogy of well HE-9 in Hellisheidi geothermal field, SW-Iceland. United Nations University Geothermal Training Programme 2003 Report Number 8, Orkustofnun, Grensásvegur 9, IS-108, Reykjavík, Iceland, pp. 165-187.

Fagan, C. J., Wilson, C. J. N., Spinks, K. D., Browne, P. R. L., and Simmons, S. F., 2006. Stratigraphy, hydrothermal alteration and evolution of the Mangakino geothermal system, Taupo Volcanic Zone, New Zealand. Proceedings, $28^{\text {th }}$ New Zealand Geothermal Workshop 2006, 7 p.

Flexser, S., 1991. Hydrothermal alteration and past and present thermal regimes in the western moat of Long Valley caldera. Journal of Volcanology and Geothermal Research, vol. 48, pp. 303-318.

Fulginati, P., Gioncada, A., and Sbrana, A., 1998. Geologic model of the magmatic-hydrothermal system of Vulcano (Aeolian Islands, Italy). Mineralogy and Petrology, vol. 62, pp. 195-222.

Fulginati, P., Malfitano, G., and Sbrana, A., 1997. The Pantelleria caldera geothermal system: Data from the hydrothermal minerals. Journal of Volcanology and Geothermal Research, vol. 75, pp. 251-270.

Funiciello, R., Mariotti, G., Parotto, M., Preite-Martinez, M., Tecce, F., Toneatti, R., and Turi, B., 1979. Geology, mineralogy, and stable isotope geochemistry of the Cesano geothermal field (Sabatini Mts. volcanic system, Northern Latium, Italy). Geothermics, vol. 8, pp. 55-73.

Furuya, S., Aoki, M., Gotoh, H., and Takenaka, T., 2000. Takigami geothermal system, northeastern Kyushu, Japan. Geothermics, vol. 29, pp. 191-211.

Getaneh, E., 2001. Borehole geology and alteration mineralogy in the upper half of well HE-3, Hellisheidi, SW-Iceland. United Nations University Geothermal Training Programme 2001 Report Number 4, Orkudtofnun, Grensásvegur 9, IS-108, Reykjavík, Iceland, pp. 59-82.

Ghazban, F., 2004. Alteration and Geochemistry of Mount Taftan Geothermal Prospect Southeastern Iran. Iranian International Journal of Science, vol. 1, pp. 43-62.

Gianelli, G., and Teklemariam, M., 1993. Water-rock interaction processes in the Aluto-Langano geothermal field (Ethiopia). Journal of Volcanology and Geothermal Research, vol. 56, pp. 429445 .

Gioncada, A., Sbrana, A., and Teklemariam, M., 1995. Hydrothermal Alteration and Fluid Inclusion Studies in the Vulcano Geothermal Wells (Italy). World Geothermal Congress Proceedings, pp. 1099-1104.

Hagerty, J. J., and Newsom, H. E., 2003. Hydrothermal alteration at the Lonar Lake impact structure, India: Implications for impact cratering on Mars. Meteoritics and Planetary Science, vol. 38, no. 3, pp. 365-381.

Hartanto, D. B., 2005. Borehole geology and alteration mineralogy of well HE-11, Hellisheidi geothermal field, SW-Iceland. United Nations University Geothermal Training Programme 
Report Number 8, Orkustofnun, Grensásvegur 9, IS-108 Reykjavík, Iceland, pp. 83-109.

Hayashi, J., and Furuya, S., 1988. Geothermal resources in the Takigami geothermal area, Kyushu, Japan. Proceedings, $10^{\text {th }}$ New Zealand Geothermal Workshop 1988, pp. 49-53.

Hedenquist, J. W., 1990. The thermal and geochemical structure of the Broadlands-Ohaaki geothermal system, New Zealand. Geothermics, vol. 19, pp. 151-185.

Hedenquist, J. W., and Browne, P. R. L., 1989. The evolution of the Waiotapu geothermal system, New Zealand, based on the chemical and isotopic composition of its fluids, minerals, and rocks. Geochimica et Cosmochimica Acta, vol. 53, pp. 2235-2257.

Henneberger, R. C., and Browne, P. R. L., 1988. Hydrothermal alteration and evolution of the Ohakuri hydrothermal system, Taupo Volcanic Zone, New Zealand. Journal of Volcanology and Geothermal Research, vol. 34, pp. 211-231.

Hulen, J. B., and Neilson, D. L., 1986. Stratigraphy and hydrothermal alteration in well Baca-8, Sulphur Springs area, Valles Caldera, New Mexico. Geothermal Resources Council Transactions, vol. 10, pp. 187-192.

Hulen, J. B., and Nielson, D. L., 1988. Clay mineralogy and zoning in CSDP corehole VC-2A: Further evidence for collapse of isotherms in the Valles Caldera. Geothermal Resources Council Transactions, vol. 12, pp. 291-298.

Inoue, A., and Utada, M., 1991. Pumpellyite and related minerals from hydrothermally altered rocks at the Kamikita area, northern Honshu, Japan. Canadian Mineralogist, vol. 29, pp. 255-270.

Karpov, G. A., and Naboko, S. I., 1990. Metal contents of recent thermal waters, mineral precipitates and hydrothermal alteration in active geothermal fields, Kamchatka. Journal of Geochemical Exploration, vol. 36, pp. 57-71.

Keith, T. E. C., and Muffler, L. J. P., 1978. Minerals produced during cooling and hydrothermal alteration of ash flow tuff from Yellowstone drill hole Y-5. Journal of Volcanology and Geothermal Research, vol. 3, pp. 373-402.

Koestono, H., 2007. Borehole geology and hydrothermal alteration of well HE-24, Hellisheidi geothermal field, SW-Iceland. United Nations University Geothermal Training Programme 2007 Report Number 10, Orkustofnun, Grensásvegur 9, IS-108 Reykjavík, Iceland, p. 199-224.

Lagat, J. K., 1995. Borehole geology and hydrothermal alteration of well OW-30, Olkaria geothermal field, Kenya. United Nations University Geothermal Training Programme 1995 Report number 6, Orkustofnun, Grensásgevur 9, IS-108 Reykjavík, Iceland, pp. 135-154.

Lagat, J. K., 2004. Geology, hydrothermal alteration and fluid inclusion studies of Olkaria Domes geothermal field, Kenya. M.Sc. thesis, Department of Geology and Geography, University of Iceland, $79 \mathrm{p}$.

Ledésert, B., Hebert, R., Genter, A., Bartier, D., Clauer, N., and Grall, C., 2010. Fractures, hydrothermal alterations and permeability in the Soultz Enhanced Geothermal System. Comptes Rendus Geoscience, vol. 342, pp. 607-615.

Liakopoulos, A., Katerinopoulos, A., Markopoulos, T., and Boulegue, J., 1991. A mineralogical petrographic and geochemical study of samples from wells in the geothermal field of Milos Island (Greece). Geothermics, vol. 20, no. 4, pp. 237-256.

Lutz, S. J., and Moore, J. N., 1997. Geologic framework of Jurassic reservoir rocks in the Dixie Valley geothermal field, Nevada: Implications from hydrothermal alteration and stratigraphy. Proceedings, Twenty-second Workshop on Geothermal Reservoir Engineering, Stanford University, Stanford, California, January 27-29, 1997, pp. 131-139.

Lutz, S. J., Moore, J. N., and Copp, J. F., 1996. Integrated mineralogical and fluid inclusion study of the Coso geothermal system, California. Proceedings, Twenty-First Workshop on Geothermal Reservoir Engineering, Stanford University, California, January 22-24, 1996, pp. 187-194.

Magaña, M. I., de Henríquez, E., and López, D., 2003. Study on diffuse degassing and alteration mineralogy in the Berlín Geothermal Field. International Geothermal Conference, Session \#9, Reykjavík, September 2003, pp. 33-39. 
Marks, N., Schiffman, P., Zirenberg, R. A., Franzson, H., and Fridleifsson, G. Ó., 2010. Hydrothermal alteration in the Reykjanes geothermal system: Insights from Iceland deep drilling program well RN-17. Journal of Volcanology and Geothermal Research, vol. 189, pp. 172-190.

Marumo, K., Nagasawa, K. and Kuroda, Y., 1980. Mineralogy and hydrogen isotope geochemistry of clay minerals in the Ohnuma geothermal area, northeastern Japan. Earth and Planetary Science Letters, vol. 47, pp. 255-262.

Masuda, H., Sakai, H., Chiba, H., Matsuhisa, Y., and Nakamura, T., 1986. Stable isotopic and mineralogical studies of hydrothermal alteration at Arima Spa, Southwest Japan. Geochimica et Cosmochimica Acta, vol. 50, pp. 19-28.

McDowell, S. D., and Elders, W. A., 1983. Allogenic layer silicate minerals in borehole Elmore \#1, Salton Sea Geothermal Field, California. American Mineralogist, vol. 68, pp. 1146-1159.

McDowell, S. D., and Paces, J. B., 1985. Carbonate alteration minerals in the Salton Sea geothermal system, California, USA. Mineralogical Magazine, vol. 49, pp. 469-479.

McKibben, M. A., Williams, A. E., and Okubo, S., 1988. Metamorphosed Plio-Pleistocene evaporites and the origin of hypersaline brines in the Salton Sea geothermal system, California: Fluid inclusion evidence. Geochimica et Cosmochimica Acta, vol. 52, pp. 1047-1056.

Nielson, D. L., Clemente, W. C., Moore, J. N., and Powell, T. S., 1996. Fracture permeability in the Matalibong-25 corehole, Tiwi geothermal field, Philippines. Proceedings, Twenty-First Workshop on Geothermal Reservoir Engineering, Stanford University, Stanford, California, January 22-24, 1996, pp. 209-216.

Neilson, D. L., and Hulen, J. B., 1983. Geologic model of the Baca geothermal reservoir, Valles Caldera, New Mexico. Proceedings, Ninth Workshop on Geothermal Reservoir Engineering, Stanford University, Stanford, California, pp. 145-150.

Parry, W. T., Hedderly-Smith, D., and Bruhn, R. L., 1991. Fluid Inclusions and Hydrothermal Alteration on the Dixie Valley Fault, Nevada. Journal of Geophysical Research, vol. 96, no. B12, pp. 19733-19748.

Prol-Ledesma, R. M., and Browne, P. R. L., 1989. Hydrothermal alteration and fluid inclusion geothermometry of Los Humeros geothermal field, Mexico. Geothermics, vol. 18, no. 5/6, pp. $677-690$.

Rae, A. J., Rosenberg, M. D., Bignall, G., Kilgour, G. N., and Milicich, S. D., 2007. Geological results of production well drilling in the western steamfield, Ohaaki geothermal system 20052007. Proceedings, $29^{\text {th }}$ New Zealand Geothermal Workshop 2007, 7 p.

Ragnarsdóttir, K. V., Walther, J. V., and Arnórsson, S., 1984. Description and interpretation of the composition of fluid and alteration mineralogy in the geothermal system at Svartsengi, Iceland. Geochimica et Cosmochimica Acta, vol. 48, pp. 1535-1553.

Ramos, S. G., 2002. Potential constraints to the development of the Rangas sector based on petrologic evaluation of the Bacman geothermal field, Philippines. Proceedings, Twenty-Seventh Workshop on Geothermal Reservoir Engineering, Stanford University, Stanford, California, January 28-30, 2002,9 p.

Raymahashay, B. C., 1968. A geochemical study of rock alteration by hot springs in the Paint Pot Hill area, Yellowstone Park. Geochimica et Cosmochimica Acta, vol. 32, pp. 499-522.

Sánchez-España, J., Velasco, F., and Yusta, I., 2000. Hydrothermal alteration of felsic volcanic rocks associated with massive sulphide deposition in the northern Iberian Pyrite belt (SW Spain). Applied Geochemistry, vol. 15, pp. 1265-1290.

Steiner, A., 1968. Clay minerals in hydrothermally altered rocks at Wairakei, New Zealand. Clays and Clay Minerals, vol. 16, pp. 193-213.

Sturchio, N. C., Muehlenbachs, K., and Seitz, M. G., 1986. Element redistribution during hydrothermal alteration of rhyolite in an active geothermal system: Yellowstone drill cores Y-7 and Y-8. Geochimica et Cosmochimica Acta, vol. 50, pp. 1619-1631.

Thomas, D., 1987. A geochemical model of the Kilauea East Rift Zone. Chapter 56, United States 
Geological Survey Professional Paper 1350, Volcanism in Hawaii, pp. 1507-1525.

Torres-Alvarado, I. S., 2000. Mineral chemistry of hydrothermal silicates in Los Azufres geothermal field, Mexico. World Geothermal Congress Proceedings, Kyushu-Tohoku, Japan, May 28-June 10, 2000, pp. 1861-1866.

Utami, P., 2000. Characteristics of the Kamojang geothermal reservoir (West Java) as revealed by its hydrothermal alteration mineralogy. World Geothermal Congress Proceedings, Kyushi-Tohoku, Japan, May 28-June 10, 2000, pp. 1921-1926.

Woldegabriel, G., 1990. Hydrothermal alteration in the Valles caldera ring fracture zone and core hole VC-1: evidence for multiple hydrothermal systems. Journal of Volcanology and Geothermal Research, vol. 40, pp. 105-122.

Yau, Y.-C., Peacor, D. R., and Essene, E. J., 1986. Occurrence of wide-chain Ca-pyriboles as primary crystals in the Salton Sea Geothermal Field, California, USA. Contributions to Mineralogy and Petrology, vol. 94, pp. 127-134.

Table C2. Representative geothermal alteration mineral assemblages for hierarchical classification shown in Figure 1. ( $\mathrm{T}=$ tholeiitic, $\mathbf{C A}=$ calc-alkaline, $\mathrm{S}=$ silicic, $\mathrm{SC}=$ siliciclastic, $\mathrm{C}=$ carbonate, $\mathbf{N}=$ neutral, $\mathrm{A}=$ acidic, $\mathrm{LT}=$ low temperature, $\mathrm{MT}=$ moderate temperature, $\mathrm{HT}=$ high temperature).

\begin{tabular}{|c|c|}
\hline Assemblage ID* & Minerals present \\
\hline T-LT & Chalcedony \pm quartz + zeolites + smectite + calcite \pm limonite + pyrite + anhydrite \\
\hline T-MT & $\begin{array}{l}\text { Quartz }+ \text { wairakite }+ \text { albite }+ \text { titanite }+ \text { epidote }+ \text { prehnite }+ \text { mixed layer clay (chlorite/smectite) } \\
\pm \text { smectite } \pm \text { chlorite }+ \text { calcite }+ \text { pyrite }+ \text { anhydrite }\end{array}$ \\
\hline T-HT & $\begin{array}{l}\text { Quartz }+ \text { wairakite }+ \text { albite }+ \text { wollastonite } \pm \text { clinopyroxene }+ \text { actinolite }+ \text { titanite }+ \text { garnet }+ \\
\text { epidote }+ \text { prehnite }+ \text { chlorite }+ \text { calcite }+ \text { pyrite }+ \text { anhydrite }\end{array}$ \\
\hline CA-N-LT & $\begin{array}{l}\text { Zeolites } \pm \text { cristobalite } \pm \text { quartz }+ \text { smectite } \pm \text { chlorite }+ \text { calcite }+ \text { hematite } \pm \text { goethite }+ \text { pyrite }+ \\
\text { anhydrite } \pm \text { barite }+ \text { native sulfur }\end{array}$ \\
\hline CA-N-HT & $\begin{array}{l}\text { Quartz }+ \text { wairakite }+ \text { albite }+ \text { adularia }+ \text { clinopyroxene }+ \text { actinolite }+ \text { titanite }+ \text { epidote }+ \\
\text { prehnite } \pm \text { biotite }+ \text { chlorite }+ \text { illite }+ \text { calcite }+ \text { pyrite }+ \text { anhydrite } \pm \text { barite } \pm \text { halides }\end{array}$ \\
\hline CA-A-LT & $\begin{array}{l}\text { Amorphous silica } \pm \text { cristobalite }+ \text { kaolinite }+ \text { smectite } \pm \text { montmorillonite }+ \text { calcite }+ \text { hematite } \pm \\
\text { goethite }+ \text { pyrite }+ \text { alunite } \pm \text { anhydrite }+ \text { native sulfur }\end{array}$ \\
\hline CA-A-HT & $\begin{array}{l}\text { Quartz + albite + clinopyroxene }+ \text { actinolite }+ \text { titanite }+ \text { epidote }+ \text { biotite } / \text { prehnite }+ \text { chlorite }+ \\
\text { illite }+ \text { calcite }+ \text { pyrite }+ \text { anhydrite } \pm \text { halides }\end{array}$ \\
\hline S-N-LT & Quartz + zeolites + adularia + smectite/kaolinite/montmorillonite + calcite + pyrite \pm anhydrite \\
\hline S-N-HT & $\begin{array}{l}\text { Quartz }+ \text { albite } \pm \text { potassium feldspar }+ \text { epidote }+ \text { sericite } / \text { muscovite }+ \text { chlorite }+ \text { calcite }+ \\
\text { pyrite } \pm \text { anhydrite }\end{array}$ \\
\hline S-A-LT & $\begin{array}{l}\text { Cristobalite }+ \text { opal } \pm \text { quartz }+ \text { zeolites }+ \text { adularia }+ \text { smectite } / \text { kaolinite } / \text { montmorillonite } / \text { mixed } \\
\text { layer clays } \pm \text { hematite }+ \text { sulfides }+ \text { alunite } \pm \text { barite }\end{array}$ \\
\hline S-A-HT & $\begin{array}{l}\text { Quartz }+ \text { albite } \pm \text { potassium feldspar }+ \text { epidote }+ \text { sericite } / \text { muscovite }+ \\
\text { montmorillonite } / \text { kaolinite } / \text { chlorite }+ \text { sulfides }+ \text { alunite } \pm \text { barite } \pm \text { halides }\end{array}$ \\
\hline SC-LT & $\begin{array}{l}\text { Potassium feldspar }+ \text { albite }+ \text { mixed layer clay (illite } / \text { smectite }) \pm \text { chlorite }+ \text { calcite } \pm \\
\text { ankerite } / \text { dolomite }+ \text { hematite }+ \text { pyrite }+ \text { anhydrite }\end{array}$ \\
\hline SC-MT & $\begin{array}{l}\text { Quartz + wairakite + potassium feldspar + albite + titanite }+ \text { epidote }+ \text { chlorite }+ \text { calcite }+ \\
\text { hematite + pyrite }+ \text { anhydrite }\end{array}$ \\
\hline SC-HT & $\begin{array}{l}\text { Quartz }+ \text { potassium feldspar }+ \text { albite } \pm \text { clinopyroxene }+ \text { actinolite }+ \text { titanite }+ \text { garnet }+ \text { epidote } \\
+ \text { biotite }+ \text { calcite }+ \text { hematite }+ \text { pyrite }\end{array}$ \\
\hline C-LT & Feldspar \pm quartz + calcite \pm ankerite/dolomite + hematite \\
\hline C-HT & Feldspar \pm quartz + clinopyroxene + actinolite + titanite + epidote + biotite \pm chlorite + calcite \\
\hline
\end{tabular}




\section{Appendix D. Hypothetical geothermal case descriptions}

Synthetic data was generated for several sampling scenarios. These simulated numerical datasets assumed a reservoir mineral assemblage, equilibrated water with that assemblage at a given temperature, and then subjected the simulated deep waters to a sequence of thermal and chemical events (e.g., boiling, cooling venting). The computed water chemistry represents the chemistry of water collected from a thermal spring or sampling well. The solution chemistries that are used as input to RTEst are summarized in Table D1

Table D1. Input chemistry used in the hypothetical cases 1-3.

\begin{tabular}{|c|rrr|}
\hline & \multicolumn{3}{|c|}{ Case } \\
\hline Analyte & \multicolumn{1}{|c|}{$\mathbf{1}$} & \multicolumn{1}{c|}{$\mathbf{2}$} & \multicolumn{1}{c|}{$\mathbf{3}$} \\
\hline \hline $\mathrm{Al}^{3+}$ mmolal & 0.471781 & 0.410382 & 0.555036 \\
$\mathrm{Ca}^{2+}$ molal & 0.05 & 0.064296 & 0.058824 \\
$\mathrm{Na}^{+}$molal & 1.79052 & 2.094249 & 2.106493 \\
$\mathrm{~K}^{+}$molal & 0.162405 & 0.192199 & 0.191065 \\
$\mathrm{Cl}^{-}$molal & 2.05163 & 2.413676 & 2.413681 \\
$\mathrm{HCO}_{3}{ }^{-}$molal & 0.038055 & 0.038123 & 0.03828 \\
$\mathrm{SiO}_{2}$ molal & 0.00388 & 0.00368 & 0.004565 \\
pH & 4.785295 & 4.816339 & 4.865366 \\
$\mathrm{H}_{2} \mathrm{O}(\mathrm{kg})$ & 1 & 1 & 1 \\
$\mathrm{Temp}^{\circ}\left({ }^{\circ} \mathrm{C}\right)$ & 25 & 25 & 25 \\
1 Open system & & & \\
2 Deep boiling & & & \\
3 Flashing & & &
\end{tabular}

Case 1: Open system (after Bethke, 2008). Brine containing $2.05163 \mathrm{molal} \mathrm{Cl}$ and $0.05 \mathrm{molal} \mathrm{Ca}$ at $\mathrm{pH}$ 5.0 is equilibrated with quartz, calcite, albite, "Maximum microcline", and muscovite at $250^{\circ} \mathrm{C}$. This geothermal water is transported to the near surface where the fluid cools to $25^{\circ} \mathrm{C}$ and $\mathrm{CO}_{2}$ vents until the $\mathrm{fCO}_{2}$ is 1 atmosphere. Any steam that was formed has condensed and has been reconstituted with the liquid water. The simulation represents geothermal fluid that approaches the surface, cools under closed conditions and then loses $\mathrm{CO}_{2}$ in a finite gas reservoir. This case is the same at example provided in the Background section.

Case 2: Deep Boiling. Brine containing 2.05163 molal $\mathrm{Cl}$ and 0.05 molal Ca at pH 5.2 is equilibrated with quartz, calcite, albite, "Maximum microcline", and muscovite at $250^{\circ} \mathrm{C}$. This geothermal water is then isothermally boiled until $15 \%$ of the water is lost while maintaining equilibrium with the reservoir mineral assemblage. The resulting water is then transported to the surface where the fluid cools to $25^{\circ} \mathrm{C}$ and $\mathrm{CO}_{2}$ vents until the $\mathrm{fCO}_{2}$ is 1 atmosphere.

Case 3: Flashing. Brine containing 2.05163 molal $\mathrm{Cl}$ and 0.05 molal $\mathrm{Ca}$ at $\mathrm{pH} 5.2$ is equilibrated with quartz, calcite, albite, "Maximum microcline", and muscovite at $250^{\circ} \mathrm{C}$. This geothermal water is then isothermally boiled until $15 \%$ of the water is lost but mineral reaction does not occur during boiling. The 
resulting water is then transported to the surface where the fluid cools to $25^{\circ} \mathrm{C}$ and $\mathrm{CO}_{2}$ vents to the atmosphere. This scenario represents fluid flashing within a well.

Table D2. Water chemistries used in the two mixing scenarios for Case 5.

\begin{tabular}{|c|rrr|}
\cline { 2 - 4 } \multicolumn{1}{c|}{} & \multicolumn{3}{c|}{ Case 5 -- Mixing Scenarios } \\
\hline Analyte & \multicolumn{1}{c|}{ Fixed $\mathrm{CO}_{2}$} & \multicolumn{1}{c|}{ Sliding $\mathrm{CO}_{2}$} & \multicolumn{1}{c|}{ Mean ESRP } \\
\hline \hline $\mathrm{Al}^{3+} \mu$ molal & 5.18420 & 5.18420 & 5.18420 \\
$\mathrm{Ca}^{2+}$ molal & 0.00200 & 0.00200 & 0.00126 \\
$\mathrm{Mg}^{2+}$ molal & $9.3537 \mathrm{E}-07$ & $9.3537 \mathrm{E}-07$ & $7.3140 \mathrm{E}-04$ \\
$\mathrm{Na}^{+}$molal & 0.05928 & 0.05928 & 0.00112 \\
$\mathrm{~K}^{+}$molal & 0.00465 & 0.00465 & 0.00010 \\
$\mathrm{Cl}^{-}$molal & 0.06775 & 0.06775 & 0.00078 \\
$\mathrm{HCO}_{3}{ }^{-}$molal & 0.00110 & 0.00055 & 0.00503 \\
$\mathrm{SiO}_{2}$ molal & 0.00635 & 0.00635 & 0.00052 \\
pH & 5.60592 & 5.98385 & 7.18730 \\
$\mathrm{H}_{2} \mathrm{O}$ (kg) & 1.000000 & 1.000000 & 1.000000 \\
$\mathrm{Temp}^{\circ}\left({ }^{\circ} \mathrm{C}\right)$ & 25.00 & 25.00 & 25.00 \\
\hline
\end{tabular}

Case 4: Missing Aluminum Data. Many older chemical analyses do not include or have unreliable values for aqueous aluminum concentrations. Rather than discarding the sample, some method of imputation can be invoked. One method is to calculate the aluminum concentration based on the assumption of equilibrium with an aluminum-bearing minerals such as K-feldspar (Pang and Reed, 1998). This condition is easily implemented in RTEst by swapping an Al-bearing mineral thought to be controlling Al concentrations for the $\mathrm{Al}^{+1+}$ basis species in the GWB react file. We test this concept by running Case 2 (deep boiling) but swapping different Al-bearing minerals for $\mathrm{Al}^{+1+}$.

Case 5: Mixing with Non-thermal Water. Many thermal waters are believed to be mixtures of thermal and non-thermal groundwater. To demonstrate the ability of RTEst to address mixing, we tested two mixing scenarios. In both scenarios, a water containing 0.002 molal $\mathrm{Ca}^{++}$and $0.06775 \mathrm{molal} \mathrm{Cl}^{-}$is equilibrated with albite, muscovite, chlinochlor-14A, K-feldspar, calcite, and quartz at $\mathrm{pH} 6.5$. In the first scenario (Fixed $\mathrm{CO}_{2}$ ), this water is cooled to $25^{\circ} \mathrm{C}$ and mixed in a 1:1 ratio with a groundwater representing the mean shallow groundwater in the Eastern Snake River Plain (ESRP) of Idaho. In the second scenario (Sliding $\mathrm{CO}_{2}$ ), the initial water chemistry is cooled to $25^{\circ} \mathrm{C}$ and the $\mathrm{fCO}_{2}$ is allowed to a value of 0.01 before it is mixed with the mean ESRP water. The chemistries of these two mixtures as well as the chemistry of the mean ESRP water are summarized in Table D2. 
Table D3. Reservoir temperatures for test cases calculated using conventional geothermometers.

\begin{tabular}{|c|c|c|c|}
\hline \multirow[b]{2}{*}{ Method } & \multicolumn{3}{|c|}{ Temperature $\left({ }^{\circ} \mathrm{C}\right)$} \\
\hline & Case 1 & Case 2 & Case 3 \\
\hline $\begin{array}{c}\text { Fournier Quartz* } \\
\text { (No Steam) }\end{array}$ & 247 & 245 & 247 \\
\hline $\begin{array}{c}\text { Fournier Quartz* } \\
\text { (Max Steam) }\end{array}$ & 221 & 220 & 221 \\
\hline $\begin{array}{c}\text { Fournier } \\
\text { Chalcedony* }\end{array}$ & 224 & 222 & 224 \\
\hline $\begin{array}{c}\text { Fournier } \\
\mathrm{Na}-\mathrm{K}\end{array}$ & 218 & 219 & 218 \\
\hline $\begin{array}{c}\text { Giggenbach } \\
\text { Na-K }\end{array}$ & 225 & 226 & 225 \\
\hline $\begin{array}{c}\text { Fournier \& Truesdell } \\
\text { Na-K-Ca }\end{array}$ & 279 & 281 & 282 \\
\hline $\begin{array}{l}{ }^{*} \mathrm{Based} \text { on } \mathrm{SiO}_{2}(\mathrm{aq}) \text { activity } \\
1 \text { Open System } \\
2 \text { Deep Boiling } \\
3 \text { Flashing }\end{array}$ & & & \\
\hline
\end{tabular}




\section{Appendix E. Supporting materials related to equilibrium water-rock interaction experiments}

\section{Rock samples}

The rock sample likely to be representing Raft River geothermal reservoir rock (metamorphosed adamellite) was collected from an outcrop in the southern side of the Albion Mountains near Almo, Idaho (Figure E1). The sample collection site is located about $30 \mathrm{~km}$ west from the RRG field. The sampling outcrop lies within the Green Creek Complex and represents Precambrian gneissic adamellite (Armstrong and Hill, 1967; Armstrong et al., 1978).

\section{Sample processing}

Blocky rock sample collected from outcrop was cut into small billets using a rock saw for the preparation of petrographic thin section. For other characterizations (whole rock chemistry, X-ray diffraction, etc.) and water-rock interaction experiments, rock sample was crushed with a sledge hammer and a Braun chipmunk jaw crusher/pulverizer (BICO Braun International). The pieces of rock were fed to a jaw crusher to get gravel-sized particles, which were then fed to rock pulverizer to produce finer grains. The crushed rock samples were wet sieved using deionized water through brass sieves to separate them into different sand size fractions. Grain fractions $0.5-0.25 \mathrm{~mm}$ (ASTM Sieve \# 35- 60), $0.25-0.125 \mathrm{~mm}$ (ASTM Sieve \# 60- 120), and $0.125-0.063 \mathrm{~mm}$ (ASTM Sieve \# 120-230) were separately retrieved. Finally, each grain-size fraction was further washed with nanopure (Milli-Q) water after ultra-sonication for 15 minutes, and dried on a hot plate at $90^{\circ} \mathrm{C}$. The washed rock samples were split using a riffle sample splitter for characterization and experimental purpose.

\section{Rock characterization}

Petrographic thin-sections of whole-rock billet and grain fractions (as grain mounts) were prepared in rock-processing laboratory at Applied Petrographic Services, Inc., Greensburg, PA, USA. Quartz, feldspars, and micas are present as major minerals in the rock (Figure E2). Mineralogy of the rock sample was further studied using X-ray diffraction (XRD). The XRD spectra of powdered rock samples were collected using a PANalytical X'Pert Pro powder diffractometer at the Center for Environmental Physics and Mineralogy (CEPM) at the University of Arizona, Tuscon. The XRD spectra were analyzed with X'Pert HighScore Plus XRD data evaluation and presentation software using the International Center for Diffraction Data, ICDD database. The XRD results also indicate that the bulk rock is primarily composed of quartz, albite, K-feldspar, and biotite (Figure E3).

Whole-rock chemical composition of samples representing each grain-size fraction were analyzed in Activation Laboratories in Ancaster, ON, Canada. For the whole-rock chemical analysis, the crushed rock powder was initially fused with lithium metaborate at $1050{ }^{\circ} \mathrm{C}$ for $2.5 \mathrm{~min}$ in a high frequency induction heating machine (SP-15A, Shuangping) and then dissolved in 5\% nitric acid (trace metal grade) for 30 min, and finally, analyzed with Varian Vista 735 ICP-OES and Perkin Elmer Sciex 6100 ICP-MS. 


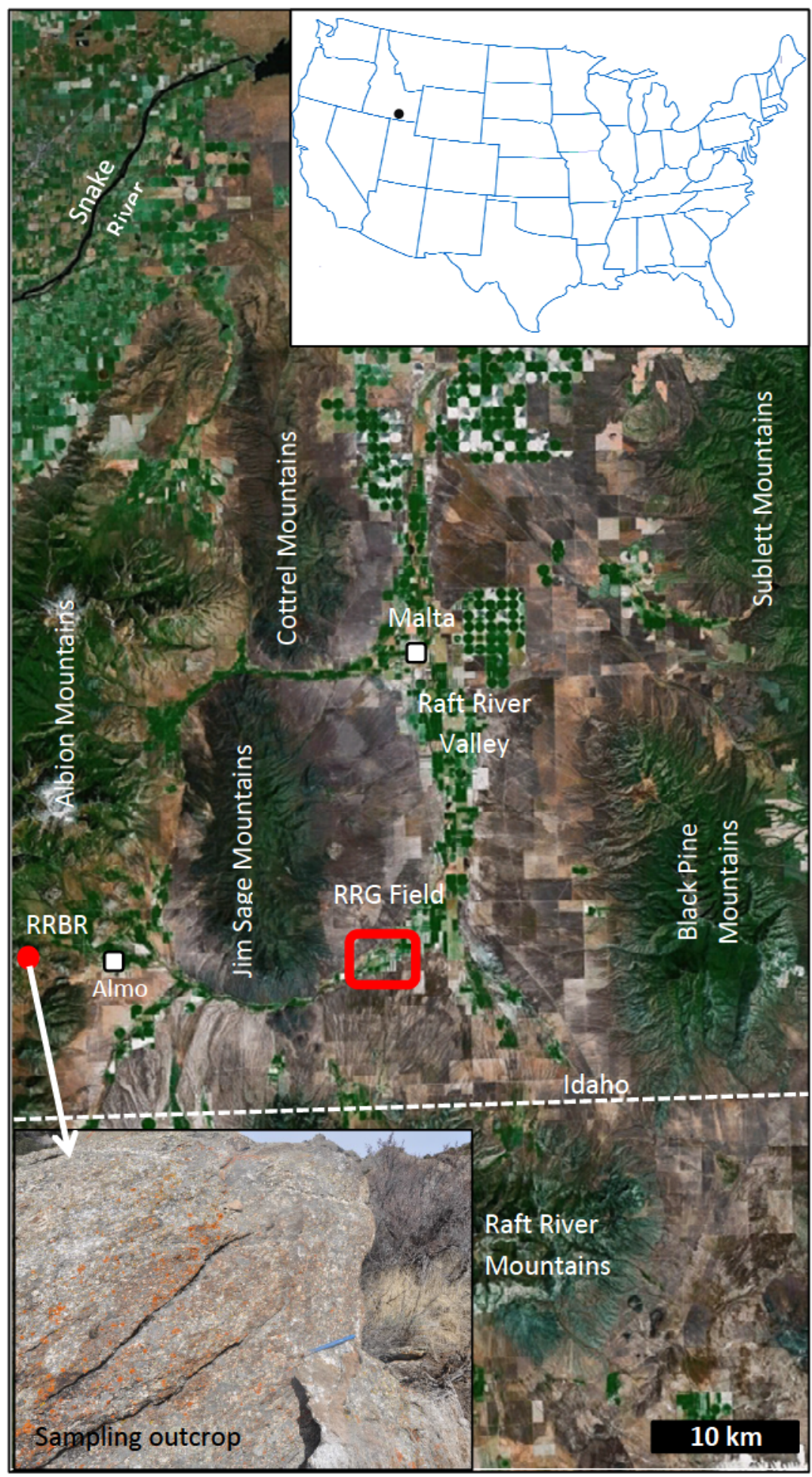

Figure E1. Arial map showing Raft River geothermal field (red box) and surrounding area in southern Idaho, USA. The red dot on the map represents the rock sample [Raft River basement rock (RRBR)] collection site for water-rock interaction experiments. 


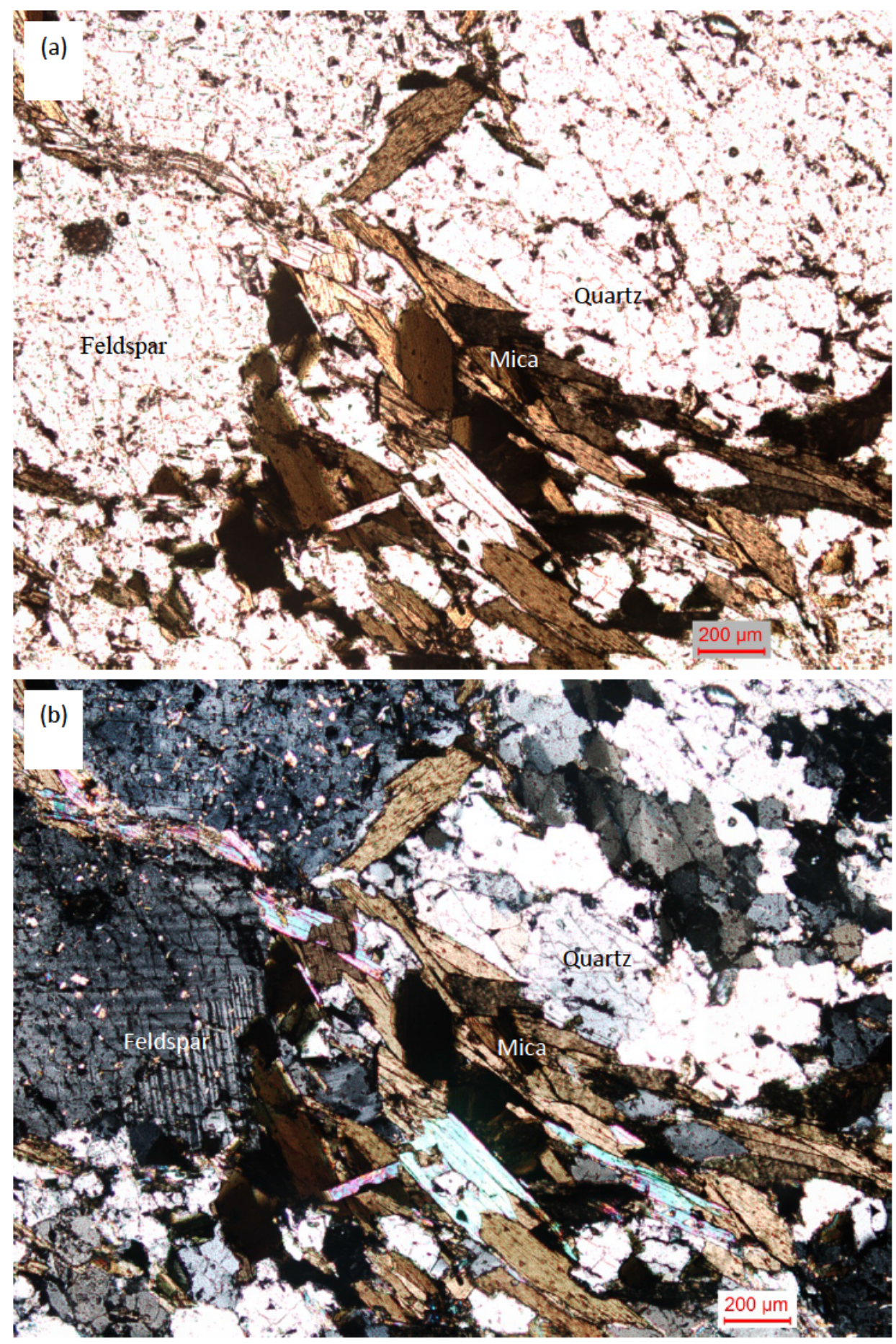

Figure E2. Photomicrograph of RRBR showing feldspars, quartz, and micas as major minerals. a) Under plane-polarized light, and b) Under cross-polarized light. 

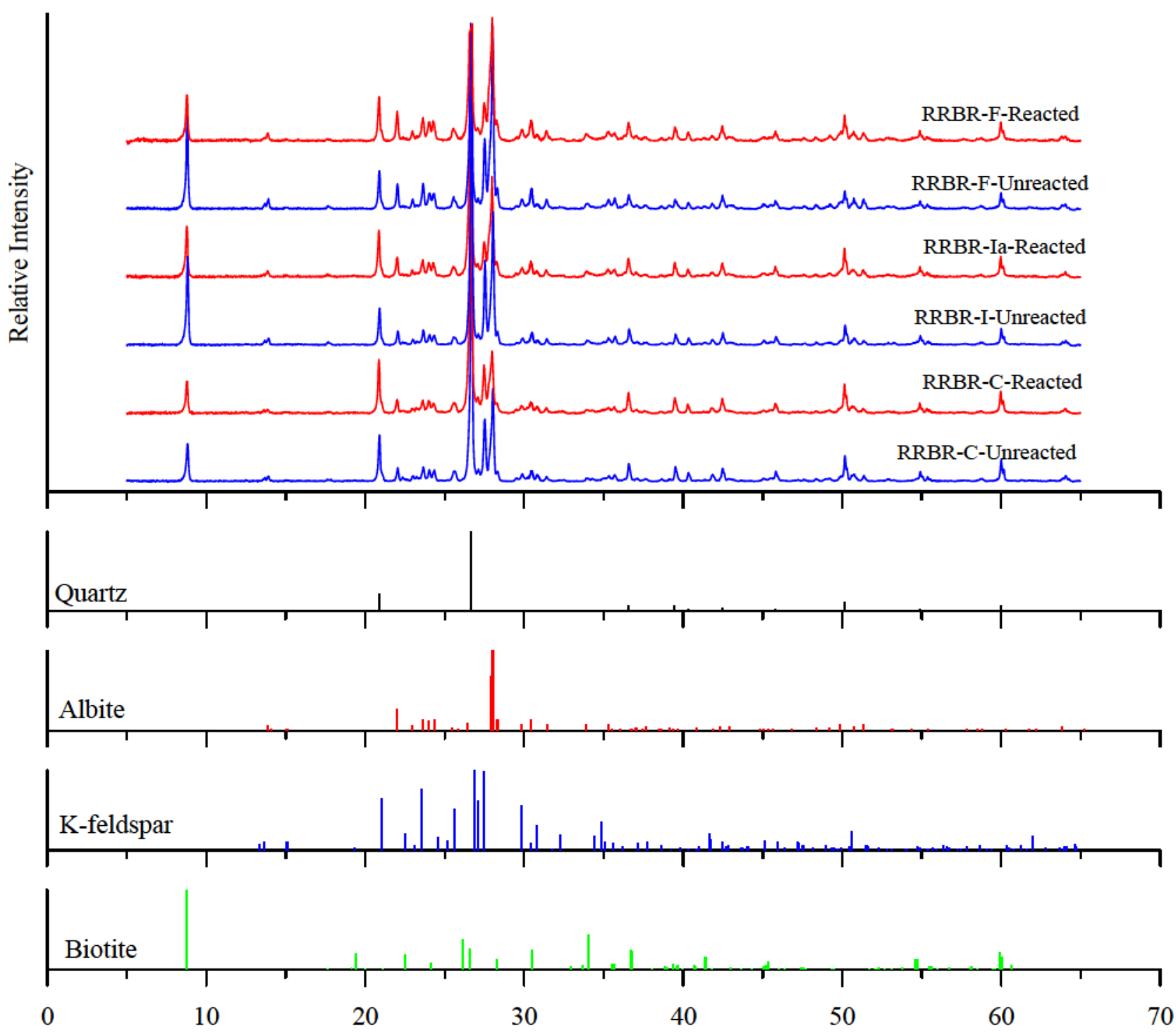

Figure E3. X-ray diffraction spectra of bulk unreacted and reacted RRB̂R 3 timples. Standard XRD intensity peaks for quartz, albite, $k$ feldspar, and biotite are also provided. 
The average (calculated using chemical composition data representing three grain-size fractions) chemical composition of rock sample is given in Table E1. Oxides of $\mathrm{Si}, \mathrm{Al}, \mathrm{K}, \mathrm{Na}, \mathrm{Fe}$, and $\mathrm{Ca}$ are the major components in the rock.

Table E1. Whole rock chemical compositions of fresh RRBR

\begin{tabular}{|l|c|}
\hline \multicolumn{2}{|c|}{ Whole rock composition (\% oxide by wt) } \\
\hline $\mathrm{SiO}_{2}$ & 71.83 \\
\hline $\mathrm{TiO}_{2}$ & 0.34 \\
\hline $\mathrm{Al}_{2} \mathrm{O}_{3}$ & 13.80 \\
\hline $\mathrm{Fe}_{2} \mathrm{O}_{3}$ & 3.25 \\
\hline $\mathrm{MnO}$ & 0.03 \\
\hline $\mathrm{MgO}$ & 0.60 \\
\hline $\mathrm{CaO}$ & 1.74 \\
\hline $\mathrm{Na}_{2} \mathrm{O}$ & 3.46 \\
\hline $\mathrm{K}_{2} \mathrm{O}$ & 3.72 \\
\hline $\mathrm{P}_{2} \mathrm{O}_{5}$ & 0.15 \\
\hline $\mathrm{CO}_{2}$ & 0.02 \\
\hline Total & 98.94 \\
\hline
\end{tabular}

The pre- and post-experimental samples were also studied with scanning electron microscope (SEM) using JEOL 6610LV in the Microscopy and Characterization Suite (MaCS) at the Center for Advanced Energy Studies (CAES) in Idaho Falls. Crushed rock particles mounted on stubs were coated with gold before SEM analysis. Figure B3 shows the SEM images of pre-experimental quartz grains representing the coarsest, intermediate, and the finest grain-size fractions. The surfaces of these pre-experimental grains are smooth without any growth (precipitate) features.

\section{Initial experimental water}

The RRG area reportedly has two types of geothermal waters - one with high total dissolved solid (TDS) and the other with low TDS. Synthetic geothermal water similar to low TDS RRG water was prepared for water rock-experiments by dissolving different chemical constituents in deionized water. The initial composition of synthetic geothermal water is given in Table E2. Certified ACS grade $\mathrm{NaCl}, \mathrm{KCl}$, and $\mathrm{CaCl}_{2} \cdot 2 \mathrm{H} 2 \mathrm{O}$ were used as source materials for $\mathrm{Na}, \mathrm{K}, \mathrm{Ca}$, and $\mathrm{Cl}$. Required amount of these chemical in the form of solid crystals were weighed using Denver Equipment balance and dissolved in Milli-Q Nanopure water (>18 meg-ohm-cm). The $\mathrm{pH}$ of the initial synthetic geothermal waters was let set by equilibration with atmospheric $\mathrm{CO}_{2}$. The initial compositions of the geothermal waters were also ascertained with iCAP 6000 Thermo Scientific Inductively Coupled Plasma-Optical Emission Spectroscopy (ICP-OES). 

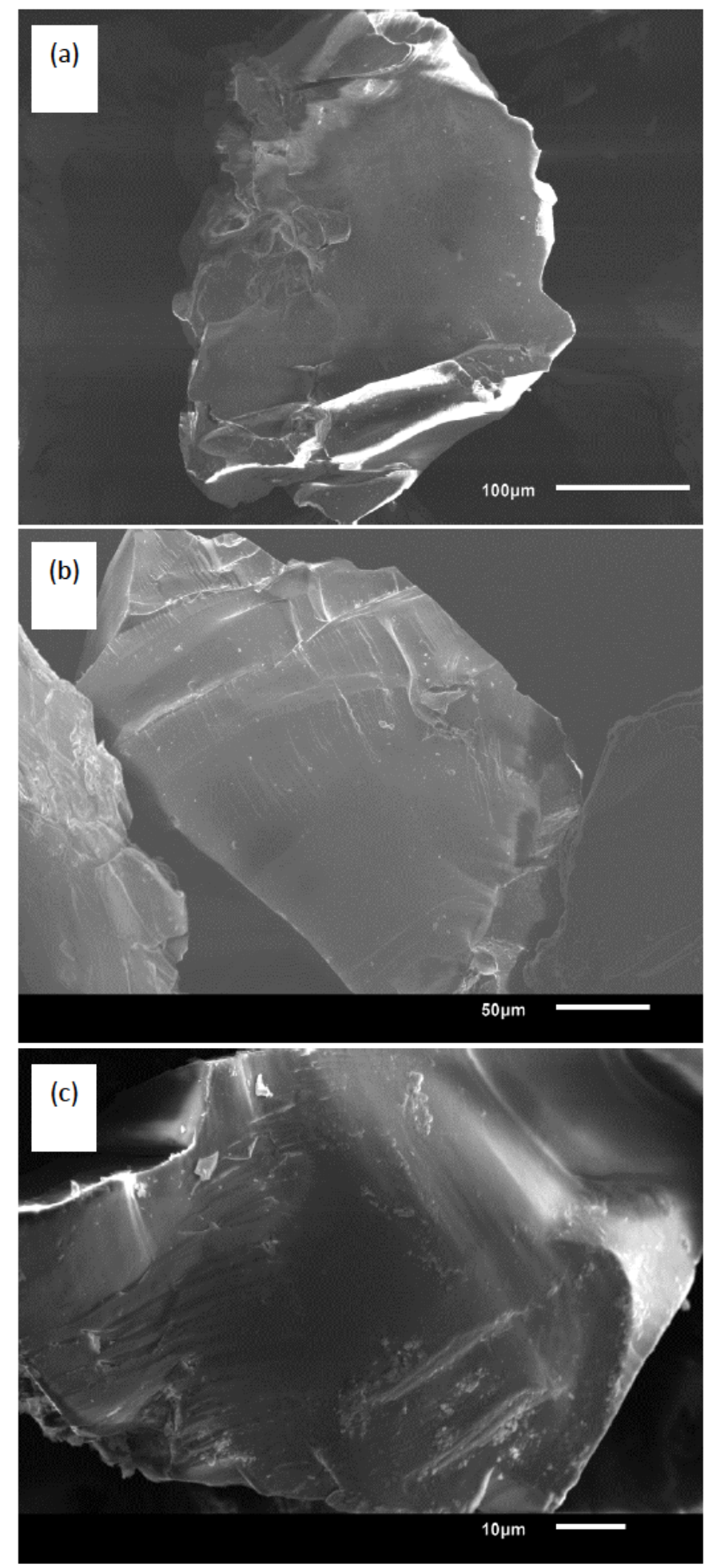

Figure E4. Scanning electron microphotograph showing unreacted quartz grains in RRBR-C (a), RRBR-I (b), and RRBR-F (c). 
Table E2. Composition of initial experimental water

\begin{tabular}{|c|c|}
\hline Elements & Concentration $(\mathrm{mg} / \mathrm{L})$ \\
\hline $\mathrm{Ca}$ & 41 \\
\hline $\mathrm{K}$ & 31 \\
\hline $\mathrm{Na}$ & 584 \\
\hline $\mathrm{Cl}$ & 1000 \\
\hline
\end{tabular}

To account for the potential presence of $\mathrm{CO}_{2}$ in the geothermal reservoir, the likely partial pressure of the $\mathrm{CO}_{2}$ at $200^{\circ} \mathrm{C}$ was calculated using the mineral equilibria buffer- prehnite-clinozoisite-calcite-quartz (for $P_{\mathrm{CO}_{2}}$ ) (Arnórsson et al., 2007) and externally supplied as a single spike into the system. All other chemical components (e.g., $\mathrm{Mg}, \mathrm{Al}, \mathrm{SiO}_{2}$, etc.) that were not present in the synthetic water, were let to be evolved as water-rock interaction progressed over time.

\section{Reactors}

The laboratory experiments were conducted in the Fluids Laboratory located in the Center for Advanced Energy Studies (CAES) building using four 1.0 L stainless steel (Type 316) reaction vessels (Model 4523 Parr $^{\circledR}$ Instrument) each equipped with independent stirring, temperature, and pressure control mechanisms (Figure E5). Maximum operating pressures and temperatures of these reactors are rated at $1900 \mathrm{psig}$ (131 bars) and $350^{\circ} \mathrm{C}$, respectively (Parr Instruments Company, 2011). The reaction vessels are constructed in such a way that both the fluid and headspace gases can be sampled at operating pressure and temperature without disassembling the reactor.

\section{Experimental}

Water-rock experiments (Table E3) were conducted at $200{ }^{\circ} \mathrm{C}$ and slightly higher than water saturation pressure to determine the role of primary and secondary minerals in controlling the equilibrium composition of geothermal fluids. The ratio of water to total rock surface area was varied by using different grain-sized materials, $0.5-0.25 \mathrm{~mm}$ (RRBR-C), $0.25-0.125 \mathrm{~mm}$ (RRBR-I), and $0.125-0.063$ $\mathrm{mm}$ (RRBR-F) and the evolution of the introduced fluid toward equilibrium was observed as a function of time. The experiment with the intermediate grain-size $(0.25-0.105 \mathrm{~mm})$ was conducted in duplicates (RRBR-Ia and RRBR-Ib).

Prior to loading the experimental materials, the $1 \mathrm{~L}$ reactors were cleaned with $5 \%$ nitric acid and rinsed multiple times with Milli-Q Nanopure water. The final cleaning procedure involved partially filling the reactor with Nanopure water and overnight heating at $150^{\circ} \mathrm{C}$. Crushed rock sample $(73 \mathrm{~g})$ and synthetic water $(730 \mathrm{~g})$ were loaded in each clean reactor cell. After sealing the reactors, atmospheric air in each reaction vessel was purged with ultra-pure $\mathrm{N}_{2}$ followed by ultra-pure $\mathrm{CO}_{2}$ gas at room temperature. Then the reactor was heated gradually to $95^{\circ} \mathrm{C}$. Any build-up pressure (due to degasing of previously dissolved $\mathrm{N}_{2} / \mathrm{CO}_{2}$ gas) was vented-out to the level of atmospheric pressure, and the reaction vessel was heated to the set-point temperature $\left(200^{\circ} \mathrm{C}\right)$ gradually. As soon as the reaction vessel reached the steady-state set-point temperature and saturated water vapor pressure ( 14.6 bars), the system pressure was increased by $\sim 1$ bar by introducing ultra-pure $\mathrm{CO}_{2}$. The spiked partial $\mathrm{CO}_{2}$ pressure was calculated using the mineral equilibria buffers- prehnite-clinozoisite-calcite-quartz (for $P_{\mathrm{CO}_{2}}$ ) (Arnórsson et al., 2007) even though all 
of these minerals were not present in the rock. A hybrid stirring mechanism was used for these experimental sets in such a way that the materials in the reaction vessel were agitated for 30 seconds at $200 \mathrm{rpm}$ every hour to ensure proper mixing of materials in reactor with minimum mechanical abrasion.

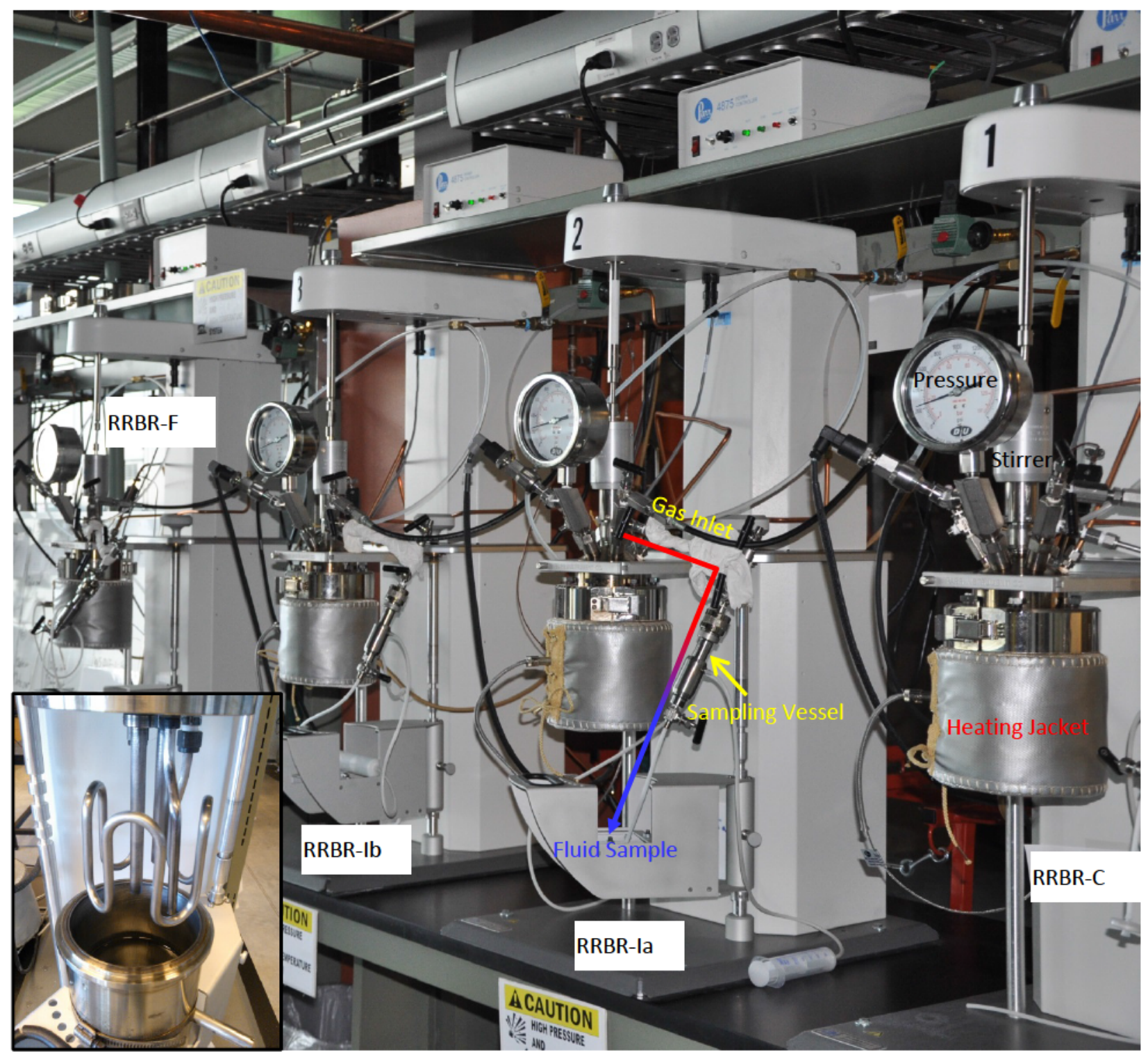

Figure E5. Water-rock interaction experiments conducted at $200{ }^{\circ} \mathrm{C}$ using bench top Parr $1 \mathrm{~L}$ stirrer reactors. In insect, a reaction vessel and its cooling coil can be seen.

Once the experiment was started, a small (ca. $10 \mathrm{~mL}$ ) liquid sample was extracted from each reactor after $2^{\mathrm{n}}\left(\mathrm{n}=0,1,2 \ldots 7\right.$, etc.) days. Fluid samples were collected using a sampling vessel (Parr ${ }^{\circledR}$ Model 4351-ID-V-C) (Error! Reference source not found.). Prior to sample collection, a small amount of fluid (2-4 $\mathrm{mL}$ ) was purged from the system to remove the 'dead sample' that was stuck in the dip tube after the previous sampling event. 
Table E3. Water-rock interaction experimental matrix

\begin{tabular}{|c|c|c|c|c|c|c|c|}
\hline $\begin{array}{c}\text { Grain-size } \\
(\mathrm{mm})\end{array}$ & Experiments & $\begin{array}{c}\text { Duration } \\
\text { days }\end{array}$ & $\begin{array}{c}\text { Mass of } \\
\text { solids (g) }\end{array}$ & $\begin{array}{c}\text { Mass of } \\
\text { solution (g) }\end{array}$ & $\mathrm{T}^{\circ} \mathrm{C}$ & $\begin{array}{c}P_{\mathrm{H}_{2} \mathrm{O}} \\
\text { (bars) }\end{array}$ & $\begin{array}{c}P_{\mathrm{CO}_{2}} \\
\text { (bars) }\end{array}$ \\
\hline \multicolumn{7}{|c|}{ Equilibrium (RRBR + synthetic water) $\left(200^{\circ} \mathrm{C}\right)$} \\
\hline $0.5-0.25$ & RRBR-C & 332 & 73 & 730 & 200 & 15.54 & 0.98 \\
\hline $0.25-0.105^{1}$ & RRBR-Ia, Ib & 324 & 73 & 730 & 200 & 15.54 & 0.98 \\
\hline $0.105-0.053$ & RRBR-F & 281 & 73 & 730 & 200 & 15.54 & 0.98 \\
\hline \multicolumn{7}{|l|}{ Cooling $\left(150^{\circ} \mathrm{C}\right)$} \\
\hline $0.25-0.105$ & RRBR-Ib PC ${ }^{2}$ & $324+187$ & 73 & 730 & $150^{4}$ & 4.76 & $0.18-0.98$ \\
\hline \multicolumn{7}{|l|}{ Mixing } \\
\hline
\end{tabular}

${ }^{1}$ Experiments in duplicates; ${ }^{2} \mathrm{PC}$ : post-cooling; ${ }^{3}$ Experiment for mixing tests, ${ }^{4}$ Conditions after cooling

In general, at each sampling time, about $8-10 \mathrm{~mL}$ of fluid sample was collected and divided into separate aliquots for the analysis of dissolved $\mathrm{CO}_{2}$, anions, cations, and $\mathrm{pH}$. In some early samples, a separate aliquot was also collected for dissolved $\mathrm{H}_{2} \mathrm{~S}$ analyses; however, as the early results of $\mathrm{H}_{2} \mathrm{~S}$ analysis with sulfide-selective electrode (Lazar Research Laboratories, Inc.) turned out to be below-detection limit, no further separate sample was collected for this analyte. All aliquot samples (except for $\mathrm{pH}$ measurement) were filtered through $0.45 \mu \mathrm{m}$ filter, and aliquot for cations were acidified to $<2 \mathrm{pH}$ with concentrated OPTIMA $\mathrm{HNO}_{3}$. Anions were analyzed with ion chromatography (Dionex ICS-2100), whereas major/minor elements were analyzed with Inductively Coupled Plasma-Optical Emission Spectroscopy (ICP-OES iCAP 6500) and trace elements were analyzed with Inductively Coupled Plasma-Mass Spectroscopy (ICP-MS Agilent 7500ce). Total dissolved inorganic C in samples was immediately analyzed with Total Carbon Analyzer (Shimadzu TOC-V). At the end of the experiments, the solid samples from three experimental sets (RRBR-C, RRBR-Ia, and RRBR-F) were separated from fluid for post-experimental solid-sample characterization.

The remaining experimental set was cooled to $150{ }^{\circ} \mathrm{C}$, and continued for additional 200 days. The postcooling samples are also used to quantify the effect of cooling on water chemistries and subsequently used for temperature prediction with RTEst.

\section{Post-experimental water samples}

Compositions of post-experimental waters are provided in Table E4. Some chemical components are also presented in Figure E6 as concentration trend over time and Figure E7 (Piper diagram). The pH values of the experimental water samples exposed to air at room temperature range from 5.34 to 5.75, with an average value of $5.53 \pm 0.10$. The total dissolved solids (TDS) of these experimental samples range from ca. $1960 \mathrm{mg} / \mathrm{L}$ in early samples to ca. $2200 \mathrm{mg} / \mathrm{L}$ in later samples with an average of around $2100 \pm 60$ $\mathrm{mg} / \mathrm{L}$. As the initial synthetic water, all experimental samples are Na-Cl type waters (Figure E7).

The dominant cations and anions in the experimental waters are the ones that were present in the initial water ( $\mathrm{Na}, \mathrm{Ca}, \mathrm{K}, \mathrm{Cl}$ ). Out of these 4 initial components, $\mathrm{Na}, \mathrm{K}$, and $\mathrm{Cl}$ remain fairly constant over time. However, concentration of Ca showed a decreasing trend over time (Figure E6). The other cations and 
$\mathrm{SiO}_{2}$ (aq) evolved in the system as the water-rock interaction progressed over time. Concentrations of cations that evolved in the system did not exceed $4 \mathrm{mg} / \mathrm{L}$, whereas a large amount of $\mathrm{SiO}_{2}(\mathrm{aq})$ mobilized into the solution from solid phase.

Table E4. Composition of water samples taken from RRBR-C as a function of time (mg/L)

\begin{tabular}{|c|c|c|c|c|c|c|c|c|c|c|c|c|}
\hline RRBR-C & Time $^{1}$ & $\mathrm{pH}^{2}$ & $\mathrm{Al}$ & $\mathrm{Ba}$ & $\mathrm{Ca}$ & $\mathrm{Cl}$ & $\mathrm{CO}_{2}(\mathrm{aq})^{3}$ & $\mathrm{~K}$ & $\mathrm{Li}$ & $\mathrm{Mg}$ & $\mathrm{Na}$ & $\mathrm{SiO}_{2}(\mathrm{aq})$ \\
\hline Out 1 & 1 & 5.75 & 0.17 & 0.80 & 42 & 1023 & 199 & 43 & 0.041 & 0.45 & 604 & 149 \\
\hline Out 2 & 2 & 5.52 & 0.14 & 0.93 & 42 & 991 & 222 & 43 & 0.047 & 0.50 & 583 & 159 \\
\hline Out 3 & 4.5 & 5.58 & 0.14 & 1.09 & 43 & 1003 & 205 & 43 & 0.053 & 0.34 & 579 & 179 \\
\hline Out 4 & 8 & 5.64 & 0.14 & 0.92 & 36 & 984 & 276 & 41 & 0.054 & 0.21 & 577 & 189 \\
\hline Out 5 & 16 & 5.62 & 0.13 & 1.00 & 34 & 981 & 250 & 40 & 0.055 & 0.16 & 584 & 196 \\
\hline Out 6 & 32 & 5.48 & 0.12 & 1.01 & 34 & 971 & 188 & 41 & 0.057 & 0.11 & 572 & 216 \\
\hline Out 7 & 65 & 5.42 & 0.11 & 0.93 & 29 & 998 & 252 & 41 & 0.065 & 0.09 & 589 & 225 \\
\hline Out 8 & 128 & 5.51 & 0.11 & 0.98 & 28 & 1016 & 265 & 43 & 0.072 & 0.05 & 576 & 234 \\
\hline Out 9 & 205 & 5.54 & 0.10 & 0.92 & 22 & 983 & 244 & 43 & 0.085 & 0.07 & 577 & 238 \\
\hline Out 10 & 298 & 5.57 & 0.09 & 1.15 & 16 & 995 & 231 & 44 & 0.101 & 0.09 & 586 & 238 \\
\hline Out 11 & 332 & 5.49 & 0.10 & 1.05 & 15 & 1004 & 210 & 43 & & 0.06 & 585 & 237 \\
\hline \multicolumn{13}{|l|}{ RRBR-Ia } \\
\hline Out 1 & 1 & 5.51 & 0.15 & 0.83 & 49 & 1020 & 226 & 44 & 0.047 & 0.90 & 578 & 154 \\
\hline Out 2 & 2 & 5.62 & 0.15 & 0.75 & 49 & 989 & 246 & 42 & 0.057 & 1.25 & 586 & 162 \\
\hline Out 3 & 4 & 5.72 & 0.12 & 0.78 & 47 & 981 & 253 & 41 & 0.048 & 1.43 & 565 & 174 \\
\hline Out 4 & 8 & 5.69 & 0.13 & 1.06 & 45 & 1040 & 277 & 43 & 0.059 & 2.00 & 583 & 194 \\
\hline Out 5 & 16 & 5.57 & 0.12 & 1.18 & 40 & 998 & 293 & 45 & 0.063 & 2.09 & 558 & 209 \\
\hline Out 6 & 31 & 5.63 & 0.12 & 1.16 & 37 & 1027 & 247 & 44 & 0.068 & 2.35 & 577 & 214 \\
\hline Out 7 & 64 & 5.54 & 0.11 & 1.15 & 35 & 1021 & 281 & 43 & 0.091 & 2.60 & 583 & 222 \\
\hline Out 8 & 128 & 5.67 & 0.08 & 0.90 & 29 & 972 & 285 & 43 & 0.114 & 2.63 & 574 & 218 \\
\hline Out 9 & 203 & 5.49 & 0.09 & 0.75 & 25 & 994 & 229 & 44 & 0.141 & 1.77 & 577 & 227 \\
\hline Out 10 & 290 & 5.61 & 0.08 & 0.74 & 21 & 984 & 294 & 45 & 0.155 & 1.05 & 593 & 228 \\
\hline Out 11 & 324 & 5.56 & 0.09 & 0.90 & 19 & 1014 & 239 & 44 & & 0.81 & 613 & 230 \\
\hline \multicolumn{13}{|l|}{ RRBR-Ib } \\
\hline Out 1 & 1 & 5.63 & 0.17 & 0.77 & 38 & 1022 & 206 & 41 & 0.055 & 1.64 & 551 & 141 \\
\hline Out 2 & 2 & 5.51 & 0.12 & 0.88 & 31 & 982 & 232 & 40 & 0.051 & 0.80 & 551 & 152 \\
\hline Out 3 & 4 & 5.49 & 0.11 & 0.94 & 30 & 988 & 204 & 40 & 0.046 & 0.30 & 550 & 157 \\
\hline Out 4 & 8 & 5.64 & 0.10 & 0.82 & 30 & 1001 & 218 & 39 & 0.049 & 0.25 & 545 & 166 \\
\hline Out 5 & 16 & 5.49 & 0.13 & 0.91 & 28 & 998 & 215 & 40 & 0.079 & 0.16 & 552 & 189 \\
\hline Out 6 & 31 & 5.34 & 0.12 & 1.14 & 26 & 996 & 166 & 40 & 0.083 & 0.22 & 560 & 194 \\
\hline Out 7 & 64 & 5.42 & 0.09 & 1.20 & 24 & 1000 & 221 & 43 & 0.089 & 0.17 & 590 & 208 \\
\hline Out 8 & 128 & 5.53 & 0.10 & 1.12 & 26 & 1004 & 230 & 43 & 0.116 & 0.18 & 586 & 222 \\
\hline Out 9 & 203 & 5.41 & 0.10 & 1.04 & 23 & 1000 & 267 & 43 & 0.139 & 0.15 & 597 & 229 \\
\hline
\end{tabular}




\begin{tabular}{|c|c|c|c|c|c|c|c|c|c|c|c|c|}
\hline Out 10 & 290 & 5.64 & 0.09 & 1.08 & 19 & 995 & 292 & 44 & 0.153 & 0.09 & 578 & 231 \\
\hline Out 11 & 324 & 5.58 & 0.10 & 0.68 & 17 & 989 & 232 & 43 & & 0.07 & 596 & 229 \\
\hline${\text { Out } 12^{4}}^{4}$ & 331 & 5.43 & 0.07 & 1.42 & 17 & 987 & 212 & 43 & & 0.07 & 584 & 128 \\
\hline${\text { Out } 13^{4}}^{4}$ & 353 & 5.46 & 0.10 & 0.69 & 11 & 1004 & 184 & 42 & & 0.06 & 577 & 113 \\
\hline Out $14^{4}$ & 421 & 5.42 & 0.14 & 0.82 & 7 & 997 & 188 & 44 & & 0.06 & 578 & 102 \\
\hline Out $15^{4}$ & 511 & 5.42 & 0.14 & 0.46 & 6 & 1017 & 198 & 42 & & 0.06 & 562 & 98 \\
\hline RRBR-F & \multicolumn{10}{|c|}{} \\
\hline Out 1 & 1 & 5.42 & 0.15 & 1.08 & 35 & 1021 & 243 & 42 & 0.047 & 0.45 & 548 & 148 \\
\hline Out 2 & 2 & 5.49 & 0.12 & 0.93 & 35 & 1022 & 206 & 45 & 0.049 & 0.21 & 562 & 178 \\
\hline Out 3 & 4 & 5.53 & 0.11 & 0.92 & 32 & 1026 & 203 & 43 & 0.052 & 0.17 & 543 & 181 \\
\hline Out 4 & 8 & 5.41 & 0.11 & 1.04 & 31 & 1010 & 249 & 43 & 0.053 & 0.15 & 552 & 198 \\
\hline Out 5 & 16 & 5.34 & 0.09 & 0.86 & 30 & 1028 & 176 & 45 & 0.058 & 0.12 & 557 & 219 \\
\hline Out 6 & 32 & 5.38 & 0.09 & 0.87 & 29 & 1021 & 196 & 43 & 0.075 & 0.15 & 574 & 221 \\
\hline Out 7 & 61 & 5.44 & 0.09 & 0.83 & 29 & 999 & 238 & 45 & 0.085 & 0.20 & 569 & 220 \\
\hline Out 8 & 127 & 5.53 & 0.08 & 0.70 & 26 & 973 & 246 & 43 & 0.103 & 0.17 & 553 & 219 \\
\hline Out 9 & 194 & 5.38 & 0.07 & 1.08 & 24 & 998 & 209 & 44 & 0.131 & 0.18 & 562 & 220 \\
\hline Out 10 & 281 & 5.54 & 0.06 & 1.05 & 26 & 972 & 259 & 42 & 0.141 & 0.10 & 565 & 224 \\
\hline Out 11 & 315 & 5.57 & 0.07 & 1.06 & 23 & 1006 & 230 & 43 & & 0.09 & 612 & 226 \\
\hline
\end{tabular}

${ }^{1}$ In days, ${ }^{2}$ Measured at room temperature open to air; ${ }^{3}$ Sampling was carried out at room temperature and atmospheric pressure. It is likely that the sample may have lost some $\mathrm{CO}_{2}$ while sampling; ${ }^{4}$ Experiments at $150^{\circ} \mathrm{C}$.

For the experimental set that was extended at lower temperature $\left(150^{\circ} \mathrm{C}\right)$, the silica concentrations show a decreasing trend (Figure E6). Although Ca concentration was decreasing prior to the cooling, the trend became steeper after cooling. Concentration of $\mathrm{Al}$ found to be increasing after cooling whereas concentrations of $\mathrm{K}, \mathrm{Na}$, and $\mathrm{Cl}$ remained fairly constant after cooling. 

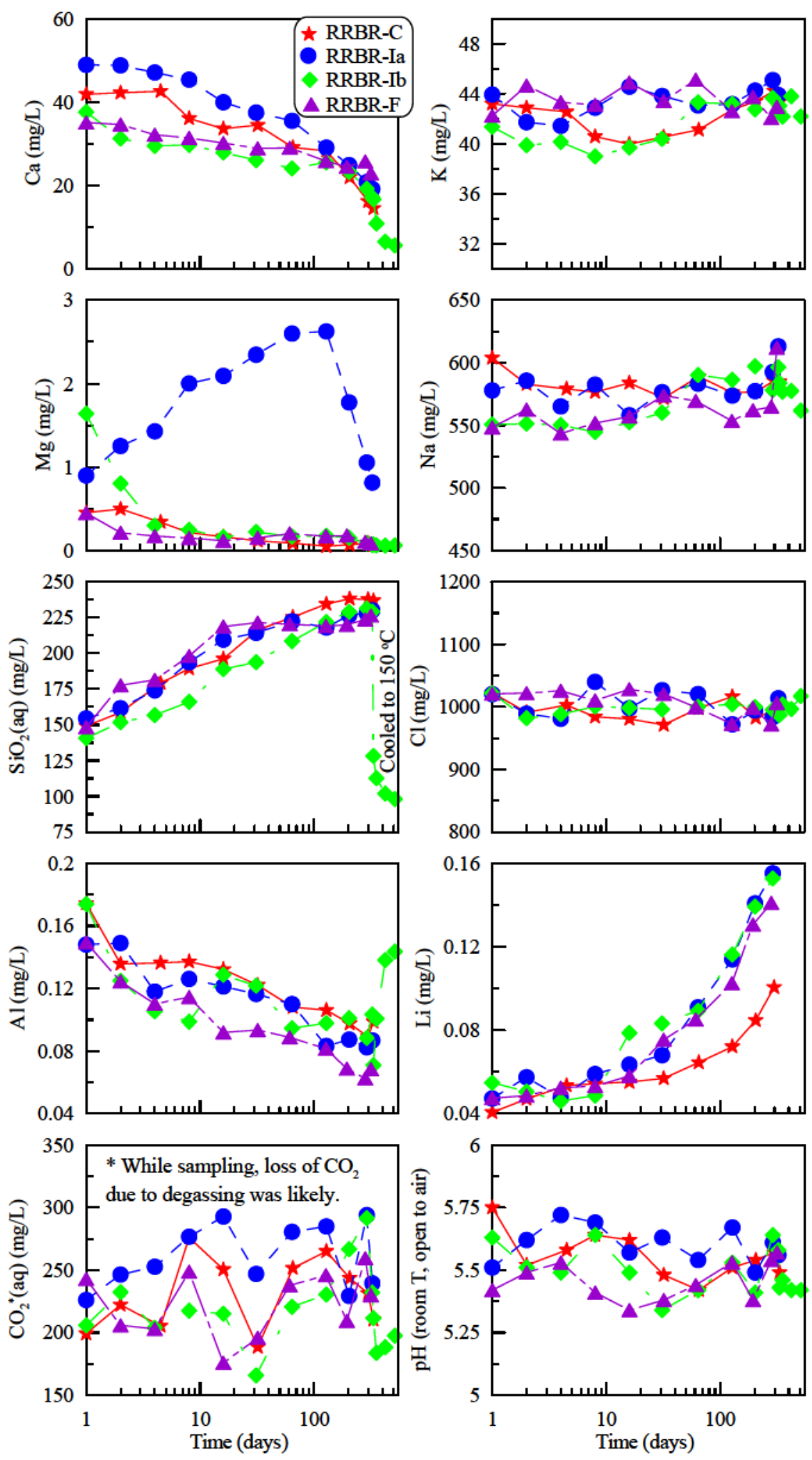

Figure E6. Concentration trends of some elements over time. Some species, particularly, SiO2(aq) indicate that the systems gradually approach to equilibrium over time. Out of the three major cations $(\mathrm{Ca} 2+, \mathrm{K}+$, and $\mathrm{Na}+)$ present in the initial water, the concentration of Ca persistently decreased over time 


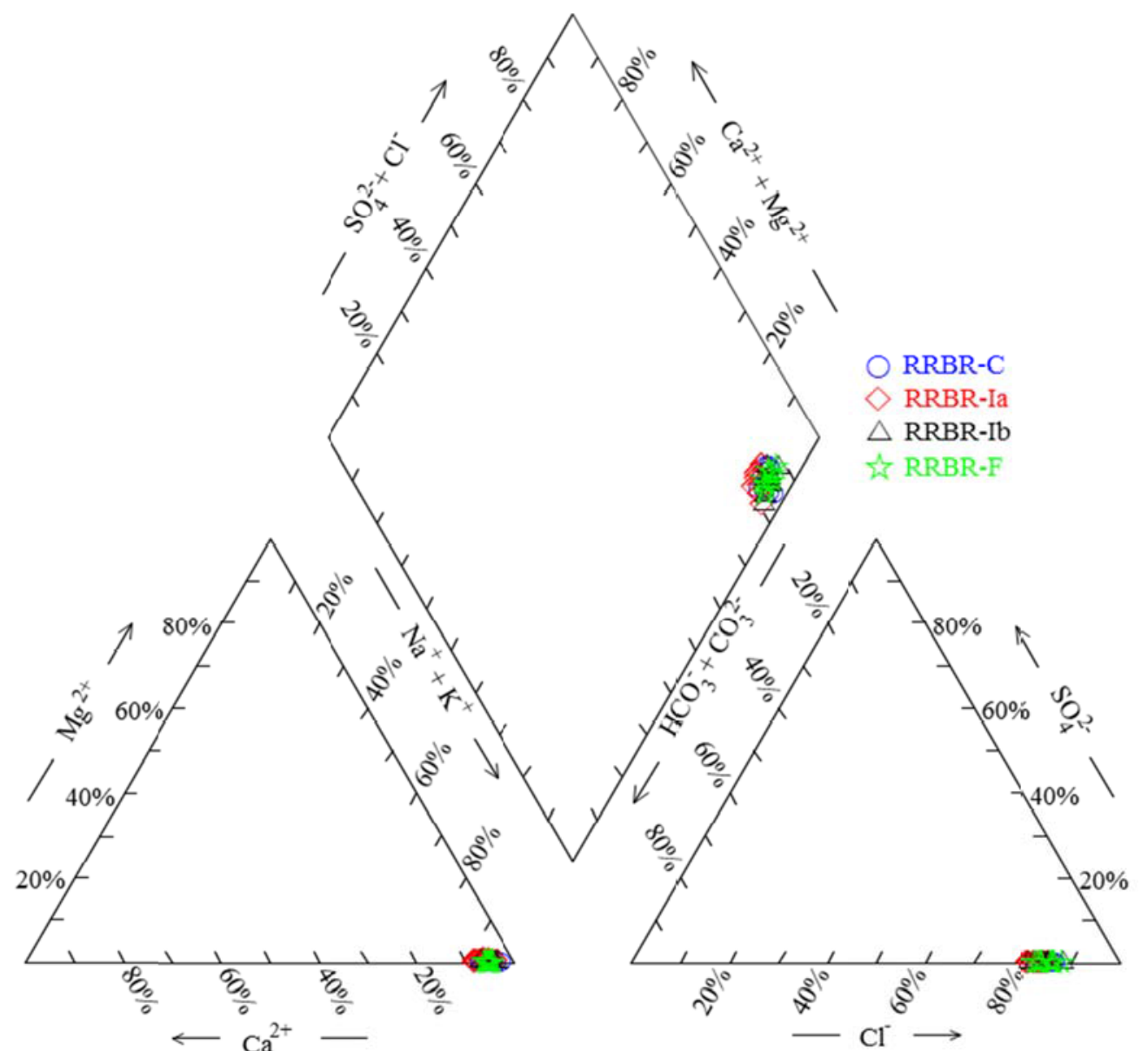

Figure E7. Composition of experimental water plotted on a Piper diagram

\section{Post-experimental solid samples}

After decommissioning of the experiments, the solid samples were separated from the solution and air dried. These samples were studied with SEM and XRD. The clays or the clay-sized fractions in the postexperimental samples were separated by flotation according to Stoke's Law.

Unlike unreacted quartz grains (Figure E4), the reacted quartz grains show surface deposits (Figures D8 and D9). Texturally, these deposits are flaky, tubular, fibrous, and botryoidal which may indicate likely secondary precipitates of clays, zeolites, and silica phases.

The XRD spectra of clay separated from RRBR-C experiment show kaolinite-like mineral phase (Figure E10). Similar XRD signatures are also observed in clay samples separated from RRBR-Ia and RRBR-F post experimental materials. The XRD spectra of bulk post-experimental solid materials appear identical to the pre-experimental XRD spectra (Figure E3).

The likely clay mineral type at equilibrium with the experimental waters was also evaluated with determining stable mineral phases by constructing cation activity ratio diagrams (Figure E11). These diagrams also indicate likely formation of kaolinite during water-rock interaction experiments. 

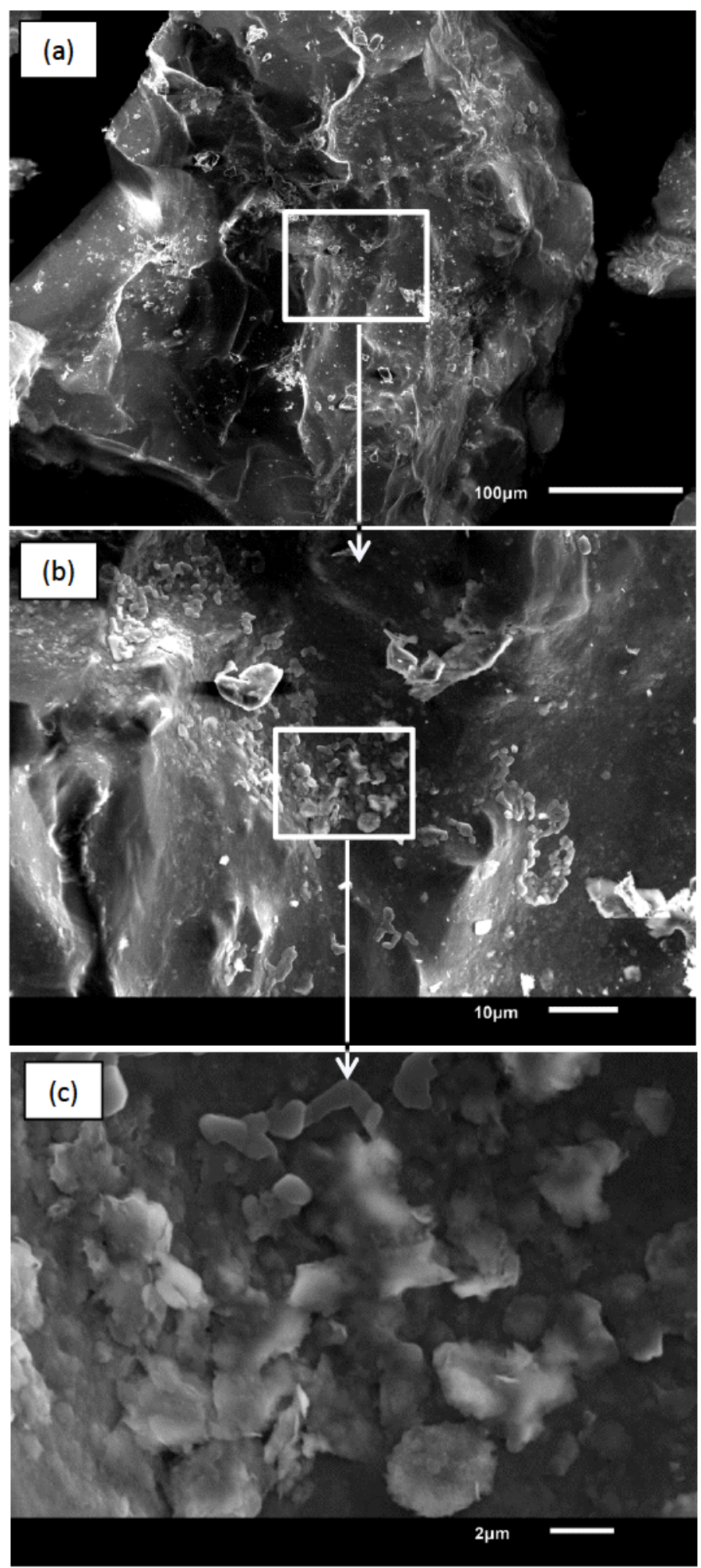

Figure E8. Scanning electron microphotograph showing reacted RRBR-C quartz grain. The surface of the grain is coated with a layer of secondary precipitates (a) at some areas, cluster of particulate secondary precipitates are accumulated on the layer of precipitates (b and c). 

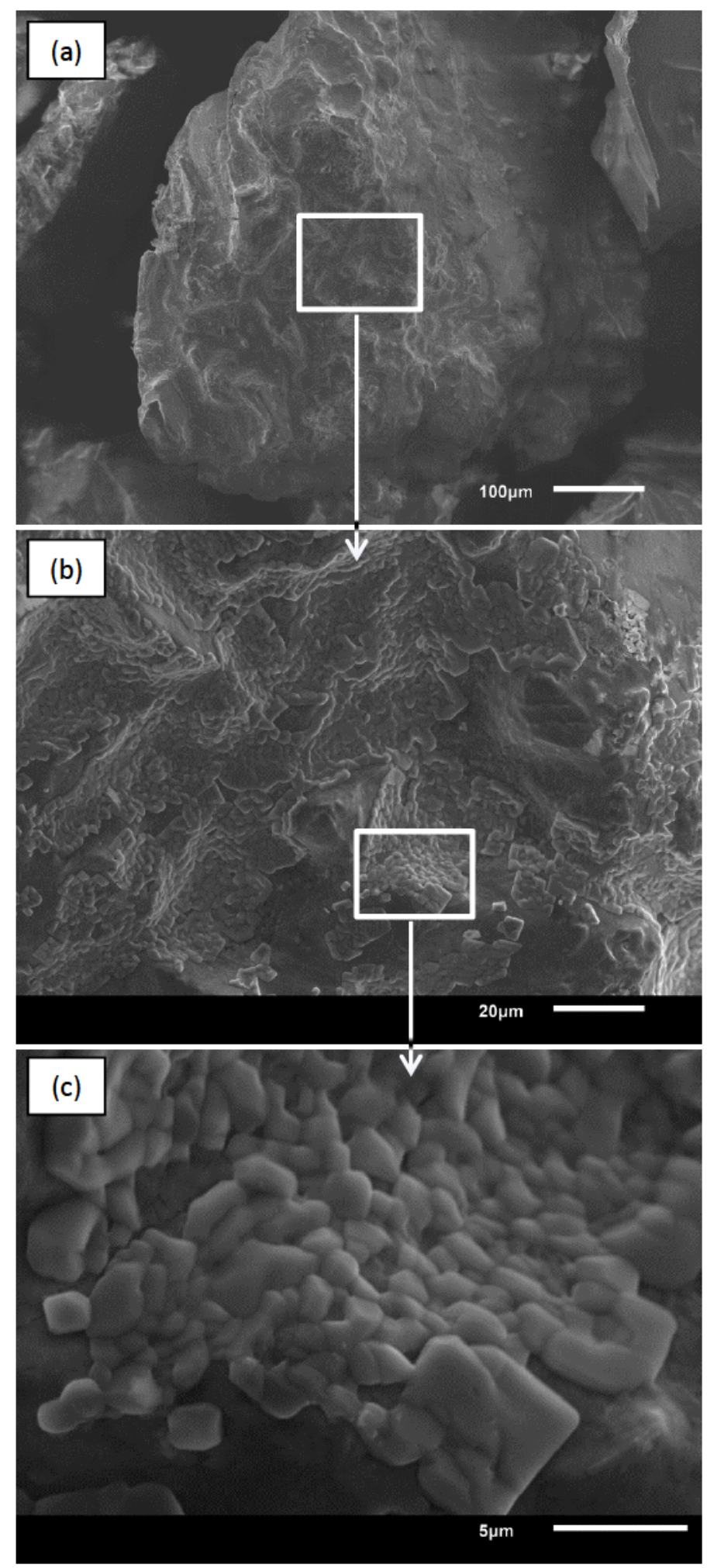

Figure E9. Scanning electron microphotograph showing another reacted RRBR-C quartz grain. The surface of the grain is coated with a botroidal layer of secondary precipitates. 


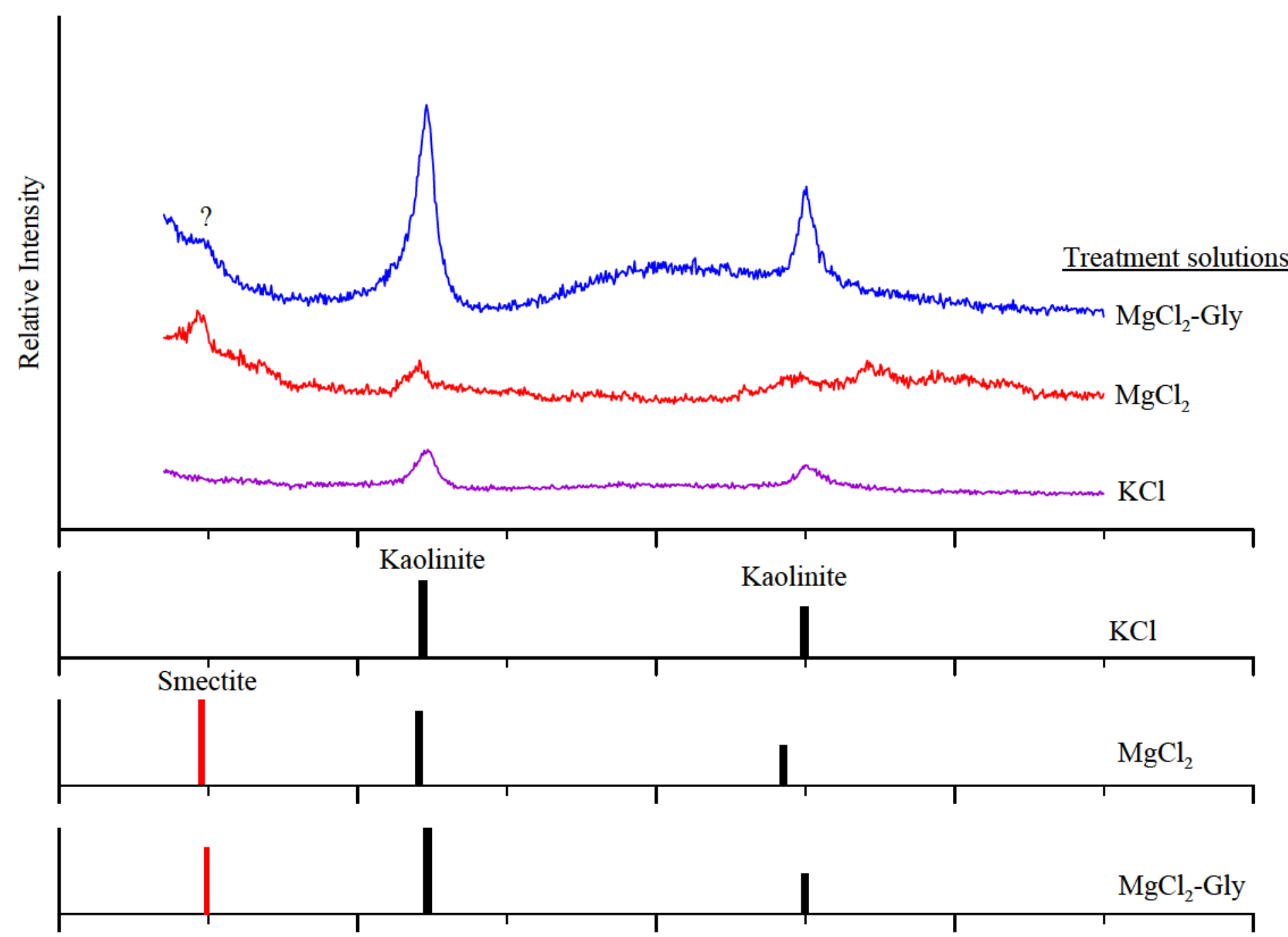

Figure E10. X-ray diffraction spectra of clay separate extracted from RRBR-C experiment. Standard XRD intensity peaks for kaolinite and smectite with treatments are also provided. 

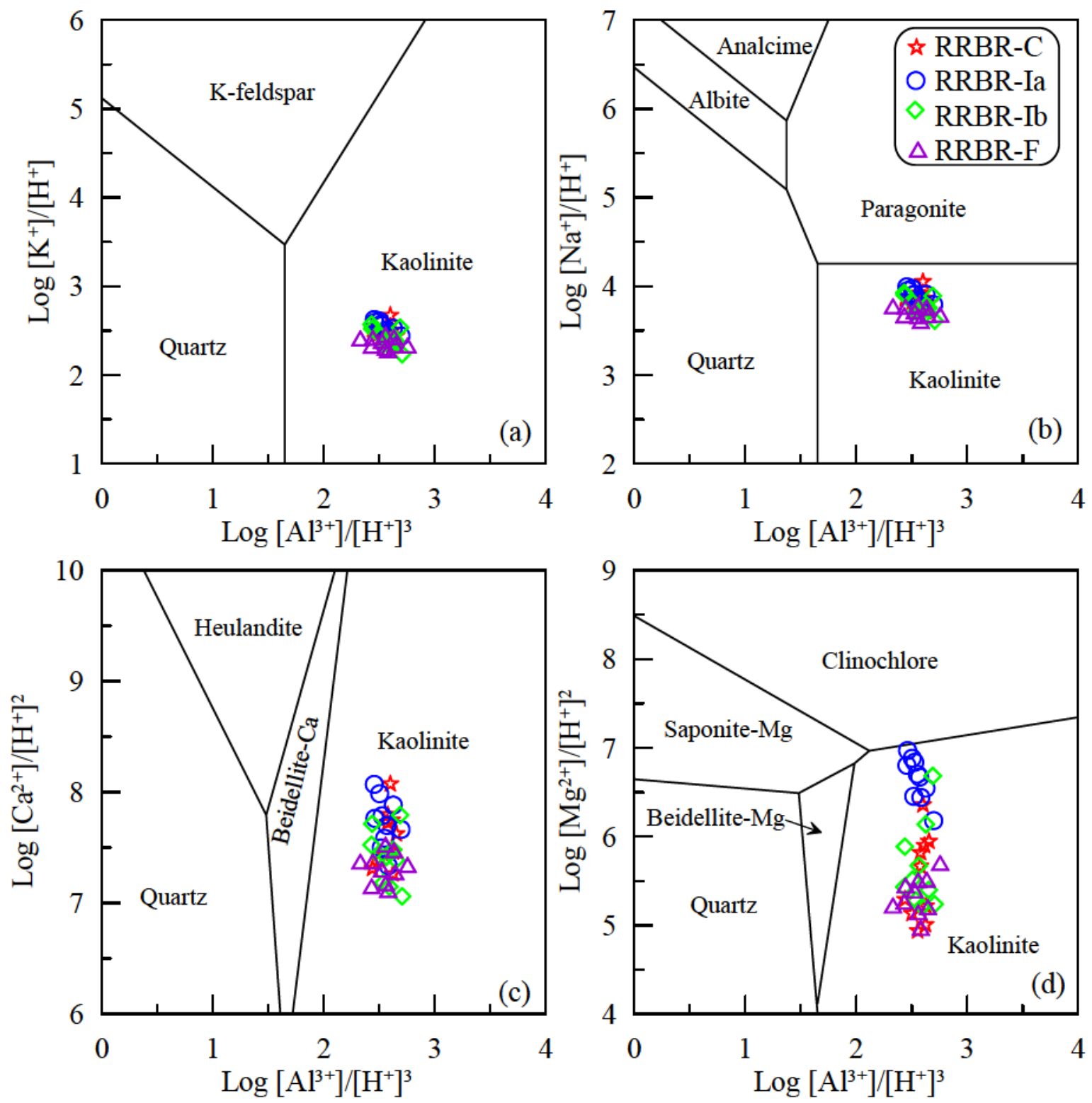

Figure E11. Activity ratio plots for experimental water samples at $200{ }^{\circ} \mathrm{C}$. These diagrams indicate that kaolinite may have been precipitated during water-rock interaction experiments.

\section{Traditional geothermometric results}

Experimental water samples plot along a narrow isothermal zone between 200 and $220^{\circ} \mathrm{C}$ on a Giggenbach diagram (Giggenbach, 1988) indicating a potential water-rock interaction temperatures (Figure E12). 


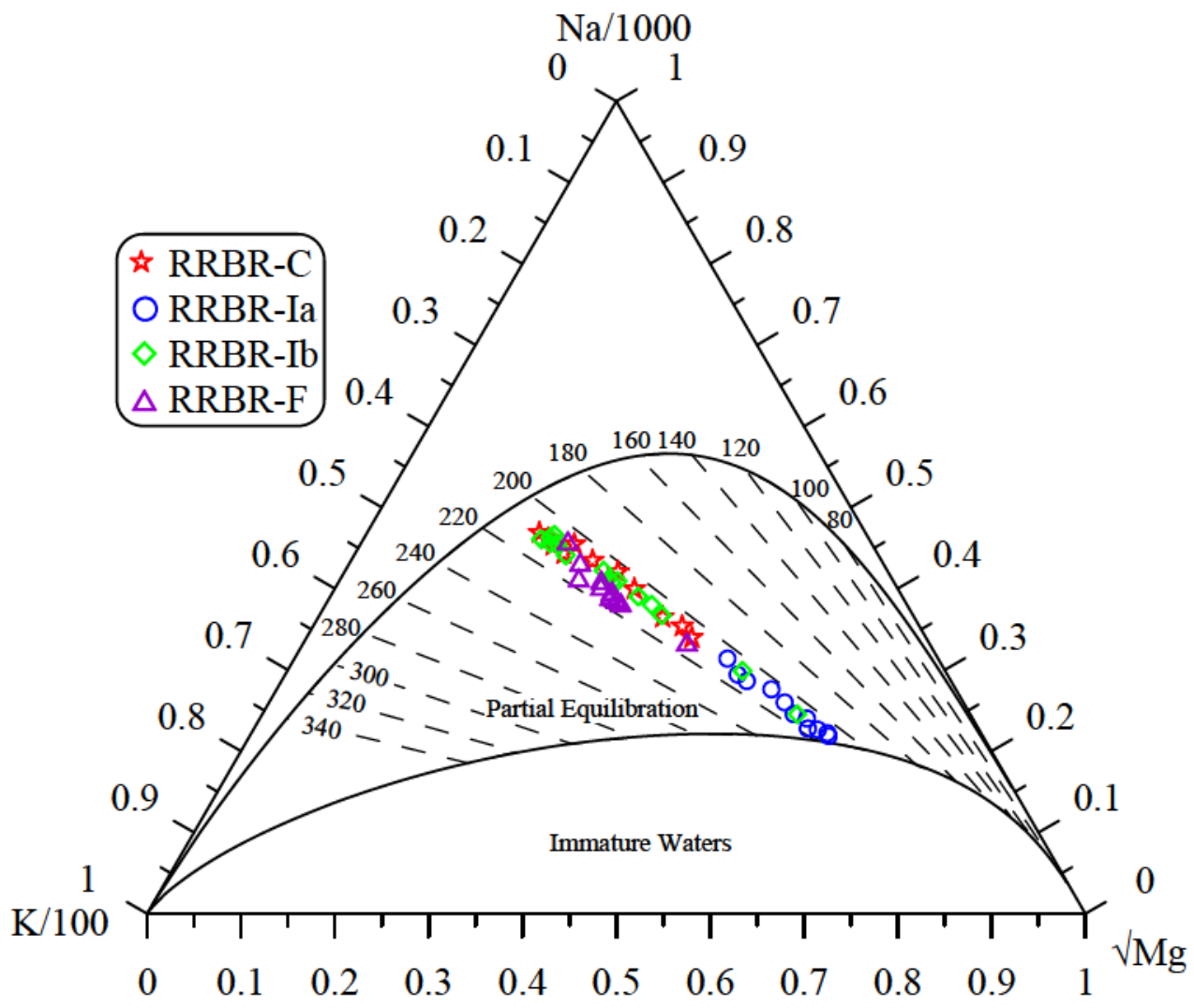

Figure E12. Experimental waters plotted on Giggenbach diagram (Giggenbach, 1988). All experimental waters lie within $200-22{ }^{\circ} \mathrm{C}$ zone in mature water field.

A suite of traditional geothermometers were used to estimate temperatures of experimental water samples (Figure E13, Figure E14, and Table E5). Temperatures obtained with silica geothermometers developed by various researchers are presented in Figure E13. All silica geothermometers yielded increasing temperatures with time; however, their estimates are cooler than the experimental temperature. Relatively, quartz temperatures with no steam loss are better estimates for the later samples compared to the estimates by other two silica geothermometers. For RRBR-Ib sample collected after cooling to $150^{\circ} \mathrm{C}$, all silica geothermometers appear to be providing cooler temperatures over time. 

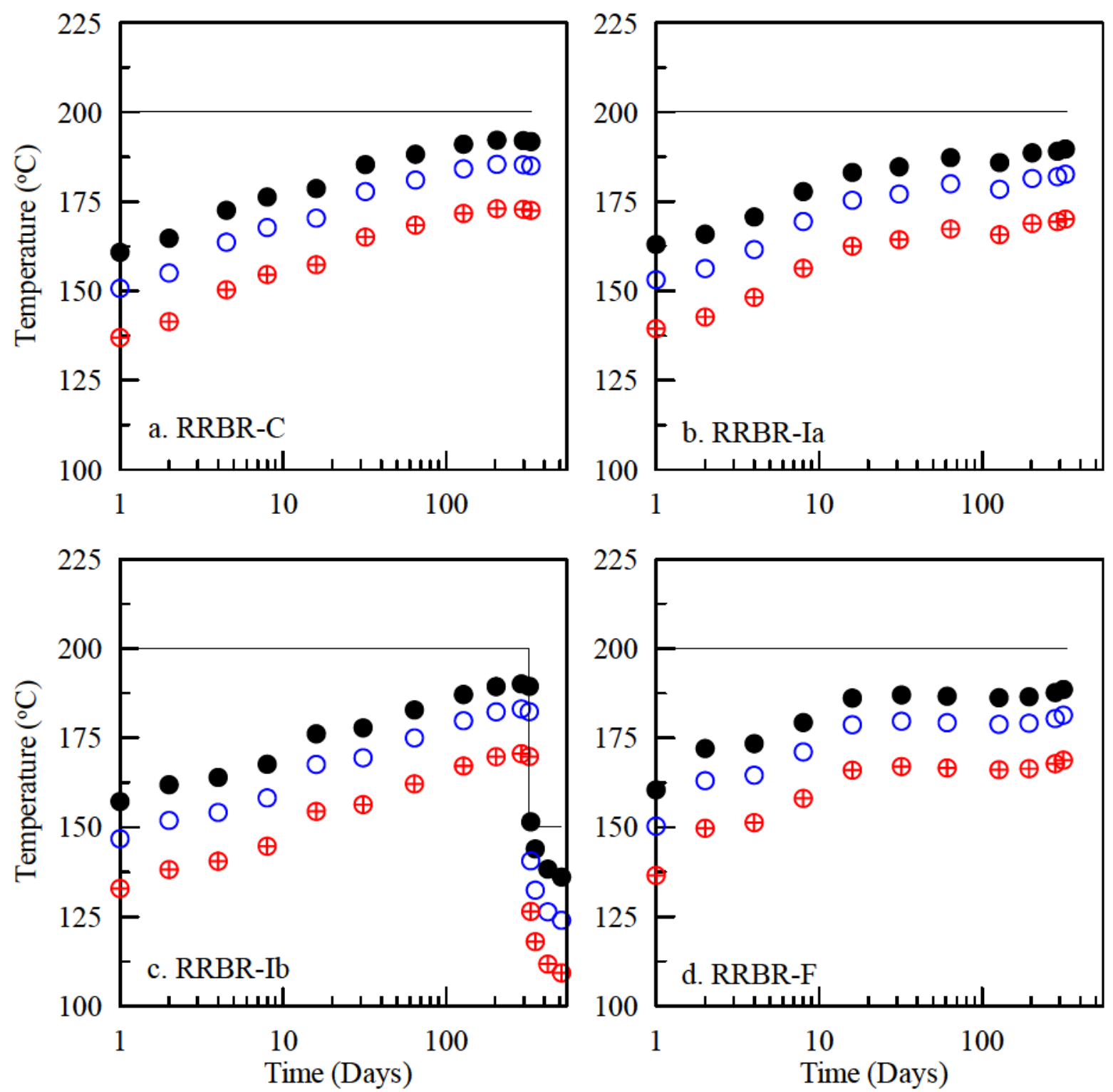

- Quartz (no steam loss) (Fournier, 1977) $\oplus$ Chalcedony (Fournier, 1977)

O Quartz (Arnorsson, 2000)

Figure E13. Temperature estimates for experimental waters with traditional silica geothermometers

Results of the traditional cations geothermometers are shown in Figure E14. With the exception of Na/K (Giggenbach, 1988), all other temperature estimates are cooler than experimental temperature. Similar to the results provide by the Gibbenbach diagram, the Giggenbach (1988) $\mathrm{Na} / \mathrm{K}$ geothermometer resulted in slightly hotter temperature for experimental samples. In general, temperature estimates of Giggenbach (1988) and Fournier (1979) Na/K geothermometers are better than other estimates. Particularly, Fournier (1979) $\mathrm{Na} / \mathrm{K}$ geothermometer resulted in good temperature estimates for RRBR-F samples (Figure E14). 

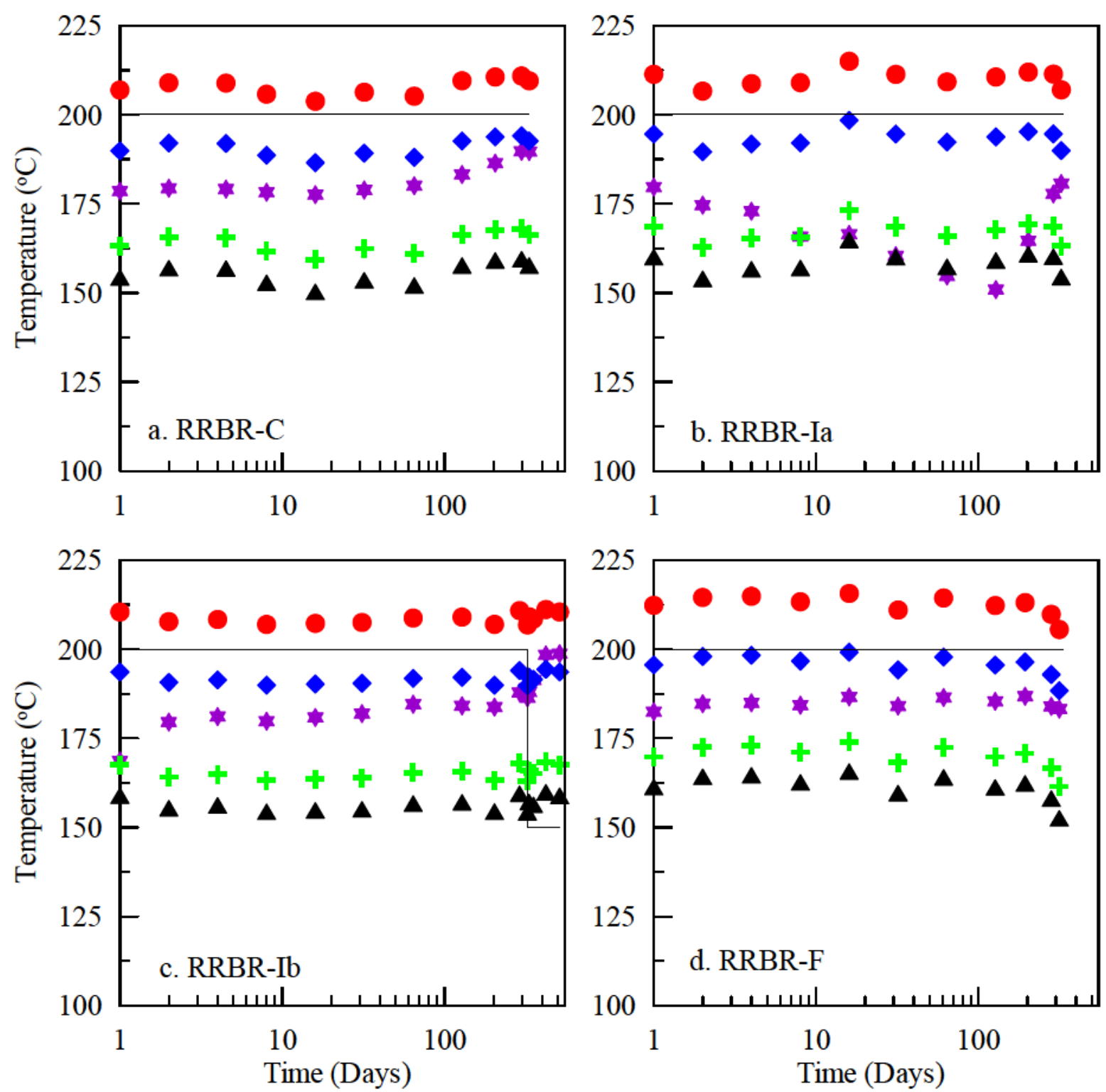

$\Delta \mathrm{Na} / \mathrm{K}$ (Truesdell, 1976)

- $\mathrm{Na} / \mathrm{K}$ (Fournier, 1979)

- $\mathrm{Na} / \mathrm{K}$ (Giggenbach, 1988, for $\mathrm{t}>180$ )

$+\mathrm{Na} / \mathrm{K}$ (Arnorsson, 1983, for t $25-280$ )

* Na-K-Ca (Fourner and Truesdell, 1973)

Figure E14. Temperature estimates for experimental waters with traditional cation geothermometers

For RRBR-Ib sample collected after cooling to $150^{\circ} \mathrm{C}$, the traditional cations geothermometers did not properly reflect cooling. Most of the cation geothermometers resulted in fairly similar temperature before and after cooling. Moreover, contrary to the decreased experimental temperature, Na-K-Ca geothermometer resulted in slightly higher temperature for samples collected after cooling to $150^{\circ} \mathrm{C}$. Such hotter temperature with Na-K-Ca geothermometer may have been resulted with disproportionate 
transfer of Ca from solution to solid phase compared to Na and $\mathrm{K}$ ions. Fairly constant temperature estimates from $\mathrm{Na} / \mathrm{K}$ geothermometers throughout the experimental duration may have been a reflection that these two cations were provided in the initial solution, and their concentrations did not vary with the progression of experiments.

Table E5. Estimated temperatures (in ${ }^{\circ} \mathrm{C}$ ) of experimental samples ${ }^{1}$ with traditional geothermometers

\begin{tabular}{|c|c|c|c|c|c|c|c|c|c|}
\hline RRBR-C & $\operatorname{Time}^{2}$ & Quartz $^{3}$ & Quartz $^{4}$ & Chalcedony $^{3}$ & $\mathrm{Na} / \mathrm{K}^{5}$ & $\mathrm{Na} / \mathrm{K}^{6}$ & $\mathrm{Na} / \mathrm{K}^{7}$ & $\mathrm{Na} / \mathrm{K}^{8}$ & $\mathrm{Na}-\mathrm{K}-\mathrm{Ca}^{9}$ \\
\hline Out 1 & 1 & 161 & 151 & 137 & 154 & 190 & 207 & 163 & 179 \\
\hline Out 2 & 2 & 165 & 155 & 141 & 157 & 192 & 209 & 166 & 179 \\
\hline Out 3 & 4.5 & 173 & 164 & 150 & 157 & 192 & 209 & 166 & 179 \\
\hline Out 4 & 8 & 176 & 168 & 155 & 153 & 189 & 206 & 162 & 178 \\
\hline Out 5 & 16 & 179 & 170 & 157 & 150 & 186 & 204 & 159 & 178 \\
\hline Out 6 & 32 & 185 & 178 & 165 & 154 & 189 & 206 & 162 & 179 \\
\hline Out 7 & 65 & 188 & 181 & 168 & 152 & 188 & 205 & 161 & 180 \\
\hline Out 8 & 128 & 191 & 184 & 172 & 158 & 193 & 210 & 166 & 183 \\
\hline Out 9 & 205 & 192 & 185 & 173 & 159 & 194 & 211 & 168 & 186 \\
\hline Out 10 & 298 & 192 & 185 & 173 & 162 & 196 & 212 & 170 & 191 \\
\hline Out 11 & 332 & 192 & 185 & 173 & 158 & 193 & 209 & 166 & 190 \\
\hline \multicolumn{10}{|l|}{ RRBR-Ia } \\
\hline Out 1 & 1 & 163 & 153 & 139 & 160 & 195 & 211 & 169 & 180 \\
\hline Out 2 & 2 & 166 & 156 & 143 & 154 & 190 & 207 & 163 & 175 \\
\hline Out 3 & 4 & 171 & 162 & 148 & 157 & 192 & 209 & 165 & 173 \\
\hline Out 4 & 8 & 178 & 169 & 156 & 157 & 192 & 209 & 166 & 166 \\
\hline Out 5 & 16 & 183 & 175 & 163 & 165 & 198 & 215 & 173 & 166 \\
\hline Out 6 & 31 & 185 & 177 & 164 & 160 & 195 & 211 & 169 & 160 \\
\hline Out 7 & 64 & 187 & 180 & 167 & 157 & 192 & 209 & 166 & 155 \\
\hline Out 8 & 128 & 186 & 178 & 166 & 159 & 194 & 211 & 168 & 151 \\
\hline Out 9 & 203 & 189 & 181 & 169 & 161 & 195 & 212 & 169 & 165 \\
\hline Out 10 & 290 & 189 & 182 & 169 & 164 & 198 & 211 & 169 & 178 \\
\hline Out 11 & 324 & 190 & 183 & 170 & 154 & 190 & 207 & 163 & 181 \\
\hline \multicolumn{10}{|l|}{ RRBR-Ib } \\
\hline Out 1 & 1 & 157 & 147 & 133 & 159 & 194 & 210 & 167 & 169 \\
\hline Out 2 & 2 & 162 & 152 & 138 & 155 & 191 & 208 & 164 & 180 \\
\hline Out 3 & 4 & 164 & 154 & 140 & 160 & 194 & 211 & 168 & 182 \\
\hline Out 4 & 8 & 168 & 158 & 145 & 154 & 190 & 207 & 163 & 180 \\
\hline Out 5 & 16 & 176 & 168 & 154 & 155 & 190 & 207 & 164 & 181 \\
\hline Out 6 & 31 & 178 & 169 & 156 & 155 & 190 & 207 & 164 & 182 \\
\hline Out 7 & 64 & 183 & 175 & 162 & 157 & 192 & 209 & 165 & 185 \\
\hline Out 8 & 128 & 187 & 180 & 167 & 157 & 192 & 209 & 166 & 184 \\
\hline Out 9 & 203 & 189 & 182 & 170 & 154 & 190 & 207 & 163 & 184 \\
\hline Out 10 & 290 & 190 & 183 & 171 & 159 & 194 & 211 & 168 & 188 \\
\hline Out 11 & 324 & 189 & 182 & 170 & 154 & 190 & 207 & 163 & 186 \\
\hline Out12 & 331 & 152 & 141 & 126 & 157 & 192 & 209 & 166 & 188 \\
\hline
\end{tabular}




\begin{tabular}{|c|c|c|c|c|c|c|c|c|c|}
\hline Out13 & 353 & 144 & 132 & 118 & 156 & 192 & 208 & 165 & 191 \\
\hline Out14 & 421 & 138 & 126 & 112 & 160 & 194 & 211 & 168 & 198 \\
\hline Out15 & 511 & 136 & 124 & 109 & 159 & 194 & 210 & 167 & 199 \\
\hline RRBR-F & \multicolumn{7}{|l|}{$\mid$} \\
\hline Out 1 & 1 & 160 & 150 & 137 & 161 & 196 & 212 & 170 & 182 \\
\hline Out 2 & 2 & 172 & 163 & 150 & 164 & 198 & 215 & 173 & 185 \\
\hline Out 3 & 4 & 173 & 165 & 151 & 165 & 198 & 215 & 173 & 185 \\
\hline Out 4 & 8 & 179 & 171 & 158 & 163 & 197 & 213 & 171 & 184 \\
\hline Out 5 & 16 & 186 & 179 & 166 & 166 & 199 & 216 & 174 & 187 \\
\hline Out 6 & 32 & 187 & 180 & 167 & 160 & 194 & 211 & 168 & 184 \\
\hline Out 7 & 61 & 187 & 179 & 167 & 164 & 198 & 214 & 172 & 186 \\
\hline Out 8 & 127 & 186 & 179 & 166 & 161 & 196 & 212 & 170 & 185 \\
\hline Out 9 & 194 & 186 & 179 & 166 & 162 & 196 & 213 & 171 & 187 \\
\hline Out 10 & 281 & 188 & 180 & 168 & 158 & 193 & 210 & 167 & 184 \\
\hline Out 11 & 315 & 189 & 181 & 169 & 153 & 188 & 206 & 161 & 183 \\
\hline
\end{tabular}

${ }^{1}$ Experiments conducted at $200{ }^{\circ} \mathrm{C} ;{ }^{2}$ in days; ${ }^{3}$ Fournier (1977); ${ }^{4}$ Arnorsson (2000); ${ }^{5}$ Truesdell (1976); ${ }^{6}$ Fournier (1979); ${ }^{7}$ Giggenbach (1988) for $\mathrm{T}>180{ }^{\circ} \mathrm{C} ;{ }^{8}$ Arnorsson et al (1983) for T range $25-280{ }^{\circ} \mathrm{C}$; ${ }^{9}$ Fourner and Truesdell (1973), Mg correction applied according to Fournier and Potter II (1979). 
Table E6. RTEst estimated temperatures (in ${ }^{\circ} \mathrm{C}$ ) and associated uncertainties of experimental samples ${ }^{1}$

\begin{tabular}{|c|c|c|c|c|c|c|}
\hline RRBR-C & Time $^{2}$ & RTest T & $\sigma_{T}$ & $\log \mathrm{fCO}_{2}$ & $\sigma_{\log f \mathrm{CO}_{2}}$ & $\Phi^{3}$ \\
\hline Out 1 & 1 & 192 & 13.2 & -0.40 & 0.41 & 0.089 \\
\hline Out 2 & 2 & 191 & 9.8 & -0.63 & 0.31 & 0.048 \\
\hline Out 3 & 4.5 & 198 & 9.0 & -0.43 & 0.277 & 0.045 \\
\hline Out 4 & 8 & 203 & 9.9 & -0.07 & 0.30 & 0.057 \\
\hline Out 5 & 16 & 203 & 8.4 & -0.18 & 0.26 & 0.041 \\
\hline Out 6 & 32 & 205 & 4.5 & -0.55 & 0.15 & 0.011 \\
\hline Out 7 & 65 & 206 & 3.9 & -0.42 & 0.13 & 0.008 \\
\hline Out 8 & 128 & 209 & 4.6 & -0.17 & 0.15 & 0.012 \\
\hline Out 9 & 205 & 207 & 2.8 & -0.27 & 0.09 & 0.004 \\
\hline Out 10 & 298 & 205 & 1.0 & -0.38 & 0.03 & 0.001 \\
\hline Out 11 & 332 & 204 & 2 & -0.64 & 0.06 & 0.002 \\
\hline \multicolumn{7}{|l|}{ RRBR-Ia } \\
\hline Out 1 & 1 & 191 & 11 & -0.62 & 0.34 & 0.061 \\
\hline Out 2 & 2 & 195 & 12 & -0.30 & 0.38 & 0.081 \\
\hline Out 3 & 4 & 197 & 12 & -0.07 & 0.34 & 0.075 \\
\hline Out 4 & 8 & 205 & 11 & 0.09 & 0.34 & 0.069 \\
\hline Out 5 & 16 & 207 & 9 & 0.00 & 0.28 & 0.044 \\
\hline Out 6 & 31 & 208 & 8 & -0.04 & 0.25 & 0.036 \\
\hline Out 7 & 64 & 208 & 7 & -0.07 & 0.22 & 0.027 \\
\hline Out 8 & 128 & 203 & 6 & 0.02 & 0.19 & 0.022 \\
\hline Out 9 & 203 & 203 & 2 & -0.46 & 0.07 & 0.002 \\
\hline Out 10 & 290 & 204 & 3 & -0.10 & 0.11 & 0.007 \\
\hline Out 11 & 324 & 203 & 2 & -0.37 & 0.05 & 0.002 \\
\hline \multicolumn{7}{|l|}{ RRBR-Ib } \\
\hline Out 1 & 1 & 186 & 12 & -0.72 & 0.37 & 0.070 \\
\hline Out 2 & 2 & 184 & 8 & -0.83 & 0.25 & 0.031 \\
\hline Out 3 & 4 & 182 & 6 & -0.97 & 0.18 & 0.015 \\
\hline Out 4 & 8 & 187 & 7 & -0.59 & 0.22 & 0.025 \\
\hline Out 5 & 16 & 199 & 6 & -0.62 & 0.18 & 0.017 \\
\hline Out 6 & 31 & 195 & 3 & -1.22 & 0.10 & 0.003 \\
\hline Out 7 & 64 & 198 & 2 & -0.71 & 0.05 & 0.002 \\
\hline Out 8 & 128 & 204 & 3 & -0.39 & 0.11 & 0.006 \\
\hline Out 9 & 203 & 205 & 2 & -0.46 & 0.08 & 0.003 \\
\hline Out 10 & 290 & 206 & 4 & -0.02 & 0.13 & 0.010 \\
\hline Out 11 & 324 & 205 & 2 & -0.38 & 0.07 & 0.002 \\
\hline Out12 & 331 & 167 & 5 & -1.52 & 0.15 & 0.008 \\
\hline Out13 & 353 & 158 & 6 & -1.78 & 0.17 & 0.011 \\
\hline Out14 & 421 & 153 & 7 & -1.99 & 0.22 & 0.016 \\
\hline Out15 & 511 & 150 & 7 & -2.01 & 0.21 & 0.015 \\
\hline \multicolumn{7}{|l|}{ RRBR-F } \\
\hline Out 1 & 1 & 186 & 9 & -0.90 & 0.29 & 0.039 \\
\hline
\end{tabular}




\begin{tabular}{|c|c|c|c|c|c|c|}
\hline Out 2 & 2 & 195 & 7 & -0.68 & 0.21 & 0.023 \\
\hline Out 3 & 4 & 194 & 6 & -0.64 & 0.19 & 0.018 \\
\hline Out 4 & 8 & 200 & 5 & -0.55 & 0.16 & 0.014 \\
\hline Out 5 & 16 & 199 & 1 & -0.92 & 0.04 & 0.001 \\
\hline Out 6 & 32 & 201 & 1 & -0.76 & 0.04 & 0.001 \\
\hline Out 7 & 61 & 202 & 3 & -0.47 & 0.09 & 0.005 \\
\hline Out 8 & 127 & 200 & 3 & -0.40 & 0.09 & 0.005 \\
\hline Out 9 & 194 & 196 & 1 & -0.74 & 0.03 & 0.001 \\
\hline Out 10 & 281 & 198 & 2 & -0.37 & 0.07 & 0.003 \\
\hline Out 11 & 315 & 200 & 2 & -0.31 & 0.07 & 0.002 \\
\hline
\end{tabular}

${ }^{1}$ Experiments conducted at $200{ }^{\circ} \mathrm{C}$; ${ }^{2}$ in days; ${ }^{3}$ objective function. 

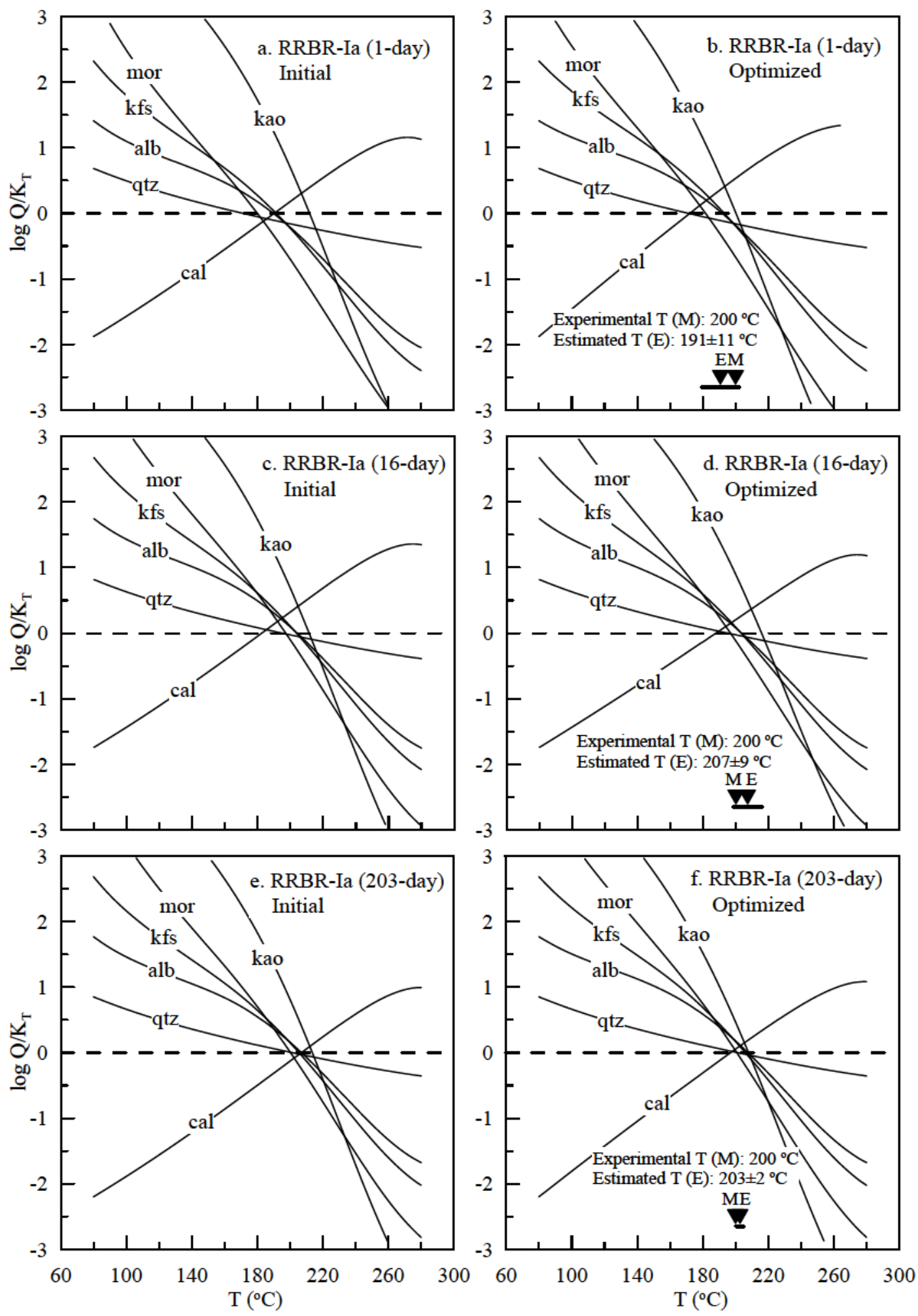

Figure E15. MEG temperature estimates for three RRBR-Ia experimental water samples collected at various water-rock interaction durations. The $\log \left(Q / K_{T}\right)$ curves for minerals calculated using original water chemistries are shown in a, $c$ and e are for samples collected after 1, 16, and 203 days whereas optimized $\log \left(\mathrm{Q} / \mathrm{K}_{\mathrm{T}}\right)$ curves for these water samples are shown in $b$, $d$, anf $\mathbf{f}$ respectively. (Minerals - alb: albite; cal: calcite; kao: kaolinite; kfs: K-feldspar; mor: mordenite-K; qtz: quartz) 

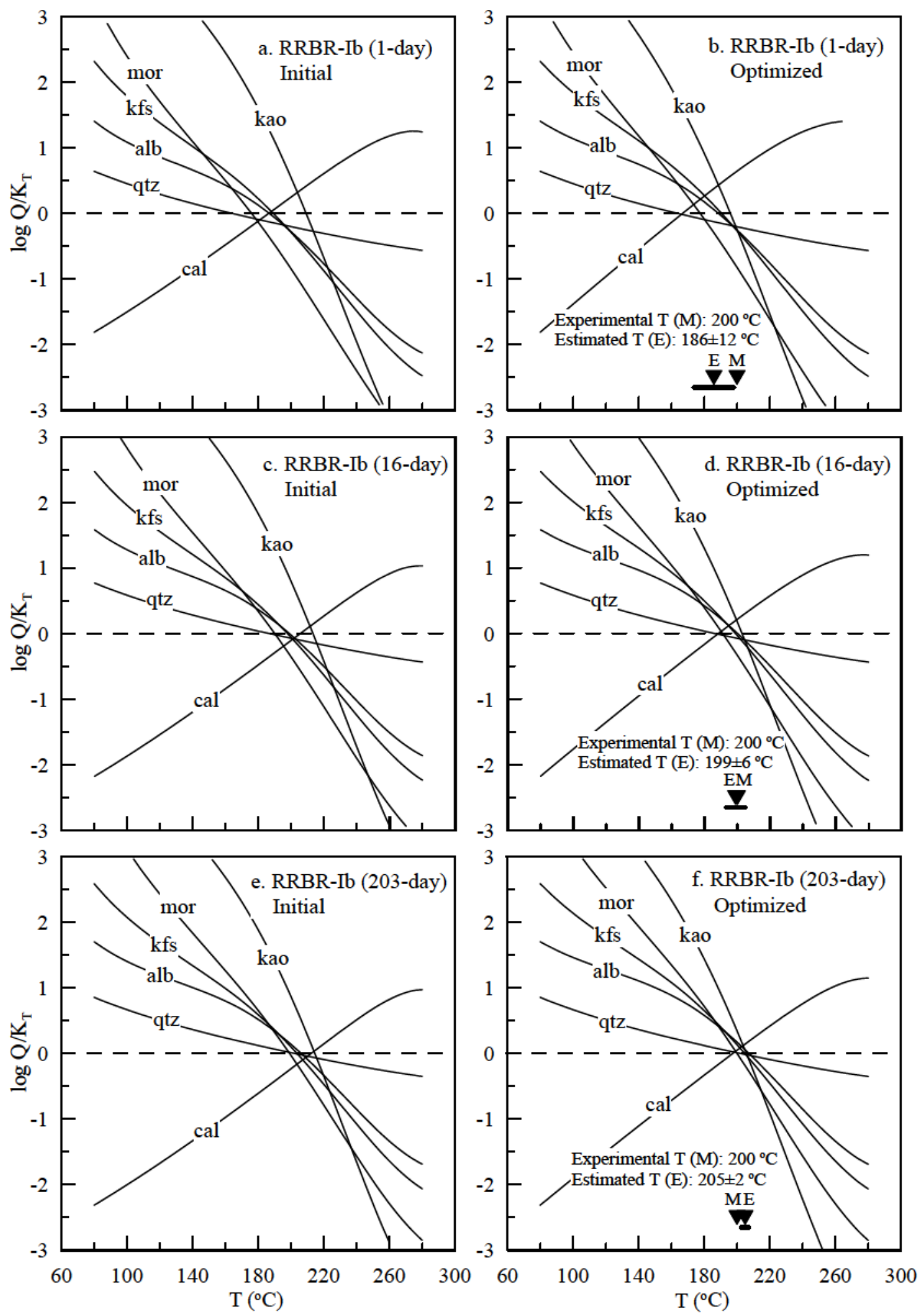

Figure E16. MEG temperature estimates for three RRBR-Ib experimental water samples collected at various water-rock interaction durations. $T$ he $\log \left(Q / K_{T}\right)$ curves for minerals calculated using original water chemistries are shown in a, $c$ and $e$ are for samples collected after 1, 16, and 203 days whereas optimized $\log \left(Q / K_{\mathrm{T}}\right)$ curves for these water samples are shown in $b, d$, anf $f$ respectively. (Minerals - alb: albite; cal: calcite; kao: kaolinite; kfs: K-feldspar; mor: mordenite-K; qtz: quartz) 

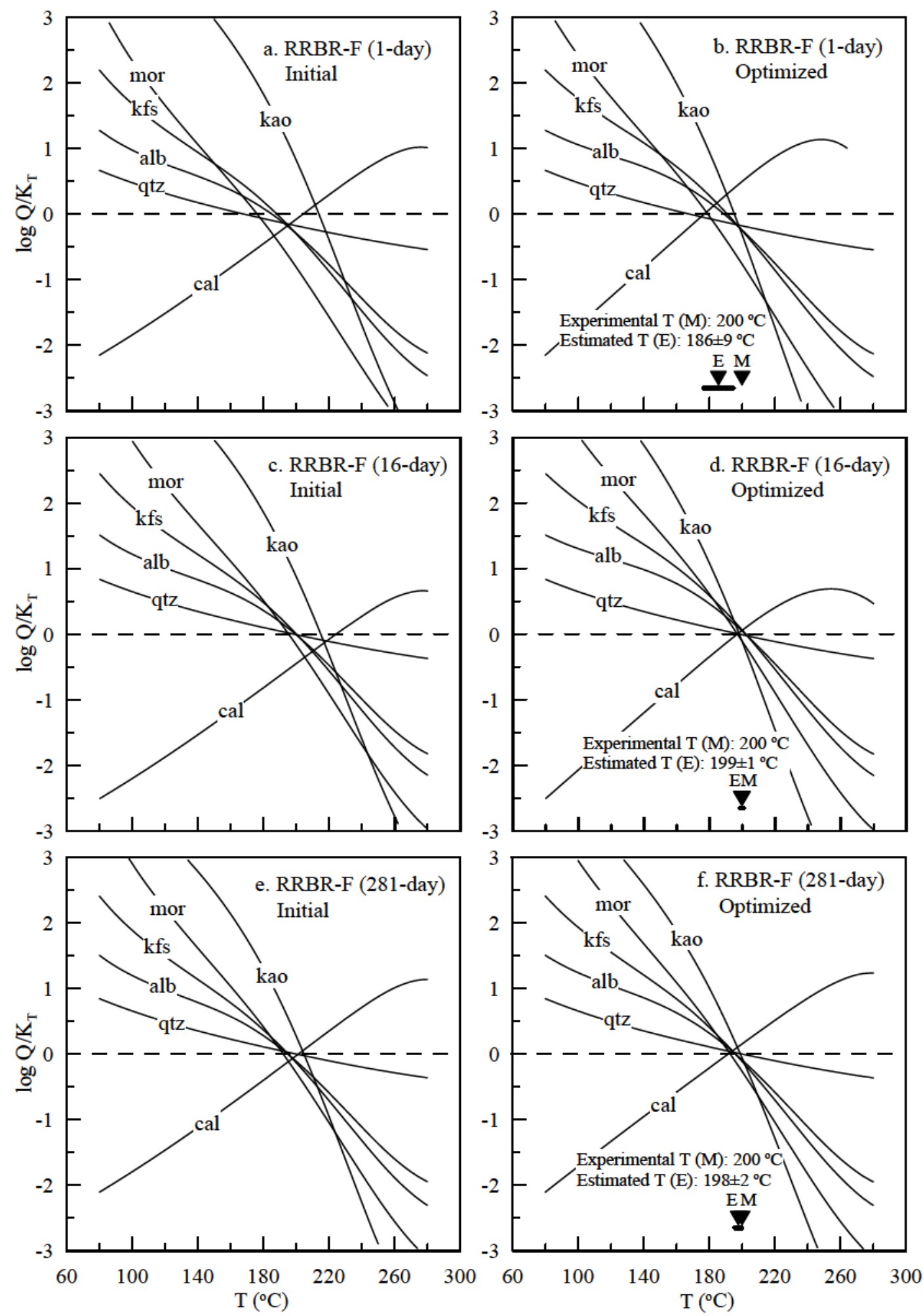

Figure E17. MEG temperature estimates for three RRBR-F experimental water samples collected at various water-rock interaction durations. $T$ he $\log \left(Q / K_{T}\right)$ curves for minerals calculated using original water chemistries are shown in a, $c$ and $e$ are for samples collected after 1, 16, and 281 days whereas optimized $\log \left(Q / K_{\mathrm{T}}\right)$ curves for these water samples are shown in $b, d$, anf $f$ respectively. (Minerals - alb: albite; cal: calcite; kao: kaolinite; kfs: K-feldspar; mor: mordenite-K; qtz: quartz) 


\section{Appendix F. Supporting materials related to mixing of experimental water with eastern Snake River Plain groundwater}

\section{Water chemistry}

Compositions of equilibrated experimental water (RRBR-Im), ESRP water (Wood well water), and mixed water samples are provided in Table F1. The RRBR-Im and Wood well waters are used as end-member water compositions. A series of mixed water samples were prepared by adding $22 \%, 26 \%, 32 \%, 43 \%$ and $59 \%$ of Wood well water in the RRBR-Im water sample. The compositions of the mixed waters are measured with analytical instruments (such as ICP-OES, IC, etc.). Furthermore, compositions of mixed waters were also calculated using the end member water compositions. For all mixed samples, bicarbonate concentrations were not measured but calculated from its concentrations in end member waters.

The Wood well water is a typical $\mathrm{Ca}-\mathrm{HCO}_{3}$ type ESRP aquifer water sample (Figure F1). This water has a relatively large concentration of $\mathrm{Mg}$. The equilibrated RRBR-Im water as well as all mixed waters are $\mathrm{Na}-\mathrm{Cl}$ type water (Figure F1).

Figure F2 shows the two end-member waters (Wood well and RRBR-Im waters) along with mixed water samples plotted on a Giggenbach diagram (Giggenbach, 1988). The RRBR-Im water sample lies on the $220^{\circ} \mathrm{C}$ isothermal line within the mature water field. This temperature is slightly higher than the waterrock interaction temperature $\left(200^{\circ} \mathrm{C}\right)$ employed during the experiment. The Wood well water is immature water. Similarly, all mixed water samples are plotted in the immature filed. 
Table F1. Composition of Wood well, experimental, and mixed waters (mg/L)

\begin{tabular}{|c|c|c|c|c|c|c|c|c|c|c|c|c|c|c|}
\hline Samples & $\%$ of Wood well water & $\mathrm{pH}^{3}$ & $\mathrm{Al}$ & $\mathrm{Ba}$ & $\mathrm{Ca}$ & $\mathrm{K}$ & $\mathrm{Mg}$ & $\mathrm{Na}$ & $\mathrm{SiO}^{2}(\mathrm{aq})$ & $\mathrm{HCO}_{3}{ }^{4}$ & $\mathrm{~F}$ & $\mathrm{Cl}$ & $\mathrm{SO}^{4}$ & $\mathrm{Fe}$ \\
\hline Wood well & $100 \%$ & 7.66 & 0.022 & 0.16 & 80 & 5 & 21 & 20 & 31 & 266 & 0.35 & 18 & 43 & 0.03 \\
\hline RRBR-Im & $0 \%$ & 5.34 & 0.105 & 0.35 & 29 & 52 & 0.25 & 606 & 236 & 319 & 1.2 & 1011 & 5.2 & 1.13 \\
\hline Mixed water 1_ $M^{1}$ & $22 \%$ & 6.21 & 0.091 & 0.27 & 40 & 43 & 4.8 & 478 & 198 & 307 & 1.1 & 816 & 16 & 0.56 \\
\hline Mixed water 2_M & $26 \%$ & 6.24 & 0.084 & 0.24 & 42 & 39 & 5.9 & 460 & 179 & 305 & 1.2 & 766 & 19 & 0.58 \\
\hline Mixed water 3_M & $32 \%$ & 6.39 & 0.082 & 0.21 & 45 & 37 & 7.1 & 414 & 176 & 302 & 0.92 & 704 & 20 & 0.44 \\
\hline Mixed water 4_M & $43 \%$ & 6.48 & 0.074 & 0.20 & 50 & 32 & 10 & 362 & 146 & 296 & 0.82 & 618 & 23 & 0.43 \\
\hline Mixed water 5_M & $59 \%$ & 6.60 & 0.061 & 0.20 & 59 & 25 & 13 & 258 & 121 & 288 & 0.69 & 463 & 28 & 0.33 \\
\hline Mixed water 1_C $\mathrm{C}^{2}$ & $22 \%$ & 5.85 & 0.087 & 0.31 & 40 & 42 & 4.8 & 479 & 192 & 307 & 1.0 & 796 & 13 & 0.90 \\
\hline Mixed water 2_C & $26 \%$ & 5.92 & 0.084 & 0.30 & 42 & 40 & 5.7 & 452 & 182 & 305 & 1.0 & 750 & 15 & 0.85 \\
\hline Mixed water 3_C & $32 \%$ & 6.01 & 0.079 & 0.29 & 45 & 37 & 6.9 & 418 & 170 & 302 & 0.93 & 691 & 17 & 0.78 \\
\hline Mixed water 4_C & $43 \%$ & 6.18 & 0.070 & 0.27 & 51 & 32 & 9.3 & 353 & 147 & 296 & 0.84 & 581 & 22 & 0.66 \\
\hline Mixed water 5_C & $59 \%$ & 6.42 & 0.057 & 0.24 & 59 & 24 & 12 & 263 & 116 & 288 & 0.71 & 430 & 27 & 0.49 \\
\hline
\end{tabular}

${ }^{1}$ Letter $\mathrm{M}$ indicates the concentrations of mixed waters are measured. ${ }^{2}$ Letter $\mathrm{C}$ indicates that the concentrations of mixed waters are calculated using two end member (Wood well and RRBR-Im water compositions). ${ }^{3} \mathrm{pH}$ values of all mixed waters were measured; however, during RTEst run, calculated $\mathrm{pH}$ values were used because the concentrations of bicarbonate in these waters were also calculated from the concentration of bicarbonate in end member waters. Use of measured $\mathrm{pH}$ values along with calculated bicarbonate concentrations in RTEst modeling resulted in large standard errors. However, use of calculated $\mathrm{pH}$ and along with calculated bicarbonate concentrations for RTEst modeling resulted in excellent results. ${ }^{4}$ All bicarbonate values of mixed waters are calculated from the concentrations of end members. 


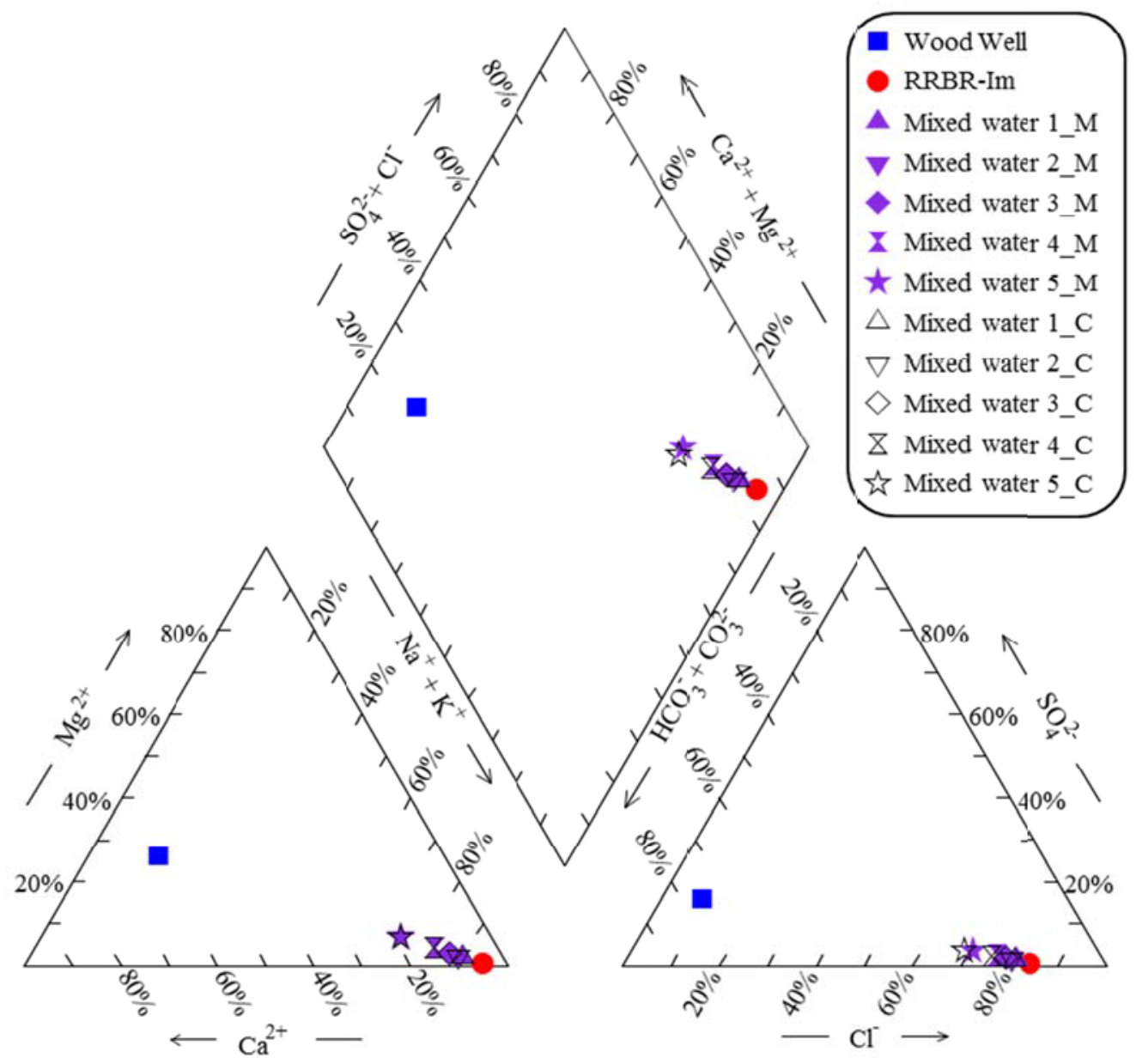

Figure F1. Compositions of two end member waters [equilibrated experimental water (RRBROut1) and ESRP ground water (Wood well)] and various mixed waters. The suffix letters $M$ and $C$ associated with sample names indicate measured and calculated concentrations of various elements. Bicarbonate concentrations for all samples (except end members) are also calculated values. 


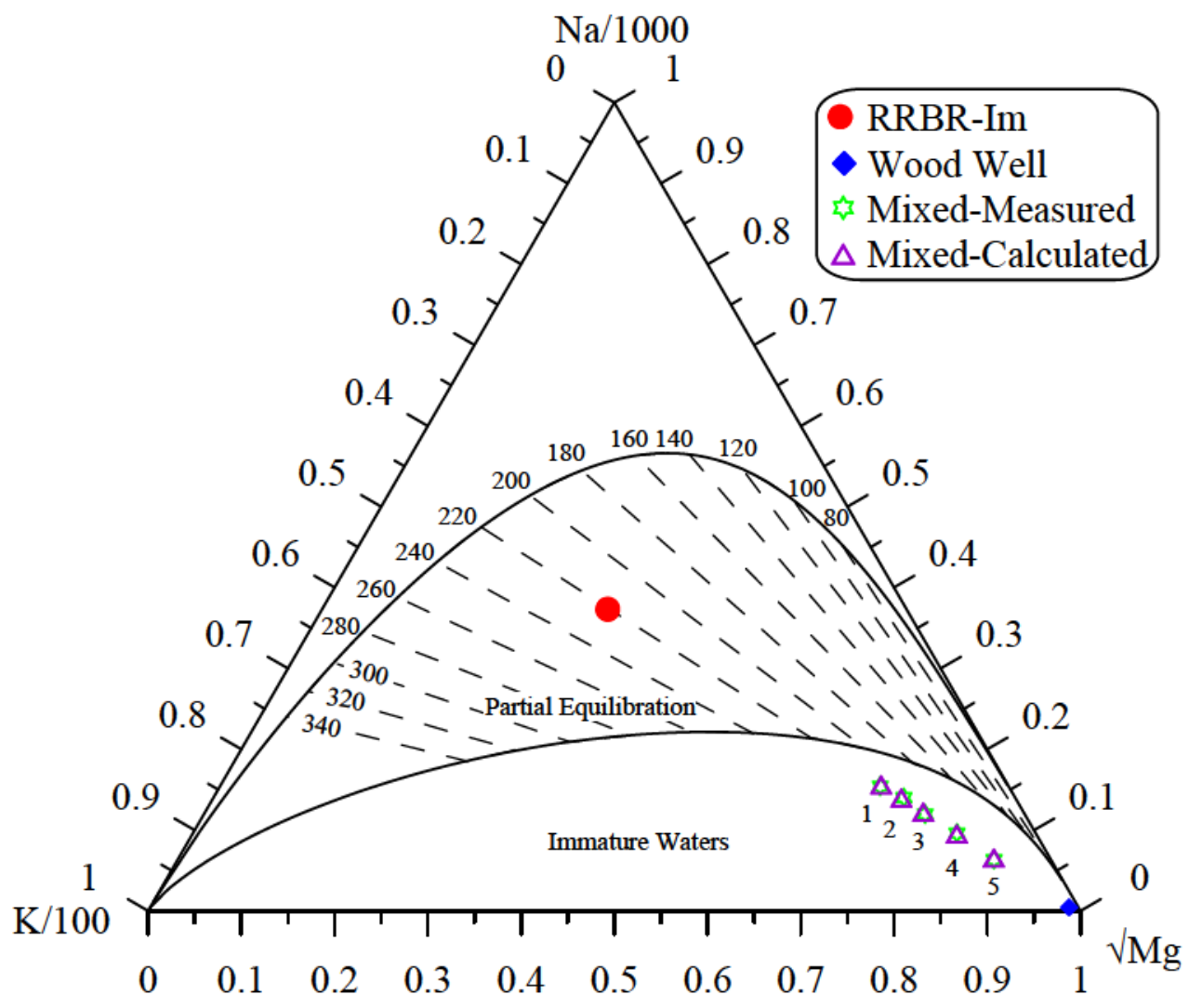

Figure F2. Wood well, RRBR-Im, and mixed water samples plotted on a Giggenbach diagram. With the exception of equilibrated RRBR-Im water, all other waters are plotted on immature water field. The numbers 1 through 5 represent mixed waters containing 22, 26, 32, 43, 59 percentage of Wood well water, respectively. 


\section{Appendix G. Supporting data and results related to the Raft River Geothermal area, Malta, Idaho}

\section{Geology}

The RRG system consists of two geologic units - Precambrian basement rocks and unconformably overlying mid-Tertiary to Quaternary sedimentary-volcanic rocks (Devine and Bonnichsen, 1980; Blackett and Kolesar, 1983). The basement rocks include metamorphosed adamellite, schist, and quartzite. The oldest unit in the area is gneissic in texture containing large phenocrysts of feldspars in the groundmass of quartz, biotite, and feldspars. Other basement units include lower and upper Narrows Schist of biotite-chlorite-muscovite with quartz and feldspars with muscovite bearing Elba Quartzite in between them. The Yost Quartzite comprising white quartzite with calcite veins is the youngest basement unit.

The younger rocks consist of a thick (up to $1600 \mathrm{~m}$ ) Tertiary sequence of rhyolites, tuffs, and fluvial-lacustrine sedimentary rocks (Salt Lake Formation) and non-indurated Pleistocene deposits of quartz sand, silt, and gravel (Raft Formation) (Blackett and Kolesar, 1983). The Salt Lake Formation consists of three members: Upper Tuffaceous Member, Jim Sage Volcanic Member, and Lower Tuffaceous Member (Jones et al., 2011). Structurally, two major fault systems, the Bridge Fault Zone and the Horse Wells Fault Zone, are identified in the area (Dolenc et al., 1981). These fault systems, most importantly, the Bridge Fault Zone, are presumed to be intersecting a basement shear zone called Narrows Structures and controlling the up flow of the geothermal water (Ayling and Moore, 2013).

\section{Water composition}

The high TDS geothermal water is generally found in southeastern RRG wells and low TDS water is mostly found in northwestern RRG wells. Both waters are of sodium-chloride type, and yield similar temperatures by a single traditional geothermometer but discordant temperatures by different geothermometers (Ayling et al., 2013).

Water chemistries (Table G1) from 8 RRG wells (RRG1, RRG2, RRG3, RRG4, RRG5, RRG6, RRG7, and RRG9) were selected for testing RTEst's ability in estimating temperature. The RRG waters are near-neutral in $\mathrm{pH}$ and dominated by sodium and chloride ions (Figure G1).

Relatively, the geothermal waters from wells RRG1, RRG2, RRG4, RRG5, and RRG9 have low total dissolved solid (TDS) whereas waters representing RRG3, RRG6, and RRG7 have high TDS. All RRG waters lie in the mature water field in Giggenbach plot suggesting that these waters are in equilibrium with reservoir minerals at $\mathrm{T}>160^{\circ} \mathrm{C}$ (Figure G2). 


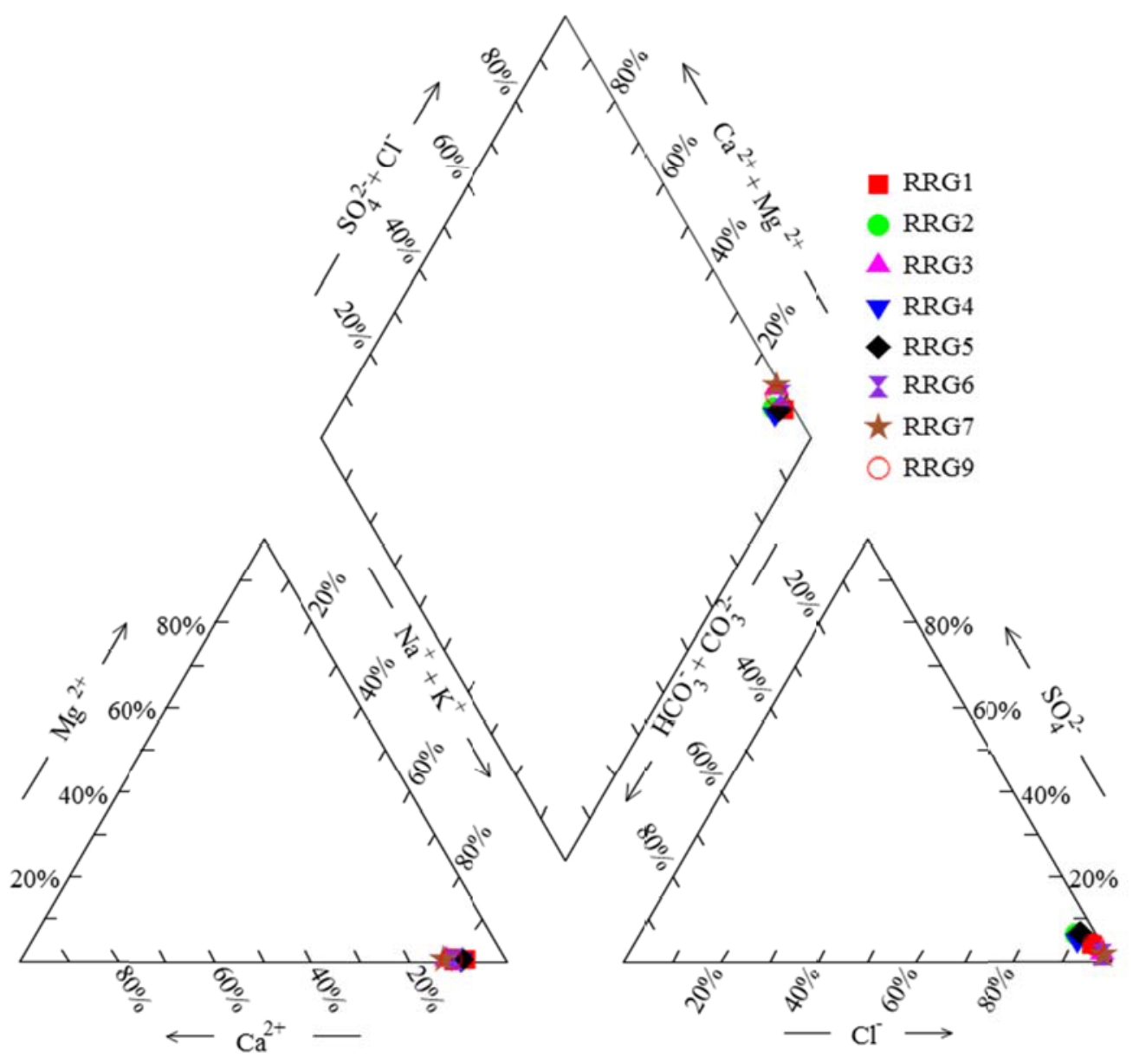

Figure G1. RRG water samples plotted on a piper diagram. 


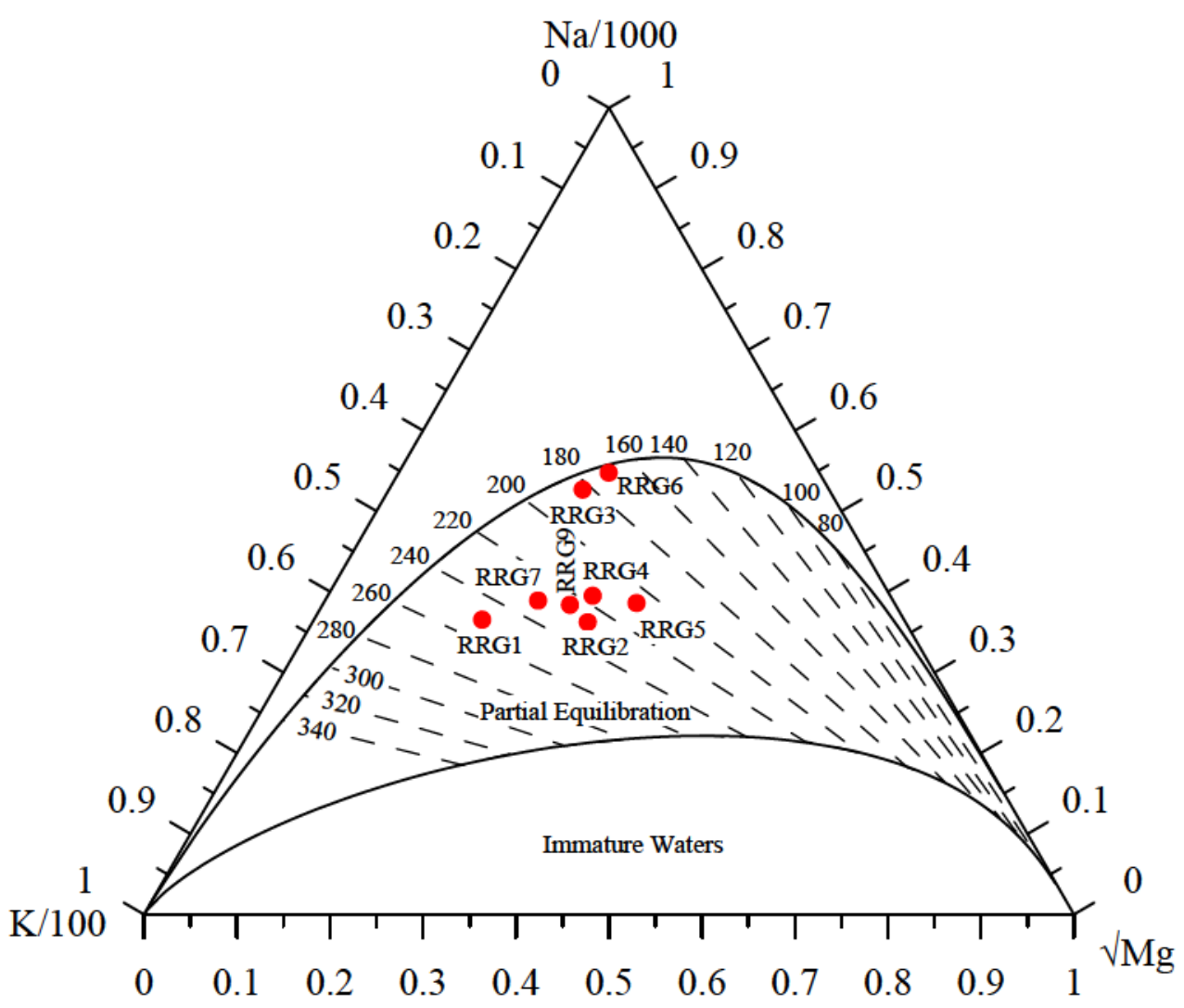

Figure G2. Giggenbach plot for Raft River geothermal wells. Water chemistries for Raft River are obtained from Dolenc et al. (1981) and Ayling and Moore (2013). Equilibration lines are derived from Giggenbach (1988).

\section{Mineral assemblages}

Rocks representing the basement and lower part of the Salt Lake Formation are considered to be the reservoir for the RRG system. Jones et al. (2011) investigated the alteration mineralogy along a newly drilled well (RRG-9). Based on their work and other information (e.g., Devine and Bonnichsen, 1980), three alternative RMAs (Table C2) from a group of mineral consisting of clays, zeolites, calcite, chalcedony, and K-feldspar are selected for MEG. Particularly, chalcedony (or quartz), feldspars, and zeolites are considered to be good MEG minerals because of their increasing solubility with increasing temperature (D'Amore et al., 1987). Although calcite shows higher tendency to re-equilibrate with onset of a new condition, it is a common mineral in most of the geothermal systems. Furthermore, it is also an important mineral for assessing the fugacity of $\mathrm{CO}_{2}$ in geothermal water during MEG optimization. Clay minerals such as illite and beidelite can be poor choices because these minerals tend to have diverse chemical composition, and it is likely that the representatives of these minerals in the thermodynamic database might not be the true members of the minerals present in the reservoir. 
Table G1. Chemistry of geothermal waters from Raft River geothermal field (mg/L) (Dolenc et al., 1981; Ayling and Moore, 2013)

\begin{tabular}{|c|c|c|c|c|c|c|c|c|}
\hline & RRG1 & RRG2 & RRG3 & RRG4 & RRG5 & RRG6 & RRG7 & RRG9 \\
\hline $\mathrm{BH}^{\mathrm{a}} \mathrm{T}\left({ }^{\circ} \mathrm{C}\right)$ & 135 & 144 & 149 & 134 & 135 & 71 & 119 & 134 \\
\hline $\mathrm{pH}$ & 7.2 & 7.6 & 7.2 & 7.5 & 7.5 & 6.5 & 7.0 & $7^{\mathrm{b}}$ \\
\hline $\mathrm{Na}$ & 670 & 387 & 1788 & 537 & 444 & 1970 & 1610 & 889 \\
\hline $\mathrm{K}$ & 83.2 & 36.5 & 90 & 43.5 & 31.9 & 81.5 & 158 & 81.1 \\
\hline $\mathrm{Ca}$ & 56.2 & 42 & 224 & 50.8 & 40.3 & 210 & 217 & 105 \\
\hline $\mathrm{Mg}$ & 0.11 & 0.1 & 0.5 & 0.15 & 0.15 & 0.66 & 0.9 & 0.38 \\
\hline $\mathrm{Li}$ & 1.89 & 1.1 & 3.1 & 1.92 & 1.58 & 4.25 & 4.44 & $\mathrm{NA}^{\mathrm{c}}$ \\
\hline $\mathrm{Cl}$ & 1181 & 577 & 3098 & 833 & 721 & 3310 & 3467 & 1445 \\
\hline $\mathrm{F}^{-}$ & 7.07 & 9.14 & 5.09 & 7.3 & 35 & 5.54 & 4.74 & 6.37 \\
\hline $\mathrm{SO}_{4}{ }^{2-}$ & 62.1 & 53 & 60 & 59.2 & 68.6 & 51.3 & 59.3 & 71 \\
\hline $\mathrm{HCO}_{3}{ }^{-}$ & 40 & 41 & 44 & 66 & 40 & 50.2 & 33 & $40^{\mathrm{b}}$ \\
\hline $\mathrm{SiO}_{2 \text { (aq) }}$ & 132 & 149 & 154 & 134 & 148 & 131 & 145 & 58.2 \\
\hline
\end{tabular}

${ }^{a}$ Bottom hole, ${ }^{b}$ not available but assumed value, ${ }^{c}$ not available and not assumed

Table G2. Alternate reservoir mineral assemblages (RMAs) used for MEG for RRG wells

\begin{tabular}{|c|l|}
\hline${ }^{1}$ RMAs & Minerals \\
\hline I & Beidelite-Mg, calcite, chalcedony, illite, mordenite-K, ${ }^{2} \mathrm{~K}-$ feldspar \\
\hline II & Calcite, chalcedony, chlorite, clinoptilolite-K, kaolinite, ${ }^{2} \mathrm{~K}$-feldspar \\
\hline III & Analcime, calcite, chalcedony, illite, laumontite, ${ }^{2} \mathrm{~K}$-feldspar \\
\hline
\end{tabular}

${ }^{1}$ Reservoir mineral assemblages, ${ }^{2}$ swapped for $\mathrm{Al}$ 
Table G3. RTEst optimized parameters ( $\mathrm{T}$ and $\left.\operatorname{logfCO} \mathrm{O}_{2}\right)$ and objective function

\begin{tabular}{|c|c|c|c|c|c|}
\hline $\mathrm{RMAs}^{\mathrm{a}}$ & Wells & $\begin{array}{l}\mathrm{T}^{\mathrm{b}} \pm \sigma^{\mathrm{c}} \\
\left({ }^{\circ} \mathrm{C}\right)\end{array}$ & $\begin{array}{c}\log f_{\mathrm{Co}_{2}} \pm \sigma^{c} \\
(\mathrm{~atm})\end{array}$ & $\begin{array}{l}\text { Objective } \\
\text { function }(\Phi)\end{array}$ & $\begin{array}{c}\text { Weighted average } \mathrm{T}_{\text {est }} \text { and } \\
\sigma\left({ }^{\circ} \mathrm{C}\right)\end{array}$ \\
\hline \multirow{8}{*}{$\begin{array}{c}\text { I } \\
\text { (Chalcedony, } \\
\text { Calcite, } \\
\text { Mordenite- } \\
\text { K, } \\
\text { Illite, } \\
\text { Beidellit- } \\
\text { Mg) }\end{array}$} & RRG1 & $132 \pm 4$ & $-1.4 \pm 0.08$ & $4.96 \mathrm{E}-03$ & \multirow[t]{8}{*}{$142 \pm 2$} \\
\hline & RRG2 & $148 \pm 5$ & $-1.15 \pm 0.11$ & 7.72E-03 & \\
\hline & RRG3 & $147 \pm 4$ & $-0.8 \pm 0.07$ & $3.50 \mathrm{E}-03$ & \\
\hline & RRG4 & $139 \pm 4$ & $-0.91 \pm 0.08$ & $5.32 \mathrm{E}-03$ & \\
\hline & RRG5 & $149 \pm 6$ & $-1.28 \pm 0.12$ & $9.18 \mathrm{E}-03$ & \\
\hline & RRG6 & $141 \pm 6$ & $-1.14 \pm 0.11$ & $8.66 \mathrm{E}-03$ & \\
\hline & RRG7 & $155 \pm 9$ & $-0.92 \pm 0.17$ & $2.17 \mathrm{E}-02$ & \\
\hline & RRG9 & $106 \pm 13$ & $-1.72 \pm 0.28$ & $6.93 \mathrm{E}-02$ & \\
\hline \multirow{8}{*}{$\begin{array}{c}\text { II } \\
\text { (Chalcedony, } \\
\text { Calcite, } \\
\text { Clinoptil-K, } \\
\text { Kaolinite, } \\
\text { Clinochl- } \\
\text { 14A) }\end{array}$} & RRG1 & $135 \pm 4$ & $-1.32 \pm 0.09$ & $8.30 \mathrm{E}-03$ & \multirow[t]{8}{*}{$146 \pm 3$} \\
\hline & RRG2 & $162 \pm 9$ & $-1.11 \pm 0.2$ & $3.43 \mathrm{E}-02$ & \\
\hline & RRG3 & $165 \pm 11$ & $-0.79 \pm 0.23$ & $4.71 \mathrm{E}-02$ & \\
\hline & RRG4 & $155 \pm 11$ & $-0.92 \pm 0.25$ & $5.43 \mathrm{E}-02$ & \\
\hline & RRG5 & $159 \pm 9$ & $-1.23 \pm 0.18$ & $2.69 \mathrm{E}-02$ & \\
\hline & RRG6 & $153 \pm 8$ & $-1.11 \pm 0.19$ & $3.22 \mathrm{E}-02$ & \\
\hline & RRG7 & $166 \pm 10$ & $-0.84 \pm 0.22$ & $4.21 \mathrm{E}-02$ & \\
\hline & RRG9 & $121 \pm 14$ & $-1.83 \pm 0.35$ & $1.28 \mathrm{E}-01$ & \\
\hline \multirow{8}{*}{$\begin{array}{c}\text { III } \\
\text { (Chalcedony, } \\
\text { Calcite, } \\
\text { Laumontite, } \\
\text { Analcime, } \\
\text { Illite) }\end{array}$} & RRG1 & $137 \pm 11$ & $-1.34 \pm 0.29$ & $3.81 \mathrm{E}-02$ & \multirow[t]{8}{*}{$147 \pm 4$} \\
\hline & RRG2 & $153 \pm 13$ & $-1.10 \pm 0.31$ & $3.87 \mathrm{E}-02$ & \\
\hline & RRG3 & $153 \pm 8$ & $-0.73 \pm 0.19$ & $1.67 \mathrm{E}-02$ & \\
\hline & RRG4 & $146 \pm 12$ & $-0.81 \pm 0.29$ & $3.66 \mathrm{E}-02$ & \\
\hline & RRG5 & $152 \pm 11$ & $-1.27 \pm 0.28$ & $3.04 \mathrm{E}-02$ & \\
\hline & RRG6 & $144 \pm 8$ & $-1.13 \pm 0.2$ & $1.86 \mathrm{E}-02$ & \\
\hline & RRG7 & $160 \pm 14$ & $-0.91 \pm 0.34$ & $4.59 \mathrm{E}-02$ & \\
\hline & RRG9 & $113 \pm 17$ & $-1.76 \pm 0.48$ & $1.15 \mathrm{E}-01$ & \\
\hline
\end{tabular}

${ }^{\mathrm{a}}$ Reservoir mineral assemblages. I: beidelite- $\mathrm{Mg}$, calcite, chalcedony, illite, mordenite-K, and $\mathrm{K}-$ feldspar; II: calcite, chalcedony, chlorite, clinoptilolite-K, kaolinite, K-feldspar; and III:

analcime, calcite, chalcedony, illite, laumontite, $\mathrm{K}$-feldspar. ${ }^{\mathrm{b}} \mathrm{RTEst}$ estimated temperature. ${ }^{\mathrm{C}} \sigma$ is standard error in each RTEst optimized parameter (temperature, mass of water, and fugacity of $\mathrm{CO}_{2}$ ). ${ }^{\mathrm{d}}$ Positive and negative numbers indicate the fraction of cold water present and steam-loss per kilogram of sampled water, respectively. 
Table G4. RTEst optimized parameters ( $\mathrm{T}$, mass of water, and $\operatorname{logfCO} \mathrm{O}_{2}$ ) and objective function

\begin{tabular}{|c|c|c|c|c|c|}
\hline RMAs $^{2}$ & Wells & $\mathrm{T}^{\mathrm{b}} \pm \sigma^{\mathrm{c}}\left({ }^{\circ} \mathrm{C}\right)$ & $\begin{array}{c}\mathrm{M}_{\mathrm{H}_{2} \mathrm{O}}{ }^{d} \pm \sigma^{c} \\
(\mathrm{~kg})\end{array}$ & $\begin{array}{c}\log f_{\mathrm{CO}_{2}} \pm \sigma^{c} \\
(\mathrm{~atm})\end{array}$ & $\begin{array}{c}\text { Objective } \\
\text { function }(\Phi)\end{array}$ \\
\hline \multirow{8}{*}{$\begin{array}{c}\text { I } \\
\text { (Chalcedony, } \\
\text { Calcite, } \\
\text { Mordenite- } \\
\mathrm{K}, \\
\text { Illite, } \\
\text { Beidellit- } \\
\mathrm{Mg} \text { ) }\end{array}$} & RRG1 & $144 \pm 5$ & $0.76 \pm 0.07$ & $-0.9 \pm 0.17$ & $8.91 \mathrm{E}-04$ \\
\hline & RRG2 & $165 \pm 8$ & $0.71 \pm 0.1$ & $-0.52 \pm 0.26$ & $1.82 \mathrm{E}-03$ \\
\hline & RRG3 & $157 \pm 7$ & $0.83 \pm 0.11$ & $-0.48 \pm 0.25$ & $1.79 \mathrm{E}-03$ \\
\hline & RRG4 & $151 \pm 7$ & $0.77 \pm 0.1$ & $-0.44 \pm 0.25$ & $1.83 \mathrm{E}-03$ \\
\hline & RRG5 & $169 \pm 8$ & $0.67 \pm 0.09$ & $-0.5 \pm 0.29$ & $1.83 \mathrm{E}-03$ \\
\hline & RRG6 & $159 \pm 7$ & $0.69 \pm 0.09$ & $-0.47 \pm 0.23$ & $1.61 \mathrm{E}-03$ \\
\hline & RRG7 & $187 \pm 8$ & $0.55 \pm 0.07$ & $0.2 \pm 0.27$ & $2.08 \mathrm{E}-03$ \\
\hline & RRG9 & $160 \pm 9$ & $0.31 \pm 0.04$ & $0.34 \pm 0.29$ & $2.60 \mathrm{E}-03$ \\
\hline \multirow{8}{*}{$\begin{array}{c}\text { II } \\
\text { (Chalcedony, } \\
\text { Calcite, } \\
\text { Clinoptil-K, } \\
\text { Kaolinite, } \\
\text { Clinochl- } \\
\text { 14A) }\end{array}$} & RRG1 & $154 \pm 9$ & $0.71 \pm 0.11$ & $-0.69 \pm 0.30$ & $2.43 \mathrm{E}-3$ \\
\hline & RRG2 & $160 \pm 34$ & $1.02 \pm 0.52$ & $-1.16 \pm 1.01$ & $3.42 \mathrm{E}-2$ \\
\hline & RRG3 & $157 \pm 43$ & $1.13 \pm 0.79$ & $-1.01 \pm 1.32$ & $4.63 \mathrm{E}-2$ \\
\hline & RRG4 & $146 \pm 42$ & $1.18 \pm 0.83$ & $-1.23 \pm 1.35$ & $5.25 \mathrm{E}-2$ \\
\hline & RRG5 & $160 \pm 32$ & $0.99 \pm 0.42$ & $-1.21 \pm 0.87$ & $2.69 \mathrm{E}-2$ \\
\hline & RRG6 & $163 \pm 37$ & $0.85 \pm 0.48$ & $-0.81 \pm 1.09$ & $3.07 \mathrm{E}-2$ \\
\hline & RRG7 & $189 \pm 38$ & $0.71 \pm 0.36$ & $-0.18 \pm 1.05$ & $3.38 \mathrm{E}-2$ \\
\hline & RRG9 & $152 \pm 69$ & $0.56 \pm 0.60$ & $-0.79 \pm 2.07$ & $1.09 \mathrm{E}-1$ \\
\hline \multirow{8}{*}{$\begin{array}{c}\text { III } \\
\text { (Chalcedony, } \\
\text { Calcite, } \\
\text { Laumontite, } \\
\text { Analcime, } \\
\text { Illite) }\end{array}$} & RRG1 & $175 \pm 40$ & $0.49 \pm 0.32$ & $0.12 \pm 1.37$ & $2.28 \mathrm{E}-2$ \\
\hline & RRG2 & $200 \pm 40$ & $0.44 \pm 0.23$ & $0.75 \pm 1.63$ & $2.06 \mathrm{E}-2$ \\
\hline & RRG3 & $185 \pm 23$ & $0.58 \pm 0.20$ & $0.41 \pm 0.80$ & $7.29 \mathrm{E}-3$ \\
\hline & RRG4 & $185 \pm 36$ & $0.51 \pm 0.25$ & $0.65 \pm 1.38$ & $1.94 \mathrm{E}-2$ \\
\hline & RRG5 & $182 \pm 22$ & $0.62 \pm 0.12$ & $-0.05 \pm 1.36$ & $1.53 \mathrm{E}-2$ \\
\hline & RRG6 & $183 \pm 17$ & $0.50 \pm 0.13$ & $0.29 \pm 0.60$ & $4.12 \mathrm{E}-3$ \\
\hline & RRG7 & $214 \pm 30$ & $0.42 \pm 0.17$ & $1.11 \pm 1.27$ & $1.52 \mathrm{E}-2$ \\
\hline & RRG9 & $191 \pm 36$ & $0.25 \pm 0.10$ & $1.38 \pm 1.44$ & $2.64 \mathrm{E}-2$ \\
\hline
\end{tabular}

${ }^{a}$ Reservoir mineral assemblages. I: beidelite-Mg, calcite, chalcedony, illite, mordenite-K, and Kfeldspar; II: calcite, chalcedony, chlorite, clinoptilolite-K, kaolinite, K-feldspar; and III:

analcime, calcite, chalcedony, illite, laumontite, K-feldspar. ${ }^{b} \mathrm{RTEst}$ estimated temperature. ${ }^{\mathrm{c}} \sigma$ is standard error in each RTEst optimized parameter (temperature, mass of water, and fugacity of $\left.\mathrm{CO}_{2}\right) .{ }^{\mathrm{d}}$ Optimized mass of thermal water. 

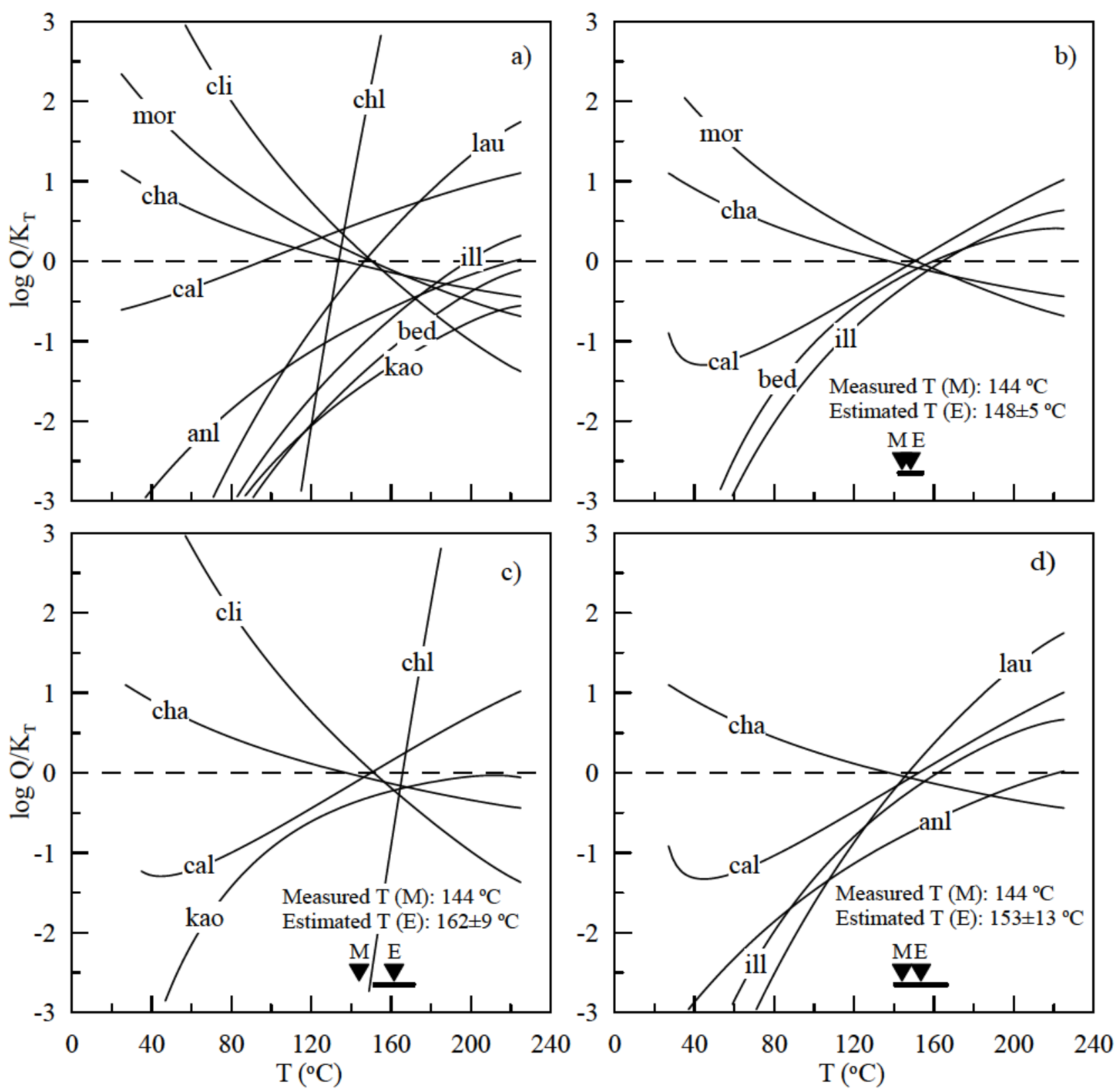

Figure G3. MEG temperature estimate for RRG2 with optimization on $\mathrm{T}$ and $\operatorname{logfCO} \mathrm{C}_{2}$. The $\log$ $\mathrm{Q} / \mathrm{K}_{\mathrm{T}}$ curves for minerals calculated using original water chemistry with $\mathrm{K}$-feldspar used for FixAl (a), optimized $\log \mathrm{Q} / \mathrm{K}_{\mathrm{T}}$ curves for mineral assemblages I (b), II (c), and III (d) c) (Minerals - anl: analcime, bed: beidelite-Mg, cal: calcite, cha: chalcedony, chl: chlorite, cliclinoptilolite-K ill: illite, kao: kaolinte, lau: laumontite, mor: mordenite-K). 

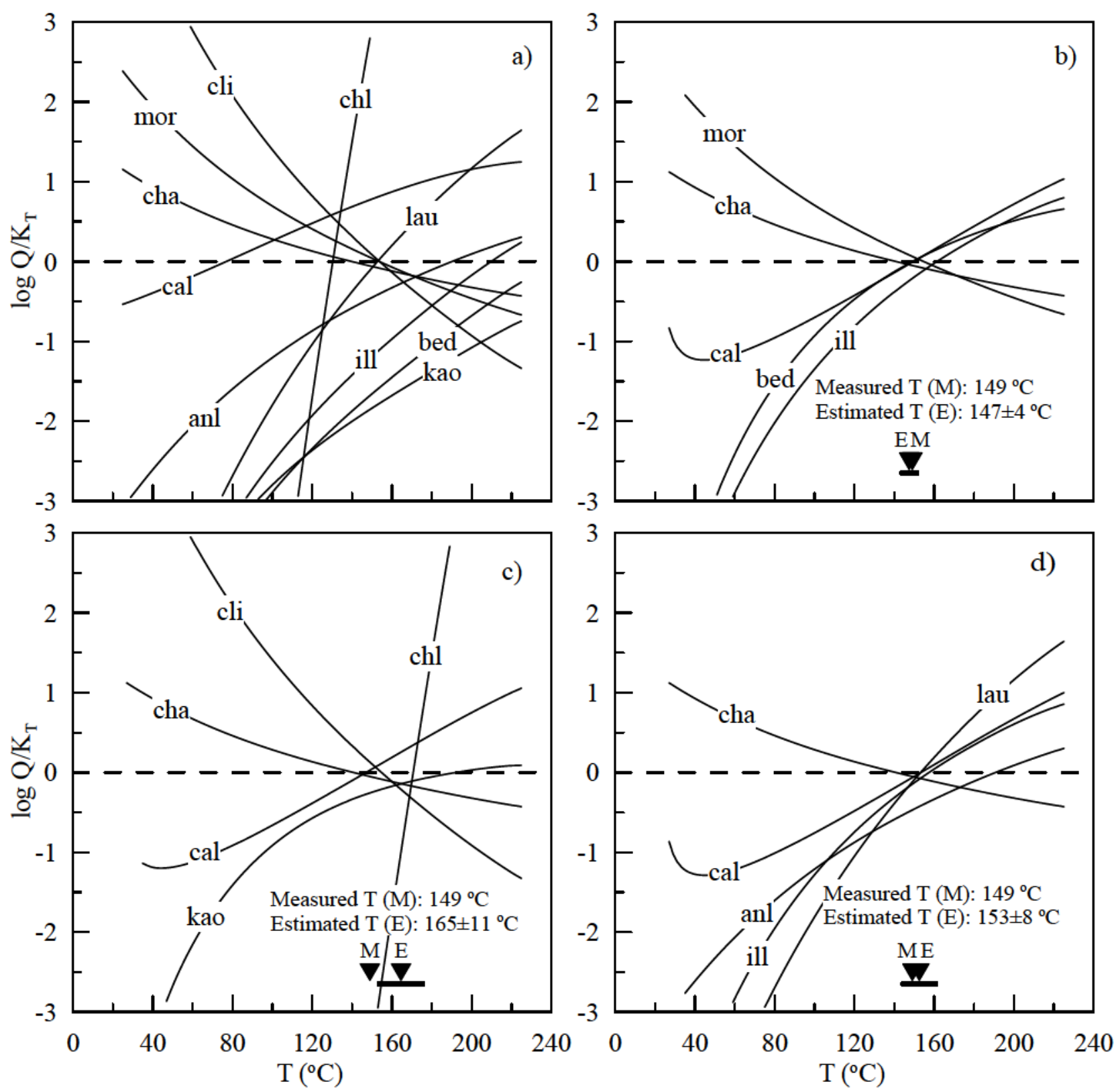

Figure G4. MEG temperature estimate for RRG3 with optimization on $\mathrm{T}$ and $\operatorname{logfCO}$. The $\log$ $\mathrm{Q} / \mathrm{K}_{\mathrm{T}}$ curves for minerals calculated using original water chemistry with $\mathrm{K}$-feldspar used for FixAl (a), optimized $\log \mathrm{Q} / \mathrm{K}_{\mathrm{T}}$ curves for mineral assemblages I (b), II (c), and III (d) c) (Minerals - anl: analcime, bed: beidelite-Mg, cal: calcite, cha: chalcedony, chl: chlorite, cliclinoptilolite-K ill: illite, kao: kaolinte, lau: laumontite, mor: mordenite-K). 

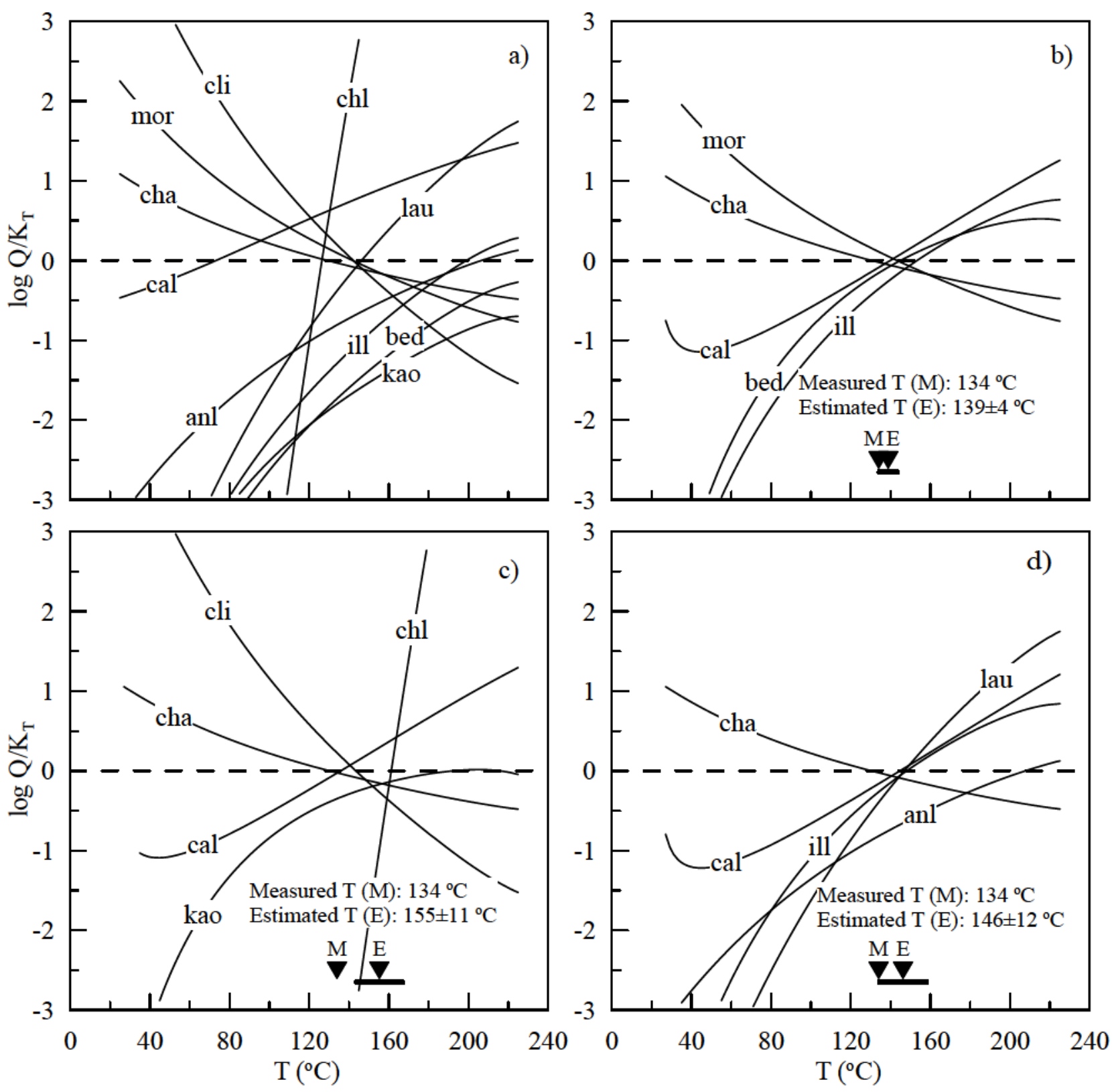

Figure G5. MEG temperature estimate for RRG4 with optimization on $\mathrm{T}$ and $\operatorname{logfCO}{ }_{2}$. The $\log$ $\mathrm{Q} / \mathrm{K}_{\mathrm{T}}$ curves for minerals calculated using original water chemistry with $\mathrm{K}$-feldspar used for FixAl (a), optimized $\log \mathrm{Q} / \mathrm{K}_{\mathrm{T}}$ curves for mineral assemblages I (b), II (c), and III (d) c) (Minerals - anl: analcime, bed: beidelite-Mg, cal: calcite, cha: chalcedony, chl: chlorite, cliclinoptilolite-K ill: illite, kao: kaolinte, lau: laumontite, mor: mordenite-K). 

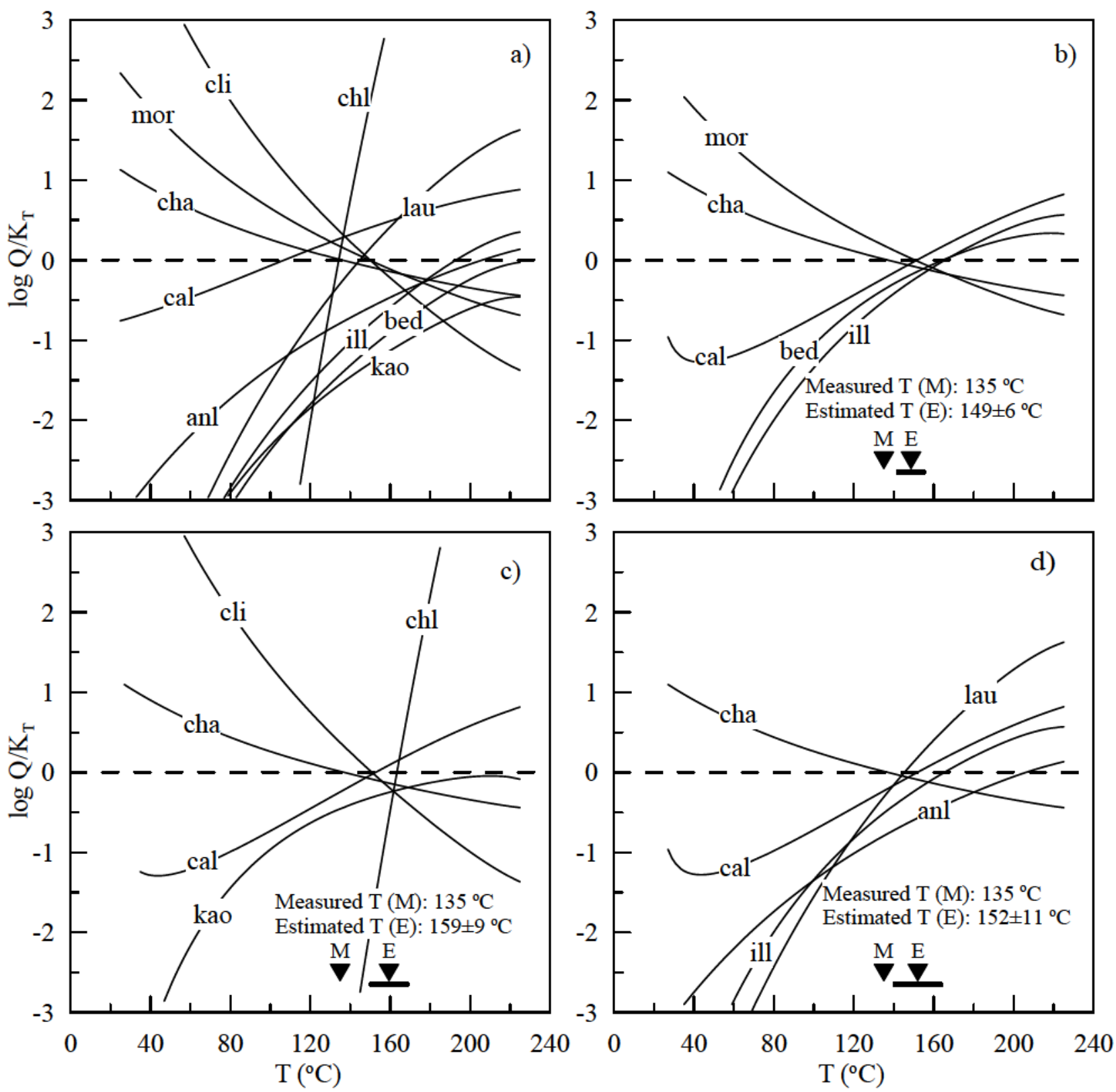

Figure G6. MEG temperature estimate for RRG5 with optimization on $\mathrm{T}$ and $\operatorname{logfCO}{ }_{2}$. The $\log$ $\mathrm{Q} / \mathrm{K}_{\mathrm{T}}$ curves for minerals calculated using original water chemistry with $\mathrm{K}$-feldspar used for FixAl (a), optimized $\log \mathrm{Q} / \mathrm{K}_{\mathrm{T}}$ curves for mineral assemblages I (b), II (c), and III (d) c) (Minerals - anl: analcime, bed: beidelite-Mg, cal: calcite, cha: chalcedony, chl: chlorite, cliclinoptilolite-K ill: illite, kao: kaolinte, lau: laumontite, mor: mordenite-K). 

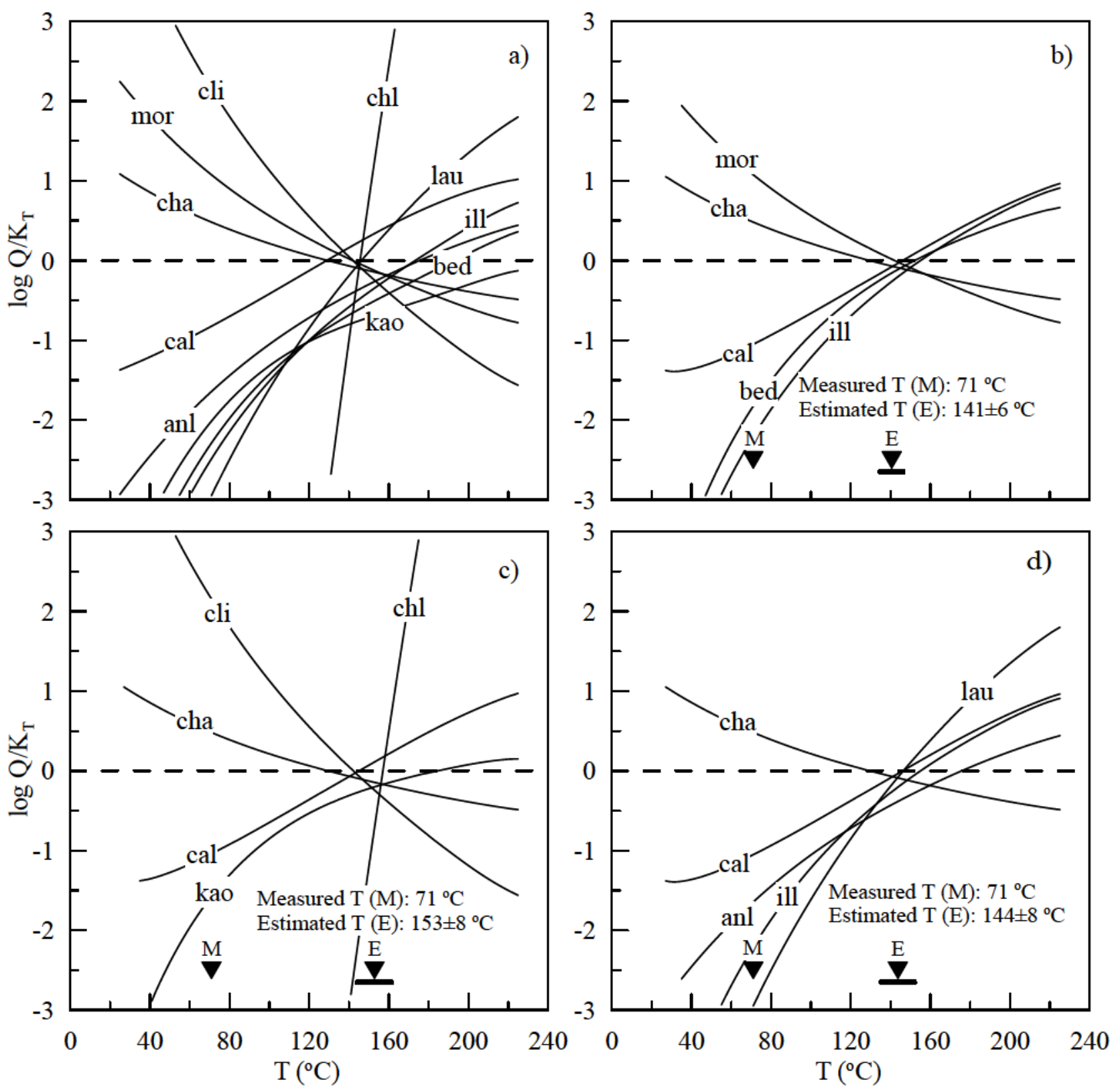

Figure G7. MEG temperature estimate for RRG6 with optimization on $\mathrm{T}$ and $\operatorname{logfCO}{ }_{2}$. The $\log$ $\mathrm{Q} / \mathrm{K}_{\mathrm{T}}$ curves for minerals calculated using original water chemistry with $\mathrm{K}$-feldspar used for FixAl (a), optimized $\log \mathrm{Q} / \mathrm{K}_{\mathrm{T}}$ curves for mineral assemblages I (b), II (c), and III (d) c) (Minerals - anl: analcime, bed: beidelite-Mg, cal: calcite, cha: chalcedony, chl: chlorite, cliclinoptilolite-K ill: illite, kao: kaolinte, lau: laumontite, mor: mordenite-K). 

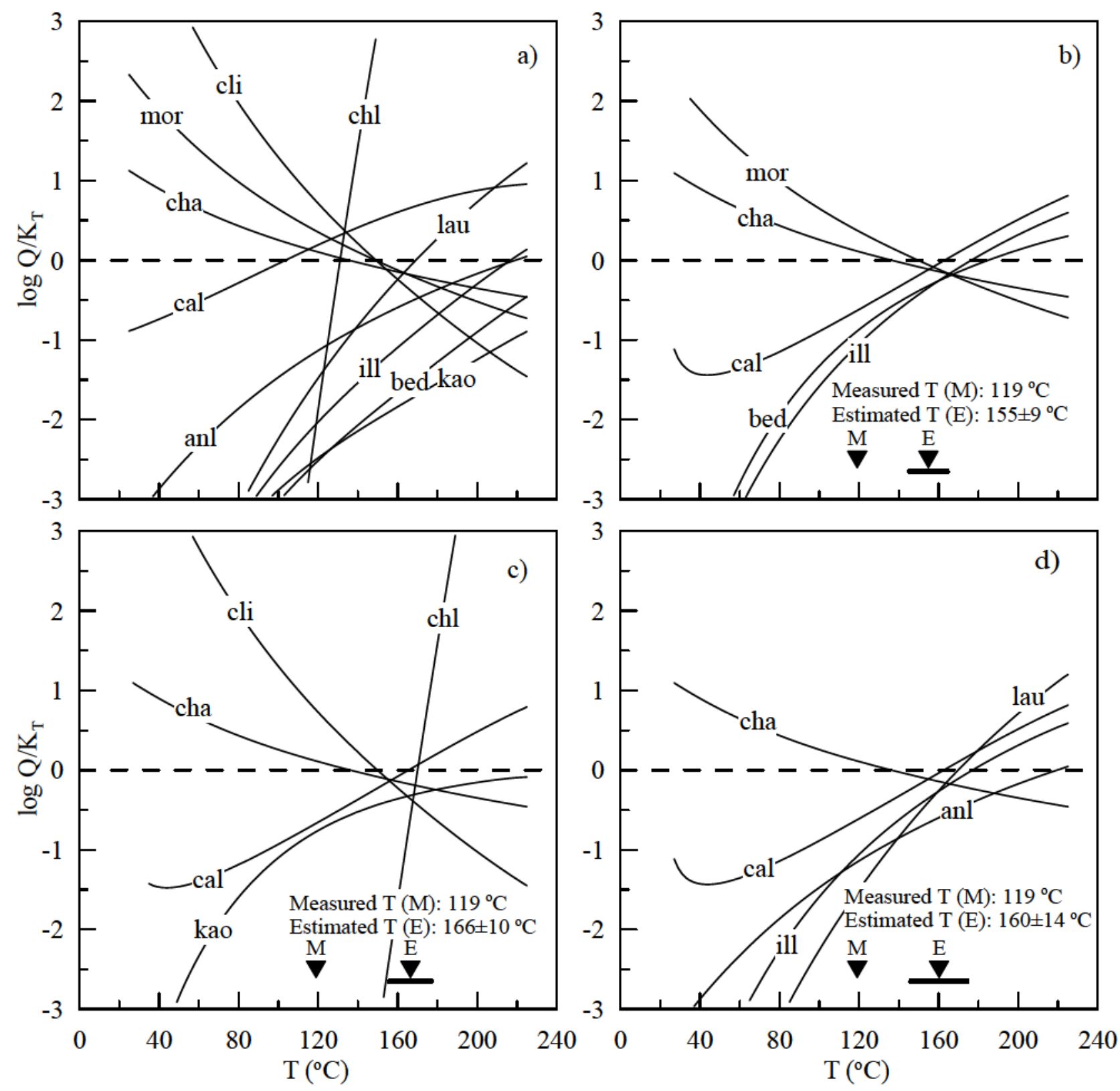

Figure G8. MEG temperature estimate for RRG7 with optimization on $\mathrm{T}$ and $\operatorname{logfCO}{ }_{2}$. The log $\mathrm{Q} / \mathrm{K}_{\mathrm{T}}$ curves for minerals calculated using original water chemistry with $\mathrm{K}$-feldspar used for FixAl (a), optimized $\log \mathrm{Q} / \mathrm{K}_{\mathrm{T}}$ curves for mineral assemblages I (b), II (c), and III (d) c) (Minerals - anl: analcime, bed: beidelite-Mg, cal: calcite, cha: chalcedony, chl: chlorite, cliclinoptilolite-K ill: illite, kao: kaolinte, lau: laumontite, mor: mordenite-K). 

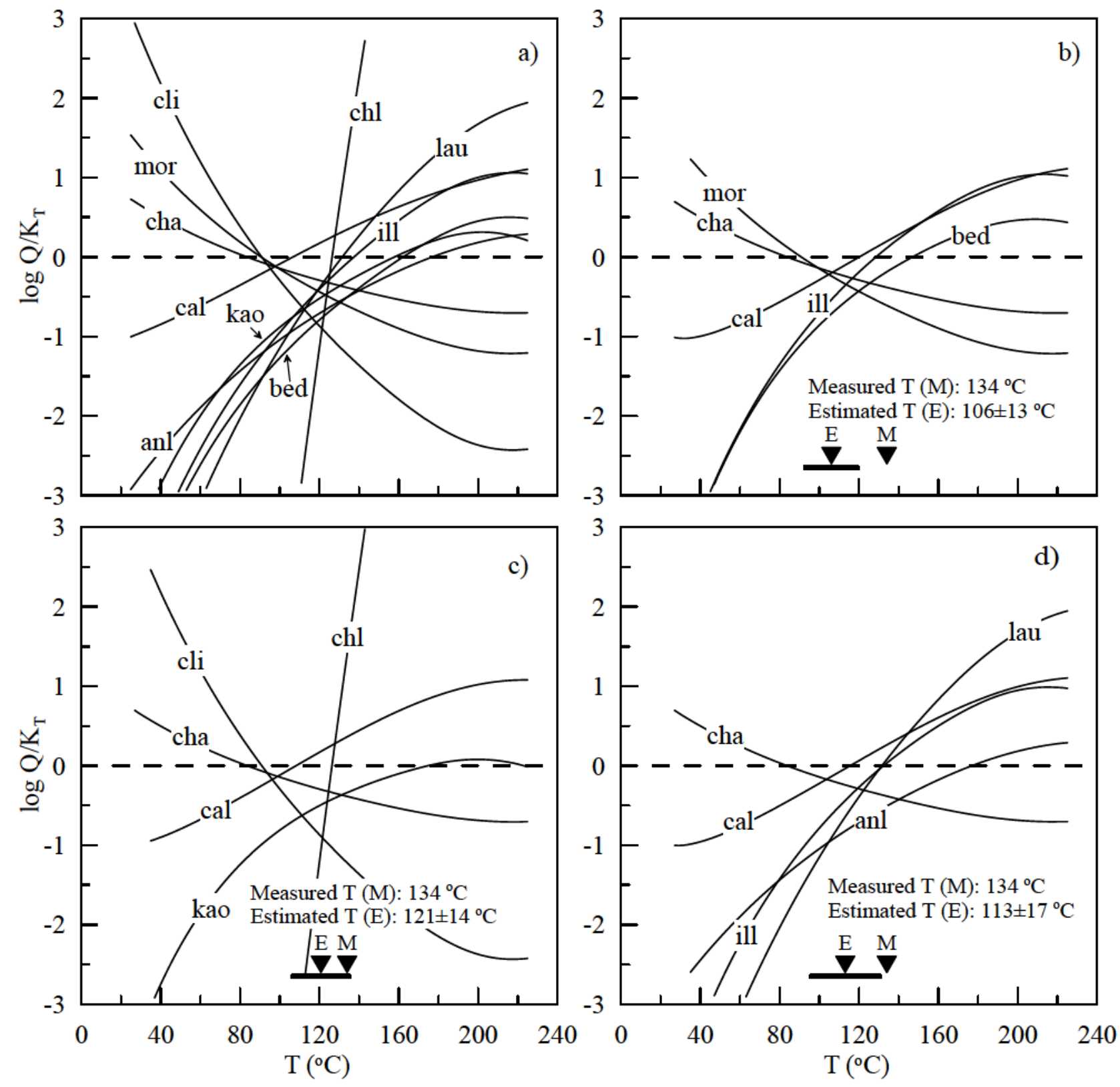

Figure G9. MEG temperature estimate for RRG9 with optimization on T and $\operatorname{logfCO}{ }_{2}$. The $\log$ $\mathrm{Q} / \mathrm{K}_{\mathrm{T}}$ curves for minerals calculated using original water chemistry with $\mathrm{K}$-feldspar used for FixAl (a), optimized $\log \mathrm{Q} / \mathrm{K}_{\mathrm{T}}$ curves for mineral assemblages I (b), II (c), and III (d) c) (Minerals - anl: analcime, bed: beidelite-Mg, cal: calcite, cha: chalcedony, chl: chlorite, cliclinoptilolite-K ill: illite, kao: kaolinte, lau: laumontite, mor: mordenite-K). 

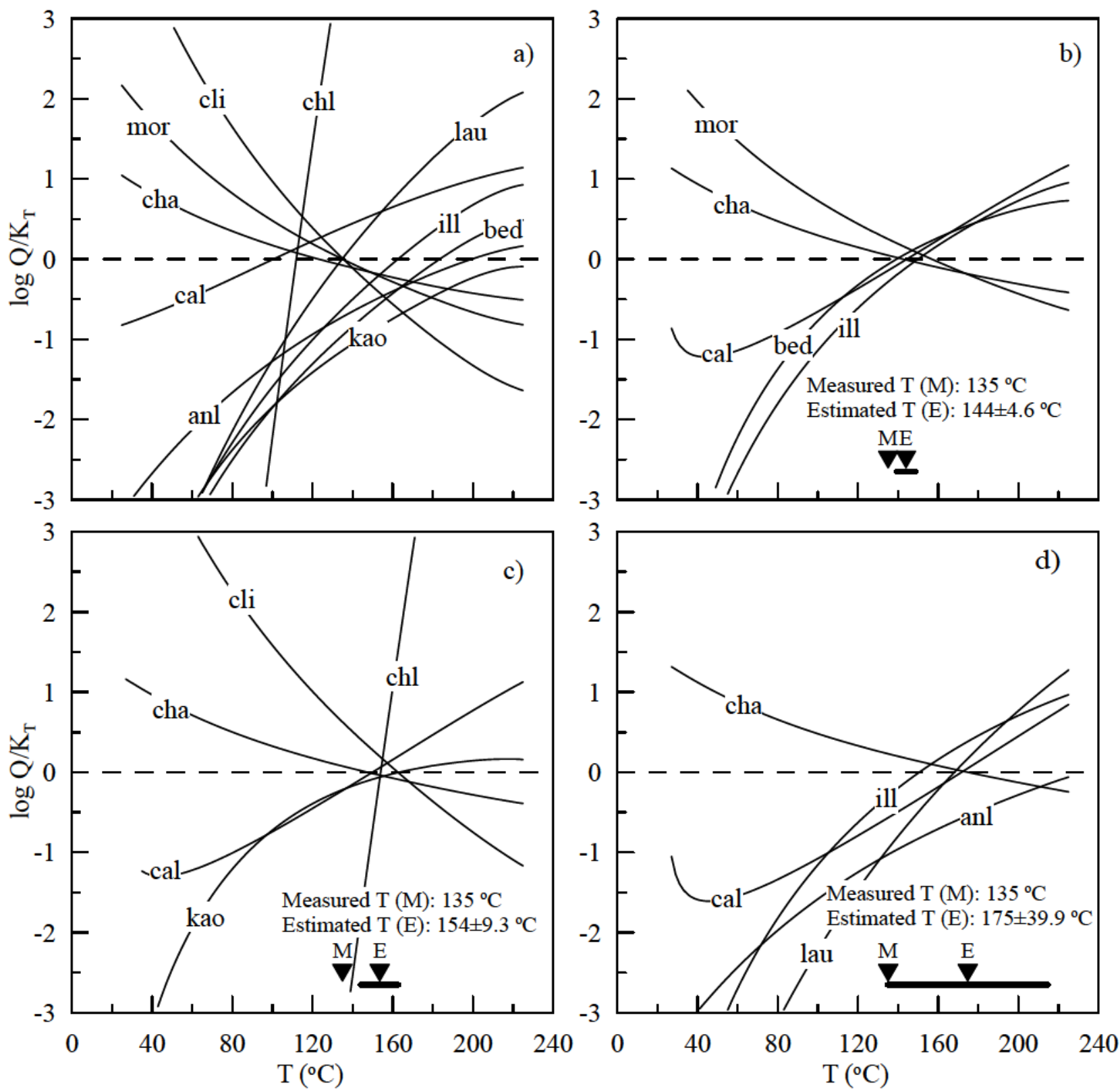

Figure G10. MEG temperature estimate for RRG1 with optimization on T, mass of water, and $\operatorname{logfCO} 2$. The $\log \mathrm{Q} / \mathrm{K}_{\mathrm{T}}$ curves for minerals calculated using original water chemistry with $\mathrm{K}$ feldspar used for FixAl (a), optimized $\log \mathrm{Q} / \mathrm{K}_{\mathrm{T}}$ curves for mineral assemblages I (b), II (c), and III (d) c) (Minerals - anl: analcime, bed: beidelite-Mg, cal: calcite, cha: chalcedony, chl: chlorite, cli-clinoptilolite-K ill: illite, kao: kaolinte, lau: laumontite, mor: mordenite-K). 

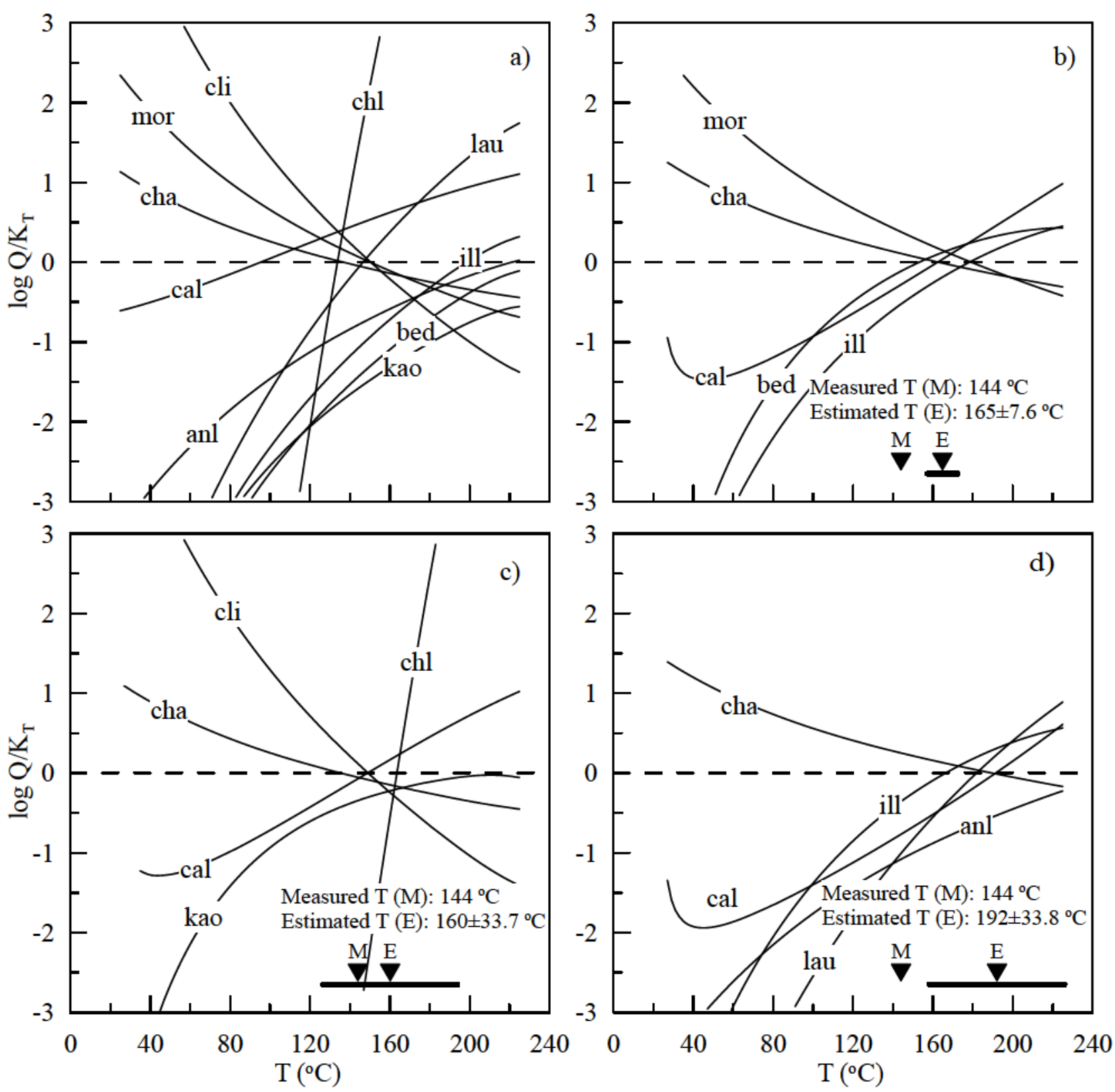

Figure G11. MEG temperature estimate for RRG2 with optimization on T, mass of water, and $\operatorname{logfCO} 2$. The $\log \mathrm{Q} / \mathrm{K}_{\mathrm{T}}$ curves for minerals calculated using original water chemistry with $\mathrm{K}$ feldspar used for FixAl (a), optimized $\log \mathrm{Q} / \mathrm{K}_{\mathrm{T}}$ curves for mineral assemblages I (b), II (c), and III (d) c) (Minerals - anl: analcime, bed: beidelite-Mg, cal: calcite, cha: chalcedony, chl: chlorite, cli-clinoptilolite-K ill: illite, kao: kaolinte, lau: laumontite, mor: mordenite-K). 

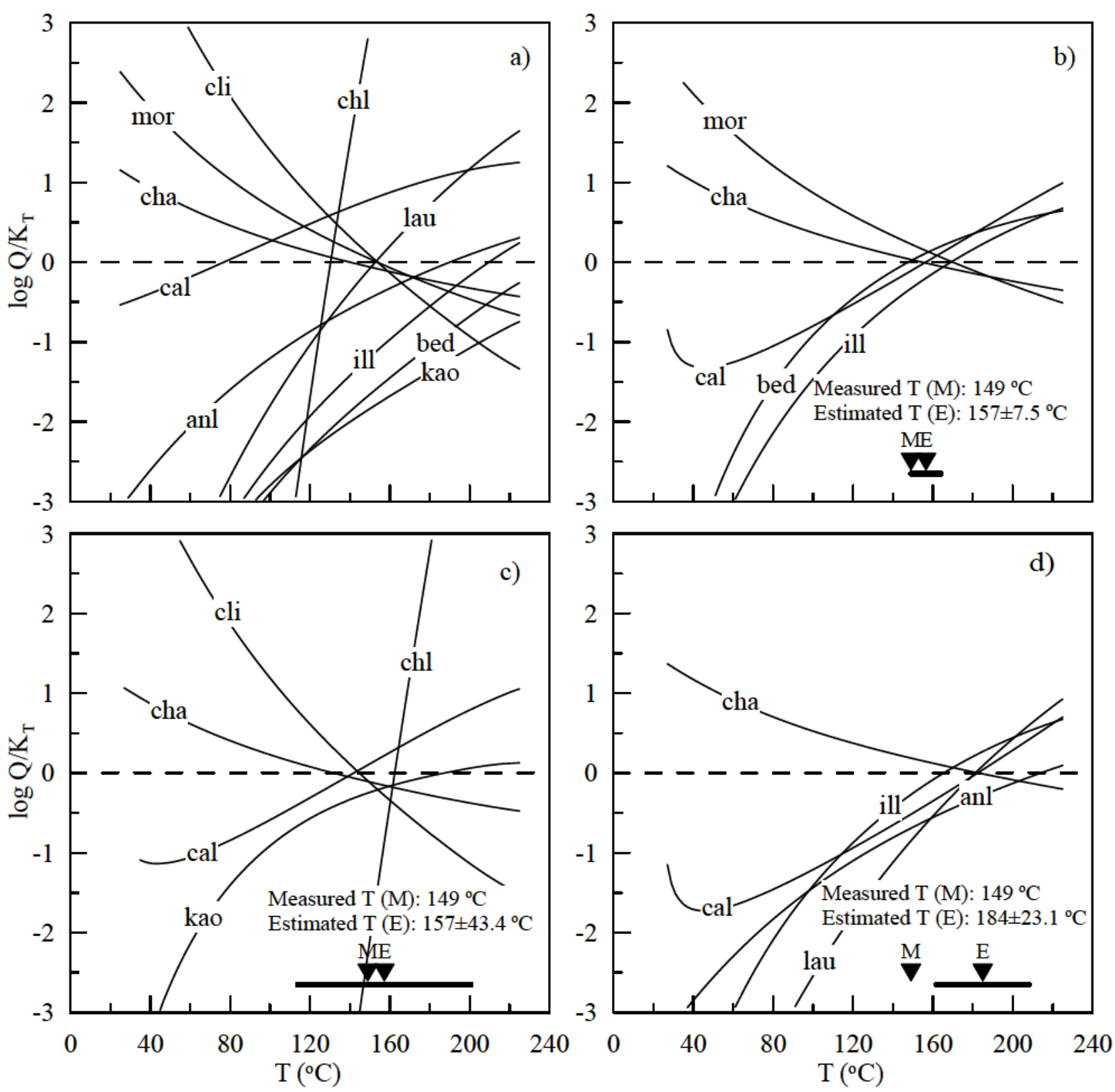

Figure G12. MEG temperature estimate for RRG3 with optimization on T, mass of water, and $\operatorname{logfCO} 2$. The $\log \mathrm{Q} / \mathrm{K}_{\mathrm{T}}$ curves for minerals calculated using original water chemistry with $\mathrm{K}$ feldspar used for FixAl (a), optimized $\log \mathrm{Q} / \mathrm{K}_{\mathrm{T}}$ curves for mineral assemblages I (b), II (c), and III (d) c) (Minerals - anl: analcime, bed: beidelite-Mg, cal: calcite, cha: chalcedony, chl: chlorite, cli-clinoptilolite-K ill: illite, kao: kaolinte, lau: laumontite, mor: mordenite-K). 

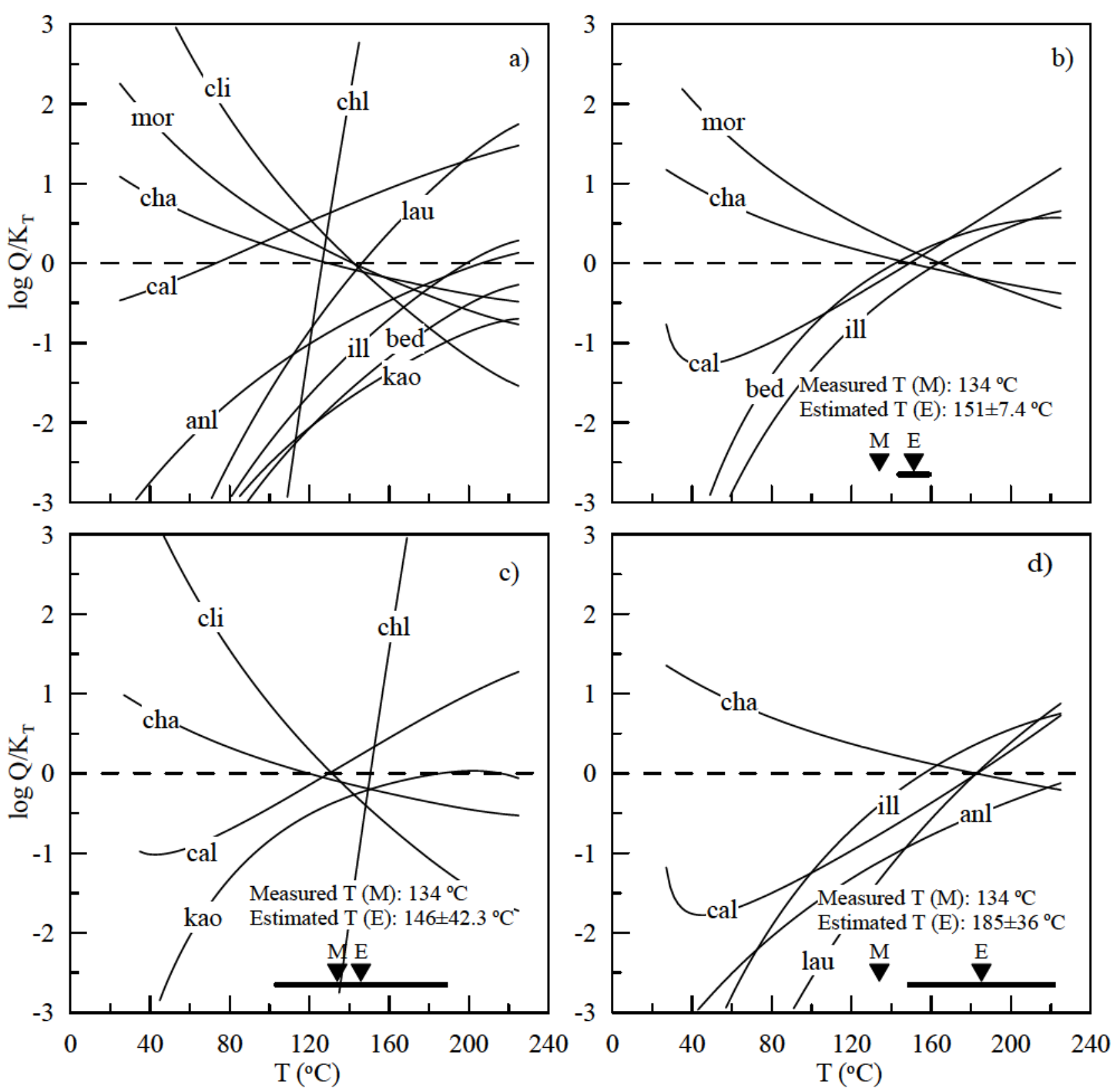

Figure G13. MEG temperature estimate for RRG4 with optimization on T, mass of water, and $\operatorname{logfCO} 2$. The $\log \mathrm{Q} / \mathrm{K}_{\mathrm{T}}$ curves for minerals calculated using original water chemistry with $\mathrm{K}$ feldspar used for FixAl (a), optimized $\log \mathrm{Q} / \mathrm{K}_{\mathrm{T}}$ curves for mineral assemblages I (b), II (c), and III (d) c) (Minerals - anl: analcime, bed: beidelite-Mg, cal: calcite, cha: chalcedony, chl: chlorite, cli-clinoptilolite-K ill: illite, kao: kaolinte, lau: laumontite, mor: mordenite-K). 

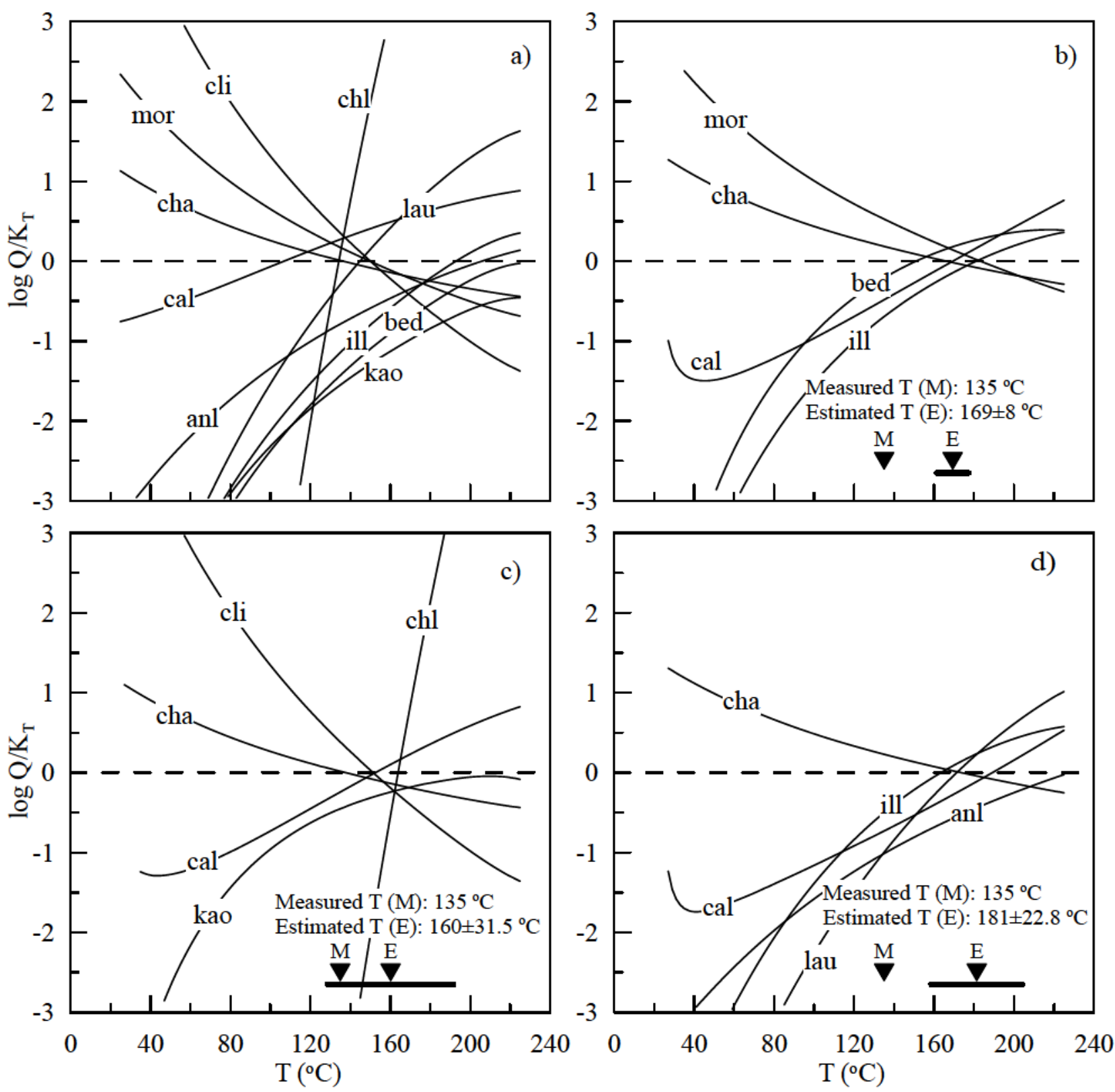

Figure G14. MEG temperature estimate for RRG5 with optimization on T, mass of water, and $\operatorname{logfCO} 2$. The $\log \mathrm{Q} / \mathrm{K}_{\mathrm{T}}$ curves for minerals calculated using original water chemistry with $\mathrm{K}$ feldspar used for FixAl (a), optimized $\log \mathrm{Q} / \mathrm{K}_{\mathrm{T}}$ curves for mineral assemblages I (b), II (c), and III (d) c) (Minerals - anl: analcime, bed: beidelite-Mg, cal: calcite, cha: chalcedony, chl: chlorite, cli-clinoptilolite-K ill: illite, kao: kaolinte, lau: laumontite, mor: mordenite-K). 

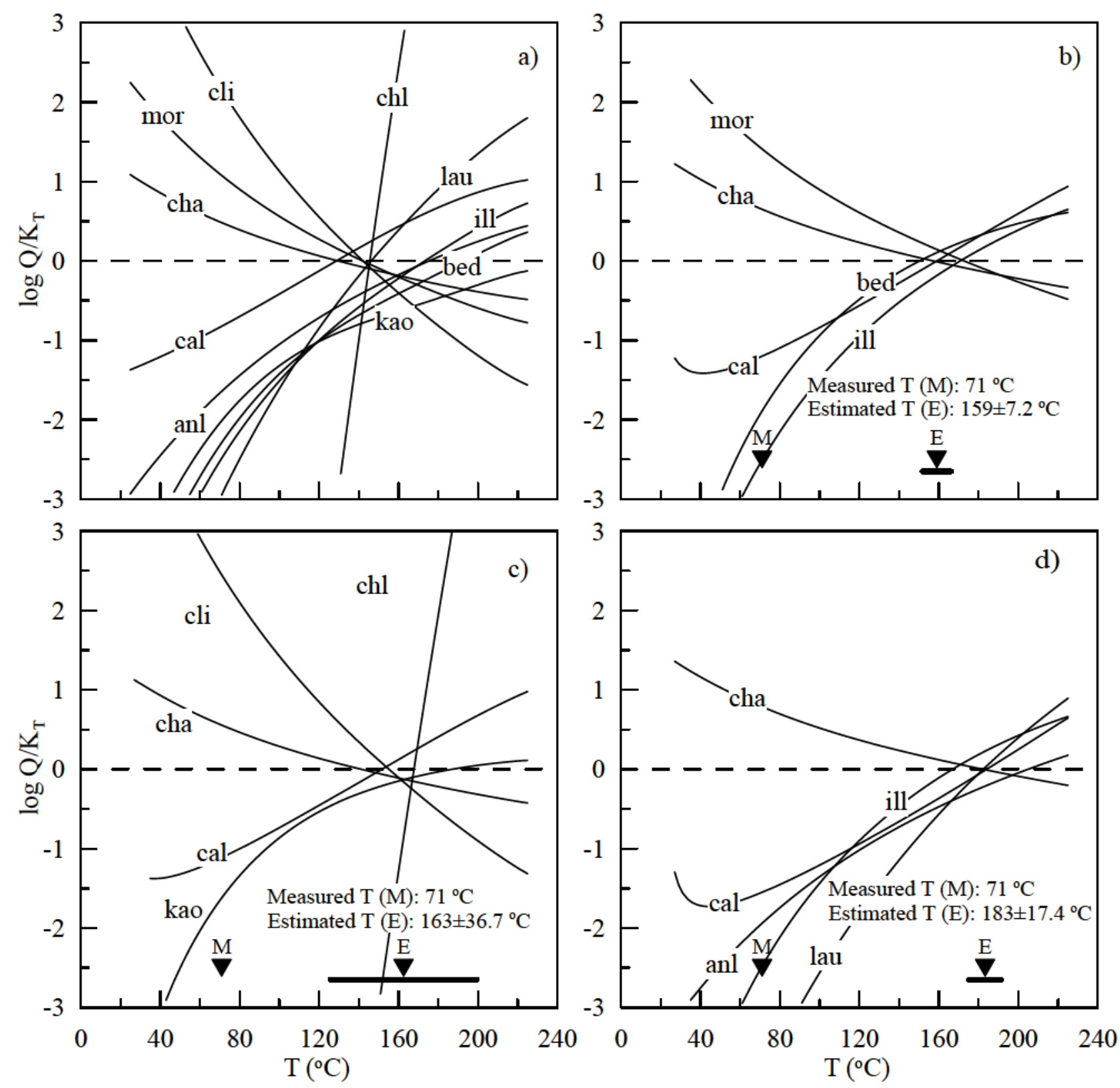

Figure G15. MEG temperature estimate for RRG6 with optimization on T, mass of water, and $\operatorname{logfCO} 2$. The $\log \mathrm{Q} / \mathrm{K}_{\mathrm{T}}$ curves for minerals calculated using original water chemistry with $\mathrm{K}$ feldspar used for FixAl (a), optimized $\log \mathrm{Q} / \mathrm{K}_{\mathrm{T}}$ curves for mineral assemblages I (b), II (c), and III (d) c) (Minerals - anl: analcime, bed: beidelite-Mg, cal: calcite, cha: chalcedony, chl: chlorite, cli-clinoptilolite-K ill: illite, kao: kaolinte, lau: laumontite, mor: mordenite-K). 

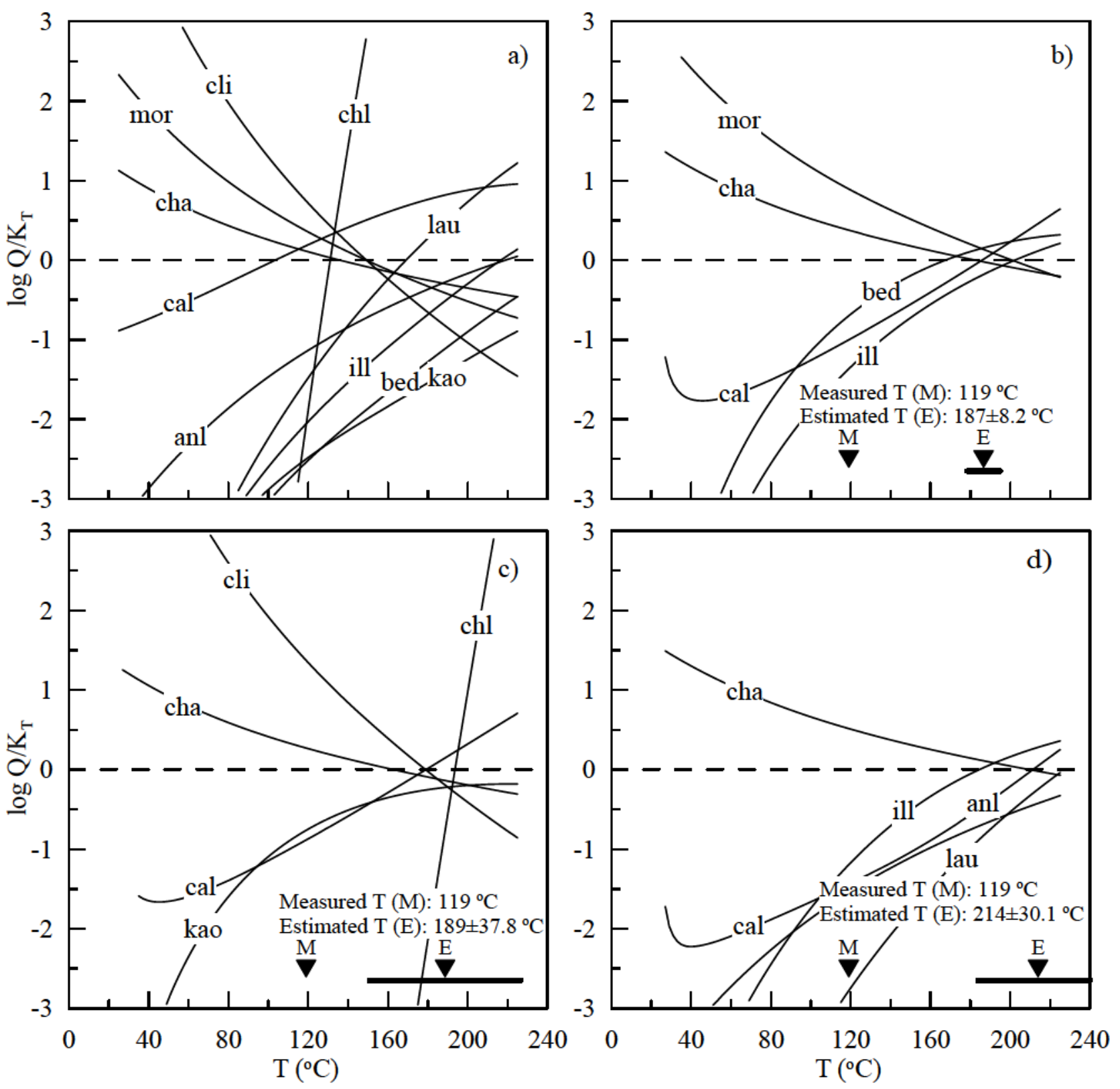

Figure G16. MEG temperature estimate for RRG7 with optimization on T, mass of water, and $\operatorname{logfCO} 2$. The $\log \mathrm{Q} / \mathrm{K}_{\mathrm{T}}$ curves for minerals calculated using original water chemistry with $\mathrm{K}$ feldspar used for FixAl (a), optimized $\log \mathrm{Q} / \mathrm{K}_{\mathrm{T}}$ curves for mineral assemblages I (b), II (c), and III (d) c) (Minerals - anl: analcime, bed: beidelite-Mg, cal: calcite, cha: chalcedony, chl: chlorite, cli-clinoptilolite-K ill: illite, kao: kaolinte, lau: laumontite, mor: mordenite-K). 

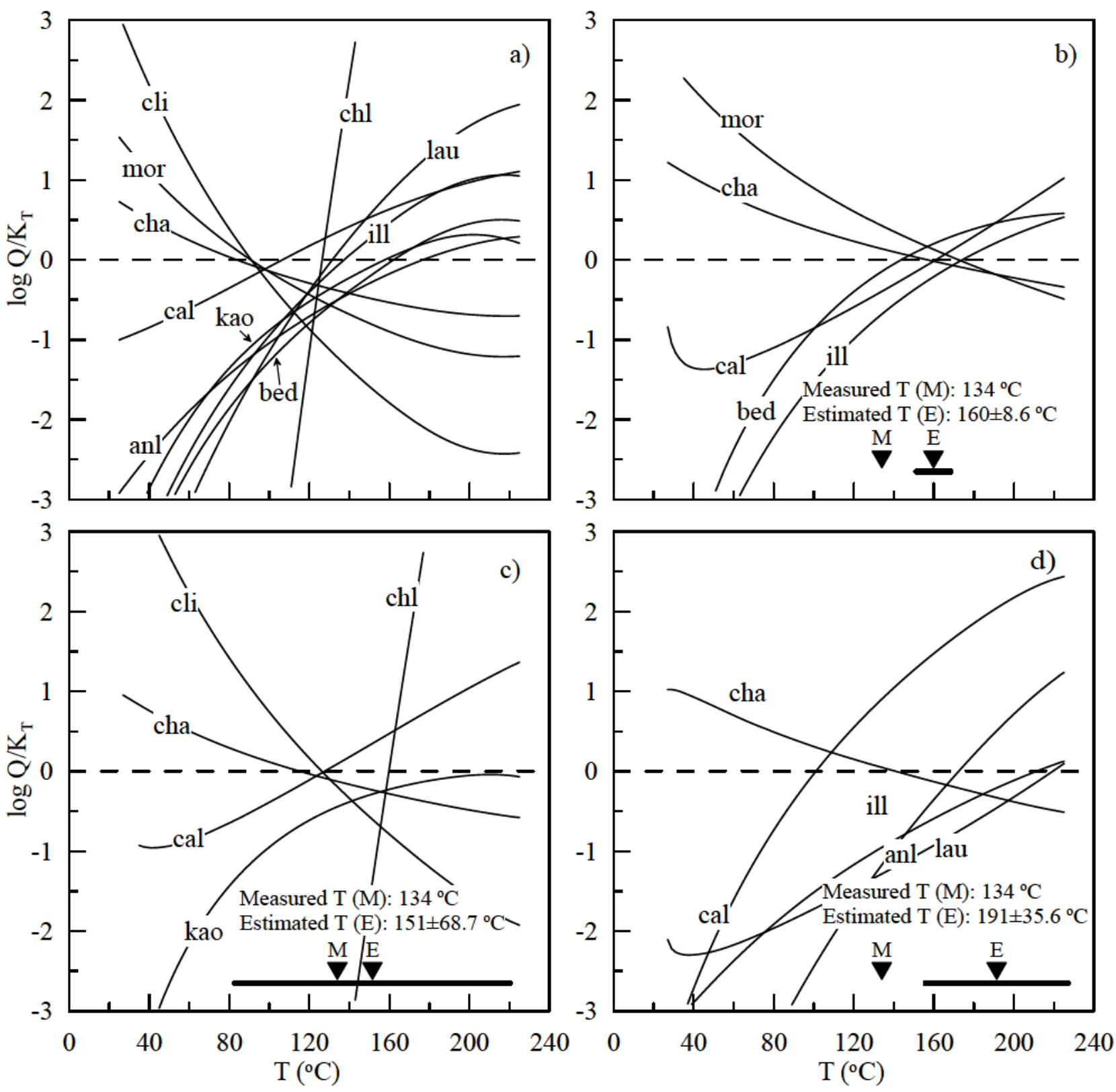

Figure C17. MEG temperature estimate for RRG9 with optimization on T, mass of water, and $\operatorname{logfCO} 2$. The $\log \mathrm{Q} / \mathrm{K}_{\mathrm{T}}$ curves for minerals calculated using original water chemistry with $\mathrm{K}$ feldspar used for FixAl (a), optimized $\log \mathrm{Q} / \mathrm{K}_{\mathrm{T}}$ curves for mineral assemblages I (b), II (c), and III (d) c) (Minerals - anl: analcime, bed: beidelite-Mg, cal: calcite, cha: chalcedony, chl: chlorite, cli-clinoptilolite-K ill: illite, kao: kaolinte, lau: laumontite, mor: mordenite-K). 


\section{Appendix H. Supporting data and results related to biotic works}

\section{qPCR assay for sulfur oxidizing genes-primer design and qPCR protocol}

For the design of the degenerate (mixed) qPCR primers used to amplify sox $B$ from environmental samples, known and sequenced SOB sox $B$ gene sequences were obtained from publicly available National Center for Biotechnology Information databases for alignment (Table ). The protein and gene sequence alignments were developed using Clustal Omega from the European Molecular Biology LaboratoryEuropean Bioinformatics Institute and Bioedit sequence alignment editor 7.0. The sequence analyses were performed giving extra weight to the sequence of the soxB genes from Thiobacillus denitrificans (facultative anaerobic sulfur oxidizing bacteria) and $S$. azorense (aerobic sulfur oxidizing bacteria). From this codon and nucleotide sequence analysis degenerate sox $B$ primers ( 7 total) were designed. These were tested in various combinations directly against the genomic DNA (gDNA) from various sulfur oxidizers. From these, one primer set (SoxB 1FDR/SoxB 3RDR) successfully amplified a correct sized (expected $494 \mathrm{bp}$ ) product from gDNA of the strains that included S. azorense, Sulfurihydrogenibium yellowstonease, Persephonella marina, and Paracoccus pantotrophus. The soxB degenerate primers nucleic acid sequences used for the qPCR assays were as follows: SoxB 1FDR 5'GAYKSYGGYGAYACHTGGC and SoxB 3RDR 5'- GGMRIISSRTCRTGSGTRTGBCC, where Y = C or $\mathrm{T}, \mathrm{K}=\mathrm{T}$ or $\mathrm{G}, \mathrm{S}=\mathrm{G}$ or $\mathrm{C}, \mathrm{H}=\mathrm{A}, \mathrm{C}$ or $\mathrm{T}, \mathrm{M}=\mathrm{C}$ or $\mathrm{A}, \mathrm{R}=\mathrm{A}$ or $\mathrm{G}$ and $\mathrm{B}=\mathrm{C}, \mathrm{G}$ or $\mathrm{T}$. 
Table H1. Bacterial strains used for alignment and design of soxB degenerate primers.

\begin{tabular}{|c|c|c|}
\hline BACTERIA & GenBank Acession no. SoxB & Genbank acession no. soxB \\
\hline Species ( $\alpha$-proteobacteria) & protein & nucleotide gene sequence \\
\hline Bradyrhizobium japonicum USDA 110 & BAC48780.1 & NC_004463.1 \\
\hline Bradyrhizobium (Agromonas) oligotrophicum S58] & | YP_007513975.1 & NC_020453.1 \\
\hline Methylobacterium extorquens DM4] & YP_003066439.1 & NC_012988.1 \\
\hline Ruegeria pomeroyi DSS-3] & YP_166249.1 & NC_003911.11 \\
\hline Roseobacter litoralis Och 149] & YP_004692103.1 & NC_015730.1 \\
\hline Magnetococcus marinus MC-1] & ABK44413.1 & NC_008576.1 \\
\hline Rhodobacter sphaeroides ATCC 17025] & ABP72768.1 & NC_009429.1 \\
\hline Nitrobacter hamburgensis X14] & ABE64399.1 & NC_007964.1 \\
\hline Paracoccus denitrificans & CAA55824.2 & N/A \\
\hline \multicolumn{3}{|l|}{ Species ( $v$-proteobacteria) } \\
\hline Allochromatium vinosum DSM 180] & YP_003444120.1 & NC_013851.1 \\
\hline Thiomicrospira crunogena XCL-2] & ABB42141.1 & NC_007520.2 \\
\hline Methylomicrobium alcaliphilum 20Z] & YP_004918642.1 & NC_016112.1 \\
\hline Thioalkalivibrio nitratireducens DSM 14787] & YP_007218372.1 & NC_019902.1 \\
\hline \multicolumn{3}{|l|}{ Species ( $\beta$-proteobacteria) } \\
\hline Cupriavidus metallidurans $\mathrm{CH} 34$ ] & YP_585558.1 & NC_007973.1 \\
\hline Methylibium petroleiphilum PM1] & YP_001021622.1 & NC_008825.1 \\
\hline Dechloromonas aromatica RCB] & YP_286328.1 & NC_007298.1 \\
\hline Advenella kashmirensis WT001] & YP_006379866.1 & NC_017964.1 \\
\hline Thiobacillus denitrificans ATCC 25259 & YP_314321.1 & NC_007404.1 \\
\hline \multicolumn{3}{|l|}{ Species ( $\varepsilon$-proteobacteria) } \\
\hline $\begin{array}{l}\text { Sulfuricurvum kujiense DSM 16994] } \\
\text {. }\end{array}$ & ADR33116.1 & NC_014762.1 \\
\hline Sulfurimonas autotrophica DSM 16294] & ADN09044.1 & NC_014506.1 \\
\hline Sulfurimonas denitrificans DSM 1251] & ABB43545.1 & NC_007575.1 \\
\hline \multicolumn{3}{|l|}{ Species ( $\delta$-proteobacteria) } \\
\hline Anaeromyxobacter dehalogenans $2 \mathrm{CP}-\mathrm{C}]$ & ABC82049.1 & NC_007760.1 \\
\hline \multicolumn{3}{|l|}{ Species (Aquificae) } \\
\hline 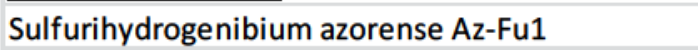 & WP_012673823.1 or YP_002729643.1 & NC_012438.1 \\
\hline Persephonella marina & WP_012676921.1 or YP_002731650.1 & NC_012440.1 \\
\hline
\end{tabular}

The qPCR assay for $s o x B$ was conducted very similarly to that for the $d s r B$ gene; we used the Rotor-Gene 3000 instrument and Platinum qPCR SuperMix chemistry with SYBR Green fluorescent dye. Agarose gel electrophoresis staining with ethidium bromide resulted in a single $\sim 0.5 \mathrm{~kb}$ PCR product from the $\mathrm{pS} 1$ standard using the soxB primers. Melt curve analysis showed a single peak, at $82-84^{\circ} \mathrm{C}$ for the $\mathrm{pS} 1$ and sulfur oxidizers' gDNA, although $P$. pantotrophus had a major peak at $\sim 92^{\circ} \mathrm{C}$. The qPCR standard curve was linear over $>5$ orders of magnitude and quantities as low as 500 soxB copies per reaction could be detected consistently, with assay efficiencies of roughly 0.85 using the FAM filter at $79^{\circ} \mathrm{C}$ and correlation coefficients $\left(\mathrm{R}^{2}\right)$ greater than 0.99 . 

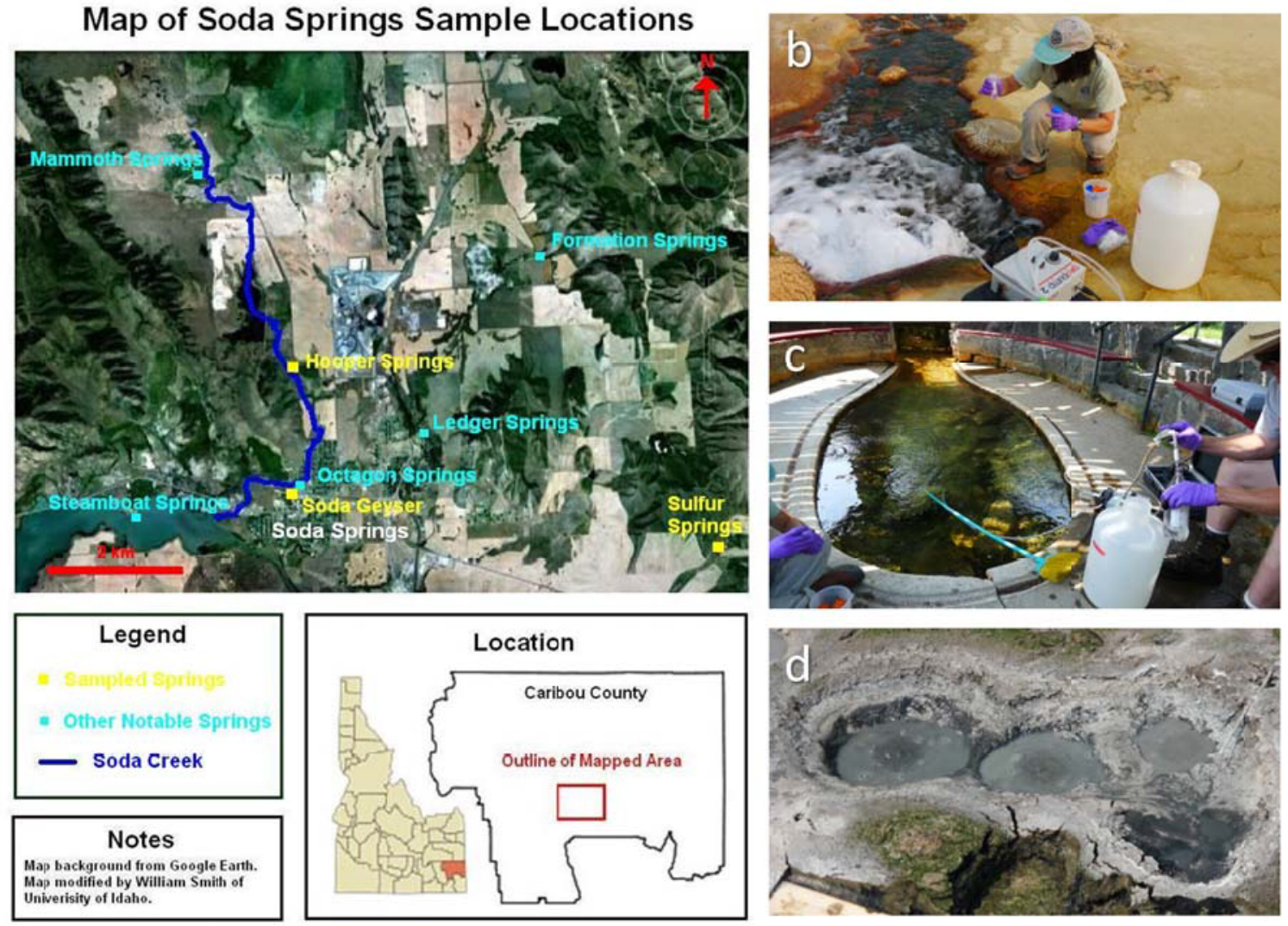

Figure H1. Map of Soda Springs area (a) and hot springs sampled: Soda Geyser outlet (b), Hooper Springs (c), Sulphur Springs (d) (reproduced from Fujita et al., 2013).

Table H2. Composition of water samples taken from Hooper Spring, Soda Geyser, and Sulphur Springs in Soda Springs, Idaho (mg/L)

\begin{tabular}{|c|c|c|c|}
\hline Samples & Hooper Spring & Soda Geyser & Sulphur Springs \\
\hline $\mathrm{T}^{1}$ & 10.7 & 30.1 & 14.2 \\
\hline $\mathrm{pH}$ & 5.71 & 6.41 & 6.28 \\
\hline $\mathrm{Al}$ & 0.0 & 0.2 & 0.1 \\
\hline $\mathrm{Ca}$ & 125.8 & 963.5 & 196.4 \\
\hline $\mathrm{Mg}$ & 132.3 & 187.2 & 48.3 \\
\hline $\mathrm{Na}$ & 33.0 & 13.2 & 6.6 \\
\hline $\mathrm{K}$ & 12.8 & 23.8 & 1.3 \\
\hline $\mathrm{SiO}_{2}(\mathrm{aq})$ & 75.8 & 34.3 & 14.7 \\
\hline $\mathrm{Fe}$ & 7.2 & 4.7 & 0.00 \\
\hline $\mathrm{F}$ & 0.00 & 0.24 & 0.00 \\
\hline $\mathrm{Cl}$ & 11.78 & 1.65 & 30.76 \\
\hline $\mathrm{SO}_{4}$ & 53.51 & 774.28 & 17.46 \\
\hline $\mathrm{NO}_{3}$ & 0.00 & 0.00 & 589 \\
\hline $\mathrm{Alkalinity}^{2}$ & 680 & 1991 & \\
\hline
\end{tabular}

${ }^{1}$ Field temperatures in ${ }^{\circ} \mathrm{C} ;{ }^{2}$ as $\mathrm{mg} / \mathrm{L} \mathrm{CaCO}{ }_{3}$

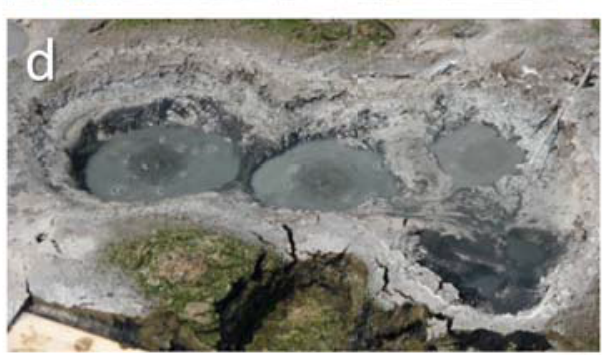



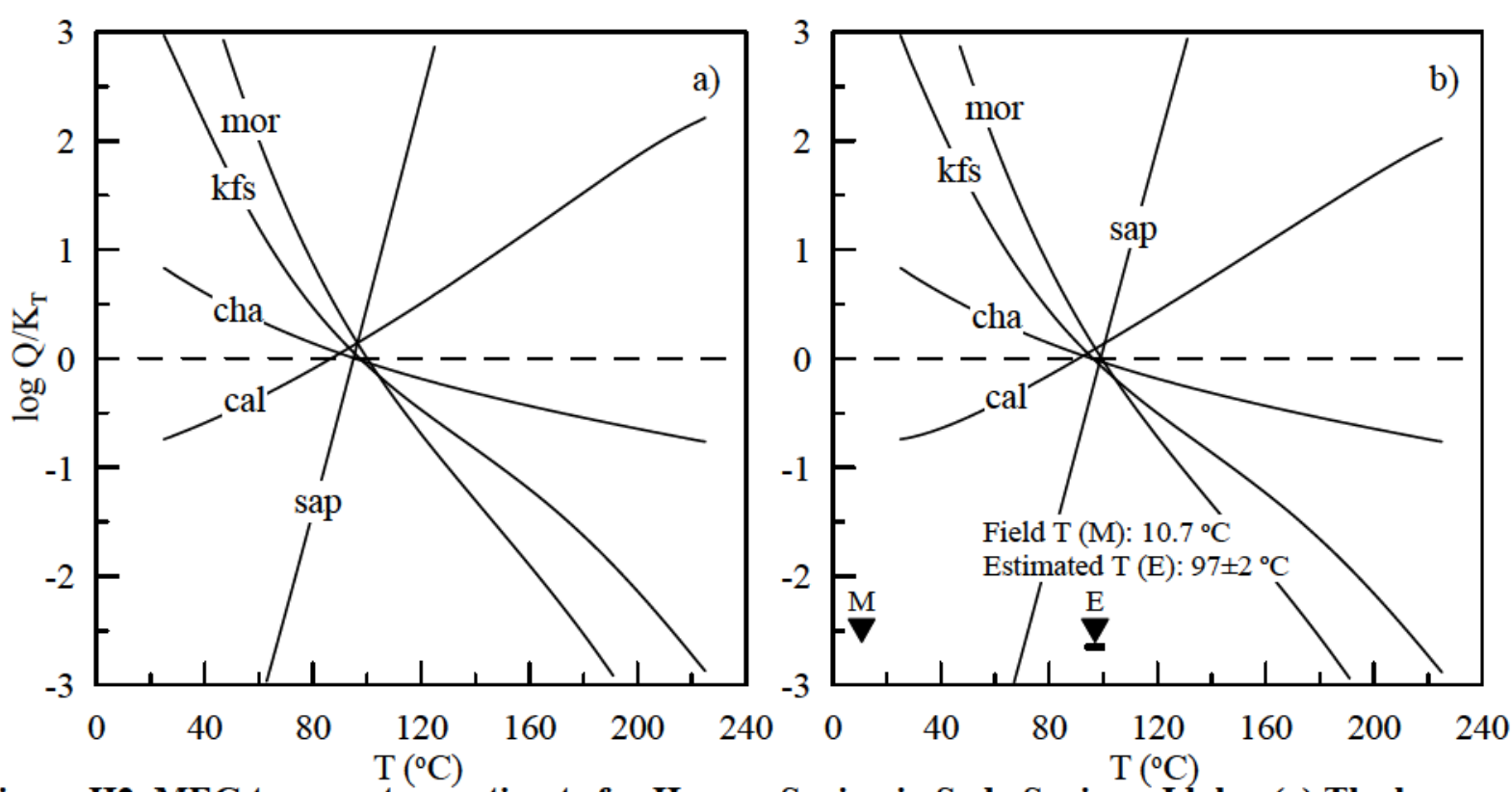

Figure H2. MEG temperature estimate for Hooper Spring in Soda Springs, Idaho. (a) The log $\left(Q / K_{T}\right)$ curves for minerals calculated using original water chemistry, (b) optimized $\log \left(Q / K_{T}\right)$ curves for assemblage minerals (cal: calcite; cha: chalcedony; kfs: K-feldspar; mor: mordenite-K; sap: saponite-Mg).
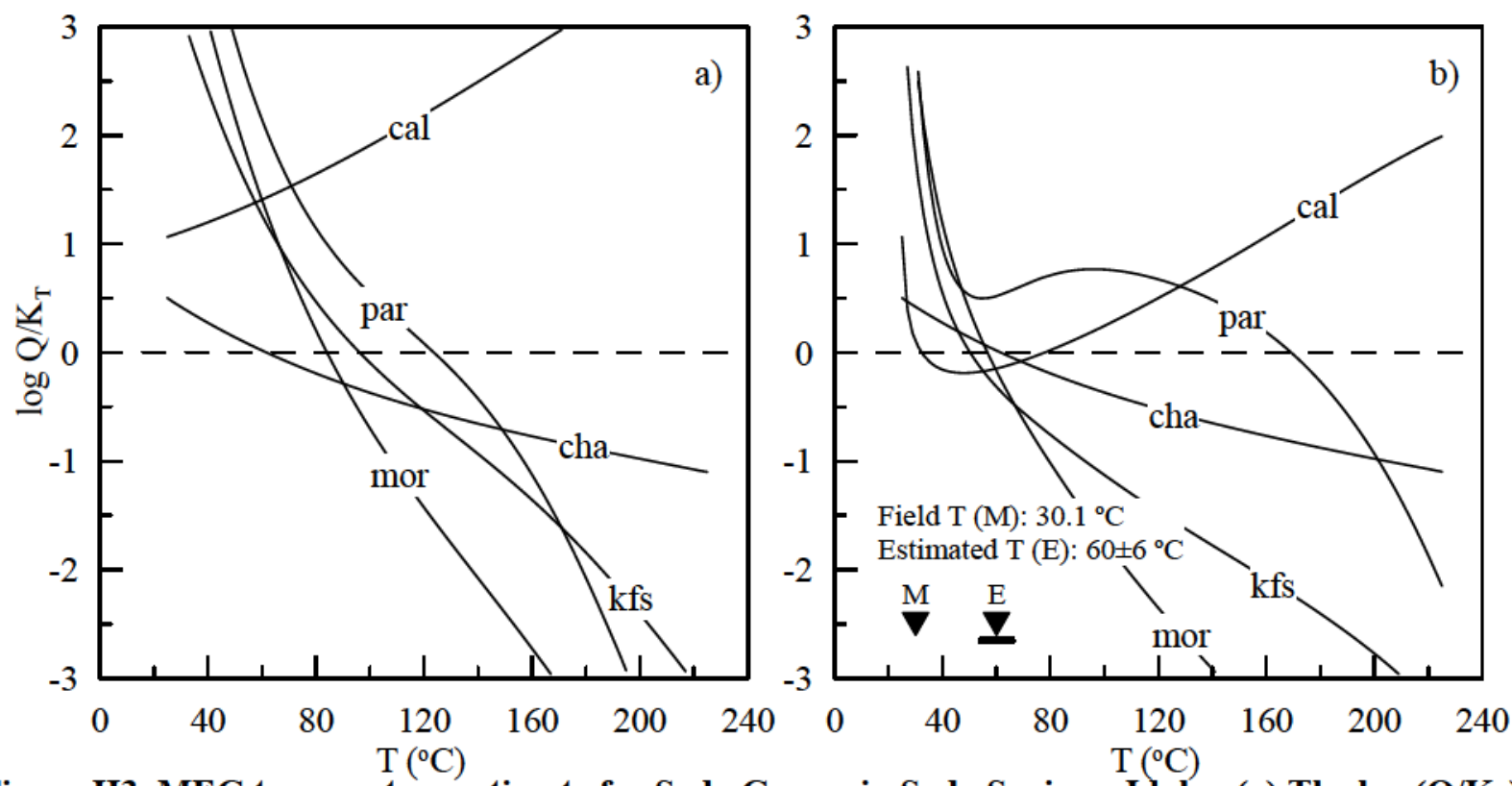

Figure H3. MEG temperature estimate for Soda Geyser in Soda Springs, Idaho. (a) $T$ he $\log \left(\mathrm{Q} / \mathrm{K}_{\mathrm{T}}\right)$ curves for minerals calculated using original water chemistry, (b) optimized $\log \left(Q / K_{T}\right)$ curves for assemblage minerals (cal: calcite; cha: chalcedony; kfs: K-feldsparmor: mordenite-K; par: paragonite). 

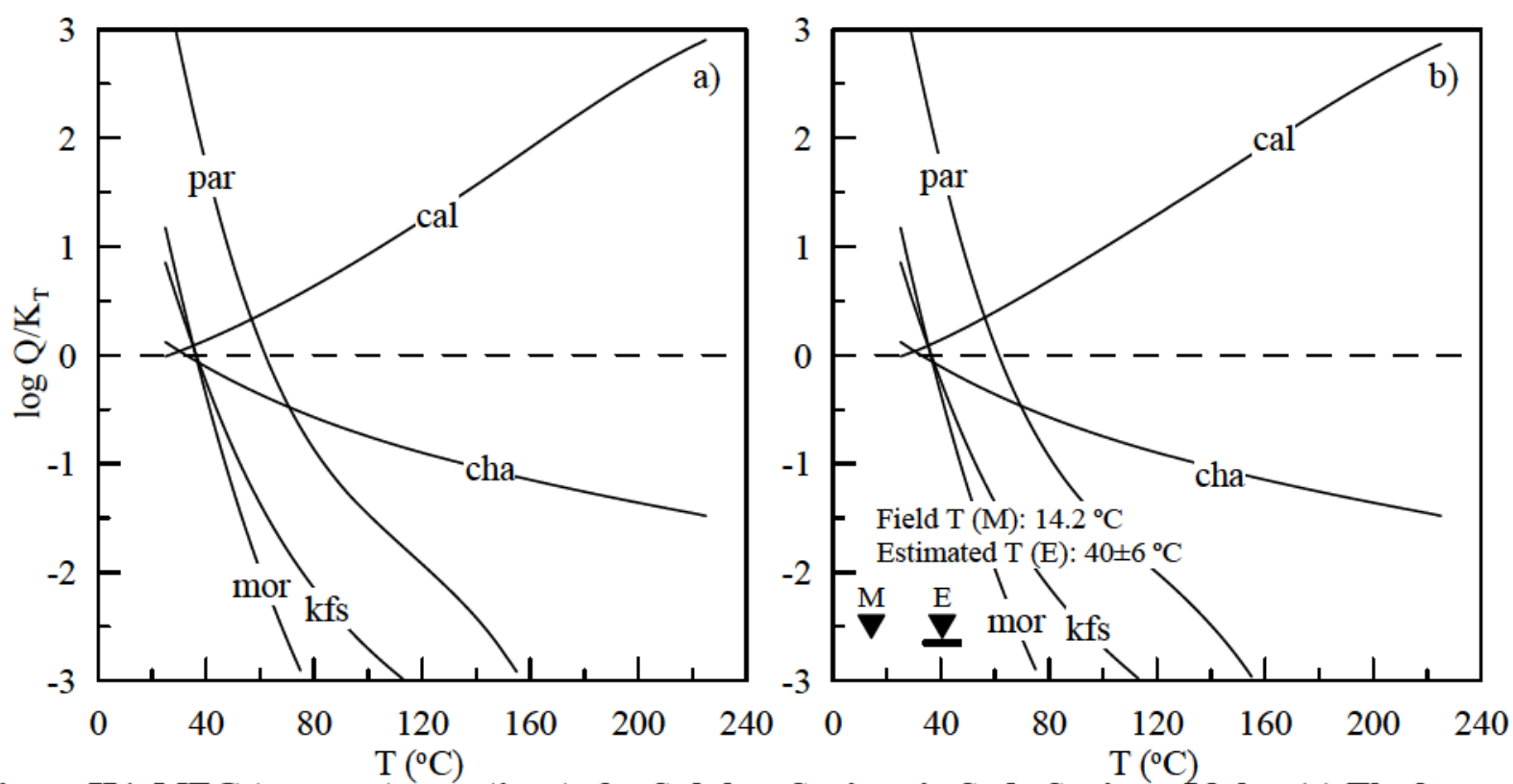

Figure H4. MEG temperature estimate for Sulphur Springs in Soda Springs, Idaho. (a) The log $\left(Q / K_{T}\right)$ curves for minerals calculated using original water chemistry, (b) optimized $\log \left(Q / K_{T}\right)$ curves for assemblage minerals (cal: calcite; cha: chalcedony; kfs: K-feldspar; mor: mordenite-K; par: paragonite).

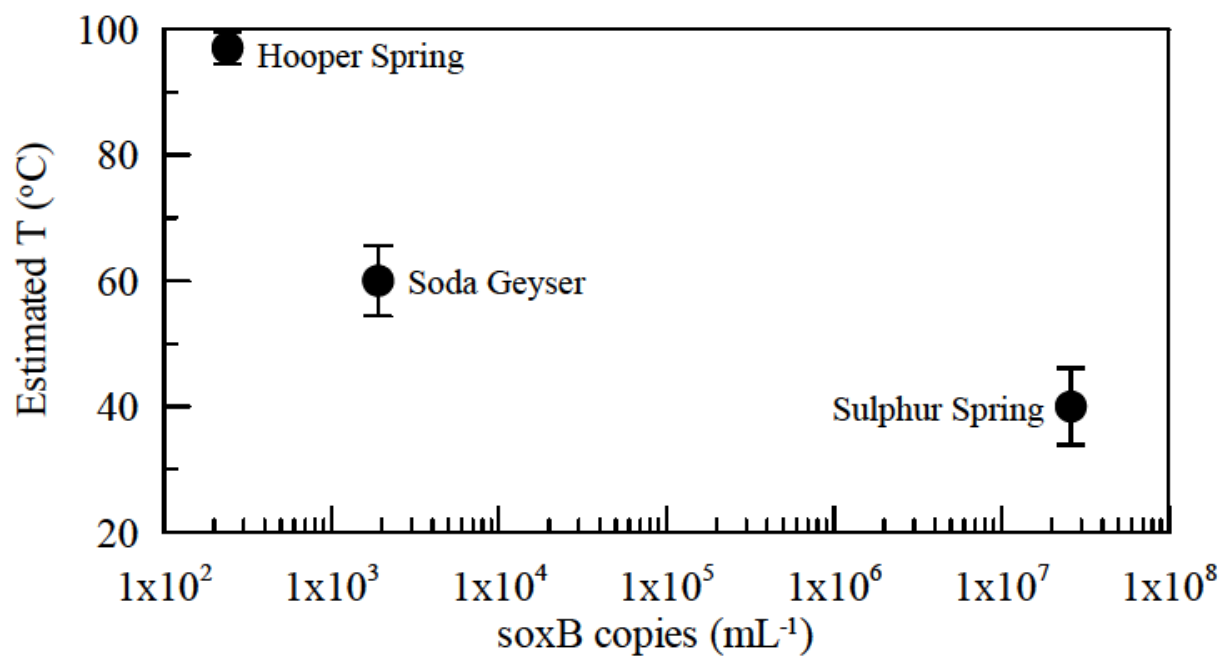

Figure H5. RTEst estimated temperature plotted against soxB density in Soda Springs samples 


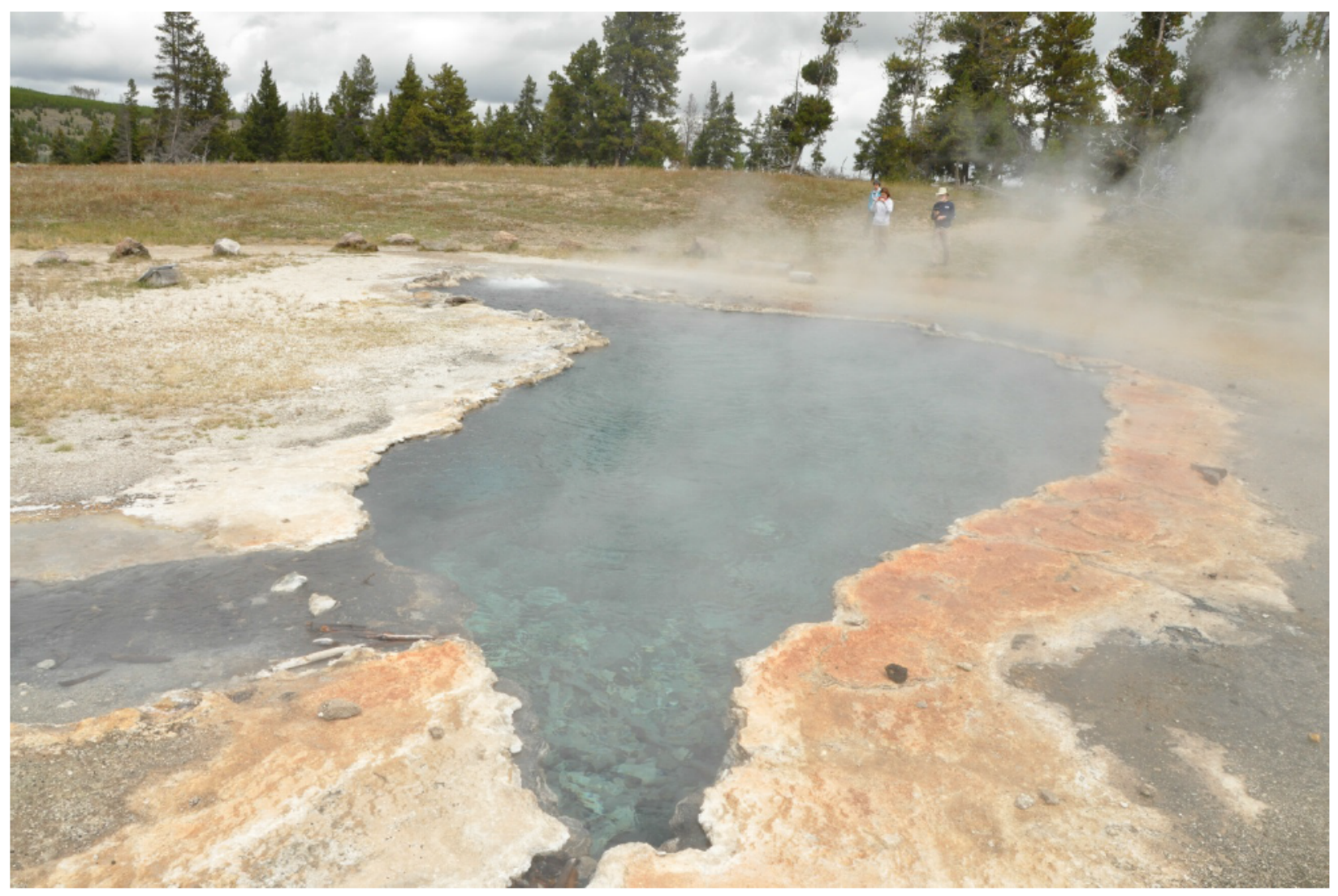

Figure H6. Ojo Caliente spring in the Lower Geyser Basin, Yellowstone National Park, Wyoming 
Table H3. Composition of Ojo Caliente water samples taken from different depths along the source shaft (mg/L)

\begin{tabular}{|c|c|c|c|c|c|}
\hline Samples1 & $0.3 \mathrm{~m}$ & $18 \mathrm{~m}$ & $35 \mathrm{~m}$ & $50 \mathrm{~m}$ & $70 \mathrm{~m}$ \\
\hline $\mathrm{pH}$ & 7.73 & 7.74 & 7.60 & 8.05 & 7.96 \\
\hline $\mathrm{T}^{2}$ & 58.7 & 68.6 & 60.7 & 69.9 & 71.9 \\
\hline $\mathrm{Ca}$ & 0.93 & 0.86 & 0.87 & 0.88 & 0.88 \\
\hline $\mathrm{Mg}$ & 0.002 & 0.001 & 0.001 & 0.001 & 0.001 \\
\hline $\mathrm{Na}$ & 331 & 327 & 326 & 328 & 335 \\
\hline $\mathrm{K}$ & 9.47 & 9.32 & 9.27 & 9.34 & 9.46 \\
\hline $\mathrm{Al}$ & 0.257 & 0.254 & 0.255 & 0.255 & 0.254 \\
\hline $\mathrm{Li}$ & 3.69 & 3.64 & 3.66 & 3.67 & 3.69 \\
\hline $\mathrm{Rb}$ & 0.216 & 0.212 & 0.212 & 0.208 & 0.214 \\
\hline $\mathrm{B}$ & 3.99 & 3.94 & 3.95 & 3.97 & 4.06 \\
\hline $\mathrm{Alkalinity}^{3}$ & 233 & 229 & 228 & 227 & 226 \\
\hline $\mathrm{Cl}$ & 301 & 299 & 300 & 297 & 300 \\
\hline $\mathrm{F}$ & 30.3 & 31 & 31 & 30.9 & 29.6 \\
\hline $\mathrm{Br}$ & 0.96 & 0.95 & 0.95 & 0.98 & 0.96 \\
\hline $\mathrm{SO} 4$ & 22.0 & 22.9 & 22.2 & 21.8 & 22.0 \\
\hline $\mathrm{H}_{2} \mathrm{~S}(\mathrm{aq})$ & 0.809 & 1.50 & 1.40 & 1.64 & 1.51 \\
\hline $\mathrm{SiO}_{2}$ (aq) & 228 & 228 & 231 & 230 & 240 \\
\hline $\mathrm{Specific} \mathrm{Cond.}^{4}$ & 1592 & 1603 & 1597 & 1615 & 1618 \\
\hline
\end{tabular}

${ }^{1}$ Samples collected in 2013 by McCleskey et al. (2014); ${ }^{2}$ flow cell temperatures in ${ }^{\circ} \mathrm{C} ;{ }^{2} \mathrm{as} \mathrm{mg} / \mathrm{L} \mathrm{HCO}_{3}$; ${ }^{3} \mu \mathrm{S} / \mathrm{cm}$; 

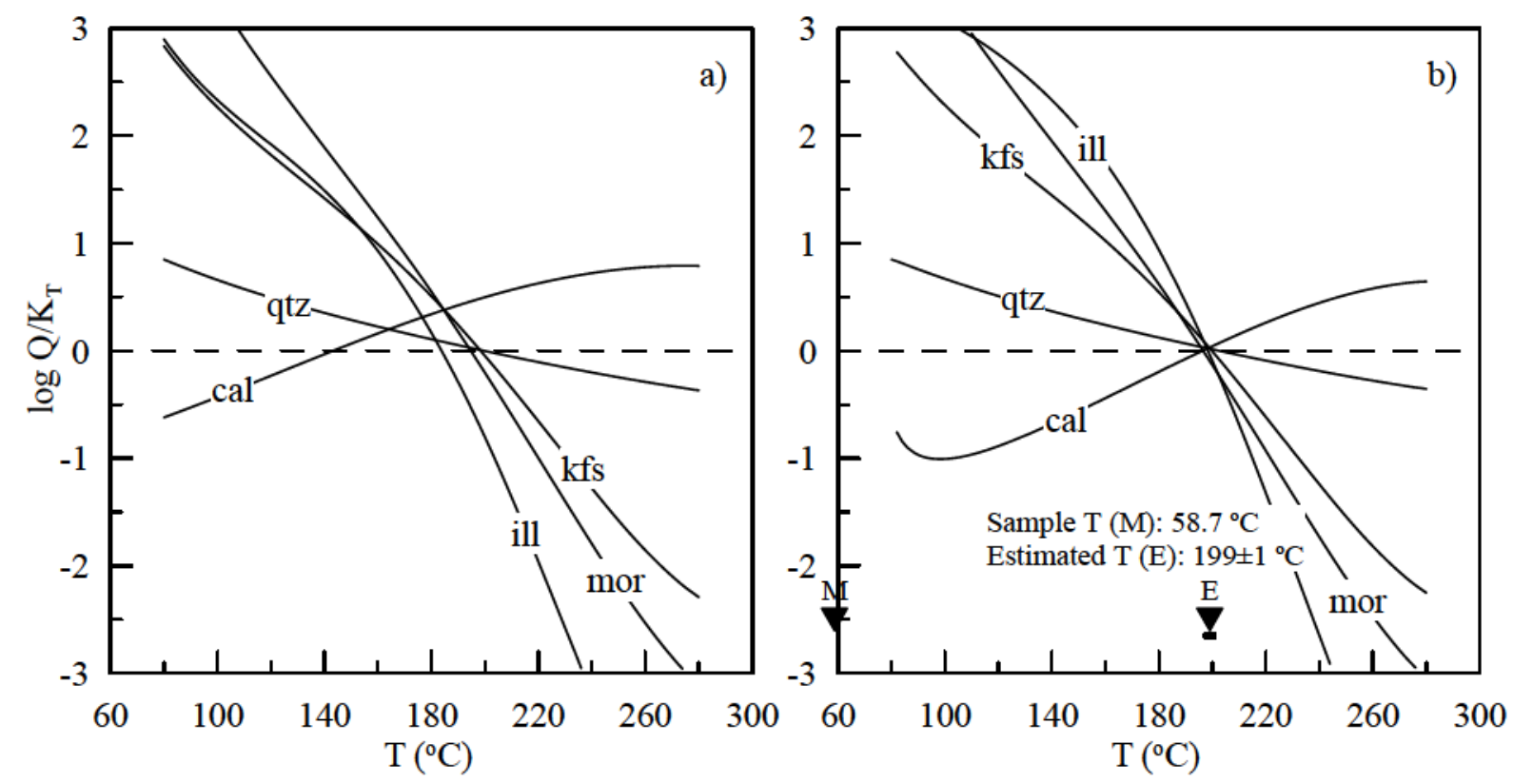

Figure H7. MEG temperature estimate for Ojo Caliente Spring (0.3 $\mathrm{m}$ sample) in Yellowstone National Park, Wyoming. (a) The $\log \left(\mathrm{Q} / \mathrm{K}_{\mathrm{T}}\right)$ curves for minerals calculated using original water chemistry, (b) optimized $\log \left(\mathrm{Q} / \mathrm{K}_{\mathrm{T}}\right)$ curves for assemblage minerals (cal: calcite; $\mathrm{kfs}$ : $\mathrm{K}$-feldspar; mor: mordenite-K; qtz: quartz).
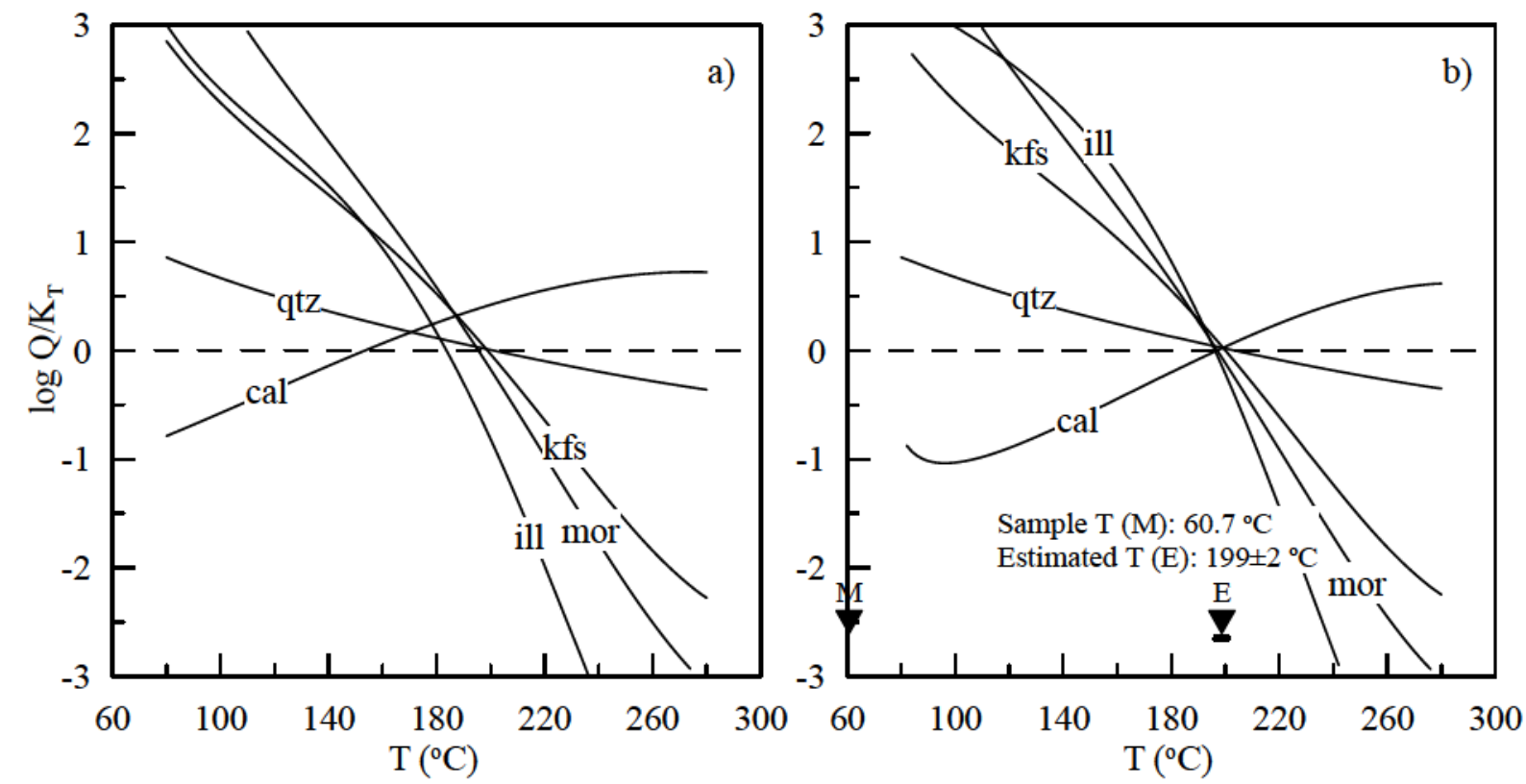

Figure H8. MEG temperature estimate for Ojo Caliente Spring (35 m sample) in Yellowstone National Park, Wyoming. (a) The $\log \left(\mathrm{Q} / \mathrm{K}_{\mathrm{T}}\right)$ curves for minerals calculated using original water chemistry, (b) optimized $\log \left(\mathrm{Q} / \mathrm{K}_{\mathrm{T}}\right)$ curves for assemblage minerals (cal: calcite; kfs: $\mathrm{K}$-feldspar; mor: mordenite-K; qtz: quartz). 

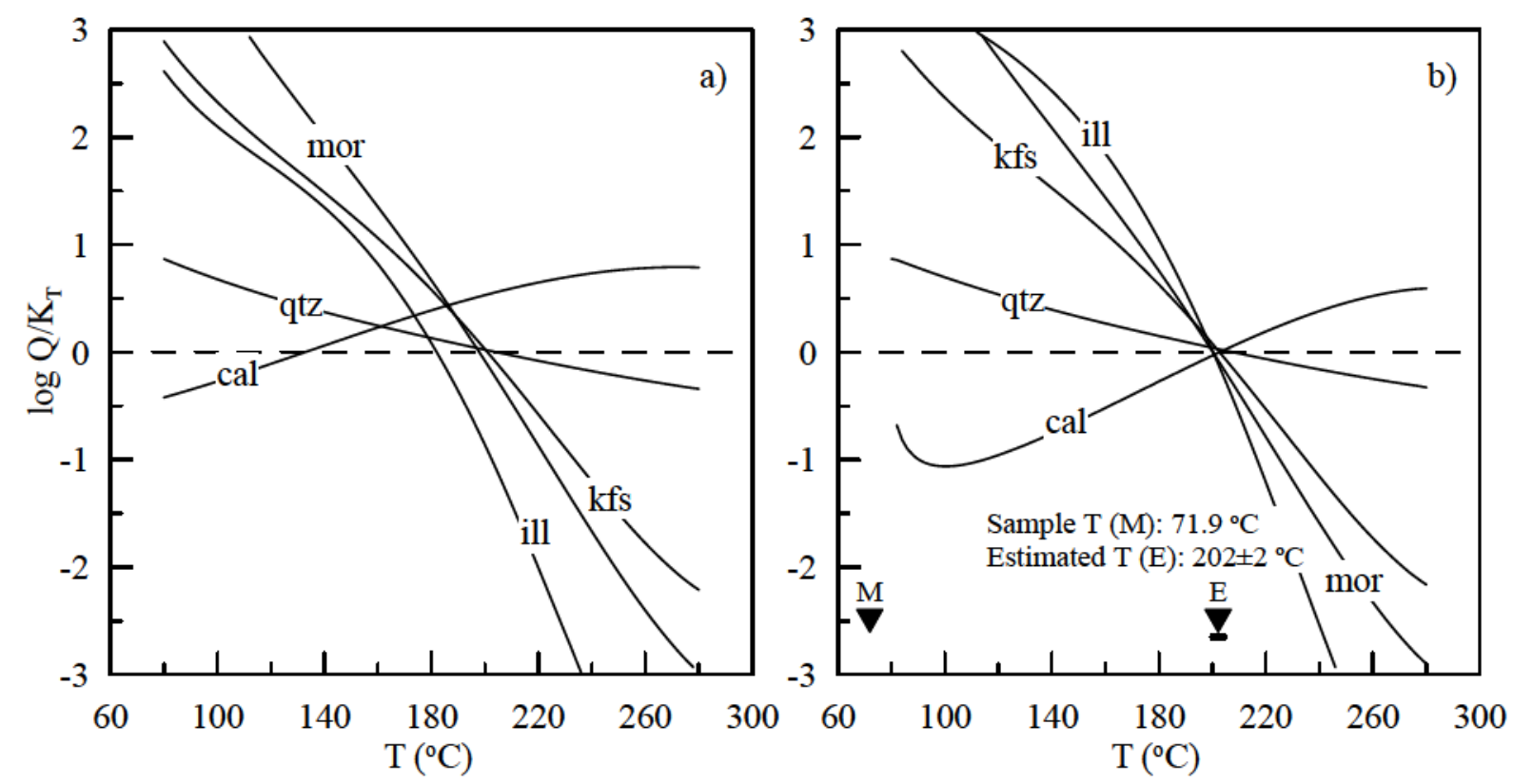

Figure H9. MEG temperature estimate for Ojo Caliente Spring (70 m sample) in Yellowstone National Park, Wyoming. (a) The $\log \left(\mathrm{Q} / \mathrm{K}_{\mathrm{T}}\right)$ curves for minerals calculated using original water chemistry, (b) optimized $\log \left(\mathrm{Q} / \mathrm{K}_{\mathrm{T}}\right)$ curves for assemblage minerals (cal: calcite; kfs: $\mathrm{K}$-feldspar; mor: mordenite-K; qtz: quartz). 


\title{
Appendix I.
}

PROCEEDINGS, Thirty-Eighth Workshop on Geothermal Reservoir Engineering

Stanford University, Stanford, California, February 11-13, 2013

SGP-TR-198

\section{MICROBIAL IMPACTS ON GEOTHERMOMETRY TEMPERATURE PREDICTIONS}

\author{
Yoshiko Fujita ${ }^{1}$, David W. Reed ${ }^{1}$, Kaitlyn R. Nowak ${ }^{1,2}$, Vicki S.Thompson ${ }^{1}$, Travis L. McLing ${ }^{1,3}$, Robert W. \\ Smith $^{3,4}$ and D. Craig Cooper ${ }^{1}$ \\ ${ }^{1}$ Idaho National Laboratory \\ Idaho Falls, ID, 83415, USA \\ ${ }^{2}$ Carnegie Mellon University \\ Pittsburgh, PA, 15213, USA \\ ${ }^{3}$ Center for Advanced Energy Studies \\ Idaho Falls, ID, 83415, USA \\ ${ }^{4}$ University of Idaho-Idaho Falls \\ Idaho Falls, ID, 83402, USA \\ e-mail: yoshiko.fujita@inl.gov
}

\begin{abstract}
Conventional geothermometry approaches assume that the composition of a water sample collected near the surface but with origins in a deep geothermal reservoir still reflects chemical equilibration with the deep reservoir rocks. However, for geothermal prospecting samples whose temperatures have dropped to $<120^{\circ} \mathrm{C}$, temperature predictions may be skewed by the activity of microorganisms as well as by changes induced by abiotic processes. Microbial metabolism can drastically and rapidly change water chemistry. We hypothesize that knowledge of microbial impacts on exploration sample geochemistry can be used to constrain input into geothermometry models and thereby improve the reliability of reservoir temperature predictions. To evaluate this hypothesis we have chosen to focus on sulfur cycling microorganisms, because they are known to induce significant changes in redox state and $\mathrm{pH}$ and therefore can impact the mineral-fluid equilibria that underlie solute geothermometry approaches. Initially we are focusing on the process of sulfate reduction. This paper reports on the development and initial testing of an assay for detecting sulfate reducing microorganisms in geothermal prospecting samples.
\end{abstract}

The assays rely on quantitative polymerase chain reaction (qPCR), which allows estimation of the number of target organisms in a particular sample without actual retrieval and characterization of the organisms themselves. We constructed a plasmid containing portions of two genes ( $d s r A$ and $d s r B$ ) directly involved with microbial sulfate reduction for use as a quantitation standard. Using the plasmid as well as DNA from other microorganisms known to be sulfate reducers or non-sulfate reducers, we developed qPCR protocols and showed the assay's specificity to sulfate reducers. A qPCR standard curve using the plasmid was linear over $>5$ orders of magnitude. The assay was applied to DNA extracted from water collected at surface springs located in and around the town of Soda Springs, Idaho. These springs produce water that is believed to be a mixture of groundwater and deep hydrothermal fluids. The qPCR results indicated that sulfate reducing genes were present in each of the samples tested, and consideration of the microbiological results together with geothermometry calculations suggests that microbial metabolism can influence reservoir temperature predictions.

\section{INTRODUCTION}

Chemical geothermometry is an important tool for geothermal resource exploration. The technique relies on the assumption that the chemical and isotopic composition of a water or gas sample derived from a deep reservoir continues to reflect chemical equilibration with the reservoir host rock at the reservoir temperature, even after the water has migrated to a shallower location, or to the surface. Various approaches have been developed to relate water composition to temperature. The most commonly employed methods use empirical correlations for different host lithologies or 
theoretical predictions based on thermodynamic data for selected minerals. More recently, approaches that combine geochemical modeling of mineral-water reactions that may occur along the path from host rock to the point of sample collection with numerical methods for multi-parameter inverse optimization have been described (Cooper et al., 2013; Spycher et al., 2011). Such methods provide the ability to assess the impact of multiple processes on solution chemistry, and may improve the accuracy of geothermometry predictions. This in turn would enable better estimates of the production potential of geothermal reservoirs and in so doing reduce the risk of expensive exploratory drilling.

These new modeling approaches present an opportunity to account for the potential effects of microbial alteration of water chemistry. During transit from a geothermal reservoir to a surface or near surface sampling point, waters often cool to temperatures below $\sim 121^{\circ} \mathrm{C}$, generally considered a physiological threshold for microbial life (although recently microorganisms have been reported to survive at even higher temperatures (Takai et al., 2008)). Numerous studies have reported on the enormous biomass constituted by microorganisms in the terrestrial and marine subsurface (Whitman et al., 1998), and their occurrence and diversity in settings ranging from the vadose zone (Holden and Fierer, 2005; Kieft and Brockman, 2001) to deep (>1 km) environments (Amend and Teske, 2005; Colwell and D'Hondt, 2013; Onstott et al., 2003; Pedersen, 2000). Geothermally derived waters in particular could be expected to be associated with microbial activity. Life depends on taking advantage of thermodynamic gradients, and the mixing of geothermal waters with cooler groundwaters, or migration of geothermal waters into geochemical environments different from the reservoir host rock would result in diverse and significant geochemical disequilibria that microorganisms can exploit for energy conservation (Reysenbach and Shock, 2002). Indeed, investigators have documented extensive phylogenetic diversity of microbial communities in both marine (Rogers and Amend, 2005; Takai and Nakamura, 2011) and terrestrial geothermal systems (Kimura et al., 2005; Marteinsson et al., 2001).

Microorganisms can impact water chemistry and geothermometry in both "passive" and active" ways. Mechanisms that would generally be considered "passive" include the release of biomolecules that can solubilize or chelate metals (Bennett et al., 2000; Ehrlich, 1996), or the sorption of ions on biological surfaces (Beveridge and Doyle, 1989; Schultze-Lam et al., 1996). For example, silica species are commonly employed in geothermometry (Arnorsson,
1975; Ferguson et al., 2009; Gunnarsson and Arnorsson, 2000), and microorganisms have the ability to mobilize silica through production of acids, alkali, and organic ligands (Rogers and Bennett, 2004). Microbial biomass can also contribute to removal of silica from solution by acting as a template for silica precipitation in hot springs (Konhauser et al., 2004). Rare earth elements, which are also often used in geoethermometry, have also been observed to be enriched in hot spring microbial biofilms and mats as compared to the surrounding water (Takahashi et al., 2005).

More "active" mechanisms with potentially large impacts on geothermometry are reactions associated with microbial growth and energy conservation. For example, the commonly used Na-K-Ca- $(\mathrm{Mg})$ geothermometer (Giggenbach, 1988) could be affected by reactions resulting in the production or dissolution of carbonate minerals. Microbial oxidation of reduced carbon for energy conservation can result in the precipitation of calcium carbonate $\left(\mathrm{CaCO}_{3}\right)$ (Ehrlich, 1996). Transformations of nitrogen compounds, as well as dissimilatory sulfate reduction, are also associated with $\mathrm{CaCO}_{3}$ precipitation (Ehrlich, 1996; Wright and Oren, 2005). Besides calcium, other ions such as magnesium, iron, and manganese can be removed from solution by carbonate mineral precipitation (Ehrlich, 1996). Conversely, solution concentrations of these ions can also be increased by microbially induced dissolution of minerals via mechanisms such as organic acid production during the course of metabolism (Uroz et al., 2009; Welch et al., 2002).

Given the abundant evidence for the significant role of microorganisms in modulating water chemistry, we hypothesize that knowledge of microbial impacts on exploration sample geochemistry can be used to constrain input into geothermometry models and thereby improve the reliability of reservoir temperature predictions. As a first step toward addressing this hypothesis, we are developing methods to detect and estimate microbial activity in geothermal prospecting samples. We have chosen to focus initially on the process of sulfate reduction. As noted previously, microbial sulfate reduction is known to promote carbonate mineral precipitation through the production of alkalinity. Sulfate reduction is also associated with significant changes in redox state, which along with $\mathrm{pH}$ is a critical factor in general for defining the mineral-fluid equilibria that form the basis of solute geothermometry approaches.

We developed assays to detect the process of sulfate reduction in environmental water samples, using 
knowledge of genes specific to sulfate reducing (SR) microorganisms. The assays rely on a common molecular biological technique known as quantitative polymerase chain reaction (qPCR), which allows estimation of the number of target organisms in a particular sample by enumerating genes specific to the organisms rather than actually retrieving and characterizing the organisms themselves. For quantitation of sulfate reducing genes using qPCR, we constructed a plasmid standard containing portions of two genes ( $d s r A$ and $d s r B$ ) directly involved with sulfate reduction and unique to sulfate reducing microorganisms. These genes code for the dissimilatory sulfite reductase enzymes that catalyze the conversion of sulfite to sulfide and are highly conserved between bacteria and archaea. The standard was constructed with $d s r A$ and $d s r B$ sequences amplified from the well known hyperthermophilic sulfate reducing archaeon Archaeoglobus fulgidus (Klenk et al., 1997). Using the plasmid as well as DNA from other microorganisms known to be sulfate reducers or nonsulfate reducers, we developed a quantitation protocol and showed the assay's specificity to sulfate reducers. As a first test with actual field samples, the assay was applied to DNA extracted from water collected at springs located in and around the town of Soda Springs, Idaho. Discharges from the springs are believed to be mixtures of shallow groundwater and deep hydrothermal fluids, with the proportions varying at individual springs (Lewicki et al., 2012). The results showed that the assays could indeed quantify microbial sulfate reducing genes in the samples, and consideration of the results together with geothermometric calculations suggests that microbial sulfur metabolism can influence reservoir temperature predictions.

\section{METHODS}

\section{Genomic DNA}

Genomic DNA (gDNA) was extracted from cultures using the UltraClean ${ }^{\circledR}$ Microbial DNA Isolation Kit (MoBio, Carlsbad, CA). Escherichia coli K12, JM109 cells were grown overnight on LB prior to harvest and gDNA extraction. Alicyclobacillus acidocaldarius cells were grown as described elsewhere for gDNA extraction (Thompson et al., 2011). Nitrosomonas europaea was provided by Daniel Arp and grown per his recommendations (http://nitrificationnetwork.org/Nerecipe.php) prior to gDNA extraction. Desulfovibrio alaskensis G20 gDNA was kindly provided by KL Reardon, USDA, Adams, OR, and Archaeoglobus fulgidus gDNA was obtained as previously described (Reed et al., 2001).

\section{PCR primer selection and analysis}

Previously reported PCR primers DSRQ2R (Chin et al., 2008), DSR1F and DSR4R (Wagner et al., 1998) and DSRp2060F (Geets et al., 2006) were ordered from Integrated DNA Technologies (Coralville, Iowa, USA). The specific primer sequences are presented parenthetically as follows:

DSRQ2R (5'GTTGAYACGCATGGTRTG), DSR1F (5'ACSCACTGGAAGCACG),

DSR4R (5'GTGTAGCAGTTACCGCA), and DSRp2060 (F5'CAACATCGTYCAYACCCAGGG); where $\mathrm{S}=\mathrm{C} / \mathrm{G}, \mathrm{Y}=\mathrm{C} / \mathrm{T}, \mathrm{R}=\mathrm{A} / \mathrm{G}$. BioEdit software version 7.0 (Hall, 1999) was used to evaluate the primer binding site conservation and $d s r A / d s r B$ PCR product lengths from the following microorganisms: Archaeoglobus fulgidus, Archaeoglobus infectus, Archaeoglobus veneficus, Bilophila wadsworthia, Desulfatiferula olefinivorans, Desulfobacterium cetonicum, Desulfobacterium vacuolatum, Desulfohalobium retbaense, Desulfomonas pigra, Desulfonatronovibrio hydrogenovorans, Desulfosalsimonas propionicica, Desulfosarcina variabilis, Desulfovibrio desulfuricans, Desulfovibrio intestinalis, Desulfovibrio piger, Desulfovibrio vulgaris, Desulfovibrio termitidis and Thiobacillus denitrificans.

\section{Preparation of $d s r A B$ standard pKN23}

The $d s r A B$ gene fragment was amplified from $A$. fulgidus gDNA using Platinum ${ }^{\circledR} \quad$ Taq DNA Polymerase High Fidelity (Life Technologies, Carlsbad, CA) and the DSR1F and DSR4R primers. The PCR product was cloned into the pCR4 vector of the TOPO TA Cloning ${ }^{\circledR}$ Kit for Sequencing and transformed into One Shot ${ }^{\circledR}$ TOP10 Competent Cells according to the manufacturer's instructions (Life Technologies). Plasmid DNA was prepared using the Qiagen Plasmid Midi Kit (Qiagen, Germantown, Md). The concentration of plasmid DNA was initially quantified using a Nanodrop spectrophotometer (Thermo Scientific, Waltham, Massachusetts, USA) and then more rigorously quantified with the QuantiT PicoGreen dsDNA Reagent Kit (Life Technologies) using a Rotor-Gene 3000 (Qiagen) with a FAM filter (absorbance at $470 \mathrm{~nm}$ and emission at $510 \mathrm{~nm})$. The constructed plasmid, named pKN23, was sent for sequencing to Idaho State University's Molecular Research Core Facility (Pocatello, Idaho, USA) to confirm the desired construct, based on the Genbank sequence for $A$. fulgidus and the primer sequences. 


\section{qPCR amplification of $d s r B$}

Using methods similar to those described previously (Agrawal and Lal, 2009), a qPCR assay was developed for amplification of the $d s r B$ gene on the Rotor-gene 3000 real-time PCR thermal cycler. For qPCR thermal cycling, the final composition of each reaction was as follows: 1X Platinum $q P C R$ SuperMix UDG (Life Technologies), $1 \mathrm{mM}$ additional $\mathrm{MgCl}_{2}$ (Life Technologies), 400ng/ $\mu \mathrm{L}$ BSA (Roche), Technologies), and DNA template. Dilutions of pKN23 representing 25 to $10^{7}$ copies of $d s r B$ were used for development of the standard curve for the assay. The following conditions were used: First, two minutes at $50^{\circ} \mathrm{C}$ to allow the UDGase to digest any contaminant DNA and then 5 minutes at $95^{\circ} \mathrm{C}$ to denature the UDGase and activate the polymerase. Next, forty cycles consisting of $95^{\circ} \mathrm{C}$ for 45 seconds, $58^{\circ} \mathrm{C}$ for 60 seconds, $72^{\circ} \mathrm{C}$ for 45 seconds, and $85^{\circ} \mathrm{C}$ for 15 seconds. During the $72^{\circ} \mathrm{C}$ and $85^{\circ} \mathrm{C}$ portions, measurements of fluorescence were taken on FAM (470nm for absorbance and $510 \mathrm{~nm}$ for emission) and SYBR $(470 \mathrm{~nm}$ for absorbance and $585 \mathrm{~nm}$ for emission) channels. Following completion of the amplification cycles, a melt curve was generated in order to confirm that the correct product was amplified. To prepare for the melt curve, the DNA was denatured at $95^{\circ} \mathrm{C}$ for 5 seconds and held at $55^{\circ} \mathrm{C}$ for 2 minutes. The melt curve was performed from $55^{\circ} \mathrm{C}$ to $99^{\circ} \mathrm{C}$, with an initial wait of 60 seconds at $55^{\circ} \mathrm{C}$ and then 5 seconds at each degree on the increase.

\section{Field site description and sample collection}

Water samples were collected from three locations (Soda Geyser outlet, Hooper Springs, and Sulfur Springs; Figure 1) in and around the town of Soda Springs, Idaho. Soda Springs is located in the fold and thrust belt on the eastern boundary of the track of the Yellowstone Hotspot, and is known for the highly $\mathrm{CO}_{2}$-charged waters that discharge from the many springs in the area. The $\mathrm{CO}_{2}$ is believed to originate from the interaction of Paleozoic carbonates and acidic hydrothermal fluids at depth (McLing et al., 2012). Mixing of upwardly migrating deep waters $\left(\mathrm{CO}_{2}\right.$-charged) with the overlying aquifer waters (basalt-equilibrated) has created a system where the water chemistry within the Soda Springs area ranges from "no basaltic impact" (e.g., deep wells or water transported through faults) to "basalt modified" springs. The Soda Geyser, centrally located in the town of Soda Springs, was created in 1937 when a geothermal exploratory well penetrated into the $\mathrm{CO}_{2}$ pressurized aquifer at approximately 100 meters below land surface. The City of Soda Springs subsequently capped the well with a timer, which allows the geyser to erupt hourly as a tourist attraction. Outflow water from the geyser has precipitated copious amounts of travertine. Hooper a
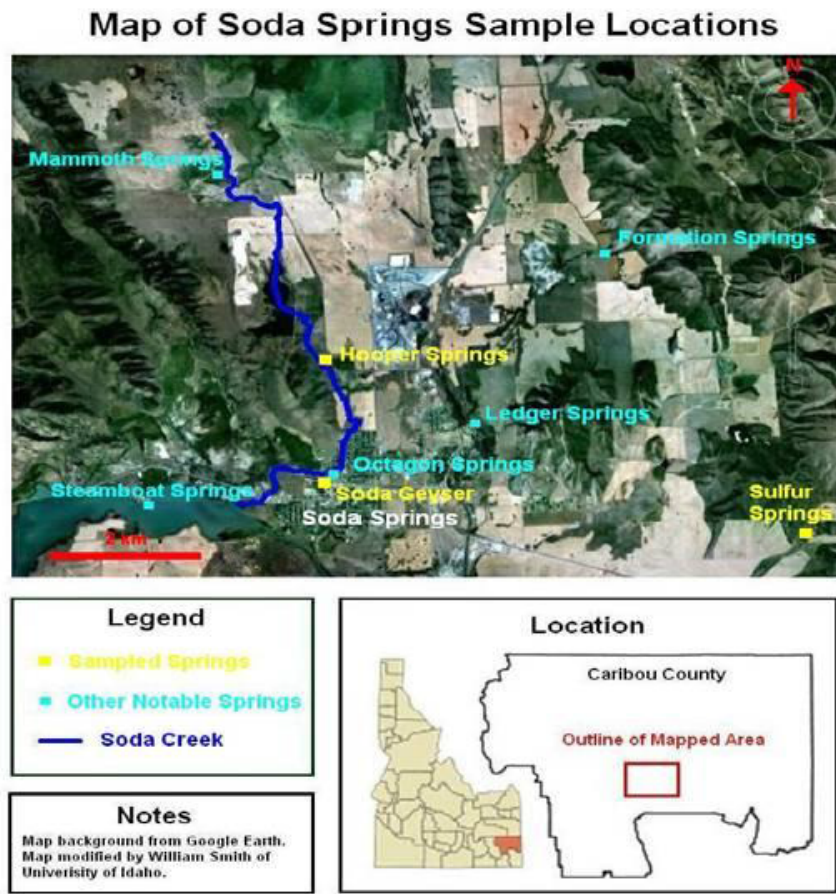
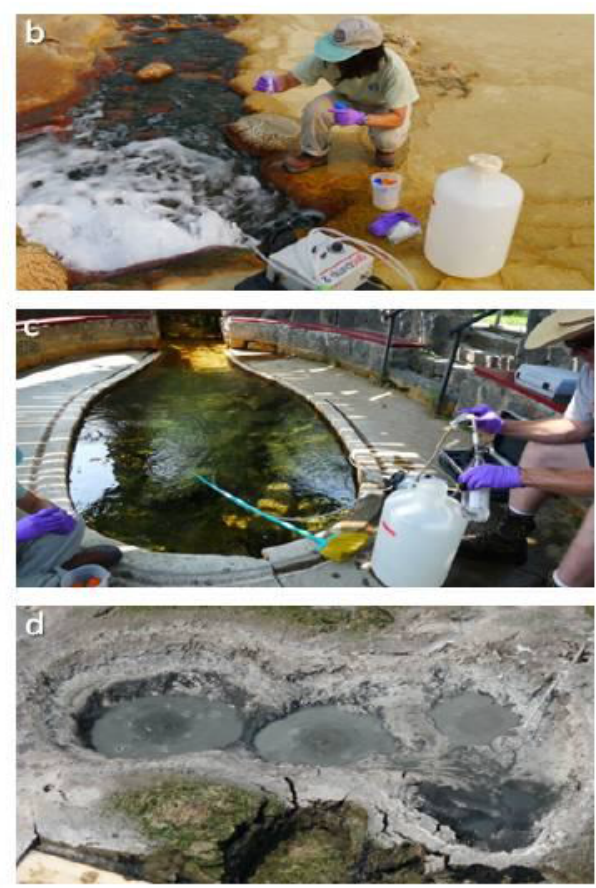

Figure 1: Map of Soda Springs area (a) and hot springs sampled: Soda Geyser outlet (b), Hooper Springs (c), Sulphur Springs (d). 
Springs is a cold $\left(11^{\circ} \mathrm{C}\right) \mathrm{CO}_{2}$ bubbling (70.0 vol.\%) spring located north of the City of Soda Springs along the western margin of the Blackfoot Valley. Sulfur Springs is a series of $\mathrm{CO}_{2}$ charged (99.6 vol.\%; (Lewicki et al., 2012)), cold $\left(14.2^{\circ} \mathrm{C}\right.$ ) springs and pools located at the mouth of Sulfur canyon several kilometers east of the City of Soda Springs. A strong $\mathrm{H}_{2} \mathrm{~S}$ odor and the presence of elemental sulfur are characteristic of this location. In addition, diffuse, dry $\mathrm{CO}_{2}$ and $\mathrm{H}_{2} \mathrm{~S}$ degassing occur in a $0.5 \mathrm{~km}$ radius around the spring (Lewicki et al., 2012). Sulfate and/or reduced sulfur species have been observed in samples collected previously at all three of these locations (Lewicki et al., 2012; Mayo et al., 1985; McLing et al., 2012).

At Soda Geyser and Hooper Springs, filtered water samples were collected for cation and anion analysis. The samples were filtered using a 0.45 micron pore size high-capacity, in-line filter capsule with a polyethersulfone membrane (Gelman Sciences), dispensing directly into acid-washed polyethylene bottles. The samples for cation analysis were then acidified to $\mathrm{pH}<2$ using Optima-grade nitric acid and sealed with Parafilm. An additional non-acidified sample was collected at each site for anion analysis. For enumeration of cell numbers, water samples ( 40 $\mathrm{mL}$; four replicates at each location) were collected at each of the three sites in polypropylene centrifuge tubes and cells were fixed in $2 \%$ formaldehyde directly after collection. Fixed cells were stored at $4^{\circ} \mathrm{C}$ prior to processing.

For DNA extraction the cells were concentrated by filtration $(0.22 \mu \mathrm{m}$ pore size $)$ onto Sterivex ${ }^{\mathrm{TM}} \mathrm{GP}$ Filter (EMD Millipore, Billerica, MA) units. At the Geyser and Hooper Springs sites, filtration of $10 \mathrm{~L}$ samples was conducted in the field, in triplicate, and the filters were immediately stored on dry ice for transport back to the laboratory, where they were stored at $-80^{\circ} \mathrm{C}$ until processing. Turbidity of the water samples at Sulfur Springs precluded filtration in the field; instead water was collected and stored on ice and then at $4^{\circ} \mathrm{C}$ until the water could be filtered similarly in the laboratory the following day, after gravity settling of much of the suspended solids. Only $50-75 \mathrm{~mL}$ could be processed through an individual filter; additional time for settling did not increase this filterable volume.

\section{Geochemical analysis}

Temperature and $\mathrm{pH}$ were measured onsite at Soda Geyser and Hooper Springs. Major metals (e.g. Ca, $\mathrm{Mg}, \mathrm{K}, \mathrm{Na}, \mathrm{Si}$ ) were analyzed by inductively coupled plasma optical emission spectrometry (ICP-OES) using standard methods recommended by the instrument manufacturers and major anions $\left(\mathrm{F}^{-}, \mathrm{Cl}^{-}\right.$,
$\mathrm{NO}_{3}{ }^{-}, \quad \mathrm{SO}_{4}{ }^{2-}, \quad \mathrm{PO}_{4}{ }^{3-}$ ) were measured by ion chromatography, again using standard methods.

\section{Direct cell enumeration and microscopy}

Total microbial cells were enumerated using acridine orange (AO) staining and epifluorescence microscopy (Nikon Eclipse E800, 1000X, filters: excitation $440 \pm 12.5 \mathrm{~nm}$, dichroic mirror $565 \mathrm{~nm}$, emission $605 \pm 27.5 \mathrm{~nm}$ ) using standard protocols (Kepner and Pratt, 1994). Triplicates were counted for the water samples. Pictures were taken with an Olympus American camera and MagniFire 2.1A software.

Field sample DNA extraction and $d s r B$
quantitation

DNA was extracted from the Sterivex filters using the PowerWater ${ }^{\circledR}$ Sterivex ${ }^{\mathrm{TM}}$ DNA Isolation Kit (MoBio) according to manufacturer recommendations and the DNA was suspended in $100 \mu \mathrm{L}$ of $10 \mathrm{mM}$ Tris $\mathrm{pH} 8.0$. For the Geyser and Hooper Springs samples two $\mu \mathrm{L}$ of extracted DNA were used as template per qPCR reaction, performed in duplicate from each of the triplicate samples. For the Sulphur Springs samples only two DNA extraction preparations were used, and the DNA was diluted 10-fold prior to inclusion in the $\mathrm{qPCR}$ reaction mix.

\section{Geothermometrv calculations}

Consideration of the thermal history of the water in the Soda Springs system is important for assessing the degree to which microorganisms may have influenced the chemistry. Because there are no deep wells into the system, the thermal history of the water can only be estimated using geochemical thermometers. The degree of accuracy of these geothermometers depends on many factors, including mineral precipitation and dissolution, groundwater mixing, and the applicability of the geothermometer used (Fournier, 1977). Of the geothermometers commonly employed to estimate maximum geothermal reservoir temperatures, silicate geothermometers (quartz and chalcedony) are considered the most applicable to the study area (Mitchell, 1976). The models as described by Fournier (1977) were applied to available water chemistry data for the sampled springs. The same data were also used for preliminary geothermometric predictions generated using the inverse geochemical modeling approach described by Cooper et. al. (2013), with an equilibrium-controlling mineral assemblage of siderite, calcite, anhydrite, dolomite, and chalcedony. 

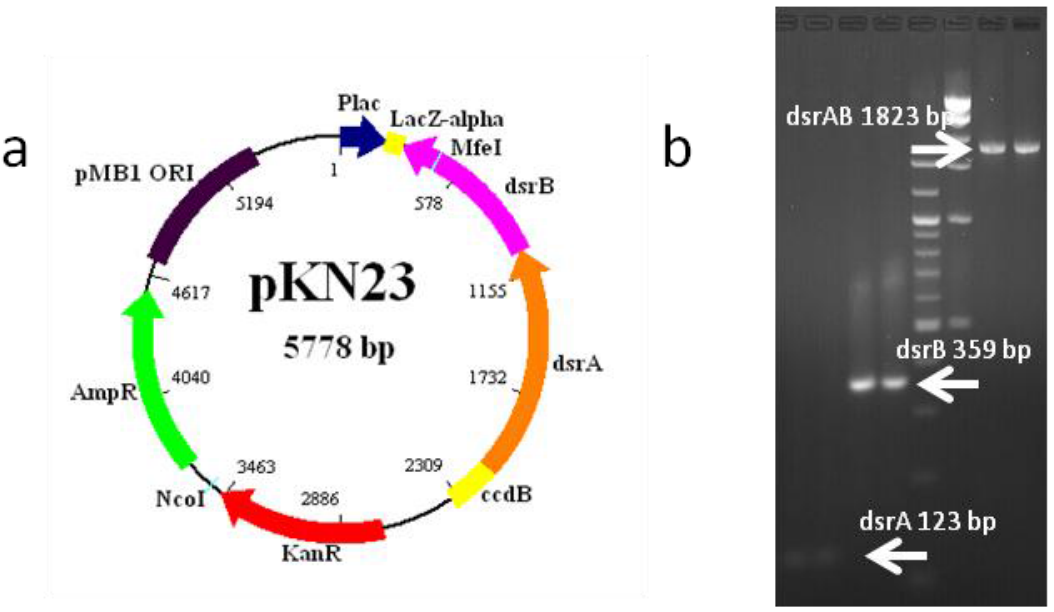

Figure 2: Construct of $p K N 23$ plasmid including gene sequence from A. fulgidus (accession M95624), dsrA nucleotide 181 to dsrB nucleotide 746 (a), and electrophoresis gel showing amplification products dsr $A B$, dsrA, and $d s r B$ from $p K N 23$ (b).

\section{RESULTS}

\section{Evaluation of $d s r$ gene primers and standard}

The $d s r A$ and $d s r B$ genes code for the dissimilatory sulfite reductase enzymes that catalyze the conversion of sulfite to sulfide and are highly conserved between bacteria and archaea. The primers used for this study were chosen because they had been used by several groups for detection of $d s r A B$ genes and had high target specificity to the $d s r B$ genes from a number of representative sulfate reducing bacteria and archaea (Agrawal and Lal, 2009). Our primer verification alignments conducted against $d s r B$ gene sequence from known SR bacteria and archaea also suggested a general applicability of the primers (data not shown). Of course, as is the case whenever specific PCR primers are applied to environmental samples, ensuring both definitive detection of all sulfate reducers present and the absence of false positives is not possible. However, because our ultimate intention is not to identify all of the individual sulfate reducing species but rather to estimate the likelihood of sulfate reducing activity to have occurred in a sample, this is not a significant concern.

The plasmid pKN23 containing the highly conserved sulfate reduction genes $d s r A$ and $d s r B$ from Archaeoglobus fulgidus was created for use as a quantitative external standard for estimating the number of SR bacteria and SR archaea in a sample. The $d s r A B$ genes were amplified in tandem by PCR from adjacent genes in A. fulgidus using the degenerate primers DSR1F and DSR4R and ligated into the host vector. Sequence analysis confirmed that the desired primer annealing sites were conserved in $\mathrm{pKN} 23$. Figure $2 \mathrm{a}$ shows the structure of the plasmid, consisting of the target gene fragments $d s r A$ and $d s r B$ as well as other specific DNA sequences used for characterization and sequencing purposes.

\section{Development of qPCR assav}

The entire $d s r A B$ fragment was too large for use in qPCR, and preliminary studies comparing $d s r A$ and $d s r B$ amplification indicated that the $d s r B$ assay would be more sensitive to low gene copy numbers than the $d s r A$ assay. Figure $2 \mathrm{~b}$ illustrates the relative sizes and abundances of the PCR amplification products, as determined by gel electrophoresis. Therefore primer pair DSRp2060F/DSR4R, targeting an approximately $360 \mathrm{bp}$ fragment of the $d s r B$ gene, was chosen for quantitative studies. This primer pair amplified a single product from the pKN23 dsr $B$ gene with optimum standard efficiencies ranging from 0.91 to 0.93 . Correlation coefficients $\left(R^{2}\right)$ were greater than 0.99 , indicating an efficient amplification (100\% DNA doubling per cycle). The standard assay curve was linear over $>5$ orders of magnitude, from $<10^{2}$ to $10^{7}$ gene copies per reaction.

The qPCR assay was tested against positive genomic DNA (gDNA) from A. fulgidus and the SRB $D$. alaskensis G20. Examination of the temperature at which the double stranded DNA product "melted" (separated into two strands) showed that the product from the A. fulgidus melted at $\sim 88^{\circ} \mathrm{C}$, the same value as for the DNA product from $\mathrm{pKN} 23$. This was expected since the melting temperature is a function 
of the specific DNA sequence, and the pKN23 $d s r B$ sequence was the same as the $A$. fulgidus $d s r B$ sequence. In contrast, the DNA from the SRB $(D$. alaskensis) melted at $92^{\circ} \mathrm{C}$. The higher melting temperature indicates that the two DNA strands are more strongly bound together, because of specific nucleotide interactions and/or a longer overall length of the hybridized region. Calculated sizes of known bacterial $d s r B$ fragments are generally larger than the calculated sizes of known archaeal fragments (calculations and alignments of $d s r B$ gene sequences retrieved from GenBank not shown), potentially contributing to the difference in peak temperatures. A size differential was also detected by gel analysis, as shown in Figure 3; the A. fulgidus archaeal product in lane 6 migrates farther in the gel, consistent with a smaller size, than the $D$. alaskensis bacterial product in lane 7. This attribute may prove useful for differentiating archaeal and bacterial $d s r B$ genes in studies where the composition of the sulfate reducing community is of interest, although additional experiments should be conducted to more rigorously assess its utility for this purpose.

The qPCR assay was also applied against genomic DNA from organisms in which the $d s r A B$ gene clusters are known to be absent (E. coli, $A$. acidocaldarius and $N$. europaea). E. coli and $N$. europaea each produced minor fluorescent signals but melt curve (data not shown) and gel analyses (Figure 3, lanes 3 and 5) suggested that the PCR products arose from non-specific priming events. $A$. acidocaldarius did not produce a fluorescent signal and the minor products observed by gel electrophoresis and staining were likewise probably due to non-specific priming. Based on these results real-time fluorescence of the amplified DNA was ultimately analyzed spectrophotometrically with the FAM filters at $85^{\circ} \mathrm{C}$, which eliminated interference from the non-specific primer binding observed in the negative control template reactions at lower temperatures $\left(72-84^{\circ} \mathrm{C}\right)$.

\section{Water chemistrv and geothermometry calculations for field samples}

Field measurements for temperature and $\mathrm{pH}$ at the three Soda Springs sites are shown in Table 1, along with available data on major ion concentrations. The temperature at the Soda Geyser outlet is significantly higher $\left(30^{\circ} \mathrm{C}\right)$ than at Hooper $\left(11^{\circ} \mathrm{C}\right)$ and Sulfur Springs $\left(14.2{ }^{\circ} \mathrm{C}\right.$, historical data). This is consistent with the fact that the Soda Geyser well accesses water from below the regional aquitard, and therefore mixing with the local shallow groundwater is

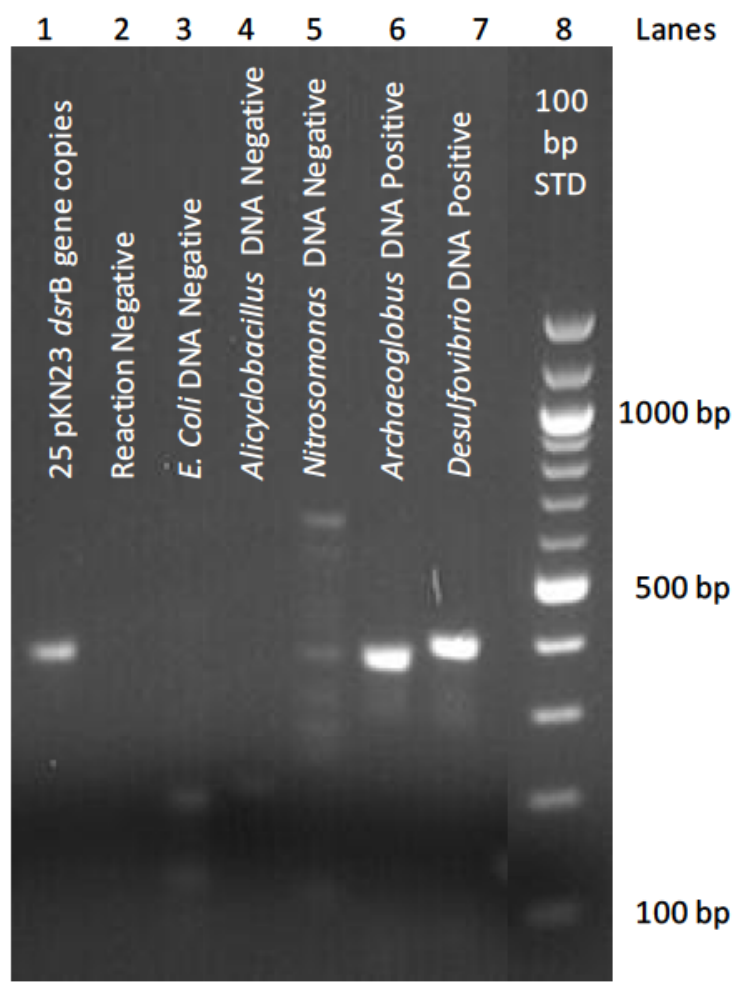

Figure 3: Ethidium bromide stained $q P C R$ products separated by agarose gel electrophoresis. Lane 1, pKN23 standard DNA; lane 2, no DNA control; lanes 3-5, DNA negative controls E. coli, A. acidocaldarius and $N$. europaea, respectively; lanes $6-7$, DNA positive controls $A$. fulgidus and $D$. alaskensis, respectively; lane $8, N E B 100$ base pair DNA standard.

expected to be minimal (Lewicki et al., 2012). In contrast, the water discharging at Hooper Springs exhibits signs of equilibration with basalt and is considered to be "well mixed" with the local groundwater (Lewicki et al., 2012; McLing et al., 2012). The water chemistry at Sulfur Springs indicates that it is sourced, like Soda Geyser, in deep Paleozoic carbonates (McLing et al., 2012). However, unlike the Soda Geyser and Hooper Springs to the west, Sulfur Springs shows no evidence, either in the local outcrops or chemically that the water has had any of the interactions with basalt that are so important to the water chemistry at Soda Geyser and Hooper Springs (McLing et al., 2012). Additionally, sulfate concentrations are particularly elevated at Sulfur Springs, indicative of thermal water interaction with carbonates. 
Table 1. Temperature, $\mathrm{pH}$, and major ion chemistry for Soda Springs samples.

\begin{tabular}{|c|c|c|c|c|c|c|c|c|c|c|c|c|c|c|}
\hline & & & & & & & & $\left(\mathrm{mg} \mathrm{t}^{-1}\right.$ & & & & & & \\
\hline & $\mathrm{T}\left({ }^{\circ} \mathrm{C}\right)$ & $\mathrm{pH}$ & $\mathrm{Ca}^{2+}$ & $\mathrm{Mg}^{2+}$ & $\mathrm{Na}^{+}$ & $\mathrm{K}^{+}$ & $\mathrm{Fe}^{2+}$ & $\mathrm{SO}_{4}{ }^{2-}$ & Cr & $\mathrm{F}^{-}$ & $\mathrm{NO}_{3}^{-}$ & $\mathrm{PO}_{4}{ }^{3-}$ & $\mathrm{HCO}_{3}^{-}$ & $\mathrm{SiO}_{2}$ \\
\hline Geyser $^{2}$ & 30.0 & 6.3 & 925.7 (42.3) & $177.7(7.9)$ & $13.1(0.4)$ & $23.5(1.2)$ & $4.9(1.0)$ & 762 & 4.95 & $<1$ & $<1$ & $<1$ & 2613 & $34.1(2.7)$ \\
\hline Hooper Springs ${ }^{b}$ & 11.0 & 6.0 & $133.5(8.2)$ & $138.2(5.8)$ & $34.0(1.4)$ & $13.0(0.2)$ & $8.0(0.8)$ & 50.9 & 12.2 & $<1$ & $<1$ & $<1$ & 101 & $71.7(4.5)$ \\
\hline Sulfur Springs ${ }^{c}$ & 14.2 & 4.8 & 599.5 & 53.4 & 12.8 & 7.8 & 101.2 & 1593 & 6 & 0.4 & 0.12 & 0.21 & 67 & 97.9 \\
\hline
\end{tabular}

${ }^{a}$ Geyser values for $\mathrm{Ca}, \mathrm{Mg}, \mathrm{Na}, \mathrm{K}, \mathrm{Fe}, \mathrm{HCO}_{3}{ }^{-}$and $\mathrm{SiO}_{2}$ are average values from four past sampling events.

${ }^{b} \mathrm{Hooper}$ Springs values for $\mathrm{Ca}, \mathrm{Mg}, \mathrm{Na}, \mathrm{K}, \mathrm{Fe}, \mathrm{HCO}_{3}{ }^{-}$and $\mathrm{SiO}_{2}$ are average values from three past sampling events.

${ }^{\mathrm{c}}$ Sulfur Springs values for $\mathrm{T}$ and $\mathrm{pH}$ are averages from 6 past sampling events. Values for $\mathrm{Ca}, \mathrm{Mg}, \mathrm{Na}, \mathrm{K}, \mathrm{Fe}$, $\mathrm{HCO}_{3}{ }^{-}$and $\mathrm{SiO}_{2}$ are from one past sampling event. Values for anions are from Mitchell (1976).

Using the data shown in Table 1 , the reservoir temperature was calculated using the quartz geothermometers as well as the multi-parameter inverse optimization approach described by Cooper et al. (2013). The predicted temperatures are shown in Table 2. Using the quartz geothermometer the predicted temperature of the deep geothermal system ranges from $86{ }^{\circ} \mathrm{C}$ at the Geyser well to $128{ }^{\circ} \mathrm{C}$ at Hooper Springs. Using the chalcedony geothermometer the calculated reservoir temperature ranges from $57{ }^{\circ} \mathrm{C}$ at Geyser to $99{ }^{\circ} \mathrm{C}$ at Hooper Springs. Typically, quartz geothermometers are considered to be the most accurate for geothermal systems in southeast Idaho (Mitchell 1976). The results from the calculated temperatures are consistent with values given in Mitchell 1976 and seem to indicate that the deep geothermal system feeding the features at Soda Springs is relatively cool. Preliminary calculations using the inverse geochemical modeling approach described by Cooper et. al. (2013), using an equilibrium-controlling mineral assemblage of siderite, calcite, anhydrite, dolomite, and chalcedony and optimizing to $\mathrm{CO}_{2}$, temperature, and $\mathrm{H}_{2} \mathrm{~S}$ (for Sulfur Springs) provide estimates of $61{ }^{\circ} \mathrm{C}$ at Geyser, $81^{\circ} \mathrm{C}$ at Sulfur Springs, and $136{ }^{\circ} \mathrm{C}$ at Hooper Springs. These results are generally consistent with the results from the quartz and chalcedony geothermometers. Note however that all of these predictive values may underestimate the true temperature of the deep reservoir, as the high concentrations of $\mathrm{Mg}^{2+}$ and the presence of a productive freshwater aquifer provide evidence for the mixing of multiple source waters.
Table 2. Geothermal reservoir temperature predictions based on water composition at Soda Spring sites.

\begin{tabular}{|l|c|c|c|}
\hline & $\begin{array}{c}\text { Quartz } \\
\text { Geothermometer } \\
\left({ }^{\circ} \mathrm{C}\right)\end{array}$ & $\begin{array}{c}\text { Chalcedony } \\
\text { Geothermometer } \\
\left({ }^{\circ} \mathrm{C}\right)\end{array}$ & $\begin{array}{c}\text { Inverse Modeling } \\
\left({ }^{\circ} \mathrm{C}\right)\end{array}$ \\
\hline Geyser & 86.0 & 57.0 & 61.1 \\
\hline Hooper Springs & 128.0 & 99.0 & 136.1 \\
\hline Sulfur Springs & 121.0 & 93.0 & 81.0 \\
\hline
\end{tabular}

Cell enumeration and quantification of SR microorganisms

Cell counts (shown in Table 3) obtained by fluorescent staining and microscopy indicated that significantly fewer cells were present in the Geyser and Hooper Springs samples (average $<10^{5}$ cells $/ \mathrm{mL}$ ) compared to the Sulfur Springs samples (average 8.5 x $10^{7}$ cells $/ \mathrm{mL}$ ). Cells at Geyser and Hooper Springs were typically very small $(\sim 1 \mu \mathrm{m})$ and mostly coccilike whereas cells from Sulfur Springs were generally larger (1-3 $\mu \mathrm{m})$ and mostly bacilli-like (Figure 4).

Table 3. Cell counts and dsrB gene numbers for Soda Springs samples (standard deviation in parentheses).

\begin{tabular}{|l|c|c|}
\hline & Cells $\left(\mathrm{ml}^{-1}\right)$ & $d s r B\left(\mathrm{ml}^{-1}\right)$ \\
\cline { 2 - 3 } Geyser & $9.3(3.1) \mathrm{E}+4$ & $3.1(2.6) \mathrm{E}+1$ \\
Hooper Springs & $4.9(1.6) \mathrm{E}+4$ & $1.9(1.3) \mathrm{E}+1$ \\
\hline Sulfur Springs & $8.5(3.4) \mathrm{E}+7$ & $9.0(3.4) \mathrm{E}+5$ \\
\hline
\end{tabular}

The $d s r B$ gene qPCR analyses suggested that SR microorganisms are present at all three of the Soda Springs sites sampled, but Sulfur Springs has by far 

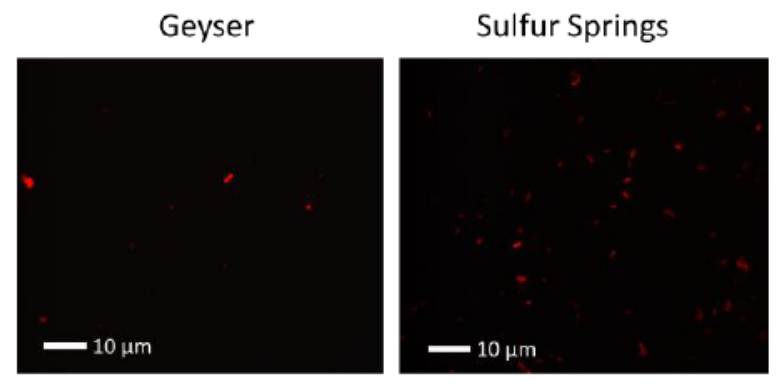

Figure 4: Epifluorescent microscopic images of representative samples from Geyser and Sulfur Springs; cells were stained with acridine orange dye and visualized at $1000 \mathrm{X}$ magnification. Note: Although cell densities in the images look similar, the Sulfur Springs sample was diluted one thousand-fold compared to the Geyser sample to facilitate counting. Cells from Hooper Springs (not shown) appeared very similar in size and shape to those from Geyser. Scale bars are 10 microns.

the largest populations (Table 3). On average $<100$ SR gene copies were present per $\mathrm{ml}$ of water from Geyser and Hooper Springs, whereas $9 \times 10^{5}$ gene copies $\mathrm{ml}^{-1}$ were present in samples from Sulfur Springs. Higher numbers of SR microorganisms might be expected given the $\sim 3$ orders of magnitude higher total cell counts at Sulfur Springs, but SR also appeared to be enriched at Sulfur Springs compared to the two other locations. Normalizing to total cell numbers, Geyser and Hooper Springs $d s r B$ gene copies constituted $0.03-0.04 \%$ of the total. At Sulfur Springs the number of $d s r B$ gene copies constituted $1.1 \%$ of the total cells counted.

Melt curve analysis of the qPCR products showed peaks for Hooper Springs at $91^{\circ} \mathrm{C}$ and Geyser at $91.5^{\circ} \mathrm{C}$ (Figure 5), similar to that observed for the SRB positive control D. Alaskensis (not shown in Figure). For the Sulfur Springs samples the peaks occurred near $89.5^{\circ} \mathrm{C}$, between the peaks observed for the SRB and SRA positive controls $\left(92^{\circ} \mathrm{C}\right.$ and $88^{\circ} \mathrm{C}$, respectively). As noted previously, the differences in melt peak temperatures may suggest that the communities of sulfate reducers differ, with sulfate reducing archaea playing a larger role at Sulfur Springs than at the other two locations, where bacteria predominate.

\section{CONCLUSIONS}

As a first step in assessing the potential implications of microbial activity on geothermometry, we developed and tested a quantitative assay for genes

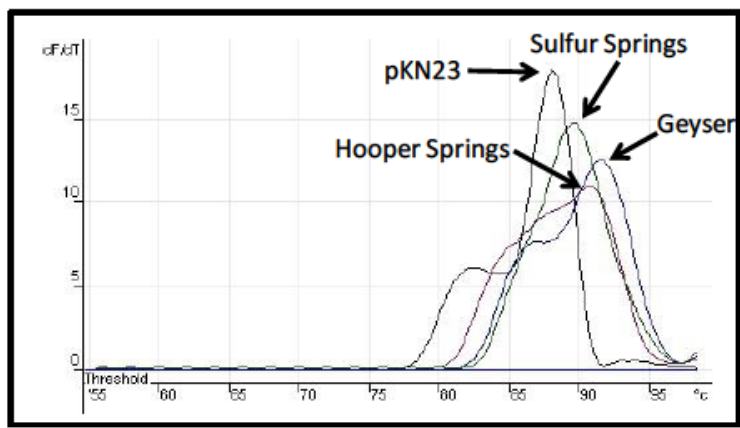

Figure 5: Representative melt curves for field sample $q P C R$ products, showing first derivative of fluorescence with respect to time ( $Y$ axis) and $P C R$ product complete denaturation temperature (X-axis). Black, pKN23; Sulphur Spring, Green; Hooper Springs, Red; Geyser, Blue.

specific to sulfate reducing bacteria and archaea. We applied it to water samples collected from a "blind" geothermal system in southeastern Idaho and obtained evidence indicating that these samples did indeed harbor sulfate reducing microorganisms. In particular, samples from a very $\mathrm{S}$ rich site (Sulfur Springs) exhibited both high biomass and high concentrations of sulfate reducing genes. These results indicate that this is an environment conducive to sulfur metabolizing activity, and thus microorganisms may play an important role in mediating water chemistry at this site. The inverse modeling calculations for geothermometry could not resolve a temperature solution without including sulfide in the geochemical calculations at levels $\geq 5$ $\mathrm{mM}$, and the resulting temperature prediction for Sulfur Springs $\left(81^{\circ} \mathrm{C}\right)$ was significantly lower than predictions using the chalcedony $\left(93{ }^{\circ} \mathrm{C}\right)$ and quartz $\left(121{ }^{\circ} \mathrm{C}\right)$ geothermometers. These observations provide preliminary evidence suggesting that microbial sulfur metabolism may influence geothermometry predictions in the Soda Springs system, and indicate that further investigation is merited. Future work will include the development of quantitative assays for other functional genes involved in sulfur cycling, and application of the assays in laboratory and/or field studies of microbial sulfur transformation and impacts on geothermometric predictions.

\section{ACKNOWLEDGMENTS}

We are very grateful to William Smith of the University of Idaho for his assistance in sample collection and geochemical characterization. Funding for this research was provided by the U.S. Department of Energy, Office of Energy Efficiency 
\& Renewable Energy, Geothermal Technologies Program.

\section{REFERENCES}

Agrawal, A., Lal, B., 2009. Rapid detection and quantification of bisulfite reductase genes in oil field samples using real-time PCR. FEMS Microbiol. Ecol. 69, 301-312.

Amend, J.P., Teske, A., 2005. Expanding frontiers in deep subsurface microbiology. Palaeogeography, Palaeoclimatology, Palaeoecology 219, 131-155.

Arnorsson, S., 1975. Application of the silica geothermometer in low temperature hydrothermal areas in Iceland. Journal Name: Am. J. Sci.; (United States); Journal Volume: 275:7, Medium: X; Size: Pages: 763-784.

Bennett, P.C., Hiebert, F.K., Rogers, J.R., 2000. Microbial control of mineral-groundwater equilibria: Macroscale to microscale. Hydrogeol. J. 8, 47-62.

Beveridge, T.J., Doyle, R., 1989. Metal ions and bacteria.

Chin, K.J., Sharma, M.L., Russell, L.A., O'Neill, K.R., Lovley, D.R., 2008. Quantifying expression of a dissimilatory (bi) sulfite reductase gene in petroleum-contaminated marine Harbor Sediments. Microb. Ecol. 55, 489-499.

Colwell, F.S., D'Hondt, S., 2013. Nature and extent of the deep biosphere. Reviews in Mineralogy and Geochemistry In press.

Cooper, D.C., Palmer, C.D., Smith, R.W., McLing, T.L., 2013. Multicomponent equilibrium models for testing geothermometry approaches, ThirtyEighth Workshop on Geothermal Reservoir Engineering, Stanford University, Stanford, CA.

Ehrlich, H.L., 1996. Geomicrobiology, 3rd ed. Marcel Dekker, Inc., New York.

Ferguson, G., Grasby, S.E., Hindle, S.R., 2009. What do aqueous geothermometers really tell us? Geofluids 9, 39-48.

Fournier, R., 1977. Chemical geothermometers and mixing models for geothermal systems. Geothermics 5, 41-50.

Geets, J., Borrernans, B., Diels, L., Springael, D., Vangronsveld, J., van der Lelie, D., Vanbroekhoven, K., 2006. DsrB gene-based DGGE for community and diversity surveys of sulfate-reducing bacteria. J. Microbiol. Methods $66,194-205$.
Giggenbach, W.F., 1988. Geothermal Solute Equilibria - Derivation of Na-K-Mg-Ca Geoindicators. Geochim. Cosmochim. Acta 52, 2749-2765.

Gunnarsson, I., Arnorsson, S., 2000. Amorphous silica solubility and the thermodynamic properties of $\mathrm{H} 4 \mathrm{SiO} 4$ degrees in the range of 0 degrees to 350 degrees C at P-sat. Geochim. Cosmochim. Acta 64, 2295-2307.

Hall, T.A., 1999. BioEdit: a user-friendly biological sequence alignment editor and analysis program for Windows 95/98/NT. Nucl. Acids. Symp. Ser. 41, 95-98.

Holden, P.A., Fierer, N., 2005. Microbial processes in the vadose zone. Vadose Zone Journal 4, 1-21.

Kepner, R.L., Pratt, J.R., 1994. Use of Fluorochromes for Direct Enumeration of Total Bacteria in Environmental-Samples - Past and Present. Microbiol. Rev. 58, 603-615.

Kieft, T.L., Brockman, F.J., 2001. Vadose Zone Microbiology, in: Fredrickson, J.K., Fletcher, M. (Eds.), Subsurface Microbiology and Biogeochemistry. Wiley-Liss, Inc., New York, NY, pp. 142-169.

Kimura, H., Sugihara, M., Yamamoto, H., Patel, B.K.C., Kato, K., Hanada, S., 2005. Microbial community in a geothermal aquifer associated with the subsurface of the Great Artesian Basin, Australia. Extremophiles 9, 407-414.

Klenk, H.P., Clayton, R.A., Tomb, J.F., White, O., Nelson, K.E., Ketchum, K.A., Dodson, R.J., Gwinn, M., Hickey, E.K., Peterson, J.D., Richardson, D.L., Kerlavage, A.R., Graham, D.E., Kyrpides, N.C., Fleischmann, R.D., Quackenbush, J., Lee, N.H., Sutton, G.G., Gill, S., Kirkness, E.F., Dougherty, B.A., McKenney, K., Adams, M.D., Loftus, B., Peterson, S., Reich, C.I., McNeil, L.K., Badger, J.H., Glodek, A., Zhou, L.X., Overbeek, R., Gocayne, J.D., Weidman, J.F., McDonald, L., Utterback, T., Cotton, M.D., Spriggs, T., Artiach, P., Kaine, B.P., Sykes, S.M., Sadow, P.W., DAndrea, K.P., Bowman, C., Fujii, C., Garland, S.A., Mason, T.M., Olsen, G.J., Fraser, C.M., Smith, H.O., Woese, C.R., Venter, J.C., 1997. The complete genome sequence of the hyperthermophilic, sulphate-reducing archaeon Archaeoglobus fulgidus. Nature 390, 364-\&.

Konhauser, K.O., Jones, B., Phoenix, V., Ferris, G., Renaut, R., 2004. The microbial role in hot spring silicification. Ambio 33, 552-558.

Lewicki, J., Hilley, G., Dobeck, L., McLing, T., Kennedy, B., Bill, M., Marino, B., 2012. Geologic 
$\mathrm{CO}_{2}$ input into groundwater and the atmosphere, Soda Springs, ID, USA. Chem. Geol.

Marteinsson, V.T., Hauksdottir, S., Hobel, C.F.V., Kristmannsdottir, H., Hreggvidsson, G.O., Kristjansson, J.K., 2001. Phylogenetic diversity analysis of subterranean hot springs in Iceland. Appl. Environ. Microbiol. 67, 4242-4248.

Mayo, A.L., Muller, A.B., Ralston, D.R., 1985. Hydrogeochemistry of the Meade thrust allochthon, southeastern Idaho, U.S.A., and its relevance to stratigraphic and structural groundwater flow control. Journal of Hydrology $76,27-61$.

McLing, T.L., Smith, W., Cooper, C., Palmer, C., Lu, C., 2012. The Characterization of $\mathrm{CO} 2$ Mineralization in Basalt Formations Using Rare Earth Elements from Natural Analogue Sites and Laboratory Experiments: Implications for the Long Term Fate of Carbon Dioxide Stored in Geologic Environments. Idaho National Laboratory, Idaho Falls, ID.

Mitchell, J., 1976. Geothermal investigations in Idaho. Part 6. Geochemistry and geologic setting of the thermal and mineral waters of the Blackfoot Reservoir area, Caribou County, Idaho. Idaho Dept. of Water Resources, Boise (USA), p. 47.

Onstott, T.C., Moser, D.P., Pfiffner, S.M., Fredrickson, J.K., Brockman, F.J., Phelps, T.J., White, D.C., Peacock, A., Balkwill, D., Hoover, R., Krumholz, L.R., Borscik, M., Kieft, T.L., Wilson, R., 2003. Indigenous and contaminant microbes in ultradeep mines. Environ. Microbiol. 5, 1168-1191.

Pedersen, K., 2000. Exploration of deep intraterrestrial microbial life: current perspectives. FEMS Microbiol. Lett. 185, 9-16.

Reed, D.W., Millstein, J., Hartzell, P.L., 2001. $\mathrm{H} 2 \mathrm{O} 2$-Forming NADH Oxidase with Diaphorase (Cytochrome) Activity from Archaeoglobus fulgidus. J. Bacteriol. 183, 7007-7016.

Reysenbach, A.-L., Shock, E., 2002. Merging Genomes with Geochemistry in Hydrothermal Ecosystems. Science 296, 1077-1082.

Rogers, J.R., Bennett, P.C., 2004. Mineral stimulation of subsurface microorganisms: release of limiting nutrients from silicates. Chem. Geol. 203, 91-108.

Rogers, K.L., Amend, J.P., 2005. Archaeal diversity and geochemical energy yields in a geothermal well on Vulcano Island, Italy. Geobiology 3, 319332.
Schultze-Lam, S., Fortin, D., Davis, B.S., Beveridge, T.J., 1996. Mineralization of bacterial surfaces. Chem. Geol. 132, 171-181.

Spycher, N., Sonnenthal, E., Kennedy, B.M., 2011. Integrating Multicomponent Chemical Geothermometry with Parameter Estimation Computations for Geothermal Exploration. GRC Transactions 35, 663-666.

Takahashi, Y., Chatellier, X., Hattori, K.H., Kato, K., Fortin, D., 2005. Adsorption of rare earth elements onto bacterial cell walls and its implication for REE sorption onto natural microbial mats. Chem. Geol. 219, 53-67.

Takai, K., Nakamura, K., 2011. Archaeal diversity and community development in deep-sea hydrothermal vents. Current Opinion in Microbiology 14, 282-291.

Takai, K., Nakamura, K., Toki, T., Tsunogai, U., Miyazaki, M., Miyazaki, J., Hirayama, H., Nakagawa, S., Nunoura, T., Horikoshi, K., 2008. Cell proliferation at $122 \mathrm{C}$ and isotopically heavy $\mathrm{CH} 4$ production by a hyperthermophilic methanogen under high-pressure cultivation. Proceedings of the National Academy of Sciences 105, 10949-10954.

Thompson, D.N., Thompson, V.S., Schaller, K.D., Apel, W.A., Lacey, J.A., Reed, D.W., 2011. Thermal and acid tolerant beta-xylosidases, genes encoding, related organisms, and methods.

Uroz, S., Calvaruso, C., Turpault, M.-P., Frey-Klett, P., 2009. Mineral weathering by bacteria: ecology, actors and mechanisms. Trends in Microbiology 17, 378-387.

Wagner, M., Roger, A.J., Flax, J.L., Brusseau, G.A., Stahl, D.A., 1998. Phylogeny of Dissimilatory Sulfite Reductases Supports an Early Origin of Sulfate Respiration. J. Bacteriol. 180, 2975-2982.

Welch, S.A., Taunton, A.E., Banfield, J.F., 2002. Effect of microorganisms and microbial metabolites on apatite dissolution. Geomicrobiol. J. 19, 343-367.

Whitman, W.B., Coleman, D.C., Wiebe, W.J., 1998. Prokaryotes: The unseen majority. Proceedings of the National Academy of Sciences 95, 6578-6583.

Wright, D.T., Oren, A., 2005. Nonphotosynthetic bacteria and the formation of carbonates and evaporites through time. Geomicrobiol. J. 22, 2753. 


\title{
Appendix J.
}

PROCEEDINGS, Thirty-Eighth Workshop on Geothermal Reservoir Engineering

Stanford University, Stanford, California, February 11-13, 2013

SGP-TR-198

\section{MULTICOMPONENT EQUILIBRIUM MODELS FOR TESTING GEOTHERMOMETRY APPROACHES}

\author{
D. Craig Cooper ${ }^{1}$, Carl D. Palmer ${ }^{1}$, Robert W. Smith ${ }^{2,3}$, and Travis L. McLing ${ }^{1,3}$, and \\ ${ }^{1}$ Idaho National Laboratory, Idaho Falls, ID, 83415, USA \\ ${ }^{2}$ University of Idaho-Idaho Falls, Idaho Falls, ID, 83402, USA \\ ${ }^{3}$ Center for Advanced Energy Studies, Idaho Falls, ID, 83415, USA \\ e-mail: craig.cooper@inl.gov
}

\section{ABSTRACT}

Geothermometry is an important tool for estimating deep reservoir temperature from the geochemical composition of shallower and cooler waters. The underlying assumption of geothermometry is that the waters collected from shallow wells and seeps maintain a chemical signature that reflects equilibrium in the deeper reservoir. Many of the geothermometers used in practice are based on correlation between water temperatures and composition or using thermodynamic calculations based a subset (typically silica, cations or cation ratios) of the dissolved constituents. An alternative approach is to use complete water compositions and equilibrium geochemical modeling to calculate the degree of disequilibrium (saturation index) for large number of potential reservoir minerals as a function of temperature. We have constructed several "forward" geochemical models using The Geochemist's Workbench to simulate the change in chemical composition of reservoir fluids as they migrate toward the surface. These models explicitly account for the formation (mass and composition) of a steam phase and equilibrium partitioning of volatile components (e.g., $\mathrm{CO}_{2}, \mathrm{H}_{2} \mathrm{~S}$, and $\mathrm{H}_{2}$ ) into the steam as a result of pressure decreases associated with upward fluid migration from depth. We use the synthetic data generated from these simulations to determine the advantages and limitations of various geothermometry and optimization approaches for estimating the likely conditions (e.g., temperature, $\mathrm{pCO}_{2}$ ) to which the water was exposed in the deep subsurface. We demonstrate the magnitude of errors that can result from boiling, loss of volatiles, and analytical error from sampling and instrumental
\end{abstract}

analysis. The estimated reservoir temperatures for these scenarios are also compared to conventional geothermometers. These results can help improve estimation of geothermal resource temperature during exploration and early development.

\section{INTRODUCTION}

A major barrier to the deployment of geothermal energy is the financial risk associated with geothermal prospecting (U.S. DOE, 2011). Geophysical surveys and test wells are expensive, and advances in prospecting are needed to reduce risk and increase the return on prospecting investments. One possibility is to improve the accuracy of geothermometry by taking advantage of advances in geochemical analyses and modeling. In geothermal systems, physical processes (e.g., mixing, boiling) and geochemical processes (e.g., mineral dissolution, precipitation) along flow paths commonly alter the composition of migrating waters. If these changes are not accurately characterized and quantified, predictions of in-situ reservoir conditions (e.g., temperature, $\mathrm{pCO}_{2}$ ) based on the chemical composition of sampled thermal waters may be erroneous, or too imprecise to be useful. However, if these processes can be correctly described and their impact on geothermometers quantified, the conditions in a deep reservoir temperature can be estimated with greater confidence.

The technical literature provides many examples of how geochemical modeling that simultaneously considers multiple mineral equilibria can be used to estimate the temperature of reservoir fluids from their geochemical fingerprints (e.g., Bethke 2008; Reed 
and Spycher, 1984; Spycher et. al., 2011). However, this technique has not yet been widely adopted by the exploration industry, and most geothermometry is conducted using traditional approaches such as silica, Na-K, Na-K-Ca, Na-K-Ca-Mg, Na-Li, and K-Mg, and various gases and stable isotopes (e.g., Armannsson and Fridriksson, 2009; Karingithi, 2010, Young et. al., 2012). These approaches are useful, but suffer from some inherent limitations, including:

- Each of these geothermometers has a different conceptual model, and reliable selection of a geothermometer requires a priori knowledge of in-situ conditions.

- Because of this disparate set of conceptual models, each geothermometer will often predict a different temperature for the same solution chemistry.

- They do not provide for a straightforward method to independently assess the accuracy and/or reliability of the temperature prediction.

- They do not directly account for changes in fluid chemistry that occur as the fluid migrates from the reservoir to the sampling point that are the result of boiling and subsequent venting of volatile components even if no net heat (enthalpy) is lost.

- They do not explicitly account for the multiple influences of mineral alteration reactions on solution chemistry in a manner that allows for improvements in thermodynamic datasets and analytical technologies to be easily adopted.

Many of these weaknesses can be addressed if geochemical reaction path modeling is used as a basis for geothermometry. Modern geochemical models couple up-to-date thermodynamic datasets with userprovided aqueous solution and gas-phase composition to rapidly calculate the temperaturedependent saturation states of a fluid with hundreds of different minerals. These calculations, coupled with inverse parameter optimization, can be used to estimate reservoir temperature by determining the point at which multiple equilibria "converge" to a common temperature.

In this paper, we outline some of the concepts for a multicomponent equilibrium approach to geothermometry and discuss how these concepts can be implemented. The potential validity of this approach is tested using simulated datasets of synthetic geothermal waters that have a known reservoir temperature and hydrogeochemical history. We use that dataset to test an inverse numerical optimization approach for estimating geothermal reservoir temperatures using multicomponent equilibrium geothermometry.

\section{MULTICOMPONENT GEOTHERMOMETRY}

A simple conceptual model of a geothermal system is illustrated in Figure 1. While different sites have unique, site-specific aspects, the base conceptual model captures key chemical and physical features common to most geothermal systems.

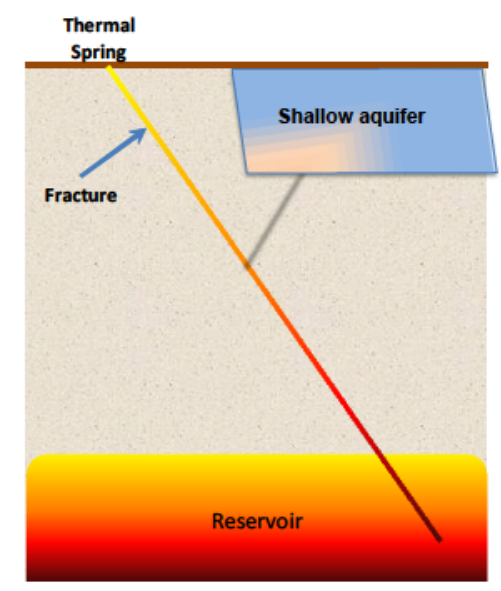

Figure 1: Conceptual model for geothermal system. Water and steam rising up to a thermal spring or shallow aquifer, experiencing cooling and venting of volatile components.

In this conceptual model, fluids in a deep reservoir are heated to reservoir temperature and react with the reservoir mineral assemblage. Equilibrium is assumed because the rates of reaction are expected to be relatively fast at these elevated temperatures. These geothermal waters then rise along a fracture, pressure drops and a portion of the water separates into a vapor phase (Figure 2).

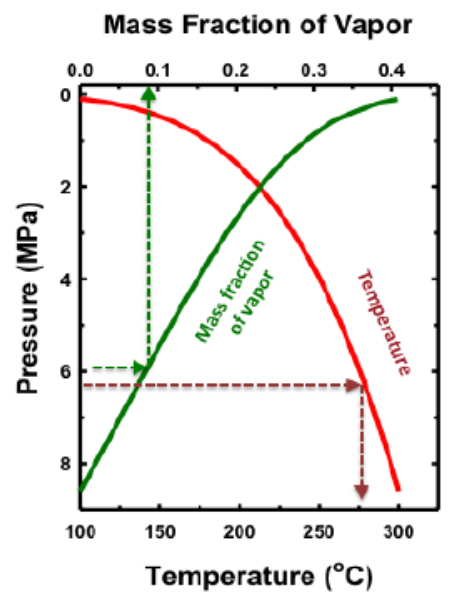

Figure 2: Pressure versus temperature (red line, bottom axis) and pressure versus mass fraction of vapor (green line, top axis) for water in constant enthalpy system. 
This process also reduces fluid temperature, even though the total combined enthalpy of the fluids remains constant due to the latent heat of vaporization. The resulting two-phase system concentrates the non-volatile constituents in the liquid phase and partitions volatile components such as $\mathrm{CO}_{2}, \mathrm{CH}_{4}, \mathrm{H}_{2}$, and $\mathrm{H}_{2} \mathrm{~S}$ to a steam phase; altering solution $\mathrm{pH}$ and redox (Eh) and shifting the saturation state for mineral equilibria. Near the surface, the geothermal system subsequently vents volatile components to the atmosphere (spring or well), or mixes with shallow groundwater (e.g., aquifer mixing). These cooler waters, or a steam condensate, are typically sampled during geothermal exploration and then analyzed for their mass and/or isotopic composition. The geochemical data collected from these samples are then used to estimate the temperature of the fluid in the deep reservoir, based on the assumption that the relatively slow rates of mineral dissolution and precipitation reactions at the lower temperatures along the migration path allow the solution to retain the geochemical fingerprint of the deep reservoir.

Some of the basic concepts of multicomponent geothermometry of been described by others (e.g., Bethke 2008; Reed and Spycher, 1984; Spycher et. al., 2011). The methodology involves calculating saturation indices of the near-surface water sample as a function of temperature. The reservoir temperature can then be defined as the temperature at which the multiple mineral species deemed likely to be present in the system are in equilibrium with the solution composition, when mineral saturation states are plotted as a function of temperature. This definition is depicted in the following example (Bethke, 2008).

A brine containing 3 molal $\mathrm{Cl}$ and 0.05 molal $\mathrm{Ca}$ at $\mathrm{pH} 5$ is equilibrated with quartz, calcite, albite, Kspar, and muscovite at $250^{\circ} \mathrm{C}$. This geothermal water is transported to the surface where the gas phase is condensed and reconstituted with the liquid phase at $25^{\circ} \mathrm{C}$ and the $\mathrm{pH}$ and dissolved constituents are measured. The system represents a closed hydrothermal system where both the liquid phase and the gas phase could be sampled. Speciation calculations are made at $25^{\circ} \mathrm{C}$, at the $\mathrm{pH}$ measured at that temperature. The water is then speciated as a function of temperature over the range of $25^{\circ} \mathrm{C}$ to $300^{\circ} \mathrm{C}$, allowing the $\mathrm{pH}$ to be calculated using The Geochemist's Workbench ${ }^{\circledR}$ (Version 9). Plotting the calculated mineral saturation indices as a function of temperature (Figure 3) shows that the indices for quartz, calcite, albite, K-feldspar, and muscovite converge common point where $\mathrm{Q} / \mathrm{K}=1(\log (\mathrm{Q} / \mathrm{K})=$ 0 ) at $250{ }^{\circ} \mathrm{C}$. This point where the saturation indices converge to zero is the reservoir temperature estimated by the multicomponent geothermometry approach. This estimate is identical to that used to generate the subsurface fluid chemistry in this simple example. However, real-world systems are more complex than this idealized example, and additional processes will need to be considered.

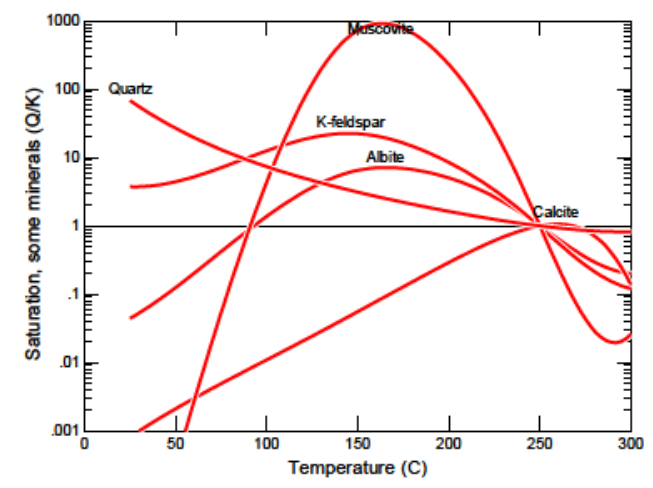

Figure 3: Plot of mineral saturation state versus temperature for a hypothetical closed geothermal system (Bethke, 2008).

For example, consider Figure 4, which shows how the system depicted in Figure 3 would behave if $\mathrm{CO}_{2}$ was lost to the atmosphere at the sampling location (e.g., a spring). Here, the mineral saturation plots for albite, K-feldspar, and quartz appear to converge, but calcite and muscovite do not. Further, the convergence of albite, $\mathrm{K}$-feldspar and quartz suggests a reservoir temperature of about $256^{\circ} \mathrm{C}$ rather than $250^{\circ} \mathrm{C}$. Even for these three minerals, the saturation occurs at $257.4,256.0$, and $249.8^{\circ} \mathrm{C}$, respectively.

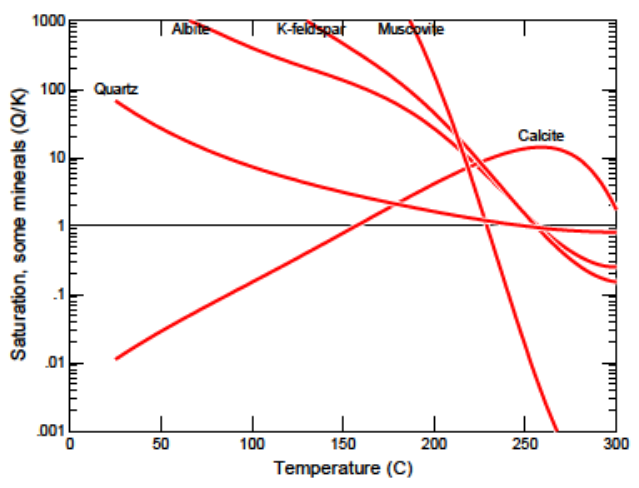

Figure 4: Plot of mineral saturation state versus temperature for the system depicted in Figure 3, but open to the atmosphere (Bethke, 2008). 
This result clearly indicates that loss of volatile constituents from a geothermal system can have a significant impact on the relationship between fluid chemistry and estimated reservoir temperature. However, field sampling programs for geothermal exploration typically do not gather sufficient data to directly account for loss of volatile constituents. Thus, the optimization process should explicitly include volatile components lost $\left(\mathrm{CO}_{2}\right.$ in this case $)$ as an optimization parameter.

In Figures 3 and 4, we have shown only the saturation indices of the minerals with which the initial reservoir fluid was equilibrated. It is important to note, however, that geochemical models can provide saturation indices for hundreds of mineral phases making graphical as well as numerical estimation of the reservoir extremely difficult, if not impossible. Fortunately, it is unnecessary and actually incorrect to include all potential solid phases in such calculations. For equilibrium, the Gibbs phase rule defines the maximum number of independent variables within a system (equation 1).

$$
\begin{aligned}
\text { 1. } & =\mathrm{C}-\mathrm{P}+2 ; \text { where } \\
\mathrm{F} & =\text { degrees of freedom (independent variables) } \\
\mathrm{C} & =\text { number of components in system } \\
\mathrm{P} & =\text { number of phases in system }
\end{aligned}
$$

For cases where there is a fluid phase present and system temperature and pressure are correlated (e.g., steam saturated water), the phase rule can be used to determine the maximum number of equilibrium phases that are appropriate for the calculation (equation 2).

$$
\text { 2. } \begin{aligned}
& \mathrm{M}=\mathrm{C}-\mathrm{F} ; \text { where } \\
& \mathrm{M}=\text { number of equilibrium minerals, and } \\
& \mathrm{M} \leq \mathrm{C}
\end{aligned}
$$

Although the Gibbs phase rule limits the number of minerals that can be considered, it does not tell us which minerals need to be included. Mineral selection represents an area of continuing uncertainty. The choice of minerals is dependent upon the reservoir lithology. The geoscience literature contains numerous studies that identify alteration mineral assemblages that form when hot water interacts with reservoir minerals (e.g., Schwartz, 1959). Many hydrothermal systems are equilibrated with the alteration mineral assemblages rather than the primary reservoir lithology (e.g., Bethke, 2008; Giggenbach, 1988). It is possible to conduct inverse numerical optimization calculations that test different feasible alteration mineral assemblages. However, this approach may not yield satisfactory results in cases where the number of minerals approaches or becomes equal to the number of independent constraints (i.e. compositional measurements). In this case, convergence to a common set and values for optimization parameter would become increasingly sensitive to inherent measurement errors. An alternative is to develop a dataset of commonly observed alteration mineral assemblages for a specific lithology at low, medium, or high reservoir temperature; and then select the appropriate mineral set - using the Gibbs Phase Rule for guidance in the number of minerals to consider. This would allow the analyst to conduct multiple calculations, using the same computational and conceptual basis, but with different input parameters; and then contrast results with available field data. The relative merits of these approaches should be assessed in future work.

Another challenge associated with geothermometry is accounting for uncertainty in geochemical analyses. The calculations associated with Figures 3 and 4 are based on idealized systems in which all the parameters were "measured" with perfect certainty. In reality, chemical analyses contain analytical errors that can contribute to the overall uncertainty in the estimation of the reservoir temperature. We need to better understand the magnitude of this uncertainty and develop methods that allow us in incorporate analytical uncertainty into the uncertainty in the estimates of reservoir temperature.

\section{APPROACH}

\section{Geochemical Calculations}

As we have discussed in the previous section, several factors need to be considered for improved geothermometry:

- Estimating the steam-water partitioning that occurs as geothermal fluids migrate from depth to the sampling location.

- Partitioning of volatiles between the gas and liquid phases

- Identifying the mineral phases that control water-rock equilibrium in the deep reservoir.

- Assessing the impact of analytical error on the estimates of reservoir temperature

With respect to steam-water partitioning, pressure reductions and cooling that occurs when fluids rise from deep geothermal systems alter the percentage of total water that is present as a liquid. For example, consider the trends in Figure 2, which depicts water partitioning in a closed, constant enthalpy system. At 
$8 \mathrm{MPa}$ pressure, the system consists of $\sim 2 \%$ steam and $\sim 98 \%$ water at $300{ }^{\circ} \mathrm{C}$. At constant total enthalpy, the same fluid at atmospheric pressure is $\sim 40 \%$ steam and $\sim 60 \%$ water and $100{ }^{\circ} \mathrm{C}$. This partitioning will concentrate dissolved ions in water and facilitate the partitioning of volatile species in to the steam phase. Liquid water loss can be treated by two different approaches:

- For a general case; specifying a \% mass loss of water due to vaporization.

- For a closed, constant enthalpy system; calculating the mass of water lost to the vapor phase along each temperature step

The mass loss of volatile species from solution (e.g., $\mathrm{CO}_{2}, \mathrm{H}_{2} \mathrm{~S}$ ) can be treated similarly. For the general case, the mass loss can be specified directly. For a closed, constant enthalpy system; mass loss of volatile components can be iteratively calculated. Both approaches use mass loss as an optimization parameter, but the closed system approach allows for calculations to be made for cases where the aqueous and gas phases may follow different paths. If volatile loss is calculated iteratively, a mass balance is performed over both phases as shown in equation 3 .

3.

$$
P_{k, k, g}=\frac{\rho_{H_{2} O, l} K_{H, k}\left\lfloor M_{k, \text { total }}-M_{H 2 O}^{0}\left(1-X_{k, g}\right)\left(\sum_{\substack{i \\ i \neq k}} a_{i, k} C_{k, i, l}\right)\right]}{1000 \phi_{k} M_{H 2 O}^{0}\left[\left(1-X_{k, g}\right)+\frac{X_{k, g} K_{H, k} \rho_{H_{2} O, l}}{R T \rho_{H_{2} O, g}}\right]}
$$

where:

$\mathrm{P}_{\mathrm{k}, \mathrm{k}, \mathrm{g}}=$ partial pressure of the kth gas component,

$\mathrm{K}_{\mathrm{H}, \mathrm{k}}=$ Henry's coefficient,

$\rho_{\mathrm{H} 2 \mathrm{O}, 1}=$ density of liquid water,

$\mathrm{M}_{\mathrm{k}, \text { total }}=$ total mass of component $\mathrm{k}$,

$\mathrm{X}_{\mathrm{kg}}=$ mass fraction of water in the gas phase,

$\mathrm{M}_{\mathrm{H} 2 \mathrm{O}}^{0}=$ initial mass of water,

$\rho_{\mathrm{H} 2 \mathrm{O}, \mathrm{g}}=$ density of the vapor phase,

$\phi_{\mathrm{k}}=$ fugacity coefficient for gas component $\mathrm{k}$

$\mathrm{C}_{\mathrm{k}, \mathrm{i}, 1}=$ molal concentrations of species $\mathrm{i}$

containing component $\mathrm{k}$ with stoichiometric

coefficient $\mathrm{a}_{\mathrm{ik}}$.

We are currently testing both of these approaches for accounting for loss of water and volatile components. However, for this paper, we are demonstrating these concepts using the more general approach that does not require the assumption of a closed, constant enthalpy system.

\section{Inverse Optimizations}

For estimating the reservoir temperature, we use an optimization approach rather than the graphical approach illustrated in Figures 3 and 4. Ultimately, these calculations will be conducted by coupling The Geochemist's Workbench ${ }^{\circledR}$ (GWB) with the general parameter estimation and optimization code PEST (Doherty, 2005). However, for this paper we have done the calculations by iteratively applying GWB to generate a dataset of mineral saturation as a function of temperature and volatile constituents lost, and then finding the optimum solution for an objective function that indicates the system's overall mineral saturation state. We have defined our objective function as the minimization of the Total Saturation Index (TSI), shown in equation 4.

4. $\mathrm{TSI}=\Sigma\left(\mathrm{SI}_{\mathrm{i}} / \mathrm{wt}_{\mathrm{i}}\right)^{2}$;

$\mathrm{SI}_{\mathrm{i}}=\log \left(\mathrm{Q}_{\mathrm{i}} / \mathrm{K}_{\mathrm{i}}\right)$ for the ith equilibrium mineral

$\mathrm{wt}_{\mathrm{i}}=$ weighting factor based on the number of thermodynamic components (i.e., independent chemical variables) and the number of time each component appears in the ith mineral dissolution reaction.

Because of the squared term in Equation 4, TSI values are always greater than or equal to zero and can pass through both positive minima and maxima. The advantages of expressing the objective function in ways other than the Euclidean norm, will be explored in future work.

For a system in equilibrium and with no measurement errors, the overall equilibrium state occurs at the point at which TSI $=0$. For real water samples subject to sampling and analytical errors, the TSI value should always be greater than zero. The weighting factor ensures that each mineral that contributes to the equilibrium state is considered equally and the results are not skewed by reaction stoichiometry. The weighting factors used in our calculations are based on writing the reactions so that a total of 1 mole of ions are added to solution. Weighting factors for some example minerals are provided in Table 1 . Other weighting methods can also be used.

Table 1: Weighting factors for selected minerals.

\begin{tabular}{|c|c|c|}
\hline Mineral & $\begin{array}{c}\text { Thermodynamic } \\
\text { Components }\end{array}$ & $\begin{array}{c}\text { Weight } \\
\text { factor }\end{array}$ \\
\hline Albite & $1 * \mathrm{Al}^{3+}, 1 * \mathrm{Na}^{+}, 3 * \mathrm{SiO}_{2}$ & 5 \\
\hline Calcite & $1 * \mathrm{Ca}^{2}, 1 * \mathrm{CO}_{3}{ }^{2-}$ & 2 \\
\hline K-feldspar & $1 * \mathrm{Al}^{3+}, 1 * \mathrm{~K}^{+}, 3 * \mathrm{SiO}_{2}$ & 5 \\
\hline Muscovite & $3 * \mathrm{Al}^{3+}, 1 * \mathrm{~K}^{+}, 3 * \mathrm{SiO}_{2}$ & 7 \\
\hline Quartz & $1 * \mathrm{SiO}_{2}$ & 1 \\
\hline
\end{tabular}




\section{Example Test Cases}

To illustrate the potential power and limitations of the multicomponent equilibrium geothermometry approach, we have tested the inverse reaction path modeling approach against simulated data from four different geothermal scenarios. The scenarios were generated using The Geochemist's Workbench ${ }^{\circledR}$, Version 9 (Bethke and Yeakel, 2011), using the thermo.dat thermodynamic database. These simulated numerical datasets assumed a reservoir mineral assemblage, equilibrated water with that assemblage at a given temperature, and then subjected the simulated deep waters to a sequence of thermal and chemical events (e.g., boiling, cooling venting). The computed water chemistry represents the chemistry of water collected from a thermal spring or sampling well. We also investigate the potential impacts of sampling errors.

For each case, the given solution chemistry was input into The Geochemist's Workbench $\otimes$, and the log $(\mathrm{Q} / \mathrm{K})$ calculated as a function of temperature for a assumed equilibrium mineral assemblage of albite, calcite, K-feldspar, muscovite, and quartz were. The calculations were conducted for the range of $25^{\circ} \mathrm{C}$ to $300^{\circ} \mathrm{C}$. The effect of mass loss of $\mathrm{CO}_{2}$ due to volatilization was assessed by numerically adding $\mathrm{CO}_{2}$ (aq) back in to the solution at increments of 0.1 molal over the range of $1 \mathrm{e}-4$ to $1.0 \mathrm{molal}$. In some cases, increments of 0.02 and 0.05 molal were also considered over the range of $1 \mathrm{e}-4$ to 0.1 molal. For each case, these calculations yielded a dataset of TSI and temperature in increments of $\mathrm{CO}_{2}$-added. This dataset was then used to estimate the both reservoir $\mathrm{CO}_{2}$ and temperature by the condition at which TSI had its minimum value using the following process:

1. The optimum mass of $\mathrm{CO}_{2}$ added $(\mathrm{mol} / \mathrm{kg}$ ) was determined by finding the minimum on a plot of TSI at $\mathrm{dTSI} / \mathrm{dT}=0$ versus $\mathrm{CO}_{2}$ added

2. The optimum temperature was determined by plotting temperature at $\mathrm{dTSI} / \mathrm{dT}=0$ versus $\mathrm{CO}_{2}$ added, and then determining the temperature at the point that corresponds to the optimum mass of $\mathrm{CO}_{2}$ added.
3. The TSI at the optimum mass of $\mathrm{CO}_{2}$ added was calculated similarly.

For cases where water was lost due to boiling, the impact of water loss was qualitatively assessed by conducting replicate calculations at different extents of water loss. The test cases are described below, and the associated solution chemistry is provided in Table 2 .

Case 1: Open system (Bethke, 2008). A brine containing 3 molal $\mathrm{Cl}$ and 0.05 molal $\mathrm{Ca}$ at $\mathrm{pH} 5$ is equilibrated with quartz, calcite, albite, K-spar, and muscovite at $250^{\circ} \mathrm{C}$. This geothermal water is transported to the surface where the fluid cools to $25^{\circ} \mathrm{C}$ and $\mathrm{CO}_{2}$ vents to the atmosphere. The system represents a geothermal water that has reached the surface, cooled under closed conditions and then was exposed to the atmosphere.

Case 2: Effect of Analytical Errors. This simulation is the same as Test Case 1 except that random errors are introduced into the data: $15 \%$ relative standard deviation for $\mathrm{Al}, 10 \%$ for $\mathrm{HCO}_{3}^{-}, 5 \%$ for $\mathrm{Ca}, \mathrm{Cl}, \mathrm{K}$, $\mathrm{Na}, \mathrm{SiO}_{2}, 0.15$ units for $\mathrm{pH}$, and $1^{\circ} \mathrm{C}$ for temperature.

Case 3: Deep Boiling. A brine containing 3 molal $\mathrm{Cl}$ and 0.05 molal $\mathrm{Ca}$ at $\mathrm{pH} 5$ is equilibrated with quartz, calcite, albite, K-spar, and muscovite at $250^{\circ} \mathrm{C}$. This geothermal water is then isothermally boiled until $15 \%$ of the water is lost while maintaining equilibrium with the reservoir mineral assemblage. The resulting water is then transported to the surface where the fluid cools to $25^{\circ} \mathrm{C}$ and $\mathrm{CO}_{2}$ vents to the atmosphere.

Case 4: Flashing. A brine containing 3 molal $\mathrm{Cl}$ and 0.05 molal $\mathrm{Ca}$ at $\mathrm{pH} 5$ is equilibrated with quartz, calcite, albite, $\mathrm{K}$-spar, and muscovite at $250^{\circ} \mathrm{C}$. This geothermal water is then isothermally boiled until $15 \%$ of the water is lost but mineral reaction does not occur during boiling. The resulting water is then transported to the surface where the fluid cools to $25^{\circ} \mathrm{C}$ and $\mathrm{CO}_{2}$ vents to the atmosphere. This scenario represents fluid flashing within a well.

Table 2: $\quad$ Solution Chemistry for Numerical Test Cases.

\begin{tabular}{|c|c|c|c|c|c|c|c|c|c|}
\hline Case & $\begin{array}{c}\mathbf{A l}^{3+} \\
(\mathbf{m g} / \mathbf{k g})\end{array}$ & $\begin{array}{c}\mathbf{C a}^{2+} \\
(\mathbf{m g} / \mathbf{k g})\end{array}$ & $\begin{array}{c}\mathbf{N a}^{+} \\
(\mathbf{m g} / \mathbf{k g})\end{array}$ & $\begin{array}{c}\mathbf{K}^{+} \\
(\mathbf{m g} / \mathbf{k g})\end{array}$ & $\begin{array}{c}\mathbf{C l}^{-} \\
(\mathbf{m g} / \mathbf{k g})\end{array}$ & $\begin{array}{c}\mathbf{H C O}_{3}^{-} \\
(\mathbf{m g} / \mathbf{k g})\end{array}$ & $\begin{array}{c}\mathbf{S i O}_{\mathbf{2}} \\
(\mathbf{m g} / \mathbf{k g})\end{array}$ & $\mathbf{p H}$ & $\begin{array}{c}\text { Sample } \\
\mathbf{T e m p} .\end{array}$ \\
\hline 1 & $8.66 \mathrm{e}-3$ & $2.00 \mathrm{e} 3$ & $6.39 \mathrm{e} 4$ & $1.01 \mathrm{e} 4$ & $1.13 \mathrm{e} 4$ & $2.39 \mathrm{e} 3$ & $2.10 \mathrm{e} 2$ & 5.10 & $25^{\circ} \mathrm{C}$ \\
\hline 2 & $9.53 \mathrm{e}-3$ & $1.96 \mathrm{e} 3$ & $6.64 \mathrm{e} 4$ & $0.98 \mathrm{e} 4$ & $1.10 \mathrm{e} 4$ & $2.20 \mathrm{e} 3$ & $2.12 \mathrm{e} 2$ & 5.09 & $24.4^{\circ} \mathrm{C}$ \\
\hline 3 & $7.65 \mathrm{e}-3$ & $2.35 \mathrm{e} 3$ & $7.66 \mathrm{e} 4$ & $1.21 \mathrm{e} 4$ & $1.33 \mathrm{e} 4$ & $2.41 \mathrm{e} 3$ & $2.07 \mathrm{e} 2$ & 5.13 & $25^{\circ} \mathrm{C}$ \\
\hline 4 & $10.2 \mathrm{e}-3$ & $2.36 \mathrm{e} 3$ & $7.52 \mathrm{e} 4$ & $1.19 \mathrm{e} 4$ & $1.31 \mathrm{e} 4$ & $0.85 \mathrm{e} 3$ & $2.45 \mathrm{e} 2$ & 5.20 & $25^{\circ} \mathrm{C}$ \\
\hline
\end{tabular}




\section{RESULTS}

Results from the inverse geochemical calculations are summarized in Table 3 . For the relatively simple scenario in Case 1, the inverse method independently predicted reservoir temperature to within $\pm 1{ }^{\circ} \mathrm{C}$. This result is a significant improvement over the results gained when only temperature is considered (e.g., Figure 4), and demonstrates how including volatile loss as part of the optimization scheme can greatly improve geothermometry.

Table 3: Results from Inverse Calculations. For all cases, the actual temperature is $250^{\circ} \mathrm{C}$.

\begin{tabular}{|c|c|c|c|c|}
\hline \multirow{2}{*}{ Case } & $\begin{array}{c}\mathbf{H}_{2} \mathbf{O} \\
\text { loss }\end{array}$ & $\begin{array}{c}\text { T } \\
\left({ }^{\circ} \mathbf{C}\right)\end{array}$ & $\begin{array}{c}\mathbf{C O}_{2} \text {-aq } \\
\text { added } \\
(\mathbf{m o l} / \mathbf{k g})\end{array}$ & $\begin{array}{c}\text { TSI at } \\
\text { optimum }\end{array}$ \\
\hline 1 & n.a. & 250.6 & 0.52 & $5.12 \mathrm{e}-4$ \\
\hline 2 & n.a. & 253.0 & 0.45 & $7.72 \mathrm{e}-4$ \\
\hline \multirow{4}{*}{3} & none & 249.7 & 0.63 & $4.50 \mathrm{e}-4$ \\
\cline { 2 - 5 } & $10 \%$ & 242.0 & 0.44 & $1.33 \mathrm{e}-3$ \\
\cline { 2 - 5 } & $20 \%$ & 233.5 & 0.29 & $2.69 \mathrm{e}-3$ \\
\cline { 2 - 5 } & $30 \%$ & 221.2 & 0.14 & $7.03 \mathrm{e}-3$ \\
\hline \multirow{4}{*}{4} & none & 259.6 & 0.08 & $6.50 \mathrm{e}-2$ \\
\cline { 2 - 5 } & $10 \%$ & 254.1 & 0.07 & $1.13 \mathrm{e}-2$ \\
\cline { 2 - 5 } & $20 \%$ & 248.7 & 0.06 & $9.27 \mathrm{e}-3$ \\
\cline { 2 - 5 } & $30 \%$ & 233.3 & 0.03 & $2.03 \mathrm{e}-2$ \\
\hline
\end{tabular}

The influence of volatile loss is also seen in the plot of Total Saturation Index (TSI) versus potential reservoir temperature for each amount of $\mathrm{CO}_{2}$ added (Figure 5). In this plot, the different colored curves correspond to different masses of $\mathrm{CO}_{2}$-added back into the system. Each of these curves shows a minimum that corresponds with the "convergence point" of saturation indices that can be qualitatively identified from a plot of temperature versus the log $(\mathrm{Q} / \mathrm{K})$ for sets of minerals that are likely to be present in a reservoir. The minimum becomes more clearly resolved as $\mathrm{CO}_{2}$ is added back into the system to account for venting.

The blue line in Figure 5 represents a fully vented system (e.g., as in Figure 4). The lines where greater than $0.3 \mathrm{~mol} / \mathrm{kg} \mathrm{H}_{2} \mathrm{O}$ of $\mathrm{CO}_{2}$-(aq) have been added back into the system represent the closed system prior to loss of volatiles (e.g., as in Figure 3). The line with the lowest minimum represents the best solution. This point can be more easily identified from the derivative of the TSI function. The point at which $\mathrm{dTSI} / \mathrm{dT}=0$ defines the minimum point in the TSI plot. An example of this is shown in Figure 6.
The zero-point for this sequence of dTSI/dT plots is used to determine the amount of $\mathrm{CO}_{2}$ needed to reach the minimum possible saturation index over a $2-\mathrm{D}$ range of $\mathrm{CO}_{2}$ and temperature. This is shown graphically in Figure 7, where the y-axis represents the set of points where a plot of TSI versus temperature is at a minimum.

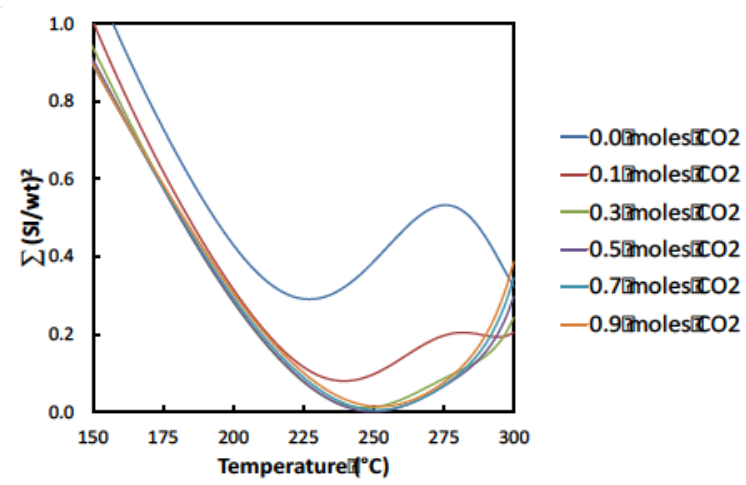

Figure 5: Plot of the total saturation index (TSI) as a function of temperature and added $\mathrm{CO}_{2}$ for a shallow water sample derived from a deep geothermal reservoir that has lost volatiles as per Case 1 (e.g. Figures 3, 4).

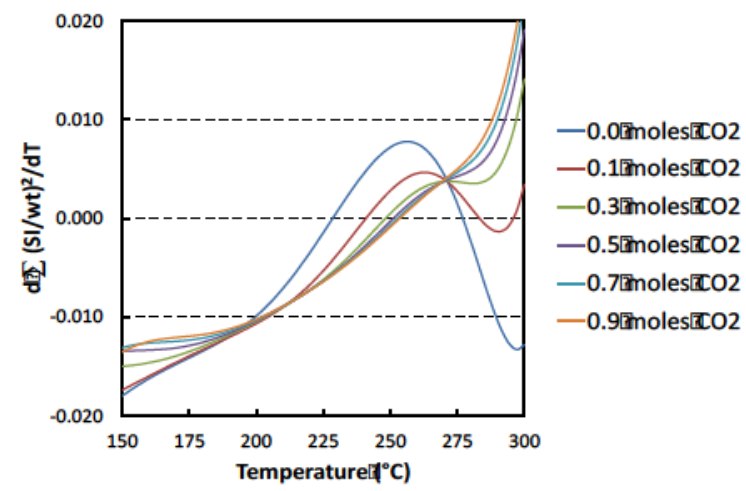

Figure 6: Plot of dTSI/dT as a function of temperature and added $\mathrm{CO}_{2}$ for the same case as in Figure 5.

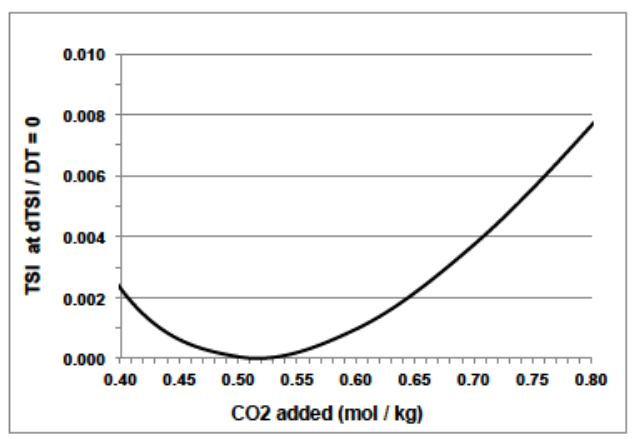

Figure 7: Plot of TSI at the point where dTSI/dT $=0$ for all amounts of $\mathrm{CO}_{2}$ added for the same case as in Figures 5 - 6 . 
The minimum of this value, when plotted against $\mathrm{CO}_{2}$ added, yields a minimum point for $\mathrm{CO}_{2}$ added, over the entire set. This minimum point for $\mathrm{CO}_{2}$ added is then used to calculate the corresponding temperature value, as shown in Figure 8.

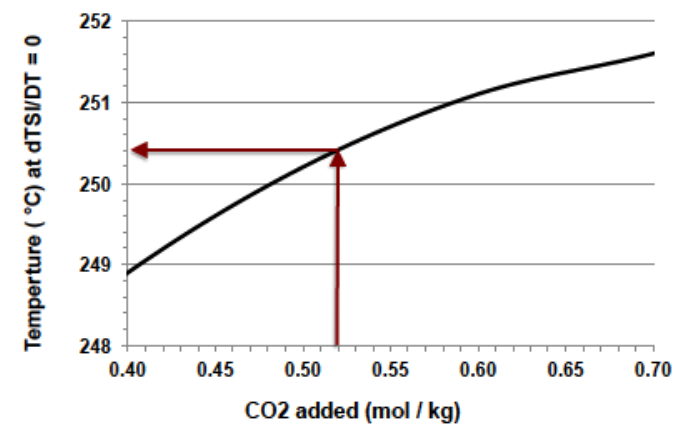

Figure 8: Plot of temperature at the point where $d T S I / d T=0$ for all amounts of $\mathrm{CO}_{2}$ added for Case 1 (e.g. Figures 3 - 7).

For Case 2, which incorporated the impact of typical analytic error, application of this inverse optimization method for geochemical modeling independently predicted reservoir temperature to within $\pm 3{ }^{\circ} \mathrm{C}$. This result suggests that typical analytical errors can be tolerated in geothermometry.

The results for Test Case 3 (deep boiling) and Test Case 4 (flashing) are also encouraging for cases where there was water loss due to boiling. When the optimum value of TSI was at an approximate minimum with respect to mass of water loss, as estimated by selecting the temperature prediction for the water loss case with the lowest TSI at the optimum point, the method predicted the correct result to within $\pm 1{ }^{\circ} \mathrm{C}$. Interestingly, the method selected an optimum point at no water loss for the deep boiling case (Case 3 ), and at $20 \%$ water loss for the steam flashing case (Case 4). In both instances, the actual amount of water loss was $15 \%$. In Case 3, there is mass transfer due to the mineral equilibria, but no mass transfer in Case 4. This suggests that, if the extent of water partitioning can be independently measured (e.g., via isotopic techniques), then comparison of predicted and actual mass loss may provide a way to estimate the extent to which mineralization occurs within the geothermal system.

A comparison of results of the multicomponent geothermometry approach with some traditional geothermometers is provided in Table 4 . The quartz geothermometer underestimates the reservoir temperature by as much as $80^{\circ} \mathrm{C}$, while the Na-K geothermometers overestimate the reservoir temperature by 13 to $22{ }^{\circ} \mathrm{C}$. In contrast, the multicomponent geothermometry method consistently estimates reservoir temperature to within $\pm 1-3{ }^{\circ} \mathrm{C}$ when water loss is taken into account.

Table 4: Comparison with temperature estimates using traditional geothermometers. Same cases as for Table 3.

\begin{tabular}{|c|c|c|c|c|}
\hline Method & $\begin{array}{l}\text { Case } 1 \\
\mathrm{~T}\left({ }^{\circ} \mathbf{C}\right)\end{array}$ & $\begin{array}{l}\text { Case 2 } \\
\mathrm{T}\left({ }^{\circ} \mathrm{C}\right)\end{array}$ & $\begin{array}{l}\text { Case } 3 \\
\mathrm{~T}\left({ }^{\circ} \mathrm{C}\right)\end{array}$ & $\begin{array}{l}\text { Case } 4 \\
\mathrm{~T}\left({ }^{\circ} \mathrm{C}\right)\end{array}$ \\
\hline $\begin{array}{c}\text { Inverse } \\
\text { Modeling }\end{array}$ & 251 & 253 & 250 & 249 \\
\hline $\begin{array}{l}{ }^{\mathrm{T}} \text { Fournier } \\
\text { Quartz } \\
\text { (no steam) }\end{array}$ & 183 & 184 & 182 & 194 \\
\hline $\begin{array}{c}{ }^{1} \text { Fournier } \\
\text { Quartz } \\
\text { (max steam) }\end{array}$ & 170 & 172 & 170 & 180 \\
\hline $\begin{array}{l}{ }^{1} \text { Fournier } \\
\text { Chalcedony }\end{array}$ & 156 & 157 & 156 & 168 \\
\hline $\begin{array}{l}{ }^{1} \text { Fournier } \\
{\mathrm{Am}-\mathrm{SiO}_{2}}\end{array}$ & 59 & 60 & 59 & 70 \\
\hline $\begin{array}{c}{ }^{2} \text { Fournier } \\
\text { Na-K }\end{array}$ & 271 & 263 & 270 & 271 \\
\hline $\begin{array}{l}{ }^{3} \text { Giggenbach } \\
\text { Na-K }\end{array}$ & 272 & 265 & 272 & 272 \\
\hline
\end{tabular}

\section{SUMMARY AND CONCLUSIONS}

The basic concepts of geothermometry have been available for about five decades and many of the early geothermometers are still being applied today. The application of these techniques can result in a wide range of estimated reservoir temperatures and limited ability to judge the uncertainty of the calculations. In this paper, we have proposed a multicomponent geothermometry technique that is an extension of the concepts provided by Reed and Spycher (1984). We take advantage of the advances that have been made in geochemical modeling, thermodynamic databases, and optimization tools to improve the estimates of reservoir temperatures.

To test these concepts, we have used The Geochemist's Workbench $\circledast$ to simulate the chemical composition of geothermal waters following cooling, loss of water vapor, loss of volatile constituents and mineral reactions. These simulations were then used to demonstrate our ability to replicate the initial reservoir temperatures. The results indicate that the 
multicomponent geothermometry presented here has excellent potential for improving the practice of geothermometry for geothermal exploration and resource characterization. These preliminary results indicate that most geothermometry problems can be usefully resolved if the following factors are properly accounted for:

- Selection of the appropriate number of mineral phases to control solution equilibrium.

- Accurately selecting which minerals to use for geochemical calculations, on the basis of regional geology.

- Properly accounting for the impact of steamwater partitioning on solution chemistry.

- Properly accounting for the impact of the loss of volatile components on solution chemistry.

Typical analytical errors have only minimal effect on estimates of reservoir temperature. Overall, the results suggest that the multicomponent geothermometry method is relatively robust and could greatly improve the industry's ability to estimate deep reservoir temperatures. Additional improvements to the multicomponent geothermometry approach that are being explored include the use of other objective functions and alternative weighting functions, improved techniques for tracking gas phase partitioning, inclusion of additional volatile components (e.g., $\mathrm{H}_{2} \mathrm{~S}, \mathrm{H}_{2}, \mathrm{CH}_{4}$ ), assessment of mineral reactions along the path from the deep reservoir and the sampling point, and methods for determining mineral assemblages. Extending this method beyond the relatively simple system explored via these simulations would require optimization of additional parameters and use of automated numerical optimization software that can conduct multi-component optimizations. This work is currently underway.

\section{ACKNOWLEDGMENTS}

Funding for this research was provided by the U.S. Department of Energy, Office of Energy Efficiency \& Renewable Energy, Geothermal Technologies Program. We are also grateful to the Center for Advanced Energy Studies for providing additional support.

\section{REFERENCES}

Ármannsson, H. and Fridriksson, T. (2009), "Application of Geochemical Methods in Geothermal Exploration", Short Course on Surface Exploration for Geothermal Resources, organized by United Nations University
Geothermal Training Programme, Ahuachapan and Santa Tecla, El Salvador, October 2009.

Bethke, C.M. and Yeakel, S. (2011), "The Geochemist's Workbench User's Guides, Aqueous Solutions LLC, Champaign IL.

Bethke, C.M. (2008), "Geochemical and Biogeochemical Reaction Modeling", Cambridge University Press, $2^{\text {nd }}$ Ed., New York, New York, USA, 543 pp.

Doherty J. (2005), "PEST, Model-Independent Parameter Estimation User Manual, $5^{\text {th }}$ Edition", Watermark Numerical Computing, www.pesthompage.org

Fournier, R.O., Sorey, M.L., Mariner, R.H., and Truesdell, A.H. (1979), "Chemical and Isotopic Prediction of Aquifer Temperatures in the Geothermal System at Long valley, California", Journal of Volcanology and Geothermal Research, 5, 17-34.

Giggenbach, W.F. (1988), "Geothermal Solute Equilibria - Derivation of Na-K-Mg-Ca Geoindicators", Geochimica et Cosmochimica Acta, 52, 2479-2765

Karingithi C.W. (2012), "Chemical Geothermometers for Geothermal Exploration", Short Course V on Exploration for Geothermal Resources, organized by United Nations University Geothermal Training Programme, Lake Bogoria and Lake Naivasha, Kenya, October 2010.

Reed, M.H. and Spycher, N.F. (1984), "Calculation of $\mathrm{pH}$ and mineral equilibria in hydrothermal waters with application to geothermometry and studies of boiling and dilution", Geochimica et Cosmochimica Acta, 48, 1479-1492.

Schwartz, G.M. (1959), "Hydrothermal Alteration", Economic Geology, 54, 161-183

Spycher, N.F., Sonnenthal, E. and Kennedy, B.M. (2011), "Integrating Multicomponent Chemical Geothermometry with Parameter Estimation Computations for Geothermal Exploration", GRC Transactions, 35, 663-666.

Truesdell, A.H. and Fournier, R.O. (1977), "Procedure for Estimating Temperature of a HotWater Component in a Mixed Water by Using a Plot of Dissolved Silica versus Enthalpy", Journal of Research of the U.S. geological Survey, 5, 49-52.

U.S. Department of Energy (2011), "Exploration Technologies, Technology Needs Assessment," Energy Efficiency and Renewable Energy, Geothermal Technologies Program, DOE/EE0663. 
Young, K., Reber, T., and Witherbee, K. (2012), "Hydrothermal exploration Best Practices and Geothermal Knowledge Exchange on OPENEI", Proc. $37^{\text {th }}$ Workshop on Geothermal Reservoir Engineering, Stanford University, Stanford, CA, SGP-TR-194 


\title{
Deep Geothermal Reservoir Temperatures in the Eastern Snake River Plain, Idaho using Multicomponent Geothermometry
}

\author{
Ghanashyam Neupane ${ }^{1,2}$, Earl D. Mattson ${ }^{2,3}$, Travis L. McLing ${ }^{2,3}$, Carl D. Palmer ${ }^{1}$, Robert W. Smith ${ }^{1,2}$, Thomas R. \\ Wood $^{1,2}$ \\ ${ }^{1}$ University of Idaho-Idaho Falls, 1776 Science Center Drive, Suite 306, Idaho Falls, ID 83402 \\ ${ }^{2}$ Center for Advanced Energy Studies, 995 University Boulevard, Idaho Falls, ID 83401 \\ ${ }^{3}$ Idaho National Laboratory, 2525 Fremont Ave, Idaho Falls, ID 83415 \\ E-mail: gneupane@uidaho.edu
}

Keywords: Geothermometry, Eastern Snake River Plain, Geothermal Energy, Yellowstone Hotspot, RTEst

\begin{abstract}
The U.S. Geological survey has estimated that there are up to 4,900 MWe of undiscovered geothermal resources and 92,000 MWe of enhanced geothermal potential within the state of Idaho. Of particular interest are the resources of the Eastern Snake River Plain (ESRP) which was formed by volcanic activity associated with the relative movement of the Yellowstone Hot Spot across the state of Idaho. This region is characterized by a high geothermal gradient and thermal springs occurring along the margins of the ESRP. Masking much of the deep thermal potential of the ESRP is a regionally extensive and productive cold-water aquifer.
\end{abstract}

We have undertaken a study to infer the temperature of the geothermal system hidden beneath the cold-water aquifer of the ESRP. Our approach is to estimate reservoir temperatures from measured water compositions using an inverse modeling technique (RTEst) that calculates the temperature at which multiple minerals are simultaneously at equilibrium while explicitly accounting for the possible loss of volatile constituents (e.g., $\mathrm{CO}_{2}$ ), boiling and/or water mixing. In the initial stages of this study, we apply the RTEst model to water compositions measured from a limited number of wells and thermal springs to estimate the regionally extensive geothermal system in the ESRP.

\section{INTRODUCTION}

Several states in the western US have high potential of geothermal energy. The US Geological Survey has estimated that there are up to 4,900 MWe of undiscovered geothermal resources and 92,000 MWe of enhanced geothermal potential within the state of Idaho (Williams et al., 2008). The southern part of the state, particularly, the Eastern Snake River Plain (ESRP), has been regarded to have high geothermal potential for enhanced geothermal system (EGS) development (Tester et al., 2006). The ESRP represents a volcanic province with a high deep thermal flux (Blackwell et al., 1992). A limited number of deep wells (such as INEL-1) and some thermal springs along the margin of ESRP provide direct evidence of a high-temperature regime at depth in the area. However, most of the shallow wells in the ESRP generally have low field-measured temperature, and it is likely that the Eastern Snake River Plain Aquifer (ESRPA) is obscuring geothermal signature at depth. The ESRPA is a prolific aquifer hosted in a thick sequence of thin-layered, highly transmissive basalt flows. Transmissivity commonly exceeds $9,290 \mathrm{~m}^{2} /$ day and in places, $92,900 \mathrm{~m}^{2} /$ day (Whitehead, 1992). The aquifer rapidly transports cold water from the Yellowstone Plateau and surrounding mountain basins to springs along the Snake River Canyon west of Twin Falls, Idaho. The estimated average linear ground-water velocities range from 0.61 to $6.1 \mathrm{~m} /$ day as determined from atmospheric tracers $\left({ }^{3} \mathrm{H} /{ }^{3} \mathrm{He}\right.$, chlorofluorocarbons) and long-term monitoring of contaminant movement in the aquifer (Ackerman et al., 2006). We believe the flush of cold water through the overlying ESRPA masks the geothermal signature of the heat existing at depth. Importantly, the geothermal gradient below the ESRP aquifer system increases rapidly (McLing et al., 2002) providing additional evidence of the presence of a deep geothermal resource in the area.

One of the prospecting tools for geothermal resources is geothermometry, which uses the chemical compositions of water from springs and wells to estimate reservoir temperature. The application of geothermometry requires several assumptions. The most important assumptions are that the reservoir minerals and fluid attain a chemical equilibrium and as the water moves from the reservoir to sampled location, it retains its chemical compositions (Fournier et al., 1974). The first assumption is generally valid (provided a long residence time); however, the second assumption is more likely to be violated because of secondary processes, such as, reequilibration at lower temperature, dilution (mixing), and loss of fluids (boiling) and volatiles (e.g., $\mathrm{CO}_{2}$ ) with the decrease in pressure.

The ESRP system as a whole (including deep reservoir and overlying cold-water aquifer system) is an open and dynamic hydrogeologic system. Most water from shallow wells and springs in the ESRP are mixed waters of multiple sources, particularly a mix of meteoric water and deep-sourced reservoir water (McLing et al., 2002). Moreover, the relative contribution of deep-sourced reservoir water to the upper cold ESRPA is thought to be small. With exception of waters issued from isolated deep-conduits (e.g., deep fractures/faults, deep wells), most of the waters from shallow wells and springs probably have very diluted if any chemical signature representing the deep-sourced reservoir water. In this situation, it is very important to determine the fraction of deep-sourced reservoir water in waters from ESRP wells and springs to reliably assess the reservoir temperature.

As part of an effort to estimate ESRP geothermal reservoir temperature, we assembled published and unpublished chemical composition of waters measured for various wells and springs. These data were analyzed graphically and statistically to identify the potential chemical signature of deep-sourced reservoir water, and then used to estimate reservoir temperatures using an inverse geochemical modeling tool (Reservoir Temperature Estimator, RTEst) being developed by our research group. In this paper, we present preliminary results of RTEst applied to ESRP water measured at a number of wells and thermal springs. 


\section{GEOLOGIC AND GEOTHERMAL SETTING}

The Snake River Plain (SRP) is a topographic depression along the Snake River (Figure 1) in south Idaho. The SRP is divided into two parts, the western Snake River Plain (WSRP) and ESRP. The WSRP is a basalt and sediment filled tectonic feature defined by normal fault-bounded graben whereas the ESRP is formed by crustal down-warping, faulting, and successive caldera formation that is linked to the middle Miocene to recent volcanic activities associated with the relative movement of the Yellowstone Hot Spot (Figure 1) (Pierce and Morgan, 1992; Hughes et al., 1999; Rodgers et al., 2002). The $100 \mathrm{~km}$ wide ESRP extends over $600 \mathrm{~km}$ (Hughes et al., 1999). Four events in the late Tertiary are important for creation and shaping the ESRP (Hughes et al., 1999): (1) successive Miocene-Pliocene rhyolitic volcanic eruptive centers from southwest near the common border of Idaho, Oregon, and Nevada trending northeast to Yellowstone National Park in northwest Wyoming, (2) Miocene to Holocene crustal extension which produced the Basin and Range province, (3) Quaternary basaltic flows, and (4) Quaternary glaciation and associated eolian, fluvial, and lacustrine sedimentation and catastrophic flooding.

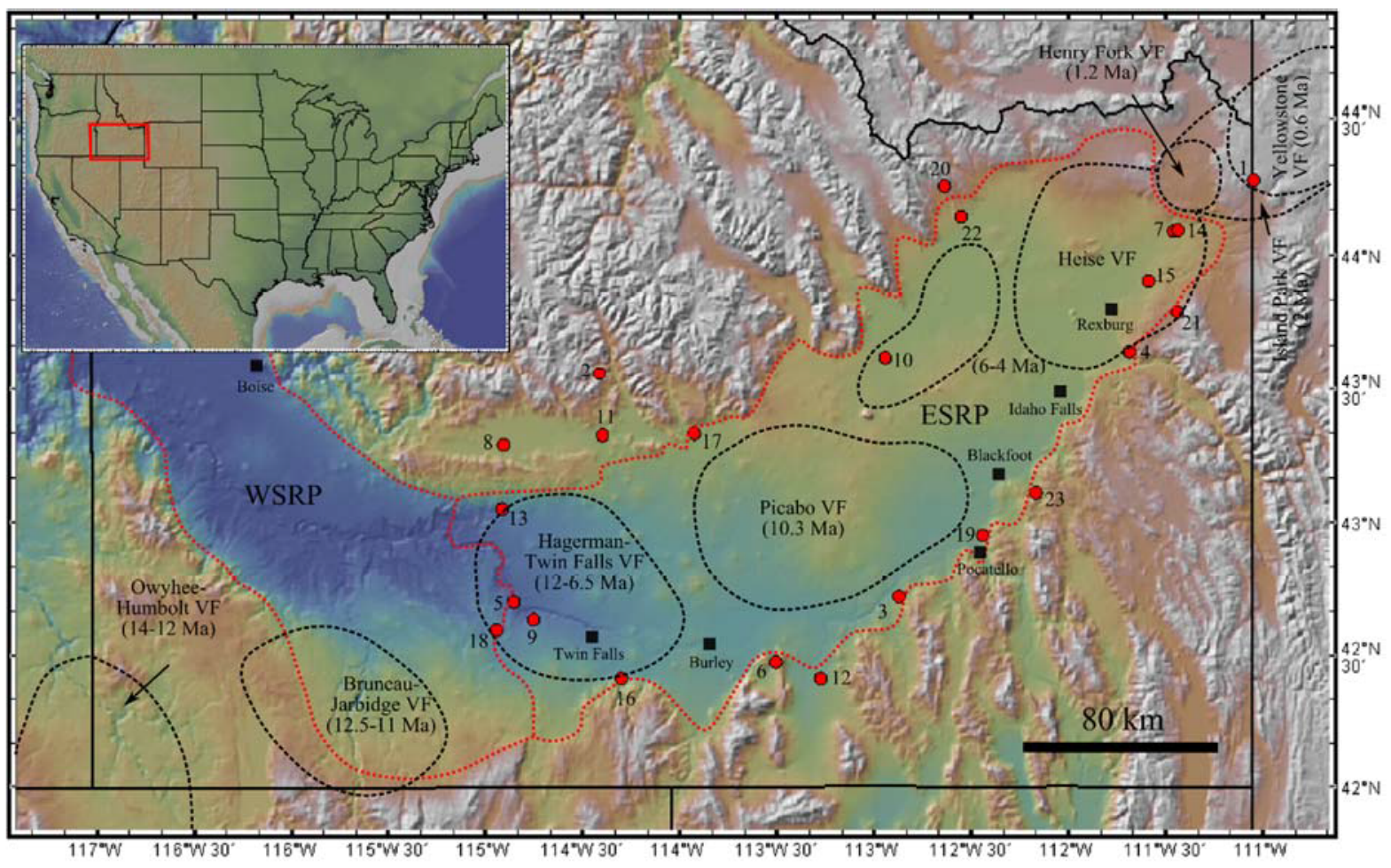

Figure 1. Shaded relief map of southern Idaho showing Snake River Plain (SRP) prepared from NASA 10-m DEM data in GeoMapApp. The dotted red lines represent boundary of the SRP. The Eastern Snake River Plain (ESRP) is separated from the Western Snake River Plain (WSRP) by stretches of the Snake River and Salmon Falls Creek (delineated by the north south trending dotted line west of Twin Falls). Areas within black-dashed polygons represent the super volcanic fields (VF) (modified after Link et al., 2005). The red dots represent locations of springs or wells in the ESRP and its margins that are used for temperature estimation. The number assigned to each spring/well corresponds to the case number given in Table 1.

The ESRP consists of thick rhyolitic ash-flow tuffs, which are overlain by $>1 \mathrm{~km}$ of Quaternary basaltic flows (Figure 2). The rhyolitic volcanic rocks at depth are the product of super volcanic eruptions associated with the Yellowstone Hotspot. These rocks progressively become younger to the northeast towards the Yellowstone Plateau (Pierce and Morgan, 1992; Hughes et al., 1999). The younger basalt layers are the result of several low-volume, monogenetic shield-forming eruptions of short-duration that emanated from northwest trending volcanic rifts in the wake of the Yellowstone Hot Spot (Hughes et al., 1999). The thick sequences of coalescing basalt flows with interlayered fluvial and eolian sediments in the ESRP constitute a very productive aquifer system above the rhyolitic ash-flow tuffs (Whitehead, 1992). 


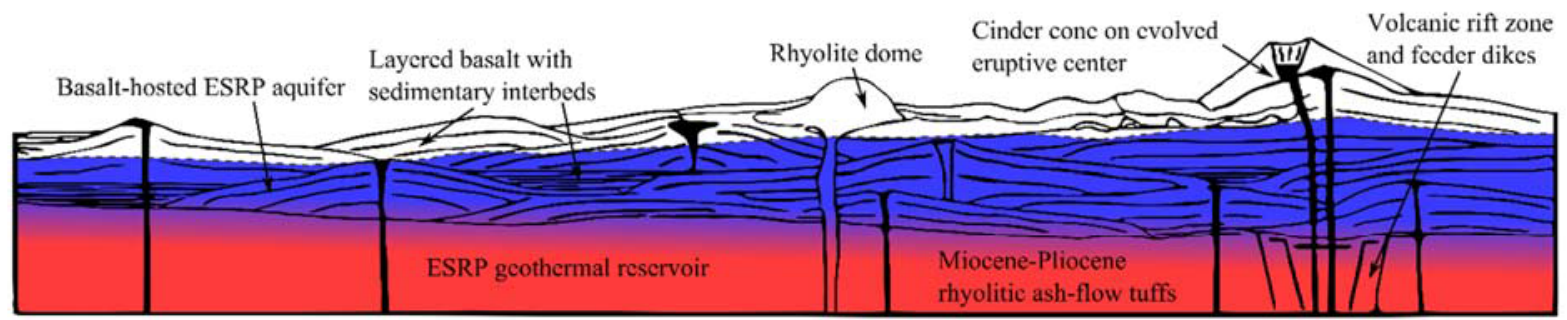

Figure 2. Schematic cross-section across the ESRP (modified from Hughes et al., 1999) showing underlying rhyolitic ash-flow tuffs and overlying basalt flows with few sedimentary layers. The underlying rhyolite ash-flow tuffs are assumed to be the ESRP geothermal resource. Small amount of thermal waters are considered to be upwelling from underlying reservoir into the overlying basalt-hosted ESRP aquifer system. The presence of very productive, cold groundwater aquifer system is regarded to mask the underlying geothermal regime in the ESRP.

Recent volcanic activity, a high heat flux ( 110 mW/ $/ \mathrm{m}^{2}$, Smith, 2004), and the occurrence of numerous peripheral hot springs suggest the presence of undiscovered geothermal resources in the ESRP. As a consequence of these geologic indicators, we hypothesize that the ESRP at depth hosts a large geothermal resource with the potential for one or more viable conventional or enhanced geothermal reservoirs. In particular, we consider the lower welded rhyolite ash-flow tuff zone (Figure 2) to have exploitable heat sources that can be tapped by EGS development. However, the regionally extensive and cold-water ESRPA couple with interactions of the upwelling thermal waters with basalt at the base of the aquifer (Morse and McCurry, 2002) is likely masking the expression of the deep thermal resource (Figure 2). The relative amount of thermal water migrating into the overlying groundwater is relatively small compared to the very large flow of water in the ESRPA. For example Mann (1986) estimated about 18.5 million $\mathrm{m}^{3} / \mathrm{yr}$ of up flow from the deeper part to the overlying aquifer compared to a 160 million $\mathrm{m}^{3} / \mathrm{yr}$ recharge form just one (Big Lost River) of the several drainages recharging the aquifer (Robertson, 1974). For this study, we are assessing if the geochemical signature of the deep reservoir fluid can be seen in the water compositions of several ESRP and peripheral hot/warm springs and wells and the applicability of estimating the reservoir temperature using multicomponent equilibrium geothermometry (MEG).

\section{THE ESRP WELLS/SPRINGS WATER CHEMISTRY DATA}

Over the last several decades, water samples from springs and wells in and around the ESRP have been analyzed by several US government agencies and researchers for water quality and management, environmental remediation, and geothermal energy exploration (e.g., Young and Mitchell, 1973; Mitchell, 1976; Mann, 1986; Avery, 1987; Fournier, 1989; Mariner and Young, 1995; Lindholm, 1996; McLing et al., 2002; Bartholomay and Twining, 2010; Kirby, 2012). A database has been compiled of publically available data from ESRP springs/wells. We used data from the US Geological Survey (USGS), Southern Methodist University (SMU), Idaho Geological Survey (IGS), Utah Geological Survey, and others. Finally, unpublished water compositions of a few ESRP springs/wells were compiled for this study. We down-selected 23 water compositions from the larger database as best representing the deep thermal regime (Table 1) of the ESRP and its margin. These data are used to provide a preliminary assessment of the deep geothermal temperatures.

\section{GEOTHERMOMETRY}

\subsection{Approach}

Most geothermometry is conducted using traditional approaches such as silica, $\mathrm{Na}-\mathrm{K}$, Na-K-Ca, Na-K-Ca-Mg, Na-Li, and $\mathrm{K}-\mathrm{Mg}$ geothermometers although gases and stable isotopes are also often used. The approach used in this paper is MEG. The basic concept of the MEG was developed in mid-1980s (Reed and Spycher, 1984); however, it has not yet been widely used as a geothermometry tool despite its advantages over traditional geothermometers. Some previous investigators (e.g., D'Amore et al., 1987; Hull et al., 1987; Tole et al., 1993) have used this technique for predicting geothermal temperature. Other researchers have used the basic principles of this method for reconstructing the composition of geothermal fluids and formation brines (Pang and Reed, 1998; Palandri and Reed, 2001). More recent efforts by some researchers (e.g., Bethke, 2008; Spycher et al., 2011; Cooper et al., 2013; Neupane et al., 2013) have been focused on improving temperature predictability of the MEG method.

In MEG, the reservoir temperature is estimated by first selecting a reservoir mineral assemblage (RMA) with which it is believed the fluid in the reservoir is equilibrated. For a water sample from a spring or shallow well, the activities of the chemical species in solution are determined and the saturation indices $\left(\mathrm{SI}=\log \mathrm{Q} / \mathrm{KT}\right.$, where $\mathrm{Q}$ is the ion activity product and $\mathrm{K}_{\mathrm{T}}$ is the temperature dependent mineral-water equilibrium constant) calculated using the laboratory measured temperature of the sample. This calculation is repeated as a function of temperature and the resulting SIs recalculated. Likely reservoir temperature is the one at which all minerals in an assemblage are in equilibrium with the reservoir fluid as indicated by near zero $\log Q / \mathrm{K}_{\mathrm{T}}$ values of these minerals on a $\log \mathrm{Q} / \mathrm{K}_{\mathrm{T}}$ versus temperature plot $\left(\log \mathrm{Q} / \mathrm{K}_{\mathrm{T}}\right.$ plot) (Reed and Spycher, 1984; Bethke, 2008). Alternately stated, reservoir minerals are expected to be in equilibrium with the fluid and they should yield a common equilibrium temperature with a near zero $\log Q / K_{T}$ value for each mineral; this common equilibrium temperature coincides with the reservoir temperature. If $\log Q / \mathrm{K}_{\mathrm{T}}$ curves of minerals in a reservoir do not show a common temperature convergence at $\log \mathrm{Q} / \mathrm{K}_{\mathrm{T}}=0$, then it suggests that either there exists errors in analytical data, the selected mineral assemblage does not represent the actual mineral assemblage in the reservoir, or the sampled water must have been subjected to composition altering physical and chemical processes during its ascent from the reservoir to the sampling point. 


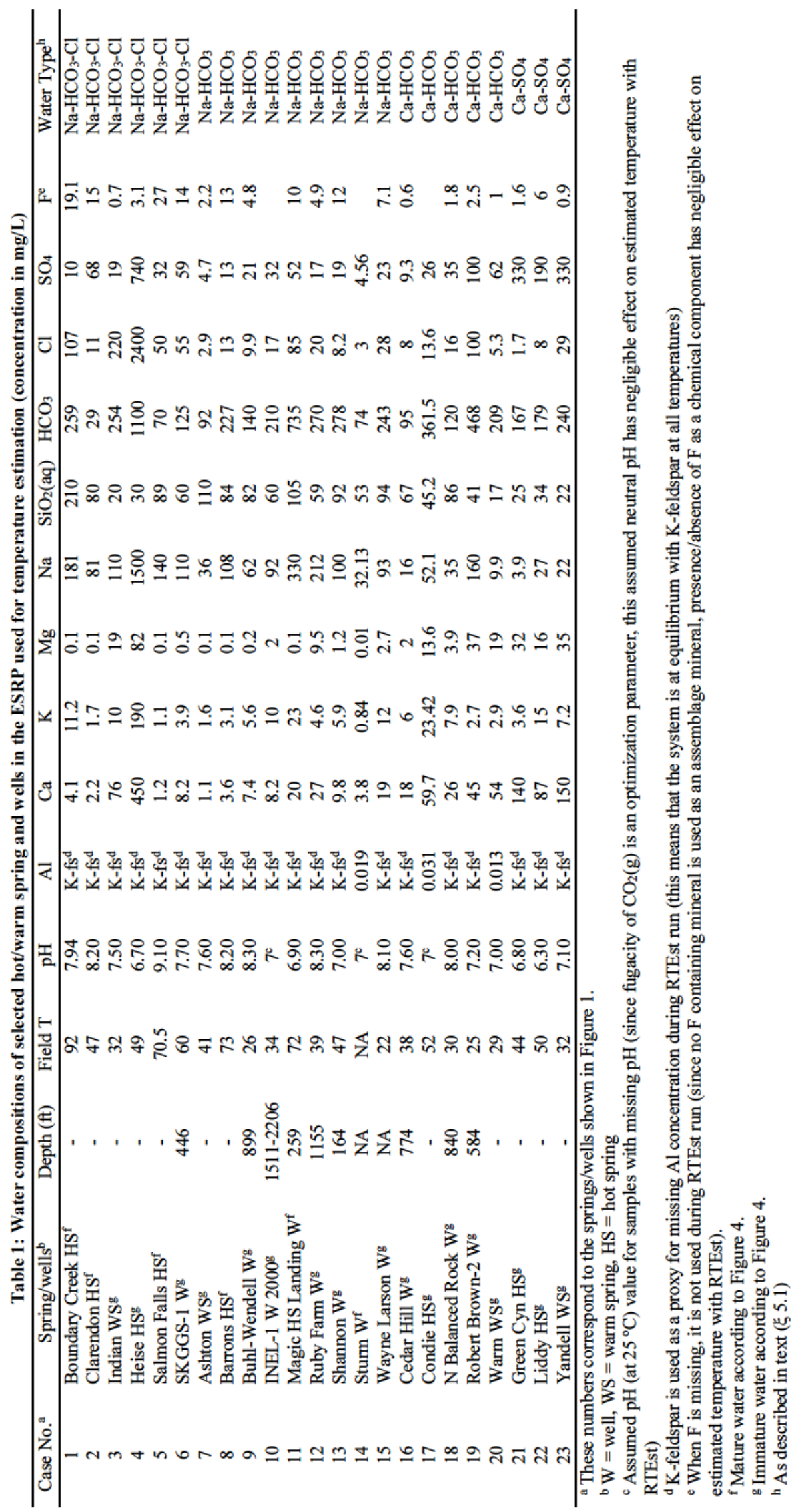


Two common composition altering processes are the loss of $\mathrm{CO}_{2}$ due to degassing and the gain/loss of water due to mixing/boiling. Particularly, the loss of $\mathrm{CO}_{2}$ from geothermal water has direct consequence on $\mathrm{pH}$ of the water, and it is often indicated by the oversaturation of calcite (Palandri and Reed, 2001). Similarly, dilution of thermal water by mixing with cooler water or enrichment of constituents (chemical components) by boiling is indicated by lack of convergence of $\log \mathrm{Q} / \mathrm{K}_{\mathrm{T}}$ curves over a small temperature range at $\log \mathrm{Q} / \mathrm{K}_{\mathrm{T}}=0$. Although, in principle, these composition altering processes can be taken into account by simply adding them into the measured water composition and looking for convergence of the saturation indices of the chosen mineral assemblage, a graphical approach becomes cumbersome even for two parameters (e.g., temperature and $\mathrm{CO}_{2}$ ). To overcome this limitation, we employed the Reservoir Temperature Estimator (RTEst), a recently developed geothermometry tool (Palmer, 2013).

RTEst couples the React module of The Geochemist's Workbench $\otimes$ (GWB) (Bethke and Yeakel, 2012) and PEST Doherty, 2005 and 2013). The GWB React module is a flexible geochemical modeling tool with the ability to model equilibrium states (aqueous species, gaseous phases, and minerals) and trace geochemical processes with respect to temperature, reaction rates, or consumption of reactant(s) (Bethke and Yeakel, 2012). Similarly, PEST is a model-independent parameter estimation and uncertainty analysis tool (Doherty, 2005 and 2013). Specifically, RTEst uses the React module for geochemical modeling and calculating $\log \mathrm{Q} / \mathrm{KT}$ of minerals for a geothermal water and PEST for guiding the overall optimization path and calculating statistical parameters and uncertainties in optimized values (estimated temperature, fugacity of $\mathrm{CO}_{2}$ and amount of solvent).

RTEst uses an optimization objective function $(\Phi)$ (Eq. 1) to implement inverse geochemical modeling to identify a temperature convergence for assemblage minerals.

$\Phi=\sum\left(S I_{i} w_{i}\right)^{2}$

where $\mathrm{SI}_{\mathrm{i}}=\log \left(\mathrm{Q}_{\mathrm{i}} / \mathrm{K}_{\mathrm{T}}\right)$ for the ith equilibrium mineral $\left(\mathrm{Q}_{\mathrm{i}}=\right.$ ion activity product for ith mineral, $\mathrm{w}_{\mathrm{i}}=$ weighting factor for the ith mineral. The weighting factor is based on the number of thermodynamic components (i.e., independent chemical variables) and the number of times each component appears in the ith mineral dissolution reaction. In other word, it is the inverse of the total number of thermodynamic components or ions in the ith mineral's formula unit.

The weighting factors for different minerals used in this paper are presented in Table 2 . The inclusion of weighting ensures that each mineral that contributes to the equilibrium state is considered equally and the results are not skewed by reaction stoichiometry. Because of the squared term in Eq. 1, the $\Phi$ values are always greater than or equal to zero. For an ideal case, the overall equilibrium state occurs at the point at which $\Phi=0$. However, for real water samples subjected to sampling and analytical errors, a $\Phi$ value of zero is unlikely to be obtained. Therefore, using real water, the optimization is always driven towards achieving the minimum $\Phi$ value. The optimization process minimizes $\Phi$ to obtain the overall equilibrium state for the reservoir assemblage minerals as a function of temperature and amount of volatile components.

\subsection{Missing components}

The MEG approach requires that measured water composition include all components present in the RMA. For aluminosilicate minerals this requires measured values of $\mathrm{Al}$ that are typically not available in historical data bases. For water compositions without measured $\mathrm{Al}$, an Al-bearing mineral (e.g., K-feldspar) was used as a proxy for $\mathrm{Al}$ during geochemical modeling as suggested by Pang and Reed (1998). This substitution is easily made in the React module used by RTEst.

\subsection{Reservoir mineral assemblage}

Based on Sant's (2012) study of secondary mineralization in a core collected north of Burley, Idaho and finding of Morse and McCurry (2002) in cores collected at Idaho National Laboratory, west of Idaho Falls, Idaho, we used an RMA consisting of idealized clays, zeolites, carbonates, feldspars, and silica-polymorph (chalcedony) (Table 2) as input to RTEst. For each water sample, major chemical components (excluding $\mathrm{SO}_{4}$ and $\mathrm{F}$ in Table 1) in water are represented by at least a mineral.

Table 2: Weighting factors for minerals used in this study

\begin{tabular}{lc}
\hline Minerals & Weighting factor $\left(\mathrm{w}_{\mathrm{i}}\right)$ \\
\hline Calcite & $1 / 2$ \\
Chalcedony & 1 \\
K-feldspar & $1 / 5$ \\
Mordenite-K & $1 / 7$ \\
Beidellite-K/Na & $1 / 6.33$ \\
Beidellite-Ca/Mg & $1 / 6.165$ \\
Clinochlore-14A & $1 / 10$ \\
Illite & $1 / 6.65$ \\
Paragonite & $1 / 7$ \\
Saponite- $\mathrm{K} / \mathrm{Na}$ & $1 / 7.33$ \\
Saponite-Ca/Mg & $1 / 7.165$ \\
\hline
\end{tabular}




\section{RESULTS AND DISCUSSION}

\subsection{Aqueous chemistry of ESRP springs/wells waters}

Figure 3 is a Piper diagram showing the compositions of the near-neutral ESRP springs and groundwaters in Table 1. Hierarchical cluster analysis [Ward (1963) as implemented in SYSTAT 13; SYSTAT Software, Inc.] based on the 6 Piper diagram end members organize these waters into four compositional groups. Two of these groups have sodium as the dominant cation $\left(\mathrm{Na}-\mathrm{HCO}_{3}-\mathrm{Cl}_{\text {and }}\right.$ $\left.\mathrm{Na}-\mathrm{HCO}_{3}\right)$ and the other two have calcium as the dominant cation $\left(\mathrm{Ca}-\mathrm{HCO}_{3}\right.$ and $\left.\mathrm{Ca}-\mathrm{SO}_{4}\right)(\mathrm{Table} 1)$. These grouping likely reflect differences in geology (e.g., sedimentary or volcanic) of the source regions of water entering the ESRP system.

On a Giggenbach diagram (Giggenbach, 1988), the majority of the ESRP waters selected for this study plot in the immature zone and the remainder lie in the zone of partial equilibration. The lack of equilibrium (immaturity) in water could be related to too low Na content, as suggested by Giggenbach (1988), as well as their higher $\mathrm{Mg}$ content. The waters containing high $\mathrm{Mg}$ content are deemed to be unsuitable for some traditional solute geothermometry; although there have been some efforts made for implementing $\mathrm{Mg}$ correction in the estimated temperature (e.g., Fournier and Potter, 1979). According to Figure 4, the mature ESRP waters could have interacted with rock at a temperature range of $140-200^{\circ} \mathrm{C}$ with an exception of Salmon Hot Spring which shows a potential waterrock interaction temperature of about $80^{\circ} \mathrm{C}$. ESRP mature waters are in the sodium dominant $\mathrm{Na}-\mathrm{HCO}_{3}-\mathrm{Cl}_{\text {or Na}} \mathrm{HCO}_{3}$ types $(\mathrm{Table}$ 1 , Figures 3 and 4).

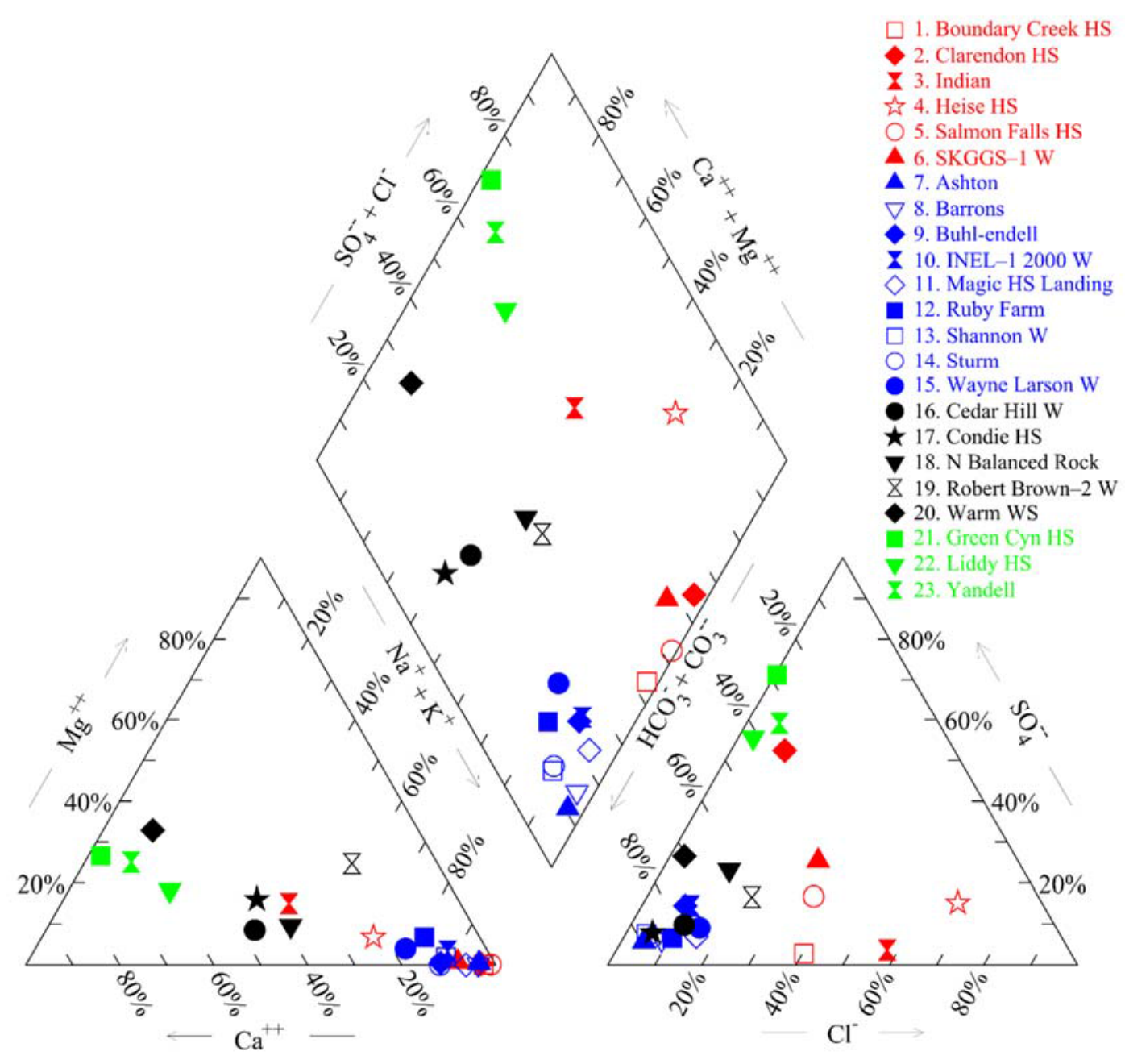

Figure 3: Chemistry of ESRP waters measured at several hot/warm springs and wells. The red, blue, black, and green symbols represent $\mathrm{Na}-\mathrm{HCO}_{3}-\mathrm{Cl}, \mathrm{Na}-\mathrm{HCO}_{3}, \mathrm{Ca}-\mathrm{HCO}_{3}$, and $\mathrm{Ca}_{-} \mathrm{SO}_{4}$ water types, respectively. 


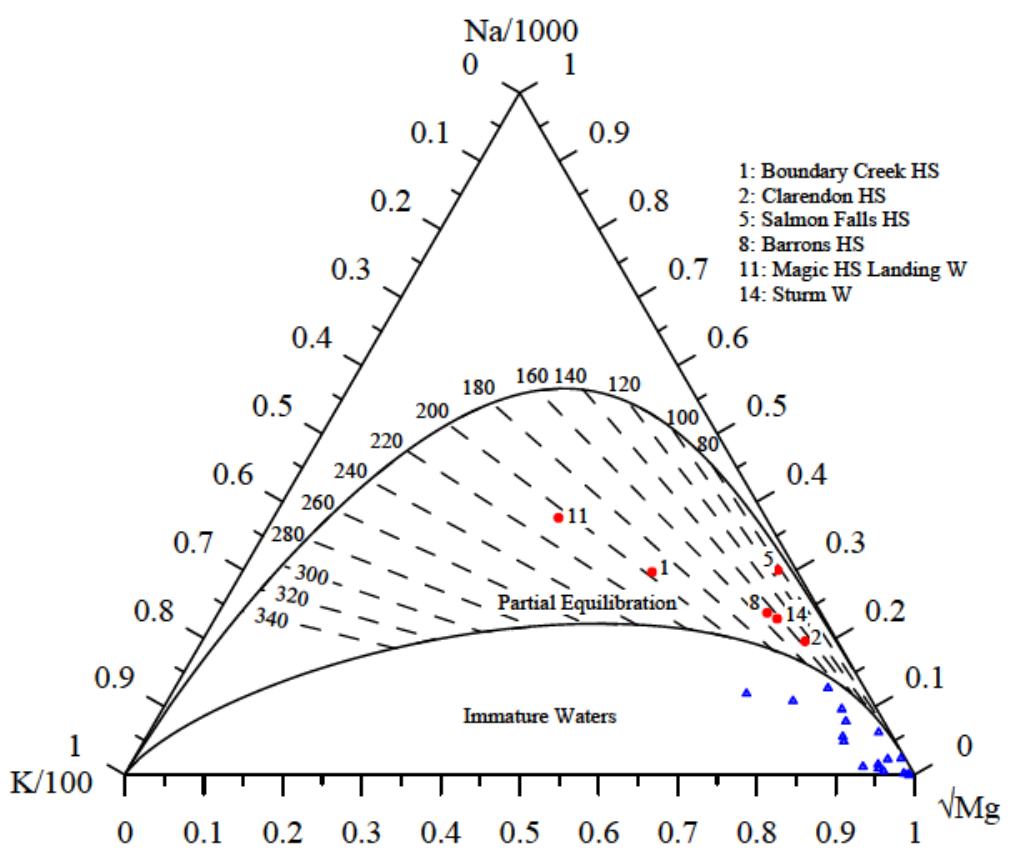

Figure 4: ESRP springs/wells waters plotted on Giggenbach diagram (Giggenbach, 1988). The red and blue symbols represent mature and immature waters, respectively.

\subsection{ESRP reservoir temperatures}

Preliminary estimate of ESRP reservoir temperatures were made using RTEst and water compositions reported in Table 1 and are reported along with optimized values for the amount of $\mathrm{H}_{2} \mathrm{O}$ and fugacity of $\mathrm{CO}_{2}$ in Table 3 . The RMAs used consisted of representive clays (Mg bearing clays - beidellite, clinochlore, illite, saponite; Na bearing clays - paragonite, beidellite, saponite; K-bearing clays - beidelite, illite), calcite, chalcedony, and zeolite (mordenite). For compositions without reported $\mathrm{Al}$ concentrations, $\mathrm{K}$-feldspar was used as a proxy for $\mathrm{Al}$.

Figure 5a shows $\log \mathrm{Q} / \mathrm{K}_{\mathrm{T}}$ curves of the RMA (calcite, chalcedony, clinochlore, mordenite-K, and paragonite) used for the reported Boundary Creek Hot Spring water compositions. The $\log \mathrm{Q} / \mathrm{K}_{\mathrm{T}}$ curves of these minerals intersect the $\log \mathrm{Q} / \mathrm{K}_{\mathrm{T}}=0$ line at different temperatures, ranging from $85^{\circ} \mathrm{C}$ (calcite) to over $180^{\circ} \mathrm{C}$ (paragonite), rendering the $\log \mathrm{Q} / \mathrm{K}_{\mathrm{T}}$ curves derived from the reported water chemistry minimally useful for estimating temperature. The wide range of equilibration temperature for the assemblage minerals is a reflection of physical and chemical processes may have modified the Boundary Creek Hot Spring water composition during its ascent to the sampling point.

To account for possible composition altering processes, RTEst (Palmer, 2013) was used to simultaneously estimate a reservoir temperature and optimize the amount of $\mathrm{H}_{2} \mathrm{O}$ and the fugacity of $\mathrm{CO}_{2}$ (Table 3). The optimized results for Boundary Creek Hot Spring are shown in Figure $5 \mathrm{~b}$. Compared to the $\log \mathrm{Q} / \mathrm{K}_{\mathrm{T}}$ curves calculated using the reported water compositions, the optimized curves (Figure $5 \mathrm{~b}$ ) converge to $\log \mathrm{Q} / \mathrm{K}_{\mathrm{T}}=0$ line within a narrow temperature range (i.e., $154 \pm 5^{\circ} \mathrm{C}$ ).

The optimized temperatures and composition parameters for the other 22 waters reported in Table 1 were similarly estimated using RTEst. The estimated reservoir temperature, mass of water lost due to boiling or gained due to mixing, and fugacity of $\mathrm{CO}_{2}$ along with the associated standard errors are presented in Table 3. 

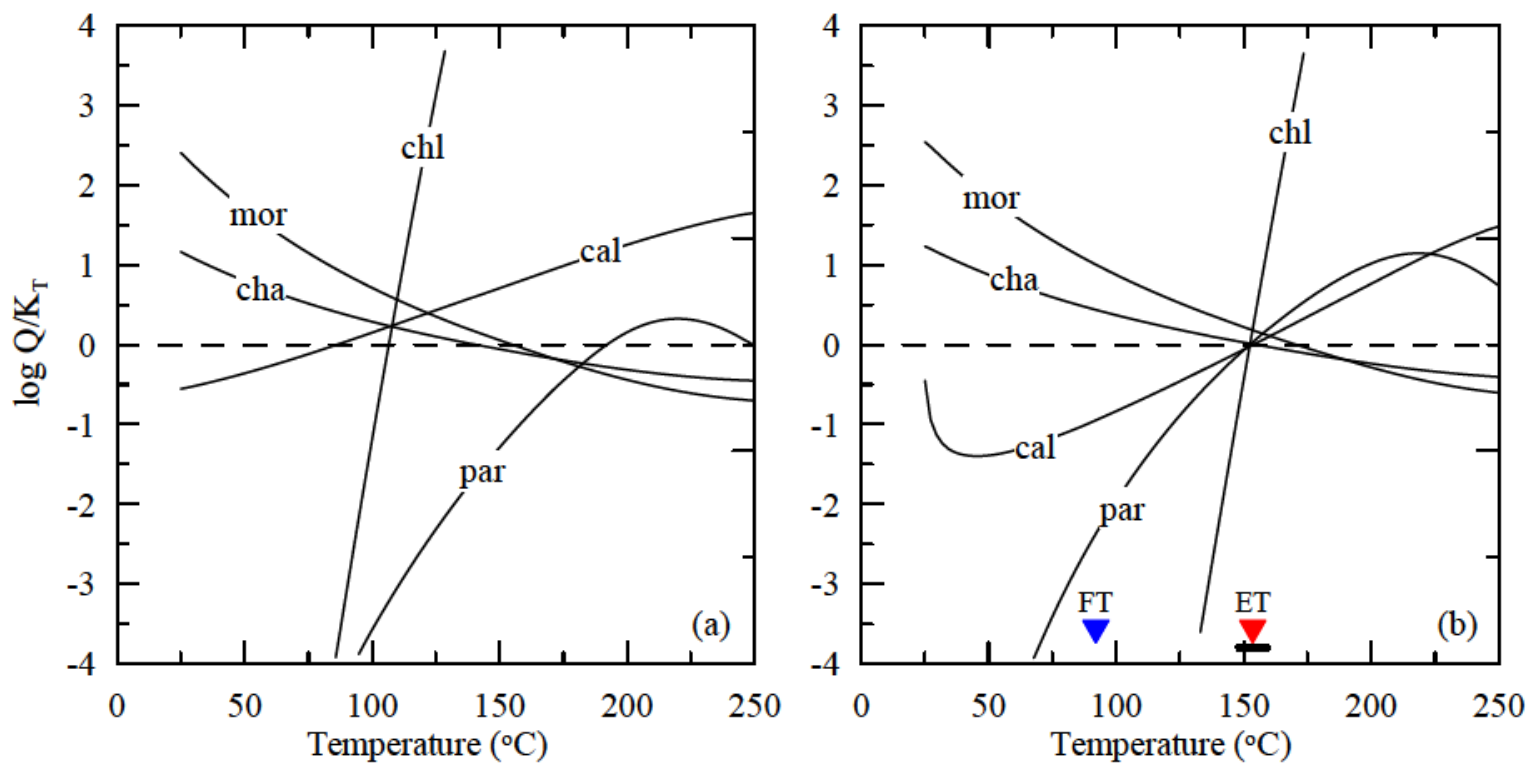

Figure 5: Temperature estimation for Boundary Creek Hot Spring. (a) The log $Q_{/} / K_{T}$ curves for minerals calculated using original water chemistry with $\mathrm{K}$-feldspar used as proxy for $\mathrm{Al}$, (b) optimized $\log \mathrm{Q} / \mathrm{K}_{\mathrm{T}}$ curves [FT: field temperature $\left(92^{\circ} \mathrm{C}\right)$; ET: estimated temperature $\left(154^{\circ} \mathrm{C}\right)$, the dark horizontal bar below ET represents the \pm standard error for the estimated temperature $\left( \pm 5^{\circ} \mathrm{C}\right)$; cal: calcite, cha: chalcedony, chl: clinochlore, mor: mordenite-K, and par: paragonite).

The reservoir temperatures estimated using RTEst had means and standard errors of $118 \pm 5^{\circ} \mathrm{C}, 104 \pm 15^{\circ} \mathrm{C}, 91 \pm 11^{\circ} \mathrm{C}$, and $79 \pm 18^{\circ} \mathrm{C}$ for the $\mathrm{Na}-\mathrm{HCO}_{3}, \mathrm{Na}-\mathrm{HCO}_{3}-\mathrm{Cl}, \mathrm{Ca}-\mathrm{HCO}_{3}$ and $\mathrm{Ca}-\mathrm{SO}_{4}$ water types, respectively. The standard error of $5{ }^{\circ} \mathrm{C}$ associate with the mean temperature of $118^{\circ} \mathrm{C}$ for the $\mathrm{Na}-\mathrm{HCO}_{3}$ waters is smaller than typically observed for the individual RTEst optimized temperatures $\left(\sim 8^{\circ} \mathrm{C}\right)$ indicating that these waters have little intra-type variation. This low variation suggests that the $\mathrm{Na}-\mathrm{HCO}_{3}$ waters have similar geochemical histories even though their locations are widely distributed across the ESRP (Figure 1). An explanation for these similarities may be that regardless of the original source of water or heat, the $\mathrm{Na}-\mathrm{HCO}_{3}$ waters have equilibrated with basalt flows below but near the base of the ESRP aquifer. This equilibration in the basalt has obscured possibly higher temperatures in the deeper rhyolite sections. The other water types exhibited lower mean temperatures and much larger standard errors $\left(11\right.$ to $\left.18^{\circ} \mathrm{C}\right)$ indicating that these waters have much greater intra-type variations likely reflecting more complex thermal interactions in multiple geologic setting leading to multiple geochemical histories.

In addition to RTEst temperatures, reservoir temperatures calculated using some traditional geothermometers are also given in Table 3 . When the entire data set is considered as one group, the estimated temperatures with chalcedony and silica geothermometers are $22 \pm 17{ }^{\circ} \mathrm{C}$ cooler than the RTEst temperatures. The Na-K-Ca and quartz temperatures are about the same $(+6 \pm 29$ and $+6 \pm 16$, respectively) as the RTEst temperatures but the former has a much greater variation than the latter.

\subsection{Limitations of the present temperature estimates}

A chief limitation of RTEst estimated temperatures as well as all geothermometry is that it provides temperature estimates for geothermal systems that have sufficient permeability to heat water and a mechanism that allows an expression of the heated water at a spring or a well. Estimated temperatures do not necessary indicate the maximum temperature of the geothermal resource that potentially could be exploited using enhance drilling and fracturing technologies (i.e., EGS) but rather the permeable zone of a reservoir at which the water is in equilibrium with the assemblage minerals. Despite this limitation, RTEst estimated temperature can be used with other data to develop better estimates of the temperature gradients to approximate the locations and depths of geothermal reservoirs suitable for EGS exploitation.

Another limitation of RTEst temperature estimates are related to overall quality and completeness of the reported water chemistry. Most of the water compositions used in this study were measured in 1970s and 1980s, and lack measured Al concentrations. Only three water samples (Warm Spring, Sturm Well, and Condie Hot Spring) in Table 3 have measured Al concentration. When these waters modeled using K-feldspar as proxy for Al, the RTEst estimated temperatures for Warm Spring, Sturm Well, and Condie Hot Spring are $53 \pm 10^{\circ} \mathrm{C}, 96 \pm 2{ }^{\circ} \mathrm{C}$, and $93 \pm 20^{\circ} \mathrm{C}$, respectively. These temperatures compare to values of $66 \pm 15^{\circ} \mathrm{C}, 121 \pm 4{ }^{\circ} \mathrm{C}$, and $78 \pm 9$ ${ }^{\circ} \mathrm{C}$, respectively reported in Table 3. For the Warm Spring and Condie Hot Springs the RTEst estimated temperatures with K-feldspar substituted for $\mathrm{Al}$ are similar (within the uncertainties) to the temperatures estimated using measured $\mathrm{Al}$ concentrations. For Sturm Well, the K-feldspar substituted temperature is $25 \pm 5{ }^{\circ} \mathrm{C}$ lower. Based on these limited results, the RTEst estimated reservoir temperatures reported in Table 3 are preliminary, and will likely be revised as the locations are resampled and $\mathrm{Al}$ concentration are measured. 
Neupane et al.

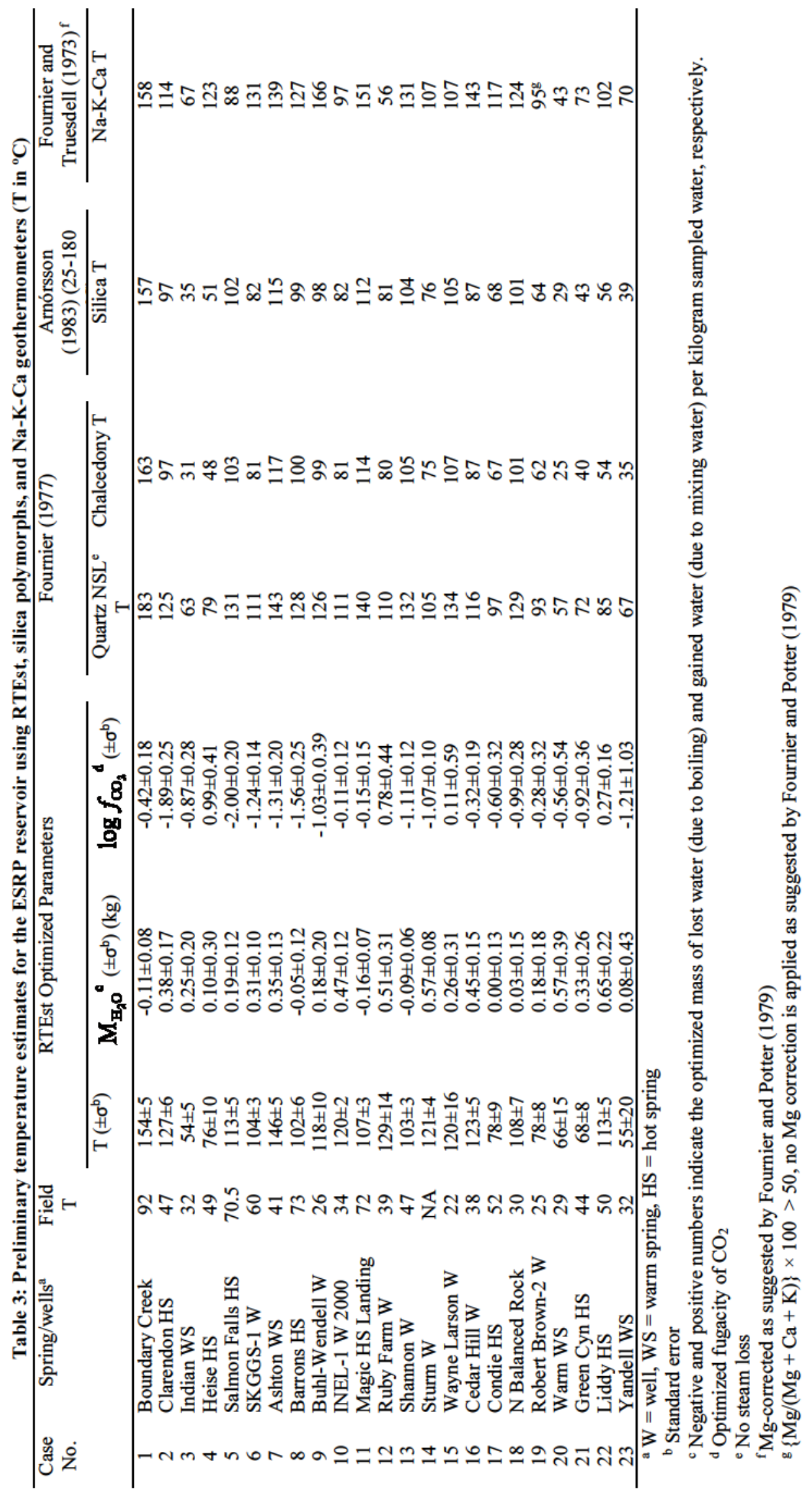


A final limitation is the use of pure water as an optimization parameter. Although pure water is appropriate to simulate boiling, it is highly unlikely that pure water was actually mixed with reservoir water. Rather mixing would have been associated with a groundwater with a varying concentration of chemical. Preliminary test case results suggest that the RTEst estimated temperatures reported in Table 3 could be higher when the local groundwater rather than pure water is used during modeling. The test case results also suggest that a larger fraction of groundwater than reported in Table 3 is estimated by RTEst. These results (higher temperature and larger mixing fraction) are consistent with the observed bottom-hole temperature of the INEL-1 $\left(146^{\circ} \mathrm{C}\right)$ which is significantly higher than the RTEst estimated temperature for a mixed water from this well $\left(120 \pm 2^{\circ} \mathrm{C}\right)$. Ongoing development of RTEst will allow for mixing of real groundwaters. Based on these consideration, we believe that the RTEst temperatures estimated report in Table 3 are minimum temperatures and that the refined estimates including mixing of real groundwater and measured $\mathrm{Al}$ concentrations will likely yield higher estimated reservoir temperatures.

\section{CONCLUSION}

Geological data suggests that the ESRP has large geothermal resource located below the cold groundwater aquifer system. Preliminary temperature estimates using RTEst and water compositions for several hot/warm springs and wells indicate the presence of higher temperature zone at depth. Specifically, $\mathrm{Na}-\mathrm{HCO}_{3}$ water type suggests the presence of relatively higher temperature. The overall geothermometry modeling results also suggest that the deeper ESRP thermal waters might have partially equilibrated within the basalt zone obscuring possibly higher temperatures in the deeper rhyolites. Several factors, such as, use of pure water during modeling and overall quality and completeness of the reported water chemistry, suggest that our current estimates of reservoir temperatures may be underestimating the true value. The collection and analysis of additional water samples from hot/warm springs and wells representing the ESRP and its marginal areas will be used to further assess and delineate the potential areas for conventional or EGS development.

\section{ACKNOWLEDGEMENTS}

Funding for this research was provided by the U.S. Department of Energy, Office of Energy Efficiency \& Renewable Energy, Geothermal Technologies Program. We appreciate the help from Will Smith and Cody Cannon for this study.

\section{REFERENCES}

Ackerman, D.J., Rattray, G. W., Rousseau, J. P., Davis, L. C., and Orr, B. R.: A Conceptual Model of Ground-Water Flow in the Eastern Snake River Plain Aquifer at the Idaho National Laboratory and Vicinity with Implications for Contaminant Transport. US Department of the Interior, US Geological Survey Scientific Investigations Report 2006-5122 DOE/ID-22198, (2006).

Arnórsson, S., Gunnlaugsson, E., and Svavarsson, H.: The chemistry of geothermal waters in Iceland. III. Chemical geothermometry in geothermal investigations. Geochimica et Cosmochimica Acta, 47, (1983), 567-577.

Avery, C.: Chemistry of thermal water and estimated reservoir temperatures in southeastern Idaho, north-central Utah, and southwestern Wyoming. The thrust belt revisited: Wyoming Geological Association $38^{\text {th }}$ Annual Field Conference Guidebook, (1987), 347-353.

Bartholomay, R.C. and Twining, B.V.: Chemical constituents in groundwater from multiple zones in the eastern Snake River Plain aquifer at the Idaho National Laboratory, Idaho, 2005-08. US Department of the Interior, U.S. Geological Survey Scientific Investigations Report 2010-5116, (2010).

Bethke, C.M.: Geochemical and Biogeochemical Reaction Modeling. Cambridge University Press, (2008), 547 pp.

Bethke, C.M. and Yeakel, S.: The Geochemist's Workbench $\circledast$ Release 9.0. Reaction Modeling Guide. Aqueous Solutions, LLC, Champaign, Illinois, (2012).

Blackwell, D.D., Kelley, S., and Steele, J. L.: Heat flow modeling of the Snake River Plain, Idaho. US Department of Energy Report for contract DE-AC07-761DO1570, (1992).

Cooper, D.C., Palmer, C.D., Smith, R.W., \& McLing, T.L.: Multicomponent equilibrium models for testing geothermometry approaches. Proceedings. $3^{\text {th }}$ Workshop on Geothermal Reservoir Engineering Stanford University, Stanford, CA, (2013).

D'Amore, F., Fancelli, R., and Caboi, R.: Observations on the application of chemical geothermometers to some hydrothermal systems in Sardinia. Geothermics, 16, (1987), 271-282.

Doherty J.: PEST, Model-Independent Parameter Estimation User Manual, $5^{\text {th }}$ Edition. Watermark Numerical Computing, www.pesthompage.org, (2005).

Doherty, J.: Addendum to the PEST Manual. Watermark Numerical Computing, www.pesthompage.org, (2013).

Fournier, R.O.: Geochemistry and dynamics of the Yellowstone National Park hydrothermal system. Annual Review of Earth and Planetary Sciences, 17, (1989), 13-53.

Fournier, R.O. and Truesdell, A.H.: An empirical Na-K-Ca geothermometer for natural waters. Geochimica et Cosmochimica Acta, 37, (1973), 1255-1275.

Fournier, R.O., White, D.E., and Truesdell, A.H.: Geochemical indicators of subsurface temperature - 1, Basic assumptions. U.S. Journal of Research of the US Geological Survey, 2, (1974) 259-262.

Fournier, R.O., and Potter II, R.W.: Magnesium correction to the Na-K-Ca chemical geothermometer. Geochimica et Cosmochimica Acta, 43, (1979), 1543-1550.

Giggenbach, W.F.: Geothermal solute equilibria. Derivation of Na-K-Mg-Ca geoindicators. Geochimica et Cosmochimica Acta, 52, (1988), 2749-2765. 
Hughes, S.S., Smith, R.P., Hackett, W.R., and Anderson, S. R.: Mafic volcanism and environmental geology of the eastern Snake River Plain. Idaho Guidebook to the Geology of Eastern Idaho. Idaho Museum of Natural History, (1999), 143-168.

Hull, C.D., Reed, M.H., and Fisher, K.: Chemical geothermometry and numerical unmixing of the diluted geothermal waters of the San Bernardino Valley Region of Southern California. GRC Transactions, 11, (1987), 165-184.

Kirby, S.M.: Summary of Compiled Fluid Geochemistry with Depth Analyses in the Great Basin and Adjoining Regions. Open-File Report 603, Utah Geological Survey, (2012).

Lindholm, G.F.: Summary of the Snake River Plain regional aquifer-system analysis in Idaho and Eastern Oregon. US Geological Survey, Professional Paper 1408-A, (1996).

Link, P.K., Fanning, C.M., Beranek, L.P.: Reliability and longitudinal change of detrital-zircon age spectra in the Snake River system, Idaho and Wyoming: An example of reproducing the bumpy barcode. Sedimentary Geology, 182, (2005), 101-142.

Mann, L.J.: Hydraulic properties of rock units and chemical quality of water for INEL-1: a 10,365-foot deep test hole drilled at the Idaho National Engineering Laboratory, Idaho (No. IDO-22070). Geological Survey, Idaho Falls, ID (USA), Water Resources Div. (1986).

Mariner, R.H. and Young, H.W.: Lead and strontium isotope data for thermal waters of the regional geothermal system in the Twin Falls and Oakley areas, South-Central Idaho. GRC Transactions, 19, (1995), 201-206.

McLing, T.L., Smith, R.W., and Johnson, T.M.: Chemical characteristics of thermal water beneath the eastern Snake River Plain. Special Papers Geological Society of America, (2002) 205-212.

Mitchell, J.C.: Geothermal Investigations in Idaho, Part 6, Geochemistry and geologic setting of the thermal and mineral waters of the Blackfoot reservoir area, Caribou County, Idaho. Idaho Dep. Water Resources, Water Inf. Bull., No. 30, (1976).

Morse, L.H. and McCurry, M.: Genesis of alteration of Quaternary basalts within a portion of the eastern Snake River Plain aquifer. Special Papers Geological Society of America, (2002) 213-224.

Neupane, G., Smith, R. W., Palmer, C. D., and McLing, T. L.: Multicomponent equilibrium geothermometry applied to the Raft River geothermal area, Idaho: preliminary results. In Geological Society of America Abstracts with Programs, 45 (7), (2013) 0).

Palandri, J.L., and Reed, M.H.: Reconstruction of in situ composition of sedimentary formation waters. Geochimica et Cosmochimica Acta, 65, (2001), 1741-1767.

Palmer, C.D.: Installation manual for Reservoir Temperature Estimator (RTEst). Idaho National Laboratory, Idaho Falls, ID, (2013)

Pang, Z.H., and Reed, M.: Theoretical chemical thermometry on geothermal waters: Problems and methods. Geochimica et Cosmochimica Acta, 62, (1998), 1083-1091.

Pierce, K.L., and Morgan, L.A.: The track of the Yellowstone hotspot: Volcanism, faulting, and uplift, in Link, P.K., Kunz, M.A., and Platt, L.B., Eds., Regional geology of eastern Idaho and western Wyoming, Geological Society of America Memoir 179, 154, (1992).

Reed, M., and Spycher, N.: Calculation of $\mathrm{pH}$ and mineral equilibria in hydrothermal waters with application to geothermometry and studies of boiling and dilution. Geochimica et Cosmochimica Acta, 48, (1984), 1479-1492.

Robertson, J.B.: (1974). Digital modeling of radioactive and chemical waste transport in the Snake River Plain aquifer at the National Reactor Testing Station, Idaho. Geological Survey, Water Resources Division, Idaho Falls, Idaho, USGS Open-File Report IDO22054, (1974).

Rodgers, D.W., Ore, H.T., Bobo, R.T., McQuarrie, N., and Zentner, N.: Extension and subsidence of the eastern Snake River Plain, Idaho. Tectonic and Magmatic Evolution of the Snake River Plain Volcanic Province. Idaho Geological Survey Bulletin, 30, (2002) 121-155.

Sant, C. J.: Geothermal alteration of basaltic core from the Snake River Plain, Idaho. MS Thesis, Utah State University, Logan, (2012).

Smith, R. P.: Geologic setting of the Snake River Plain aquifer and vadose zone. Vadose Zone Journal, 3, (2004), 47-58.

Spycher, N., Sonnenthal, E., and Kennedy, B.M.: Integrating Multicomponent Chemical Geothermometry with Parameter Estimation Computations for Geothermal Exploration. GRC Transactions, 35, (2011), 663-666.

Tester, J.W., Anderson, B.J., Batchelor, A.S., Blackwell, D.D., DiPippo, R., Drake, E.M., Garnish, J., Livesay, B., Moore, M.C., Nichols, K., Petty, S., Toksöz, M.N., and Veatch, R. W.: The future of geothermal energy - impact of enhanced geothermal systems (EGS) on the United States in the $21^{\text {st }}$ century. Massachusetts Institute of Technology, (2006), p. 372.

Tole, M.P., Ármannsson, H., Pang, Z.H., and Arnórsson, S.: Fluid/mineral equilibrium calculations for geothermal fluids and chemical geothermometry. Geothermics 22, (1993), 17-37.

Truesdell, A.H. and Fournier, R. O.: Procedure for estimating the temperature of a hot-water component in a mixed water by using a plot of dissolved silica versus enthalpy. Journal of Research of the US Geological Survey, 5, (1977), 49-52.

Ward, J.H., Jr.: Hierarchical grouping to optimize an objective function. Journal of the American Statistical Association, 58, (1963), 236-244.

Whitehead, R.L.: Geohydrologic framework of the Snake River Plain regional aquifer system, Idaho and eastern Oregon. Regional aquifer system analysis-Snake River Plain, Idaho. US Department of the Interior, US Geological Survey Professional Paper $1408-B,(1992)$. 
Neupane et al.

Williams, C.F., Reed, M.J., Mariner, R.H., DeAngelo, J., and Galanis, S.P. Jr.: Assessment of moderate- and high-temperature geothermal resources of the United States. US Department of the Interior, US Geological Survey, Fact Sheet 2008-3082, (2008).

Young, H.W. and Mitchell, J.C.: Geothermal investigations in Idaho. Part 1. Geochemistry and geologic setting of selected thermal waters (No. NP-22003/1). U.S. Geological Survey and Idaho Dept. of Water Administration, (1973). 


\title{
Appendix L.
}

\section{Mineral Selection for Multicomponent Equilibrium Geothermometry}

\author{
C. D. Palmer ${ }^{1,2}$, S. R. Ohly ${ }^{4}$, R. W. Smith ${ }^{1,2}$, G. Neupane ${ }^{1,2}$, T. McLing ${ }^{1,2}$, and E. Mattson ${ }^{3}$ \\ ${ }^{1}$ University of Idaho-Idaho Falls, Idaho Falls, ID \\ ${ }^{2}$ Center for Advanced Energy Studies, Idaho Falls, ID \\ ${ }^{3}$ Idaho National Laboratory, Idaho Falls, ID \\ ${ }^{4}$ Idaho State University, Department of Geosciences, Pocatello, ID \\ palmerc7@comcast.net
}

\begin{abstract}
Keywords
Geothermometry, multicomponent equilibria, optimization, alteration minerals, geochemistry
\end{abstract}

\begin{abstract}
Multicomponent geothermometry requires knowledge of the mineral phases in the reservoir with which the geothermal fluids may be equilibrated. These minerals phases are most often alteration products rather than primary minerals. We have reviewed the literature on geothermal systems representing most major geologic environments typically associated with geothermal activity and identified potential alteration products in various environments. We have included this information in RTEst, a code we have developed to estimate reservoir conditions (temperature, $\mathrm{CO}_{2}$ fugacity) from the geochemistry of near-surface geothermal waters. The information has been included in RTEst through the addition of filters that decrease the potential number of minerals from all possibilities based on the basis species to those that are more relevant to the particular conditions in which the user is interested. The three groups of filters include host rock type (tholeiitic, calc-alkaline, silicic, siliciclastic, carbonate), water type (acidic, neutral), and the temperature range over which the alteration minerals were formed (low, medium, high). The userchosen mineral assemblage is checked to make sure that it does not violate the Gibbs phase rule. The user can select one of three mineral saturation weighting schemes that decrease the chance the optimization from being skewed by reaction stoichiometry or analytical uncertainty.
\end{abstract}

\section{Introduction}

A major barrier to the deployment of geothermal energy is the financial risk associated with geothermal prospecting (U.S. Department of Energy, 2011). Geophysical surveys and test wells are expensive, and advances in prospecting are needed to reduce risk and increase the return on prospecting investments. One possibility is to improve the accuracy of geothermometry by taking advantage of advances in geochemical analyses and modeling.

Geothermometry is an important tool for estimating deep reservoir temperature from the geochemical composition of shallower and cooler waters. The underlying assumption of geothermometry is that the waters collected from shallow wells and seeps maintain a chemical signature that reflects equilibrium in the deeper reservoir. Many of the geothermometers used in practice are based on correlation between water temperatures and composition or using thermodynamic calculations based a subset (typically silica, cations or cation ratios) of the dissolved constituents. Alternatively, "complete" water compositions can be used in multicomponent equilibrium geochemical models to calculate the degree of disequilibrium (saturation index) for a suite of potential reservoir minerals as a function of temperature and the reservoir temperature estimated from the common intersection of the saturation indices with the zero (equilibrium) line. Some of the basic concepts of this multicomponent geothermometry approach of been described by others (e.g., Bethke, 2008; Reed and Spycher, 1984; Spycher et al., 2011; Spycher et al., 2014; Cooper et al., 2013) and are being applied in several geothermal systems (Neupane et al., 2014).

While multicomponent equilibrium geothermometry can be used for estimating of reservoir temperature based on a given set of minerals, selecting which minerals that should be members of that set represents an area of continuing uncertainty. The choice of minerals is dependent upon several factors (e.g. Browne, 1978) including the reservoir lithology. The geoscience literature contains numerous studies that identify alteration mineral assemblages that form when hot water interacts with reservoir minerals (e.g., Schwartz, 1959). Many hydrothermal systems are equilibrated with the alteration mineral assemblages rather than the primary reservoir lithology (Bethke, 2008; Giggenbach, 1988).. Incorporating knowledge of these assemblages into a multicomponent equilibrium model would aid analysts in performing geothermometry. 


\section{Alteration Minerals for Multicomponent Equilibrium Geothermometry}

We have reviewed 48 geothermal systems representing all major geologic environments typically associated with geothermal activity (reference listed in Appendix). For each geothermal field, primary lithology, mineralogy, maximum reservoir temperature, water composition, and secondary mineral assemblages were recorded and evaluated. Although Browne (1978) listed 6 major factors that influence the crystallization of various assemblages in active geothermal fields (temperature, pressure, reservoir rock type, permeability, fluid composition, and duration of hydrothermal activity), in this study, we observed three factors (reservoir lithology, fluid composition, and temperature) were most influential in determining the alteration mineral assemblages. Based on our analysis of the reports listed in the Appendix, we developed a hierarchical 16-category classification of these geothermal systems shown in Figure 1 that included 5 lithologies or rock types (Tholeiitic, Calc-alkaline, Silicic, Siliciclastic, and carbonates), 3 temperature regimes (low, 50-150 ${ }^{\circ} \mathrm{C}$; moderate, 150 to $300^{\circ} \mathrm{C}$; and high, $>300{ }^{\circ} \mathrm{C}$ ), and 2 water types (neutral and acid). Representative geothermal alteration mineral assemblages for each

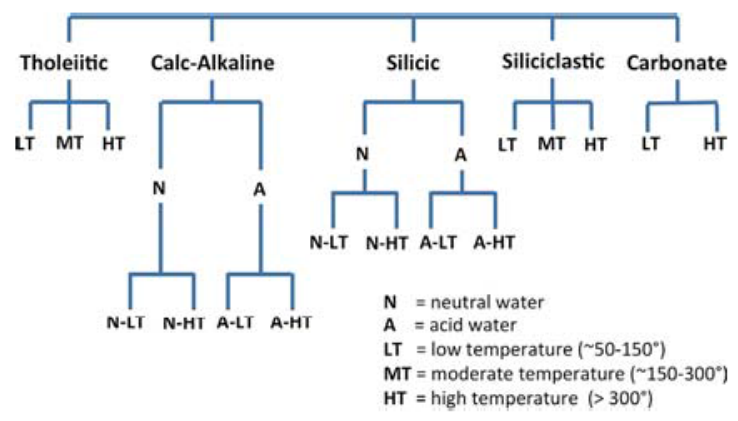

Figure 1. Hierarchical listing of influencing parameters and assemblage groups.
Table 1. Representative geothermal alteration mineral assemblages for hierarchical classification shown in Figure 1. ( $\mathrm{T}=$ tholeiitic, $\mathrm{CA}=$ calc-alkaline, $\mathrm{S}=$ silicic, $\mathrm{SC}=$ siliciclastic, $\mathrm{C}=$ carbonate, $\mathrm{N}=$ neutral, $\mathrm{A}=$ acidic, $\mathrm{LT}=$ low temperature, $\mathrm{MT}=$ moderate temperature, $\mathrm{HT}=$ high temperature).

\begin{tabular}{|c|c|}
\hline $\begin{array}{c}\text { Assemblage } \\
\text { ID* }\end{array}$ & Minerals Present \\
\hline T-LT & $\begin{array}{l}\text { Chalcedony } \pm \text { quartz }+ \text { zeolites }+ \text { smectite }+ \text { calcite } \pm \text { limonite }+ \text { pyrite }+ \\
\text { anhydrite }\end{array}$ \\
\hline T-MT & $\begin{array}{l}\text { Quartz }+ \text { wairakite }+ \text { albite }+ \text { titanite }+ \text { epidote }+ \text { prehnite }+ \text { mixed layer clay } \\
\text { (chlorite/smectite }) \pm \text { smectite } \pm \text { chlorite }+ \text { calcite }+ \text { pyrite }+ \text { anhydrite }\end{array}$ \\
\hline T-HT & $\begin{array}{l}\text { Quartz + wairakite + albite + wollastonite } \pm \text { clinopyroxene }+ \text { actinolite }+ \\
\text { titanite + garnet + epidote }+ \text { prehnite }+ \text { chlorite }+ \text { calcite }+ \text { pyrite }+ \text { anhydrite }\end{array}$ \\
\hline CA-N-LT & $\begin{array}{l}\text { Zeolites } \pm \text { cristobalite } \pm \text { quartz }+ \text { smectite } \pm \text { chlorite }+ \text { calcite }+ \text { hematite } \pm \\
\text { goethite }+ \text { pyrite }+ \text { anhydrite } \pm \text { barite }+ \text { native sulfur }\end{array}$ \\
\hline CA-N-HT & $\begin{array}{l}\text { Quartz }+ \text { wairakite }+ \text { albite }+ \text { adularia }+ \text { clinopyroxene }+ \text { actinolite }+ \text { titanite } \\
+ \text { epidote }+ \text { prehnite } \pm \text { biotite }+ \text { chlorite }+ \text { illite }+ \text { calcite }+ \text { pyrite }+ \text { anhydrite } \\
\pm \text { barite } \pm \text { halides }\end{array}$ \\
\hline CA-A-LT & $\begin{array}{l}\text { Amorphous silica } \pm \text { cristobalite }+ \text { kaolinite }+ \text { smectite } \pm \text { montmorillonite }+ \\
\text { calcite }+ \text { hematite } \pm \text { goethite }+ \text { pyrite }+ \text { alunite } \pm \text { anhydrite }+ \text { native sulfur }\end{array}$ \\
\hline CA-A-HT & $\begin{array}{l}\text { Quartz + albite + clinopyroxene + actinolite + titanite + epidote + biotite/ } \\
\text { prehnite + chlorite + illite + calcite + pyrite + anhydrite } \pm \text { halides }\end{array}$ \\
\hline S-N-LT & $\begin{array}{l}\text { Quartz + zeolites + adularia + smectite/kaolinite/montmorillonite }+ \text { calcite }+ \\
\text { pyrite } \pm \text { anhydrite }\end{array}$ \\
\hline S-N-HT & $\begin{array}{l}\text { Quartz + albite } \pm \text { potassium feldspar + epidote }+ \text { sericite/muscovite }+ \text { chlorite } \\
+ \text { calcite }+ \text { pyrite } \pm \text { anhydrite }\end{array}$ \\
\hline S-A-LT & $\begin{array}{l}\text { Cristobalite }+ \text { opal } \pm \text { quartz }+ \text { zeolites }+ \text { adularia }+ \text { smectite/kaolinite/ } \\
\text { montmorillonite/mixed layer clays } \pm \text { hematite }+ \text { sulfides }+ \text { alunite } \pm \text { barite }\end{array}$ \\
\hline S-A-HT & $\begin{array}{l}\text { Quartz }+ \text { albite } \pm \text { potassium feldspar }+ \text { epidote }+ \text { sericite/muscovite }+ \\
\text { montmorillonite/kaolinite/chlorite }+ \text { sulfides }+ \text { alunite } \pm \text { barite } \pm \text { halides }\end{array}$ \\
\hline SC-LT & $\begin{array}{l}\text { Potassium feldspar }+ \text { albite }+ \text { mixed layer clay (illite/smectite) } \pm \text { chlorite }+ \\
\text { calcite } \pm \text { ankerite/dolomite }+ \text { hematite }+ \text { pyrite }+ \text { anhydrite }\end{array}$ \\
\hline SC-MT & $\begin{array}{l}\text { Quartz + wairakite + potassium feldspar + albite + titanite + epidote + chlo- } \\
\text { rite + calcite + hematite + pyrite + anhydrite }\end{array}$ \\
\hline SC-HT & $\begin{array}{l}\text { Quartz }+ \text { potassium feldspar }+ \text { albite } \pm \text { clinopyroxene }+ \text { actinolite }+ \text { titanite }+ \\
\text { garnet }+ \text { epidote }+ \text { biotite }+ \text { calcite }+ \text { hematite }+ \text { pyrite }\end{array}$ \\
\hline C-LT & Feldspar \pm quartz + calcite \pm ankerite/dolomite + hematite \\
\hline C-HT & $\begin{array}{l}\text { Feldspar } \pm \text { quartz }+ \text { clinopyroxene }+ \text { actinolite }+ \text { titanite }+ \text { epidote }+ \text { biotite } \pm \\
\text { chlorite }+ \text { calcite }\end{array}$ \\
\hline
\end{tabular}
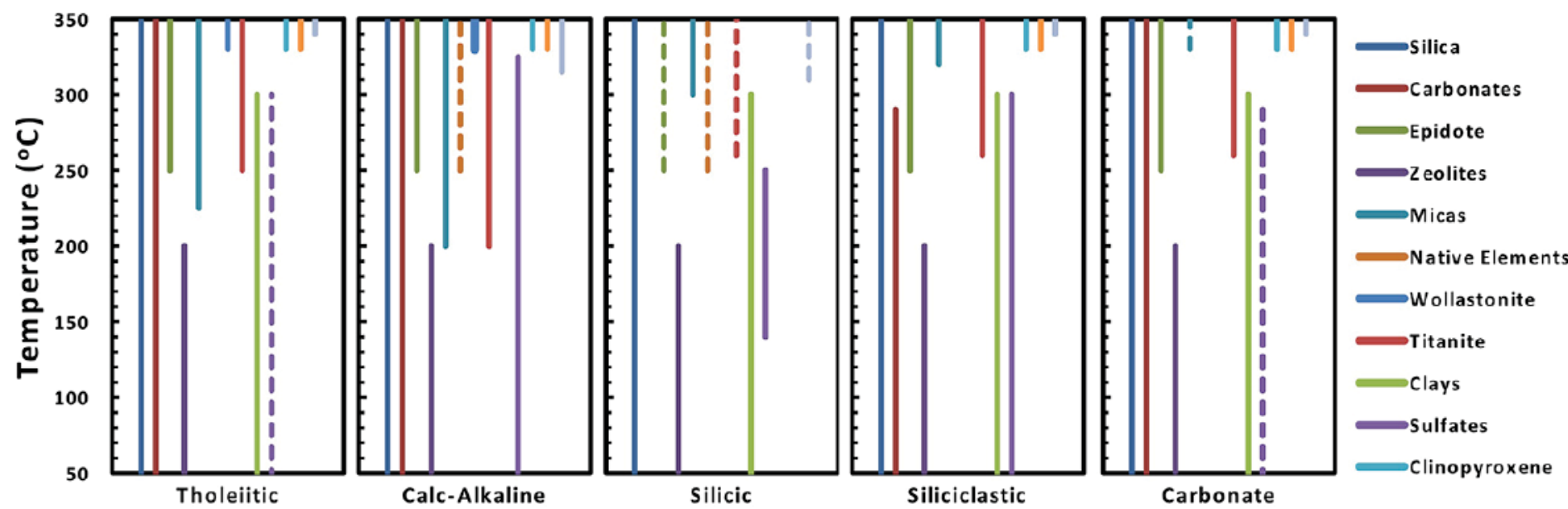

Figure 2. Temperature intervals for mineral groups in rock types. Solid lines indicate significant presence and dashed lines indicate occasional presence. 
of the 16 classification are provided in Table 1. Figure 2 shows the generalized relationship among specific types of alteration minerals, lithology, and temperature.

\section{Incorporating Mineralogical Knowledge into RTEst}

We have developed a multicomponent optimization approach that takes into account several processes that can affect geothermometry including formation of a steam phase, loss of volatile components (e.g., $\mathrm{CO}_{2}$ ), and mixing with other waters to estimate conditions to which a water sample was exposed in the deeper portions of the reservoir. To make these estimates, we have implemented this approach in the Reservoir Temperature Estimator (RTEst) code. RTEst minimizes the weighted sum of squares of the saturation indices of a user-selected set of minerals believed to be at equilibrium within the reservoir by adjusting the temperature, fugacity of $\mathrm{CO}_{2}\left(\mathrm{fCO}_{2}\right)$, and mass of water. RTEst uses the React module in The Geochemist's Workbench (GWB) (Bethke and Yeakel, 2011) to do the geochemical calculations while using PEST (Doherty, 2005, 2013) to perform the optimization calculations.

In RTEst, the user selects the set of reservoir minerals with which the reservoir fluid is believed to be equilibrated on the "Mineral Assemblage" tab of the "RTEst Input File Generator" window (Figure 3). For a water analysis that includes, $\mathrm{Ca}, \mathrm{Na}$, $\mathrm{K}, \mathrm{Al}, \mathrm{Cl}, \mathrm{HCO}_{3}^{-}, \mathrm{SiO}_{2}$, and $\mathrm{pH}$, and for which no filters are used, RTEst loads 89 potential mineral phases from the GWB default thermo.dat thermodynamic database from which the user can select those to be used in the mineral assemblage. GWB includes several alternate thermodynamic data bases as

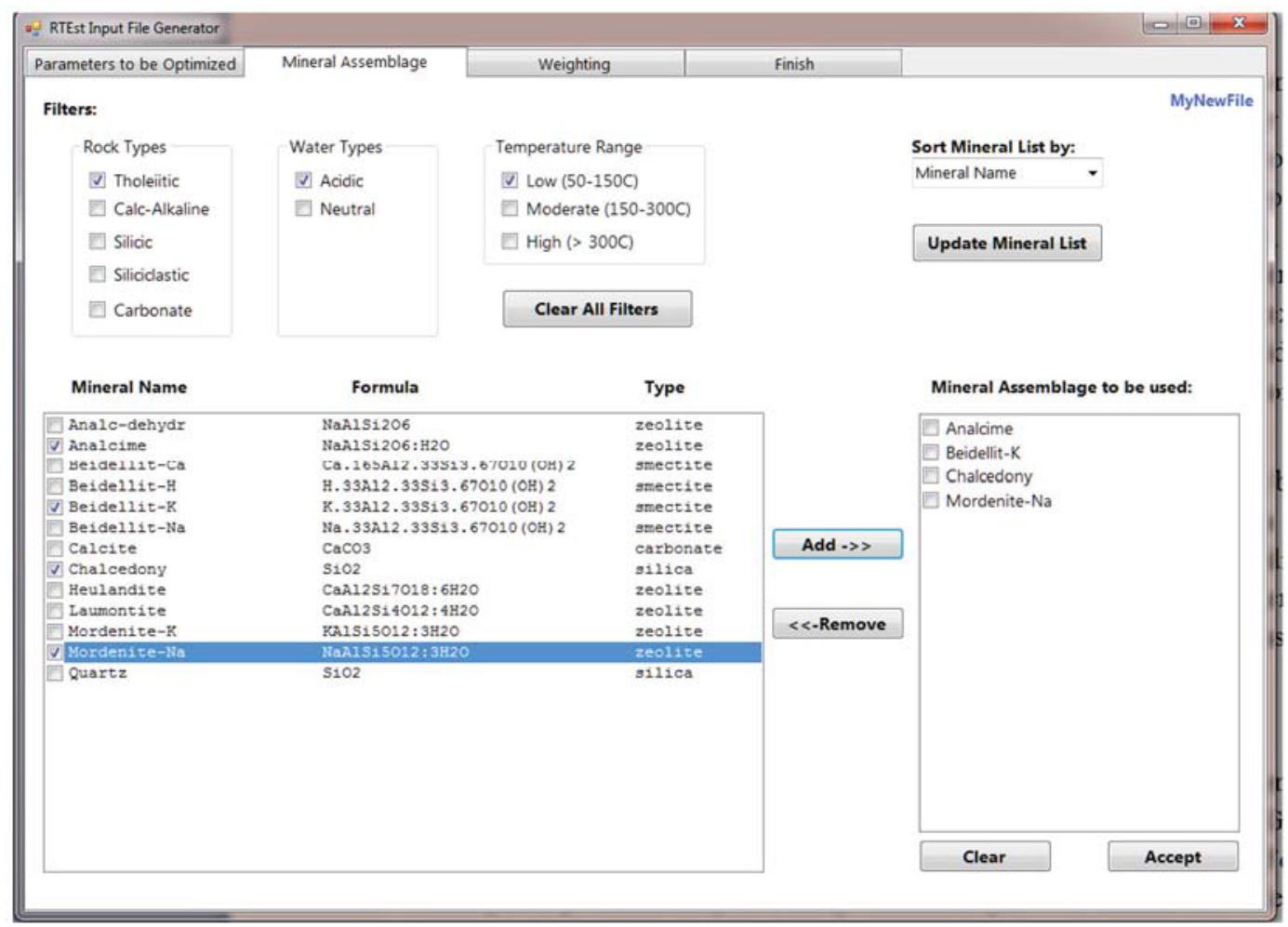

Figure 3 . Tab within RTEst that is used to choose the mineral assemblage with which the reservoir fluid is equilibrated. well as the capability to accommodate user data bases (Bethe and Yeakel, 2011). The user can then check those minerals they wish to include in the mineral assemblage and click the "Add- $>>$ " button. To remove a mineral from the assemblage, the user simply checks the mineral name and clicks the " $<<-R e-$ move" button.

To assist the user in making reasonable choices, a series of filters (based on our analysis of alteration mineral assemblage; Table 1) can be applied to limit the number of choices to minerals that are more likely to be present in the particular geologic setting being considered. There are three groups of filters: host rock type (i.e., lithology), water type, and temperature range. Selections within the host rock type group include tholeiitic, calc-alkaline, silicic, siliciclastic, and carbonate. Water types include acidic or neutral waters, and the temperature range options include low $\left(50-100^{\circ} \mathrm{C}\right)$, moderate $\left(150-300^{\circ} \mathrm{C}\right)$ or high $\left(>300^{\circ}\right)$. For the example shown in Figure 3, the user is considering choices for a tholeiitic host rock with acid water type where the phases were formed under low temperature conditions. With the application of these filters, the number of potential mineral choices has been reduced from 89 to 13 .

The user can check more than one box within a group. For example, it may be uncertain if the reservoir is best described as silicic or siliciclastic. If more than one box is checked the list of potential minerals is the union of the sets for the individual choices. In addition, the temperature range filter represents an initial assessment of the user of the expected reservoir temperature. If the RTEst estimated temperature is outside of the temperature range, the user can reselect the more appropriate range.

\section{The Phase Rule}

While the user can only select minerals that are plausible based on the chemical analysis of the water, it is possible to choose a combination of minerals that violates the Gibbs phase rule which defines the maximum number of independent variables within a system. For cases where there is a fluid phase present and system temperature and pressure are correlated (e.g., steam saturated water), a simplified version of the phase rule can be used to determine the maximum number of equilibrium mineral phases that are appropriate for the calculation

$$
M=C-F
$$

where $\mathrm{M}$ is the number of equilibrium minerals, $\mathrm{C}$ is the number of components, and $\mathrm{F}$ is the degrees of freedom. fter selecting the minerals to be included in assemblage, RTEst tests for the independence of the choices 
and generates an error message if the phase rule is violated. ote, however, that although Eq. calculates the theoretical maximum number of mineral phases that may be in equilibrium the true number of phases in the real system may be less.

\section{Temperature and Parameter Optimization}

With the establishment of a mineral assemblage that is consistent with the Phase Rule, RTEst estimates an equilibrium reservoir temperature (as well as a $\mathrm{fCO}_{2}$ and water mixing or boiling) by minimizing an objective function $(\Phi)$ that is the weighted sum of the squares of the saturation indexes for the selected equilibrium minerals

$$
\Phi=\sum\left(S I_{i} w_{i}\right)^{2}
$$

where $\mathrm{SI}_{\mathrm{i}}=\log \left(\mathrm{Q}_{\mathrm{i}} / \mathrm{K}_{\mathrm{i}, \mathrm{T}}\right)$ for the ith equilibrium mineral $\left(\mathrm{Q}_{\mathrm{i}}\right.$ and $\mathrm{K}_{\mathrm{i}, \mathrm{T}}$ are the ion activity product and temperature dependent equilibrium constant, respectively for ith mineral) and $\mathrm{w}_{\mathrm{i}}$ is the weighting factor for the ith mineral. Possible weighting factors are described below.

\section{Weighting Factors}

Once the mineral assemblage is chosen, the weighting factors for the mineral saturation indices must be selected. The weighting factors ensure that each mineral that contributes to the equilibrium state is considered equally and the results are not skewed by reaction stoichiometry or differences in analytical uncertainty. There are three options of weighting factors in RTEst: inverse of variance, normalization, or unit weights. In general, unit weights are not recommended because during the optimization process, a clay mineral that has many basis species would be artificially weighted over a mineral such as quartz which has only one basis species. The normalization option is the weighting method that was employed by Cooper et al. (2013) and the reader is referred to that work for additional information.

The inverse of variance method calculates the weights based on the conditional variance of the saturation index given the solubility product of the mineral. The method calculates the propagation of error from the analytical uncertainty of the basis species for the mineral and the stoichiometry of the mineral making simplifying assumption about the correlation between the basis species. The conditional variance in the saturation index of mineral $\mathrm{k}, S_{S I_{k}}^{2}$, is approximately

$$
s_{S I_{k}}^{2} \approx\left(\frac{1}{\ln (10)}\right)^{2}\left[\sum_{i=1}^{n c} v_{i k}\left(\frac{s_{C_{i}}}{C_{i}}\right)^{2}\right]
$$

where $\mathrm{v}_{\mathrm{ik}}$ is the stoichiometric coefficient of the ith basis species in the kth mineral phase and $s_{C} / C_{i}$ is the coefficient of variation of the concentration of the ith basis species, (i.e., the analytical uncertainty in the reported concentration). More details can be found Palmer et al. (2014). An example "Weighting" tab in the "RTEst Input File Generator" form with some mineral saturation weights is shown in Figure 4. It should be noted that none of the weighting options explicitly account for potential errors or uncertainty in the temperature dependent equilibrium constants

\begin{tabular}{|c|c|c|c|}
\hline \multicolumn{4}{|c|}{ RTEst Input File Generator } \\
\hline \multicolumn{3}{|c|}{ Parameters to be Optimized } & \multirow{2}{*}{$\begin{array}{l}\text { Mineral Assemblage } \\
\text { Reset to Default }\end{array}$} \\
\hline Inverse of Variance & - & File & \\
\hline \multicolumn{4}{|l|}{ Inverse of Variance } \\
\hline $\begin{array}{l}\text { Normalization } \\
\text { Unit Weights }\end{array}$ & & ting & Factor \\
\hline
\end{tabular}
in the thermodynamic data bases.

"Analcime", 2.0344711469279

"Beidellit-K", 1.49128705731699

"Chalcedony", 20

"Mordenite-Na", 2.00360974925215

Figure 4. Example of the "Weighting" tab in the "RTEst Input File Generator" form.

\section{Summary}

Based on a survey of the literature we have identified alteration mineral assemblages and associated equilibrium mineral phases that may control reservoir fluids compositions. This knowledge has been included in the multicomponent equilibrium geothermometry code RTEst through the addition of filters that limit the potential number of minerals from all possibilities based on the basis species to those that are more relevant to the particular conditions in which the user is interested. The three groups of filters include host rock type (tholeiitic, calc-alkaline, silicic, siliciclastic, carbonate), water type (acidic, neutral), and the temperature range over which the alteration minerals were formed (low, medium high). Once the minerals that are to be included in the assemblage are chosen, RTEst determines if there is a violation of the Gibbs phase rule and if so returns an error message to the user. While these filters are no replacement for geochemical expertise or an actual knowledge of reservoir characteristics, they greatly assist users in obtaining improved estimates of conditions (temperatures, $\mathrm{fCO} 2$, steam formation) to which the geothermal waters may have been subjected.

\section{References}

Armannson, H., Fridriksson, T., 2009. Application of Geochemical Methods in Geothermal Exploration. Short Course on Surface Exploration for Geothermal Resources organized by the United Nations University Geothermal Training Programme, Ahuachapan and Sata Tecla, El Salvador, p. 12.

Bethke, C.M., 2008. Geochemical and Biogeochemical Reaction Modeling, 2nd ed. Cambridge University Press, New York, New York, USA. 
Bethke, C.M., Yeakel, S., 2011. The Geochemist's Workbench User's Guide. Aqueous Solutions, Champaign, IL.

Browne, P. R. L., 1978. Hydrothermal alteration in active geothermal fields. Annual Reviews in Earth and Planetary Science, vol. 6, pp. 229-250

Cooper, D.C., Palmer, C.D., Smith, R.W., \& McLing, T.L., 2013. Multicomponent equilibrium models for testing geothermometry approaches. Proceedings of the Thirty-Eighth Workshop on Geothermal Reservoir Engineering, Stanford University, Stanford, CA.

Doherty, J., 2005. PEST, Model-Independent Parameter Estimation User Manual, 5 th ed. Watermark Numerical Computing.

Doherty, J., 2013. Addendum to the PEST Manual. Watermark Numerical Computing.

Giggenbach, W.F., 1988. Geothermal solute equilibria. Derivation of Na-K$\mathrm{Mg}-\mathrm{Ca}$ geoindicators. Geochimica et Cosmochimica Acta 52, 2749-2765.

Neupane, G., Mattson, E.D., McLing, T.L., Palmer, C.D., Smith, R.W., and Wood, T.R., (2014). Deep geothermal reservoir temperatures in the Eastern Snake River Plain, Idaho using multicomponent geothermometry. Proceedings, Thirty-ninth Workshop on Geothermal Reservoir
Engineering, Stanford University, Stanford, California, February 24-26, 2014 SGP-TR-202.

Palmer, C.D., 2014. Reservoir Temperature Estimator (RTEst) User Manual. University of Idaho, p. 10.

Pang, Z.-H., Reed, M., 1998. Theoretical Chemical Thermometry on Geothermal Waters: Problems and Methods. Geochimica et Cosmochimica Acta 62, 1083-1091.

Reed, M., Spycher, N., 1984. Calculation of $\mathrm{pH}$ and mineral equilibria in hydrothermal waters with application to geothermometry and studies of boiling and dilution. Geochimica et Cosmochimica Acta 48, 1479-1492.

Schwartz, G.M., 1959. Hydrothermal alteration. Economic Geology 54, 161-183.

Spycher, N.F., Sonnenthal, E., Kennedy, B.M., 2011. Integrating multicomponent chemical geothermometry with parameter estimation computations for geothermal exploration. Geothermal Resources Council Transactions $35,663-666$.

U.S. Department of Energy, 2011. Exploration Technologies, Technology Needs Assessment, Energy Efficiency and Renewable Energy, Geothermal Technology Program, DOE/EE-0663

\section{APPENDIX}

Literature sources considered in developing representative geothermal alteration mineral assemblages:

Agostini, S., Corti, G., Doglioni, C., Carminati, E., Innocenti, F., Tonarini, S., Manetti, P., Di Vincenzo, G., and Montanari, D., 2006. Tectonic and magmatic evolution of the active volcanic front in El Salvador: insight into the Berlín and Ahuachapán geothermal areas. Geothermics, vol. 35 , pp. 368-408.

Ashley, R. P., Cunningham, C. G., Bostick, N. H., Dean, W. E., and Chou, I.-M., 1991. Geology and geochemistry of three sedimentary-rock-hosted disseminated gold deposits in Guizhou Province, People's Republic of China. Ore Geology Reviews, vol. 6, pp. 133-151.

Ayling, B., Molling, P., Nye, R., and Moore, J., 2011. Fluid geochemistry at the Raft River geothermal field, Idaho: New data and hydrogeological implications. Proceedings, Thirty-sixth Workshop on Geothermal Reservoir Engineering, Stanford University, Stanford, California, January 31-February 2, 2011, $11 \mathrm{p}$.

Battaglia, S., Gianelli, G., Rossi, R., and Cavarretta, G., 1991. The Sulphur Springs geothermal field, St. Lucia, Lesser Antilles: Hydrothermal mineralogy of wells SL-1 and SL-2. Journal of South American Earth Sciences, vol. 4, no. 1/2, pp. 1-12.

Beaufort, D., Westercamp, D., Legendre, O., and Meunier, A., 1990. The fossil hydrothermal system of Saint Martin, Lesser Antilles: geology and lateral distribution of alterations. Journal of Volcanology and Geothermal Research, vol. 40, pp. 219-243.

Bertini, G., Gianelli, G., Pandeli, E., and Puxeddu, M., 1985. Distribution of hydrothermal minerals in Larderello-Travale and Mt. Amiata geothermal fields (Italy). Geothermal Resources Council Transactions, vol. 9, part 1, pp. 261-266.

Blackett, R. E., and Kolesar, P. T., 1983. Geology and alteration of the Raft River geothermal system, Idaho. Geothermal Resources Council Transactions, vol. 7, pp. 123-127.

Cathelineau, M., Oliver, R., Nieva, D., and Garfias, A., 1985. Mineralogy and distribution of hydrothermal mineral zones in Los Azufres (Mexico) geothermal field. Geothermics, vol. 14, no. 1, pp. 49-57.
Cavarretta, G., Gianelli, G., and Puxeddu, M., 1980. Hydrothermal metamorphism in the Larderello geothermal field. Geothermics, vol. 9, pp. 297-314.

Clemente, W. C., and Villadolid-Abrigo, F. L., 1993. The Bulalo geothermal field, Philippines: Reservoir characteristics and response to production. Geothermics, vol. 22, no. 5/6, pp. 381-394.

Cole, D. R., and Ravinsky, L. I., 1984. Hydrothermal alteration zoning in the Beowave geothermal system, Eureka and Lander counties, Nevada. Economic Geology, vol. 79, pp. 759-767.

Cook, N. D. J., and Ashley, P. M., 1992. Meta-evaporite sequence, exhalative chemical sediments and associated rocks in the Proterozoic Willyama Supergroup, South Australia: implications for metallogenesis. Precambrian Research, vol. 56, pp. 211-226.

De Vivo, B., Belkin, H. E., Barbieri, M., Chelini, W., Lattanzi, P., Lima, A., and Tolomeo, L., 1989. The Campi Flegrei (Italy) geothermal system: A fluid inclusion study of the Mofete and San Vito fields. Journal of Volcanology and Geothermal Research, vol. 36, pp. 303-326.

Donoghue, E., Troll, V. R., Harris, C., O'Halloran, A., Walter, T. R., and Torrado, F. J. P., 2008. Low-temperature hydrothermal alteration of intracaldera tuffs, Miocene Tejeda caldera, Gran Canaria, Canary Islands. Journal of Volcanology and Geothermal Research, vol. 176, pp. 551-564.

Dudoignon, P., Meunier, A., Beaufort, D., Gachon, A., and Buigues, D., 1989. Hydrothermal alteration at Mururoa Atoll (French Polynesia). Chemical Geology, vol. 76, pp. 385-401.

Elders, W. A., Hoagland, J. R., and McDowell, S. D., 1979. Hydrothermal mineral zones in the geothermal reservoir of Cerro Prieto. Geothermics, vol. 8, pp. 201-209.

Enami, M., Liou, J. G., and Bird, D. K., 1992. Cl-bearing amphibole in the Salton Sea geothermal system, California. Canadian Mineralogist, vol. 30, pp. 1077-1092.

Eshaghpour, M., 2003. Borehole geology and alteration mineralogy of well HE-9 in Hellisheidi geothermal field, SW-Iceland. United Nations University Geothermal Training Programme 2003 Report Number 8, Orkustofnun, Grensásvegur 9, IS-108, Reykjavík, Iceland, pp. 165-187. 
Fagan, C. J., Wilson, C. J. N., Spinks, K. D., Browne, P. R. L., and Simmons, S. F., 2006. Stratigraphy, hydrothermal alteration and evolution of the Mangakino geothermal system, Taupo Volcanic Zone, New Zealand. Proceedings, $28^{\text {th }}$ New Zealand Geothermal Workshop 2006, 7 p.

Flexser, S., 1991. Hydrothermal alteration and past and present thermal regimes in the western moat of Long Valley caldera. Journal of Volcanology and Geothermal Research, vol. 48, pp. 303-318.

Fulginati, P., Gioncada, A., and Sbrana, A., 1998. Geologic model of the magmatic-hydrothermal system of Vulcano (Aeolian Islands, Italy). Mineralogy and Petrology, vol. 62, pp. 195-222.

Fulginati, P., Malfitano, G., and Sbrana, A., 1997. The Pantelleria caldera geothermal system: Data from the hydrothermal minerals. Journal of Volcanology and Geothermal Research, vol. 75, pp. 251-270.

Funiciello, R., Mariotti, G., Parotto, M., Preite-Martinez, M., Tecce, F., Toneatti, R., and Turi, B., 1979. Geology, mineralogy, and stable isotope geochemistry of the Cesano geothermal field (Sabatini Mts. volcanic system, Northern Latium, Italy). Geothermics, vol. 8, pp. 55-73.

Furuya, S., Aoki, M., Gotoh, H., and Takenaka, T., 2000. Takigami geothermal system, northeastern Kyushu, Japan. Geothermics, vol. 29, pp. 191-211.

Getaneh, E., 2001. Borehole geology and alteration mineralogy in the upper half of well HE-3, Hellisheidi, SW-Iceland. United Nations University Geothermal Training Programme 2001 Report Number 4, Orkudtofnun, Grensásvegur 9, IS-108, Reykjavik, Iceland, pp. 59-82.

Ghazban, F., 2004. Alteration and Geochemistry of Mount Taftan Geothermal Prospect Southeastern Iran. Iranian International Journal of Science, vol. 1, pp. 43-62.

Gianelli, G., and Teklemariam, M., 1993. Water-rock interaction processes in the Aluto-Langano geothermal field (Ethiopia). Journal of Volcanology and Geothermal Research, vol. 56, pp. 429-445.

Gioncada, A., Sbrana, A., and Teklemariam, M., 1995. Hydrothermal Alteration and Fluid Inclusion Studies in the Vulcano Geothermal Wells (Italy). World Geothermal Congress Proceedings, pp. 1099-1104.

Hagerty, J. J., and Newsom, H. E., 2003. Hydrothermal alteration at the Lonar Lake impact structure, India: Implications for impact cratering on Mars. Meteoritics and Planetary Science, vol. 38, no. 3, pp. 365-381.

Hartanto, D. B., 2005. Borehole geology and alteration mineralogy of well HE-11, Hellisheidi geothermal field, SW-Iceland. United Nations University Geothermal Training Programme Report Number 8, Orkustofnun, Grensásvegur 9, IS-108 Reykjavik, Iceland, pp. 83-109.

Hayashi, J., and Furuya, S., 1988. Geothermal resources in the Takigami geothermal area, Kyushu, Japan. Proceedings, $10^{\text {th }}$ New Zealand Geothermal Workshop 1988, pp. 49-53.

Hedenquist, J. W., 1990. The thermal and geochemical structure of the Broadlands-Ohaaki geothermal system, New Zealand. Geothermics, vol. 19, pp. 151-185.

Hedenquist, J. W., and Browne, P. R. L., 1989. The evolution of the Waiotapu geothermal system, New Zealand, based on the chemical and isotopic composition of its fluids, minerals, and rocks. Geochimica et Cosmochimica Acta, vol. 53, pp. 2235-2257.

Henneberger, R. C., and Browne, P. R. L., 1988. Hydrothermal alteration and evolution of the Ohakuri hydrothermal system, Taupo Volcanic Zone, New Zealand. Journal of Volcanology and Geothermal Research, vol. 34, pp. 211-231.

Hulen, J. B., and Neilson, D. L., 1986. Stratigraphy and hydrothermal alteration in well Baca-8, Sulphur Springs area, Valles Caldera, New Mexico. Geothermal Resources Council Transactions, vol. 10, pp. 187-192.

Hulen, J. B., and Nielson, D. L., 1988. Clay mineralogy and zoning in CSDP corehole VC-2A: Further evidence for collapse of isotherms in the Valles Caldera. Geothermal Resources Council Transactions, vol. 12, pp. 291-298.
Inoue, A., and Utada, M., 1991. Pumpellyite and related minerals from hydrothermally altered rocks at the Kamikita area, northern Honshu, Japan. Canadian Mineralogist, vol. 29, pp. 255-270.

Karpov, G. A., and Naboko, S. I., 1990. Metal contents of recent thermal waters, mineral precipitates and hydrothermal alteration in active geothermal fields, Kamchatka. Journal of Geochemical Exploration, vol. 36 , pp. 57-71.

Keith, T. E. C., and Muffler, L. J. P., 1978. Minerals produced during cooling and hydrothermal alteration of ash flow tuff from Yellowstone drill hole Y-5. Journal of Volcanology and Geothermal Research, vol. 3, pp. 373-402.

Koestono, H., 2007. Borehole geology and hydrothermal alteration of well HE-24, Hellisheidi geothermal field, SW-Iceland. United Nations University Geothermal Training Programme 2007 Report Number 10, Orkustofnun, Grensásvegur 9, IS-108 Reykjavík, Iceland, p. 199-224.

Lagat, J. K., 1995. Borehole geology and hydrothermal alteration of well OW-30, Olkaria geothermal field, Kenya. United Nations University Geothermal Training Programme 1995 Report number 6, Orkustofnun, Grensásgevur 9, IS-108 Reykjavík, Iceland, pp. 135-154.

Lagat, J. K., 2004. Geology, hydrothermal alteration and fluid inclusion studies of Olkaria Domes geothermal field, Kenya. M.Sc. thesis, Department of Geology and Geography, University of Iceland, 79 p.

Ledésert, B., Hebert, R., Genter, A., Bartier, D., Clauer, N., and Grall, C., 2010. Fractures, hydrothermal alterations and permeability in the Soultz Enhanced Geothermal System. Comptes Rendus Geoscience, vol. 342, pp. 607-615.

Liakopoulos, A., Katerinopoulos, A., Markopoulos, T., and Boulegue, J., 1991. A mineralogical petrographic and geochemical study of samples from wells in the geothermal field of Milos Island (Greece). Geothermics, vol. 20 , no. 4 , pp. 237-256.

Lutz, S. J., and Moore, J. N., 1997. Geologic framework of Jurassic reservoir rocks in the Dixie Valley geothermal field, Nevada: Implications from hydrothermal alteration and stratigraphy. Proceedings, Twenty-second Workshop on Geothermal Reservoir Engineering, Stanford University, Stanford, California, January 27-29, 1997, pp. 131-139.

Lutz, S. J., Moore, J. N., and Copp, J. F., 1996. Integrated mineralogical and fluid inclusion study of the Coso geothermal system, California. Proceedings, Twenty-First Workshop on Geothermal Reservoir Engineering, Stanford University, California, January 22-24, 1996, pp. 187-194.

Magaña, M. I., de Henríquez, E., and López, D., 2003. Study on diffuse degassing and alteration mineralogy in the Berlin Geothermal Field. International Geothermal Conference, Session \#9, Reykjavik, September 2003, pp. 33-39.

Marks, N., Schiffman, P., Zirenberg, R. A., Franzson, H., and Fridleifsson, G. Ó., 2010. Hydrothermal alteration in the Reykjanes geothermal system: Insights from Iceland deep drilling program well RN-17. Journal of Volcanology and Geothermal Research, vol. 189, pp. 172-190.

Marumo, K., Nagasawa, K. and Kuroda, Y., 1980. Mineralogy and hydrogen isotope geochemistry of clay minerals in the Ohnuma geothermal area, northeastern Japan. Earth and Planetary Science Letters, vol. 47, pp. 255-262.

Masuda, H., Sakai, H., Chiba, H., Matsuhisa, Y., and Nakamura, T., 1986. Stable isotopic and mineralogical studies of hydrothermal alteration at Arima Spa, Southwest Japan. Geochimica et Cosmochimica Acta, vol. 50, pp. 19-28.

McDowell, S. D., and Elders, W. A., 1983. Allogenic layer silicate minerals in borehole Elmore \#1, Salton Sea Geothermal Field, California. American Mineralogist, vol. 68, pp. 1146-1159.

McDowell, S. D., and Paces, J. B., 1985. Carbonate alteration minerals in the Salton Sea geothermal system, California, USA. Mineralogical Magazine, vol. 49 , pp. $469-479$. 
McKibben, M. A., Williams, A. E., and Okubo, S., 1988. Metamorphosed Plio-Pleistocene evaporites and the origin of hypersaline brines in the Salton Sea geothermal system, California: Fluid inclusion evidence. Geochimica et Cosmochimica Acta, vol. 52, pp. 1047-1056.

Nielson, D. L., Clemente, W. C., Moore, J. N., and Powell, T. S., 1996. Fracture permeability in the Matalibong- 25 corehole, Tiwi geothermal field, Philippines. Proceedings, Twenty-First Workshop on Geothermal Reservoir Engineering, Stanford University, Stanford, California, January 22-24, 1996, pp. 209-216.

Neilson, D. L., and Hulen, J. B., 1983. Geologic model of the Baca geothermal reservoir, Valles Caldera, New Mexico. Proceedings, Ninth Workshop on Geothermal Reservoir Engineering, Stanford University, Stanford, California, pp. 145-150.

Parry, W. T., Hedderly-Smith, D., and Bruhn, R. L., 1991. Fluid Inclusions and Hydrothermal Alteration on the Dixie Valley Fault, Nevada. Journal of Geophysical Research, vol. 96, no. B12, pp. 19733-19748.

Prol-Ledesma, R. M., and Browne, P. R. L., 1989. Hydrothermal alteration and fluid inclusion geothermometry of Los Humeros geothermal field, Mexico. Geothermics, vol. 18, no. 5/6, pp. 677-690.

Rae, A. J., Rosenberg, M. D., Bignall, G., Kilgour, G. N., and Milicich, S. D., 2007. Geological results of production well drilling in the western steamfield, Ohaaki geothermal system 2005-2007. Proceedings, $29^{\text {th }} \mathrm{New}$ Zealand Geothermal Workshop 2007, 7 p.

Ragnarsdóttir, K. V., Walther, J. V., and Arnórsson, S., 1984. Description and interpretation of the composition of fluid and alteration mineralogy in the geothermal system at Svartsengi, Iceland. Geochimica et Cosmochimica Acta, vol. 48, pp. 1535-1553.

Ramos, S. G., 2002. Potential constraints to the development of the Rangas sector based on petrologic evaluation of the Bacman geothermal field, Philippines. Proceedings, Twenty-Seventh Workshop on Geothermal Reservoir Engineering, Stanford University, Stanford, California, January $28-30,2002,9$ p.
Raymahashay, B. C., 1968. A geochemical study of rock alteration by hot springs in the Paint Pot Hill area, Yellowstone Park. Geochimica et Cosmochimica Acta, vol. 32, pp. 499-522.

Sánchez-España, J., Velasco, F., and Yusta, I., 2000. Hydrothermal alteration of felsic volcanic rocks associated with massive sulphide deposition in the northern Iberian Pyrite belt (SW Spain). Applied Geochemistry, vol. 15 , pp. 1265-1290.

Steiner, A., 1968. Clay minerals in hydrothermally altered rocks at Wairakei, New Zealand. Clays and Clay Minerals, vol. 16, pp. 193-213.

Sturchio, N. C., Muehlenbachs, K., and Seitz, M. G., 1986. Element redistribution during hydrothermal alteration of rhyolite in an active geothermal system: Yellowstone drill cores Y-7 and Y-8. Geochimica et Cosmochimica Acta, vol. 50, pp. 1619-1631.

Thomas, D., 1987. A geochemical model of the Kilauea East Rift Zone. Chapter 56, United States Geological Survey Professional Paper 1350, Volcanism in Hawaii, pp. 1507-1525.

Torres-Alvarado, I. S., 2000. Mineral chemistry of hydrothermal silicates in Los Azufres geothermal field, Mexico. World Geothermal Congress Proceedings, Kyushu-Tohoku, Japan, May 28-June 10, 2000, pp. 1861-1866.

Utami, P., 2000. Characteristics of the Kamojang geothermal reservoir (West Java) as revealed by its hydrothermal alteration mineralogy. World Geothermal Congress Proceedings, Kyushi-Tohoku, Japan, May 28-June 10, 2000, pp. 1921-1926.

Woldegabriel, G., 1990. Hydrothermal alteration in the Valles caldera ring fracture zone and core hole VC-1: evidence for multiple hydrothermal systems. Journal of Volcanology and Geothermal Research, vol. 40, pp. 105-122.

Yau, Y.-C., Peacor, D. R., and Essene, E. J., 1986. Occurrence of wide-chain Ca-pyriboles as primary crystals in the Salton Sea Geothermal Field, California, USA. Contributions to Mineralogy and Petrology, vol. 94, pp. 127-134. 
Appendix M.

Proceedings World Geothermal Congress 2015

Melbourne, Australia, 19-25 April 2015

\title{
Geothermal Reservoir Temperatures in Southeastern Idaho using Multicomponent Geothermometry
}

\author{
Ghanashyam Neupane ${ }^{1,2, *}$, Earl D. Mattson ${ }^{1,2}$, Travis L. McLing ${ }^{1,2}$, Carl D. Palmer ${ }^{3}$, Robert W. Smith ${ }^{2,3}$, Thomas R. \\ Wood $^{2,3}$, Robert K. Podgorney ${ }^{1,2}$ \\ ${ }^{1}$ Idaho National Laboratory, 2525 Fremont Ave, Idaho Falls, ID 83415 \\ ${ }^{2}$ Center for Advanced Energy Studies, 995 University Boulevard, Idaho Falls, ID 83401 \\ ${ }^{3}$ University of Idaho-Idaho Falls, 1776 Science Center Drive, Suite 306, Idaho Falls, ID 83402 \\ *E-mail: ghanashyam.neupane@inl.gov
}

Keywords: Geothermometry, geothermal energy, geochemistry, RTEst, southeastern Idaho

\begin{abstract}
Southeastern Idaho exhibits numerous warm springs, warm water from shallow wells, and hot water from oil and gas test wells that indicate a potential for geothermal development in the area. Although the area exhibits several thermal expressions, the measured geothermal gradients vary substantially $\left(19-61^{\circ} \mathrm{C} / \mathrm{km}\right)$ within this area. We have estimated reservoir temperatures from chemical composition of thermal waters in southeastern Idaho using an inverse modeling technique (Reservoir Temperature Estimator, RTEst) that calculates the temperature at which multiple minerals are simultaneously at equilibrium while explicitly accounting for the possible loss of volatile constituents (e.g., $\mathrm{CO}_{2}$ ), boiling and/or water mixing. The temperature estimates in the region varied from moderately warm $\left(59^{\circ} \mathrm{C}\right)$ to over $175^{\circ} \mathrm{C}$. Specifically, hot springs near Preston, Idaho resulted in the highest reservoir temperature estimates in the region.
\end{abstract}

\section{INTRODUCTION}

Southeastern Idaho has potential geothermal resources as suggested by geologic evidence such as Pleistocene basaltic flows, young volcanic features, and warm to hot springs (Mitchell, 1976; Ralston et al., 1981; Souder, 1985). More direct evidence of a hightemperature regime at depth in the area is provided by a limited number of deep wells with high bottom-hole temperatures such as King 1-2 well (a temperature of $249^{\circ} \mathrm{C}$, Table 1). Despite this geologic evidence and hight bottom-hole temperatures, estimates of reservoir temperature based on traditional geothermometers applied to the chemistry of waters from springs in the region generally suggest a moderate temperature (Mitchell, 1976). As a part of an effort to assess the geothermal potential of southern Idaho, we assembled chemical composition of waters measured from numerous springs and wells in the region and applied a multicomponent equilibrium geothermometry (MEG) technique to estimate reservoir temperatures in this area.

\section{GEOLOGY AND GEOTHERMAL SETTING OF THE AREA}

\subsection{Geology}

The study area is located in both the Basin and Range and Rocky Mountains provinces. Specifically, the western part of the area has geographic characteristics of the Basin and Range such as wide and sediment filled basins separating fault-bound ranges, whereas the eastern part consists of several thrust-bound narrow sub-parallel ridges with thinly filed basins (Mabey and Oriel, 1970). Geologically, the fold-thrust belt in the area is a part of Sevier fold-thrust zone, locally known as the Idaho-Wyoming foldthrust belt (Armstrong and Oriel, 1965).

Geology of the area (Figure 1) includes thick sequences Paleozoic and Mesozoic carbonate-rich sedimentary sequences deposited in Cordilleran miogeocline (Armstrong and Oriel, 1965). During the Jurassic-Cretaceous periods these sedimentary sequences were deformed by compressive stresses associated with the Sevier orgony resulting in numerous west-dipping low-angled thrust faults (Armstrong and Oriel, 1965). Starting in the Eocene and continuing to the recent, extensional activities resulted in Basin and Range type topography with normal faults bounding ranges and wide valleys (Armstrong and Oriel, 1965; Dixon, 1982). Quaternary volcanic activity in some areas in the region (McCurry et al., 2011) resulted in volcanic features such as the Blackfoot Volcanic Field (BVF) with dominant olivine tholeiite lava flows and occasional rhyolitic lava domes (McCurry et al., 2008; Pickett, 2004).

\subsection{Geothermal Setting}

The presence of several hot springs and warm springs indicate potential geothermal resources in southeastern Idaho. The western part of study area represents the amagmatic Basin and Range type geothermal system where convective upwelling dominates the thermal discharge along the extensional faults. The discharge of hot/warm water from springs and seeps in eastern and northern parts of the study area are also reported to be controlled by deep normal faults (Dansart et al., 1994). However, some recent works (e.g., McCurry et al., 2011; Welhan et al., 2014) also suggest a deep magmatic geothermal resource in this area. The conceptual model of magmatic-sourced geothermal setting in the fold-thrust belt in southeastern Idaho considers a magmatic geothermal resource at a depth of $12-14 \mathrm{~km}$ in an area beneath a $58 \mathrm{ka}$ rhyolite domes at China Hat located within the BVF (Welhan et al., 2014). According to this hypothesis, the deep-sourced magmatic hydrothermal fluid from this zone migrates eastwards along the 
Neupane et al.

thrust faults and permeable Paleozoic and Mesozoic layers into a shallower $(3-5 \mathrm{~km})$ reservoir. The high-temperature and highsalinity (sodium-chloride) thermal fluids encountered at depth in some deep wildcat petroleum wells (e.g., King 2-1 well in Table 1) in the region are reported to be associated with these migrated magmatic fluids (Welhan et al., 2014).

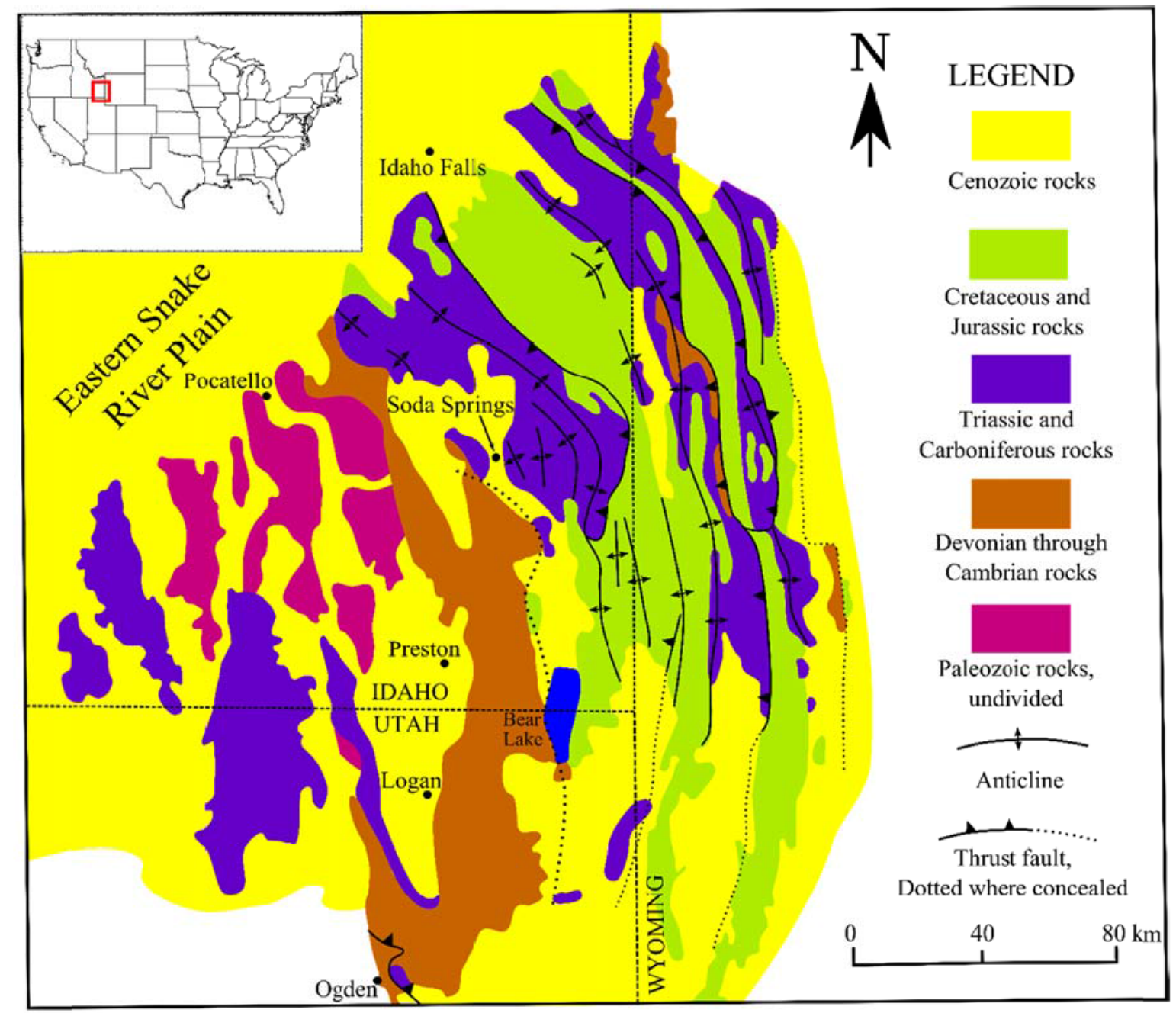

Figure 1. Simplified geologic map of Idaho-Wyoming fold-thrust belt (Armstrong and Oriel, 1965).

Table 1. Depth and bottom-hole temperatures of several wild-cat oil exploration wells in southeastern Idaho (Ralston et al., 1981; Souder, 1985; Blackwell et al., 1992)

\begin{tabular}{|l|c|c|}
\hline \multicolumn{1}{|c|}{ Wells } & Depth $(\mathrm{m})$ & Bottom-hole T $\left({ }^{\circ} \mathrm{C}\right)$ \\
\hline King 2-1 & 3927 & 249 \\
\hline Grand Valley & 4931 & 140 \\
\hline Mike Spencer Canyon & 4259 & 112 \\
\hline Bald Mountain-2 & 3830 & 148 \\
\hline Black Mountain-1 & 4158 & 100 \\
\hline Big Elk Mountain-1 & 1545 & 103 \\
\hline Federal 1-8 & 5105 & 188 \\
\hline Big Canyon Federal 1-13 & 3551 & 161 \\
\hline IDST-A1 & 4952 & 180 \\
\hline Tincup & 5059 & 160 \\
\hline N Eden Federal 22-11 & 2618 & 92 \\
\hline
\end{tabular}




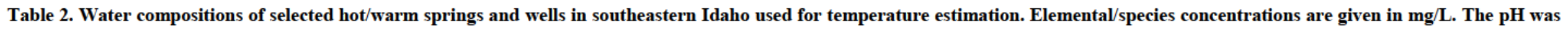
measured in the field.

\begin{tabular}{|c|c|c|c|c|c|c|c|c|c|c|c|c|c|c|}
\hline Springs/Wells ${ }^{\mathrm{a}}$ & $\mathrm{T}\left({ }^{\circ} \mathrm{C}\right)$ & $\mathrm{pH}$ & $\mathrm{Na}$ & $\mathrm{K}$ & $\mathrm{Ca}$ & $\mathrm{Mg}$ & $\mathrm{SiO}_{2(\mathrm{aq})}$ & $\mathrm{HCO}_{3}$ & $\mathrm{SO}_{4}$ & $\mathrm{Cl}$ & $\mathrm{F}$ & Map Code ${ }^{b}$ & Water type $^{\mathrm{c}}$ & Data source $^{d}$ \\
\hline Woodruff WS & 27 & 7.3 & 910 & 87 & 130 & 45 & 29 & 454 & 58 & 1600 & 0.6 & WO & \multirow{12}{*}{ I } & 1 \\
\hline E. Bingham W & 63 & 6.2 & 4600 & 770 & 320 & 36 & 68 & 930 & 48 & 7800 & 3.9 & EB & & 1 \\
\hline Squaw HS-1 & 69 & 6.5 & 4184 & 708 & 135 & 23 & 126 & 816 & 27 & 6877 & 4.3 & \multirow{10}{*}{$\mathrm{SQ} \& \mathrm{BC}$} & & 2 \\
\hline Squaw HS-2 & 73 & 6.6 & 3844 & 533 & 241 & 26 & 126 & 866 & 23 & 6396 & 4.8 & & & 2 \\
\hline Squaw HS W-1 & 82 & 7.8 & 4300 & 880 & 250 & 23 & 130 & 733 & 54 & 7700 & 7 & & & 3 \\
\hline Squaw HS W-2 & 84 & 6.5 & 4368 & 782 & 279 & 24 & 124 & 791 & 35 & 7398 & 4.3 & & & 2 \\
\hline Squaw HS W-3 & 82 & 6.9 & 3996 & 694 & 261 & 21 & 139 & 725 & 35 & 7291 & 4.9 & & & 1 \\
\hline Battle Creek HS-1 & 43 & 6.7 & 3161 & 552 & 174 & 19 & 109 & 696 & 35 & 5241 & 6 & & & 2 \\
\hline Battle Creek HS-2 & 77 & 6.5 & 3071 & 535 & 166 & 15 & 107 & 697 & 29 & 5048 & 6 & & & 2 \\
\hline Battle Creek HS-3 & 81 & 6.5 & 3053 & 533 & 162 & 19 & 109 & 757 & 37 & 5034 & 6 & & & 2 \\
\hline Battle Creek HS-4 & 82 & 6.8 & 4184 & 686 & 215 & 24 & 97 & 610 & 33 & 6967 & 6.4 & & & 2 \\
\hline Wayland HS-1 & 84 & 7 & 3100 & 660 & 160 & 16 & 80 & 699 & 50 & 5400 & 12 & & & 3 \\
\hline Alpine WS & 37 & 6.5 & 1500 & 180 & 560 & 100 & 40 & 880 & 1000 & 2800 & 2.7 & $\mathrm{AL}$ & & 1 \\
\hline Wayland HS-2 & 77 & 6.9 & 499 & 77 & 82 & 22 & 64 & 454 & 323 & 585 & 1 & SQ \& BC & & 1 \\
\hline Treasurton WS-1 & 35 & 6.6 & 563 & 127 & 265 & 68 & 54 & 704 & 788 & 632 & 2.2 & & & 2 \\
\hline Treasurton WS-2 & 40 & 6.4 & 542 & 110 & 336 & 48 & 54 & 726 & 735 & 629 & 2 & & & 1 \\
\hline Cleavland WS & 55 & 6.2 & 444 & 90 & 259 & 41 & 62 & 565 & 517 & 574 & 1.7 & & & 1 \\
\hline Maple Grove HS-1 & 72 & 7.3 & 490 & 110 & 89 & 24 & 55 & 491 & 260 & 630 & 1.1 & & & 3 \\
\hline Maple Grove HS-2 & 60 & 6.8 & 501 & 82 & 93 & 29 & 85 & 495 & 261 & 601 & 1.1 & MG & II & 2 \\
\hline Maple Grove HS-3 & 76 & 6.8 & 492 & 80 & 93 & 25 & 86 & 494 & 251 & 584 & 1 & & & 2 \\
\hline Maple Grove HS-4 & 71 & 7.8 & 494 & 76 & 69 & 31 & 52 & 424 & 255 & 595 & 0.9 & & & 4 \\
\hline Maple Grove HS-5 & 78 & 6.6 & 492 & 82 & 85 & 30 & 84 & 494 & 256 & 596 & 1.1 & & & 2 \\
\hline Maple Grove HS-6 & 75 & 6.3 & 550 & 71 & 132 & 24 & 66 & 466 & 282 & 586 & 0.3 & & & 1 \\
\hline Auburn HS & 57 & 6.4 & 1327 & 162 & 509 & 76 & 68 & 822 & 996 & 1737 & 0.6 & $A \& T$ & & 1 \\
\hline Johnson S & 54 & 6.4 & 1494 & 176 & 454 & 45 & 88 & 973 & 1129 & 1947 & & $A \otimes J$ & & 1 \\
\hline Ben Meek W-1 & 40 & 7.4 & 348 & 20 & 23 & 5 & 90 & 526 & 5 & 321 & 11 & & & 1 \\
\hline Ben Meek W-2 & 45 & 7.3 & 360 & 24 & 25 & 7 & 80 & 524 & 15 & 320 & 10 & $\mathrm{BM}$ & III & 1 \\
\hline Ben Meek W-3 & 40 & 6.9 & 368 & 22 & 24 & 7 & 89 & 513 & 13 & 322 & 9.6 & & & 1 \\
\hline Rockland W-2 & 20 & 7.3 & 60 & 24 & 120 & 22 & 70 & 220 & 26 & 280 & 0.2 & RL2 & IV & 5 \\
\hline Bear Lake HS-1 & 40 & 7 & 155 & 48 & 230 & 41 & 43 & 263 & 769 & 72 & 4.2 & BL & $\mathrm{V}$ & 1 \\
\hline
\end{tabular}


Neupane et al.

\begin{tabular}{|c|c|c|c|c|c|c|c|c|c|c|c|c|c|c|}
\hline Bear Lake HS-2 & 39 & 7.2 & 151 & 44 & 227 & 41 & 46 & 255 & 791 & 75 & 4.2 & & & 1 \\
\hline Bear Lake HS-3 & 33 & 7.1 & 163 & 43 & 227 & 41 & 40 & 271 & 758 & 74 & 4 & & & 1 \\
\hline Bear Lake HS-4 & 48 & 6.6 & 180 & 61 & 210 & 55 & 35 & 256 & 800 & 79 & 7.1 & & & 1 \\
\hline Downata HS & 43 & 6.7 & 20 & 9 & 43 & 15 & 29 & 214 & 18 & 20 & 0.4 & DW & \multirow{17}{*}{ VI } & 1 \\
\hline Black River WS & 26 & 6.2 & 147 & 217 & 674 & 245 & 33 & 2357 & 1132 & 110 & 3.7 & $\mathrm{BR}$ & & 6 \\
\hline Pescadaro WS & 26 & 6.4 & 63 & 14 & 188 & 65 & 31 & 658 & 225 & 83 & 1.8 & $\mathrm{PD}$ & & 1 \\
\hline Henry WS & 20 & 6.4 & 25 & 8 & 284 & 44 & 40 & 870 & 145 & 32 & 1 & $\mathrm{HE}$ & & 1 \\
\hline Steamboat HS & 51 & 7 & 28 & 27 & 645 & 248 & 84 & 2380 & 472 & 8 & 0.3 & \multirow{2}{*}{ SS } & & 7 \\
\hline Soda Springs G & 28 & 6.5 & 12 & 23 & 851 & 193 & 35 & 2613 & 801 & 6 & 1.6 & & & 1 \\
\hline Lava HS-1 & 45 & 6.6 & 170 & 39 & 120 & 32 & 32 & 542 & 110 & 190 & 0.7 & \multirow{2}{*}{$\mathrm{LH}$} & & 3 \\
\hline Lava HS-2 & 43 & 6.7 & 176 & 37 & 103 & 29 & 35 & 528 & 91 & 179 & 0.7 & & & 1 \\
\hline Portneuf R WS-1 & 34 & 6.2 & 81 & 62 & 280 & 64 & 38 & 1060 & 270 & 62 & 0.8 & \multirow{2}{*}{ PR } & & 8 \\
\hline Portneuf R WS-2 & 41 & 6.3 & 85 & 60 & 275 & 48 & 47 & 1060 & 259 & 53 & 0.7 & & & 1 \\
\hline Corral Creek W-1 & 42 & 6.5 & 101 & 237 & 701 & 263 & 28 & 2845 & 898 & 41 & 2.3 & \multirow{4}{*}{$\mathrm{CC}$} & & 6 \\
\hline Corral Creek W-12 & 41 & 6.8 & 97 & 242 & 620 & 246 & 30 & 2763 & 908 & 43 & 3.5 & & & 6 \\
\hline Corral Creek W-13 & 41 & 6.6 & 101 & 233 & 697 & 263 & 30 & 2723 & 896 & 40 & 2.4 & & & 6 \\
\hline Corral Creek W-14 & 36 & 6.6 & 99 & 233 & 649 & 253 & 30 & 2803 & 884 & 40 & 2.5 & & & 6 \\
\hline Dyer W & 21 & 7.7 & 50 & 3 & 50 & 13 & 68 & 188 & 1 & 61 & & \multirow{2}{*}{ D \& A } & & 1 \\
\hline Anderson W & 20 & 7.7 & 45 & 7 & 50 & 10 & 111 & 199 & 0 & 45 & & & & 1 \\
\hline Rockland W-1 & 20 & 7.6 & 27 & 13 & 37 & 8 & 160 & 180 & 15 & 28 & 0.6 & RL1 & & 5 \\
\hline
\end{tabular}

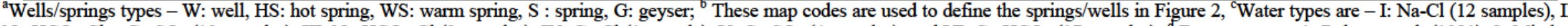

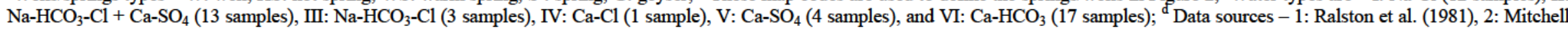
(1976A), 3: Young and Mitchell (1973), 4: Dion (1969), 5: Parliman and Young (1992), 6: Mitchell (1976B), 7: Souder (1985), 8: Mitchell et al. (1980) 


\section{SOUTHEASTERN IDAHO WATER CHEMISTRY DATA}

Chemical compositions of numerous water samples from southeastern Idaho were assembled to assess the potential geothermal reservoir temperatures in the region. Over the last several decades, water samples from springs and wells in the southeastern Idaho have been analyzed by several US government agencies and researchers for water quality and management, environmental remediation, and geothermal energy exploration (e.g., Young and Mitchell, 1973; Mitchell, 1976A,B; Ralston et al., 1981; Souder, 1985; Avery, 1987). A database has been compiled of publically available data from southeastern Idaho springs/wells. From a larger database, 50 selected water compositions (Table 2, Figure 2) were used for a preliminary assessment of the deep geothermal temperatures in southeastern Idaho.

\section{GEOTHERMOMETRY}

\subsection{Approach}

A newly developed geothermometry tool known as Reservoir Temperature Estimator (RTEst) (Palmer, 2013; Neupane et al., 2013, 2014 ) is used to estimate deep geothermal temperature in southeastern Idaho. The RTEst is an inverse geochemical tool that implements MEG with a capability of process optimization for secondary processes such as boiling, mixing, and gas loss. More detailed description about RTEst can be found elsewhere (e.g., Palmer, 2013; Neupane et al., 2014).

\subsection{Missing Components}

The MEG approach requires that measured water composition include all components present in the reservoir mineral assemblage (RMA). For aluminosilicate minerals, this requires measured values of $\mathrm{Al}$ that are often not available in historical data bases. For water compositions without measured $\mathrm{Al}$, an Al-bearing mineral (e.g., K-feldspar) was used as a proxy for $\mathrm{Al}$ during geochemical modeling as suggested by Pang and Reed (1998).

\subsection{Reservoir Mineral Assemblage}

Based on general lithology of the southeastern Idaho and literature assessment of secondary minerals for dominant rock and water types, we used reservoir mineral assemblages (RMAs) consisting of idealized clays, zeolites, carbonates, feldspars, and silicapolymorph (chalcedony) (Table 3 ) to determine temperatures from these waters.

Table 3. Weighting factors for minerals used in this study

\begin{tabular}{|l|c|}
\hline Minerals & Weighting factor $\left(\mathrm{w}_{\mathrm{i}}\right)$ \\
\hline Calcite & $1 / 2$ \\
\hline Chalcedony & 1 \\
\hline K-feldspar & $1 / 5$ \\
\hline Mordenite-K & $1 / 7$ \\
\hline Clinochlore-14A & $1 / 10$ \\
\hline Paragonite & $1 / 7$ \\
\hline Saponite-K/Na & $1 / 7.33$ \\
\hline Disordered dolomite & $1 / 4$ \\
\hline
\end{tabular}

\section{RESULTS AND DISCUSSION}

\subsection{Southeastern Idaho Springs/Wells Waters}

Compositions of waters from hot/warm springs and wells in southeastern Idaho are presented in Table 2 . The $\mathrm{pH}$ of the southeastern Idaho thermal waters range from 6.2 to 8.1, with arithmetic mean, median, and standard deviation 6.87, 6.70, and 0.51, respectively. Similarly, the field temperature of southeastern Idaho springs/wells range between 20 to $84^{\circ} \mathrm{C}$. The aqueous chemistry of these southeastern Idaho thermal waters shows a large range in total dissolved solids (TDS) from about $250 \mathrm{mg} / \mathrm{L}$ (Downata Hot Spring) to more than $14,000 \mathrm{mg} / \mathrm{L}$ (East Bingham Well).

The dominant cations in the southeastern Idaho thermal waters are $\mathrm{Na}$ and $\mathrm{Ca}$ with minor amounts of $\mathrm{Mg}$ (Figure 3). The thermal waters include samples dominated by $\mathrm{Cl}^{-}, \mathrm{HCO}_{3}^{-}$, or $\mathrm{SO}_{4}{ }^{2-}$ while others appear to be dominated by more than one anion. Hierarchical cluster analysis using Ward's (1963) method as implemented in SYSTAT 13 (SYSTAT Software, Inc.) was performed using the 6 Piper diagram end members $\left(\mathrm{Ca}^{2+}, \mathrm{Mg}^{2+}, \mathrm{Na}^{+}+\mathrm{K}^{+}, \mathrm{Cl}^{-}, \mathrm{HCO}_{3}{ }^{-}+\mathrm{CO}_{3}{ }^{2-}, \mathrm{SO}_{4}^{2-}\right)$ for classifying water in the southeastern Idaho. Six compositional groups were identified within the 50 thermal water samples: $\mathrm{Na}-\mathrm{Cl}$ (12 samples), $\mathrm{Na}-\mathrm{HCO}-\mathrm{Cl}+\mathrm{Ca}-\mathrm{SO}_{4}$ (13 samples), $\mathrm{Na}-\mathrm{HCO}_{3}-\mathrm{Cl}$ (3 samples), $\mathrm{Ca}-\mathrm{Cl}$ (1 sample), $\mathrm{Ca}-\mathrm{SO}_{4}$ (4 samples), and $\mathrm{Ca}-\mathrm{HCO}_{3}$ (17 samples) (Table 2). These groups likely reflect differences in sources of water, water-rock interactions, and structural control of the local geothermal systems. 


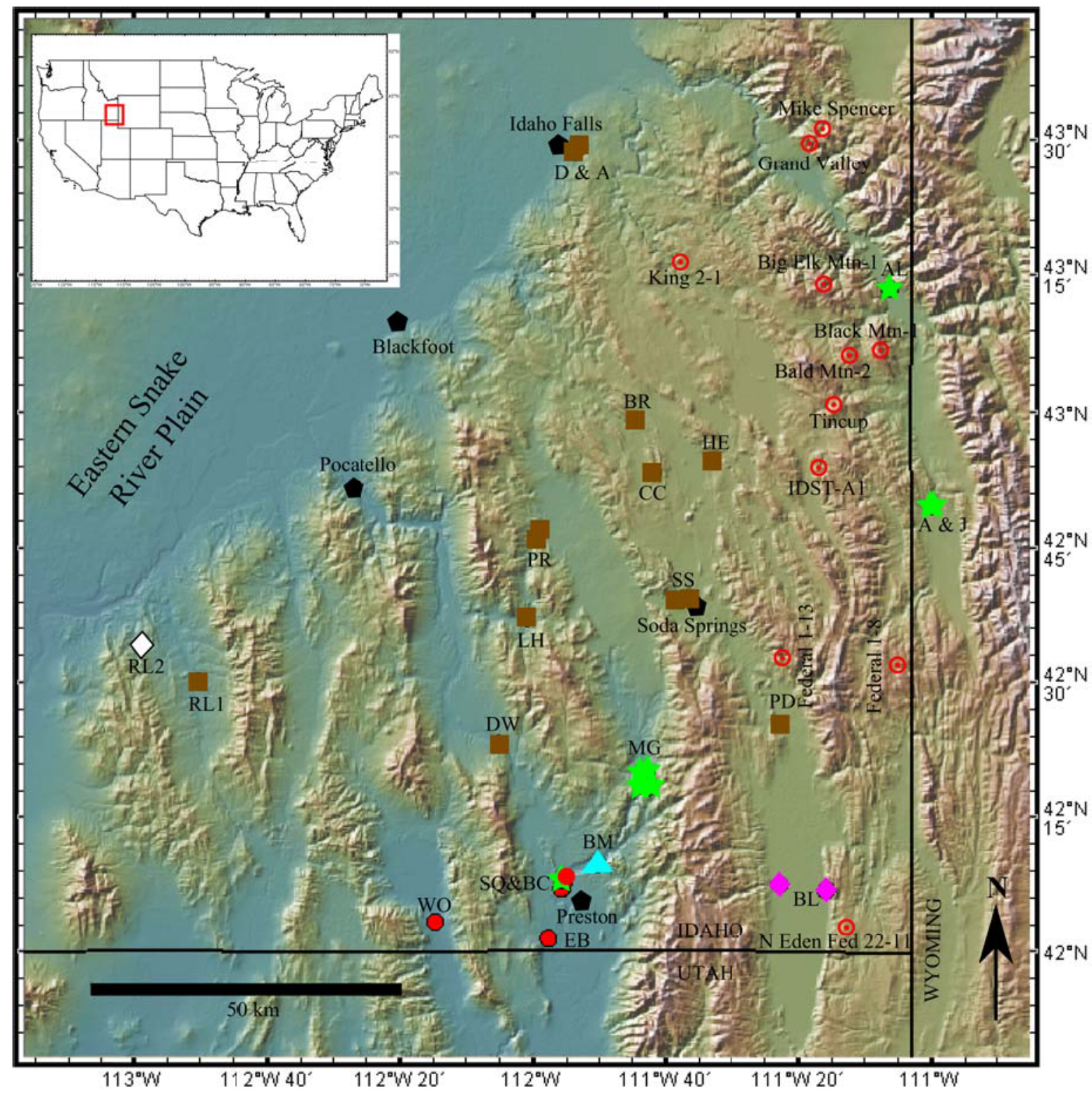

Figure 2. Shaded relief map of southeastern Idaho prepared from NASA 10-m DEM data in GeoMapApp. Water

compositions of selected hot/warm springs and wells [water types - red circles (๑) Group I; green stars ( ): Group II; cyan triangles $(\triangle)$ : Group III; open diamond $(\diamond)$ : Group IV; magenta diamonds $(\diamond)$ : Group V; and brown squares ( $\square$ ): Group VI] in southeastern Idaho are used for temperature estimation (Table 4). The springs/wells codes correspond to the map code given in Table 2 . The wild-cat petroleum wells (Table 1) are represented by red target (O) signs. 
The Na-Cl and Ca-SO $\mathrm{S}_{4}$ type waters may have been originated with the water-rock interactions involving pockets of evaporites in the area. Oriel and Platt (1980) have reported the presence of evaporites (e.g., halite, gypsum, and alum) in Middle Jurassic sequences (Pruess Redbeds) in southeastern Idaho. Recently, Welhan et al. (2014) indicated that the high-salinity waters in some deep wild-cat petroleum wells may be related to magmatic waters from a zone as deep as $12-14 \mathrm{~km}$ under the BVF in the foldthrust belt in southeastern Idaho. However, all Na-Cl type waters considered in this study are from the surface expressions (hot/warm springs) or from the rather shallow (compared to the deep wild-cat petroleum wells) wells located in the western part (Basin and Range Province). The Na-Cl type waters from this part of the study area may have been originated by the water-rock interactions involving evaporites. This type of water is also reported from the Raft River Geothermal Area (RRGA) located to the west of the present study area. Moreover, there is likely an additional source of evaporites in the Tertiary rocks (Ayling and Moore, 2013). All Ca-SO $\mathrm{S}_{4}$ type waters are from hot springs near Bear Lake, located near Idaho-Wyoming-Utah triple point. Deep sourced water from a nearby deep wild-cat petroleum well (N Eden Federal well with depth $>2500 \mathrm{~m}$ ) has very high $\mathrm{SO}_{4}$ concentration; however, this water has low $\mathrm{Ca}$ concentration and high $\mathrm{Na}$ concentration (Souder, 1985). The Ca-SO $\mathrm{S}_{4}$ type waters that Bear Lake hot springs issue may have separate sources of $\mathrm{Ca}$ and $\mathrm{SO}_{4}$ or there may have some ongoing cation exchange reaction involving $\mathrm{Ca}$ and $\mathrm{Na}$ along the flow path from depth to the surface.

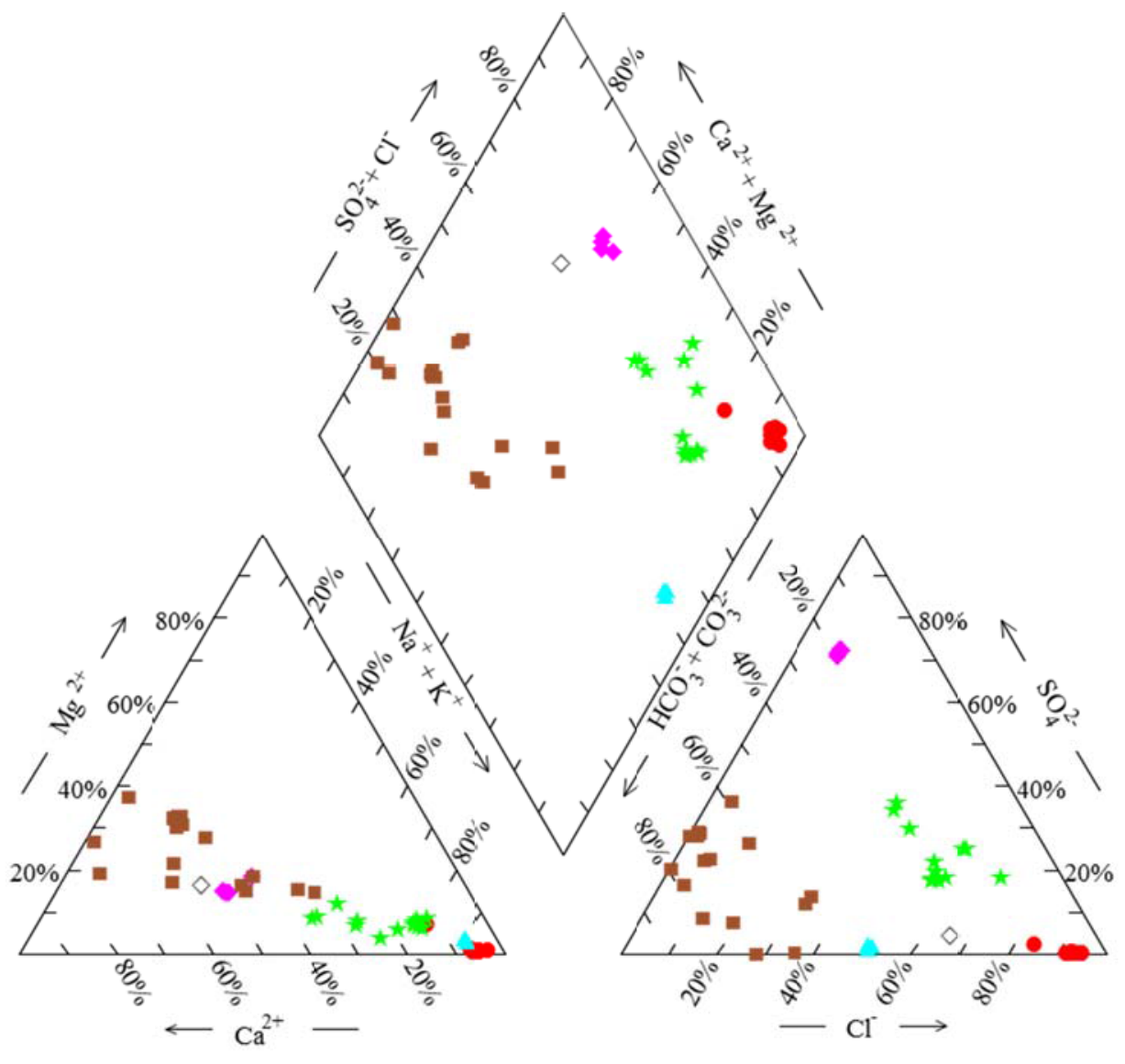

Figure 3. Reported chemistry of waters measured from several hot/warm springs and wells located in southeastern Idaho.

(Water types - red circles $(\bullet)$ Group I; green stars ( $\star$ ): Group II; cyan triangles $(\triangle)$ : Group III; open diamond $(\diamond)$ : Group IV; magenta diamonds $(\diamond)$ : Group V; and brown squares ( $\square)$ : Group VI.)

The $\mathrm{Ca}-\mathrm{HCO}_{3}$ type waters are scattered throughout the area. These waters typically exhibit low $\mathrm{Cl}$ concentrations (Table 2). With some exceptions (e.g., Black River Warm Spring, Corral Creek Wells, Soda Geyser, Pescadaro Warm Spring), these waters also have low $\mathrm{SO}_{4}$ concentration. This type of water is generally regarded as a product of the interaction of groundwater with $\mathrm{Ca}$-rich rocks at shallower depth. In the adjoining ESRP, the $\mathrm{Ca}-\mathrm{HCO}_{3}$ type water represents the water in the active part of the ESRP aquifer whereas the deeper waters in ESRP area are $\mathrm{Na}-\mathrm{HCO}_{3}$ type (Mann, 1986; McLing et al., 2002).

Only one sample that represents the Ca-Cl type water is from Rockland W-2 located in the westernmost part of the study area (Figure 2). In a previous study (Neupane et al., 2014), this type of water was not identified in the Eastern Snake River Plain (ESRP) 
geothermal system located to the west-northwest side of the present study area (Figures 1 and 2). The apparent lack of Ca-Cl waters in the ESRP system could be related to limited numbers of water samples used in that study (Neupane et al., 2014) or this type of water is not a common water in south Idaho (including ESRP and southeastern Idaho), and it represents an outlier in the present study. Although this water has some similarity with the $\mathrm{Ca}-\mathrm{HCO}_{3}$ and $\mathrm{Ca}-\mathrm{SO}_{4}$ types of water in terms of high Ca content compared to the $\mathrm{Na}+\mathrm{K}$ concentrations, its high $\mathrm{Cl}$ concentration with low $\mathrm{Na}$ concentration makes it difficult to assign it as a direct product of a particular water-rock interaction.

The remaining two types of waters $-\mathrm{Na}-\mathrm{HCO}_{3}-\mathrm{Cl}$ and $\mathrm{Na}-\mathrm{HCO}_{3}-\mathrm{Cl}+\mathrm{Ca}-\mathrm{SO}_{4}$ are mixed waters. Although the cluster analysis did not classify a separate group of $\mathrm{Na}-\mathrm{HCO}_{3}$ type water, this water is a representative of the deep water in adjoining ESRP area. It is likely that these waters are $\mathrm{Na}-\mathrm{Cl}$ type waters but interacted with carbonate sections with or without gypsum/anhydride layers.

\subsection{Southeastern Idaho Geothermal Temperatures}

\subsubsection{Giggenbach Diagram}

When plotted on a Giggenbach diagram (Giggenbach, 1988), the majority of the southeastern Idaho waters selected for this study plot in the immature zone with some waters lie in the zone of partial equilibration (Figure 4). The mature waters in Figure 4 are from hot springs and wells near Preston, Idaho (Battle Creek and Squaw hot springs), and these water could have interacted with rock at a temperature range of $260-300^{\circ} \mathrm{C}$. The lack of equilibrium (immaturity) in majority of southeastern Idaho waters could be related to low Na content, as suggested by Giggenbach (1988), as well as to their higher $\mathrm{Mg}$ content. The waters containing high $\mathrm{Mg}$ content are deemed to be unsuitable for some traditional solute geothermometry; although there have been some efforts made for implementing Mg correction in the estimated temperature (e.g., Fournier and Potter, 1979).

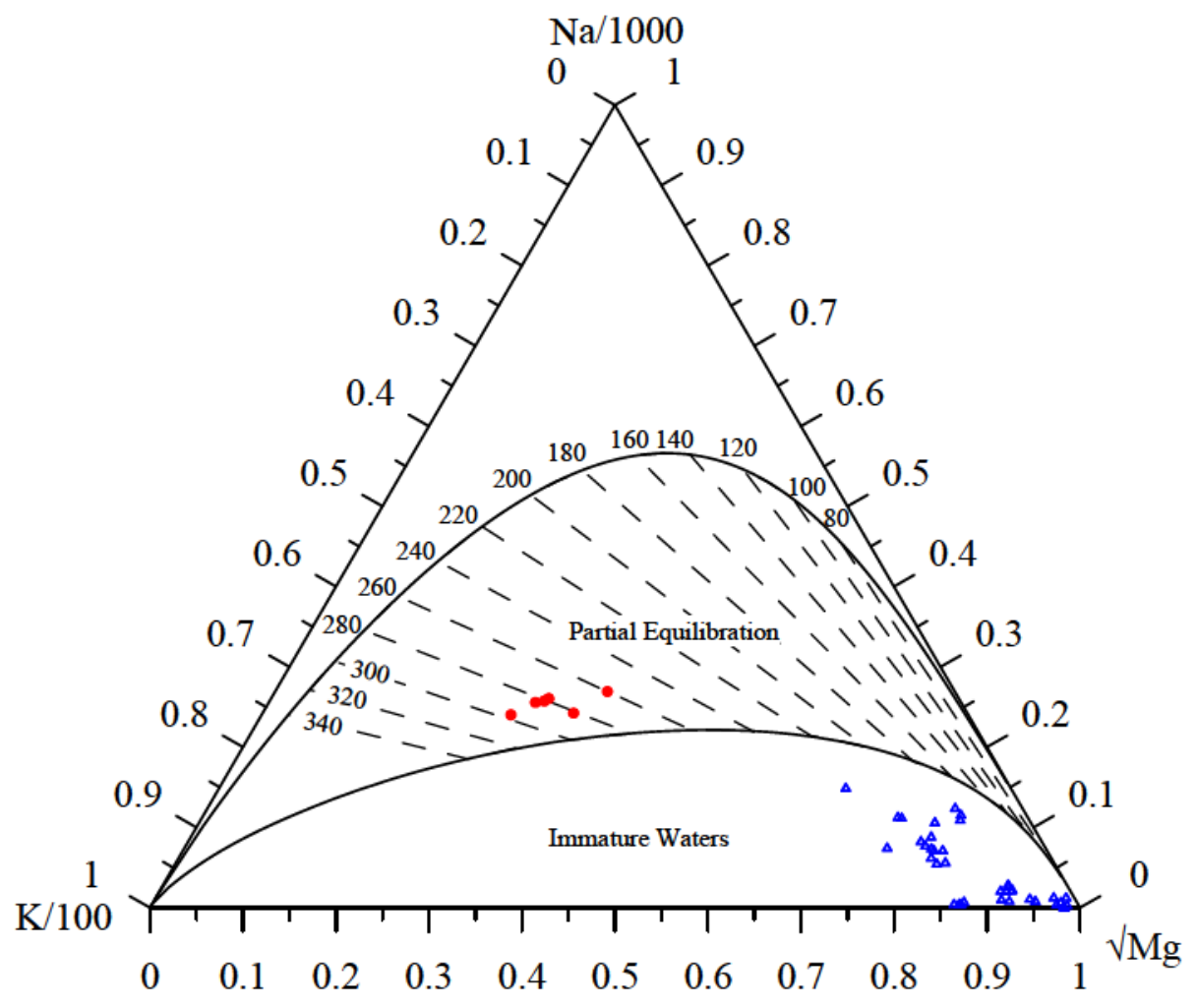

Figure 4. Southeastern Idaho waters from hot/warm springs and wells plotted on Giggenbach diagram (Giggenbach, 1988). The red and blue symbols represent mature and immature waters, respectively. All mature waters belong to Group 1 type waters.

\subsubsection{Temperatures Estimated by MEG}

Estimates of reservoir temperatures for southeastern Idaho thermal waters (Table 2) were made using RTEst. The RMAs used consisted of representative minerals ( $\mathrm{Mg}$ bearing minerals - clinochlore, illite, saponite, disordered dolomite; Na bearing minerals paragonite, saponite; K-bearing minerals - K-feldspar, mordenite-K, illite; Ca bearing minerals - calcite, disordered dolomite; and chalcedony) (Table 3). For the selected compositions of southeastern Idaho thermal waters that do not have measured Al concentration, a value determined by assuming equilibrium with $\mathrm{K}$-feldspar was used in the geochemical modeling. 
In MEG, the reservoir temperature is estimated by first selecting a reservoir mineral assemblage (RMA) with which it is believed the fluid in the reservoir is equilibrated. For a water sample from a spring or shallow well, the activities of the chemical species in solution are determined and the saturation indices $\left[\mathrm{SI}=\log \left(\mathrm{Q} / \mathrm{K}_{\mathrm{T}}\right)\right.$, where $\mathrm{Q}$ is the ion activity product and $\mathrm{K}_{\mathrm{T}}$ is the temperature dependent mineral-water equilibrium constant) calculated using the laboratory measured temperature of the sample. This calculation is repeated as a function of temperature and the resulting SIs recalculated. Likely reservoir temperature is the one at which all minerals in an assemblage are in equilibrium with the reservoir fluid as indicated by near zero $\log \mathrm{Q} / \mathrm{K}_{\mathrm{T}}$ values of these minerals on a $\log \left(\mathrm{Q} / \mathrm{K}_{\mathrm{T}}\right)$ versus temperature plot $\left[\log \left(\mathrm{Q} / \mathrm{K}_{\mathrm{T}}\right)\right.$ plot] (Reed and Spycher, 1984; Bethke, 2008). Alternately stated, reservoir minerals are expected to be in equilibrium with the fluid and they should yield a common equilibrium temperature with a near zero $\log \left(\mathrm{Q} / \mathrm{K}_{\mathrm{T}}\right)$ value for each mineral; this common equilibrium temperature coincides with the reservoir temperature. If log $\left(\mathrm{Q} / \mathrm{K}_{\mathrm{T}}\right)$ curves of minerals in a reservoir do not show a common temperature convergence at $\log \left(\mathrm{Q} / \mathrm{K}_{\mathrm{T}}\right)=0$, then it suggests that there exists errors in analytical data, the selected mineral assemblage does not represent the actual mineral assemblage in the reservoir, or the sampled water must have been subjected to composition altering physical and chemical processes during its ascent from the reservoir to the sampling point.

Figure 5a shows $\log \left(\mathrm{Q} / \mathrm{K}_{\mathrm{T}}\right)$ curves of the RMA (calcite, chalcedony, disordered dolomite, mordenite- $\mathrm{K}$, and paragonite) used for the reported Battle Creek Hot Spring-1 water compositions. The $\log \left(\mathrm{Q} / \mathrm{K}_{\mathrm{T}}\right)$ curves of these minerals intersect the $\log \left(\mathrm{Q} / \mathrm{K}_{\mathrm{T}}\right)=0$ at a wide range of temperatures, ranging from $40^{\circ} \mathrm{C}$ (calcite) to over $250^{\circ} \mathrm{C}$ (paragonite), making the $\log \left(\mathrm{Q} / \mathrm{K}_{\mathrm{T}}\right.$ ) curves derived from the reported water chemistry minimally useful for estimating temperature. The range of equilibration temperature for the assemblage minerals is a reflection of physical and chemical processes that may have modified the Battle Creek Hot Spring-1 water composition during its ascent to the sampling point.
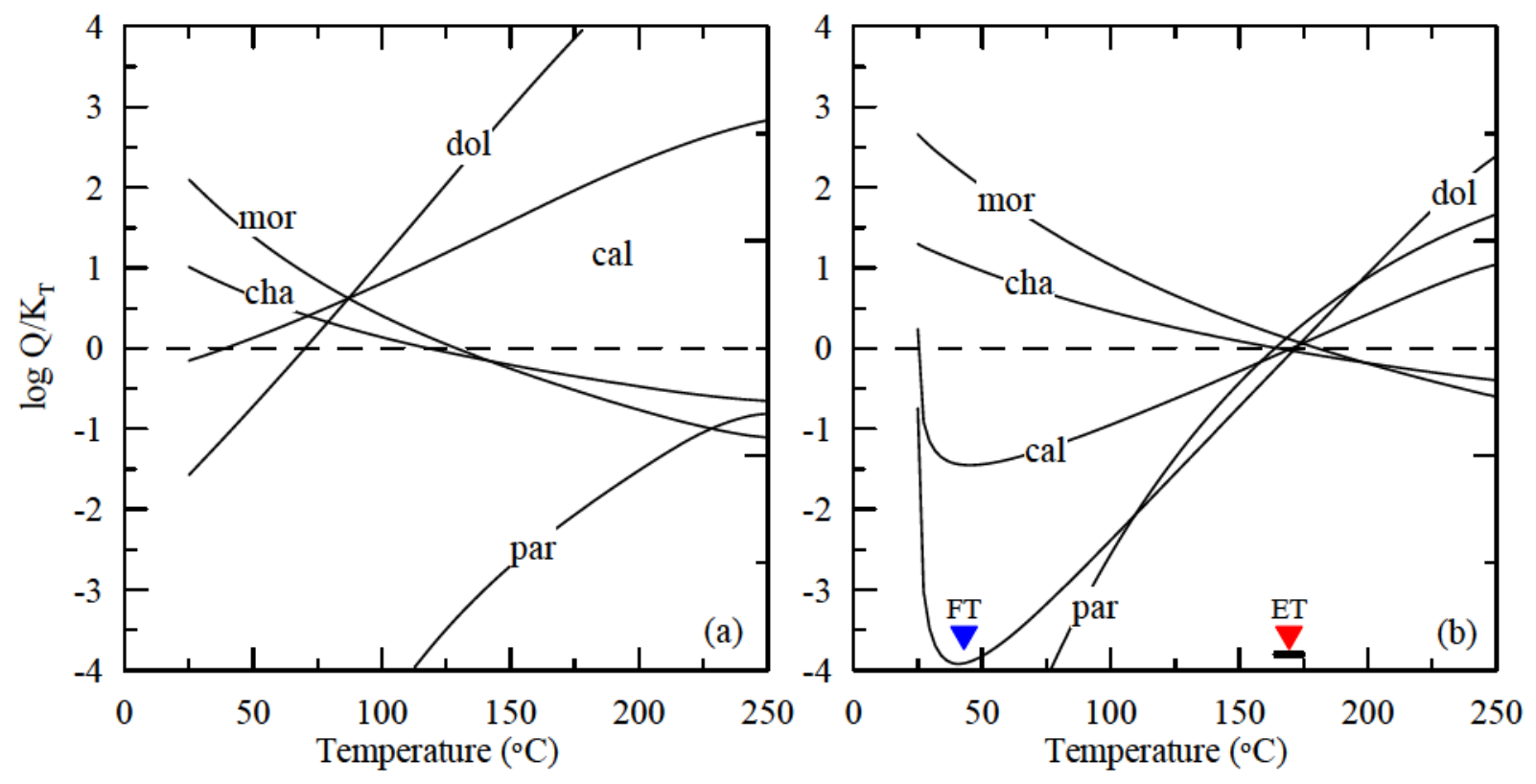

Figure 5. Temperature estimation for Battle Creek Hot Spring near Preston, Idaho. (a) The $\log Q / K_{T}$ curves for minerals calculated using original water chemistry with $\mathrm{K}$-feldspar used as proxy for $\mathrm{Al}$, (b) optimized $\log \mathrm{Q} / \mathrm{K}_{\mathrm{T}}$ curves [FT: field temperature $\left(43^{\circ} \mathrm{C}\right)$; ET: estimated temperature $\left(169^{\circ} \mathrm{C}\right)$, the dark horizontal bar below ET represents the \pm standard error for the estimated temperature $\left( \pm 5^{\circ} \mathrm{C}\right)$; cal: calcite, cha: chalcedony, dol: disordered dolomite, mor: mordenite-K, and par: paragonite). 
Table 4. Temperature estimates for southeastern Idaho thermal waters RTEst and other geothermometers

\begin{tabular}{|c|c|c|c|c|c|c|c|c|c|}
\hline Springs/Wells ${ }^{\mathrm{a}}$ & $\mathrm{T}^{\mathrm{b}} \pm \sigma^{\mathrm{c}}$ & $\mathrm{M}_{\mathrm{H}_{2} \mathrm{O}}{ }^{d} \pm \sigma^{c}$ & $\log f_{\mathrm{Co}_{2}} \pm \sigma^{\mathrm{c}}$ & $\varphi^{\mathrm{e}}$ & Quartz $^{f}$ & Chalcedony $^{\mathrm{g}}$ & Silica $^{\text {h }}$ & $\mathrm{Na}-\mathrm{K}-\mathrm{Ca}^{\mathrm{i}}$ & Types $^{\mathrm{j}}$ \\
\hline Woodruff HS & $97 \pm 3$ & $0.61 \pm 0.03$ & $1.04 \pm 0.12$ & $3.51 \mathrm{E}-04$ & 78 & 47 & 49 & 56 & \multirow{12}{*}{ I } \\
\hline E. Bingham W & $161 \pm 4$ & $0.61 \pm 0.02$ & $2.36 \pm 0.14$ & $4.67 \mathrm{E}-04$ & 117 & 88 & 88 & 193 & \\
\hline Squaw HS-1 & $179 \pm 9$ & $0.45 \pm 0.08$ & $2.22 \pm 0.3$ & $2.09 \mathrm{E}-03$ & 151 & 125 & 123 & 204 & \\
\hline Squaw HS-2 & $157 \pm 6$ & $0.31 \pm 0.06$ & $1.87 \pm 0.19$ & $9.04 \mathrm{E}-04$ & 151 & 125 & 123 & 183 & \\
\hline Squaw HS W-1 & $175 \pm 5$ & $0.38 \pm 0.05$ & $2.42 \pm 0.17$ & $6.94 \mathrm{E}-04$ & 152 & 127 & 125 & 229 & \\
\hline Squaw HS W-2 & $174 \pm 6$ & $0.43 \pm 0.05$ & $2.26 \pm 0.19$ & $8.73 \mathrm{E}-04$ & 150 & 124 & 122 & 217 & \\
\hline Squaw HS W-3 & $171 \pm 7$ & $0.35 \pm 0.07$ & $2.16 \pm 0.24$ & $1.33 \mathrm{E}-03$ & 156 & 132 & 129 & 216 & \\
\hline Battle Creek HS-1 & $169 \pm 5$ & $0.46 \pm 0.04$ & $2.14 \pm 0.15$ & $5.72 \mathrm{E}-04$ & 142 & 116 & 114 & 205 & \\
\hline Battle Creek HS-2 & $175 \pm 6$ & $0.50 \pm 0.04$ & $2.19 \pm 0.18$ & 8.37E-04 & 141 & 115 & 113 & 215 & \\
\hline Battle Creek HS-3 & $170 \pm 5$ & $0.47 \pm 0.03$ & $2.12 \pm 0.15$ & $5.24 \mathrm{E}-04$ & 142 & 116 & 114 & 202 & \\
\hline Battle Creek HS-4 & $171 \pm 4$ & $0.51 \pm 0.03$ & $2.23 \pm 0.14$ & $4.95 \mathrm{E}-04$ & 136 & 109 & 107 & 204 & \\
\hline Wayland HS-1 & $175 \pm 5$ & $0.54 \pm 0.03$ & $2.5 \pm 0.15$ & $5.80 \mathrm{E}-04$ & 125 & 97 & 97 & 230 & \\
\hline Alpine WS & $98 \pm 9$ & $0.46 \pm 0.11$ & $1.27 \pm 0.34$ & $3.30 \mathrm{E}-03$ & 92 & 61 & 63 & 92 & \multirow{13}{*}{ II } \\
\hline Wayland HS-2 & $144 \pm 7$ & $0.60 \pm 0.06$ & $0.82 \pm 0.27$ & $1.67 \mathrm{E}-03$ & 114 & 85 & 85 & 84 & \\
\hline Treasurton WS-1 & $111 \pm 3$ & $0.44 \pm 0.04$ & $1.24 \pm 0.14$ & $4.78 \mathrm{E}-04$ & 105 & 76 & 77 & 78 & \\
\hline Treasurton WS-2 & $111 \pm 9$ & $0.45 \pm 0.12$ & $1.17 \pm 0.39$ & $3.79 \mathrm{E}-03$ & 105 & 76 & 77 & 113 & \\
\hline Cleavland WS & $119 \pm 7$ & $0.45 \pm 0.09$ & $0.92 \pm 0.29$ & $1.99 \mathrm{E}-03$ & 112 & 83 & 84 & 106 & \\
\hline Maple Grove HS-1 & $126 \pm 4$ & $0.55 \pm 0.04$ & $1.43 \pm 0.16$ & $6.29 \mathrm{E}-04$ & 106 & 77 & 78 & 97 & \\
\hline Maple Grove HS-2 & $123 \pm 4$ & $0.27 \pm 0.07$ & $0.77 \pm 0.18$ & 7.33E-04 & 128 & 101 & 100 & 73 & \\
\hline Maple Grove HS-3 & $124 \pm 3$ & $0.28 \pm 0.05$ & $0.78 \pm 0.14$ & $4.78 \mathrm{E}-04$ & 129 & 101 & 101 & 82 & \\
\hline Maple Grove HS-4 & $115 \pm 7$ & $0.49 \pm 0.08$ & $0.96 \pm 0.28$ & $1.90 \mathrm{E}-03$ & 104 & 74 & 75 & 54 & \\
\hline Maple Grove HS-5 & $126 \pm 6$ & $0.31 \pm 0.09$ & $0.76 \pm 0.25$ & $1.43 \mathrm{E}-03$ & 128 & 100 & 99 & 67 & \\
\hline Maple Grove HS-6 & $122 \pm 5$ & $0.44 \pm 0.07$ & $0.69 \pm 0.22$ & $1.13 \mathrm{E}-03$ & 115 & 86 & 87 & 97 & \\
\hline Auburn HS & $107 \pm 9$ & $0.26 \pm 0.17$ & $0.99 \pm 0.39$ & $3.78 \mathrm{E}-03$ & 117 & 88 & 88 & 104 & \\
\hline Johnson S & $116 \pm 13$ & $0.18 \pm 0.26$ & $1.08 \pm 0.52$ & $6.64 \mathrm{E}-03$ & 130 & 103 & 102 & 134 & \\
\hline Ben Meek W-1 & $106 \pm 7$ & $0.02 \pm 0.18$ & $-0.15 \pm 0.33$ & $2.44 \mathrm{E}-03$ & 131 & 104 & 103 & 86 & \multirow{3}{*}{ III } \\
\hline Ben Meek W-2 & $106 \pm 4$ & $0.12 \pm 0.09$ & $0.01 \pm 0.2$ & $9.00 \mathrm{E}-04$ & 125 & 97 & 97 & 72 & \\
\hline Ben Meek W-3 & $109 \pm 4$ & $0.06 \pm 0.1$ & $-0.16 \pm 0.2$ & $9.28 \mathrm{E}-04$ & 131 & 103 & 102 & 73 & \\
\hline Rockland-W2 & $110 \pm 7$ & $0.29 \pm 0.13$ & $0.23 \pm 0.34$ & $2.79 \mathrm{E}-03$ & 118 & 90 & 90 & 93 & IV \\
\hline Bear Lake HS-1 & $113 \pm 7$ & $0.57 \pm 0.06$ & $0.86 \pm 0.27$ & $1.84 \mathrm{E}-03$ & 95 & 64 & 66 & 73 & \multirow{2}{*}{ V } \\
\hline Bear Lake HS-2 & $111 \pm 7$ & $0.53 \pm 0.07$ & $0.75 \pm 0.28$ & $1.98 \mathrm{E}-03$ & 98 & 68 & 69 & 94 & \\
\hline
\end{tabular}


Neupane et al.

\begin{tabular}{|c|c|c|c|c|c|c|c|c|c|}
\hline Bear Lake HS-3 & $107 \pm 8$ & $0.56 \pm 0.07$ & $0.77 \pm 0.31$ & $2.46 \mathrm{E}-03$ & 92 & 61 & 63 & 92 & \\
\hline Bear Lake HS-4 & $121 \pm 4$ & $0.64 \pm 0.02$ & $1.02 \pm 0.12$ & $4.41 \mathrm{E}-04$ & 86 & 55 & 57 & 90 & \\
\hline Downata HS & $97 \pm 3$ & $0.62 \pm 0.03$ & $0.17 \pm 0.17$ & $6.61 \mathrm{E}-04$ & 78 & 47 & 49 & 49 & \multirow{17}{*}{$\mathrm{V}$} \\
\hline Black River WS & $103 \pm 3$ & $0.48 \pm 0.04$ & $2.17 \pm 0.13$ & 4.53E-04 & 83 & 52 & 55 & 85 & \\
\hline Pescadaro WS & $68 \pm 8$ & $0.24 \pm 0.21$ & $-0.11 \pm 0.43$ & $4.59 \mathrm{E}-03$ & 81 & 49 & 52 & 41 & \\
\hline Henry WS & $60 \pm 16$ & $-0.12 \pm 0.98$ & $-0.41 \pm 0.94$ & $2.18 \mathrm{E}-02$ & 92 & 61 & 63 & 89 & \\
\hline Steamboat HS & $96 \pm 11$ & $-0.12 \pm 0.25$ & $1.77 \pm 0.43$ & $3.41 \mathrm{E}-04$ & 128 & 100 & 99 & 46 & \\
\hline Soda Springs G & $59 \pm 15$ & $-0.09 \pm 0.59$ & $0.91 \pm 0.72$ & $1.31 \mathrm{E}-02$ & 86 & 55 & 57 & 88 & \\
\hline Lava HS-1 & $94 \pm 6$ & $0.56 \pm 0.07$ & $0.84 \pm 0.27$ & $1.81 \mathrm{E}-03$ & 82 & 51 & 53 & 67 & \\
\hline LAVA HS- 2 & $94 \pm 5$ & $0.52 \pm 0.07$ & $0.76 \pm 0.25$ & $1.51 \mathrm{E}-03$ & 86 & 55 & 57 & 64 & \\
\hline Portneuf R WS-1 & $100 \pm 6$ & $0.53 \pm 0.08$ & $1.35 \pm 0.28$ & $1.93 \mathrm{E}-03$ & 89 & 59 & 61 & 92 & \\
\hline Portneuf R WS-2 & $101 \pm 9$ & $0.44 \pm 0.13$ & $1.29 \pm 0.4$ & $3.90 \mathrm{E}-03$ & 99 & 69 & 70 & 111 & \\
\hline Corral Creek W-1 & $98 \pm 3$ & $0.51 \pm 0.03$ & $2.55 \pm 0.12$ & $3.97 \mathrm{E}-04$ & 77 & 45 & 48 & 98 & \\
\hline Corral Creek W-2 & $100 \pm 4$ & $0.45 \pm 0.05$ & $2.57 \pm 0.15$ & $5.79 \mathrm{E}-04$ & 79 & 48 & 51 & 97 & \\
\hline Corral Creek W-3 & $98 \pm 3$ & $0.48 \pm 0.04$ & $2.51 \pm 0.12$ & $3.90 \mathrm{E}-04$ & 79 & 48 & 51 & 99 & \\
\hline Corral Creek W-4 & $98 \pm 3$ & $0.49 \pm 0.04$ & $2.53 \pm 0.13$ & 4.67E-04 & 79 & 48 & 51 & 100 & \\
\hline Dyer W & $121 \pm 3$ & $0.41 \pm 0.03$ & $0.41 \pm 0.11$ & $5.28 \mathrm{E}-04$ & 117 & 88 & 88 & 57 & \\
\hline Anderson W & $144 \pm 4$ & $0.33 \pm 0.03$ & $0.81 \pm 0.12$ & $7.44 \mathrm{E}-04$ & 143 & 117 & 115 & 74 & \\
\hline Rockland-W1 & $131 \pm 4$ & $-0.13 \pm 0.09$ & $-0.31 \pm 0.16$ & $5.97 \mathrm{E}-04$ & 165 & 142 & 138 & 88 & \\
\hline
\end{tabular}

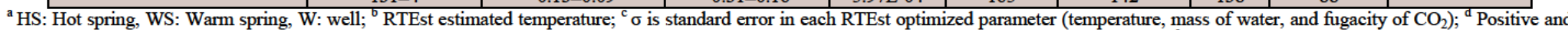

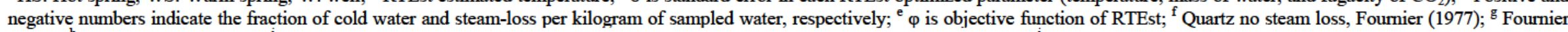

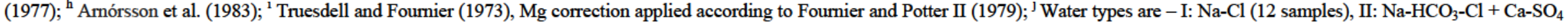
(13 samples), III: $\mathrm{Na}-\mathrm{HCO}_{3}-\mathrm{Cl}$ (3 samples), IV: $\mathrm{Ca}-\mathrm{Cl}$ (1 sample), V: Ca-SO 4 (4 samples), and VI: $\mathrm{Ca}-\mathrm{HCO}_{3}$ (17 samples). 
Two common composition altering processes are the loss of $\mathrm{CO}_{2}$ due to degassing and the gain/loss of water due to mixing/boiling. Particularly, the loss of $\mathrm{CO}_{2}$ from geothermal water has direct consequence on $\mathrm{pH}$ of the water, and it is often indicated by the oversaturation of calcite (Palandri and Reed, 2001). Similarly, dilution of thermal water by mixing with cooler water or enrichment of constituents (chemical components) by boiling is indicated by lack of convergence of $\log \left(\mathrm{Q} / \mathrm{K}_{\mathrm{T}}\right)$ curves over a small temperature range at $\log \left(\mathrm{Q} / \mathrm{K}_{\mathrm{T}}\right)=0$. Although, in principle, these composition altering processes can be taken into account by simply adding them into the measured water composition and looking for convergence of the saturation indices of the chosen mineral assemblage, a graphical approach becomes cumbersome even for two parameters (e.g., temperature and $\mathrm{CO}_{2}$ ).

To account for possible composition altering processes, RTEst (Palmer, 2013) was used to simultaneously estimate a reservoir temperature and optimize the amount of $\mathrm{H}_{2} \mathrm{O}$ and the fugacity of $\mathrm{CO}_{2}$ (Table 4). The optimized results for Battle Creek Hot Spring1 are shown in Figure $5 \mathrm{~b}$. Compared to the $\log \left(\mathrm{Q} / \mathrm{K}_{\mathrm{T}}\right)$ curves calculated using the reported water compositions (Figure 5a), the optimized curves (Figure $5 \mathrm{~b}$ ) converge to $\log \left(\mathrm{Q} / \mathrm{K}_{\mathrm{T}}\right)=0$ within a narrow temperature range (i.e., $169 \pm 5^{\circ} \mathrm{C}$ ).

The optimized temperatures and composition parameters for the other southeastern Idaho waters reported in Table 2 were similarly estimated using RTEst. The estimated reservoir temperatures, mass of water lost due to boiling or gained due to mixing, and fugacity of $\mathrm{CO}_{2}$ along with the associated standard errors are presented in Table 4.

\subsubsection{Temperature Estimates with Traditional Geothermometers}

In addition to RTEst, some traditional geothermometers were also used for reservoir temperatures estimation (Table 4). Because most of the waters from hot/warm springs and wells in southeastern Idaho are issuing immature waters (Figure 4), the use of traditional geothermometers to estimate their temperatures is not very reliable. Temperatures obtained with silica polymorphs and $\mathrm{Na}-\mathrm{K}-\mathrm{Ca}$ geothermometers appear somewhat comparable with the RTEst temperatures. Mean and standard deviation of estimated temperatures for each group of waters with RTEst, chalcedony, and Na-K-Ca geothermometers are presented in Table 5. Groupwise mean chalcedony calculated reservoir temperatures are consistently cooler than the mean RTEst calculated reservoir temperature for each group.

Chalcedony reservoir temperatures were calculated using the silica concentrations assuming that the sample waters completely represent the thermal water. On the other hand, RTEst reservoir temperatures are calculated with MEG using optimized (reconstructed) waters. Table 4 provides the RTEst optimized fraction of cold water (positive numbers) or steam-lost (prior to sampling) per kilogram of sample water from hot/warm springs and wells in southeastern Idaho. Whenever RTEst indicates that the sample water has appreciable fraction of cold water, in general, a higher RTEst temperature is calculated for that sample.

Table 5: Mean and standard deviation ${ }^{\mathrm{a}}$ of estimated temperature for each group of water

\begin{tabular}{|l|c|c|c|c|c|c|}
\hline Geothermometer & Group 1 $^{\mathrm{b}}$ & Group 2 & Group 3 $^{\mathrm{d}}$ & Group 4 $^{\mathrm{e}}$ & Group $^{\mathrm{f}}$ & ${\text { Group } 6^{\mathrm{g}}}^{\mathrm{c}}$ \\
\hline RTEst & $165 \pm 22$ & $119 \pm 11$ & $107 \pm 1$ & 110 & $113 \pm 6$ & $98 \pm 22$ \\
\hline Chalcedony $^{\mathrm{h}}$ & $110 \pm 24$ & $85 \pm 13$ & $102 \pm 4$ & 90 & $62 \pm 5$ & $67 \pm 28$ \\
\hline $\mathrm{Na}-\mathrm{K}-\mathrm{Ca}^{\mathrm{i}}$ & $196 \pm 46$ & $91 \pm 21$ & $77 \pm 8$ & 93 & $87 \pm 10$ & $79 \pm 21$ \\
\hline
\end{tabular}

${ }^{a}$ Standard deviation for RTEst temperatures are calculated using RTEst temperatures of each group without incorporating standard error associated with estimated temperature of individual sample; ${ }^{b} \mathrm{Na}-\mathrm{Cl}$ type water $(\mathrm{n}=12) ;{ }^{\mathrm{c}} \mathrm{Na}-\mathrm{HCO}_{3}-\mathrm{Cl}+\mathrm{Ca}-\mathrm{SO}_{4}$ type water $(\mathrm{n}=13) ;{ }^{\mathrm{d}} \mathrm{Na}-\mathrm{HCO}_{3}-\mathrm{Cl}$ type water $(\mathrm{n}=3) ;{ }^{\mathrm{e}} \mathrm{Ca}-\mathrm{Cl}$ type water $(\mathrm{n}=1)$, since this water type is represented by one sample, no standard deviations were calculated; ${ }^{\mathrm{f}} \mathrm{Ca}-\mathrm{SO}_{4}$ type water $(\mathrm{n}=4) ;{ }^{\mathrm{g}} \mathrm{Ca}-\mathrm{HCO}_{3}$ type water $(\mathrm{n}=17) ;{ }^{\mathrm{h}}$ Fournier $(1977) ;{ }^{\mathrm{i}}$ Truesdell and Fournier (1973), Mg correction applied according to Fournier and Potter II (1979).

Mg-corrected Na-K-Ca temperatures are relatively similar to the RTEst temperatures; however, the trend between mean RTEst and $\mathrm{Na}-\mathrm{K}-\mathrm{Ca}$ temperature varies with groups. In general, Na-K-Ca resulted in cooler temperature at lower temperature range and hotter temperature in the upper temperature range compared to the RTEst temperatures (Figure 6). The main weakness of this geothermometer is its less reliability for waters with significant amount of $\mathrm{Mg}$. Compared to the RTEst temperatures, Na-K-Ca temperatures are lower for all but Group 1 waters. The cooler Na-K-Ca temperatures for most of the waters are resulted in due to the large $\mathrm{Mg}$-correction factor because of the high $\mathrm{Mg}$ content. Furthermore, the $\mathrm{Mg}$ concentration in southeastern Idaho waters seems to be controlled by minerals other than chlorite. Since southeastern Idaho waters have traversed through or are in contact with thick carbonate (limestone/dolomite) sequences, concentration of $\mathrm{Mg}$ in these waters appears to be controlled by disordered dolomite. Similarly, for some springs/wells (e.g., Anderson/Dryer wells) that issue water from non-carbonate terrain, concentration of $\mathrm{Mg}$ is controlled by smectite-type clays. The overprediction of temperature for Group 1 waters is reported to be caused by the disproportionate (relative to $\mathrm{Na}$ and $\mathrm{K}$ ) loss of $\mathrm{Ca}$ due to calcite precipitation (Young and Lewis, 1981). If there were no other presampling consequences (such as mixing/loss of $\mathrm{CO}_{2}$ ) that might have happened to the water that Battle Creek Hot Spring in Preston Idaho issues, it is reasonable to assume that this water might have lost $\mathrm{Ca}$ due to calcite precipitation such that calcite is oversaturated in this water at field temperature or above ( Figure 5a). The Na-K-Ca geothermometer may not produce a reliable temperature for a system where the Ca concentration is independently controlled by non-Ca feldspar minerals (e.g., carbonates) without causing corresponding changes in concentration of $\mathrm{K}$ and $\mathrm{Na}$ (Fournier and Truesdell, 1973). However, the supersaturation of calcite in this water (Battle Creek Hot Spring) is caused by loss of $\mathrm{CO}_{2}$ due to degassing. The RTEst modeling estimates temperature using reconstructed water where calcite and other assemblage minerals are at equilibrium at reservoir temperature (Figure $5 \mathrm{~b}$ ). For southeastern Idaho waters, the Na-K-Ca geothermometer may fail to estimate a reliable temperature because most of the assumptions on which it is based are likely to be violated here. 


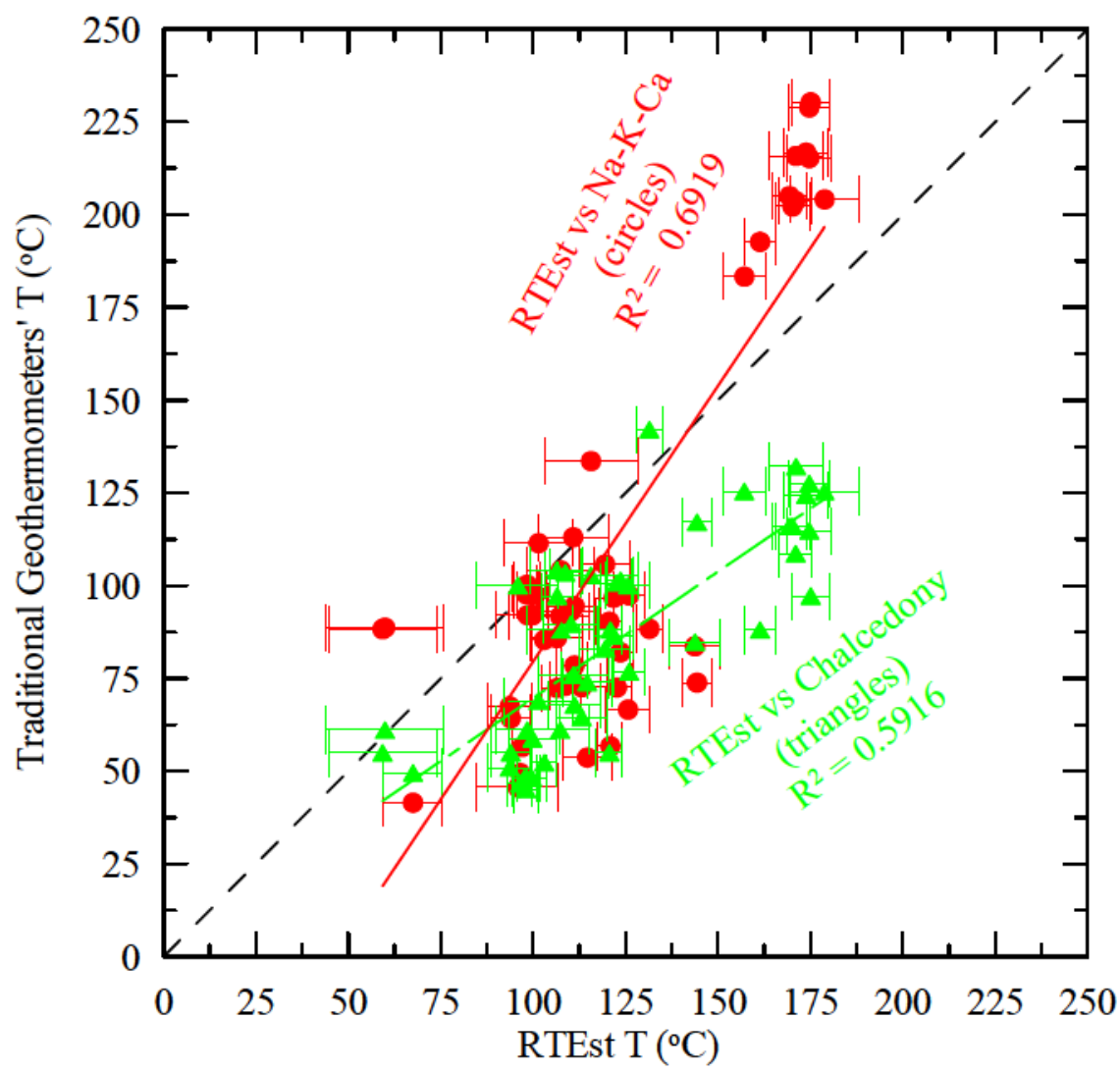

Figure 6. RTEst temperatures versus chalcedony [green triangles $(\Delta)$ ] and Na-K-Ca [red circles $\left({ }^{\ominus}\right)$ ] temperatures for the southeastern Idaho thermal waters.

\subsubsection{Estimated Temperatures Versus Bottom-hole Temperature of Wild-cat Petroleum Wells}

In general, RTEst calculated reservoir temperatures appear positively correlated with nearby bottom-hole temperatures, supporting the argument that MEG can be used to predict deep geothermal reservoirs. As reported in Table 1, some of the wild-cat petroleum wells in the fold-thrust belt in southeastern Idaho provide measured temperature at depth. Although these wells are located several kilometers away from the springs/wells that are used in RTEst temperature estimates (Figure 2), the bottom-hole temperatures at these wells could be compared with the RTEst temperatures in the region. It is important to note that even the bottom-hole temperatures of nearby wells are sometimes varied significantly. For example, Bald Mountain-2 (3830 m) has a reported temperature of $148{ }^{\circ} \mathrm{C}$ whereas as the nearby well Black Mountain-1 $(4158 \mathrm{~m})$ has a bottom hole temperature of $100{ }^{\circ} \mathrm{C}$. Such variation in temperature at depth in nearby wells may suggest that the deep temperatures could be related to their vicinity with the thermal water flow paths controlled by deep discontinuity such as faults. Nevertheless, for some springs, the temperature estimates are close to the bottom-hole temperatures in nearby deep wells.

The North Eden Federal 22-11 well $(2618 \mathrm{~m})$ is located east of the Bear Lake, near the triple junction of Idaho, Utah, and Wyoming. This well has slightly lower bottom-hole temperature $\left(92{ }^{\circ} \mathrm{C}\right)$ than the RTEst temperature estimates (107-121 with standard error \pm 4 to \pm 8 ) for nearby hot springs (Bear Lake Hot Springs represented by letter code BL in Figure 2). Similarly, RTEst temperature estimate for Alpine Spring (letter code AL in Figure 2) $\left(98 \pm 9^{\circ} \mathrm{C}\right)$ is very similar to the bottom-hole temperatures of nearest deep wells, (Big Elk Mountain- $1\left(1545 \mathrm{~m}, 103^{\circ} \mathrm{C}\right)$ and Black Mountain-1. On the other hand, the bottom-hole temperatures at Federal $1-8\left(188^{\circ} \mathrm{C}\right)$ and Federal $1-13\left(161^{\circ} \mathrm{C}\right)$ are significantly higher than the estimated temperature $\left(68 \pm 8^{\circ} \mathrm{C}\right)$ for the closest spring (Pescadaro Warm Spring with PD letter code in Figure 2). The highest bottom-hole temperature was recorded for King 2-1 $\left(3927 \mathrm{~m}, 249^{\circ} \mathrm{C}\right)$ well; however, there is no RTEst temperature estimates in the vicinity of this well. Similarly, there is no deep measured temperature in the vicinity of Battle Creek and Squaw Hot Springs near Preston so that we could not directly compare our the highest estimated temperature in southeastern Idaho. However, these hot springs themselves are issuing rather hot waters (up to $84^{\circ} \mathrm{C}$ ); and some of the recent shallow wells in the area are reportedly producing water with temperature over $100^{\circ} \mathrm{C}$.

\section{OBSERVATIONS}

Geological setting coupled with the direct evidences of thermal expressions such as hot/warm springs in the area suggest that southeastern Idaho has good potential for geothermal resources. Our temperature estimates using RTEst with thermal water compositions measured from southeastern Idaho indicate the presence of relatively hotter zones at depth. Specifically, thermal waters of Battle Creek Hot Springs and Squaw Hot Springs provided a promising geothermal prospect near Preston, Idaho. In other 
areas, however, the moderately high temperature estimates might reflect the mixing of local groundwater to the deeper thermal water or re-equilibration of high temperature thermal waters at lower temperature zone near surface. Several factors, such as, use of pure water during modeling and overall quality and completeness of the reported water chemistry, might have also contributed in underestimating the true temperature at depth.

\section{ACKNOWLEDGEMENTS}

Funding for this research was provided by the U.S. Department of Energy, Office of Energy Efficiency \& Renewable Energy, Geothermal Technologies Program. We appreciate the help from Will Smith and Cody Cannon for this study.

\section{REFERENCES}

Armstrong, F.C., and Oriel, S.S.: Tectonic development of Idaho-Wyoming thrust belt. Bull. Am. Ass. Petrol. Geol, 49, 1847-1866, (1965).

Arnórsson, S., Gunnlaugsson, and Svavarsson, H.: The chemistry of geothermal waters in Iceland. III. Chemical geothermometry in geothermal investigations. Geochimica et Cosmochimica Acta, 47, (1983) 567-577

Avery, C.: Chemistry of thermal water and estimated reservoir temperatures in southeastern Idaho, north-central Utah, and southwestern Wyoming. Thirty-Eighth Field Conference, Wyoming Geological Association Guidebook, 347- 353, (1987).

Ayling, B., and Moore, J.: Fluid geochemistry at the Raft River geothermal field, Idaho, USA: New data and hydrogeological implications. Geothermics 47, (2013), 116-126.

Bethke, C.M.: Geochemical and Biogeochemical Reaction Modeling. Cambridge University Press, (2008), 547 pp.

Blackwell, D.D., Kelley, S., and Steele, J. L.: Heat flow modeling of the Snake River Plain, Idaho. US Department of Energy Report for contract DE-AC07-761DO1570, (1992).

Dansart, W.J., Kauffman, J. D., and Mink, L. L.: Overview of Geothermal Investigations in Idaho, 1980 to 1993. Idaho Water Resources Research Institute, University of Idaho, (1994).

Dion, N. P.: Hydrologic reconnaissance of the Bear River Basin in southeastern Idaho: Idaho Dept. of Water Resources Water Inf. Bull. 13, (1969), 66 p.

Dixon, J. S.: Regional structural synthesis, Wyoming salient of western overthrust belt. AAPG Bulletin, 66, (1982), 1560-1580.

Fournier, R.O. and Truesdell, A.H.: An empirical Na-K-Ca geothermometer for natural waters. Geochimica et Cosmochimica Acta, 37, (1973), 1255-1275.

Fournier, R.O.: Chemical geothermometers and mixing models for geothermal systems. Geothermics, 5, (1977) 41-50.

Fournier, R.O.: A revised equation for the Na/K geothermometer. GRC Transactions, 3, (1979), 221-224.

Fournier, R.O., and Potter II, R.W.: Magnesium correction to the Na-K-Ca chemical geothermometer. Geochimica et Cosmochimica Acta, 43, (1979), 1543-1550.

Giggenbach, W.F.: Geothermal solute equilibria. Derivation of Na-K-Mg-Ca geoindicators. Geochimica et Cosmochimica Acta, 52, (1988), 2749-2765.

Lewicki, J. L., Hilley, G. E., Dobeck, L., McLing, T. L., Kennedy, B. M., Bill, M., \& Marino, B. D.V.: Geologic $\mathrm{CO}_{2}$ input into groundwater and the atmosphere, Soda Springs, ID, USA. Chemical Geology, 339, (2013), 61-70.

Mabey, D.R. and Oriel, S.S.: Gravity and magnetic anomalies in the Soda Springs region southeastern Idaho. Geological Survey Professional Paper 646-E, US Geological Survey, (1970).

McCurry, M., Welhan, J., Polun, S., Autenrieth, K., and Rodgers, D.W., 2011. Geothermal Potential of the Blackfoot ReservoirSoda Springs Volcanic Field: A Hidden Geothermal Resource and Natural Laboratory in SE Idaho. GRC Transactions, 35, 917-924.

McCurry, M., Hayden, K.P., Morse, L.H., and Mertzman, S.: Genesis of post-hotspot, A-type rhyolite of the Eastern Snake River Plain volcanic field by extreme fractional crystallization of olivine tholeiite. Bull. Volcanol. 70, (2008) 361-383.

Mitchell, J.C.: Geothermal Investigations in Idaho: Part 5, Geochemistry and geologic setting of the thermal waters of the northern Cache valley area, Franklin county, Idaho. Idaho Dep. Water Resources, Water Inf. Bull., No. 30, (1976A).

Mitchell, J.C.: Geothermal Investigations in Idaho, Part 6, Geochemistry and geologic setting of the thermal and mineral waters of the Blackfoot reservoir area, Caribou County, Idaho. Idaho Dep. Water Resources, Water Inf. Bull., No. 30, (1976B).

Mitchell, J.C., Johnson, L.L, and Anderson, J.E.: Geothermal Investigations in Idaho, Part 9, Potential for direct heat application of geothermal resources. Idaho Dep. Water Resources, Water Inf. Bull., No. 30, (1980)

Neupane, G., Smith, R.W., Palmer, C.D., and McLing, T.L.: Multicomponent equilibrium geothermometry applied to the Raft River geothermal area, Idaho: preliminary results. In Geological Society of America Abstracts with Programs, 45 (7), (2013).

Neupane, G., Mattson, E.D., McLing, T.L., Palmer, C.D., Smith, R.W., and Wood, T.R.: Deep geothermal reservoir temperatures in the Eastern Snake River Plain, Idaho using multicomponent geothermometry. PROCEEDINGS, Thirty-Ninth Workshop on Geothermal Reservoir Engineering Stanford University, Stanford, California, February 24-26, 2014 SGP-TR-202, (2014).

Oriel, S.S. and Platt, L.B.: Geologic map of the Preston $1^{\circ} \mathrm{X} 2^{\circ}$ quadrangle, southeastern Idaho and western Wyoming. Miscellaneous Investigation Series, Map I-1127, United States Geological Survey, Department of Interior, (1980). 
Palandri, J.L., and Reed, M.H.: Reconstruction of in situ composition of sedimentary formation waters. Geochimica et Cosmochimica Acta, 65, (2001), 1741-1767.

Palmer, C.D.: Installation manual for Reservoir Temperature Estimator (RTEst). Idaho National Laboratory, Idaho Falls, ID, (2013).

Pang, Z.H., and Reed, M.: Theoretical chemical thermometry on geothermal waters: Problems and methods. Geochimica et Cosmochimica Acta, 62, (1998), 1083-1091.

Parliman, D.J. and Young, H.W.: Compilation of selected data for thermal-water wells and springs, 1921 through 1991. US Geological Survey, Open-File Report 92-175, (1992)

Pickett, K.E., 2004. Physical volcanology, petrography, and geochemistry of basalts in the bimodal Blackfoot volcanic field, southeastern Idaho. MS Thesis, Idaho State University, Pocatello, Idaho.

Ralston, D.R., Arrigo, J.L., Baglio, J.V. Jr., Coleman, L.M., Souder, K., Mayo, A.L.: Geothermal evaluation of the thrust area zone in southeastern Idaho. Idaho Water and Energy Research Institute, University of Idaho, (1981).

Reed, M., and Spycher, N.: Calculation of $\mathrm{pH}$ and mineral equilibria in hydrothermal waters with application to geothermometry and studies of boiling and dilution. Geochimica et Cosmochimica Acta, 48, (1984), 1479-1492.

Souder, K.C.: The hydrochemistry of thermal waters of southeastern Idaho, western Wyoming, and northeastern Utah. MS Thesis, University of Idaho, Moscow, Idaho, (1985).

Truesdell, A.H.: Summary of Section III. Geochemical techniques in exploration. Proceedings of the Second United Nations Symposium on the Development and Use of Geothermal Resources, San Francisco 1975, v. 1, p. liii - lxxix, (1976).

Ward, J.H., Jr.: Hierarchical grouping to optimize an objective function. Journal of the American Statistical Association, 58, (1963), 236-244.

Welhan, J., Gwyunn, M., Payne, S., McCurry, M., Plummer, M., Wood, T.: The Blackfoot volcanic field, southeast Idaho: a hidden high-temperature geothermal resource in the Idaho thrust belt. PROCEEDINGS, Thirty-Ninth Workshop on Geothermal Reservoir Engineering Stanford University, Stanford, California, February 24-26, 2014 SGP-TR-202, (2014).

Young, H.W. and Lewis, R.E.: Application of a Magnesium Correction to the Sodium-Potassium-Calcium Geothermometer for Selected Thermal Waters in Southeastern Idaho. GRC Transactions, 5, (1981), 145-148.

Young, H.W. and Mitchell, J.C.: Geothermal investigations in Idaho. Part 1. Geochemistry and geologic setting of selected thermal waters (No. NP-22003/1). U.S. Geological Survey and Idaho Dept. of Water Administration, (1973). 


\title{
Validation of Multicomponent Equilibrium Geothermometry at Four Geothermal Power Plants
}

\author{
Ghanashyam Neupane $^{1,2}$, Jeffrey S. Baum ${ }^{3}$, Earl D. Mattson ${ }^{1}$, Gregory L. Mines ${ }^{1}$, Carl D. Palmer ${ }^{4}$, Robert W. Smith ${ }^{2,4}$ \\ ${ }^{1}$ Idaho National Laboratory, 2525 Fremont Ave, Idaho Falls, ID 83415 \\ ${ }^{2}$ Center for Advanced Energy Studies, 995 University Boulevard, Idaho Falls, ID 83401 \\ ${ }^{3}$ Brown University, 324 Book Street, Providence, RI 02912 \\ ${ }^{4}$ University of Idaho-Idaho Falls, 1776 Science Center Drive, Suite 306, Idaho Falls, ID 83402 \\ E-mail: ghanashyam.neupane@inl.gov
}

Keywords: RTEst, MEG, Geothermal, Raft River, Neal Hot Springs, Roosevelt Hot Springs, Steamboat Springs

\begin{abstract}
This paper evaluates our ability to predict geothermal reservoir temperatures using water compositions measured from surface hot springs or shallow subsurface wells at four geothermal sites prior to the startup of geothermal energy production using RTEst, a multicomponent equilibrium geothermometer we have developed and are testing. The estimated reservoir temperatures of these thermal expressions are compared to measured bottom-hole temperatures of production wells at Raft River, ID; Neal Hot Springs, OR; Roosevelt Hot Springs, UT; and Steamboat Springs, NV geothermal sites. In general, temperatures of the producing reservoir estimated from the composition of water from surface expressions/shallow wells using RTEst are similar to the measured bottom-hole temperatures. For example, estimates for the Neal Hot Springs system are within $\pm 10^{\circ} \mathrm{C}$ of the production temperatures. However, some caution must be exercised in evaluating RTEst predictions. Estimated temperature for a shallow Raft River well (Frazier well) is found to be slightly lower (ca. $15^{\circ} \mathrm{C}$ ) than the bottom-hole temperatures from the geothermal plant production wells. For the Raft River system, local geology and fluid mixing model indicate that the fluid source for this shallow well may not have originated from the production reservoir. Similarly, RTEst results for Roosevelt Hot springs and Steamboat Springs geothermal areas were found consistent with the reservoir temperatures obtained from deep wells. These results suggest that the RTEst could be a valuable tool for estimating temperatures and evaluation geothermal resources.
\end{abstract}

\section{INTRODUCTION}

The US Geological Survey has estimated that there are up to 73,000 MWe of undiscovered geothermal potential and 727,000 MWe of enhanced geothermal potential distributed over 13 western states in the United States (Williams et al., 2008). However, these vast potential resources of energy are largely remained unexplored because of the cost associated with the direct exploration methods such as deep drilling or less-reliability of other cost-effective exploration methods such as traditional geothermometry. Unlike other renewables such as wind and solar, geothermal energy requires high upfront costs for direct resource exploration and evaluation. For example, direct method of exploration such as deep exploratory boreholes can cost millions of dollars each. Moreover, the success rate of this costly exploration practice was reported to be in the range of $35-50 \%$ (Speer, 2012). The high failure risk along with a significant upfront cost associated with geothermal exploration limits investment for the commercial realization of geothermal resources. Similarly, traditional geothermometry could result in varied temperature estimates for the same resource creating uncertainty in resource evaluation. Therefore, cost effective and more reliable exploration methods are important to expedite development of the vast potential of geothermal resources in the US.

One of the prospecting tools for geothermal resources that we believe can be improved is geothermometry, which uses the chemical compositions of water from springs and wells to estimate reservoir temperature. The application of geothermometry requires several assumptions including that the reservoir minerals and fluid attain chemical equilibrium and as the water moves from the reservoir to the sampling location, it retains its chemical signatures (Fournier et al., 1974). The first assumption is generally valid (provided there is a sufficiently long residence time); however, the second assumption is more likely to be violated. As reservoir fluids move toward the surface, the pressure on the fluid decreases resulting in boiling and subsequent loss of volatiles (e.g., $\mathrm{CO}_{2}$ ). The fluid temperature will decrease as a result of the associated heat of vaporization as well as thermal conduction. Boiling will increase the concentrations of nonvolatile components in the liquid phase. The loss of acid volatiles such as $\mathrm{CO}_{2}$ and $\mathrm{H}_{2} \mathrm{~S}$ will alter the pH while the loss of redox active species such as $\mathrm{H}_{2} \mathrm{~S}$ can shift the ratios of redox pairs (e.g., $\mathrm{HS}^{-} / \mathrm{SO}_{4}{ }^{2-}$ ). These changes in temperature and solute concentrations may result in re-equilibration of the liquid phase with minerals in the zone above the main reservoir. In addition, this altered thermal water may mix with non-thermal waters which will further alter solute concentrations. These processes mask the initial geochemical signature of the reservoir fluid resulting in temperature estimates from traditional geothermometers being diverse and often being inaccurate or inconclusive.

Geothermal temperature predictions using multicomponent equilibrium geothermometry (MEG) (e.g., Reed and Spycher, 1984) provide apparent improvement in reliability and predictability of temperature over traditional geothermometers. An additional advantage of MEG is that it considers a suite of chemical data obtained from water analyses for temperature estimation. Although MEG has advantages over the traditional geothermometers, it is also subjected to the same physical and chemical processes that likely violate the basic assumptions used for traditional geothermometry. Therefore, it is important to reconstruct the composition of geothermal water and if the processes that alter water composition can be inferred and accounted for, the reservoir temperature can be estimated with a greater certainty. 
Recently, we have developed an MEG approach (Reservoir Temperature Estimator, RTEst) and tested it with synthetic geothermal waters (Cooper et al., 2013) and natural geothermal waters from south Idaho, USA (Neupane et al., 2014 and 2015). In this paper, we apply this geothermometry tool to water compositions measured prior to the startup of geothermal energy production from surface hot springs and deep wells at four geothermal sites (Neal Hot Springs, OR; Raft River, ID; Roosevelt Hot Springs, UT; and Steamboat Springs, NV) (Figure 1). The reservoir temperatures estimated from these thermal expressions are compared to measured bottom-hole temperatures of production wells from respective geothermal sites.

\section{APPROACH}

\subsection{General}

RTEst is a geothermometry tool based on MEG. In this approach, the reservoir temperature is assumed to be the temperature at which all minerals in an assemblage that is characteristic of the reservoir are in equilibrium with the reservoir fluid. RTEst estimates the reservoir temperature from measured water composition using an inverse geochemical modeling technique that calculates the temperature at which multiple minerals are simultaneously at equilibrium (ensuring Gibb's Phase Rule is not violated) while explicitly accounting for the possible loss of volatile constituents (e.g., $\mathrm{H}_{2} \mathrm{O}, \mathrm{CO}_{2}$ ) and water mixing. In addition, RTEst provides estimated uncertainty associated with calculated temperatures and other parameters.

Sometimes, reported water chemistries of geothermal waters may lack or have erroneous amount of some primary component species. For example, many reported geothermal waters do not have measured aluminum (Al) concentrations (Pang and Reed, 1998), and most reported fluid chemistries do not have data for gaseous components or the reported values could have been far from the actual concentrations in the fluid because of the inherent difficulty of sampling and analyzing these components (Arnórsson et al., 2006). Different approaches have been put forward to reconstruct the composition of geothermal fluids and sedimentary formation brines (Pang and Reed, 1998; Palandri and Reed, 2001). In general, these approaches assume an equilibrium state between in situ fluid and reservoir mineral assemblage (RMA) in the reservoir and use a specific mineral to control the concentration of that missing (or having erroneous concentration) component. For example, when measured Al concentration is not available, an Al-bearing mineral (e.g., K-feldspar) can be used for $\mathrm{Al}$ and estimate temperature with MEG (FixAl method of Pang and Reed, 1998). In this paper, we have used this method for determining the concentration of $\mathrm{Al}$ in water samples without measured concentration $\mathrm{Al}$ during RTEst modeling.

To increase confidence that RTEst can improve estimates of reservoir temperatures, we have selected four geothermal sites (Raft River, ID; Neal Hot Springs, OR; Roosevelt Hot Springs, UT; and Steamboat Springs, NV) for which water composition from surface hot springs or shallow wells were available prior to the startup of geothermal energy productions. Reservoir temperature at each of these sites was estimated from the shallow water compositions using RTEst and RMAs based on available geological information. These estimated reservoir temperatures are then compared to bottom-hole temperatures from productions wells. Ideally, the estimated temperatures should be greater than or equal to the bottom-hole temperatures.

\subsection{Reservoir Mineral Assemblage}

Based on general lithology of each geothermal site (discussed below) and literature assessment of secondary minerals for dominant rock and water types, we developed reservoir mineral assemblages (RMAs) consisting of idealized clays, zeolites, carbonate, feldspars, and silica-polymorph (chalcedony and quartz) to determine reservoir temperatures.

Using an appropriate RMA and measured water composition, RTEst estimates an equilibrium reservoir temperature (as well as a fugacity of $\mathrm{CO}_{2}$ and water mixing or boiling) by minimizing an objective function $(\Phi)$ that is the weighted sum of the squares of the saturation indexes for the selected equilibrium minerals

$$
\Phi=\sum\left(S I_{i} w_{i}\right)^{2}
$$

where $\mathrm{SI}_{\mathrm{i}}=\log \left(\mathrm{Q}_{\mathrm{i}} / \mathrm{K}_{\mathrm{i}, \mathrm{T}}\right)$ for the ith equilibrium mineral $\left(\mathrm{Q}_{\mathrm{i}}\right.$ and $\mathrm{K}_{\mathrm{i}}, \mathrm{T}$ are the ion activity product and temperature dependent equilibrium constant, respectively for ith mineral) and $\mathrm{w}_{\mathrm{i}}$ is the weighting factor for the ith mineral.

The weighting factors ensure that each mineral that contributes to the equilibrium state is considered equally and the results are not skewed by reaction stoichiometry or differences in analytical uncertainty. There are three options for weighting factors in RTEst: inverse of variance, normalization, or unit weights and they are discussed in more detail by Palmer et al. (2014). In this paper, we used normalization method for weighting that assumes that the analytical error for all thermodynamic components expressed as basis species are equal and that the thermodynamic activity of water is unity and invariant. Weighting factors (normalization factors) for several minerals are given in Palmer et al (2014).

\subsection{RTEst Modeling}

In general, two schemes of RTEst optimization were considered in this paper: using temperature and fugacity of $\mathrm{CO}_{2}$ as optimization parameters (no change in mass of water), and using mass of water, temperature, and fugacity of $\mathrm{CO}_{2}$ as optimization parameters. For the latter scheme of RTEst modeling, pure water was considered to account for the mixing and boiling. Initially, for all water samples, RTEst modeling with optimization on three parameters was conducted. If the three-parameter RTEst modeling resulted in a change in mass of water of less than $\pm 30 \%$ (the estimated $95 \%$ confidence interval), mass of water was removed from the optimization and only the two parameters (temperature and $\mathrm{CO}_{2}$ fugacity) are reported in this paper. 


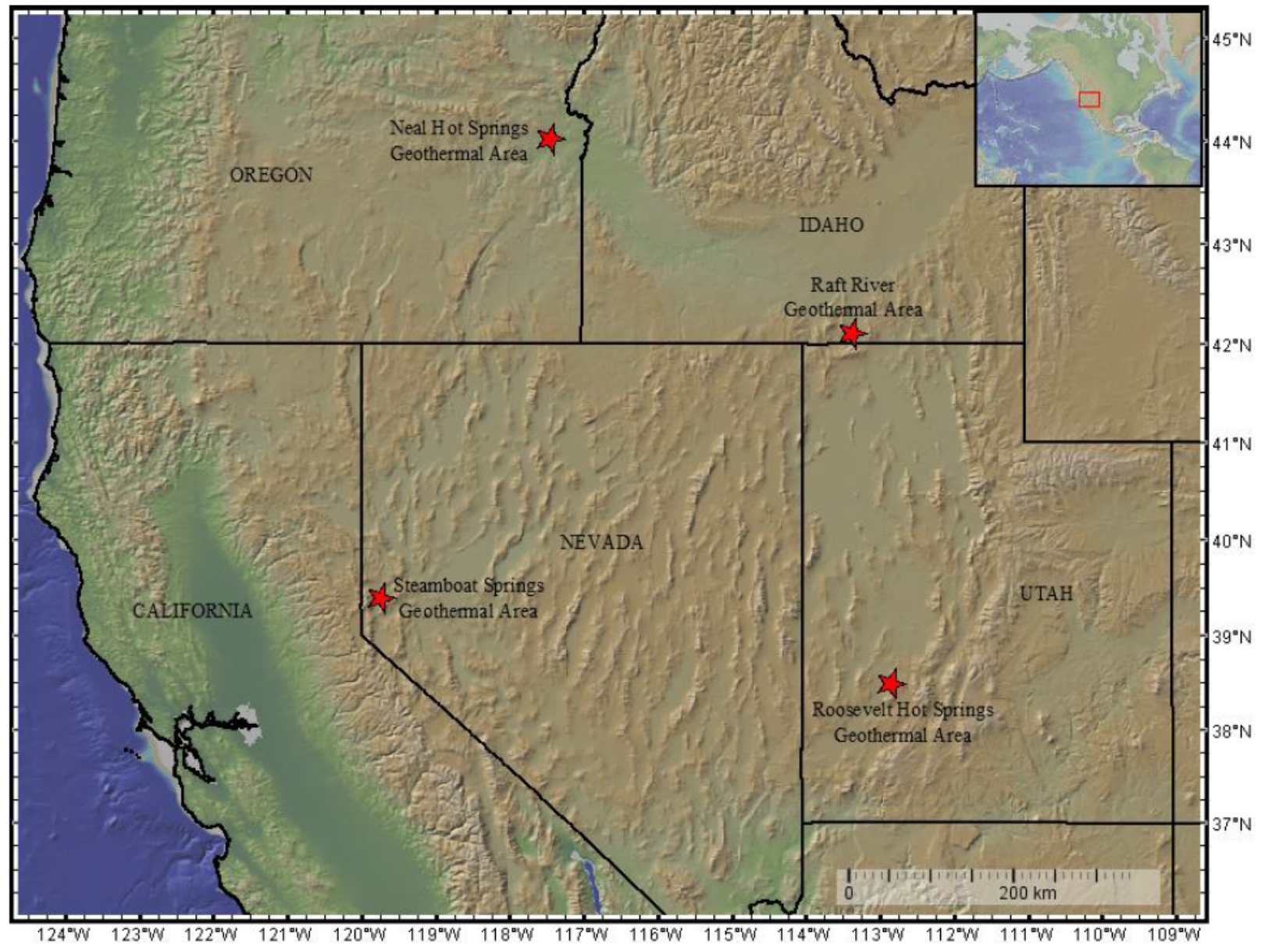

Figure 1. Shaded relief map showing locations of geothermal areas used in this study. The map was prepared from NASA 10-m DEM data in GeoMapApp.

\section{SITES}

\subsection{Raft River}

\section{$\underline{3.1 .1 \text { General }}$}

The Raft River geothermal (RRG) field in south-central Idaho (Figure 1) is a designated Known Geothermal Resource Area (KGRA) with the highest measured bottom-hole temperature of $149{ }^{\circ} \mathrm{C}$ (Dolenc et al., 1981). Extensive exploration and development activities conducted by the USGS and the US Department of Energy in the mid to late 1970s and early 1980s has proved the viability of this area to generate commercial electricity using geothermal energy (Dolenc et al., 1981; Ayling and Moore, 2013). Currently, U.S. Geothermal, Inc. operates a $13 \mathrm{MWe}$ geothermal power plant at this site.

\section{$\underline{3.1 .2}$ Hydrogeological setting}

The RRG system consists of two geologic units - Precambrian basement rocks and unconformably overlying mid-Tertiary to Quaternary sedimentary-volcanic rocks (Devine and Bonnichsen, 1980; Blackett and Kolesar, 1983). The basement rocks include metamorphosed adamellite, schist, and quartzite. The younger rocks consist of a thick (up to $1600 \mathrm{~m}$ ) Tertiary sequence of rhyolites, tuffs, and fluvial-lacustrine sedimentary rocks (Salt Lake Formation) and non-indurated Pleistocene deposits of quartz sand, silt, and gravel (Raft Formation) (Blackett and Kolesar, 1983). Structurally, two major fault systems, the Bridge Fault Zone and the Horse Wells Fault Zone, are identified in the area (Dolenc et al., 1981). These fault systems, most importantly, the Bridge Fault Zone (Figure 2), are presumed to be intersecting a basement shear zone called Narrows Structures and controlling the up flow of the geothermal water (Ayling and Moore, 2013).

The reservoir is fracture-controlled; hydrothermal water circulates along fractures in the Precambrian basement and rises through northwest-striking normal faults (Dolenc et al. 1981). Water then permeates fractured Tertiary lacustrine sediments of the Salt Lake Formation and rises up through these fractures towards the surface (Dolenc et al. 1981). The majority of Raft River geothermal fluid resides in the Precambrian quartzite and quartz monzonite. Equilibrium controlling minerals in the reservoir include chalcedony, calcite, clinochlore-14A, kaolinite, and potassium mordenite (Devine and Bonnichsen, 1980; Jones et al., 2011; Palmer et al., 2014). 
Neupane et al.

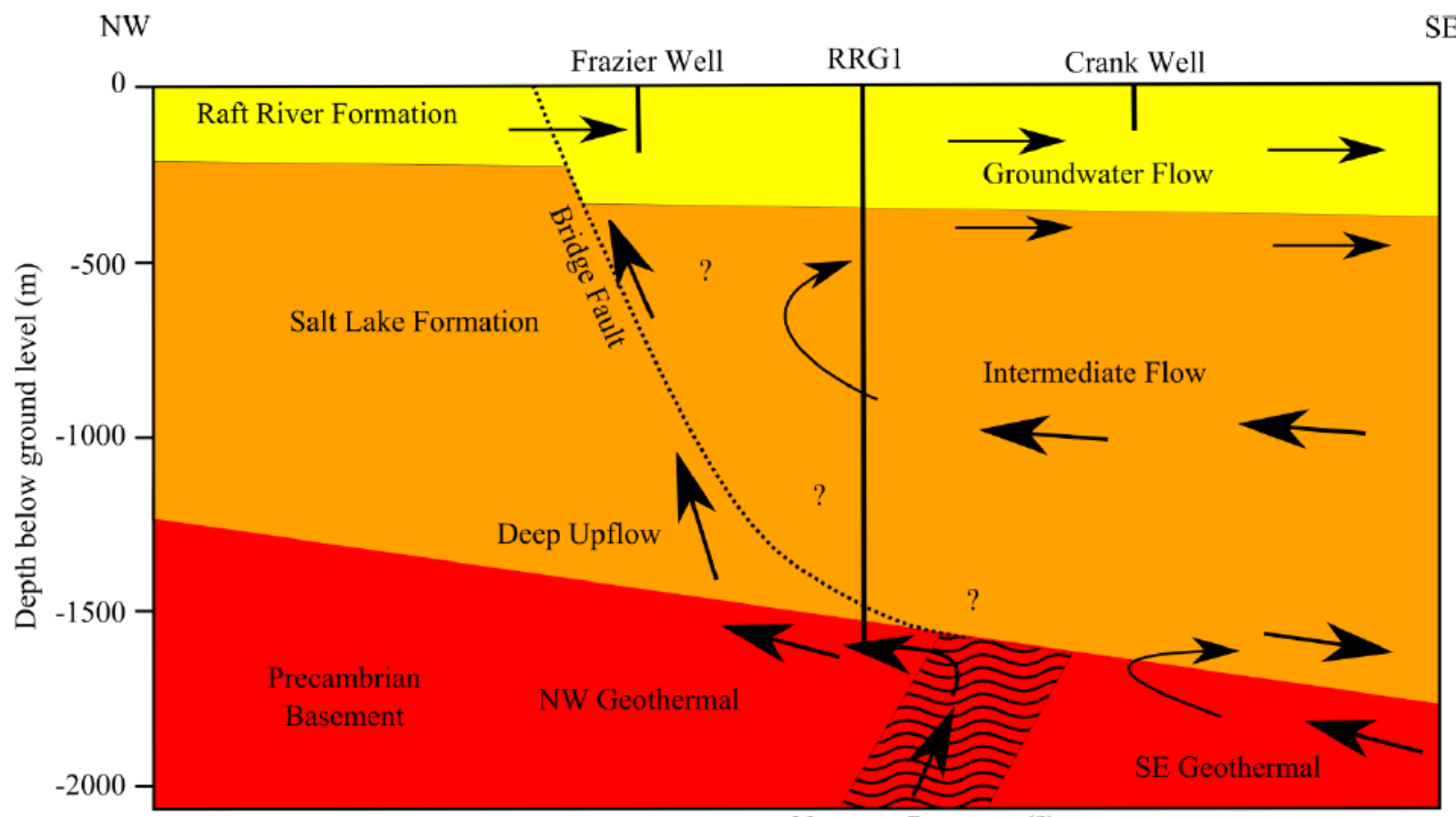

Narrows Structure (?)

Figure 2. Schematic cross-section of the Raft River geothermal area with approximate locations of the wells used in this study. (Modified from Ayling and Moore, 2013).

\section{$\underline{3.1 .3 \text { Water Chemistry }}$}

Both high- and low-TDS waters are produced at the site. The high TDS geothermal water is generally found in southeastern RRG wells and low TDS water is mostly found in northwestern RRG wells. Both waters are of sodium-chloride type, and yield similar temperatures by a single traditional geothermometer but discordant temperatures by different geothermometers (Ayling and Moore, 2013).

Table 1. Water chemistry of hot springs and deep wells from four geothermal sites $(\mathrm{mg} / \mathrm{L})$.

\begin{tabular}{|l|c|c|c|c|c|c|c|c|c|c|c|c|c|}
\hline \multicolumn{1}{|c|}{ Samples } & $\mathrm{T}\left({ }^{\circ} \mathrm{C}\right)$ & $\mathrm{pH}^{\mathrm{a}}$ & $\mathrm{Ca}$ & $\mathrm{K}$ & $\mathrm{Mg}$ & $\mathrm{Na}$ & $\mathrm{SiO}_{2}(\mathrm{aq})$ & $\mathrm{F}$ & $\mathrm{Cl}$ & $\mathrm{SO}_{4}$ & $\mathrm{HCO}_{3}$ & $\mathrm{Al}$ & $\mathrm{Source}^{b}$ \\
\hline Raft River (Frazier) & 93 & 7.4 & 53 & 22 & 0.4 & 560 & 90 & 5.7 & 900 & 57 & 55 & $\mathrm{FixAl}$ & 1 \\
\hline Raft River (Crank) & 90 & 7.7 & 130 & 35 & 0.4 & 1110 & 97 & 14 & 1900 & 61 & 36 & $\mathrm{FixAl}$ & 1 \\
\hline Raft River 1 & 141 & $7.3^{\mathrm{c}}$ & 56 & 34 & 0.6 & 455 & 121 & 7.9 & 776 & 36 & 41 & $\mathrm{FixAl}$ & 2 \\
\hline Neal HS & 87 & 7.32 & 8.8 & 16 & 0.2 & 190 & 180 & 9.4 & 120 & 120 & 200 & 0.21 & 3 \\
\hline Neal PW1 & 65 & 7.19 & 7.89 & 15.3 & 0.045 & 196 & 203 & 9 & 120 & 99 & 209 & FixAl & 4 \\
\hline Roosevelt HS50 & 85 & $7.9^{\mathrm{d}}$ & 19 & 472 & 3.3 & 2080 & 189 & 7.1 & 3810 & 65 & 158 & FixAl & 5 \\
\hline Roosevelt HS57 & 55 & 7.9 & 22 & 488 & - & 2500 & 146 & 7.5 & 4240 & 73 & 156 & FixAl & 5 \\
\hline Roosevelt PW (54-3) & $>260$ & $6.9^{\mathrm{e}}$ & 8 & 461 & 0.25 & 2320 & 263 & 6.8 & 3860 & 72 & 232 & FixAl & 5 \\
\hline Steamboat HS23 & 95.5 & 7.3 & 4.2 & 82 & 0.017 & 675 & 287 & 2.2 & 897 & 141 & 363 & FixAl & 6 \\
\hline Steamboat 21N & 70.5 & 7.8 & 3 & 78 & 0.004 & 725 & 263 & 2.3 & 917 & 147 & 379 & FixAl & 6 \\
\hline Steamboat N27 & 78 & 6.2 & 5.6 & 74 & 0.012 & 645 & 254 & 2.1 & 864 & 145 & 321 & FixAl & 6 \\
\hline Steamboat HS6 & 97 & 7.4 & 6.8 & 65 & 0.016 & 660 & 214 & 2.2 & 871 & 123 & 287 & FixAl & 6 \\
\hline Steamboat HS4 & 76.5 & 6.5 & 5.4 & 70 & 0.011 & 690 & 205 & 2.1 & 913 & 134 & 412 & FixAl & 6 \\
\hline Steamboat HS50 & 53 & 5.9 & 24 & 62 & 0.061 & 570 & 182 & 1.9 & 773 & 117 & 412 & FixAl & 6 \\
\hline Steamboat HS26 & 95.5 & 7.3 & 11.2 & 71 & 0.018 & 640 & 235 & 2.5 & 857 & 112 & 412 & FixAl & 6 \\
\hline Steamboat PW1 & 169 & $6.25^{\mathrm{f}}$ & 3 & 64 & 0.3 & 637 & 319 & 3 & 771 & 102 & 296 & FixAl & 7,8 \\
\hline
\end{tabular}

${ }^{\mathrm{a}}$ Field $\mathrm{pH}$ unless otherwise indicated. For samples with assumed $\mathrm{pH}$, averaged $\mathrm{pH}$, or $\mathrm{pH}$ value measured at unknown temperature, 25 ${ }^{\circ} \mathrm{C}$ is used as input temperature for RTEst optimization. ${ }^{\mathrm{b}}$ Sources - 1: Young and Mitchell (1973); 2: Dolenc et al (1981); 3: Marinar, 1980; 4: US Geothermal Inc., personnel Communication (2014); 5: Capuano and Cole (1982); 6: Nehring (1980); 7: Goranson, 1991; 8: Marinar and Janik (1995). ${ }^{\mathrm{c}} \mathrm{pH}$ measurement temperature not known. It is likely the sample was cooled significantly for $\mathrm{pH}$ measurement, ${ }^{\mathrm{d}}$ Assumed as equal to a value measured in 1957 (Roosevelt HS57). ${ }^{\mathrm{e}}$ Average value calculated from available pH values for Roosevelt Hot Springs wells measured at cooler temperatures. ${ }^{\mathrm{f}}$ Average value calculated from measured values of three cooler samples. 
Water chemistries from two Raft River shallow wells [Frazier (126 m) and Crank (165)] and one deep geothermal well (RRG1, 1521 m) (Young and Mitchell, 1973; Dolence et al., 1981) were selected for testing RTEst's ability in estimating reservoir temperature. The waters from these wells are near-neutral in $\mathrm{pH}$ and dominated by sodium and chloride ions (Table 1 and Figure 3). All RRG waters lie in the mature water field in Giggenbach plot (Figure 4) suggesting that these waters are in equilibrium with reservoir minerals at $\mathrm{T}>140$ ${ }^{\circ} \mathrm{C}$. Specifically, Giggenbach plot shows relatively high temperature water-rock interaction for water from RRG1 than waters from two shallow RRG wells (Figure 4).

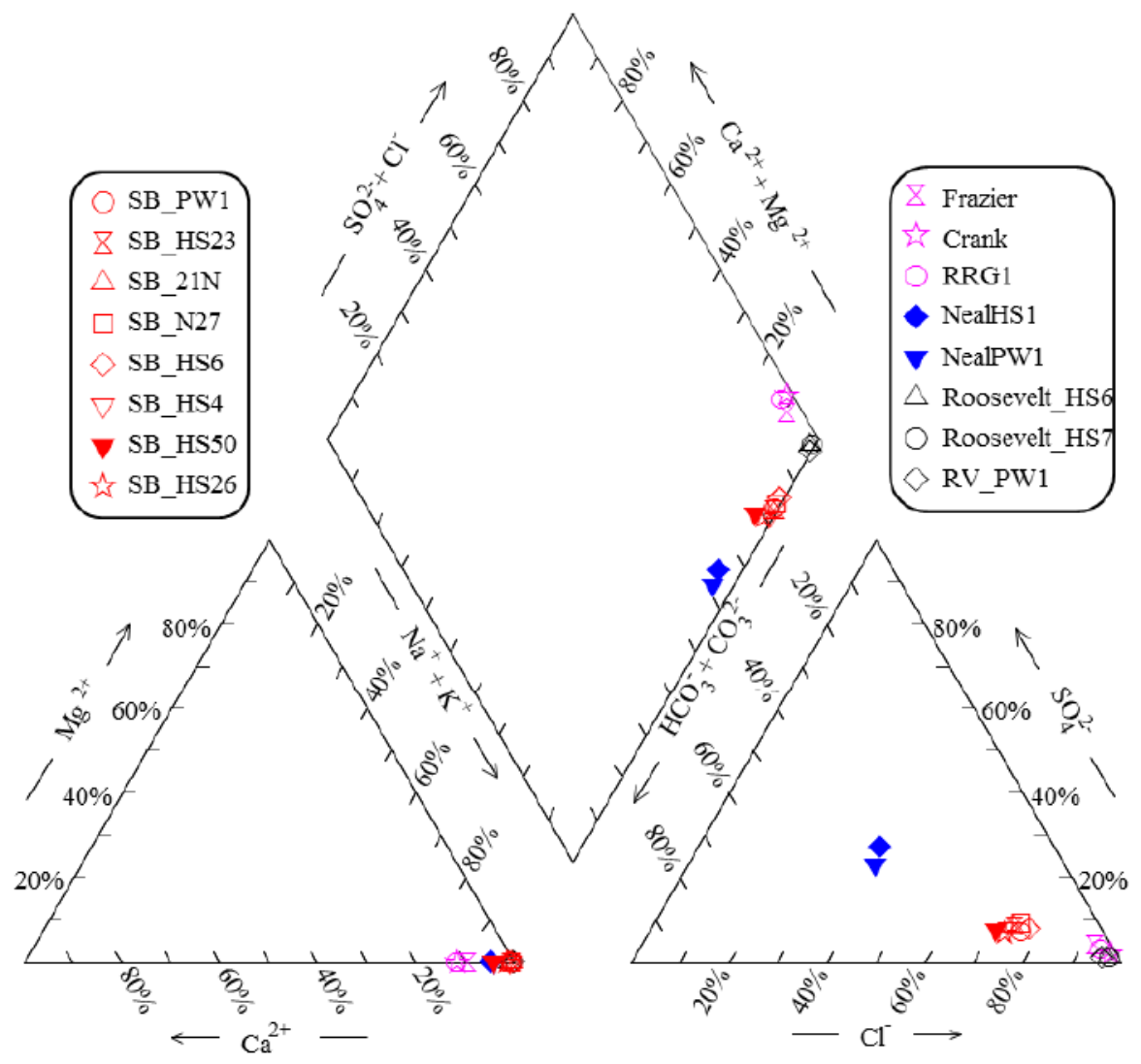

Figure 3. Composition of waters samples from four geothermal areas plotted on a Piper diagram.

\subsection{Neal Hot Springs}

\section{$\underline{3.2 .1 \text { General }}$}

The NHS geothermal area (Figure 1) is located near Vale, Oregon, at the confluence of the Bully and Cottonwood Creeks. Presence of hot $\left(90^{\circ} \mathrm{C}\right)$ springs drew attention to the region as a potential site for geothermal development. Initial exploratory activities in the area were conducted by Chevron Minerals in 1979. The bottom-hole temperatures in several production wells are recorded in the Range from 135 to $145^{\circ} \mathrm{C}$ (U.S. Geothermal, personal communication). Currently, U.S. Geothermal Inc. operates a 22 MWe power plant at this site.

\subsubsection{Hydrogeological Setting}

Geologically, this area consisted of volcanics and sediments that can be grouped into three units - the middle Miocene Columbia River Basalt Group, middle Miocene Oregon-Idaho graben fillings of silicic and basaltic lavas and volcaniclastic rocks, and the late MiocenePliocene western Snake River Plain calc-alkaline lavas, lacustrine, fluvial, and volcaniclastic rocks (Edwards, 2013).

The NHS geothermal area lies along a fault zone potentially developed by the intersection of the Oregon-Idaho graben (representing the northern extremity of the Basin and Range extensional faulting) to the south and the Vale fault zone (an extension of western Snake River Plain) to the north-northeast (Edwards, 2013). Abundant crustal extension in the region has created anomalously thin continental crust with high heat flow (Colwell, 2013). The NHS geothermal reservoir is assumed to be fault-controlled. Specifically, the area is bound to the east and west by two west-dipping normal faults, Neal and Sugarloaf Butte faults, respectively. 
Neupane et al.

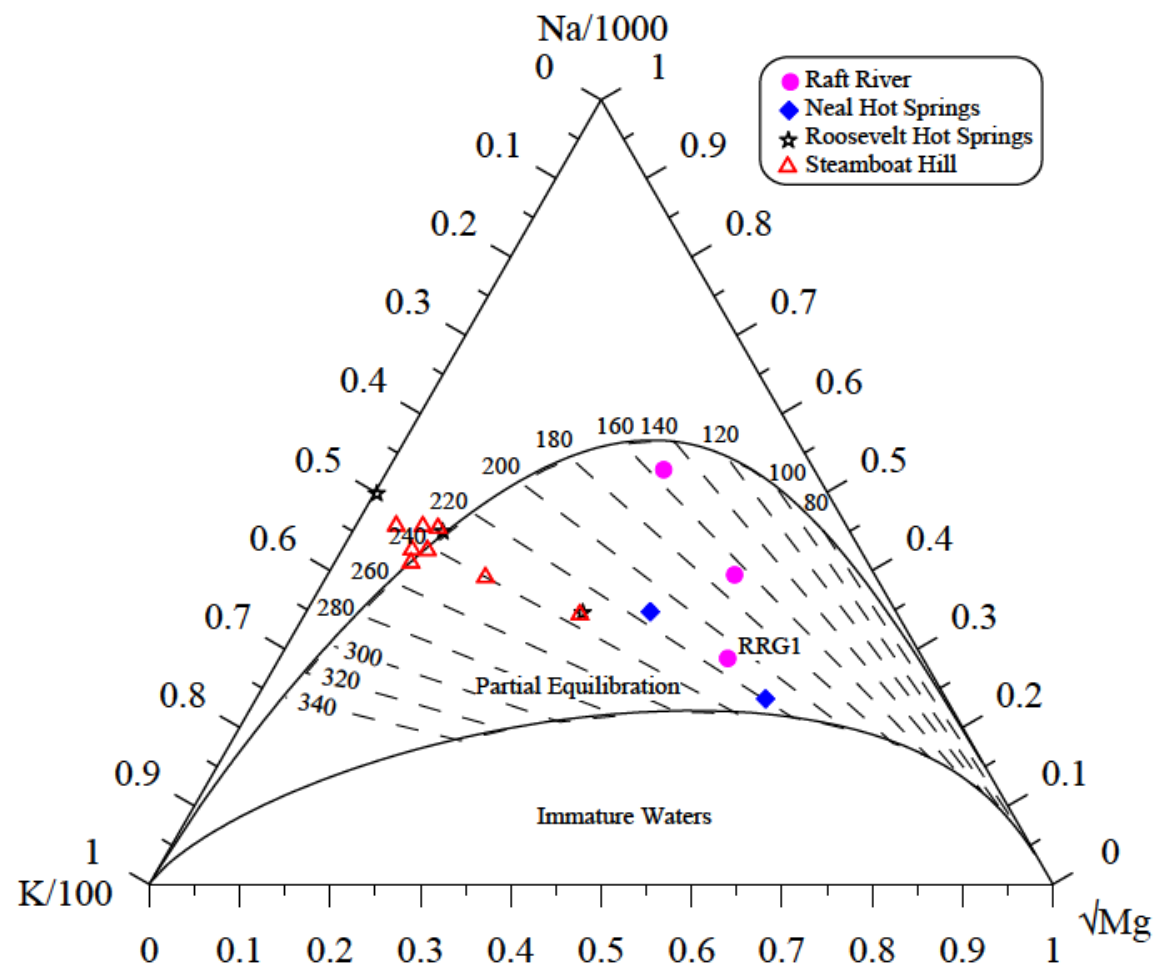

Figure 4. Water samples from four geothermal areas are plotted on a Giggenbach diagram (Giggenbach, 1988). All water samples lie in the mature water zone(s).

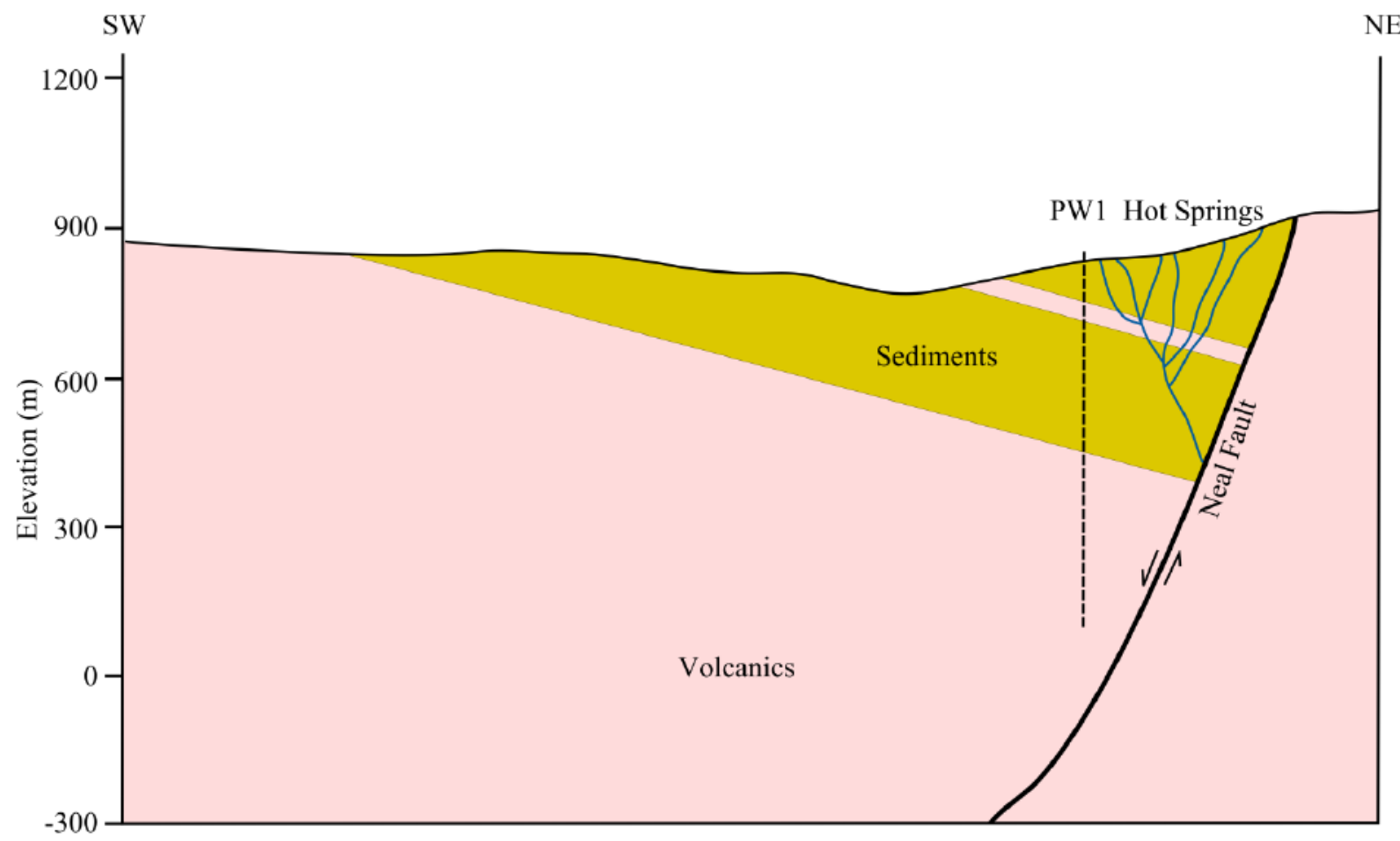

Figure 5. Simplified schematic cross-section of the Neal Hot Springs geothermal area near Vale, Oregon with approximate locations of production well and hot springs used in this study. Diagram modified from CGISS (2011). 
Fluids ascend up Neal Fault (Figure 5) and also travel laterally through the Cottonwood Creek Fault, a northwest-striking, concealed low-angle fault that links the Neal and Sugarloaf Butte faults. Production wells intersect the Neal fault or associated relay ramp and stepover faults between 680 and 1900 meters below the surface (Edwards, 2013). Well temperatures range from $135-145^{\circ} \mathrm{C}$ (U.S. Geothermal, personal communication). The hot springs issue from a north-plunging intersection between the Neal fault and the splay of the east-dipping Horse butte fault. All production wells terminate in the Basalt of Malheur Gorge, a basalt formation correlated with the Columbia River Basalt (Edwards, 2013). Equilibrium controlling minerals in the reservoir are considered to be chalcedony, calcite, potassium mordenite, sodium saponite, and magnesium beidellite based on the general lithology and water chemistry of the area (Palmer et al., 2014).

\section{$\underline{3.2 .3 \text { Water Chemistry }}$}

Pre-production water chemistry data representing the Neal Hot Spring and a production well [Neal PW1 (703 m)] are given in Table 1. These water chemistry data were assembled from a published USGS report (Mariner et al., 1980) and from personnel communication with US Geothermal Inc.

Both waters are Na-Cl type with significant concentrations of $\mathrm{SO}_{4}$ and $\mathrm{HCO}_{3}$ (Figure 3). They also have very similar concentrations of other chemical constituents (e.g., Ca, K, etc.). The Giggenbach diagram (Figure 4) for NHS area waters indicates that both waters are mature waters with potential water-rock interaction that occurred at 200 to $220^{\circ} \mathrm{C}$.

\subsection{Roosevelt Hot springs}

\section{$\underline{3.3 .1 \text { General }}$}

The Roosevelt Hot Springs (RHS) geothermal area is located near Milford in Beaver County, Utah (Figure 1). Presence of hot springs was first reported in 1908 by a surveyor who traversed the area. Subsequently, numerous bathing and recreational facilities were built in the area. The area got increased attention for its geothermal potential after a residential well that was drilled to a depth of about $84 \mathrm{~m}$ in 1968 was steamy. Afterwards the area was revisited and designated as a KGRA in 1971 (Peterson, 1975). Numerous studies and field explorations of the area in the early 1970s culminated with the construction of the first production well in 1975. Deep boreholes in the area provide reservoir temperatures range 225 to $268{ }^{\circ} \mathrm{C}$ (Capuano and Cole, 1982). Currently, PacifiCorp operates a 34 MWe power plant (Blundell Geothermal Power Plant) at this site.

\subsubsection{Hydrogeological Setting}

Geographically, RHS geothermal area is located near the eastern margin of the Basin and Range Province. Locally, the area lies in the Milford basin (valley) to the west from the Mineral Mountains. Multiple Oligocene to Pleistocene magmatic activities have been reported in the region (Becker and Blackwell, 1993). The Mineral Mountains plutonic complexes consist of quartz monzonite intruded into Paleozoic and Mesozoic sedimentary rocks (Becker and Blackwell, 1993). Late Cenozoic volcanic activities in the vicinity of RHS geothermal area include several flows of rhyolites, basalts, latities. The youngest volcanic activities in the area are represented by 0.8 to 0.5 Ma rhyolite domes and flows along the crest of the Mineral Mountains and Pleistocence-Holocene basalts in the Cove Fort basaltic field to the northeast of the Mineral Mountains (Becker and Blackwell, 1993).

Structurally, the RHS geothermal field sits at the intersection of the north-striking, west-dipping Opal Mound Fault and the east-trending Negro Mag Wash Fault (Becker and Blackwell, 1993). Geothermal activity in this region is resulted from the presence of faults that may have been linked to the regional heating source, a large magma chamber located at depth, through a highly fractured zone (Faulder, 1991; Becker and Blackwell, 1993) (Figure 6). Therefore, persistent magmatic and volcanic events and favorable structural settings might have generated long hydrothermal activities in the area. Admittedly, the area has been reported to have significant deposits of sinter indicating very active hydrothermal activities in the past (Moore and Nielson, 1994). Equilibrium controlling minerals in the reservoir are considered to be quartz, calcite, potassium mordenite, paragonite, and clinochlore-14A (Capuano and Cole, 1982, Faulder, 1991; Becker and Blackwell, 1992; Moore and Nielson, 1994; Palmer et al., 2014).

\subsubsection{Water Chemistry}

Three water samples representing RHS geothermal site were selected from Capuano and Cole (1982) for this study (Table 1). Two of the three water samples were collected from the same hot spring expression but at different times. The remaining one sample represents the water collected from a deep production well [Roosevelt PW 54-3 $(878 \mathrm{~m})$ ] in the area.

RHS geothermal waters are near neutral in $\mathrm{pH}, \mathrm{Na}-\mathrm{Cl}$ type (Figure 3) with TDS level up to 7,000 mg/L (Capuano and Cole, 1982). It has been reported that the geothermal waters throughout the field have consistently similar compositions, although some variation in concentrations of $\mathrm{Ca}, \mathrm{Mg}, \mathrm{HCO}_{3}$, and $\mathrm{SO}_{4}$ are present (Moore and Nielson, 1994). All water samples from RHS geothermal area considered in this study are thermally mature waters that may have interacted with rocks at temperature $220-240^{\circ} \mathrm{C}$ (Figure 4 ). 


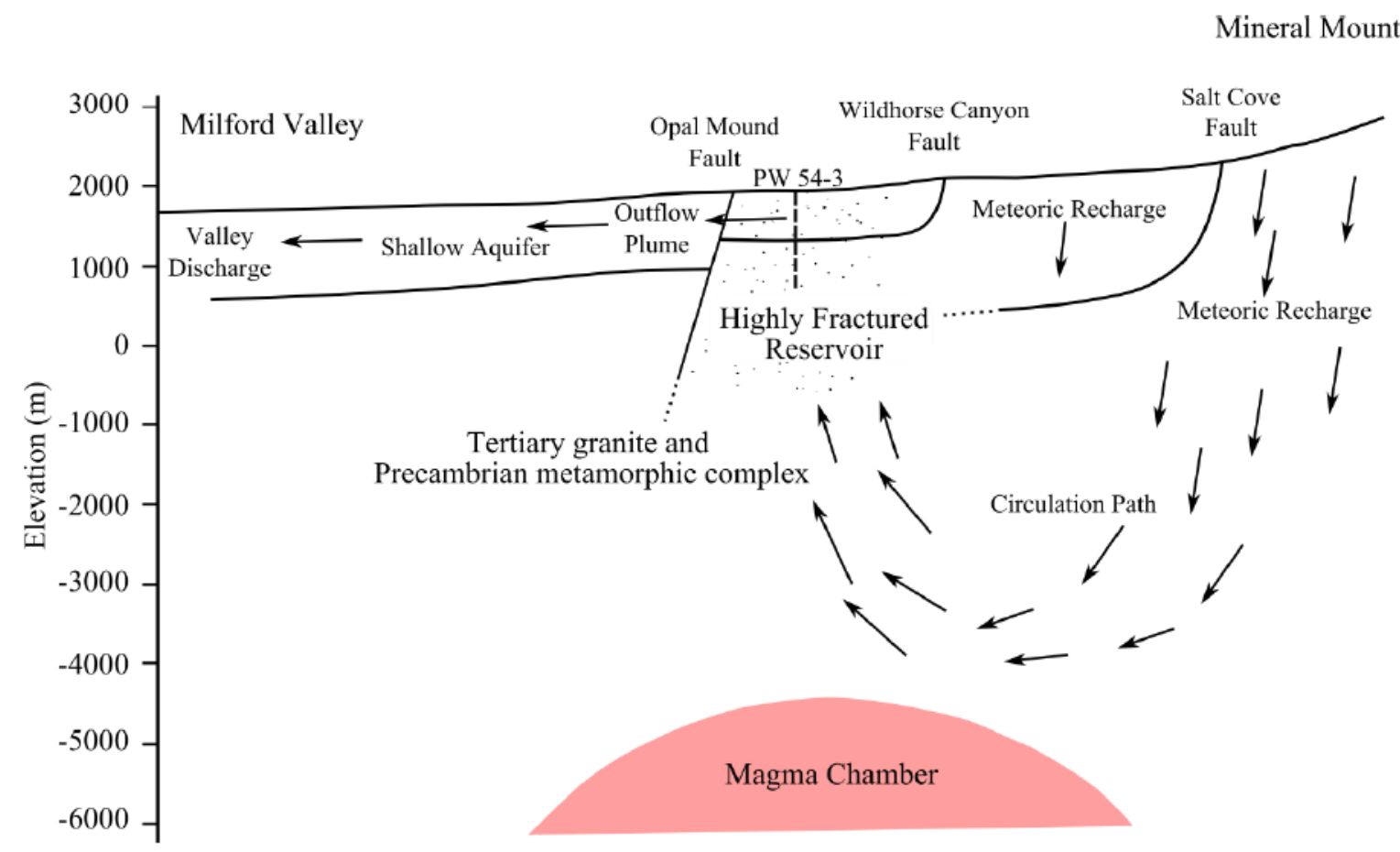

Figure 6. Schematic cross-section of the Roosevelt Hot Springs geothermal area in southwest Utah with approximate location of a well (PW 54-3) used in this study. All hot springs in this area are dried up in early 1960s. Diagram modified after Faulder (1991).

\subsection{STEAMBOAT SPRINGS}

\subsubsection{General}

The Steamboat Springs geothermal area is located about $15 \mathrm{~km}$ south of Reno in Nevada (Figure 1). Numerous hot springs in the area are located near the northeastern end of Steamboat Hills, which lies in a basin between the Carson Range to the West and the Virginia Range to the East (White et al., 1964). Abundant hot springs in the area have drawn attention to this spot as a potential geothermal resource since explorers reached the area in the 1800s (White, 1968). The exploration well was drilled in 1920 by Phillips Petroleum in 1979; however, the geothermal power production in the area began in 1986 (Nehring 1980; Mariner and Janik, 1995). Currently, Ormat Technologies Inc. operates 6 power plants generating 78 MWe at this site.

\subsubsection{Hydrogeological Setting}

The basement rocks in the region are early Mesozoic metamorphosed volcanic and sedimentary rocks intruded by Cretaceous granodiorite related to the Sierra Nevada batholith (Thompson and White, 1964). Tertiary dikes and extrusive volcanic rocks of various compositions are also reported in the Steamboat geothermal area (White et al., 1964). Steep faults trending northeast and north in the basement rocks are responsible for the formation of a series of basins between the Carson Range and the Virginia Range. Locally, three fault systems have been recognized in the area: an east-northeast system striking parallel to the Steamboat Hills; a contemporaneous northwest-striking fault system; and a system of young, north-striking faults termed the Steamboat Springs fault zone (Thompson and White, 1964; White, 1968). Movement on the Steamboat Springs fault zone created three terraces (low, main, and upper) with abundant spring activity (Nehring, 1980). The Main terrace is located at the intersection of north and northwest components of the Steamboat fault zone, and overlies most of the regional geothermal reservoir (Nehring, 1980) (Figure 7). The area is heated by a Cretaceous granodiorite body that intruded into the Mesozoic basement rocks (Nehring, 1980). The fault systems in the area make the conduits that control the hot springs activities.

Bottom-hole temperature measurements in the area range from $235^{\circ} \mathrm{C}$ at the Caithness to $170^{\circ} \mathrm{C}$ at the PW Production well (Figure 8). Mariner and Janik (1995) proposed a generalized flow model to explain this reservoir heterogeneity (Figure 8). The model assumes that all of the thermal water in the region originated from an upflow zone near Caithness. Extensive boiling occurred as water moved laterally, cooling down to $200^{\circ} \mathrm{C}$ and feeding a high- temperature production field. Another upflow zone separates high-temperature wells from the $180^{\circ} \mathrm{C}$, moderate-temperature PW production field. Equilibrium controlling minerals in the reservoir include quartz, calcite, illite, beidellite, and paragonite (Thompson and White, 1964; White et al., 1964; Nehring, 1980, Mariner and Janik, 1995; Palmer et al., 2014). 


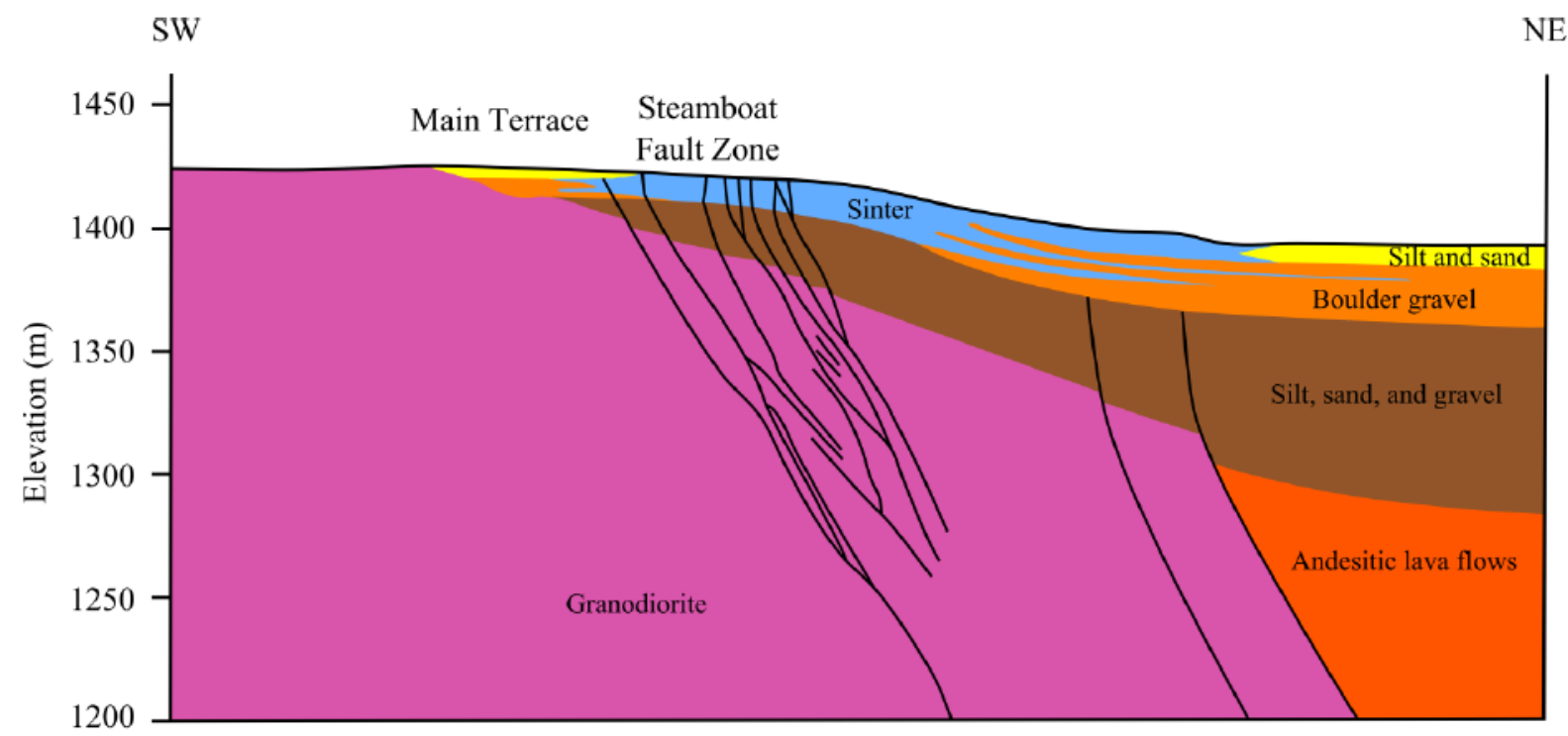

Figure 7. Schematic cross-section of Steamboat Springs geothermal area in Nevada. Steamboat Springs are located in the Main Terrace near fault zone. Diagram modified after White et al., (1964).

SW

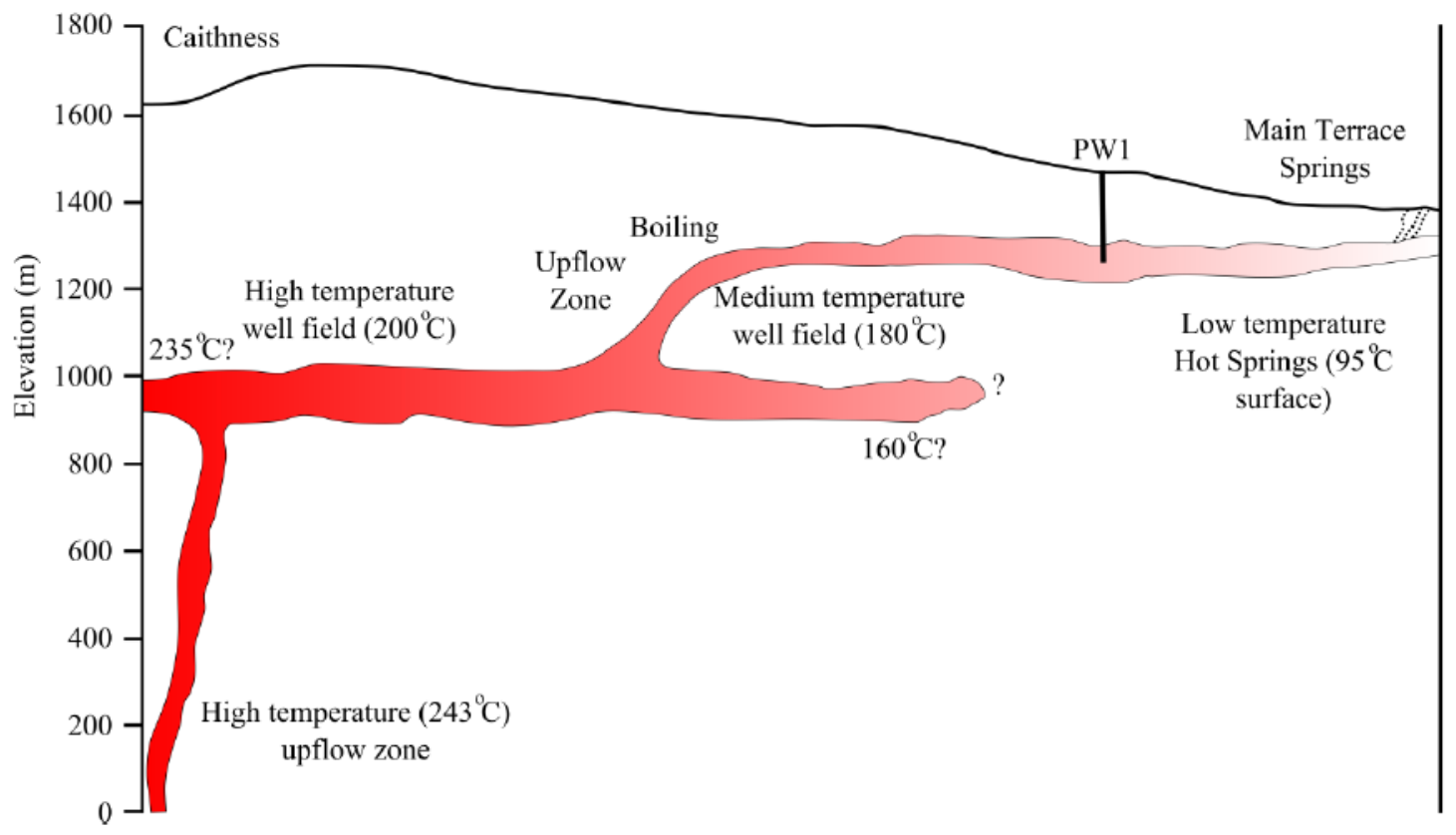

Figure 8. Schematic cross-section shown generalized flow pattern in the Steamboat Spring geothermal area in Nevada. The cross-section is roughly parallel to the Steamboat fault zone. Modified from Mariner and Janik (1995).

\subsubsection{Water Chemistry}

Compositions of five water samples representing Main Terrace Steamboat Springs, two water samples representing Lower Terrace Steamboat Springs (Steamboat HS50 and Steamboat HS26), and a production well [Steamboat PW1 (192 m) (Nehring, 1980; Goranson, 1991; Marinar and Janik, 1995) are given in Table 1. The composition of the production well was also measured from water sample collected prior to the startup of geothermal energy production (Goranson, 1991).

All water samples are near neutral in $\mathrm{pH}$, and are characteristically Na-Cl type waters (Figure 3 ). The TDS level in these water samples ranges from 2000 to $2600 \mathrm{mg} / \mathrm{L}$. The recorded spring temperatures range from 53 to $97{ }^{\circ} \mathrm{C}$. Similalry, the recorded water temperature for the production well is $129^{\circ} \mathrm{C}$. All water samples from Steamboat Springs geothermal area are thermally mature waters that may have interacted with rocks at about $240^{\circ} \mathrm{C}$ (Figure 4). 


\section{RESULTS AND DISCUSSION}

\subsection{Raft River}

For the development of RTEst temperature estimates, an RMA consisting of chalcedony, calcite, clinochlore (chlorite), kaolinite, and potassium mordenite were used. These minerals are selected from the literature review on general lithology and water chemistry of the RRG system (Devine and Bonnichsen, 1980; Dolenc et al., 1981; Blackett and Kolesar, 1983; Jones et al., 2011; Palmer et al., 2014). For the RRG water samples, RTEst modeling using two optimization parameters (temperature and fugacity of $\mathrm{CO}_{2}$ ) appear to be satisfactory as the results with three optimization parameters indicated insignificant mixing or boiling for these waters.

The $\log \left(\mathrm{Q} / \mathrm{K}_{\mathrm{T}}\right)$ curves of these minerals intersect the $\log \left(\mathrm{Q} / \mathrm{K}_{\mathrm{T}}\right)=0$ at different temperatures, ranging from about $60{ }^{\circ} \mathrm{C}(\mathrm{calcite})$ to close to $200^{\circ} \mathrm{C}$ (kaolinite), making the pre-optimized $\log \left(\mathrm{Q} / \mathrm{K}_{\mathrm{T}}\right)$ curves minimally helpful to assess reservoir temperature (Figure $\left.9 \mathrm{a}\right)$. However, chalcedony, clinochlore, and potassium mordenite intersect each other close to the $\log \left(\mathrm{Q} / \mathrm{K}_{\mathrm{T}}\right)=0$ within a short range of temperature $\left(95-120^{\circ} \mathrm{C}\right)$. The presence of such a wide range of equilibration temperature for potential assemblage minerals is a reflection that physical and chemical processes that may have modified the composition of RRG waters prior to sampling. The preoptimized $\log \left(\mathrm{Q} / \mathrm{K}_{\mathrm{T}}\right)$ curves for other two $\mathrm{RRG}$ waters (Frazier and $\mathrm{RRG1}$ ) also show similar trends.

To account for the likely composition altering physical and chemical processes, RTEst was used to optimize the measured water compositions as a function of temperature and fugacity of $\mathrm{CO}_{2}$. The RTEst optimization with three optimization parameters (temperature, fugacity of $\mathrm{CO}_{2}$, and mass of water) for these waters was deemed to be unnecessary because the difference in mass of water appeared to be insignificant. The RTEst optimized $\log \left(\mathrm{Q} / \mathrm{K}_{\mathrm{T}}\right)$ curves for assemblage minerals are shown in Figure $9 \mathrm{~b}$. Compared to the pre-optimized $\log \left(\mathrm{Q} / \mathrm{K}_{\mathrm{T}}\right)$ curves for these minerals, the optimized $\log \left(\mathrm{Q} / \mathrm{K}_{\mathrm{T}}\right)$ curves intersect each other close to $\log \left(\mathrm{Q} / \mathrm{K}_{\mathrm{T}}\right)=0$ within a narrow range of temperature, thereby facilitating estimation of reservoir temperature. For the Crank well, the estimated temperature with standard error is $133 \pm 9{ }^{\circ} \mathrm{C}$. The temperature estimates for Frazier and RRG1 wells are $122 \pm 5{ }^{\circ} \mathrm{C}$ and $135 \pm 4{ }^{\circ} \mathrm{C}$, respectively (Table 2). The bottom-hole temperatures for several RRG deep wells are reported to be in the range from 135 to $149{ }^{\circ} \mathrm{C}$ (Dolenc et al., 1981). The RTEst temperature estimates for Crank and RRG1 wells are within the measured bottom-hole temperatures of the deep RRG wells whereas the estimated temperature for the Frazier appears to be slightly cooler.
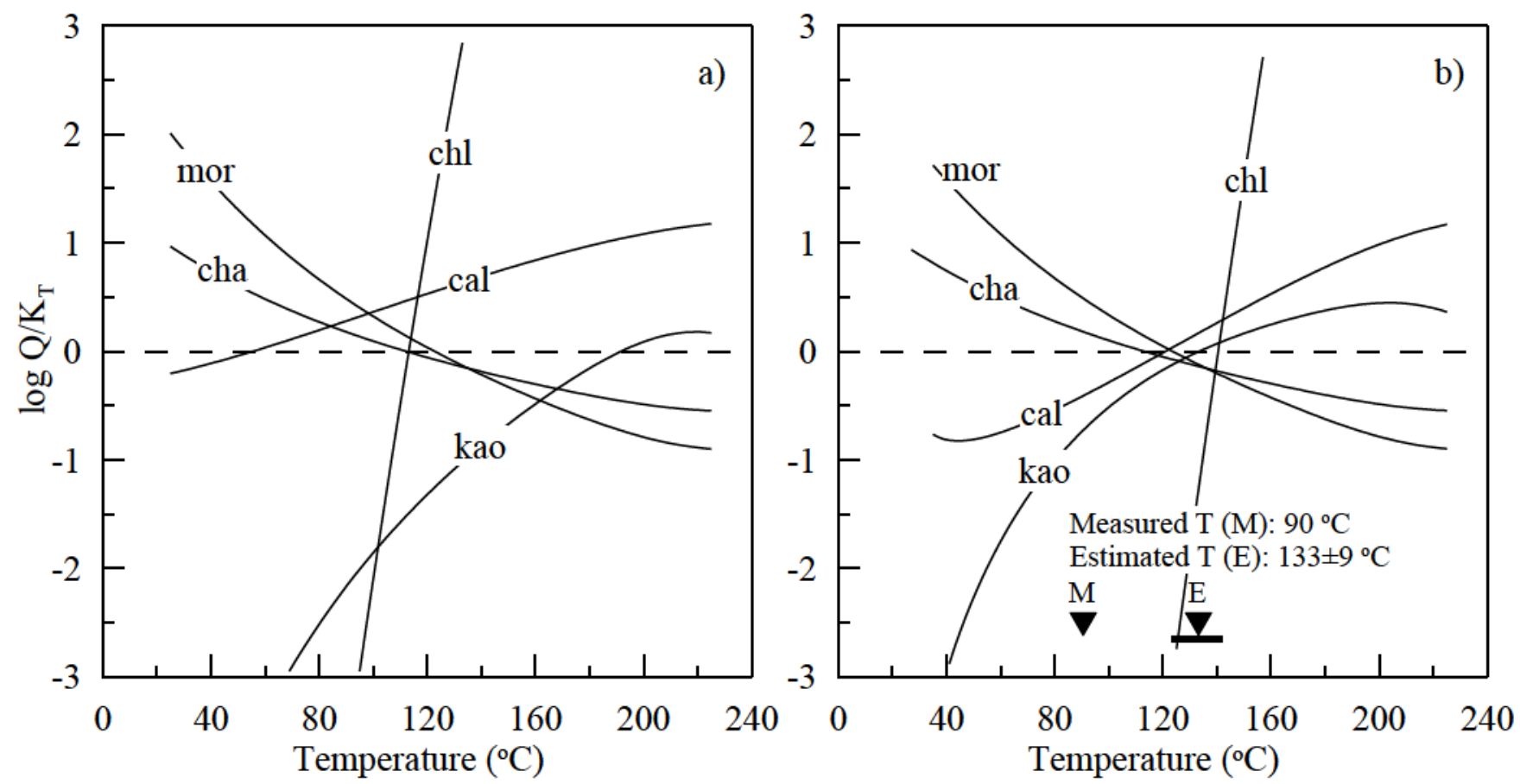

Figure 9. RTEst temperature estimate for Crank well (Raft River Geothermal area) with optimization on $\mathrm{T}_{\text {and }}$ logfCO $\mathrm{O}_{2}$ (a) The $\log \left(\mathrm{Q} / \mathrm{K}_{\mathrm{T}}\right)$ curves for minerals calculated using original water chemistry with $\mathrm{K}$-feldspar used for FixAl, (b) optimized $\log \left(\mathrm{Q} / \mathrm{K}_{\mathrm{T}}\right)$ curves for minerals (minerals -cal: calcite; cha: chalcedony; chl: clinochlore; kal: kaolinite; and mor: mordenite-K). 
Table 2. RTEst modeling results for various water samples representing four geothermal areas.

\begin{tabular}{|l|c|c|c|c|c|c|c|}
\hline Springs/Wells & \multicolumn{2}{|c|}{$\mathrm{RTEst} \mathrm{T} \pm \sigma\left({ }^{\circ} \mathrm{C}\right)$} & \multicolumn{2}{|c|}{$\mathrm{dH}_{2} \mathrm{O} \pm \sigma(\mathrm{kg})^{1}$} & \multicolumn{2}{|c|}{$\log \mathrm{fCO} \mathrm{O}_{2} \pm \sigma$} & \multicolumn{1}{c|}{$\Phi$} \\
\hline Raft River (Frazier) & 122 & 5 & & & -1.51 & 0.13 & $1.90 \mathrm{E}-02$ \\
\hline Raft River (Crank) & 133 & 9 & & & -1.45 & 0.22 & $4.60 \mathrm{E}-02$ \\
\hline Raft River 1 & 135 & 4 & & & -1.3 & 0.09 & $8.30 \mathrm{E}-03$ \\
\hline Neal HS & 151 & 7 & & & -0.29 & 0.13 & $9.27 \mathrm{E}-03$ \\
\hline Neal PW1 & 157 & 4 & & & -0.43 & 0.07 & $3.11 \mathrm{E}-03$ \\
\hline Roosevelt HS50a & 201 & 15 & & & 0.61 & 0.29 & $5.61 \mathrm{E}-02$ \\
\hline Roosevelt HS50b & 268 & 22 & -0.53 & 0.07 & 2.12 & 0.33 & $3.23 \mathrm{E}-04$ \\
\hline Roosevelt HS57a & 218 & 25 & & & 0.61 & 0.56 & $1.77 \mathrm{E}-01$ \\
\hline Roosevelt HS57b & 245 & 10 & -0.57 & 0.05 & 2.03 & 0.26 & $2.73 \mathrm{E}-04$ \\
\hline Roosevelt PW (54-3) & 235 & 10 & & & 0.77 & 0.18 & $1.63 \mathrm{E}-02$ \\
\hline Steamboat HS23 & 216 & 5 & & & 0.90 & 0.08 & $5.05 \mathrm{E}-03$ \\
\hline Steamboat 21N & 213 & 4 & & & 0.79 & 0.06 & $3.23 \mathrm{E}-03$ \\
\hline Steamboat N27 & 212 & 2 & & & 0.31 & 0.04 & $1.38 \mathrm{E}-03$ \\
\hline Steamboat HS6 & 195 & 3 & & & 0.42 & 0.05 & $2.70 \mathrm{E}-03$ \\
\hline Steamboat HS4 & 197 & 2 & & & 0.33 & 0.05 & $1.71 \mathrm{E}-03$ \\
\hline Steamboat HS50a & 175 & 4 & & & -0.06 & 0.07 & $5.82 \mathrm{E}-03$ \\
\hline Steamboat HS50b & 158 & 1 & 0.44 & 0.04 & -0.71 & 0.05 & $7.97 \mathrm{E}-05$ \\
\hline Steamboat HS26a & 192 & 8 & & & 0.80 & 0.12 & $1.49 \mathrm{E}-02$ \\
\hline Steamboat HS26b & 163 & 4 & 0.81 & 0.15 & -0.27 & 0.15 & $5.71 \mathrm{E}-04$ \\
\hline Steamboat PW1 & 227 & 2 & & & 0.25 & 0.03 & $5.98 \mathrm{E}-04$ \\
\hline
\end{tabular}

The negative and positive numbers for $\mathrm{dH}_{2} \mathrm{O}$ indicate the potential amount of cooler water present in and steam lost water per kilogram of sampled water due to mixing and boiling, respectively.

\subsection{Neal Hot Springs}

An RMA consisting of chalcedony, calcite, potassium mordenite, sodium saponite, and magnesium beidellite was selected by reviewing lithology and water types of the area (Edwards, 2013; Palmer et al., 2014) for the development of temperature estimates. The RTEst modeling results of NHS samples are given in (Table 2).
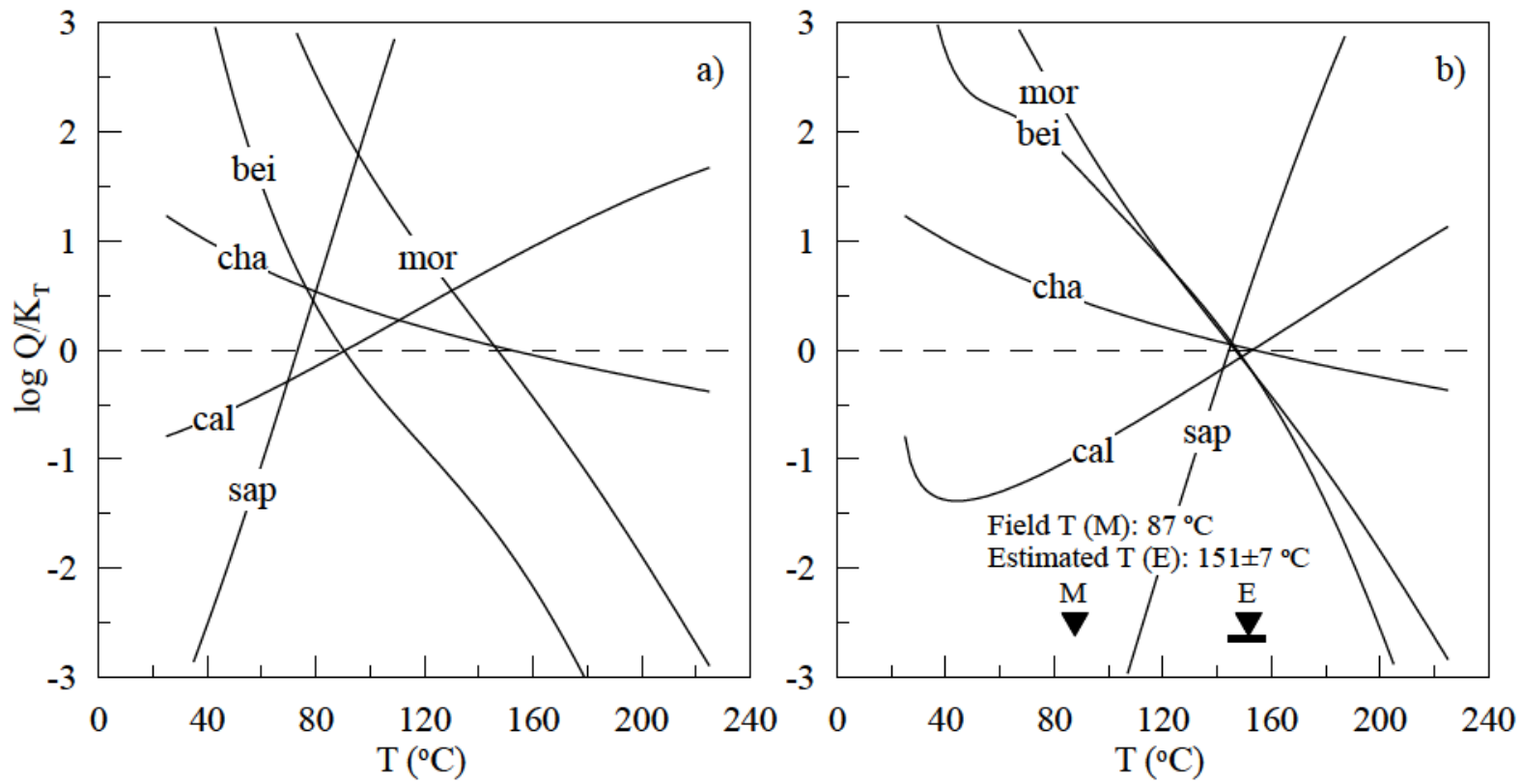

Figure 10. RTEst temperature estimate for Neal Hot Spring with optimization on $T$ and $\operatorname{logfCO} \mathrm{O}_{2}$. (a) $\mathrm{The} \log \left(\mathrm{Q} / \mathrm{K}_{\mathrm{T}}\right)$ curves for minerals calculated using original water chemistry, (b) optimized $\log \left(\mathrm{Q} / \mathrm{K}_{\mathrm{T}}\right)$ curves for assemblage minerals (bei: Beidellite-Mg; cal: calcite; cha: chalcedony; mor: mordenite-K sap: saponite-Na). 
RTEst modeling of water composition for the Neal Hot Spring resulted in an estimated temperature of $151 \pm 7^{\circ} \mathrm{C}$ (Figure 10 ). Similarly, RTEst temperature estimates for the Neal PW1 is $157 \pm 4^{\circ} \mathrm{C}$ (Table 2). The similar water compositions and temperature estimates for these two sources indicate that these two waters may have originated from the same source. Furthermore, the estimated temperatures for these two waters are similar to that of bottom-hole temperatures (135-145 $\left.{ }^{\circ} \mathrm{C}\right)$ reported for several production wells in NHS geothermal area.

\subsection{Roosevelt Hot Springs}

A mineral assemblage consisting of quartz, calcite, potassium mordenite, paragonite, and clinochlore-14A was selected for RTEst modeling after reviewing published literatures on parent rocks, water chemistry, and hydrothermal alteration products in the area (Capuano and Cole, 1982, Faulder, 1991; Becker and Blackwell, 1992; Moore and Nielson, 1994; Palmer et al., 2014). The RTEst modeling results of RHS samples are given in (Table 2). For both RHS geothermal area hot springs, RTEst optimizations using two- and three-parameters are presented.

Three-parameter ( $\mathrm{T}$, mass of water, and fugacity of $\mathrm{CO}_{2}$ ) optimization results for the Roosevelt HS50 are illustrated in Figure 11. The estimated temperature for this sample is $265 \pm 22^{\circ} \mathrm{C}$. Similarly, temperature estimates for the other water sample (Roosevelt HS 57), the estimated temperature is $245 \pm 10^{\circ} \mathrm{C}$. For RHS waters (Roosevelt HS50 and Roosevelt HS57), it is important to note that the temperature estimates with modeling with three-parameter optimization are close to the reported bottom-hole temperatures (up to $271^{\circ} \mathrm{C}$ ) for several deep wells in RHS geothermal area.

Ideally, use of local groundwater seems desirable to account for mixing. However, the use of local groundwater can often leads to physically meaningless results such as negative concentrations for some species (e.g., Mg, Al, etc.). Previously, Hull et al. (1987) have used pure water to account for the mixing in the San Bernandino Valley region in California. They found that the use of local groundwater did not produce acceptable results for this system and postulated that either the mixing water is different than the local groundwater (some water of unknown composition) or some geochemical reactions may have been responsible for selective precipitation and/or cation exchange of some elements (e.g., Mg, Al, Ca, etc.) after mixing. Similarly, our effort to use local groundwater at numerous geothermal sites in the Snake River Plain in Idaho also resulted in poor results although this is still being explored.
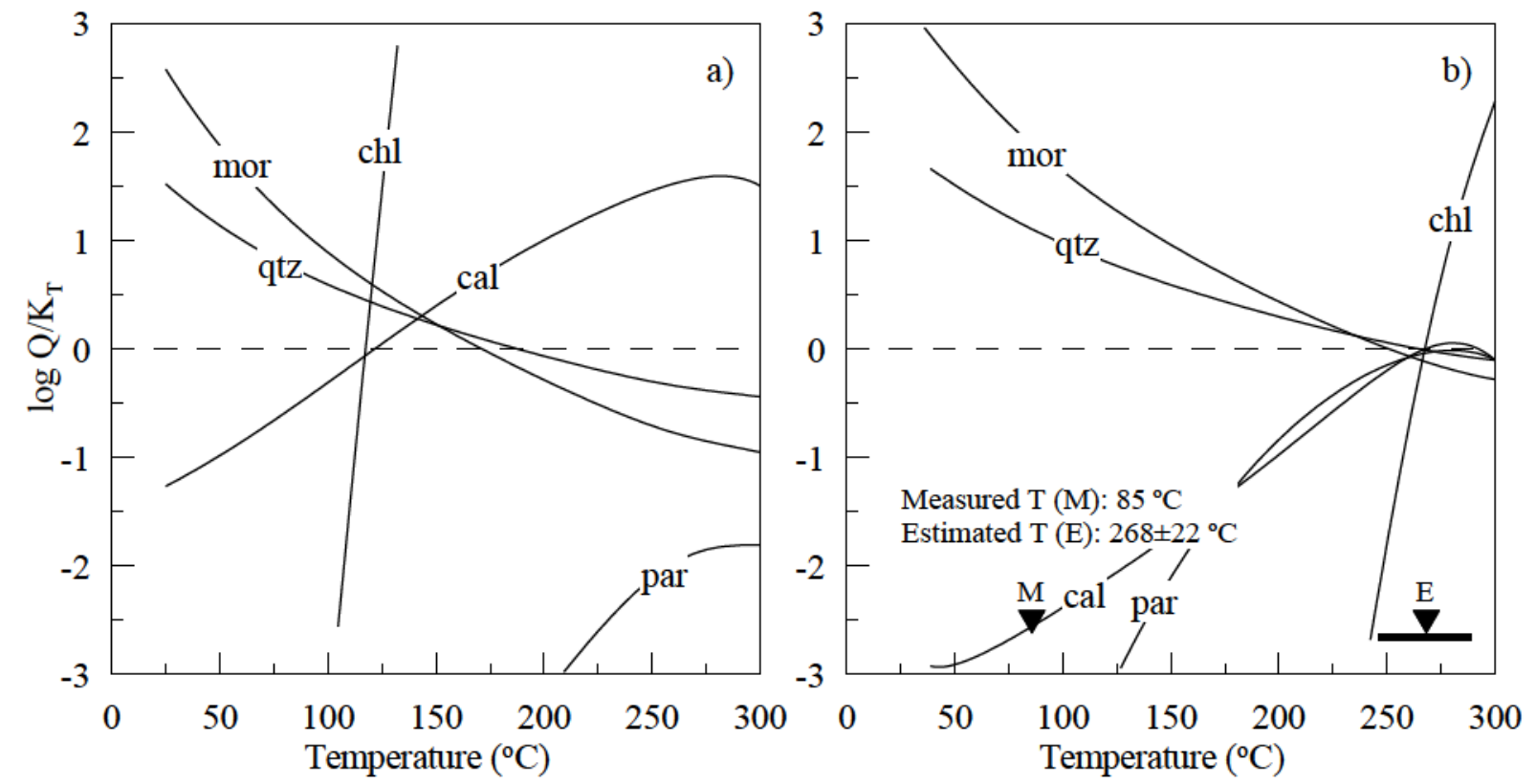

Figure 11. RTEst temperature estimate for Roosevelt $\mathrm{HS50}$ with optimization on T, mass of water, and $\operatorname{logfCO}$. (a) The log $\left(Q / K_{T}\right)$ curves for minerals calculated using original water chemistry, (b) optimized $\log \left(Q / K_{T}\right)$ curves for assemblage minerals (cal: calcite; chl: clinochlore; mor: mordenite-K, par: paragonite, and qtz: quartz).

For Roosevelt HS50 and Roosevelt HS57, the temperature estimates with two-parameter optimization are cooler than the temperature estimates with three-parameter optimization (Table 2). The value of objective function of the RTEst modeling with three-parameter optimization for these two samples are two to three orders of magnitude less than the values of objective function with two-parameter optimizations. The results of three-parameter optimizations indicate that these two water samples (Roosevelt HS50 and Roosevelt HS57 in (Table 2) may have undergone two-fold dilution by mixing, or they may have lost some proportions of chemical components due to precipitation. Moore and Nielson (1994) have reported extensive sinter deposits in the area as an indication of precipitation of minerals from the hot springs water. Whichever process was active prior to sampling, the net effect of that would results in a cooler temperature if that process is not accounted for. At present, RTEst is not built to account for potential precipitation of minerals along the flow path. 
However, it can be implemented by using mass of water as an optimization parameter. On the other hand, results of the production well (Roosevelt PW 54-3), indicate insignificant mixing (Table 2). In fact, the three-parameter optimization of Roosevelt PW 54-3 water sample indicated about $10 \%$ mixing (results not presented) which is very similar with the mixing results provided by Capuano and Cole (1982).

Another difference between two- versus three-parameter optimizations for Roosevelt HS50 and Roosevelt HS57 waters is significantly larger estimated $\mathrm{CO}_{2}$ fugacity of $\mathrm{CO}_{2}$ for the three-parameter optimizations. The estimated $\mathrm{CO}_{2}$ fugacity translates to a $\mathrm{CO}_{2}$ partial pressure in excess of 130 bars (total pressure $>183$ bars) for the reservoir requiring a minimum of $1800 \mathrm{~m}$ of hydrostatic head. The significance of the estimated fugacity of $\mathrm{CO}_{2}$ with the three-parameter optimization in this case may have been obscured because of the strong negative correlation between estimated mass of water and fugacity of $\mathrm{CO}_{2}\left(\mathrm{R}^{2}>0.96\right)$. However, considering the magmatic heat source, presumed depth of circulation paths, and active reservoir in the area (Figure 6), it is plausible to have that level of $\mathrm{CO}_{2}$ partial pressure in the system.

The temperature estimate from the first sample (Roosevelt HS50) is relatively hotter than the estimate from the second (Roosevelt HS57) sample. These two samples were taken seven years apart; the first in 1950 and the second in 1957. Although seven years is quite short in a geologic time-scale, hot springs can change significantly over the course of seven years. In fact, the hot springs in RHS geothermal area have not discharged since 1962 (Petersen, 1975). Thus, the hot spring was in a consistent period of decline from 1950 to 1957 , and probably, they were doing so long before 1950. One hypothesis on the decline of hot spring activity in RHS geothermal area suggests that the connection between the hot spring and the reservoir was sealed by deposition of solids such as silica (Petersen, 1975). This hypothesis is supported by the chemical analyses of the two samples; silica decreases almost by $23 \%$ (from 189 to $146 \mathrm{mg} / \mathrm{L}$ ppm) from 1950 to 1957 (Table 1). Furthermore, the apparent dilution appeared in the RTEst results of hot spring waters (Roosevelt HS50 and Roosevelt HS57) may have been related to the precipitation of some silica or silicate phases.

\subsection{Steamboat Springs}

A mineral assemblage consisting of quartz, calcite, illite, magnesium beidellite, and paragonite was selected after reviewing the geologic literatures in the area (e.g., Thompson and White, 1964; White et al., 1964; Nehring, 1980, Mariner and Janik, 1995) for the development temperature estimates. Figure 12 shows the pre-optimized and RTEst optimized (optimization parameters are temperature and fugacity of $\left.\mathrm{CO}_{2}\right) \log \left(\mathrm{Q} / \mathrm{K}_{\mathrm{T}}\right)$ curves of the assemblage minerals for a Main Terrace hot spring (Steamboat HS23). The estimated reservoir temperaturebased on water composition from this spring is $216 \pm 5^{\circ} \mathrm{C}$. For all other Steamboat Springs geothermal area water samples, RTEst results are presented in Table 2.

RTEst modeling of the Main Terrace hot springs generally resulted in a temperature around $200^{\circ} \mathrm{C}$ (Table 2). Similarly, RTEst modeling (using temperature and fugacity of $\mathrm{CO}_{2}$ as optimization parameters) of the Lower Terrace hot springs resulted in temperature $\geq 175{ }^{\circ} \mathrm{C}$; however, for these springs, RTEst modeling using three-optimization parameters (temperature, fugacity of $\mathrm{CO}_{2}$ and mass of water) show significant boiling but lower reservoir temperature $\left(158-163{ }^{\circ} \mathrm{C}\right)$. For the production well (Steamboat PW1 in Table 2), the estimated temperature is $227 \pm 2{ }^{\circ} \mathrm{C}$.
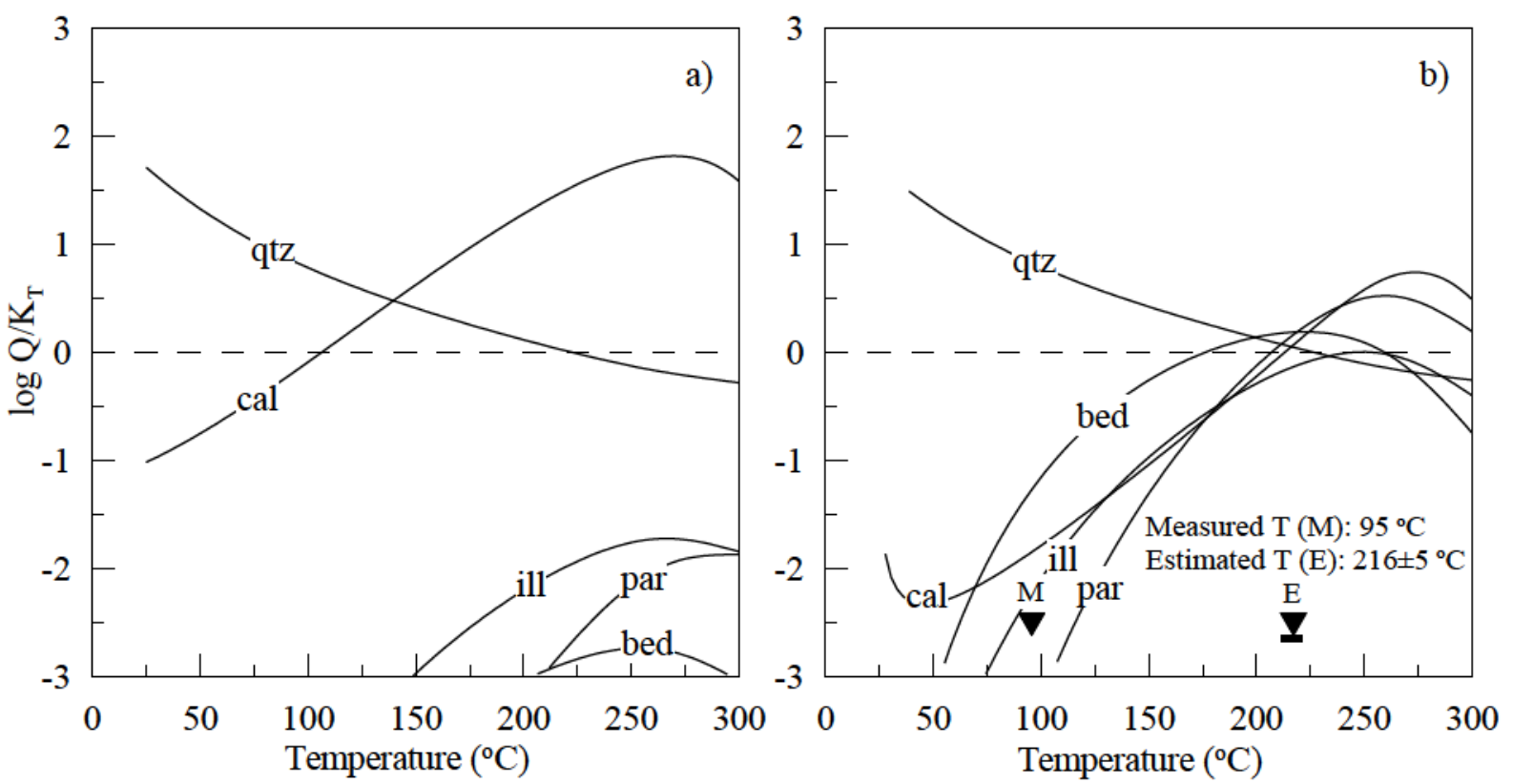

Figure 12. RTEst temperature estimate for Steamboat Hot Spring -23 with optimization on $T$ and $\operatorname{logfCO}$. (a) $\mathrm{The}_{\mathrm{log}}\left(\mathrm{Q} / \mathrm{K}_{\mathrm{T}}\right)$ curves for minerals calculated using original water chemistry, (b) optimized $\log \left(\mathrm{Q} / \mathrm{K}_{\mathrm{T}}\right)$ curves for assemblage minerals (cal: calcite; bed: beidellite-Mg, chl: ill: illite, par: paragonite, and qtz: quartz). 
In general, RTEst is able to trace the source of geothermal fluid to the high-temperature geothermal field using hot spring water compositions. Temperature estimates from the Steamboat hot springs are cooler than the recorded temperature at the primary resource location (below Caithness in Figure 8). However, temperature estimate using the production well is very close to the primary resource temperature. These results may suggest a degree of re-equilibration at lower temperature along the flow path (conduit) between the hotter area near Caithness and locations of hot springs. However, there may be a second conduit that is serving as source water to the Main Terrace and Lower Terrace hot springs.

\section{SUMMARY AND CONCLUSIONS}

The recently developed MEG tool RTEst was used with geochemistry data from hot springs and wells to estimate reservoir temperatures in four geothermal areas. These reservoir temperatures were compared with measured bottom-hole temperatures of production wells to assess accuracy of the estimates (Figure 13). RTEst generally predicted temperature for these geothermal sites within (or near) the range or of production temperatures (Figure 13 and Table 3 ).

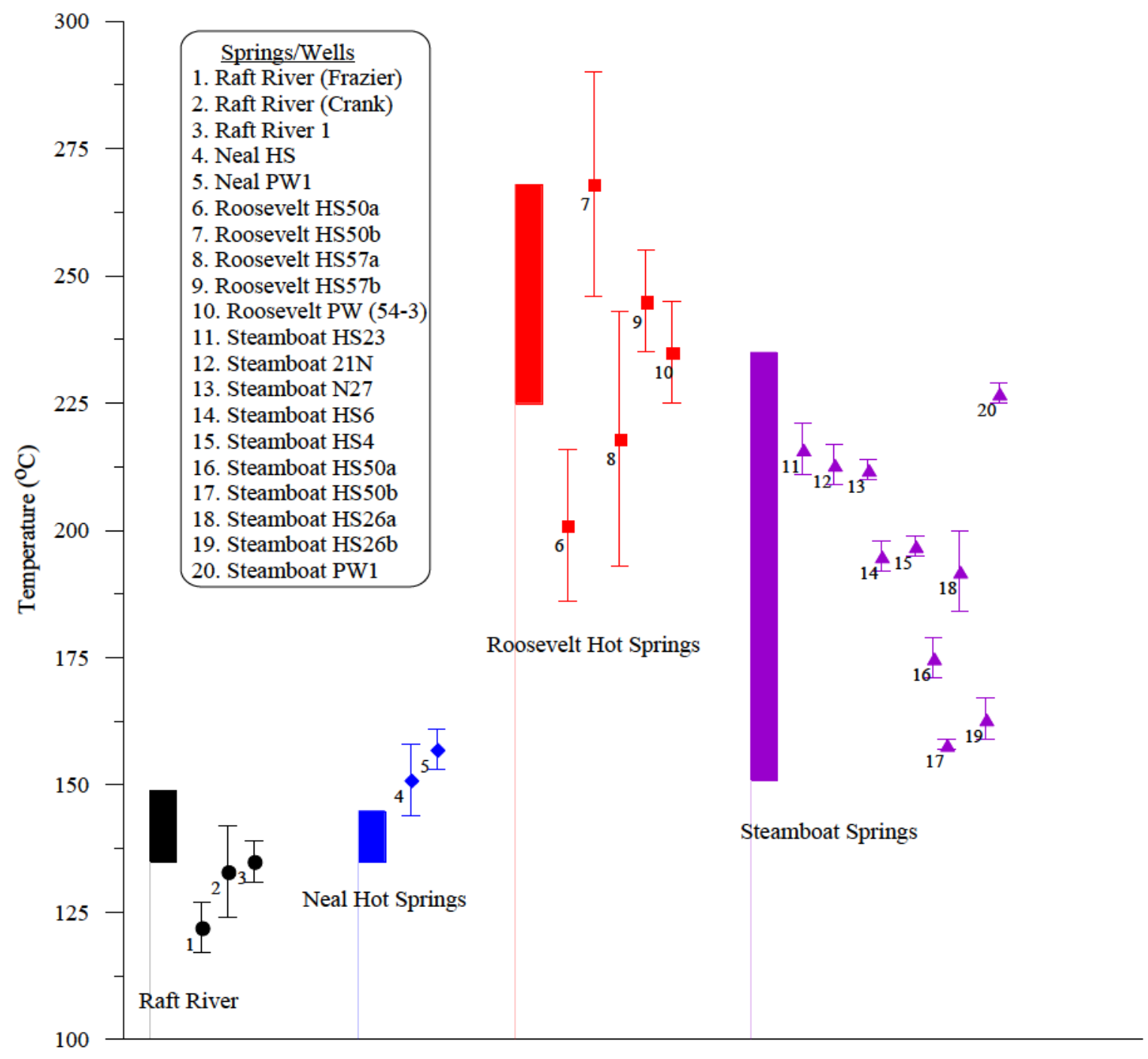

Figure 13. Comparison of bottom-hole temperatures measured in producing boreholes and RTEst estimated temperatures for hot springs and shallow wells in four geothermal fields. Vertical solid bars represent the range of measured bottom-hole temperatures. Bottom-hole temperatures are obtained from Dolenc et al. (1981) for Raft River; US Geothermal Inc., personnel communication (2014) for Neal Hot Springs; Capuano and Cole (1982) for Roosevelt Hot Springs; Marinar and Janik (1995) for Steamboat Springs. Error bars in estimated temperature data points represent $\pm 1 \sigma$ (standard error).

These four geothermal sites are varied in heat source, reservoir temperatures, reservoir lithology and mineralogy (Table 3), and structural complexity. Although waters from these systems are near-neutral in $\mathrm{pH}$ and are of dominantly $\mathrm{Na}-\mathrm{Cl}$ type (Table 3), their total 
dissolved solid contents vary as do some ions. For example, Raft River waters have comparatively lower concentrations of bicarbonate compared to other three sites. Similarly, Neal Hot Springs waters are $\mathrm{Na}-\mathrm{Cl}-\mathrm{SO}_{4}-\mathrm{HCO}_{3}$ type with higher relative amount of $\mathrm{SO} \mathrm{O}_{4}$ and $\mathrm{HCO}_{3}$ compared to other three sites. Thermal water in these sites may have differently evolved from the reservoir to shallow sampling points. For example, Steamboat Springs reportedly has a long permeable zone through which the hot water boils and cools as it moves along before issuing as hot springs (Mariner and Janik, 1995) (Figure 8). Similarly, Roosevelt Hot Springs area has thick deposition of sinter (Moore and Nielson, 1994) but such deposits are not reported in Raft River (Dolenc et al., 1981).

Estimates from Neal Hot Springs closely matched production temperatures (Table 3). This system is by far the least complex of the four sites studied, as fluid circulates up along one main fault and reservoir temperature is also fairly homogeneous. For the Raft River site, fluid circulates several chemically distinct pathways (Ayling and Moore, 2013). Geothermometry calculations of reservoir temperatures using shallow well data predicted slightly cooler reservoir temperature. The cooler temperatures for the shallow Raft River wells may reflect the compartmentalized geothermal system in the area, and it is likely that these wells may not receive fluid from the producing reservoir. Reservoir heterogeneity also exists in Steamboat Springs geothermal area, where geothermal fluid undergoes cooling as it traverses the reservoir (Mariner and Janik, 1995) (Figure 8). Geothermometry from surface hot springs, in general, indicated a reservoir with temperature around $200{ }^{\circ} \mathrm{C}$. The highest estimated reservoir temperature from hot spring water composition is $216 \pm 5{ }^{\circ} \mathrm{C}$ which is slightly cooler than the hottest bottom-hole temperature $\left(235^{\circ} \mathrm{C}\right)$ measured at the primary upflow zone (Mariner and Janik, 1995). The hot spring sample collected in 1950 from Roosevelt Hot Springs predicted a reservoir temperature similar (when mixing scheme of the RTEst is applied) to the highest recorded temperature within the explored part of the reservoir temperature (Figure 13). However, the predicted reservoir temperature from the same hot spring seven years later produced a slightly lower temperature for the reservoir. The lower temperature estimate may be a result of a decline in hot spring activity and ensuing precipitation of silica (Petersen, 1975).

Table 3. Lithology, water type, and estimated temperatures for four geothermal sites

\begin{tabular}{|l|l|l|l|l|l|}
\hline \multicolumn{1}{|c|}{ Site } & \multicolumn{1}{|c|}{ Lithology } & \multicolumn{1}{c|}{ Water Type } & \multicolumn{1}{c|}{ Mineral Assemblage } & \multicolumn{1}{c|}{ BHT $^{\mathrm{a}}$} & RTEst T $^{\mathrm{a}}$ \\
\hline Raft River & $\begin{array}{l}\text { Silicic: metamorphosed quartz } \\
\text { monzonite, schist, quartzite, volcanics }\end{array}$ & $\begin{array}{l}\text { Near neutral, } \\
\text { Na-Cl type }\end{array}$ & $\begin{array}{l}\text { Calcite, chalcedony, clinochlore-14A, } \\
\text { kaolinite, K-feldspar, mordenite-K }\end{array}$ & $135-149$ & $122-133$ \\
\hline $\begin{array}{l}\text { Neal Hot } \\
\text { Springs }\end{array}$ & $\begin{array}{l}\text { Tholeiitic: basaltic lavas, silicic } \\
\text { volcanics, lacustrine sediments }\end{array}$ & $\begin{array}{l}\text { Near neutral, } \\
\text { Na-Cl-SO } 4^{-} \\
\mathrm{HCO}_{3} \text { type }\end{array}$ & $\begin{array}{l}\text { Calcite, chalcedony, mordenite-K, } \\
\text { saponite-Na, and Beidellite-Mg }\end{array}$ & $135-145$ & 151 \\
\hline $\begin{array}{l}\text { Roosevelt } \\
\text { Hot Springs }\end{array}$ & $\begin{array}{l}\text { Silicic: quartz monzonite, } \\
\text { sedimentary rocks }\end{array}$ & $\begin{array}{l}\text { Near neutral, } \\
\text { Na-Cl type }\end{array}$ & $\begin{array}{l}\text { Calcite, clinochlore-14A, K-feldspar, } \\
\text { mordenite-K, paragonite, and quartz }\end{array}$ & $225-268$ & $201-268$ \\
\hline $\begin{array}{l}\text { Steamboat } \\
\text { Springs }\end{array}$ & $\begin{array}{l}\text { Silicic: metamorphosed vocanics and } \\
\text { sedimentary rocks, granodiorite }\end{array}$ & $\begin{array}{l}\text { Near neutral, } \\
\text { Na-Cl }\end{array}$ & $\begin{array}{l}\text { Calcite, beidellite-Mg, illite, K- } \\
\text { feldspar, paragonite, and quartz }\end{array}$ & $151-235$ & $158-216$ \\
\hline
\end{tabular}

${ }^{a}$ Bottom-hole temperature (in ${ }^{\circ} \mathrm{C}$ ) range of the production wells. ${ }^{b}$ Given RTEst temperature range (in ${ }^{\circ} \mathrm{C}$ ) only includes temperature estimates based on hot springs and shallow wells.

Finally, it is noteworthy to state that geothermal reservoirs are often heterogeneous. If the flow path of water used for the RTEst modeling does not pass through the hottest region of the reservoir, estimated temperatures are likely to be lower than the reservoir maximum temperature. Furthermore, in a compartmentalized system such as Raft River, application of geothermometry can even be more challenging because of uncertainty that whether the well fluid sampled is from the hottest geothermal reservoir or from a secondary reservoir with lower temperature. Despite these difficulties, MEG approach implemented in RTEst can be an effective geochemical exploration tool when used in conjunction with geological, geophysical, and hydrological studies for the comprehensive assessment of the geothermal potential of an area.

\section{ACKNOWLEDGEMENTS}

Funding for this research was provided by the U.S. Department of Energy, Office of Energy Efficiency \& Renewable Energy, Geothermal Technologies Program. A part of this study was also supported through the U.S. Department of Energy, Office of Science, Office of Workforce Development for Teachers and Scientists (WDTS) under the Science Undergraduate Laboratory Internship (SULI) program. We would also like to acknowledge Ian Warren of US Geothermal Inc. for providing information on Neal Hot Springs.

\section{REFERENCES}

Arnórsson, S., Bjarnasson, J.Ö., Giroud, N., Gunnarsson, I., Stefánsson, A.:. Sampling and analysis of geothermal fluids. Geofluids, 6, (2006), 203-216.

Ayling, B. and Moore, J.: Fluid geochemistry at the Raft River geothermal field, Idaho, USA: New data and hydrogeological implications. Geothermics, 47, (2013), 116-126.

Becker, D. J. and Blackwell, D. D.: A Hydrothermal Model of the Roosevelt Hot Springs Area, Utah, USA. PROCEEDINGS, 15th New Zealand Geothermal Workshop, Vol. 15, 247-252, (1993).

Blackett, R.E. and Kolesar, P.T.: Geology and alteration of the Raft river geothermal system, Idaho, GRC Transactions, 7 (1983), 123127. 
Neupane et al.

Capuano, R. M. and Cole, D. R.: Fluid-mineral equilibria in a hydrothermal system, Roosevelt Hot Springs, Utah. Geochimica et Cosmochimica Acta, 46(8), (1982), 1353-1364.

CGISS: Geology NHS2011. Center for Geophysical Investigation of the Shallow Surface, Boise State University, Boise, Idaho, (2011).

Colwell, C.R .: Integrated Geophysical Exploration of a Known Geothermal Resource: Neal Hot Springs. Masters' Thesis, Boise State University, Boise, Idaho, (2013).

Cooper, D.C., Palmer, C.D., Smith, R.W., and McLing, T.L.: Multicomponent equilibrium models for testing geothermometry approaches. PROCEEDINGS, 38th Workshop on Geothermal Reservoir Engineering Stanford University, Stanford, CA, (2013).

Devine, S.C. and Bonnichsen, B.: Petrography of Drill Cores from the Raft River Geothermal Area, Southern Idaho. Technical Report 80-10, Idaho Geological Survey, (1980).

Dolenc, M.W., Hull, L.C., Mizell, S.A., Russell, B.F., Skiba, P.A., Strawn, J.A., and Tullis, J.A.: Raft River geoscience case study, EG\&G Report Number 2125, Vol. 1, (1981), 145 pp.

Edwards, J.H.: Structural Controls of the Neal Hot Springs Geothermal System, Eastern Oregon. Masters' Thesis, University of Nevada, Reno, Nevada, (2013).

Faulder, D.D.: Conceptual geologic model and native state model of the Roosevelt Hot Springs hydrothermal system. PROCEEDINGS, Sixteenth Workshop on Geothermal Reservoir Engineering, Stanford University, Stanford, California, January 23-25, 1991, SGPTR-134, (1991).

Fournier, R.O., White, D.E., and Truesdell, A.H.: Geochemical indicators of subsurface temperature - 1, Basic assumptions. U.S. Journal of Research of the US Geological Survey, 2, (1974), 259-262.

Giggenbach, W.F.: Geothermal solute equilibria. Derivation of Na-K-Mg-Ca geoindicators. Geochimica et Cosmochimica Acta, 52, (1988), 2749-2765.

Goranson, C.: Summary and interpretation of six years of groundwater monitoring data and four years of geothermal production and injection well operations at the SB GEO, Inc. geothermal binary power plant, Steamboat Springs, Nevada. Report Document I \& II, SB GEO, Inc., (1991).

Hull, C.D., Reed, M.H., and Fisher, K.: Chemical geothermometry and numerical unmixing of the diluted geothermal waters of the San Bernardino Valley Region of Southern California. GRC Transactions, 11, (1987), 165-184.

Jones, C., Moore, J., Teplow, W., and Craig, S.: Geology and hydrothermal alteration of the Raft River geothermal system, Idaho. PROCEEDINGS, Thirty-Sixth Workshop on Geothermal Reservoir Engineering, Stanford University, Stanford, California, January 31 - February 2, 2011, SGP-TR-191, (2011).

Mariner, R.H. and Janik, C.J.: Geochemical data and conceptual model for the Steamboat Hills geothermal system, Washoe County, Nevada, GRC Transactions, 19, (1995), 191-200.

Mariner, R.H., Swanson, J.R., Orris, G.J., Presser, T.S., and Evans, W.C.: Chemical and isotopic data for water from thermal springs and wells of Oregon, USGS Open-File Report 80-737, US Geological Survey, (1980).

Moore, J.N. and Nielson, D.L.: An overview of the geology and geochemistry of the Roosevelt Hot Springs Geothermal System, Utah. Utah Geological Association Publication, 23, (1994), 25-36.

Nehring, N.L.: Geochemistry of Steamboat Springs, Nevada. USGS Open-File Report 80-887, US Geological Survey, (1980).

Neupane, G., Mattson, E.D., McLing, T.L., Palmer, C.D., Smith, R.W., and Wood, T.R.: Deep geothermal reservoir temperatures in the Eastern Snake River Plain, Idaho using multicomponent geothermometry. PROCEEDINGS, Thirty-Ninth Workshop on Geothermal Reservoir Engineering, Stanford University, Stanford, California, February 24-26, 2014 SGP-TR-202, (2014).

Neupane, G., Mattson, E.D., McLing, T.L., Palmer, C.D., Smith, R.W., Wood, T.R., and Podgorney, R.K.: Geothermal reservoir temperatures in southeastern Idaho using multicomponent geothermometry. PROCEEDINGS, World Geothermal Congress 2015, Melbourne, Australia, 19-25 April 2015, (2015).

Palmer, C.D., Ohly, S.R., Smith, R.W., Neupane, G., McLing, T., Mattson, E.: Mineral selection for multicomponent equilibrium geothermometry. GRC Transactions, 38, (2014), 453-459.

Palandri, J.L. and Reed, M.H. (2001). Reconstruction of in situ composition of sedimentary formation waters. Geochimica et Cosmochimica Acta, 65, 1741-1767.

Pang, Z.H. and Reed, M.: Theoretical chemical thermometry on geothermal waters: Problems and methods. Geochimica et Cosmochimica Acta, 62, (1998), 1083-1091.

Petersen, C.A.: Geology and Geothermal Potential of the Roosevelt Hot Springs Area, Beaver County, Utah, (1975), Doctoral dissertation, University of Utah, Salt Lake City, Utah.

Reed, M. and Spycher, N.: Calculation of $\mathrm{pH}$ and mineral equilibria in hydrothermal waters with application to geothermometry and studies of boiling and dilution. Geochimica et Cosmochimica Acta, 48, (1984), 1479-1492. 
Speer, B.: Geothermal Brief: Market and Policy Impacts Update. NREL/TP-6A20-53288, Golden, CO, National Renewable Energy Laboratory, (2012).

Thompson, G.A. and White, D.E.: Regional geology of the Steamboat Springs area, Washoe County, Nevada. Geological Syrvey Professional Paper 458-A, US Geological Survey, (1964)

White, D.E.: Hydrology, activity, and heat flow of the Steamboat Springs thermal system, Washoe County, Nevada. Geological Syrvey Professional Paper 458-C, US Geological Survey, (1968).

White, D.E., Thompson, G.A., and Sandberg, C.H.: Rocks, structure, and geologic history of Steamboat Springs thermal area, Washoe County, Nevada. Geological Syrvey Professional Paper 458-B, US Geological Survey, (1964).

Williams, C.F., Reed, M.J., Mariner, R.H., DeAngelo, J., and Galanis, S.P. Jr.: Assessment of moderate- and high-temperature geothermal resources of the United States. US Department of the Interior, US Geological Survey, Fact Sheet 2008-3082, (2008). 
Appendix O.

\section{$\underline{\text { SAO/NASA ADS }} \underline{\text { Physics Abstract Service }}$}

- Find Similar Abstracts (with default settings below)

- $\underline{\text { Reads History }}$

- Translate This Page

Title:

Approaches for Multicomponent Equilibrium Geothermometry as a Tool for Geothermal Resource Exploration

Authors: Smith. R. W.; Palmer. C. D.; Cooper, D.

Affiliation:

AA(Univ Idaho, Idaho Falls, ID, USA; smithbob@uidaho.edu), AB(Idaho National Laboratory, Idaho Falls, ID, USA; palmerc7@cableone.net), AC(Idaho National Laboratory, Idaho Falls, ID, USA; craig.cooper@inl.gov)

Publication: American Geophysical Union, Fall Meeting 2012, abstract \#V23F-08

Publication Date: $12 / 2012$

Origin: $\underline{\mathrm{AGU}}$

Keywords:

[1009] GEOCHEMISTRY / Geochemical modeling, [1034] GEOCHEMISTRY / Hydrothermal systems

Bibliographic Code: 2012AGUFM.V23F..08S

\section{Abstract}

Geothermometry is an important tool to estimate deep reservoir temperature from the geochemical composition of shallower and cooler waters. The underlying assumption of geothermometry is that the shallow waters maintain a chemical signature that reflects equilibrium in the deeper reservoir. Many of the geothermometers used in practice are based on empirical observations and correlation between water temperatures and composition using a subset (typically silica, cations or cation ratios) of the dissolved constituents. An alternative approach is to use complete water compositions and equilibrium geochemical modeling to calculate the degree of disequilibrium (Saturation Index) for large number of potential reservoir mineral as a function of temperature. Key to applying this approach is to define the often unknown primary/secondary mineral assemblage controlling equilibrium in the deep reservoir and to apply develop parameter optimization approaches to estimate the likely conditions (e.g., temperature, $\mathrm{PCO}_{2}$ ) to which the water was exposed in the deep subsurface. Selection of mineral assemblages can be addressed by a combination of practical (e.g., taking into account common alteration mineral assemblages) as well as theoretical (limiting the number of minerals by the phase rule) considerations. Because the values of Saturation Indexes are a function of reaction stoichiometry, simultaneous interpretation requires that values be weighted or normalized. The approach used here is to write reaction in terms of thermodynamic components and then divide the saturation index by the total count of components in the reaction (e.g., 1 for quartz, 2 for calcite, 5 for albite, and 7 for muscovite). This approach is tested against both synthetic and field derived data sets to estimate reservoir temperatures which are compared to actual temperatures or temperatures estimated from commonly employed approaches for geothermometry. 
Add this article to private library Remove this article from private library

Submit corrections to this record View record in ADSLabs NEW!

Find Similar Abstracts:
Use:
Authors
$\checkmark$ Title
$\checkmark$ Keywords (in text query field)
$\checkmark$ Abstract Text
Return: Query Results
Database: $\square$ Astronomy
Query Form
$\checkmark$ Physics
$\square$ arXiv e-prints

Return $100 \quad$ items starting with number 1

Send Query

Reset 
Appendix $\mathrm{P}$.

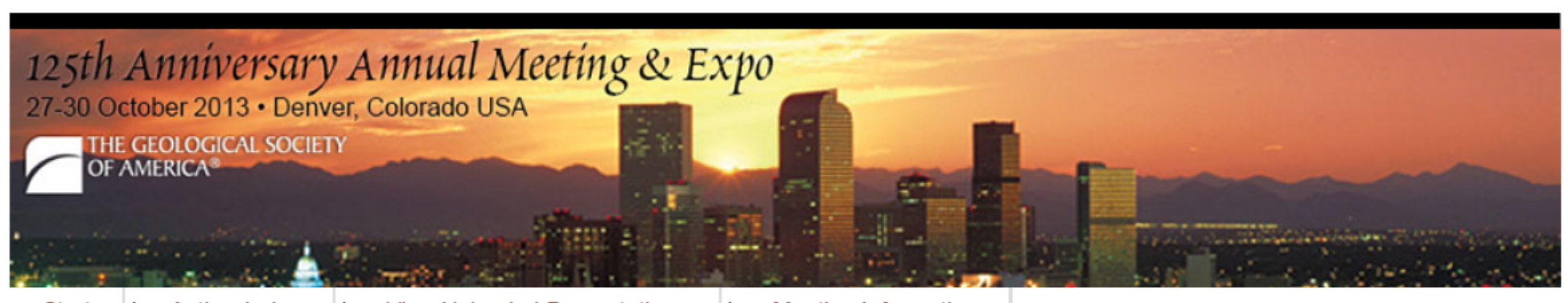

Start | Author Index | View Uploaded Presentations | Meeting Information

Paper No. 387-11

Presentation Time: 4:05 PM

\section{MULTICOMPONENT EQUILIBRIUM GEOTHERMOMETRY APPLIED TO THE RAFT RIVER GEOTHERMAL AREA, IDAHO: PRELIMINARY RESULTS}

NEUPANE, Ghanashyam ${ }^{1}$, SMITH, Robert W. ${ }^{1}$, PALMER, Carl D. ${ }^{2}$, and MCLING, Travis L. ${ }^{2}$, (1) University of Idaho-Idaho Falls, Center for Advanced Energy Studies, 995 University Boulevard, Idaho Falls, ID 83401, gneupane@uidaho.edu, (2) Idaho National Laboratory, 2525 Fremont Ave, Idaho Falls, ID 83415

The Raft River Geothermal (RRG) area in Idaho is a designated Known Geothermal Resource Area (KGRA) with a temperature in the range of $135-150^{\circ} \mathrm{C}$. It has been a site for intense exploratory and production activities since late $1970 \mathrm{~s}$, thus the RRG area offers a well characterized geothermal system to test a multicomponent equilibrium geothermometry (MEG) approach. We have developed a new MEG optimization approach to find a common equilibrium temperature for geothermal fluid for a likely reservoir mineral assemblage by minimizing the weighted sum of squares of the mineral saturation indices through modification of temperature and volatile components (e.g., water and carbon dioxide gain or loss). An automated MEG tool called RTEst (Reservoir Temperature Estimator) that couples PEST and Geochemist's Workbench is applied to RRG area. Water compositions from four RRG wells (RRG1, RRG2, RRG3, and RRG5) using several alternate mineral assemblages consisting of clays, zeolites, carbonates, feldspars, and silica-polymorphs were considered in the development of temperature estimates. The results indicate that RRG waters are affected by composition altering processes (such as boiling, mixing, and $\mathrm{CO}_{2}$ degassing). For example, in most cases, our results suggest that RRG waters have lost significant amounts of $\mathrm{CO}_{2}$ due to degassing. In general, results for RRG wells indicate that MEG will lead to an erroneous temperature estimates if composition altering processes are not taken into account. When these effects are taken into account, RTEst estimated an average reservoir temperature of $158^{\circ} \mathrm{C}$ with $95 \%$ confidence limit of $\pm 28^{\circ} \mathrm{C}$ for the RRG. Compared to the measured production well temperatures, the RTEst optimized temperature estimate for the reservoir is slightly higher. Similarly, when compared, the RTEst temperature estimates are similar in accuracy with quartz (no steam loss) temperature estimates $\left(136-164^{\circ} \mathrm{C}\right)$ but lower than Na-K-Ca $\left(169-187^{\circ} \mathrm{C}\right)$ and $\mathrm{Na}-\mathrm{K}\left(183-208^{\circ} \mathrm{C}\right)$ temperature estimates. However, unlike traditional geothermometers, the RTEst's capability to predict temperatures up to $300^{\circ} \mathrm{C}$ with associated uncertainties in the temperature estimates improves our ability to predict and interpret reservoir temperatures for geothermal resource exploration.

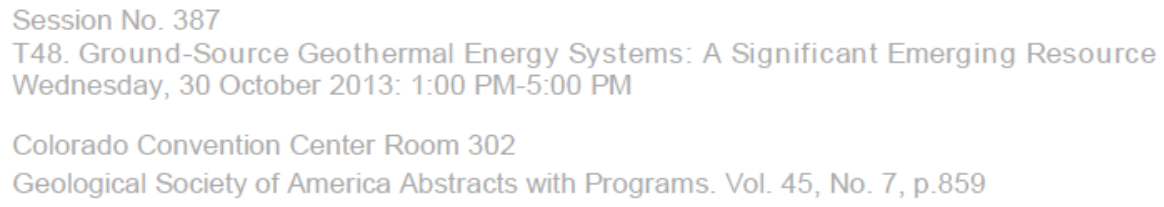

(C) Copyright 2013 The Geological Society of America (GSA), all rights reserved. Permission is hereby granted to the author(s) of this abstract to reproduce and distribute it freely, for noncommercial purposes. Permission is hereby granted to any individual scientist to download a single copy of this electronic file and reproduce up to 20 paper copies for noncommercial purposes advancing science and education, including classroom use, providing all reproductions include the complete content shown here, including the author information. All other forms of reproduction and/or transmittal are prohibited without written permission from GSA Copyright Permissions.

See more of: Ground-Source Geothermal Energy Systems: A Significant Emerging Resource See more of: Topical Sessions 


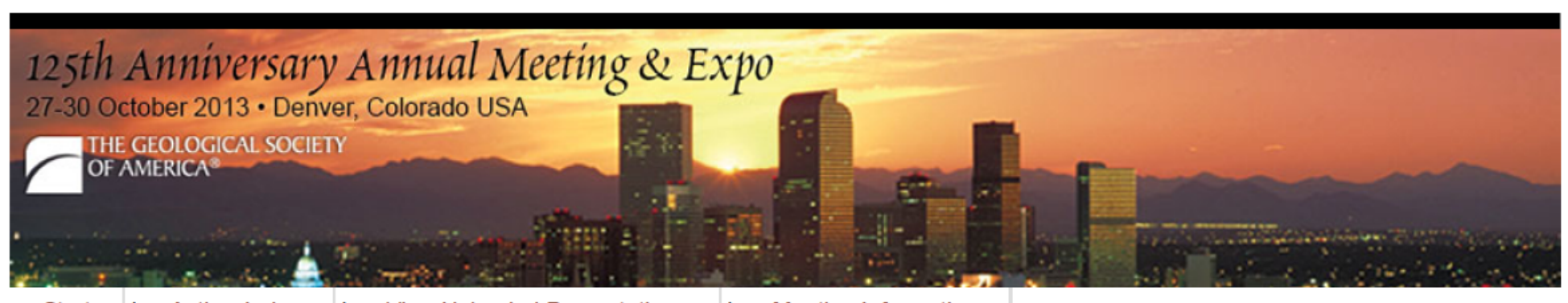

Start | Author Index | View Uploaded Presentations | Meeting Information

Paper No. 338-4

Presentation Time: 9:45 AM

\title{
CONSTRAINING MULTICOMPONENT EQUILIBRIUM GEOTHERMOMETER TEMPERATURE ESTIMATES USING LABORATORY EXPERIMENTS: PRELIMINARY RESULTS
}

\begin{abstract}
NEUPANE, Ghanashyam ${ }^{1}$, SMITH, Robert W. ${ }^{1}$, MCLING, Travis L. ${ }^{2}$, PALMER, Carl D. ${ }^{2}$, and SMITH, William W. ${ }^{1},(1)$ University of Idaho-Idaho Falls, Center for Advanced Energy Studies, 995 University Boulevard, Idaho Falls, ID 83401, gneupane@uidaho.edu, (2) Idaho National Laboratory, 2525 Fremont Ave, Idaho Falls, ID 83415
\end{abstract}

More accurate chemical geothermometers can potentially decrease economic risk associated with geothermal prospecting by providing more reliable temperature estimates. However, when applying the suite of traditional geothermometers, diverse temperature estimates result because 1) each geothermometer utilize only a subset of the available water chemical composition data, and 2) they do not explicitly account for many composition altering physicochemical processes along its flow path. Multicomponent equilibrium geothermometry (MEG) has an advantage over traditional geothermometers in its ability to use a complete chemical analysis of a water sample for temperature prediction. Nevertheless, the uncertainty associated with MEG estimated temperature relies in part on a correct understanding of mineral-water interactions occurring at depth in reservoir and proper quantification of composition altering processes along its flow path. Laboratory experiments simulating reservoir conditions (e.g., T and $\mathrm{P}$ ) is one approach for understanding mineral-water interactions and quantifying composition altering processes occurring during fluid migration. As part of project to develop approaches for MEG, we are conducting a series of water-rock interaction experiments at $200-250^{\circ} \mathrm{C}$ using 1-liter stirred Parr bench-top reactors. Representative reservoir rock samples from Raft River Geothermal area in Idaho were crushed to different grain-sized fractions and reacted separately with synthetic geothermal fluids for $>2$ months. Fluid samples were extracted at different times to evaluate the chemical evolution of system and to test the accuracy and uncertainty in temperature estimates with MEG. Preliminary results based on water compositions in association with likely mineral assemblage in these experiments demonstrate that with the increasing extent of reaction over time, the temperatures estimated with MEG approach the experimental temperature with decreasing uncertainty. Additional experiments with the goal of simulating some of the composition altering chemical and physical processes are planned. We expect that these water-rock interaction experiments simulating reservoir and flow path processes will allow us to constrain MEG temperature estimates with reduced and quantifiable uncertainty.

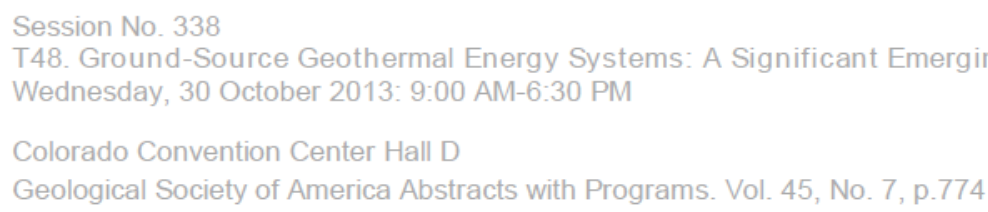

(C) Copyright 2013 The Geological Society of America (GSA), all rights reserved. Permission is hereby granted to the author(s) of this abstract to reproduce and distribute it freely, for noncommercial purposes. Permission is hereby granted to any individual scientist to download a single copy of this electronic file and reproduce up to 20 paper copies for noncommercial purposes advancing science and education, including classroom use, providing all reproductions include the complete content shown here, including the author information. All other forms of reproduction and/or transmittal are prohibited without written permission from GSA Copyright Permissions.

See more of: Ground-Source Geothermal Energy Systems: A Significant Emerging Resource (Posters) See more of: Topical Sessions

$<$ Previous Abstract | Next Abstract $\gg>$ 
Appendix R.

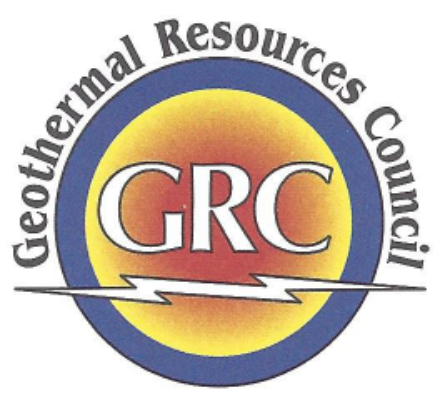

October 17, 2014

Carl D. Palmer

560 NW Silverado Dr.

Beaverton, OR 97006

\section{Dear Carl,}

The Geothermal Resources Council is pleased to inform you that your presentation, Mineral Selection for Multicomponent Equilibrium Geothermometry, was determined to be one of the best of 147 presentations at the 2014 GRC Annual Meeting in Portland, Oregon.

Congratulations, we sincerely appreciate your effort and professionalism in contributing to the knowledge base of our industry and have enclosed a certificate recognizing your achievement. We are proud of your success and know that this award was well earned and will bring you much personal satisfaction. We look forward to your contribution at the 2015 Annual Meeting.

Sincerely,

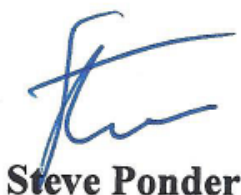

Executive Director 


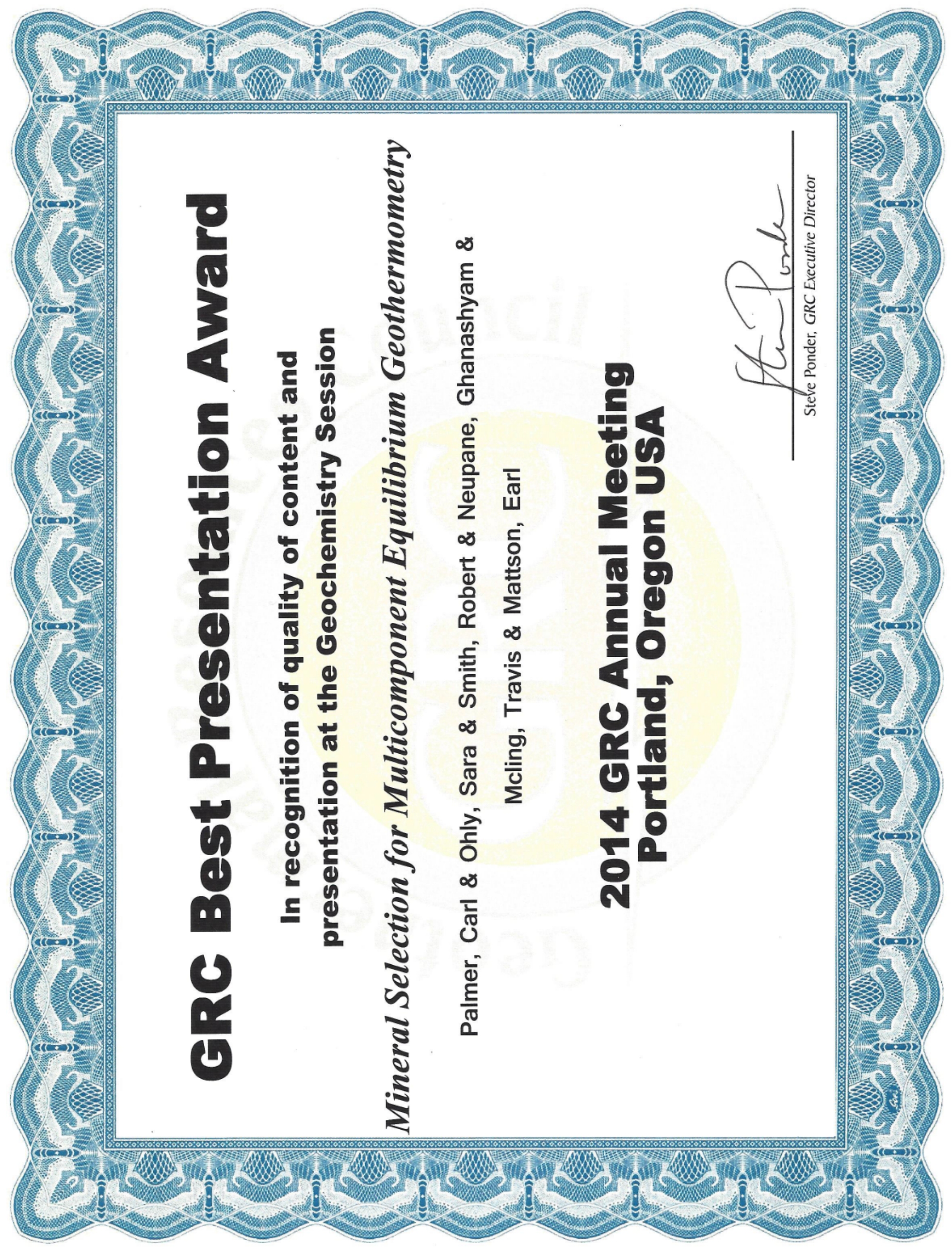

